\title{
III. Personelle „Säuberung“ der Justizverwaltung und der Anwaltschaft: die Beamten- und Personalpolitik bei der Rechtspflege
}

\section{Die Gestaltung der beamtenrechtlichen Grundlagen für die personellen Veränderungen: vergebliches Streben der Justizleitung nach Wiederherstellung der persönlichen Unabhängigkeit des Richters}

\begin{abstract}
a. "Revolutionäre" Maßnabmen der nationalsozialistischen Landesjustizchefs, Entstehung und Durchfübrung der Aprilgesetze 1933: die Kontroverse um das Ausmaß der „Säuberung" der Justizbeamtenschaft und des Anwaltsstandes
\end{abstract}

Die ersten Schritte zur personellen „Säuberung“ des Justizapparates nach der Machtergreifung unternahmen die Justizverwaltungen der Länder, deren Schlüsselpositionen - anfangs kommissarisch - mit Nationalsozialisten besetzt wurden und die bis zur Überleitung ihrer Kompetenzen auf das Reichsjustizministerium auch für die Durchführung der auf diesem Gebiet erlassenen Reichsgesetze zuständig blieben; das Reichsjustizministerium war hier zunächst auf die Personalverwaltung des Reichsgerichts, der Reichanwaltschaft und des Reichspatentamtes beschränkt. Dabei wurden in verschiedenen Ländern die allerersten Maßnahmen, die sich vor allem gegen jüdische Justizbeamte und Rechtsanwälte richteten, in einem wirksamen Zusammenspiel des Terrors von unten und der Anordnung von oben getroffen. So drangen z. B. am Vormittag des 9. März SA-Trupps in das Landgericht Chemnitz ein, zwangen jüdische Beamte - darunter den Landgerichtspräsidenten - zum Verlassen des Gebäudes und nahmen sie zum Teil in Schutzhaft. ${ }^{1}$ Die Vorfälle, die sich am 10. März in Kaiserslautern und Saarbrücken sowie am 11. März in Breslau ereigneten und zu einem mehrtägigen Stillstand der Rechtspflege (Justitium nach $\S 245 \mathrm{ZPO}$ ) bei den dortigen Gerichten führten, werden in anderem Zusammenhang behandelt. ${ }^{2}$ In Breslau erzwang der kommissarische Polizeipräsident, SA-Gruppenführer Heines, eine „Säuberung“ der Justiz auf eigene Faust: die jüdischen Beamten wurden durch polizeiliche Kontrollen der Eingänge zu den Gerichten an der Ausübung ihres Amtes gehindert. Heines erklärte, er könne „die ungestörte Abwicklung des Geschäftsganges bei den Justizbehörden" nur dann garantieren, wenn die Justizverwaltung ,unter dem Eindruck der Erregung dieser Tage sich dem Wunsch der nationalen Bevölkerung" nicht verschließe

1 Vgl. Ber. der Deutschen Allgemeinen Zeitung, Abendausg. v. 9.3.33, S.1 (Arch. des IfZ, Sign. MZ 75/15).

2 Vgl. Kapitel IV.1.a., S. $322 \mathrm{f}$. 
und „für ein Eindämmen des Einflusses jüdischer Rechtspflegeorgane“ sorge; „andernfalls seien Unruhen vor den Gerichtsgebäuden und Behelligung jüdischer Rechtspflegeorgane zu besorgen ". ${ }^{3}$ Da sich auch das alarmierte - noch von Staatssekretär Hölscher geleitete - preußische Justizministerium gegenüber diesen Eigenmächtigkeiten als hilflos erwies ${ }^{4}$, mußte der Oberlandesgerichtspräsident in Breslau nach Verhandlungen die Bedingungen Heines' akzeptieren, um den Gerichtsbetrieb wenigstens mit den „arischen“ Beamten wiederaufnehmen zu können: er mußte sich damit einverstanden erklären, daß nur 17 ausgewählte jüdische Rechtsanwälte zum Auftreten vor den Breslauer Gerichten berechtigt wurden und dafür besondere Ausweise ausgestellt bekamen'; dieser Anzahl jüdischer Anwälte, die angeblich dem prozentualen Anteil der jüdischen Bevölkerung Breslaus entsprach, glaubte Heines polizeilichen Schutz gewähren (!) zu können. Die anderen Rechtsanwälte sollten jedoch in ihrer übrigen Berufstätigkeit zunächst nicht eingeschränkt sein. Die jüdischen richterlichen Beamten blieben nach wie vor - gleichfalls in ungesetzlicher Weise - „an der Ausübung ihres Amtes behindert" ${ }^{6}$

Unterdessen trieb der BNSDJ die Entwicklung auf diesem Gebiet voran. Auf einer Tagung in Leipzig am 14. März forderte der Bund, alle deutschen Gerichte „einschließlich des Reichsgerichts" von jüdischen Richtern und Beamten unverzüglich zu säubern, jüdischen Rechtsanwälten die Ausübung ihres Berufs an allen Gerichten zu sperren und denen, die Mitglieder der SPD oder KPD waren, die Zulassung zur Rechtsanwaltschaft überhaupt zu entziehen. In jedem Jahr sollte ein Viertel der jüdischen Anwälte ausscheiden, so daß nach Ablauf von vier Jahren ,kein Angehöriger fremder Rasse mehr Anwalt" sei. ${ }^{7}$ Diese Forderungen müssen auf dem Hintergrund der katastrophalen wirtschaftlichen Lage des Anwaltstandes gesehen werden, der außer an den allgemeinen Auswirkungen der Wirtschaftskrise - Rückgang der Prozesse, der Armenanwaltsgebühren usw. - an Überfüllung litt: die Zahl der Rechtsanwälte war von 15846 im Jahre 1929 auf 19208 im Jahre 1933 gestiegen. $^{8}$

Um den Forderungen des BNSDJ Nachdruck zu verleihen, kam es nunmehr auch in anderen Städten zur gewaltsamen Besetzung von Gerichten, so in Oels (18.3.), Gleiwitz (24.3.), Görlitz (29.3.) und Königsberg (31.3.).9 Sie führte ebenfalls zur Aussetzung und Vertagung von Verfahren und der Bitte der örtlichen Justizverwaltung an

${ }^{3}$ Mitteilung der Pressestelle des Breslauer Polizeipräsidiums, Vossische Zeitung v. 17.3.33, S. 2 (Arch. des IfZ, Sign. MZ 81/81).

4 Vgl. Anm. 2.

s Schr. des OLGPräs. Breslau „an sämtliche an Breslauer Gerichten zugelassenen Rechtsanwälte“ v. 16.3.33, worin er bat, „daß die jüdischen Rechtsanwälte sich im Rahmen dieser Richtlinien halten“ sollten, um ,eine Entspannung der allgemeinen Lage“ zu erreichen (abgedruckt bei H. Göppinger, Der Nationalsozialismus und die jüdischen Juristen, Villingen 1963, S. 22). Vgl. dazu den Ber. des Vors. der Breslauer Anwaltskammer an StS. Schlegelberger v. 25.3.33 (Akten des RJM, Arch. des IfZ, Sign. MA 108).

- Vgl. Schr. des stellv. LGPräs. an die betroffenen Richter, Vossische Zeitung v. 14.3.33, S. 2 (Arch. des IfZ, Sign. MZ 81/81).

7 Vgl. Wiedergabe der BNSDJ-Forderungen in der Vossischen Zeitung v. 17.3.33, S. 2 (a.a.O.).

8 Zur Lage und Entwicklung der RAschaft s. die Begründung zum Entw. eines Zweiten G. zur Anderung der Rechtsanwaltsordnung vom Dezember 1935 (Akten der RK, BA, Sign. R 43 II/1534). Danach hatten noch 1934 über $37 \%$ aller RAe ein Jahreseinkommen unter 3000 RM „und somit nicht das für eine bescheidene Lebensführung erforderliche Existenzminimum“. Von diesen waren 2480 ohne nachweisbares Einkommen, während 4500 ein durchschnittliches Jahreseinkommen von $1500 \mathrm{RM}$ besaßen. Vgl. dazu vor allem: F. Ostler, Die deutschen Rechtsanwälte 1871-1971, Essen 1982, S. 207 ff. mit zahlreichen Nachweisen.

9 Vgl. die verschiedenen Pressemeldungen in: Das Schwarzbuch, Tatsachen und Dokumente. Die Lage der Juden in Deutschland 1933, Paris 1934, S. 104 ff., 108. 
die jüdischen Beamten, kurzfristig Urlaub zu nehmen, um wenigstens einen Stillstand der gesamten Tätigkeit der betroffenen Gerichte zu vermeiden. Nachdem es in dieser Hinsicht in Berlin noch ruhig geblieben war, schürte der "Völkische Beobachter" am 19. März in einem Bericht über die Breslauer Vorgänge das Feuer: während dort „immerhin ein ganz bescheidener Anfang einer Säuberungsaktion gemacht" worden sei, habe sich an den Berliner Gerichten nichts geändert. „Wie lange soll Moabit [Sitz des Berliner Kriminalgerichts] ... als Neu-Jerusalem in der Justiz gelten? Man darf hoffen, daß auch hier der eiserne Besen nicht mehr lange auf sich warten läßt!" ${ }^{\text {"10 }}$ Um gewaltsamen Aktionen vorzubeugen, nahm die Berliner Justizverwaltung für das am 1.April beginnende neue Geschäftsjahr zahlreiche Umbesetzungen vor: so wurden beim Landgericht I drei Strafkammervorsitzende an Zivilkammern versetzt und beim Amtsgericht Berlin-Mitte alle jüdischen Richter aus den Strafabteilungen, aus dem Schnellgericht und dem Jugendgericht herausgenommen. Bei den Sonderkammern, bei denen schwebende Verfahren von längerer Dauer liefen, war eine sofortige Umbesetzung jedoch nicht möglich. Jüdische Staatsanwälte wurden als Sitzungsvertreter nicht mehr verwendet. ${ }^{11}$ Eine Zulassungssperre für jüdische Rechtsanwälte am Gericht wurde auf einer Kundgebung gefordert, die der BNSDJ am 22. März im Anwaltszimmer des Landgerichts I veranstaltete. ${ }^{12}$

Als auch das Landgericht und das Amtsgericht in Leipzig von seiten der Partei mit Forderungen nach Beurlaubungen und Umbesetzungen unter Druck gesetzt wur$\operatorname{den}^{13}$, drohten die Aktionen auf das dort angesiedelte Reichsgericht überzugreifen. Schon hatte der jüdische Präsident des VIII. Zivilsenats David zweimal - am 16. und am 18. März - durch Abgesandte der Rechtsabteilung der NSDAP die Aufforderung erhalten, zumindest den Vorsitz am 2. Senat des Ehrengerichtshofs für Rechtsanwälte niederzulegen. Reichsgerichtspräsident Bumke beurlaubte daraufhin den in den Brennpunkt des Parteiinteresses gerückten Senatspräsidenten zunächst, offensichtlich um die übrigen jüdischen Richter des Gerichts nicht auch noch zu gefährden. ${ }^{14}$ Als für Montag, den 20. März, eine Aktion gegen das Reichsgericht angekündigt wurde, suchte Schlegelberger nach Rücksprache mit dem erkrankten Gürtner zusammen mit Bumke den Chef der Reichskanzlei auf und teilte ihm mit, „solche Einmischungen Unberufener wie in Breslau, dem Leipziger Amts- und Landgericht und im Falle David“ könne das Reichsgericht „unter keinen Umständen hinnehmen“; es müsse vielmehr abgewartet werden, „was auf dem Wege des Gesetzes erfolge“. Er bat Lammers, sofort mit Hitler zu telefonieren: wenn er hinsichtlich des Reichsgerichts „nicht noch heute eine befriedigende Auskunft erhalte", müsse er die Angelegenheit auf der für den nächsten Tag anberaumten Kabinettssitzung - auf der er Gürtner vertrat - zur Sprache bringen. Tatsächlich konnte ihm Lammers noch am selben Tage mitteilen, daß Hitler „eine Aktion beim Reichsgericht untersagt habe“. Schlegelberger eilte daraufhin nach Leipzig, um die Lage durch vorläufige Maßnahmen zu entschärfen. Seine

10 Vgl. VB, Berliner Ausg./Ausg. A v. 19./20.3.33, 3. Beibl. (Bayer StBibl., Sign. $2^{\circ}$ Eph. Pol. 74 $\left.{ }^{\text {h }}, 1933,3-4\right)$.

1 Vgl. Vossische Zeitung v. 20.3 .33 (a.a.O.) und VB, Norddt. Ausg. v. 21.3.33, S. 2 (Arch. des IfZ, Sign. MZ 9/22). An den Berliner Strafgerichten der LGBezirke II und III gab es nur vereinzelt jüdische Richter.

12 Vgl. Der Angriff v. 23.3.33, S. 2 (Arch. des IfZ, Sign. MZ 18/6).

13 Vgl. auch zum folgenden Verm. Schlegelbergers v. 19.3.33 (Akten des RJM, Arch. des IfZ, Sign. MA 108).

14 Dieses Motiv Bumkes vermutet zumindest D. Kolbe, Reichsgerichtspräsident Dr. Erwin Bumke, Studie zum Niedergang des Reichsgerichts und der deutschen Rechtspflege, Karlsruhe 1975, S. 223. 
dortige Besprechung am 2. April ergab, daß außer dem von der Partei beanstandeten David, der unterdessen „im Hinblick auf die politische und völkische Neuordnung“ seine Versetzung in den Ruhestand beantragt hatte ${ }^{15}$, auch Reichsgerichtsrat Grossmann - der sich als SPD-Mitglied Anfang November 1932 durch eine Rede in einer Reichsbannerversammlung exponiert hatte und den einzigen „politischen“ Fall am Reichsgericht darstellte ${ }^{16}$ - sein Abschiedsgesuch eingereicht hatte. Zwei weitere Reichsgerichtsräte schieden aus Krankheitsgründen kurz vor Erreichung der Altersgrenze aus, einer blieb als „Frontkämpfer 1914/1918“ unbehelligt. Für drei Räte wurde die Überweisung an Zivilsenate vorgesehen, nachdem der Präsident der für das Reichsgericht zuständigen Anwaltskammer dazu „verbindlich“ erklärt hatte, daß kein Rechtsanwalt beim Reichsgericht „von sich aus einen in einem Zivilsenat tätigen Reichsgerichtsrat deshalb ablehnen [werde], weil er jüdisch oder jüdischer Abstammung“ sei. Zwei Reichsanwälte sollten „einstweilen in Sitzungen nicht auftreten“. Den drei Juden unter den Rechtsanwälten beim Reichsgericht sollte offenbar ebenso wie sich von auswärts ankündigenden jüdischen Anwälten „durch Vermittlung der Anwaltskammer von dem Erscheinen bis auf weiteres“ abgeraten werden. ${ }^{17}$

Schlegelberger hatte somit zu ähnlichen „besänftigenden“ Mitteln gegriffen wie die Berliner Justizverwaltung. In Berlin hatten diese Maßnahmen indessen nicht zu verhindern vermocht, daß es im Zuge der für den 1.April angesetzten anti-jüdischen Boykottaktion - die nicht nur gegen jüdische Geschäfte, sondern u.a. auch gegen jüdische Rechtsanwälte gerichtet war und bei der auf Massenversammlungen die Zulassung von Juden zum Anwaltsberuf „entsprechend ihrer Beteiligung an der deutschen Volkszahl“" gefordert werden sollte ${ }^{18}$ - schon am Vormittag des 31. März zur Besetzung des Landgerichts I, des Amtsgerichts Mitte und des Jugendgerichts kam, bei der die jüdischen Anwälte und Beamten einschließlich des Landgerichtspräsidenten zum Verlassen der Gebäude gezwungen wurden. Der stellvertretende Landgerichtspräsident und der Amtsgerichtspräsident ordneten daraufhin im Einvernehmen mit dem Kammergerichtspräsidenten die Schließung der Gebäude an. ${ }^{19}$

In dieser Situation - die dringend eine Regelung des Problems „von oben“ verlangte - erließ der am 27. März zum kommissarischen preußischen Justizminister ernannte Nationalsozialist Hanns Kerrl eine Anordnung, die den Oberlandesgerichtspräsidenten, Generalstaatsanwälten und Präsidenten der Strafvollzugsämter Preußens noch am Abend des 31. März in Form eines Funkspruchs übermittelt wurde. Darin führte er aus, „die Erregung des Volkes über das anmaßende Auftreten amtierender jüdischer Rechtsanwälte und jüdischer Richter" habe solche Ausmaße erreicht, daß gerade in der Zeit des antijüdischen Boykotts damit gerechnet werden müsse, daß „das Volk zur Selbsthilfe schreitet“. Da solche Selbsthilfeaktionen „eine Gefahr für die Aufrechterhaltung der Autorität der Rechtspflege“ darstellten, müßten ihre Ursachen spätestens mit dem Beginn des Boykotts beseitigt sein. Daher sei „umgehend allen amtie-

$15 \mathrm{Vgl}$. bereits die Meldung in der Vossischen Zeitung v. 20.3 .33 (a.a.O.).

16 Vgl. F. K. Kaul, Geschichte des Reichsgerichts, Bd. IV, 1933-1945, Glashütten/Taunus 1971, S. 54 f.

17 Vgl. Verm. Schlegelbergers über das Ergebnis der Leipziger Besprechungen v. 2.4.33 (Akten des RJM, a.a.O.).

18 Vgl. Punkt 1 und 9 der Anordnung der Parteileitung v. 28.3.33 über die Organisation des Boykotts, VB, Süddt. Ausg. v. 29.3.33 (abgedruckt bei W. Scheffler, Judenverfolgung im Dritten Reich, Berlin 1960, S. 66 ff.).

19 Vgl. Der Angriff v. 31.3.33, S. 1 (Arch. des IfZ, Sign. MZ 18/6). 
renden jüdischen Richtern nahezulegen, sofort ihr Urlaubsgesuch einzureichen und diesem sofort stattzugeben“. Die Kommissorien jüdischer Assessoren seien sofort zu widerrufen, jüdische Schöffen, Geschworene usw. nicht mehr einzuberufen, jüdische Staatsanwälte und Beamte im Strafvollzug umgehend zu beurlauben. Mit den Anwaltskammern oder örtlichen Anwaltsvereinen sei ,noch heute zu vereinbaren, daß ab morgen früh, 10 Uhr nur noch bestimmte jüdische Rechtsanwälte, und zwar in einer Verhältniszahl, die dem Verhältnis der jüdischen Bevölkerung zur sonstigen Bevölkerung etwa entspricht, auftreten“. Die Auswahl dieser Anwälte habe im Einvernehmen mit den Gaurechtsstellen der NSDAP oder dem Vorsitzenden der Gaugruppe des BNSDJ zu erfolgen. Allen nicht derart autorisierten jüdischen Anwälten und denjenigen Richtern, die sich weigerten, sofort ihr Urlaubsgesuch einzureichen, sei „kraft Hausrechts das Betreten des Gerichtsgebäudes zu untersagen". Um dieses Verbot auch tatsächlich erzwingen zu können, sollte dem Wunsch der Parteidienststellen Rechnung getragen werden, ,durch uniformierte Wachen die Sicherheit und Ordnung innerhalb des Gerichtsgebäudes zu überwachen“. Ferner seien jüdische Anwälte nicht mehr als Armenanwälte, Pflichtverteidiger, Konkursverwalter, Zwangsverwalter usw. zu bestellen, da das "ein Vergehen gegen die Boykottpflicht des deutschen Volkes“ darstelle. Auch sollten Aufträge zur Vertretung von Rechtsstreitigkeiten des Staates an jüdische Anwälte zurückgezogen und nicht mehr vergeben werden. Durch ,entsprechende Verhandlungen" sei der Rücktritt des Vorstandes der Anwaltskammer herbeizuführen und mit der vorläufigen Wahrnehmung ihrer Geschäfte ein Kommissar zu beauftragen, der ,nach Anhörung der nationalsozialistischen oder sonstigen nationalen Anwaltsorganisationen zu bestellen" sei. Verweigerten Vorstandsmitglieder ihren Rücktritt, sei an ihn zu berichten. ${ }^{20}$ Nach Durchführung aller dieser Maßnahmen sei „für die Aufrechterhaltung einer geordneten und würdigen Rechtspflege“ zu sorgen. In einer Rundverfügung vom 4. April 1933, die auch sämtlichen preußischen Landgerichtspräsidenten und Oberstaatsanwälten zuging, bestimmte Kerrl, daß diese Anordnung „,bis auf weiteres in Kraft bleibe. ${ }^{21}$ Durch weitere, in den ersten Apriltagen erlassene Rundverfügungen unterband Kerrl auch die Amtstätigkeit der jüdischen Notare, verbot die Ernennung jüdischer Rechtskandidaten zu Referendaren und stellte klar, daß sich das Vertretungsverbot für die jüdischen Anwälte auch auf die Unterzeichnung von Klagen und Schriftsätzen in jenen Sachen bezog, in denen Anwaltszwang herrschte. $^{22}$

In Bayern hatten sich die Dinge bis zu diesem Zeitpunkt ähnlich entwickelt. ${ }^{23}$ Hier hatte Hans Frank als kommissarischer Justizminister den bayerischen Oberlandesgerichtspräsidenten und Generalstaatsanwälten am 25. März mitgeteilt, „die in der politischen Neuordnung zum Ausdruck gekommene Volksmeinung" mache es erforderlich, „daß Richter jüdischer Abstammung nicht mehr mit der Handhabung der Strafrechtspflege und der Disziplinargerichtsbarkeit befaßt werden und daß Staatsanwälte

20 Zur Gleichschaltung der Anwaltsorganisationen, die im folgenden nicht dargestellt werden kann, vgl. F. Ostler, a.a.O. (Anm. 8), S.229ff., und H. Göppinger, a.a.O. (Anm. 5), S. $44 \mathrm{ff}$.

21 Vgl. Anordnung Kerrls v. 31.3.33 und seine RV v. 4.4.33 (Akten des preuß. JM, Geh. StArch. Berlin, Sign. Rep. 84 a/4542). Der Funkspruch Kerrls v. 31.3 .33 ist abgedruckt in: Die Juden und die Justiz. Bearbeitet im Auftrag des Reichsministers der Justiz von S. Lorenzen, 2. Aufl., Berlin-Hamburg 1943, S. $175 \mathrm{ff}$.

22 Vgl. die RVen des preuß. JM v. 1.4.33, 3.4.33 und 4.4.33 (Lorenzen, a.a.O., S. 177 f.).

${ }^{23} \mathrm{Zu}$ den Besetzungen der Gerichte in Kaiserslauten und Zweibrücken im pfälzischen Landesteil Bayerns s. Kapitel IV.1.a., S.323. 
und Amtsanwälte jüdischer Abstammung nicht mehr als Vertreter der Anklage in Gerichtssitzungen tätig werden" dürften. Für schwebende Verfahren könnten mit vorheriger Genehmigung des Justizministeriums nur dann Ausnahmen gemacht werden, „wenn ein Wechsel in der Person des bisherigen Bearbeiters eine Beeinträchtigung wichtigster Interessen der Rechtspflege zur Folge haben müßte“. Auch jüdische Handelsrichter seien „möglichst nicht mehr zur Dienstleistung heranzuziehen“. ${ }^{24}$ Über diese Entschließung, die zunächst nur eine Versetzung in weniger exponierte Stellen bedeutete - eine Maßnahme, die auch in Hessen und Württemberg ergriffen wurde $^{25}$-, berichtete Frank noch am selben Tag im bayerischen Ministerrat. Er erhielt ferner dessen Zustimmung für eine Verordnung, „nach der die jüdischen Rechtsanwälte aus den Vorständen der Anwaltskammer ausgeschaltet und als Konkursverwalter usw. nur im Einvernehmen mit dem Justizministerium und dessen nachgeordneten Stellen bestellt werden " durften. ${ }^{26}$ Doch am Vorabend des Boykotts wies Frank - offensichlich in Abstimmung mit Kerrl - seine Oberlandesgerichtspräsidenten und Generalstaatsanwälte telegrafisch an, nunmehr sämtliche jüdische Richter und Staatsanwälte „zur Aufrechterhaltung von Ruhe und Ordnung im Rechtsbetrieb und der damit zusammenhängenden Sitzungspolizei und zur Wahrung des Ansehens der Rechtspflege“ mit Wirkung vom 1.April „bis auf weiteres“ zu beurlauben. ${ }^{27}$ Im Gegensatz zur Regelung in Preußen war von diesem Tage an sämtlichen jüdischen Rechtsanwälten das Betreten des Gerichtsgebäudes bis auf weiteres verboten; ferner sollten sich alle jüdischen Notare und Notariatsverweser der Vornahme von Amtsgeschäften enthalten. ${ }^{28}$ Der bayerische Ministerrat billigte Franks Anordnungen nachträglich, beschloß jedoch, alle weiteren Maßnahmen auf diesem Gebiet bis zur reichsgesetzlichen Regelung zurückzustellen. ${ }^{29}$

Mit ihren Anordnungen hatten die beiden Kommissare - unter dem Vorwand möglicher Störungen der Rechtspflege im Verlauf des anti-jüdischen Boykotts und unter Beiseiteschiebung des geltenden Beamtenrechts - ,mit einem Schlage die deutsche Justiz fast judenfrei“" gemacht: allein in Preußen wurden nach den Berichten, die die Oberlandesgerichtspräsidenten aufgrund einer Rundverfügung vom 6. April zu erstatten hatten, 643 Juden aus dem höheren Justizdienst beurlaubt. ${ }^{30} \mathrm{Ganz}$ offensichtlich war es das abgesprochene Ziel der beiden nationalsozialistischen Exponenten in der Justiz, vollendete Tatsachen zu schaffen, die das Reichsjustizministerium und das Reichsinnenministerium bei der in Vorbereitung befindlichen reichsgesetzlichen Ordnung dieser Probleme nur noch anzuerkennen brauchten: es war die gleiche Methode, durch eine „revolutionär“ geschaffene Lage eine bestimmte gesetzliche Regelung zu

24 Entschließung des bayer. JM v. 25.3 .33 (Akten des bayer. JM, BayHStArch., Abt. I, Sign. MJu 12 004).

${ }^{25}$ Vgl. Göppinger, a.a.O. (Anm. 5), S. 26, und U. D. Adam, Judenpolitik im Dritten Reich, Düsseldorf 1979, S. 48 f., mit weiteren Nachweisen.

${ }^{26}$ Vgl. Prot. der Ministerratssitzung v. 25.3.33 (Akten der bayer. Staatskanzlei, GehStArch. München, Sign. MA 99526).

${ }^{27}$ Entschließung des bayer. JM an die OLGPräs. und GStAe in München, (telegrafisch) in Nürnberg, Bamberg und Zweibrücken (Akten des bayer. JM, a.a.O.).

${ }^{28}$ Text der Entschließungen in Bayer. Staatszeitung/Staatsanzeiger Nr.78 v. 2./3.4.33, S.15.

29 Vgl. Prot. der Ministerratssitzung v. 7.4.33 (Akten der Bayer. Staatskanzlei, a.a.O.).

${ }^{30}$ Vgl. Lorenzen, a.a.O., S.177. Es handelte sich um: 10 (davon im Bezirk Berlin 6) Senatspräs. und LGPräs.; 111 (74) LGDir., OLGRäte und AGDir.; 313 (178) LGRäte, 21 (14) StAe und EStAe; 182 (92) Ger.Assessoren sowie 6 (3) sonstige Beamte. Für die Gesamtzahlen der in Preußen im April 1933 vorhandenen jüdischen und nichtjüdischen Justizbeamten s. S. 166 und Anm. 140. 
erzwingen, die später z.B. bei der Realisierung des Nürnberger Blutschutzgesetzes mit Erfolg angewendet wurde. ${ }^{31}$ Es sollte sich jedoch erweisen, daß Kerrl und Frank zu weit vorgeprellt waren.

Immerhin mußten die Reichsministerien nunmehr handeln, um den ungesetzlichen Schwebezustand zu beenden. Schon am 4.April wollte sich Frank beim Reichsjustizministerium über die Aufrechterhaltung seiner radikalen Maßnahmen Klarheit verschaffen: er bat „umgehend“ um Mitteilung, „ob die Frage der Behandlung jüdischer Richter, Staatsanwälte und Rechtsanwälte noch in dieser Woche geregelt wird, oder wenn dies nicht der Fall sein sollte, in welcher Weise etwa die Regelung in Aussicht genommen“ sei. ${ }^{32} \mathrm{Daß}$ dabei von dem Erreichten möglichst nichts zurückgenommen werden sollte, darüber wurde das Reichsjustizministerium durch zahlreiche „einstimmige Entschließungen“ nationalsozialistischer Juristenorganisationen und Einzeleingaben belehrt, die die gesetzliche Festschreibung der getroffenen Maßnahmen forderten. ${ }^{33}$ Diese Forderung stellte auch der Vertreter der neu gegründeten Breslauer „Vereinigung nationaler Anwälte“ in einer Unterredung mit Schlegelberger am 22. März. Der Staatssekretät hielt ihm entgegen, es sei „vom Standpunkt des nationalen Gedankens nicht erfreulich“, wenn gerade diejenigen Anwälte, die ihre jüdischen Kollegen an der Ausübung ihres Berufes hindern wollten, „den unmittelbaren wirtschaftlichen Vorteil von dieser Maßnahme hätten“. Das Reichsjustizministerium, das zu den Breslauer Vorgängen geschwiegen habe, da es sich „in erster Linie um eine preußische Angelegenheit handle“, sei jedenfalls der Auffassung, „daß möglichst bald an Stelle der Willkürregelung eine amtliche Regelung treten müsse“. Hinsichtlich der Weiterbeschäftigung der jüdischen Richter liege „eine Entschließung des Amtes noch nicht vor“: hier müsse „mit großer Vorsicht“ vorgegangen und vor allem geprüft werden,

„ob nicht das Gut der richterlichen Unabhängigkeit so hoch stehe, daß demgegenüber andere Erwägungen zurücktreten [!] müßten. Vor allem müsse geprüft werden, inwieweit man den berechtigten nationalen Empfindungen, ohne in die Unabsetzbarkeit des Richter einzugreifen[!], auf anderem Wege, z. B. auf dem Wege der Geschäftsverteilung entgegenkommen könne. Wie sich das RJM endgültig entscheiden werde, lasse sich unter diesen Umständen zur Zeit noch nicht voraussagen." 34

Die dem nachträglichen Betrachter als reine Illusion anmutende Vorstellung, daß die nationalsozialistische Führung die persönliche Unabhängigkeit der Richter respektieren würde und ihre personalpolitischen Forderungen - zumindest weitgehend durch Versetzung erfüllt werden könnten, stellte für die Justizleitung zum damaligen Zeitpunkt durchaus noch keine aussichtslose Hoffnung dar. Äußerte doch Hitler in seiner Regierungserklärung vor dem Reichstag am 23. März, die er anläßlich der Vorlage des Ermächtigungsgesetzes abgab, u.a. folgendes: „Unser Rechtswesen muß in er-

31 Vgl. dazu Kapitel VII.3.c., S.870 ff.

32 Schr. Franks an das RJM v. 4.4 .33 (Akten des bayer. JM, a.a.O.).

$33 \mathrm{Vgl}$. Akten des RJM (Arch. des IfZ, Sign. MA 108). Die Sammlung enthält auch Eingaben jüdischer Anwaltsvertreter und Landesverbände, die auf die Härten hinweisen, die eine Beibehaltung dieser Maßnahmen für die Betroffenen bedeuteten, und das Ministerium um die Bewahrung der verfassungsmäßig gewährleisteten Rechte aller deutschen Staatsbürger baten, deren Antastung nicht „im Interesse des Vaterlandes“ liegen könne (so im Schr. des Preußischen Landesverbandes jüdischer Gemeinden, der die Geschäfte der Reichsvertretung der jüdischen Landesverbände Deutschlands führte, v. 31.3.33).

34 Aufz. des anwesenden MinDir. Volkmar v. 26.3.33 (Akten des RJM, a.a.O.). 
ster Linie der Erhaltung dieser Volksgemeinschaft dienen. Der Unabsetzbarkeit des Richters auf der einen Seite muß eine Elastizität der Urteilsfindung zum Zweck der Erhaltung der Gesellschaft entsprechen.“" ${ }^{35}$ An diese Bemerkung Hitlers - obwohl sie die richterliche Unabsetzbarkeit deutlich an die Bedingung knüpfte, daß der Richter im Sinne der Führung judizierte - klammerten sich die führenden Juristen wie Ertrinkende an einen Strohhalm: Schon sechs Tage später nahm das Plenum des Reichsgerichts eine Entschließung an, die Hitler zugeleitet wurde und in der es hieß, das Reichsgericht begrüße es

„dankbar, daß der Herr Reichskanzler in der Regierungserklärung vom 23. März 1933 die richterliche Unabsetzbarkeit als Grundlage des Rechtswesens anerkannt hat. Nur das Bewußtsein seiner Unabhängigkeit kann dem Richter die innere Freiheit geben, deren es zur Führung seines hohen Amtes bedarf. In solcher Freiheit, nur dem Gesetz unterworfen, durch seine Urteilsfindung der Erhaltung der Volksgemeinschaft zu dienen, ist die wahre Aufgabe des Richters.“

Der von Hitler ausgesprochenen Mahnung, daß die Justiz nur auf dem Boden der Nation existieren könne und deshalb die Entscheidungen der Führung berücksichtigen müsse, werde „kein deutscher Richter sich verschließen“. Das Schreiben Schlegelbergers, mit dem er diese Resolution Hitler übermittelte, endete bezeichnenderweise mit dem Satz, daß der Reichsgerichtspräsident Hitler zugleich dafür danke, daß er „nichtbehördliche Eingriffe in die Rechtspflege des Reichsgerichts verhindert“ habe. ${ }^{36}$ Nur wenige Tage später schloß sich der Vorstand der Anwaltskammer beim Reichsgericht mit einer Entschließung an, daß auch er sich „der hohen Bedeutung bewußt" sei, „die dieser Zusicherung der Reichsregierung ganz besonders in den jetzigen bewegten Zeiten beizumessen“ sei. Der im letzten Jahrzehnt mehrfach gefährdete Rechtsgedanke, zu dem Hitler in seiner Rede „ein unzweideutiges, feierliches Bekenntnis“ abgelegt habe, könne seine

„volle Geltung nur wiedererlangen, wenn die Erhaltung der Unabhängigkeit des deutschen Richters dauernd gesichert bleibt. Deshalb geben wir uns der Zuversicht hin, daß bei allen gesetzlichen und sonstigen [!] Maßnahmen, die die jetzt begonnene Neuordnung des staatlichen Lebens in deutschen Landen erfordert, darüber gewacht werden wird, daß das unschätzbare Gut der richterlichen Unabhängigkeit - nicht nur in ihren äußeren Formen, sondern auch in ihren inneren geistigen Beziehungen - sowohl mittelbar wie unmittelbar unangetastet bleibt.“"37

In diesen Resolutionen wird die Absicht der leitenden Juristen deutlich, Hitler auf seine Erklärung festzulegen und den Schutz für die versprochene persönliche Unabhängigkeit der Richter durch eigene Loyalitätsbezeugungen zu erkaufen. Hitler nährte diese Illusion erneut, als er beim Empfang einer Abordnung des Deutschen Richterbundes am 7.April versicherte, „daß er die Unabhängigkeit der Richter aufrecht erhal-

35 Hervorheb. vom Verf. Hitler fuhr fort: „Nicht das Individuum kann der Mittelpunkt der gesetzlichen Sorge sein, sondern das Volk. Landes- und Volksverrat sollen künftig mit barbarischer Rücksichtslosigkeit ausgebrannt werden. Der Boden der Existenz der Justiz kann kein anderer sein als der Boden der Existenz der Nation. Möge diese daher auch stets die Schwere der Entscheidungen derer berücksichtigen, die unter dem harten Zwang der Wirklichkeit das Leben der Nation verantwortlich zu gestalten haben“ (Verhandl. des Reichstags, VIII. Wahlperiode 1933, Bd.457, Sten. Berichte, Arch. des IfZ, Sign. Da 03.01); mit geringen Abweichungen veröffentlicht im VB, Süddt. Ausg. v. 24.3.33, S. 1 f.

36 Vgl. Schr. des RJM (i.V. Schlegelberger) an Hitler v. 30.3.33 (Akten der RK, BA, Sign. R 43 II/1505). Die Entschließung des RG v. 29.3.33 wurde am 31.3.33 in der Presse veröffentlicht.

37 Vgl. Schr. des RJM (i.V. Schlegelberger) an Hitler v. 5.4.33 (a.a.O.). Zu den Loyalitätserklärungen der Richter- und Anwaltsvereine s. H. Weinkauff, Die deutsche Justiz und der Nationalsozialismus, Bd. I, Stuttgart 1968, S. $103 \mathrm{f}$. 
ten werde, wenn auch gewisse Maßnahmen notwendig seien“. Der Richterbund zog daraus den Schluß, daß die eingreifenden Bestimmungen des am selben Tage erlassenen Berufsbeamtengesetzes so bald wie möglich wieder aufgehoben würden. ${ }^{38}$ Die Garantie der richterlichen Unabhängigkeit hing jedoch nicht von Erklärungen, sondern von der konkreten gesetzlichen Regelung des Beamten- und Richterrechts ab.

Bereits am 20. März hatte das preußische Staatsministerium, d.h. die kommissarische Regierung Preußens, vom preußischen Justizministerium einen Gesetzentwurf angefordert, der die „Beschränkung in der Wahrnehmung der Ämter der Rechtspflege durch Nichtangehörige christlicher [!] Bekenntnisse“ beinhalten sollte. Noch am selben Tag übersandte Staatssekretär Hölscher - der seit Papens „Preußenschlag“ vom Juli 1932 das Justizministerium kommissarisch leitete - einen solchen Entwurf. Danach sollten alle Richter und Staatsanwälte, die nicht christlichen Bekenntnisses waren und ihr Amt erst nach dem 9. November 1918 angetreten hatten, mit ihrer gesetzlichen Pension in den Ruhestand versetzt werden, soweit sie nicht Kriegsteilnehmer gewesen waren. Die Zulassung von Rechtsanwälten und Notaren sollte entsprechend gehandhabt werden; auch der Vorbereitungsdienst für die höhere Justizlaufbahn sollte nur Angehörigen der christlichen Konfession offenstehen. ${ }^{39}$

Während sich dieser Entwurf ausschließlich gegen die Juden - wenn auch nur gegen Justizbeamte und Anwälte jüdischen Glaubens - richtete, reichte der kommissarische preußische Finanzminister Popitz dem Staatsministerium drei Tage später einen Entwurf ein, der jede Diskriminierung und Diffamierung der auszuscheidenden Amtsinhaber vermied und sich darüber hinaus nicht nur auf die Justizbeamten, sondern auch auf die Beamten der staatlichen und kommunalen Verwaltung bezog. Er sah vor, „daß jeder Beamte ohne Angabe von Gründen während der Geltungsdauer des Gesetzes unter Gewährung des ihm gesetzlich zustehenden Ruhegehalts pensioniert werden" könne. ${ }^{40}$ Nachdem Frick auf der Sitzung des Reichskabinetts am 24. März die „Reform der Beamtengesetzgebung“ als vordringliche Aufgabe bezeichnet hatte und das Kabinett sich über den Kreis der zu beteiligenden Ministerien geeinigt hatte ${ }^{41}$, lud Vizekanzler v. Papen die Beteiligten - darunter Schlegelberger - für den 27. März zur Beratung des Popitzschen Entwurfs ins preußische Staatsministerium ein. Aber die Beratung wurde am 25. März abgesagt und der gesamte Vorgang wenige Tage später im preußischen Staatsministerium zu den Akten gelegt ${ }^{42}$, da nunmehr das Reichsin-

38 Vgl. Ber. über den Empfang in der DRiZ v. 15.5.33, S.155f. Auch Frank gab z. B. am 21.5.33 auf der außerordentlichen Vertreterversammlung des Vereins sächsischer Richter und Staatsanwälte in Chemnitz „die feierliche Erklärung ab, daß die nationale Regierung an der Unabhängigkeit des Richtertums mit aller Kraft festhalten“"werde, DRiZ v. 15.6.33, S.162.

39 Schr. Hölschers an MinDir. Landfried im preuß. StMin. v. 20.3.33 (Akten des preuß. StMin., GehStArch. Berlin, Sign. Rep. 90/2338). Vgl. auch zum folgenden Adam, a.a.O. (Anm. 25), S. 55 ff.

${ }^{40}$ So Göring in der Chefbespr. des preuß. Staatsministeriums v. 5.5.33 (GehStArch. Berlin, Sign. Rep. 90 A/ 41) über den von Popitz gemeinsam mit dem Leiter der Kommunalpolitischen Abteilung im preuß. MdI, MinDir. Surén, ausgearbeiteten Entwurf. Der Entwurf war dem Schr. Popitz' an MinDir. Landfried vom preuß. StMin. v. 23.3.33 (Akten des preuß. StMin., a.a.O., Sign. Rep. 90/469) beigelegt, ist aber nicht mehr überliefert. Zur Vorgeschichte des BBG vgl. im folgenden G. Schulz, Die Anfänge des totalitären Maßnahmenstaates (Bracher, Sauer, Schulz, Die nationalsozialistische Machtergreifung, T.II, Frankfurt a. M. 1974), S. 159 ff., H. Mommsen, Beamtentum im Dritten Reich, Stuttgart 1966, S. 39 ff., und Adam, a.a.O.

41 Vgl. Niederschr. über die Ministerbesprechung am 24. März 1933, vorm. 11.30 Uhr (Akten der Reichskanzlei. Die Regierung Hitler. Teil I, Bd. 1 [s. Kapitel I, Anm. 3], Dok. Nr.72, S. 248 ff., und BA, Sign. R 43 I/ 1460).

42 Vgl. Einladungsschr. Papens v. 25.3.33, Absage des preuß. StMin. vom selben Tag und Verf. MinRat Bergbohms v. 29.3.33 (Akten des preuß. StMin., a.a.O.). 
nenministerium die Bearbeitung an sich zog. Der von diesem Ministerium am 28. März vorgelegte Entwurf griff - wie die erwähnten Vorläufer - in die durch Artikel 129 der Reichsverfassung geschützten „wohlerworbenen Rechte“ der Beamten ein und war daher überhaupt erst aufgrund des Ermächtigungsgesetzes realisierbar. Er sah vor, daß Beamte „zur Wiederherstellung eines nationalen, von Parteieinflüssen freien Berufsbeamtentums und zur Vereinfachung der Verwaltung ... in den Ruhestand versetzt werden“ konnten, „auch wenn die nach den Vorschriften der Reichs- und Landesgesetzgebung hierfür erforderlichen Voraussetzungen“ nicht vorlagen. Er verzichtete ebenfalls auf eine diffamierende Angabe von Gründen und - soweit der Beamte mindestens zehn Jahre im Amt war - auch auf jede Kürzung oder Streichung der Pension. Für das Reichsjustizministerium waren zwei Bestimmungen des Entwurfs von besonderer Bedeutung: Einmal, daß die Versetzung in den Ruhestand „von der Anstellungsbehörde ausgesprochen" werden sollte, d.h. die Entscheidung darüber im Ermessen der Landesbehörden blieb; zum anderen, daß diese Maßnahme auf richterliche Beamte nicht angewendet, die Unabsetzbarkeit der Richter also respektiert werden sollte. Auch sollten diese Maßnahmen bis zum 30. Juni - also innerhalb von drei Monaten - durchgeführt und nach diesem Termin „die für das Berufsbeamtentum geltenden allgemeinen Vorschriften wieder voll wirksam“ sein. ${ }^{43}$ Der Entwurf zielte darauf ab, die Erfüllung der personalpolitischen Forderungen der nationalsozialistischen Führung durch einen einmaligen befristeten Eingriff in das geltende Beamtenrecht zu ermöglichen, danach aber den Zustand „unverbrüchlichen“ Rechts wiederherzustellen, um die Beamten nicht auf die Dauer zu beunruhigen. Diese Konzeption war für das Reichsjustizministerium sicher akzeptabel; war es doch die von Gürtner auch bei anderen Gelegenheiten befolgte Methode, die Ausschaltung rechtsstaatlicher Prinzipien in Ausnahmesituationen hinzunehmen, um sie anschließend nach Möglichkeit wieder in Geltung zu setzen.

Die Forderung auf Entfernung der jüdischen Richter, der Kerrl und Frank durch Beurlaubung bereits provisorisch entsprochen hatten, erfüllte dieser vor dem Boykott fertiggestellte Entwurf des Reichsinnenministeriums allerdings nicht. Demgegenüber strebten die von seiten der Partei unterbreiteten Vorschläge „eine wirklich radikale Säuberung und Neugestaltung des Beamtenkörpers" an. ${ }^{44}$ Offenbar am 31. März oder 1. April besprach Frick den Entwurf seines Ministeriums mit Hitler ${ }^{45}$, wobei spätestens dabei die Entscheidung fiel, die Richter einzubeziehen und die Entlassung der jüdischen Beamten nicht durch eine „Blankovollmacht“ zu ermöglichen und den einzelnen Behörden zu überlassen - was sicher eine unterschiedliche und willkürliche Behandlung bewirkt hätte -, sondern im Gesetz selbst vorzuschreiben und die Voraussetzungen dafür zu konkretisieren. Da aber nicht nur jüdische, sondern auch andere

43 Text des aus 13 Paragraphen bestehenden Entw. bei Mommsen, a.a.O., S.151 ff. Die zwischen Mommsen und Schulz kontroverse Frage, ob dieser Entw. mit dem von Popitz identisch war oder vom Referenten für Beamtenrechtsfragen im RMdI, MinRat Seel, ausgearbeitet wurde, ist in unserem Zusammenhang ohne Belang.

44 So der Geschäftsführer der nat.soz. Reichstagsfraktion Fabricius im Schr. an StS. Pfundtner v. 29.3.33 anläßlich der Ủbersendung eines von der Arbeitsgemeinschaft nationalsozialistischer Beamter Neukölln ausgearbeiteten „Gesetzentwurfs zum Schutze der wohlerworbenen Beamtenrechte und gegen Ämterjägerei“" an das RMdI, der die Rücknahme grundsätzlich aller nach dem 9.11.1918 erfolgten Anstellungen und Beförderungen vorbehaltlich einer späteren Prüfung forderte (vgl. Mommsen, a.a.O., S. 46).

45 Vgl den im folgenden behandelten Brief Hitlers an Hindenburg v. 5.4.33. 
Gruppen von Beamten aus ihren Ämtern entfernt werden sollten, mußte der Entwurf in den ersten Apriltagen völlig umgearbeitet, die betroffenen Beamtenkategorien genau bezeichnet und die anzuwendenden Mittel und Maßnahmen festgelegt werden.

Zu den im Gesetz zu regelnden Problemen gehörte auch die Behandlung jüdischer Frontkämpfer. Von ihnen hatte Hindenburg zahlreiche Eingaben erhalten, die von seinem Büro an das Innenministerium weitergeleitet und dort dem für die Ausarbeitung des Entwurfs zuständigen Referenten vorgelegt wurden. So erinnerte ein jüdischer Rechtsanwalt, der im Kriege schwer verwundet worden war, den Reichspräsidenten an seine Kundgebung zum „Tag von Potsdam“, in der Hindenburg der Gefallenen gedacht und ,in steter Treue“ die Frontkameraden und Kriegshinterbliebenen gegrüßt hatte. Angesichts der Forderung des BNSDJ, alle „Fremdrassigen“ aus der Justiz zu entfernen, bat der Jurist den Reichspräsidenten,

„die deutschen Juden, die wie alle anderen Kameraden für Volk und Vaterland gekämpft und geblutet haben, vor der entsetzlichen Schande des Ausstoßes aus der Volksgemeinschaft durch die Vernichtung ihrer Existenz, ihres Arbeitsfeldes und damit ihrer selbst und ihrer Angehörigen zu bewahren".46

Am 4. April schrieb Hindenburg an Hitler einen Brief, in dem sich diese Gedanken wiederfinden: ihm seien Fälle gemeldet worden, ,in denen kriegsbeschädigte Richter, Rechtsanwälte und Justizbeamte von untadeliger Amtsführung lediglich deshalb zwangsbeurlaubt wurden und später entlassen werden sollen, weil sie jüdischer Abstammung sind“. Angesichts der Kundgebung, die er „mit ausdrücklicher Zustimmung der Reichsregierung am Tage der nationalen Erhebung" erlassen habe, sei für ihn eine solche Behandlung dieses Personenkreises „persönlich ganz unerträglich“. Er bat daher Hitler „eindringlichst, sich dieser Frage persönlich anzunehmen“ und für alle Zweige des öffentlichen Dienstes vorzusehen, daß jüdische Beamte und Rechtsanwälte, „die kriegsbeschädigt oder Frontsoldaten oder Söhne von Kriegsgefallenen sind oder selbst Söhne im Felde verloren haben“, im Amt bleiben sollten: „wenn sie wert waren, für Deutschland zu kämpfen und zu bluten, sollen sie auch als würdig angesehen werden, dem Vaterland in ihrem Beruf weiter zu dienen ". ${ }^{47}$

In seiner Antwort vom folgenden Tag rechtfertigte Hitler die anti-jüdischen Maßnahmen unter anderem mit dem großen Anteil der Juden vor allem im Rechtsanwaltsberuf und mit der notwendigen Beseitigung von „Fremdkörpern“ aus wichtigen Staatsstellen, sagte aber zu, daß die „edlen Motive“ des Reichspräsidenten berücksichtigt würden.

Er führte aus, daß das Gesetz, „das die Lösung dieser Fragen der Willkür einzelner Aktionen entrückt ..., schon am Ende der vergangenen Woche [d.h. am 31.3./1.4.] in den ersten Beratungen durchgesprochen worden“ sei und „eine Berücksichtigung derjenigen Juden, die entweder selbst Kriegsdienste geleistet haben, oder durch Krieg zu Schaden kamen“ bereits enthalte; es werde „so schnell als möglich bearbeitet". ${ }^{48}$ Der Entwurf des Gesetzes „zur Wiederherstellung des Berufsbeamtentums“ wurde nun-

46 Vgl. Schr. des Nürnberger RAs. S. an den Reichspräs. v. 21.3.33 nebst Eingangsverm. des RMdI, „erg. H. Seel“" (Akten des RJM, Arch. des IfZ, Sign. MA 108).

47 Schr. Hindenburgs an Hitler v. 4.4.33, abgedruckt bei W. Hubatsch, Hindenburg und der Staat, Göttingen 1966, S.375f.

48 Schr. Hitlers an Hindenburg v. 5.4.33, a.a.O., S. 376 ff. Zu dem von Hitler angesprochenen Anteil der Juden an der Rechtsanwaltschaft s. Statistik auf S. 151. 
mehr tatsächlich so zügig fertiggestellt, daß Frick den Chef der Reichskanzlei bereits am 6.April bitten konnte, seine Verabschiedung auf die Tagesordnung der nächsten Kabinettssitzung zu setzen. ${ }^{49}$

Durch die vorgreifenden Maßnahmen der kommissarischen Justizminister in den Ländern war für das Reichsjustizministerium eine schleunige gesetzliche Regelung nicht nur hinsichtlich der Richter und Staatsanwälte, sondern auch bezüglich der Rechtsanwälte vordringlich geworden. Als Schlegelberger Hitler am 31. März in dieser Sache Vortrag hielt, bekam er jedoch den Auftrag, lediglich die Frage der künftigen Neuzulassung von Rechtsanwälten zu regeln, die Behandlung der bereits zugelassenen Rechtsanwälte dagegen vorläufig zurückzustellen. In einem persönlichen Schreiben an Hitler vom 3. April berichtete der Staatssekretär über die inzwischen in Preußen, Bayern und Baden durchgeführten Maßnahmen, die eine völlig neue Lage geschaffen hätten, und schlug nun auch für die Berufsausübung zugelassener jüdischer Rechtsanwälte „eine beschleunigte, einheitliche reichsrechtliche Regelung“ vor. Nach „Ablauf des für die Boykottfrage wichtigen Mittwoch dieser Woche“ - an dem über die Fortführung des unterbrochenen Judenboykotts entschieden werden sollte - beabsichtige er daher, „die Frage der Behandlung der jüdischen Rechtsanwälte zum Gegenstand einer Aussprache mit den Landesjustizverwaltungen zu machen“; er bat um Mitteilung, ob sich diese Absicht zeitlich und sachlich in Hitlers Pläne einfüge. Nachdem Hitler zugestimmt hatte ${ }^{50}$, trug Schlegelberger seine Absicht am nächsten Tag im Reichskabinett nochmals vor und stieß auf keine Bedenken. ${ }^{51}$

Auf diesem Gebiet war allerdings Eile geboten, denn schon ging Kerrl in Preußen daran, seine provisorischen Maßnahmen „rechtlich“ zu untermauern und ihnen Dauercharakter zu verleihen. In einer Verfügung wies er die Oberlandesgerichtspräsidenten an, allen nicht mehr bei Gericht zugelassenen jüdischen Rechtsanwälten anheimzustellen, Gesuche um Wiederzulassung einzureichen. Voraussetzung für die Bearbeitung dieser Gesuche durch das preußische Justizministerium sollte jedoch die „einwandfreie und vorbehaltlose Erklärung des Gesuchstellers" sein, daß die ,jetzt bestehende Lage“ von ihm „rechtsverbindlich anerkannt [?]“ werde: nur „wenn die Loyalität des Gesuchstellers gegenüber der Regierung der nationalen Erhebung durch ein solches Anerkenntnis erwiesen und bestätigt" werde, könnten diese Gesuche berücksichtigt werden. Angeblich war es das Ziel dieser Aktion, „unter Wahrung des Standpunktes der Regierung ... Entscheidungen zu treffen, die nicht notwendige Härten vermeiden"; in Wirklichkeit handelte es sich um ein reines Täuschungs- und Erpressungsmanöver mit dem Zweck, von möglichst vielen jüdischen Rechtsanwälten die "freiwillige“ Anerkennung ihrer Ausschaltung zu erhalten. Um in dieser Hinsicht möglichst rasch vollendete Tatsachen zu schaffen, unterrichtete Kerrl die Oberlandesgerichtspräsidenten, daß sämtliche Gesuche „spätestens bis Dienstag, dem 11.April, mit der Frühpost" in seiner Hand sein müßten. ${ }^{32}$ Wie aussichtslos diese Gesuche wa-

49 Vgl. Schr. Fricks an Lammers v. 6.4 .33 (Akten der RK, BA, Sign. R 43 II/423).

so Vgl. persönl. Schr. Schlegelbergers an Hitler v. 3.4 .33 mit dem Verm. „Einverstanden H“ (a.a.O., Sign. R 43 II/600).

51 Vgl. Niederschr. über die Sitzung des Reichsministeriums am 4.April 1933, 5 Uhr nachmittags (Akten der Reichskanzlei. Die Regierung Hitler. Teil I, Bd. 1 [s. Kapitel I, Anm. 3], Dok. Nr. 88, S. 292 ff., und BA, Sign. R $43 \mathrm{I} / 1461)$

52 Erl. des preuß. JM, Wortlaut im Auszug in der Vossischen Zeitung, Abendausg. v. 7.4.33 (Arch. des IfZ, Sign. MZ 81/81). Zum Erfolg dieser Aktion vgl. Freislers Ausführungen im folgenden S. 142. 
ren, wurde schon aus der Erklärung des neuen, kommissarisch bestellten Vorstandes der Berliner Anwaltskammer Neubert vor der Presse am 7. April ersichtlich, daß jüdische Anwälte ,in Berlin künftig nur im Verhältnis des Anteils der jüdischen Einwohner an der Gesamtbevölkerung“, d.h. statt der bisher rund 2000 jüdischen Anwälte nur noch 35 zugelassen würden. Dafür seien aber nur frontbewährte Kriegsteilnehmer und „einige sehr alte jüdische Anwälte berücksichtigt worden“.53

Unterdessen wurden auch Stimmen laut, die warnten, daß eine so weitgehende Beschränkung der Zulassung jüdischer Rechtsanwälte „den bereits katastrophalen Arbeitsmarkt der Angestellten mit einem neuen Zustrom belasten“"werde, da die betroffenen Anwälte ihr Personal kündigten: die Reichsvereinigung der Rechtsanwalts- und Notariatsangestellten betonte, daß bei jüdischen Rechtsanwälten allein in Berlin 3500, im Reich 35000 bis 40000 Angestellte beschäftigt seien, die nach ihrer Entlassung kaum anderweitig unterkämen, da „ein sehr großer Teil jahrelang in dem gleichen Büro beschäftigt war und in einem höheren Lebensalter stehe. ${ }^{54}$

Angesichts der geschilderten Probleme prallten auf der von Schlegelberger organisierten Besprechung der Justizleitung des Reichs mit den Chefs der Landesjustizverwaltungen, die am Vormittag des 7.April in Berlin stattfand, die gegensätzlichen Auffassungen aufeinander. Während das Reichsjustizministerium das Ausscheiden der jüdischen Rechtsanwälte analog dem vorliegenden Gesetzentwurf über die Beamten regeln und damit bestimmte Ausnahmen zugunsten der Juden zulassen wollte, beharrten vor allem Kerrl und Frank auf der radikalen Lösung und erklärten, falls die reichsrechtliche Regelung bewirken sollte, „daß auch nur ein Teil der gegenwärtig vorläufig ausgeschlossenen jüdischen Rechtsanwälte wieder zuzulassen ist, würde dies zu einer ungeheuren Erregung des Volkes und zu Zusammenstößen führen“. Einer der Justizminister - vermutlich Kerrl - drohte sogar, „daß die SA auf eigene Faust solche Anwälte aus dem Gerichtsgebäude herausholen würde" ${ }^{55}$ Die Mehrheit der Landesjustizchefs formulierte einen Gegenantrag in Gesetzesform, der nach Gürtners Worten „über den Bereich des Justizressorts weit" hinausging. ${ }^{56}$

Um sich gegen die radikalen Chefs der Landesjustizverwaltungen durchsetzen zu können, mußte sich Gürtner bei Hitler Rückendeckung holen. Gelegenheit dazu bot die Kabinettssitzung am Nachmittag desselben Tages, in der u.a. das „Gesetz zur Wiederherstellung des Berufsbeamtentums" verabschiedet wurde. Nachdem Gürtner über die Vormittagssitzung berichtet hatte, führte Hitler aus, „daß man im Augenblick nach seiner Auffassung nur das Notwendige regeln solle“. Das Kabinett stimmte folgenden Grundsätzen für das zu entwerfende Rechtsanwaltsgesetz zu: Es sollte nur für Rechtsanwälte, nicht für andere Berufe gelten, zeitlich befristet und „in den Grundzügen dem Gesetz zur Wiederherstellung des Berufsbeamtentums angepaßt werden“. Von

53 Vgl. DAZ, Morgenausg. v. 8.4.33 (Arch. des IfZ, Sign. MZ 75/16). Die Namensliste der 35 Anwälte wurde am 8.4.33 bekanntgegeben, vgl. Vossische Zeitung, Morgenausg. v. 9.4 .33 (a.a.O., Sign. MZ 81/81).

$54 \mathrm{Vgl}$. Schr. der genannten Reichsvereinigung im Gewerkschaftsbund der Angestellten (GDA), auszugsweise zit. in der Vossischen Zeitung, Abendausg. v. 7.4 .33 (a.a.O.).

ss So der Ber. Gürtners in seinem persönl. Schr. an Hitler v. 8.4.33 (Akten der RK, BA, Sign. R 43 II/1534). Gürtner hatte trotz seiner Erkrankung in die Sitzung geholt werden müssen (vgl. dazu Kapitel I.7, S. 72).

56 So Gürtner im Reichskabinett, vgl. Niederschr. über die Ministerbesprechung am 7. April, nachmittags 4.15 Uhr (Akten der Reichskanzlei. Die Regierung Hitler., a.a.O., Dok. Nr.93, S.311ff., und BA, Sign. R 43 I/ 1461). Der Antrag der LJMin. bezog sich offensichtlich auch auf andere freie Berufe wie Ärzte, Apotheker usw. 
einer Einführung des Numerus clausus für Rechtsanwälte sollte vorläufig abgesehen werden. Ferner sollte die Zulassung auch von nichtjüdischen Rechtsanwälten zurückgenommen werden können, ,wenn diese sich kommunistisch betätigt haben“ ${ }^{57}$

$\mathrm{Da}$ am selben Tag noch eine Abendsitzung des Kabinetts vorgesehen war, beeilte sich das Reichsjustizministerium, nach diesen Grundsätzen sofort einen unterschriftsreifen Entwurf herzustellen und vollendete Tatsachen zu schaffen, ehe sich die andere Seite an Hitler wandte. Kerrl, der im Reichsjustizministerium anrief, um sich nach dem Ergebnis der Kabinettsberatung zu erkundigen, wurde lediglich mitgeteilt, „das Gesetz sei noch nicht redigiert und der Herr Staatssekretär könne darüber nichts sagen“. Er erfuhr den Inhalt des Gesetzes, das Hitler noch am selben Abend ausfertigte, nach seinen eigenen Worten erst, als es am 10. April im Reichsgesetzblatt verkündet und ,in der Presse allgemein veröffentlicht wurde". ${ }^{58}$

Als Frick in der Nachmittagssitzung des Kabinetts das „Gesetz zur Wiederherstellung des Berufsbeamtentums" vorgetragen hatte, bat Schlegelberger ${ }^{59}$ - von Reichsfinanzminister Schwerin von Krosigk unterstützt - „dringend, in $\S 7$ [der die Frist für die vorgesehenen Maßnahmen festlegte] eine zusätzliche Bestimmung des Inhalts zu schaffen, daß die zuständige Behörde die Entlassungen aus dem Amte usw. auch vor dem 30. September als beendet erklären könne“. Hier wird das Bestreben des Justizministeriums deutlich, den Ausnahmezustand in seinem Ressort abzukürzen, um mit der wieder garantierten Unabsetzbarkeit der Richter auch ihre persönliche Unabhängigkeit möglichst schnell wiederherzustellen - ein Ziel, das es in der Folge jedoch nicht erreichen solite. Nachdem sich das Reichskabinett mit der Einfügung der von Schlegelberger gewünschten Bestimmung einverstanden erklärt hatte, stimmte es dem Entwurf $\mathrm{zu}^{60}$

Das von Hitler, Frick und Schwerin von Krosigk unterzeichnete Gesetz zur Wiederherstellung des Berufsbeamtentums vom 7. April 1933 (RGBl. I, S. 175) sollte - neben dem Reichsbeamtengesetz - für die Justizverwaltung die Rechtsgrundlage zur Durchführung ihrer Personalpolitik in den folgenden Jahren abgeben. Es bestimmte, daß Beamte - auch solche im einstweiligen Ruhestand sowie Richter, Referendare und Notare $^{61}-$ „zur Wiederherstellung eines nationalen Berufsbeamtentums und zur Vereinfachung der Verwaltung aus dem Amt entlassen werden“ konnten, „auch wenn die nach dem geltenden Recht hierfür erforderlichen Voraussetzungen nicht" vorlagen $(\S 1)$. Zu entlassen waren „Beamte, die seit dem 9. November 1918 in das Beamtenverhältnis eingetreten sind, ohne die für ihre Laufbahn vorgeschriebene oder übliche Vorbildung oder Eignung" zu besitzen. Diese sogenannten Parteibuchbeamten erhielten noch drei Monate lang ihre Bezüge, hatten danach aber keinen Anspruch auf Wartegeld, Ruhegeld oder Hinterbliebenenversorgung (§ 2). Laut Durchführungsver-

57 Vgl. Niederschr., a.a.O.

s8 So Kerrl auf der Zusammenkunft der Landesjustizminister in Stuttgart am 6.5 .33 (Niederschr. im BayHStArch., Abt. I, Sign. MJu 16833).

59 Schlegelberger vertrat in der Nachmittagssitzung Gürtner, der wegen seiner Erkrankung ausschließlich beim Tagesordnungspunkt 8 (Zulassung jüdischer RAe) anwesend war.

60 Niederschr., a.a.O. In derselben Sitzung verabschiedete das Kabinett noch das von Schlegelberger vorgetragene G. über das Kündigungsrecht der durch das Gesetz zur Wiederherstellung des Berufsbeamtentums betroffenen Personen v. 7.4.33 (RGBI. I, S. 187), das den Betroffenen wegen ihrer geschmälerten Bezüge eine vorzeitige Lösung ihrer Mietverträge unter Verkürzung der Kündigungsfristen ermöglichen sollte.

61 So nach der 3. DurchfVO v. 6.5.33 (RGB1. I, S. 245). 
ordnung vom 11.April 1933 (RGBl. I, S. 195) gehörten zu dieser Kategorie als „ungeeignet" grundsätzlich alle Beamte, die einer kommunistischen Organisation angehörten. Beamte, die „nicht arischer Abstammung “ waren, mußten in den Ruhestand versetzt werden; davon ausgenommen waren aber Beamte, die unter folgende drei Ausnahmen fielen: wenn sie „bereits seit dem 1.August 1914““ Beamte waren („Altbeamte"), wenn sie im Weltkrieg ,an der Front" gekämpft hatten, oder wenn ihre Väter oder Söhne im Kriege gefallen waren $(\S 3)$. Die aus dem Amt entfernten nicht „arischen" Beamten erhielten normales Ruhegeld, wenn sie mindestens eine zehnjährige Dienstzeit vollendet hatten. Nach der erwähnten Durchführungsverordnung galt bereits als „nicht arisch“, wer einen jüdischen Eltern- oder Großelternteil besaß; wenn ein solcher Beamter nicht bereits am 1.August 1914 Beamter gewesen war, mußte er nachweisen, daß er unter die genannten Ausnahmen fiel. Aus dem Dienst konnten ferner Beamte entlassen werden, „die nach ihrer bisherigen politischen Betätigung nicht die Gewähr dafür bieten, daß sie jederzeit rückhaltlos für den nationalen Staat eintreten“. Auch sie erhielten ihre Bezüge noch für drei Monate, danach - wenn sie zehn Jahre im Dienst waren - aber nur drei Viertel ihres Ruhegehalts $(\S 4)$. Die Durchführungsverordnung verpflichtete jeden Beamten, der zuständigen Behörde „auf Verlangen Auskunft darüber zu geben“, ob er bisher einer politischen Partei, dem Reichsbanner, dem Republikanischen Richterbund oder der Liga für Menschenrechte angehört hatte. Für alle Beamten galt, daß sie sich die Versetzung, in ein anderes Amt derselben oder einer gleichwertigen Laufbahn, auch in ein solches von geringerem Rang und planmäßigem Diensteinkommen“ gefallen lassen mußten, „wenn es das dienstliche Bedürfnis erfordert". Der Beamte behielt auf jeden Fall seine bisherigen Bezüge und seine Amtsbezeichnung; lehnte er eine solche Versetzung ab, so konnte er seine Pensionierung beantragen und bekam sein volles Ruhegeld $(\S 5)$. Diese Bestimmung war hauptsächlich geschaffen worden, um einen unliebsamen Beamten, dem man sonst nichts anhaben konnte, dennoch aus der Zentralinstanz zu einer Mittel- oder Lokalbehörde versetzen zu können. Ferner konnte jeder Beamte - auch wenn er noch nicht dienstunfähig war - „zur Vereinfachung der Verwaltung“ in den endgültigen Ruhestand versetzt werden; seine Stelle durfte jedoch nicht wiederbesetzt werden (§6). Nach einer Ergänzung der Begründung und nach Zulassung einer Wiederbesetzung der Stelle durch ein entsprechendes Gesetz vom Juni 1933 sollte dieser Paragraph zu einem tauglichen Instrument werden, um „bedenkliche“ Beamte loswerden zu können, auf die sonst keine Bestimmung des Berufsbeamtengesetzes zutraf. ${ }^{62}$ Über die vorgesehenen Maßnahmen - Entlassung, Zurruhesetzung und Versetzung entschied unter Ausschluß des Rechtsweges „die oberste Reichs- oder Landesbehörde“ ( $\$ 7$ Abs. 1). Solange die Justizverwaltung noch nicht „verreichlicht“ war, bedeutete das, daß das Reichsjustizministerium nur für die Durchführung des Gesetzes im eigenen Haus, beim Reichsgericht, der Reichsanwaltschaft und dem Reichspatentamt zuständig war, während sie im übrigen den Landesbehörden oblag. Die Entscheidungen mußten den betroffenen Beamten bis spätestens 30. September 1933 zugestellt werden; nach der von Schlegelberger vorgeschlagenen Ergänzung konnte diese Frist aber „im Einvernehmen mit dem Reichsminister des Innern verkürzt werden, wenn

62 Über das G. zur Änderung des G. zur Wiederherstellung des Berufsbeamtentums v. 23.6.33 (RGBl. I, S. 389) vgl. im folgenden S. $160 \mathrm{f}$. 
die zuständige oberste Reichs- oder Landesbehörde erklärt, daß in ihrer Verwaltung die Maßnahmen dieses Gesetzes durchgeführt sind“ ( $\$ 7$ Abs. 2). Gegen die aufgrund dieses Gesetzes entlassenen oder in den Ruhestand versetzten Beamten konnte bis zum 31. Dezember - entgegen dem bisher geltenden Recht - noch nachträglich ein Dienstverfahren "wegen während des Dienstverhältnisses begangener Verfehlungen“ eingeleitet werden, um ihnen Ruhegeld, Hinterbliebenenversorgung, Amtsbezeichnung usw. abzuerkennen ( $\S 14)$. Erforderliche Ausführungs- und Ergänzungsvorschriften zum Gesetz durfte der Reichsinnenminister im Einvernehmen mit dem Reichsfinanzminister erlassen, die obersten Landesbehörden nur, soweit sie sich dabei im Rahmen der Reichsvorschriften hielten ( $(17)$. Der für die Wiederherstellung einer „unabhängigen" Rechtspflege bedeutsame Schlußparagraph $(\S 18)$ bestimmte, daß nach $\mathrm{Ab}$ lauf der im vorliegenden Gesetz festgelegten Fristen „die für das Berufsbeamtentum geltenden allgemeinen Vorschriften wieder voll wirksam" sein sollten.

Das Gesetz über die Zulassung zur Rechtsanwaltschaft vom 7. April 1933 (RGBl. I, S. 188), das Gürtner so eilig und gegen die Opposition der Landesjustizminister durchgesetzt hatte und das im Gegensatz zum Berufsbeamtengesetz auch seine Unterschrift trug, lehnte sich eng an die Bestimmungen des letzteren Gesetzes an. Es sah vor, daß die Zulassung von Rechtsanwälten, die „im Sinne des Gesetzes zur Wiederherstellung des Berufsbeamtentums“ nicht „arischer" Abstammung waren, bis zum 30. September 1933 zurückgenommen werden konnte, machte aber dieselben Ausnahmen für Anwälte, die seit dem 1.August 1914 zugelassen („Altanwälte"), Frontkämpfer oder Väter bzw. Söhne von Gefallenen waren (§ 1). Entsprechend konnte Juden die Neuzulassung versagt werden, auch den als Ausnahmen weiter zugelassenen jüdischen Anwälten dann, wenn sie bei einem anderen Gericht als dem bisherigen zugelassen werden wollten $(\S 2)$. Personen, die sich ,in kommunistischem Sinne betätigt" hatten, durften den Anwaltsberuf auf keinen Fall mehr ausüben ( $(3)$. Bis zur Entscheidung über eine Zurücknahme der Zulassung konnte die Justizverwaltung ein Vertretungsverbot erlassen - gegenüber jenen jüdischen Anwälten, die unter die vorgesehenen Ausnahmen fielen, jedoch nur dann, wenn sie sich kommunistisch betätigt hatten $(\S 4){ }^{63}$

Sowohl das Berufsbeamtengesetz wie das Rechtsanwaltsgesetz - dem übrigens bald ein entsprechendes Gesetz über die Löschung jüdischer Patentanwälte aus der Liste des Reichspatentamtes folgen sollte ${ }^{64}$ - blieben weit hinter den Erwartungen zurück, die die nationalsozialistischen Chefs der Landesjustizverwaltungen hinsichtlich der gesetzlichen Regelung für die Ausschaltung der Juden hegten. Um den von Kerrl und Frank angedrohten Aktionen des „erregten Volkes“ gegen den Wiedereinzug eines erheblichen Teils der beurlaubten jüdischen Richter, Staatsanwälte und Rechtsanwälte in die Gerichte vorzubeugen, wandte sich Gürtner schon am 8. April in einem persönlichen Schreiben an Hitler: Er sei zwar überzeugt, „daß sich die Bevölkerung der reichsrechtlichen Regelung fügen und die Staatsautorität sich auch in diesem Punkt ohne weiteres durchsetzen“ werde, bäte Hitler aber dennoch, „als Kanzler und als

${ }^{63}$ Die übrigen zwei Paragraphen des G. besagten, daß die Zurücknahme der Zulassung für den betroffenen Anwalt einen wichtigen Grund zur Kündigung der Dienstverträge mit seinen Angestellten darstellte ( $(5)$ und er auch bei der Kündigung von Mietverträgen den ausgeschlossenen Beamten (vgl. dazu Anm.60) gleichgestellt wurde $(\S 6)$.

64 G. betr. die Zulassung zur Patentanwaltschaft und zur Rechtsanwaltschaft v. 22.4.33 (RGBl. I, S. 217). 
Führer der Bewegung“ seinen ausdrücklichen Willen zu bekunden, „daß selbstverständlich auch diese Anordnung der Reichsregierung von jedermann zu respektieren“ sei. ${ }^{65}$

Wenn allerdings diejenigen Richter, Staatsanwälte und Rechtsanwälte in Preußen, die unter die vorgesehenen Ausnahmen fielen, gehofft hatten, unmittelbar nach Inkrafttreten der beiden Gesetze ihre Tätigkeit wieder aufnehmen zu können, sollten sie eine arge Enttäuschung erleben: die Rechtsanwälte, die bei Gericht erschienen, um ihre Termine wahrzunehmen, wurden von den Vorsitzenden belehrt, daß die Verfügungen Kerrls zunächst in Kraft blieben. Um über diesen, dem Gesetz widersprechenden Zustand Klarheit zu gewinnen, ersuchte das Berliner Tageblatt das preußische Justizministerium um ein Interview, das ihm am 11. April von Freisler, der seit März Ministerialdirektor in diesem Ministerium war, gewährt wurde. Dabei führte Freisler aus, die befristet beurlaubten Richter täten gut daran, ihre Präsidenten „um Verlängerung der Urlaubsgesuche“ anzugehen, bis das Justizministerium - „nicht nach den Richtlinien verstaubter Paragraphen, sondern vom Gesichtspunkt des Wertes des einzelnen Juristen und Beamten im Volksganzen" aus - die endgültige Entscheidung getroffen habe. Es sei notwendig, daß auch "die nichtarischen Anwälte, die die Voraussetzungen für die Zulassung an sich zu erfüllen glauben, Geduld hätten und sich mit Rücksicht auf die Volksstimmung [!] zurückhielten". Wie viele von ihnen wiederzugelassen würden, lasse sich nicht sagen, da „die Frontkämpfer unter der nichtarischen Anwaltschaft ... statistisch nicht erfaßt" seien und daher „erst nach Prüfung der einzelnen Angaben in den Gesuchen Zahlen" genannt werden könnten. Hinsichtlich der jüdischen Notare sei die Rechtslage so, „daß sie erklärt hätten, sich der Amtsausübung zu enthalten. Sie seien also im Sinne des Gesetzes an der Ausübung ihres Amtes behindert." Für die Regelung dieses Problems sowie der Frage, ob nichtarische Anwälte künftig wieder zum Amt des Konkursverwalters oder zu ähnlichen Ämtern zugelassen werden könnten, „habe das Ministerium an sich Zeit bis zum 30 . September “(!) ${ }^{66}$ Es sollte sich erweisen, daß Kerrl - der aufgrund der Entscheidung der preußischen Regierung mit der Durchführung des Berufsbeamtengesetzes in seinem Geschäftsbereich beauftragt wurde $^{67}$ - zunächst seine eigene Politik weiterverfolgte. In einer Verfügung vom 18. April verbot er die Ernennung und Beförderung von Justizbeamten, die „möglicherweise" Juden waren, ohne Prüfung und Berücksichtigung der gesetzlich vorgesehenen Ausnahmen. ${ }^{68}$ Sein bereits Anfang April erlassenes Verbot der Ernennung von Juden zu Referendaren weitete er am 28. April auf die Ernennung von Gerichtsassessoren aus. ${ }^{69}$ Aber auch für die nichtjüdischen Juristen richtete Kerrl eine besondere „Auslese“ ein: für diejenigen von ihnen, die die große Staatsprüfung bestanden hatten und sich um die Ernennung zum Gerichtsassessor, zum Notar oder um die Zulassung zur Rechtsanwaltschaft bewarben, führte Kerrl eine zusätzliche Prüfung ein, bei der der Bewerber - neben dem bereits erbrachten Nachweis seiner intellektuellen Befähi-

${ }^{65}$ Vgl. voranstehende Anm. 55. Das Schr. trägt den handschriftl. Verm.: „Kenntnis genommen H.“.

${ }^{66}$ Vgl. Die Reform der Justiz. Interview mit Ministerialdirektor Freisler (Berliner Tageblatt v. 12.4.33, Ausschnitt in den Akten des RJM, Arch. des IfZ, Sign. MA108).

67 Und zwar im Einvernehmen mit dem preuß. Finanzminister, vgl. Erste Ausf.Vorschrift des preuß. Staatsministeriums zum BBG v. 24.4.33 (GS S.157).

${ }_{68}$ RV des preuß. JM v. 18.4.33 (Akten des preuß. JM, GehStArch. Berlin, Sign. Rep. 84 a/6334).

69 RV des preuß. JM v. 28.4.33 (Lorenzen, a.a.O., S. 181). 
gung und fachlichen Schulung - nachzuweisen hatte, „daß Volksverbundenheit, soziales Einfühlungsvermögen, Verständnis für die gesamte völkische Entwicklung und für die Notwendigkeiten der Entwicklungsrichtung des Volkes in Gegenwart und Zukunft die Grundlage seiner Persönlichkeit“ waren. Das Ergebnis der Nachprüfung, die ein von Kerrl ernannter dreiköpfiger Ausschuß vornahm, wurde dabei „gleichwertig neben den übrigen gesetzlich festgesetzten Voraussetzungen berücksichtigt": fiel es negativ aus, so erhielt der Bewerber zwar ein Zeugnis über das Bestehen der großen Staatsprüfung, schied aber mit dessen Zustellung aus dem Justizdienst aus. ${ }^{70}$

Gürtners gegenüber Hitler geäußerte Befürchtung, daß die Chefs der Landesjustizverwaltungen versuchen würden, die Ausführung der beiden Gesetze zu sabotieren, war nicht unbegründet. Am 22. April trafen sich die Justizminister der Länder auf Einladung Franks im bayerischen Justziministerium, um zu beraten, wie die hemmenden Bestimmungen der beiden Gesetze - vor allem des Anwaltsgesetzes - unterlaufen werden könnten ${ }^{71}$ : anstelle der bisherigen illegalen Aktionen, die bei Hitler offenbar nicht mehr auf Gegenliebe stießen, sollte nunmehr eine Art administrativer Obstruktion getrieben werden. Über diese Frage hinaus wurden auf dieser Konferenz - an der bezeichnenderweise auch der Leiter der rechtspolitischen Abteilung der Reichsleitung der NSDAP Schraut und der kommissarische Reichsgeschäftsführer des BNSDJ Heuber teilnahmen - Maßnahmen ergriffen, um künftig ein geschlossenes Vorgehen der Landesjustizverwaltungen sicherzustellen und mit Unterstützung der Rechtsabteilung der NSDAP ein institutionelles Gegengewicht gegen das Reichsjustizministerium zu bilden. In seinem einleitenden Referat sprach Frank davon, „daß das Verhältnis zwischen Reich und Ländern sich in einem kritischen Stadium befinde“. Wenn auch der Führer „durch gewisse politische Umstände zur Rücksichtnahme auf Mächte veranlaßt“ sei, „die mit der Reichsleitung der N.S.D.A.P nicht identisch“ seien, und auch aus außenpolitischen Gründen „eine allzu weitgehende Offenlegung der Kampfziele auf dem Gebiete der Rasse" vermeiden müsse, so sollten die "Justizminister als Vorbilder revolutionären Wollens" mit aller Schärfe „an den Endzielen der Bewegung festhalten und sich von niemand etwas abringen lassen“.

Auf Vorschlag Kerrls wurde ein ständiger Ausschuß gegründet, der aus ihm selbst, Frank und dem kommissarischen Justizminister Sachsens Thierack bestand. Dieses Gremium sollte „dem Reichsjustizministerium gegenüber die Geschlossenheit der Länderjustizminister verkörpern" und u. a. auch deren Vorstellung über die Durchführung der beiden Reichsgesetze vertreten. Kerrl machte dabei die vielsagende Bemerkung, daß die Arbeit der Länderjustizminister ,hoffentlich nicht mehr lange im Gegensatz zum Reichsjustizministerium geleistet werden müsse“.

Freisler, den Kerrl zur Konferenz mitgebracht hatte, berichtete zunächst, wie die Reichsgesetze die „Säuberung“ der Justiz in Preußen durchkreuzten, und machte anschließend Vorschläge, auf welche Weise sie trotzdem weitergetrieben werden könne.

70 AV des preuß. JM betr. Auslese für das Richteramt (Amt des Staatsanwalts) und für die Rechtsanwaltschaft (Notariat) v. 24.4.33 und 10.5.33 (JMBl., S. 130, 142). Es wurden fünf Dreierausschüsse gebildet, deren Vorsitz Kerrl, Freisler, Crohne, Nadler und Wagemann (späterer Präs. des Landeserbhofgerichts Celle) vom preuß. JM übernahmen.

71 Vgl. zum folgenden Niederschr. über die Konferenz der Justizminister der Deutschen Länder am 22. April 1933 im Bayerischen Staatsministerium der Justiz (Akten des bayer. JM, BayHStArch., Abt. I, Sign. MJu 16833). 
Seit Beginn der nationalsozialistischen Revolution sei die Rechtsentwicklung „von dem Volk und von den Ländern getragen worden; Hemmschuh sei das Reichsjustizministerium“. Das werde besonders „auf dem Gebiet der Säuberung der Justiz von rassefremden Elementen“ deutlich, die dank der Maßnahmen der Landesjustizchefs ,in den beiden größten und in anderen Ländern so gut wie endgültig ausgeschlossen" gewesen seien. „Die Rechtsgrundlage dieser Maßnahmen“ habe nur demjenigen Schwierigkeiten bereiten können, „der nicht anerkannte, daß die gelungene Revolution neues Recht zu schaffen imstande sei“. Freisler schilderte, auf welchem Wege das preußische Justizministerium diese „Rechtsgrundlage“ zu schaffen versucht habe: indem alle Betroffenen „freiwillig [!] die Rechtsverbindlichkeit des Geschaffenen für sich anerkennen " sollten. ${ }^{72}$ Selbst von seiten der Anwaltschaft, bei der das am schwierigsten zu erreichen gewesen sei, seien

„4000 Zustimmungserklärungen eingegangen, die alle den vorgeschriebenen Satz enthielten, daß der Unterzeichnete seine Loyalität gegenüber der Regierung dadurch zum Ausdruck bringe, daß er die tatsächlich geschaffene Lage als für sich rechtsverbindlich [!] anerkenne ... Als Gegenleistung habe der Minister lediglich versprochen, Gesuche, die diese Erklärungen enthielten, darauf zu prüfen, ob im Einzelfalle eine nicht notwendige Härte vorgekommen sei.“

Diese Aktion sei „unmittelbar vor dem Abschluß gestanden, als das Reichskabinett unter dem Einfluß des Reichsjustizministeriums die Gesetze beschlossen habe“, obwohl dieses Ministerium vorher die eindeutige Meinung der Landesjustizminister gehört hatte. Die reichsgesetzliche Regelung habe „mit einem Schlag die Lage verändert" und sei weniger für die Beamtenschaft als für die Anwaltschaft unbefriedigend, besonders für Berlin, „wo nach Berechnungen der Presse 1200-1400 jüdische Anwälte wieder zugelassen werden müßten, mehr als es dort deutsche Anwälte gebe“.$^{73} \mathrm{Im}$ merhin wäre auch nach dem Erlaß dieser Gesetze noch etwas zu retten gewesen, „wenn die Ausführung der Gesetze in das pflichtmäßige, keiner Kontrolle unterworfene Ermessen der Landesjustizverwaltungen gestellt worden wäre"; leider seien aber reichsrechtliche Ausführungsbestimmungen ergangen und weitere noch zu erwarten. Da es „zur Zeit aussichtslos“ sei, eine Änderung der Gesetze zu erreichen, und ein Reichsgesetz nun einmal „respektiert und ausgeführt werden müsse“, bleibe derzeit nur die Möglichkeit, den im Gesetz enthaltenen Begriff des jüdischen „Frontkämpfers" möglichst eng und den Begriff des Anwalts, der sich kommunistisch betätigt habe, möglichst weit auszulegen. Dabei entwickelte Freisler eine Auslegungskunst, die dem späteren Präsidenten des Volksgerichtshofs alle Ehre machte:

„Man könne z.B. sehr wohl auf dem Standpunkt stehen, daß Anwälte, die systematisch die Rechtspflege durch ihr Auftreten lächerlich gemacht oder systematisch Verträge entworfen hätten, die deutsche Bauern in die Hand gewissenloser Grundstücksspekulanten gebracht hätten, im Sinne des Bolschewismus tătig gewesen [!] seien, und das sei auch kommunistische Betätigung."

Auch beim Begriff des Frontkämpfers könne nicht nur zwischen Front und Etappe, sondern auch zwischen „Frontriechern“ und „Frontkämpfern“ unterschieden werden: die bloße Anwesenheit bei einzelnen Kampfhandlungen genüge nicht, „vielmehr müsse eine gewisse seelische Einstellung [!] dazukommen. Es müsse eine individuelle

${ }^{72} \mathrm{Zu}$ Kerrls diesbezüglichem Erlaß s. voranstehend S. 135 u. Anm. 52.

${ }^{73}$ Die Aussage Freislers war übertrieben und falsch: vgl. das Zahlenverhältnis zwischen den wiederzugelassenen jüdischen und den „,arischen“ Berliner RAen im folgenden S. 149 u. Tabelle S.151. 
Prüfung Platz greifen, ob jemand als Frontkämpfer zu betrachten sei oder nicht“. Solange diese Begriffe nicht näher umrissen seien, könne man mit ihnen ,sehr viel anfangen“. Bei den jüdischen Richtern sei mit dieser Methode allerdings nicht viel zu erreichen, von ihnen müsse „ein nicht unerheblicher Prozentsatz wieder hereingenommen werden“. Man könne sie höchstens ,im Grundbuchamt oder in Beschwerdekammern verschwinden“ lassen und „so auf Stellen versetzen, auf denen zu bleiben sie keine Lust hätten" und ihre Pensionierung beantragen würden. Möglichkeiten biete hier allenfalls $\S 4$ des Berufsbeamtengesetzes, in dem nicht nur bei früherer Betätigung in Parlamenten usw., sondern schon bei bloßer Mitgliedschaft in demokratischen Parteien nationale Unzuverlässigkeit angenommen werde. Jedenfalls stellten nähere Ausführungsbestimmungen des Reichsjustizministeriums oder des Reichsinnenministeriums „eine ungeheure Gefahr“ dar und müßten um jeden Preis verhindert werden. Man werde aber "gut tun, auch keine landesrechtlichen Vorschriften herauszugeben, sondern das Gesetz einfach auszuführen“. Schraut ergänzte die Ausführungen Freislers mit dem Vorschlag, daß bei auftauchenden Zweifeln nicht das Reichsjustizministerium, sondern die Rechtsabteilung in der Reichsleitung der Partei befragt werden sollte.

Die Konferenzteilnehmer kamen überein, daß der neugebildete Dreierausschuß den Berliner Zentralbehörden als einstimmiges Ergebnis ihrer Beratungen folgendes mitteilen sollte: einmal, „daß die Vielgestaltigkeit des Lebens der Bestimmung der Begriffe Frontkämpfer und anderer Begriffe" spotte und eine solche Bestimmung nur „die loyale Ausführung des Gesetzes hemmen" würde; zum anderen, daß auch ohne sie die Einheitlichkeit der Ausführung gesichert sei, weil alle Landesjustizminister das Gesetz gleich auffaßten und in zweifelhaften Fällen „die Sache dem heute gebildeten Ausschuß vorgelegt" werde. Wie Frank den Teilnehmern mitteilte, werde der Ausschuß bestimmte Grundsätze aufstellen, „die von den Ministern der anderen Länder ihren Maßnahmen einfach zu Grunde gelegt werden könnten“, er werde sie aber „von Person zu Person, nicht von Amt zu Amt bekanntgeben“(!).

Als der Hamburger Justizsenator Rothenberger die Konferenz davon informierte, daß das Reichsinnenministerium alle Ministerpräsidenten und Innenminister der Länder für den 25. April zu einer Sitzung eingeladen habe, auf der die Ausführungsbestimmungen zum Berufsbeamtengesetz besprochen werden sollten, erklärte Frank, er werde „als einstimmigen Beschluß der heutigen Tagung sogleich dem Herrn Reichsinnenminister telegraphisch bekannt geben“, daß der neu gebildete Ausschuß zu dieser Sitzung hinzugezogen werden solle. Trotz der bestimmten Behauptung Kerrls, bei dieser Sitzung "werde man zugegen sein und die Ansichten der Länderjustizminister durchzusetzen wissen“, fand die Berliner Besprechung am 25. April ohne Beteiligung dieses Ausschusses statt: die Justiz war in ihr ausschließlich durch das Reichsjustizministerium vertreten.

Auf dieser Besprechung im Reichsinnenministerium wurden Ausführungsvorschriften beraten ${ }^{74}$, die Freislers Absicht einer „freien“ Auslegung der gesetzlichen Bestimmungen weitgehend vereitelten: In einer Durchführungsverordnung vom 6. Mai ${ }^{75}$

$74 \mathrm{Zu}$ dieser Bespr. vgl. Aktenverm. des RMdI v. 27.4.33 und Aufz. von Staatsrat Dr. Schultz (Hamburg) v. 27.4.33, beide abgedruckt bei Mommsen, a.a.O., S. $159 \mathrm{ff}$.

75 Vgl. 3. DurchfVO zum BBG v. 6.5.33 (RGBl. I, S. 245). Die 2. DurchfVO v. 4.5.33 (RGBl. I, S. 233) betraf die analoge Anwendung der Bestimmungen des BBG auf Angestellte und Arbeiter bei Behörden usw. 
wurde als „Frontkämpfer“ anerkannt, wer „bei der fechtenden Truppe an einer Schlacht, einem Gefecht, einem Stellungskampf oder an einer Belagerung teilgenommen" hatte. Als Nachweis dienten die Eintragungen in der Kriegsstammrolle oder in der Kriegsrangliste, so daß für eine subjektive Beurteilung des Einzelfalles kein Raum blieb. Dabei galten die Kämpfe „im Baltikum, in Oberschlesien, gegen Spartakisten und Separatisten sowie gegen die Feinde der nationalen Erhebung" gleichfalls als Weltkriegskämpfe. Bei den „Altbeamten“ wurde einem planmäßigen Beamten gleichgestellt, wer am 1. August 1914 zwar noch nicht ernannt war, aber „sämtliche Voraussetzungen für die Erlangung seiner ersten planmäßigen Anstellung erfüllt“, d.h. die letzte erforderliche Prüfung abgelegt und sich später als Beamter bewährt hatte. Die Annahme der nationalen Unzuverlässigkeit eines Beamten sollte entgegen Freislers Absichten nicht allein durch die Zugehörigkeit zu einer politischen Partei, etwa zur SPD oder zum Zentrum - mit Ausnahme allerdings der KPD -, begründet werden. Bei der Bewertung der politischen Betätigung sollten selbst „gelegentliche Entgleisungen im Wahlkampf" gegen die nationale Bewegung keine Rolle spielen, dagegen „gehässige" Beschimpfungen ihrer Führer sowie die dienstliche Benachteiligung und Verfolgung national gesinnter Beamter angerechnet werden. Der Verordnung war auch das Muster des Fragebogens beigegeben, der bei der Durchführung der $\S \S 2$ bis 4 des Berufsbeamtengesetzes verwendet werden sollte. ${ }^{76}$

Mit seiner Ernennung zum „Reichsjustizkommissar ${ }^{477}$, mit der er im staatlichen Bereich auf die Reichsebene angehoben worden war, machte sich bei Hans Frank eine veränderte Einstellung sowohl zu der in München beschworenen Einheitsfront der Landesjustizminister wie auch zur Durchführung der beiden Reichsgesetze bemerkbar. Damit begann jene Rivalität zwischen ihm und Kerrl um die Einflußnahme auf die Reichsjustiz, die schließlich mit einem Bruch enden sollte. ${ }^{78}$ Anstelle jenes in München gebildeten Dreierausschusses betrachtete sich nunmehr Frank allein als Sprecher der Landesjustizverwaltungen gegenüber dem Reich, und als Reichskommissar, der - zumindest der Bezeichnung nach - für die Gleichschaltung der Justiz in den Ländern verantwortlich war, trat er für die korrekte einheitliche Ausführung der reichsgesetzlichen Bestimmungen ein. Schon in seinen eigenen Ausführungsbestimmungen zum Rechtsanwaltsgesetz für Bayern vom 18. April hob Frank - im Gegensatz zu Kerrl - das am 31. März erlassene Vertretungsverbot für jüdische „Altanwälte“ pauschal wieder auf, ebenso für jene, die nach übereinstimmender Feststellung des zuständigen Oberlandesgerichtspräsidenten und des Anwaltskammervorstandes als Frontkämpfer bzw. als Väter oder Söhne eines Gefallenen unter die vorgesehenen Ausnahmen fielen. Gegen die übrigen jüdischen Anwälte ließ er gemäß $\S 4$ des Rechtsanwaltsgesetzes das Vertretungsverbot bestehen, bis er bzw. sein Ministerium über die Zurücknahme der Zulassung entschieden hatte. Zu diesem Zweck hatten die Anwaltskammervorstände diese Anwälte bis zum 1. Juni den Oberlandesgerichtspräsidenten zu benennen, die die Betroffenen und die Vorstände der beteiligten Gerichte hören, Ermittlungen anstellen und die Vorgänge mit einer eigenen Stellungnahme

${ }^{76}$ Die das Verfahren regelnden Bestimmungen der VO werden an dieser Stelle nicht behandelt, da sie in die späteren Durchführungsvorschriften Kerrls Eingang fanden (vgl. S. 154 ff.).

77 Zur Ernennung Franks am 22.4.33 und seiner Rolle als „Reichskommissar für die Gleichschaltung der Justiz in den Ländern und für die Erneuerung der Rechtsordnung" s. Kapitel II.2., S.86ff. und 89ff.; Kapitel VII.2.a., S. $754 \mathrm{ff}$.

78 Vgl. dazu Kapitel II.2., S.87f., und II.4., S. 104. 
dem Ministerium bis zum 1. Juli vorlegen sollten. Gegen Rechtsanwälte, die sich kommunistisch betätigt hatten, sollte der zuständige Anwaltskammervorstand die Zurücknahme der Zulassung beim Oberlandesgerichtspräsidenten beantragen, der ein einstweiliges Vertretungsverbot verhängte und Frank für die endgültige Entscheidung berichtete. ${ }^{79}$

$\mathrm{Zu}$ der in München beschlossenen nächsten Tagung der Landesjustizminister, die am 6. Mai in Stuttgart stattfand ${ }^{80}$, lud Frank ostentativ Reichsjustizminister Gürtner ein. Um sich vor den nationalsozialistischen Landesjustizchefs durch Kerrl nicht den Rang ablaufen zu lassen, kritisierte Frank, der die Stuttgarter Versammlung leitete, zwar auch weiterhin, daß die beiden Reichsgesetze über die Köpfe der Landesjustizminister zustande gekommen seien - hier werde er als Reichsjustizkommissar künftig Wandel schaffen -, und bezeichnete vor allem das Anwaltsgesetz als eine „Unmöglichkeit“, da es mit den Zielen der Bewegung schlechtweg "unvereinbar" sei, die auch er als Führer des BNSDJ unvermindert anstrebe. Aber das Tempo der revolutionären Entwicklung werde ausschließlich durch den Führer bestimmt, der die innen- und auBenpolitischen Folgen berücksichtigen müsse und „in dem Falle nicht der Führer unserer Partei, sondern der Reichskanzler im Reichsorganismus“ sei. Deshalb hätten auch die Landesjustizminister als Parteigenossen ihre Aufgabenkreise in Staat und Partei zu trennen und den Willen Hitlers, der sich in staatlichen Gesetzen manifestiere, strikt zu befolgen. Mit deutlicher Anspielung auf die vorprellende Politik Kerrls äußerte Frank, es gehe nicht an, „ein Sondertempo in der revolutionären Entwicklung einschlagen“ zu wollen: „Dieser Ehrgeiz - ein Land möchte das andere in den revolutionären Belangen übertrumpfen - wirkt sich hemmend für das Gesamtwollen unseres Führers aus und ist daher auch als Willensrichtung einzustellen. Wir sind hier eine Kampffront, die in einer Linie vorrückt.“ Damit „dem Willen des Reichsgesetzgebers in den Ländern der Durchbruch eröffnet" werde, kündigte Frank an, daß er als Reichsjustizkommissar zumindest in denjenigen Ländern, die zu den Reichsgesetzen bisher noch keine Ausführungsbestimmungen erlassen hatten, für einheitliche Durchführungsvorschriften sorgen werde, und zwar nach dem Muster, wie er sie in Bayern erlassen habe, ,und nicht unbedingt nach dem Muster, das in einem anderen Land [!] für die Ausführungsbestimmungen erlassen wurde“.

Kerrl reagierte auf Franks Ausführungen mit heftigen Angriffen auf das Reichsjustizministerium, das ihm mit der vorschnellen gesetzlichen Regelung für die Zulassung jüdischer Rechtsanwälte „sehr unangenehm in die Quere gekommen“ sei: er wäre „vier Tage später in der Lage gewesen, die Frage [in Preußen] als geregelt anzusehen". Nach der Besprechung mit dem Reichsjustizministerium am Vormittag des 7. April hätten sich die Landesjustizminister „der Hoffnung hingegeben, daß das, was sie wollten, auch unbedingt in der Reichsgesetzgebung“ enthalten sein werde, nämlich, „daß in das Gesetz selbst nicht etwa die von uns für selbstverständlich angesehenen [!] Ausnahmen hineinkämen, sondern daß diese Ausnahmen absolut der Ausführung überlassen würden“. Nachdem er an jenem Apriltag vergebens versucht habe, te-

79 Vgl. Bekanntmachung des bayer. JM zur Ausführung des Reichsgesetzes über die Zulassung zur Rechtsanwaltschaft v. 18.4.33 (Bayer. JMBl. 1933, S. 17).

$80 \mathrm{Vgl}$. zum folgenden Niederschr. über die Zusammenkunft der Reichs- und Landesjustizminister in Stuttgart am 6. Mai 1933, Marmorsaal des Neuen Schlosses (Akten des bayer. JM, BayHStArch., Abt. I, Sign. MJu 16833). 
lefonisch etwas über die weitere Behandlung der Sache durch das Reichsjustizministerium zu erfahren, habe er nach Erlaß des Gesetzes „außerordentlich enttäuscht“ feststellen müssen, daß dessen Inhalt ,genau entgegengesetzt den in der Länderministerkonferenz beschlossenen Richtlinien“ gestaltet worden sei. Das Gesetz entspreche nicht dem Willen der Landesjustizminister „und auch nicht dem unseres Führers“, mit dem er „sehr häufig darüber gesprochen“ habe. Man könne das Gesetz „natürlich nicht dem Führer zur Last legen, sondern nur dem Reichsjustizministerium“, das hier ohne Rücksicht auf die Landesjustizminister „seinen eigenen Weg gegangen“ sei. Wenn Hitler das absolute Zahlenverhältnis der Juden in der Rechtsanwaltschaft gewußt hätte ${ }^{81}$, wäre er nicht bereit gewesen, die jüdischen Beamten und Anwälte ,über einen Kamm scheren“ zu lassen und „ohne weiteres die Bestimmung des Berufsbeamtengesetzes, die allen denen, die am 1 . August $1914 \mathrm{im} \mathrm{Amte}$ waren, nun auch die $\mathrm{Zu}$ lassung zur Rechtsanwaltschaft gestattet, gutzuheißen“. Wenn dann das Reichsjustizministerium in einer voreiligen Ausführungsbestimmung dazu festgestellt habe, „wer am 1. August 1914 als Rechtsanwalt zugelassen wurde, könne nunmehr ohne Rücksicht auf mein Vertretungsverbot wieder eintreten", so habe das einfach nicht den Tatsachen entsprochen,

„sondern es war ganz selbstverständlich, daß jetzt von uns eine sorgfältige Prüfung stattfinden mußte, und zwar deshalb, weil wir nicht nach dem Grundsatz verfahren können, heraus aus den Kartoffeln, rein in die Kartoffeln. Wir können nicht sagen: Wir lassen euch alle zu und prüfen hinterher nach, wen wir herausschmeißen wollen, sondern die jetzt von uns getroffene Durchführung des Gesetzes mußte zur Folge haben, daß das, was in der Verordnung bestimmt wurde, endgültig durchgeführt wird.“

Da „von allen Seiten“ gegen ihn „gehetzt“ worden sei, daß er „die Durchführung des Gesetzes nicht loyal betreiben würde“, habe er schließlich doch Ausführungsbestimmungen erlassen ${ }^{82}$, obwohl alle Landesjustizminister bei ihrer letzten Konferenz in München auf solche Bestimmungen verzichtet und allein durch ihre Absprache ein einheitliches Verfahren gewährleistet hätten: dafür - fuhr Kerrl mit einem Seitenhieb auf Frank fort - „wäre nicht einmal die Einsetzung eines Reichskommissars für die Gleichschaltung notwendig“ gewesen. Die Durchführung des Anwaltsgesetzes werde nunmehr in Berlin „unerhörte“ Konsequenzen haben; statt der von ihm gegenwärtig zugelassenen 36 jüdischen Anwälte werde man dort 1135 wieder zulassen müssen, die dann 1982 arischen Anwälten gegenüberständen; in Preußen, wo es insgesamt 8352 nichtjüdische Anwälte gäbe, würden ,nach den bisherigen noch längst nicht endgültigen Feststellungen" 1706 Juden wieder zugelassen werden müssen. ${ }^{83}$ Noch habe sein Ministerium die Wiederzulassung bis zum 11. Mai vertagt, aber bei den genannten Resultaten wisse er nicht, wie die Befürchtung - die er schon in der Besprechung am 7.April dem Reichsjustizminister gegenüber geäußert habe - abgewendet werden könne, „daß das Volk selbst sich gegen die Durchführung“ des Gesetzes auflehnen werde. Seine bisherigen Maßnahmen hätten nur vermeiden wollen, „daß die Reichsregierung selbst in eine so unbequeme und unangenehme Lage hineinversetzt werde“.

81 Daß Hitler darüber informiert war, geht aus der Bemerkung in seinem Schr. an Hindenburg v. 5.4.33 (vgl Anm. 48) hervor, daß ,in Berlin und anderen Städten das Judentum bis zu $80 \%$ und darüber“ der Rechtsanwalts- und Ärztestellen innehabe.

$82 \mathrm{Zu} \mathrm{Kerrls} \mathrm{AV} \mathrm{v.} 25.4 .33$ vgl. das folgende.

83 Vgl. die endgültigen Zahlen für Preußen und Berlin im folgenden S. 149. 
Wie ihm Göring und Popitz versichert hätten, würde das Reichskabinett das Gesetz nicht in der Form erlassen haben, wenn es ,auch nur eine Ahnung von diesen Resultaten gehabt hätte“, beide hätten sich sonst „mit allen Mitteln dagegen gesträubt“. Beide unterstützten daher auch seine Ansicht, daß künftig „bei Reichskabinettssitzungen nicht nur Personen, die in Rahmengesetzen keine praktischen Erfahrungen haben“, sondern der jeweilige preußische Fachminister - bei Justizangelegenheiten also er selbst - zur Beratung zugezogen werden sollten. Mit dieser Forderung gedachte Kerrl unmittelbaren Einfluß auf die Gestaltung der Justiz im Reich zu nehmen und Frank als Reichsjustizkommissar aus der maßgeblichen Rolle zu verdrängen. Wäre er „in der Kabinettssitzung zugegen gewesen“, fuhr Kerrl fort, „wäre es ausgeschlossen gewesen, daß das Gesetz Tatsache geworden wäre“. Da er nicht übersehe, „ob die Reichsregierung überhaupt in Betracht ziehen kann, heute schon eine Änderung des Gesetzes vorzunehmen“, sei er nunmehr gebunden, das Gesetz nach den reichsrechtlichen Bestimmungen - und zwar nicht „peu à peu“, sondern „mit einem Schlag“ durchzuführen. „Wir müssen dann abwarten“, fügte er drohend hinzu, „was kommen wird."

Während der württembergische Justizminister Mergenthaler erklärte, daß die Durchführung des Rechtsanwaltsgesetzes wegen des geringen Anteils jüdischer Anwälte in seinem Lande keine Schwierigkeiten bereite, betonte der Vertreter der badischen Justiz, Oberregierungsrat Reinle, daß sich dieses Gesetz in Baden ebenfalls ,verheerend“ auswirke: von 220 jüdischen Anwälten würden 190 wieder zugelassen werden müssen; vor allem in dem jüdischen Ballungszentrum Mannheim müsse man angesichts der Volksstimmung ,geradezu Angst vor dem Moment“ haben, „wo diese ganze Judenschar in die Gerichtsgebäude zurückkehrt“. Von den ca. 40 jüdischen Richtern, Staatsanwälten und Notaren, die wie in Preußen zunächst alle beurlaubt seien, könne man „vielleicht 15 entfernen“. Die badische Justizverwaltung habe sich deshalb „bis jetzt von Ausführungsbestimmungen zurückgehalten, weil wir uns nicht festlegen wollten“. Um das Anwaltsgesetz durchzuführen und dennoch das Problem der jüdischen Anwälte in Berlin und anderen Städten zu lösen, schlug Frank vor, „eine Dislocierung der Anwälte" zu ermöglichen, indem z.B. der preußische Justizminister befugt werden sollte, den Ort zu bestimmen, an dem ein Berliner jüdischer Anwalt wieder zugelassen werde. Er bat Gürtner um eine Äußerung, ob er in diesem Sinne „nicht doch im Reichskabinett auf eine Änderung des Reichsgesetzes“ hinwirken könne.

Die geforderte Niederlassung an einem fremdbestimmten Ort mußte für den betroffenen jüdischen Anwalt eine erhebliche Härte, wenn nicht den Ruin seiner wirtschaflichen Existenz bedeuten: mußte er sich doch dort - als ,Jude“ deklariert - in Konkurrenz zu den alteingesessenen „arischen“ Rechtsanwälten eine völlig neue Klientel aufbauen. Welche Nebenabsichten die preußische Justizleitung mit der gewünschten Ermächtigung zur „Dislozierung“ verband, machte Freisler auf der Stuttgarter Tagung ziemlich deutlich: Es sei „ganz klar, daß die Orte, wo wir diese Leute hinschieben, wenig von dieser Maßnahme erbaut sein werden (Heiterkeit und Zustimmung)“. Angesichts der Schwierigkeiten, die sie daher am neuen Niederlassungsort erwarteten, bestehe die „Hoffnung, daß eine ganze Menge von Berliner Anwälten dann auf die Zulassung verzichten“ werde. Voraussetzung dafür sei allerdings, „daß der Justizminister in weitgehendem Umfang das Recht haben muß, den Verbannungsort [?] 
zu bestimmen“. Diese Regelung könne „sogar vielleicht auf einem anderen als reichsgesetzlichen Wege" getroffen werden.

In der Erwiderung, die Gürtner angesichts der gegen ihn und sein Ministerium gerichteten Anwürfe mit bewundernswerter Gelassenheit und Sachlichkeit vorbrachte, bestand er auf der einheitlichen und gleichmäßigen Ausführung der erlassenen Gesetze durch die Länder nach den reichsrechtlichen Vorschriften, für die nicht zuletzt gerade das neu errichtete Reichsjustizkommissariat die Gewähr bieten solle. Es handle sich hierbei nicht bloß um eine Frage der Justiz, sondern um „eine Frage der Staatsautorität, der Autorität der Reichsregierung schlechthin“. Der Vollzug des Anwaltsgesetzes böte mit Ausnahme der „Städte Berlin, Frankfurt, Breslau und Mannheim“ kein unbefriedigendes Ergebnis, denn wenn man den Anteil der verbleibenden jüdischen Rechtsanwälte an der Rechtsanwaltschaft Preußens oder ganz Deutschlands betrachte, ergäben sich „selbstverständlich ganz andere Zahlen“. Um die vorgetragenen, auch ihm bekannten, örtlich begrenzten Probleme zu lösen, könne der an sich nächstliegende Weg einer Änderung des erlassenen Gesetzes augenblicklich auf keinen Fall beschritten werden, und zwar „aus Gründen, die ganz abseits vom Inhalt der Gesetze liegen“: von allem anderen abgesehen, konnte ein erneut anhebendes, allgemeines Tauziehen auch um die bereits gesicherten Inhalte der Gesetze keinesfalls in Gürtners Sinn liegen. Ob die vorgeschlagene Dislozierung von Anwälten ohne Gesetzesänderung ermöglicht werden könne, meinte Gürtner, müsse erst geprüft werden. Über einen Punkt aber könne „nicht diskutiert werden“: die Behandlung der jüdischen Frontkämpfer; aus seiner eigenen und der ihm bekannten Einstellung Hindenburgs zu dieser Frage heraus bezeichnete Gürtner jede Einschränkung dieser Ausnahme als „untragbar“. Es gäbe aber auch „noch ein paar andere Fragen, die in der Praxis zu Zweifeln Anlaß gegeben“ hätten. Wenn z. B. ein Anwalt am 1. August 1914 zugelassen war, aber in der Zwischenzeit seine Zulassung zum Zwecke der Änderung unterbrochen habe - also etwa vom Landgericht zum Oberlandesgericht übergetreten sei -, so sei "die Meinung laut geworden, daß er nicht mehr unter die Zulassung fallen soll“" ${ }^{84}$ Eine solche Auslegung sei aber „mit dem Gedanken des Reichsgesetzes nicht vereinbar". Auch dem von verschiedenen Seiten geforderten Verbot, die weiterhin zugelassenen jüdischen Anwälte zu Armenanwälten, Konkursverwaltern, Testamentsvollstreckern usw. zu bestellen, wolle er „sehr widerraten“, da damit praktisch erneut „eine Differenzierung unter den zugelassenen Anwälten“ vorgenommen würde; die Handhabung dieses Problems solle man nach wie vor "ganz in das richterliche Ermessen stellen“.

Diese Empfehlung sollte Kerrl noch im selben Monat beiseiteschieben. ${ }^{85}$ Immerhin mußte er sich aber bequemen, die Zulassung jüdischer Rechtsanwälte nach den reichsgesetzlichen Bestimmungen zu vollziehen. Die von ihm in Stuttgart erwähnten preußischen Ausführungsvorschriften vom 25. April wichen jedoch von denen Franks in mehrfacher Hinsicht ab. So sollte „der jetzt überall bestehende Zustand“, d.h. sein generelles Vertretungsverbot vom 31. März, bis zum 8. Mai aufrechterhalten werden eine Regelung, die hinsichtlich der jüdischen Altanwälte und Frontkämpfer dem $§ 4$

\footnotetext{
${ }^{84}$ Nach Kerrls AV (s. übernächste Anm.) mußte diese Tatsache dem preuß. JM angezeigt werden, offenbar in der Absicht, sie gegen den betreffenden Anwalt verwerten zu können.

85 S. nachfolgend S. 163.
} 
des Rechtsanwaltsgesetzes glatt widersprach. Ferner wurden im Gegensatz zur bayerischen Regelung von vornherein NS-Stellen und weitere Behörden in das Verfahren eingeschaltet. Die Oberlandesgerichtspräsidenten hatten dem preußischen Justizminister bis zum 5. Mai eine Liste derjenigen Rechtsanwälte ihres Bezirks einzureichen, bei denen nicht nur nach Ansicht des Oberlandesgerichtspräsidenten, des Landgerichtspräsidenten, des aufsichtsführenden Amtsrichters oder des - am 22. April nach Vorschlägen des BNSDJ bzw. der NSDAP in Preußen neu gewählten - Vorstandes der Anwaltskammer eine Überprüfung in Frage kam, sondern auch nach Ansicht des Gauobmannes des BNSDJ (!) oder ,anderer nach Meinung des OLGPräs. in Frage kommenden Stellen“. In diesem Sammelbericht war bei jedem Rechtsanwalt zu vermerken, ob er am 1. August 1914 zugelassen war, ob die Zulassung seitdem jemals unterbrochen war, das Gericht der Zulassung sich geändert hatte und der Anwalt seinen Beruf während der Zulassung auch dauernd ausgeübt oder sich „ausschließlich oder hauptsächlich als Syndikus bestimmer Firmen oder in ähnlichen Stellen betätigt“ hatte ( 1 1). Diejenigen jüdischen Rechtsanwälte, die die Ausnahmeregelung des Gesetzes für sich beanspruchten, mußten die entsprechenden Belege bis zum 4. Mai dem zuständigen Oberlandesgerichtspräsidenten einreichen, der sie bis zum 6. Mai dem preußischen Justizminister zustellte $(\S 2)$. Die Oberlandesgerichtspräsidenten sollten ferner die zuständigen Gauobleute des BNSDJ, Anwaltskammervorstände, Polizeibehörden, Staatsanwaltschaften und ,andere ihnen geeignet erscheinende Organisationen" um Mitteilung ersuchen, welche Rechtsanwälte sich in kommunistischem Sinn betätigt hatten, und diese Mitteilungen und Unterlagen bis spätestens zum 20. Mai dem Justizministerium einreichen ( $\S 3$ ). Bot dieses Material eine ausreichende Grundlage für eine Prüfung, sollte sich der betroffene Anwalt dazu äußern und entlastende Beweise beibringen können $(\S 4)$. Jüdische Rechtsanwälte, die sich vom vorläufigen Vertretungsverbot irrtümlich betroffen glaubten, konnten je eine Unbedenklichkeitsbescheinigung des zuständigen Oberlandesgerichtspräsidenten, Generalstaatsanwalts und Vorstandes der Anwaltskammer beibringen; bei Vorliegen aller drei Bescheinigungen wurde in Aussicht gestellt, daß das Justizministerium das Verbot aufhob, falls nicht „andere Gründe“ (!) entgegenstanden ( $(5)$. Die endgültige Entscheidung über die künftige Nichtzulassung behielt sich in allen Fällen der Justizminister vor $(\S 6)^{86}$

Die aufgrund dieser Verfügung bis zum 11. Mai 1933 - dem von Kerrl auch in Stuttgart genannten Datum - durchgeführte Prüfung ergab, daß von den in Berlin (Kammergerichtsbezirk) 3890 zugelassenen Rechtsanwälten, von denen 1892 „Arier“ und 1998 Juden waren, 797 Juden als Altanwälte und 406 als Frontkämpfer eingestuft wurden. Gegen 487 Juden und 37 „Kommunisten“ wurden Vertretungsverbote verhängt. Insgesamt wurden in Berlin künftig 1203 jüdische Anwälte zugelassen. In PreuBen (einschließlich Berlin) gab es 11814 Anwälte, darunter 3515 jüdische, von denen 735 als Frontkämpfer und 1383 als Altanwälte anerkannt wurden; gegen 923 Juden und 118 „Kommunisten“ wurden Vertretungsverbote verhängt. In Preußen blieben insgesamt 2158 jüdische Anwälte zugelassen ${ }^{87}$; der von Kerrl als Reaktion darauf an-

${ }^{86} \mathrm{Vgl}$. AV des preuß. JM v. 25.4.33 betr. Ausführung des Reichsgesetzes über die Zulassung zur Rechtsanwaltschaft v. 7.4.33 (JMBl., S. 127).

$87 \mathrm{Vgl}$. Verlautbarung des preuß. JM v. 11.5.33, Ber. von Wolff's Telegraph. Büro v. 12.5.33 (Akten der RK, BA, Sign. R 43 II/1534). Dort auch die Aufschlüsselung für die zwölf anderen preuß. OLGBezirke. Wieso in Berlin 271, in Preußen 316 jüdische Anwälte mehr ausschieden als Vertretungsverbote erlassen wurden, wurde in der Verlautbarung nicht erklärt. 
gekündigte Entrüstungssturm des Volkes blieb jedoch aus: nur vereinzelt kam es zu Zusammenstößen mit jüdischen Rechtsanwälten. ${ }^{88}$

Bis zum 30. April 1934 sollte sich die Zahl der jüdischen Anwälte in Preußen, die aufgrund des Rechtsanwaltsgesetzes aus ihrem Beruf entfernt wurden, auf 1084 erhöhen. Da bis dahin weitere 280 Juden durch Tod, freiwillige Löschung und aus anderen Gründen ausgeschieden waren, gab es in den dreizehn Oberlandesgerichtsbezirken Preußens zu diesem Zeitpunkt noch 2009 zugelassene jüdische Rechtsanwälte (s. Tabelle S. 151) ${ }^{89}$

Damit war der jüdische Anteil an der Anwaltschaft in Preußen von $28,5 \%$ am 7. April 1933 auf 18,5\% am 30. April 1934 gesunken. In Bayern, wo die Zahl der jüdischen Rechtsanwälte 440, d.h. 17,8\% aller bayerischen Rechtsanwälte (2473) betragen hatte, waren schon bis zum 30. September 193398 wegen ihrer Abstammung, 11 wegen „kommunistischer Betätigung“ und 19 durch Tod, Aufgabe der Zulassung o. ä. ausgeschieden, so daß die verbleibenden 312 jüdischen Anwälte noch 12,6\% der Gesamtzahl ausmachten. ${ }^{89 a}$ In den zwölf außerpreußischen Oberlandesgerichtsbezirken einschließlich der vier bayerischen wurde bis April 1934 insgesamt 339 jüdischen Anwälten die Zulassung entzogen; hier verblieben ca. $1200 \mathrm{im}$ Beruf, so daß zu diesem Zeitpunkt im ganzen Reich rund 3200 jüdische Rechtsanwälte zugelassen blieben. ${ }^{90}$

Vom Berufsverbot wurden vor allem die jüngeren jüdischen Anwälte betroffen: Da nach der vor dem Ersten Weltkrieg geltenden Regelung der juristischen Laufbahn am 1.August 1914 nur Anwalt sein konnte, wer mindestens 25 Jahre alt war, fielen unter die Ausnahme der Altanwälte nur 45jährige und ältere Juden. Da ferner im Ersten Weltkrieg kaum jemand Frontkämpfer sein konnte, der nach 1900 geboren war, mußten auch die unter diese Kategorie Fallenden mindestens 33 Jahre alt sein. Einen Sonderfall bildeten hier nur die Söhne gefallener jüdischer Frontkämpfer.

Bei der Durchführung des Berufsbeamtengesetzes begann Kerrl mit den Notaren. Während Frank die Ausführung des Gesetzes und die Aufhebung der Beurlaubungen in den vorgesehenen Fällen für Notare, Richter und Staatsanwälte gemeinsam schon Mitte April angeordnet hatte ${ }^{91}$, verfügte Kerrl am 16. Mai zunächst das hinsichtlich der Notare anzuwendende Verfahren ${ }^{92}$ : Die Landesgerichtspräsidenten sollten eine Liste derjenigen Notare ihres Bezirks anlegen, die unter die Bestimmungen der $\S \S 2$ bis 4 des Gesetzes fielen, und sie auffordern, spätestens bis 22. Mai den ausgefüllten Fragebogen, den die Dritte Durchführungsverordnung vom 6. Mai für den jeweils zutreffenden Paragraphen vorschrieb, nebst ergänzender Äußerung einzureichen. Soweit die Notare bereits anläßlich der Durchführung des Rechtsanwaltsgesetzes ${ }^{93}$ Urkunden

${ }^{88}$ Laut Lorenzen, a.a.O. (Anm. 21), S. 182, „vor einem Gericht einer großen Stadt“.

89 Vgl. die Übersicht nach dem Stand 1.5.34 (DJ 1934, S.950). Abweichend von der voranstehenden Verlautbarung vom 11.5.33 wird die Zahl der vor der Durchführung des Rechtsanwaltsgesetzes zugelassenen nichtarischen Rechtsanwälte für Berlin mit 1879, für Preußen mit 3370 angegeben.

${ }^{89 a}$ Vgl. Chronik der Bayerischen Justizverwaltung, Eintr. v. 30.9.33 (Arch. des IfZ, Sign. Fa 285/6).

${ }^{90}$ Nach einer Zusammenstellung der Reichsrechtsanwaltskammer v. 11.4.34 (vgl. Lorenzen, a.a.O., S. 184). Danach wurden in den OLGBezirken Bamberg 11, Braunschweig 3, Darmstadt 22, Dresden 39, Hamburg 79, Jena 6, Karlsruhe 52, München 55, Nürnberg 34, Oldenburg keinem, Rostock 2, Stuttgart 15 und Zweibrücken 21 jüdischen Rechtsanwälten die Zulassung entzogen.

91 Vgl. dazu im folgenden S. 154 und Anm.97.

92 Vgl. AV des preuß. JM v. 16.5.33 (JMBl., S.151).

${ }^{33}$ In Preußen (mit Ausnahme des Rheinlandes) herrschte das Anwaltsnotariat. 
1. Die „Säuberung“ und ihre rechtlichen Grundlagen

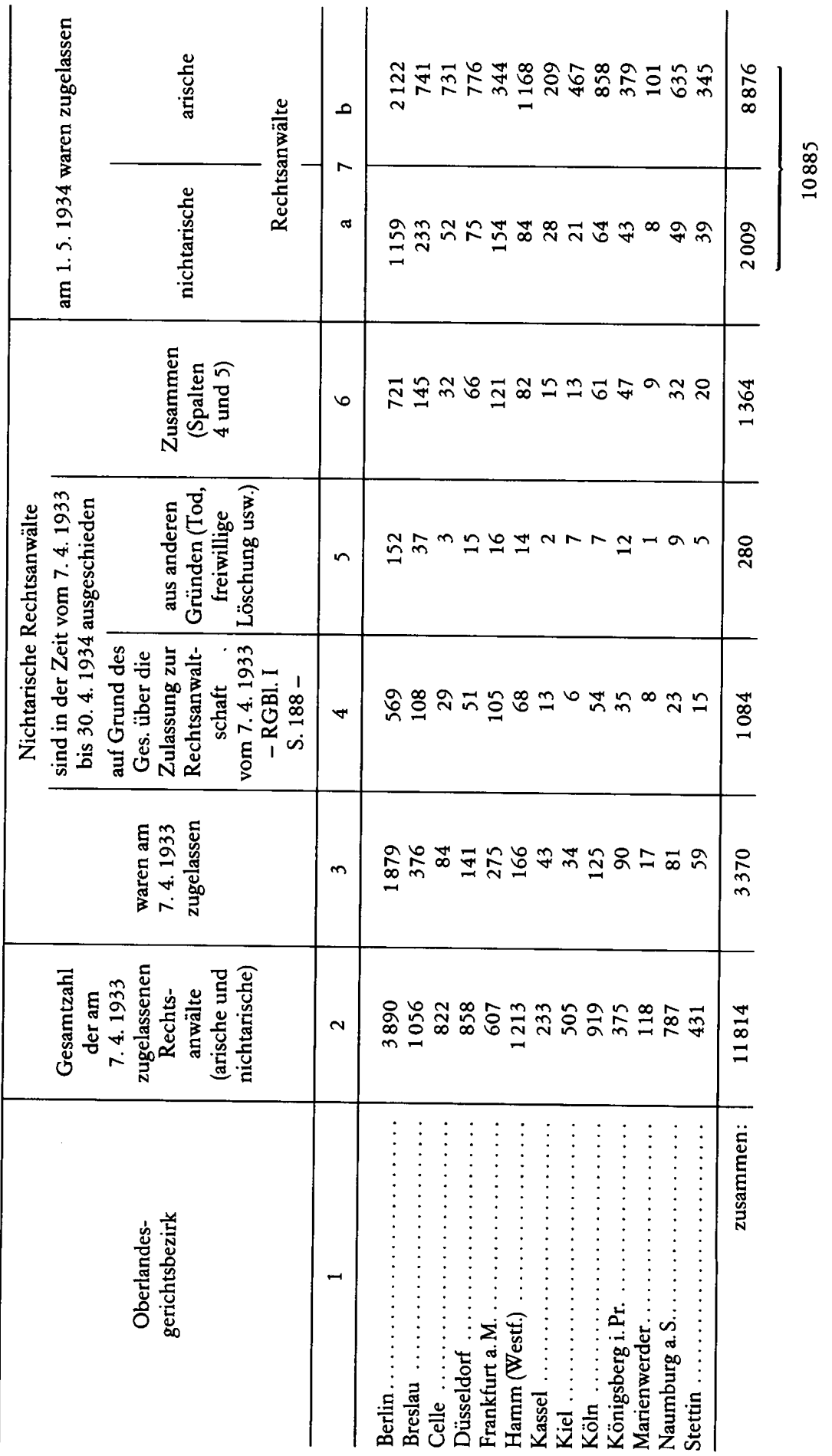




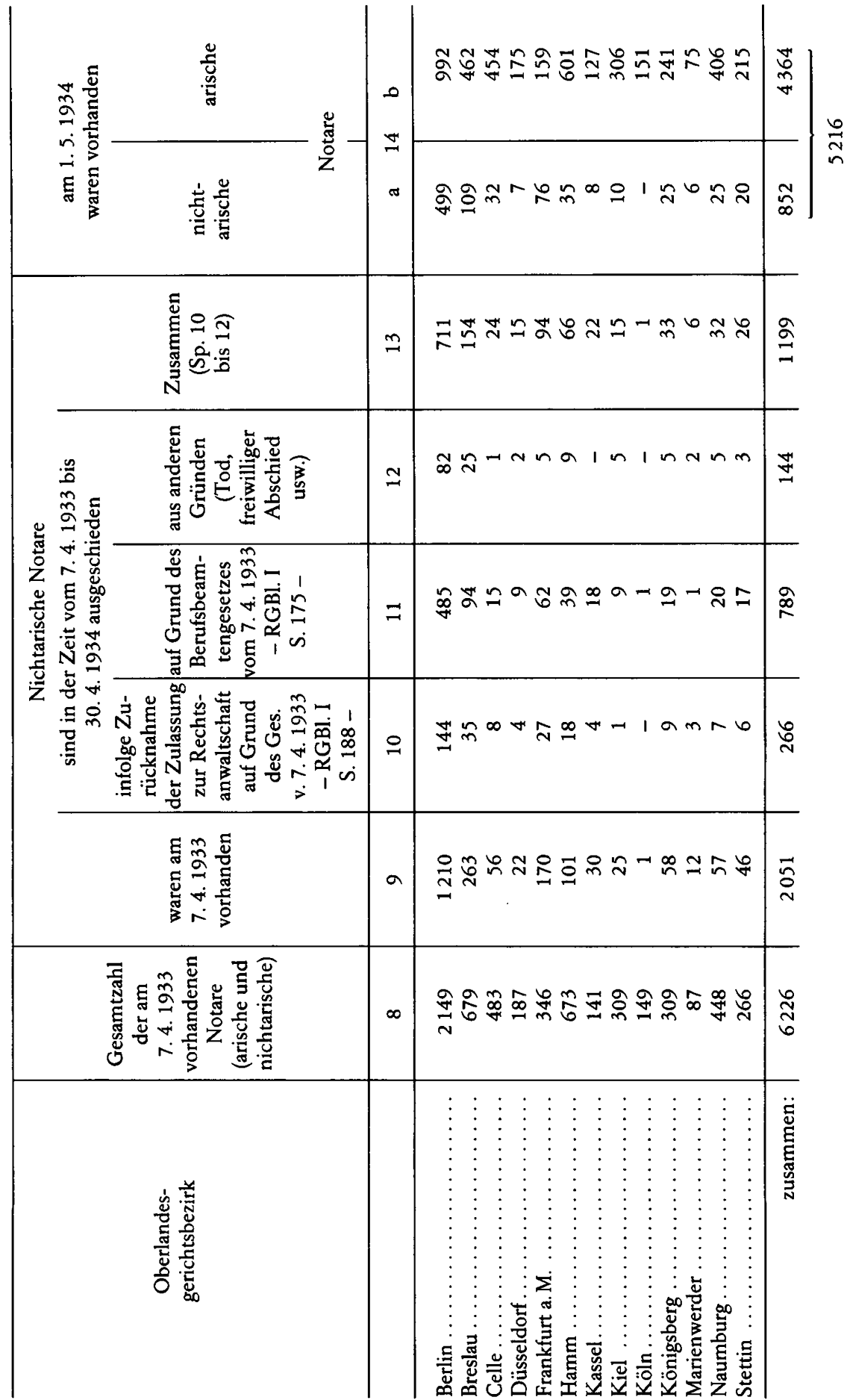


vorgelegt hatten, konnten sie sich darauf beziehen. Den im Berufsbeamtengesetz als Ausnahmen vorgesehenen, am 1.August 1914 planmäßig angestellten Beamten sollten diejenigen jüdischen Notare gleichgestellt werden, die an diesem Datum bereits ernannt waren. ${ }^{94}$ Die Oberlandesgerichtspräsidenten sollten die von den Landgerichtspräsidenten eingegangenen Formblätter und Erklärungen nebst einem Bericht über jeden Notar sowie eine Liste der mutmaßlich vom Gesetz betroffenen Notare bis zum 24. Mai an das preußische Justizministerium einreichen, das dann endgültig über das berufliche Schicksal des Notars entschied.

Wie aus der Übersicht des preußischen Justizministeriums nach dem Stand vom 1. Mai $1934^{95}$ (s. Tabelle S. 152) hervorgeht, wurden nach diesem Verfahren von den 2051 im April 1933 in Preußen zugelassenen jüdischen Notaren 789 ihres Amtes enthoben. Da bis zu diesem Zeitpunkt bereits 266 aufgrund des Rechtsanwaltsgesetzes und weitere 144 durch Tod, freiwilligen Abschied usw. ausgeschieden waren, ging die Zahl der jüdischen Notare in Preußen auf 852 zurück.

Am 22. Mai 1933 ordnete Kerrl die Durchführung des Berufsbeamtengesetzes hinsichtlich der Referendare an. ${ }^{96}$ Alle preußischen Referendare hatten ihrem Oberlandesgerichtspräsidenten gegenüber eine dienstliche Erklärung über ihre arische $\mathrm{Ab}$ stammung abzugeben. Entsprechende Urkunden dazu waren nur bei Verweigerung der Erklärung oder in zweifelhaften Fällen vorzulegen. Jüdische Referendare ( $33 \mathrm{BBG}$ ) hatten gegebenenfalls nachzuweisen, daß sie Frontkämpfer (Freikorpskämpfer) waren oder ihr Vater im Kriege gefallen war. Bei der Entscheidung der Frage, ob ein Referendar die für seine Laufbahn vorgeschriebene Eignung besaß ( 2 BBG) oder national zuverlässig war (§ $4 \mathrm{BBG})$, waren die Stellungnahmen der Gauleiter von besonderer Bedeutung; „um unverantwortliche Einflüsse und Äußerungen persönlicher Feindschaft möglichst auszuschalten", sollten Angaben von anderer Seite, unteren Parteiorganen usw. von „den Gauleitern oder den Standartenführern der SA. oder SS.“ überprüft werden. Referendare, die offensichtlich unter die $\S \S 2$ bis 4 des Berufsbeamtengesetzes fielen, ohne eine der vorgesehenen Ausnahmen zu erfüllen, konnten sich binnen einer Woche dazu äußern oder selbst um ihre Entlassung aus dem Justizdienst nachsuchen: diesen Gesuchen war durch die Oberlandesgerichtspräsidenten „ohne weiteres zu entsprechen“. Bis zum 1.Juli soliten die Oberlandesgerichtspräsidenten dem preußischen Justizminister eine Liste der für die Entlassung in Betracht kommenden Referendare nebst beigebrachten Erklärungen und Unterlagen vorlegen; soweit nicht bereits geschehen, waren sie „zur Entlastung der ausbildenden Stellen“ bis zur Entscheidung des Justizministers vorsorglich zu beurlauben. In einer zweiten Liste sollten jene jüdischen Referendare, die unter die Ausnahmen fielen, sowie die Gründe dieser Einstufung aufgeführt werden. Als Zeitpunkt für die Entlassung jener jüdischen Referendare, die bereits zur großen Staatsprüfung zugelassen waren oder sich spätestens am 1.Juni 1933 dazu meldeten, wurde der Tag der Ablegung der mündlichen

94 Nach der Regelung in Bayern, wo wie im Rheinland das Nurnotariat eingerichtet war, genügte es, wenn der Betreffende zu diesem Zeitpunkt als Notariatsverweser oder als rechtskundiger Hilfsarbeiter (Notariatspraktikant) bei einem Notariat gegen Entgelt beschäftigt war, vgl. Bekanntmachung des bayer. JM v. 18.4.33 über den Vollzug des BBG, hier Maßnahmen im Notariatswesen (Bayer. Staatszeitung/Staatsanzeiger Nr. 91 v. 20.4.33, S. 11).

95 DJ 1934, S.950.

${ }^{96} \mathrm{RV}$ des preuß. JM an die OLGPräs. v. 22.5.33 (Akten des preuß. JM, GehStArch. Berlin, Sign. Rep. 84a/ 6334, abgedruckt im JMBl., S. 164). 
Prüfung festgelegt. Jüdischen Rechtskandidaten, die beim Eingang der vorliegenden Verfügung noch nicht zur ersten juristischen Prüfung zugelassen waren, mußte die Zulassung verwehrt werden: in diesen Fällen blieb es bei Kerrls Rundverfügung vom 3. April 1933, daß Juden nicht mehr zu Referendaren ernannt werden durften. Deshalb mußte künfig jeder Rechtskandidat, der zu dieser Prüfung zugelassen werden wollte, auch den Ruf- und Familiennamen der Eltern und Großeltern angeben und eine Erklärung über seine „arische“ Abstammung abgeben mit der Folge, daß er bei unwahren Angaben von der Prüfung ausgeschlossen oder seine unterdessen erfolgte Ernennung zum Beamten angefochten wurde.

Während Hans Frank in Bayern die Beurlaubung von Richtern und Staatsanwälten, soweit sie seit dem 1. August 1914 etatmäßige Beamte waren, bereits am 10. April aufgehoben und unverzüglich die Prüfung der unter die Ausnahmen des Berufsbeamtengesetzes fallenden jüdischen Justizbeamten angeordnet hatte - ihre Beurlaubung wurde aufgehoben, sobald sie den entsprechenden Nachweis erbracht hatten ${ }^{97}$-, blieben diese Beamten in Preußen weiter beurlaubt. Die Durchführung des Berufsbeamtengesetzes bei den Justizbeamten leitete Kerrl am 23. Mai - sechs Wochen nach Erlaß des Gesetzes - mit einem pathetischen Aufruf an alle Angehörigen der preußischen Justizverwaltung ein, in dem er auf die Schwere und Bedeutung der ihm übertragenen Entscheidung für den nationalsozialistischen Staat hinwies und zu genauer, von „Gunst oder Mißgunst“ freier und vor allem schneller Ausführung seiner Anweisungen aufforderte, da sich "die Beamtenschaft in ihrer ungeheuren Mehrheit" danach sehne, ,in völlig gesicherter Rechtslage [!] frei und freudig an den Aufgaben“ des neuen Staates mitarbeiten zu können. Das Ziel sei der Aufbau eines Justizapparates, „in dem von jedem einzelnen Beamten angenommen werden darf, daß er ein treuer Kämpfer der nationalen Erhebung ist" ${ }^{\text {. }}{ }^{88}$

In einer Allgemeinverfügung vom selben Tage ordnete er folgendes Verfahren an"9: Zunächst prüfte die unmittelbar zuständige Dienstaufsichtsbehörde, auf welche der ihr unterstellten Beamten die Voraussetzungen der $\S \S 2$ bis 4 des Gesetzes zutrafen. Je nachdem, ob es sich um jüdische oder politisch belastete Beamte handelte, war das weitere Verfahren verschieden. Stand bereits fest, daß der Beamte nicht „arischer" $\mathrm{Ab}$ stammung war $(\S 3 \mathrm{BBG})$, mußte er innerhalb von drei Tagen durch Vorlage der erforderlichen Urkunden nachweisen, daß er unter die vorgesehenen Ausnahmen fiel, und ferner durch Ausfüllung der betreffenden Passagen des - durch die Durchführungsverordnung vom 6. Mai vorgeschriebenen - Fragebogens erklären, ob und wann er einer politischen Partei oder einer der ihnen gleichgestellten Organisationen angehörte. Diese politischen Angaben wurden deshalb auch von Juden angefordert, weil sie beim Vorliegen konkurrierender Voraussetzungen gegebenenfalls aufgrund der $\mathrm{Pa}$ -

${ }^{7}$ Vgl. Entschließung des bayer. JM an die OLGPräs. und GStAe v. 10.4.33 (Akten des bayer. JM, BayHStArch., Abt. I, Sign. MJu 12 004), präzisiert durch die Bekanntmachung des bayer. JM v. 18.4.33 über den Vollzug des Reichsgesetzes zur Wiederherstellung des Berufsbeamtentums (Bayer. Staatszeitung/Staatsanzeiger Nr. 91 v. 20.4.33, S.11). Bestehen blieb jedoch die Anordnung, daß jüdische Richter nicht mehr in der Strafrechtspflege und der Disziplinargerichtsbarkeit sowie jüdische StAe nicht mehr als Anklagevertreter in Gerichtssitzungen verwendet werden durften.

98 JMBl., S. 159.

99 Vgl. AV des preuß. JM v. 23.5.33 betr. Ausführung des Gesetzes zur Wiederherstellung des Berufsbeamtentums im Bereich der Justizverwaltung (JMBl., S. 160). 
ragraphen 2 oder 4 und damit ohne bzw. mit verminderter Pension entlassen werden konnten. Die mit der ersten Prüfung betraute Dienststelle gab ein Verzeichnis der Beamten mit den abgegebenen Erklärungen und beigebrachten Urkunden nebst einem Begleitbericht über jeden einzelnen Beamten auf dem Dienstweg an die zuständige Provinzialbehörde, d.h. bei Richtern an den Oberlandesgerichtspräsidenten, bei Staatsanwälten an den Generalstaatsanwalt und bei Vollzugsbeamten an den Präsidenten des Strafvollzugsamts, weiter, und zwar getrennt nach denjenigen Beamten, die unter die Ausnahmen fielen (Verzeichnis I), und denjenigen, bei denen das nicht der Fall war (Verzeichnis II). Bezeichnenderweise hatten dabei auch diejenigen Behörden, bei denen die Berichte nur durchliefen, zu prüfen, „ob Anlaß zu Beanstandungen gegeben ist, und ihre Bedenken bei der Weitergabe hervorzuheben“. Die genannten Provinzialbehörden prüften die Verzeichnisse vor: Ergaben sich hinsichtlich der im Verzeichnis I aufgeführten Ausnahmefälle - auch bezüglich einer eventuellen Eigenschaft als Parteibuchbeamte und der politischen Zuverlässigkeit - keine Bedenken, so durften sie die Beurlaubung dieser Beamten selbständig aufheben, soweit es sich nicht um Richter in Beförderungsstellen und Beamte im höheren Dienst der Staatsanwaltschaft handelte. Erschien ihnen die Wiederverwendung eines Beamten an seinem bisherigen Dienstort nicht angängig, so war seine Versetzung gemäß $§ 5$ des Berufsbeamtengesetzes in Aussicht zu nehmen und hierüber gesondert zu berichten. Bei der Überprüfung waren Anregungen des Gauleiters der NSDAP oder höherer Führer anderer NS-Organisationen zu berücksichtigen und im Bericht an das Justziministerium „unter allen Umständen zur Sprache zu bringen und urschriftlich beizufügen“. In den Fällen des Verzeichnisses II hatten die Provinzialbehörden zu vermerken, ob den Beamten bei ihrer Versetzung in den Ruhestand ein Ruhegeld zustand. Beide Verzeichnisse waren bis zum 15.Juni an den preußischen Justizminister weiterzuleiten. Wurde die „arische" Abstammung eines Beamten zwar nicht von seiner Dienstaufsichtsbehörde, aber „von zuverlässiger Seite, namentlich in Vorstellungen von seiten der nationalen Verbände" angezweifelt, hatte er sich mit dreitägiger Frist dazu zu äußern. Ergab die Prüfung, daß er Jude war, so war er als Ergänzung des jeweils zutreffenden Verzeichnisses schnellstens nachzumelden; ergab sie hingegen seine Eigenschaft als „Arier“, so war sein Fall besonders zu berichten. Bei allen anderen Beamten konnte auf Feststellungen über ihre Abstammung verzichtet werden, soweit sie am 1. August 1914 bereits planmäßige Beamte waren. Waren sie dagegen erst nach diesem Datum ernannt worden, so hatten sie eine dienstliche Erklärung abzugeben, in der sie versichern mußten, daß ihnen „trotz sorgfältiger Prüfung keine Umstände bekannt" seien, die die Annahme ihrer nichtarischen Abstammung rechtfertigen könnten. Die von den Beamten des höheren Dienstes abgegebenen Erklärungen waren von den Provinzialbehörden gesammelt an den preußischen Justizminister weiterzureichen. Waren Beamte zu einer vorbehaltlosen Abgabe dieser Erklärung nicht bereit, mußte das beschriebene Verfahren eingeleitet werden; verweigerten sie die Abgabe ohne Grund, war zu berichten. Die Provinzialbehörden hatten dem preußischen Justizminister bis zum 1.Juli anzuzeigen, daß alle Berichte vorlagen und alle erforderlichen Erklärungen von den Beamten abgegeben waren.

Hinsichtlich der Parteibuchbeamten (§ 2 BBG) und politisch unzuverlässigen Beamten $(\S 4 \mathrm{BBG})$ hatten die unmittelbaren Dienstaufsichtsbehörden Einzelberichte zu erstatten. Dabei kamen die Voraussetzungen des Paragraphen 2 im Bereich der Justiz- 
verwaltung fast kaum in Betracht, da bei den strengen Vorbildungsvorschriften keine Beamten ohne die für ihre Laufbahn erforderliche Ausbildung ins Amt kamen und bei der sozialen Herkunft und konservativen Gesinnung der überwiegenden Mehrzahl der Justizbeamten die Mitgliedschaft in einer kommunistischen Organisation oder Betätigung in kommunistischem Sinn höchst selten war. Dennoch kamen sowohl hier wie bei den politisch unzuverlässigen Beamten "den Anregungen der Gauleiter der NSDAP., die sich mit den Provinzialbehörden in Verbindung setzen werden und mit denen dauernd Fühlung gehalten werden muß [!], als Unterlage für die Entscheidung des Justizministers Bedeutung zu“. Vorstellungen von örtlichen Stellen der Bewegung, die unmittelbar bei der Dienstaufsichtsbehörde eines Beamten erhoben wurden, sollten jedoch von den Provinzialbehörden den Gauleitern oder den höheren Führern der jeweiligen NS-Organisationen zur Überprüfung vorgelegt werden. Im übrigen konnte die Nachprüfung „auf alle Fälle beschränkt werden, in denen die der Dienstaufsichtsbehörde bekannten Tatsachen aus dem Werdegang eines Beamten oder auf Grund seines Verhaltens innerhalb oder außerhalb des Dienstes es mindestens zweifelhaft [!] erscheinen lassen, ob nicht sein Verbleiben im Staatsdienst den Belangen der nationalen Erhebung oder allgemein des deutschen Volkes abträglich sein würde“. Für die Überprüfung hatte der betreffende Justizbeamte eine Erklärung über seine berufliche Vorbildung bzw. seine Zugehörigkeit zu einer politischen Partei oder Organisation abzugeben, d.h. die betreffenden Passagen des Fragebogens auszufüllen; vor Abschluß der Prüfung hatte er Gelegenheit, sich innerhalb von drei Tagen dazu zu äußern. Die Überprüfung der politischen Zuverlässigkeit ( $\$ 4 \mathrm{BBG}$ ) sollte sich dabei in erster Linie auf Beamte in leitender Stellung erstrecken, während bei den übrigen Justizbeamten "großmütig verfahren“ werden sollte, denn - so begründete der selbst aus der mittleren Justizlaufbahn stammende Kerrl diese unterschiedliche Behandlung in seiner Verfügung - ,je gedrückter die wirtschaftliche Lage eines Beamten gewesen“ sei, desto größer sei die Wahrscheinlichkeit, daß ihn nur „von außen an ihn herantretende Einflüsse“ zu einer entsprechenden politischen Betätigung bestimmt hätten und er nach deren Beseitigung nunmehr in der Lage sein werde, „dem nationalen Staate in Treue zu dienen“. Die Provinzialbehörden hatten die Beendigung der Überprüfung hinsichtlich der Parteibuchbeamten und der politischen Zuverlässigkeit der Justizbeamtenschaft in ihrem Geschäftsbereich dem preußischen Justizminister gleichfalls bis 1.Juli 1933 anzuzeigen oder zu melden, ,inwieweit und warum das nicht der Fall“ sei. In Kerrls Verfügung wurden die Justizbehörden ferner angewiesen, von der Möglichkeit der Versetzung nach Paragraph 5 des Berufsbeamtengesetzes Gebrauch zu machen, „um eine bessere Zusammensetzung des Personalbestandes einer Behörde herbeizuführen oder eine Überbesetzung zu beseitigen, die bisher wegen der Unversetzbarkeit der Richter hingenommen werden mußte“. Über diese Maßnahmen und über Versetzungen in den Ruhestand zur Vereinfachung der Verwaltung ( $\S 6 \mathrm{BBG})$ war ebenfalls zu berichten.

Räumte Kerrls Verfügung den Parteistellen bei der Durchführung des Berufsbeamtengesetzes ohnehin schon eine weitgehend Einflußnahme ein, so suchte er die Wünsche der regionalen Parteiführer auch durch persönliche Fühlungnahmen zu berücksichtigen. Am 27. Juni traf er sich z. B. in Westerland auf Sylt insgeheim mit dem schleswig-holsteinischen Gauleiter und Oberpräsidenten Lohse, der „Vertrauensleute“ für Justizangelegenheiten im Oberlandesgerichtsbezirk Kiel sowie in den Landge- 
richtsbezirken Flensburg und Altona mitbrachte, um die gewünschten Personalveränderungen in der Provinz Schleswig-Holstein eingehend zu besprechen. ${ }^{100}$

Im Gegensatz zu den Beamten bei der allgemeinen und inneren Verwaltung Preußens ${ }^{101}$ brauchte nach diesen Bestimmungen bei der Justizverwaltung nicht jeder Beamte den Fragebogen nach dem Muster der 3. Durchführungsverordnung vom 6. Mai 1933 auszufüllen. Als diese Tatsache vom preußischen Innenministerium moniert wurde, da die anstelle des Fragebogens vorgeschriebene „dienstliche Erklärung“ nicht ausreiche, wies Kerrl diese Beanstandung mit dem Argument zurück, die Beamten der Justiz ständen derart unter der Kontrolle der Öffentlichkeit, daß auch nur bloße Zweifel hinsichtlich ihrer Rassezugehörigkeit sofort bekannt würden. Er untermauerte seine Behauptung mit folgenden Ausführungen, die ein bezeichnendes Licht auf das Ausmaß der Bespitzelung der Justizbehörden durch die Partei werfen:

„Als ich im Zusammenhang mit dem Judenboykott am 1.4.d.Js. die - bis dahin amtlich nicht vorbereitete - Zurückziehung aller jüdischen Richter u. StA. aus der Rechtspflege anordnete, ist deren Beurlaubung von einem Tag zum andern mit einer solchen Vollständigkeit durchgeführt worden, daß die Notwendigkeit ergänzender Maßnahmen nur in sehr wenigen Einzelfällen noch bestand. Dabei sind auch Beamte erfaßt worden, an deren arischer Abstammung selbst ihre nächsten Mitarbeiter nicht gezweifelt hatten [!]. Zu diesem Ergebnis haben die Fachschaften ${ }^{102}$ und Betriebszellen der NSDAP. [!], die bei den Behörden der Justizverw. eine gesicherte Stellung einnehmen, entscheidend beigetragen.“

Da nach seinen Ausführungsbestimmungen jeder von zuverlässiger Seite geäußerte Zweifel die Dienstaufsichtsbehörde zur Nachprüfung anhand des Fragebogens veranlasse, sei eine sorgfältige Durchführung des Gesetzes auf jeden Fall gewährleistet. ${ }^{103}$ Erst als auch der preußische Ministerpräsident forderte, daß jeder Beamte zur Ausfüllung zumindest jenes Teils des Fragebogens verpflichtet werden sollte, der die Zugehörigkeit zu politischen Parteien und bestimmten Organisationen betraf, damit „der gesamte Beamtenkörper auf seine politische Zuverlässigkeit hin durchgeprüft" werden könne ${ }^{104}$, ordnete Kerrl nach längerem Hin und Her schließlich am 9. September diese Maßnahme an, die nunmehr innerhalb von 24 Stunden überstürzt durchgeführt werden mußte; die Provinzialbehörden sollten daher auch sofort prüfen und berichten, ob die abgegebenen Erklärungen zu Entlassungen oder Versetzungen $(\$ \S 4,5$ BBG) Anlaß gaben. ${ }^{105}$

Während der Durchführung des Berufsbeamtengesetzes und des Rechtsanwaltsgesetzes machte das Reichsinnenministerium das Reichsjustizministerium darauf auf-

${ }^{100}$ Vgl. Schr. des preuß. JM an Lohse v. 23.6.33 (Akten des preuß. JM, a.a.O.).

101 Vgl. RdErl. des preuß. MdI, zugleich i.N. des MinPräs. und der übrigen StMin., mit Ausnahme des JM, v. 31.5 .33 (MBliV, S.619).

${ }^{102}$ Gegen diese Betätigung der Fachschaften wandte sich vor allem Göring als preuß. MinPräs.: Als die Beamtenabteilung der NSDAP Gau Groß-Berlin ihre Fachschaftsgruppenleiter durch RdSchr. v. 27.9.33 anwies, ihr "untragbare" Beamten namhaft zu machen, die noch nicht entlassen seien, verbot Göring solche $\mathrm{Er}$ mittlungen und wies darauf hin, „daß die Fachschaften sich jeder Einmischung in Angelegenheiten der Staatsverwaltung zu enthalten haben und daß insbesondere die Behandlung und Beurteilung von Personalangelegenheiten ... ausscbließlich Sache des Behördenleiters und der von ihm damit beauftragten Beamten ist“. Erl. Görings v. 4.10.33 an die preuß. Staatsminister zur Bekanntgabe an die Fachschaftsgruppen ihres Geschäftsbereichs (Akten des preuß. JM, GehStArch. Berlin, Sign. Rep. 84a/6334).

103 Vgi. Schr. des preuß. MdI an den preuß. JM v. 3.6.33 und Antwortschr. Kerrls v. 15.6.33 (a.a.O.)

$104 \mathrm{Vgl}$. Schr. des preuß. MinPräs. (i.V. Körner) an den preuß. JM v. 12.6.33 und anschließende Korrespondenz (a.a.O.).

105 Vgl. die RV des preuß. JM v. 9. u. 18.9.33 an die Provinzialbehörden, LGPräs. und OStAe (a.a.O.). 
merksam, daß vor allem die Justizverwaltungen in Preußen, Bayern und Hamburg den Begriff des „Frontkämpfers“ gegenüber jüdischen Anwälten anders als vorgeschrieben auslegten, indem sie den Eintrag in der Kriegsstammrolle oder Kriegsrangliste nicht als ausreichend ansahen und die besondere Feststellung forderten, daß der Betreffende tatsächlich einer "fechtenden Truppe“ angehört hatte. Diese Methode - die die Landesjustizminister am 22. April in München auf Vorschlag Freislers unter sich verabredet hatten, um die Zulassung jüdischer Rechtsanwälte möglichst zu drosseln - sei unzulässig, da die Aufteilung der mobilen Armeekorps in „fechtende Truppe“ und „Kolonnen und Trains" nach der Kriegsgliederung des Heeres keine eindeutigen Kriterien abgäbe: einerseits hätten die Fuhrparkkolonnen „besonders im Stellungskrieg Munition und Material bis in die vorderste Front gebracht ... und zahlreiche Verluste erlitten“, während andererseits „die Stabsquartiere der Armee-Oberkommandos, Heeresgruppenkommandos und des Großen Hauptquartiers oft nicht im Operationsgebiet, sondern im Etappen- oder sogar im Heimatgebiet" gelegen hätten. Die eigenmächtige Handhabung der Frage durch die Landesjustizverwaltungen müsse „zu Folgen führen, die der Gesetzgeber nicht gewollt haben kann“, deshalb müsse noch einmal eindeutig festgelegt werden, daß ausschließlich die Durchführungsbestimmungen des Reiches für die Ausführung des Rechtsanwaltsgesetzes maßgebend seien. Das Reichsinnenministerium schlug ferner vor, daß Beamte und Anwälte, die sich zwar früher einmal im kommunistischen Sinne betätigt, aber „ehrlich ihre Überzeugung gewechselt" und sich nachweislich schon vor Jahren einem nationalen Verbande angeschlossen hatten, im Dienst belassen oder als Rechts- bzw. Patentanwälte zugelassen werden konnten. ${ }^{106}$

Um den Wünschen des Reichsinnenministeriums zu entsprechen, legte Gürtner dem Reichskabinett am 14.Juli den Entwurf einer Durchführungsverordnung zum Rechtsanwaltsgesetz vor, der eine entsprechende Vorschrift zugunsten ehemaliger Kommunisten enthielt und in der für die Bestimmung des „Frontkämpfers“ abermals die Eintragung in die Stammrolle oder Kriegsrangliste für maßgeblich erklärt wurde. Gürtner betonte aber dem Kabinett gegenüber, daß diese Lösung „für Berlin eine weitere Zulassung von 200 nicht arischen Rechtsanwälten bedeuten“"würde. Reichswehrminister v. Blomberg sah die Eintragung auch als das maßgebende Kriterium an, hielt jedoch die von Hitler vorgeschlagene und von Schwerin v. Krosigk unterstützte Nachprüfung der Frontkämpfereigenschaft durch eine Art „militärischen Richterkollegiums“ bei einer begrenzten Zahl von Zweifelsfällen für möglich. Auf den Einwand Gürtners, daß jüdische Kriegsteilnehmer doch nicht anders als die übrigen behandelt werden könnten, erwiderte Hitler,

„daß bei den Juden die Sachlage anders wäre. Das jüdische Volk insgesamt würde abgelehnt. Daher müßten alle Juden entfernt werden. Eine Ausnahme könnte man nur bei Juden machen, die am blutigen Kampf [!] teilgenommen hätten. Nur die Teilnahme an einer Kampfhandlung, nicht aber der Aufenthalt in der Kampfzone wäre entscheidend. Daher müßte eine Beratungsstelle oder ein Prüfungshof zur Nachprüfung der Eintragung in die Kriegsstammrolle vorgesehen werden."

106 Vgl. Schr. des RMdI an den RJM v. 30.6.33, dem preuß. JM am 7.7.33 zugestellt (a.a.O.). 
Das Kabinett stimmte daraufhin der Vorlage mit der Maßgabe zu, daß Gürtner und Blomberg als die beteiligten Reichsminister die gewünschten Änderungen vornehmen sollten. ${ }^{107}$

Die von Hitler und den beiden Reichsministern unterzeichnete Durchführungsverordnung vom 20. Juli ${ }^{108}$ legte nochmals fest, daß für die Bestimmung der Frontkämpfereigenschaft ausschließlich die Ausführungsvorschriften des Reichs maßgebend waren. Als Stelle für eine eventuelle Nachprüfung sah sich das Reichsjustizministerium selbst vor: war ein Anwalt trotz entsprechender Eintragungen in der Kriegsstammrolle oder -rangliste nicht als Frontkämpfer anerkannt worden, so konnte er das Reichsjustizministerium um Entscheidung angehen. Eine solche Entscheidung konnte andererseits auch die Landesjustizverwaltung einholen, wenn sie trotz Vorliegen dieser Eintragungen hinsichtlich der Frontkämpfereigenschaft Bedenken hatte. Die Entscheidung, die der Reichsjustizminister im Benehmen mit dem Reichswehrminister traf, war „endgültig und bindend“ (§ 1). Ferner konnte die frühere Betätigung eines Anwalts in kommunistischem Sinne dann außer Betracht bleiben, wenn er sich „schon vor dem 30.Januar 1933 einer Partei oder einem Verbande, die sich hinter die Regierung der nationalen Erhebung gestellt haben, angeschlossen“ und darin bewährt hatte. Auch sollte die Verteidigung oder Vertretung von KPD-Angehörigen - die Freisler den Landesjustizministern am 22. April in München ohne weiteres als kommunistische Betätigung eines Anwalts anzusehen empfohlen hatte - nur dann als solche gewertet werden, wenn es nach Häufigkeit, Art der Führung oder den Umständen, unter denen die Verteidigung übernommen wurde, gerechtferigt war (§ 2). War im Falle eines jüdischen Frontkämpfers oder eines früheren kommunistischen Anwalts bzw. Kommunisten-Verteidigers die Zurücknahme der Zulassung bereits ausgesprochen, ohne daß diese Bestimmungen berücksichtigt worden waren, so war „der Zurücknahmebescheid und die Löschung in der Liste der Rechtsanwälte oder Patentanwälte aufzuheben“ (§3). Mit dieser Verordnung hatte das Reichsjustizministerium zumindest das Mögliche getan, um den von einigen Landesjustizverwaltungen angewandten Auslegungspraktiken entgegenzutreten, und den Frontkämpfern unter den jüdischen Anwälten eine Art Berufung gegen die Entscheidungen der Landesjustizverwaltungen ermöglicht. Es hatte die Befugnis erlangt, in diesen Fällen die Entscheidung der Landesjustizverwaltung zu korrigieren. Die entsprechende Ausnahme für Justizbeamte, die früher einmal im kommunistischen Sinne tätig waren und sich rechtzeitig vor der Machtergreifung der nationalen Bewegung angeschlossen hatten, wurde in Form eines Ergänzungsgesetzes vom gleichen Datum vorgesehen, das einen entsprechenden $\S 2 \mathrm{a}$ in das Berufsbeamtengesetz einfügte. ${ }^{109}$

Bereits vier Wochen vorher war ein Änderungsgesetz erlassen worden, das für die Justizverwaltung von erheblicher Bedeutung war. Nach der ursprünglichen Fassung des $\S 6$ des Berufsbeamtengesetzes war die Versetzung eines Beamten, bei dem die Voraussetzungen der $\S \S 2$ bis 4 nicht vorlagen, in den Ruhestand nur „zur Vereinfa-

${ }_{107}$ Vgl. Niederschr. über die Sitzung des Reichskabinetts am 14. Juli 1933, vorm. 11.35 Uhr in der Reichskanzlei (Akten der Reichskanzlei. Die Regierung Hitler. Teil I, Bd.1 [s. Kapitel I, Anm.3], Dok. Nr. 193, S. 659 ff., und BA, Sign. R 43 I/1464).

108 VO zur Durchf. der Gesetze über die Zulassung zur Rechtsanwaltschaft und zur Patentanwaltschaft v. 20.7.33 (RGBl. I, S. 528).

109 Vgl. G. zur Ergänzung des G. zur Wiederherstellung des Berufsbeamtentums v. 20.7.33 (RGBI. I, S. 518). 
chung der Verwaltung“ möglich. Schon am 5. Mai waren Kerrl und seine Ministerkollegen im preußischen Kabinett zu der Ansicht gelangt, daß „die jetzige Fassung des Gesetzes mit ihren eng begrenzten Tatbeständen" ungenügend sei, um einen unliebsamen Beamten aus dem Dienst entfernen zu können, der weder als Jude entlassen werden konnte noch sich vor 1933 politisch abträglich betätigt hatte.

„Es gehe auch nicht an, nur um diese Entfernung trotzdem zu erreichen, einen Beamten etwa durch die Anwendung des $\S 4$ des Gesetzes (politische Unzuverlässigkeit) zu diffamieren und finanziell zu schädigen. Unbedingt erforderlich sei daher eine Vorschrift wie sie der ursprüngliche Gesetzentwurf des Finanzministers Professor Dr. Popitz ${ }^{10}$ vorgesehen habe, daß jeder Beamte ohne Angabe von Gründen während der Geltungsdauer des Gesetzes unter Gewährung des ihm gesetzlich zustehenden Ruhegehalts pensioniert werden könne.“

Da eine Abhilfe im Wege der preußischen Gesetzgebung nicht möglich war, wurde Popitz beauftragt, im Einvernehmen mit Kerrl und dem preußischen Innenministerium einen für das Reichskabinett bestimmten Änderungsvorschlag zum Berufsbeamtengesetz auszuarbeiten. ${ }^{111}$

Das erwähnte Gesetz vom 23. Juni änderte den $\S 6$ des Berufsbeamtengesetzes dahingehend, daß die Versetzung in den Ruhestand nunmehr auch ,im Interesse des Dienstes" erfolgen konnte, behielt aber die Bestimmung bei, daß die Stellen der aus diesen Gründen pensionierten Beamten nicht mehr besetzt werden durften; nur bei Beamten in Eingangsstellen durfte die für das Besoldungswesen zuständige oberste Behörde „ausnahmsweise die Wiederbesetzung der Stelle zulassen“. ${ }^{112}$ Am 11.Juli teilte Freisler dem preußischen Finanzminister mit, daß bei der Justizverwaltung vom $\S 6$ des Berufsbeamtengesetzes ,in einer nicht ganz unbeträchtlichen Zahl von Fällen Gebrauch gemacht werden" müsse, da zahlreiche jüdische Richter weiter beschäftigt werden müßten, darunter nicht wenige, auf die zwar der $\S 4$ nicht anwendbar sei, deren Weiterverwendung ,aber gleichwohl mit den Grundsätzen nationalsozialistischer Staatsführung nicht vereinbar" sei. Darüber hinaus müßten verbleibende jüdische Richter von bestimmten Arbeitsgebieten - vor allem der Spruchrichtertätigkeit - ferngehalten werden, ,um überhaupt ihre Weiterbeschäftigung gegenüber den auf Ausschluß aller nichtarischen Personen von der Rechtspflege abzielenden Tendenzen zu ermöglichen“. Auf dem Wege der Versetzung, „die ohnehin erheblichen tatsächlichen Schwierigkeiten begegnet“, sei dieses Problem nicht zu lösen. Zur Illustration wies Freisler darauf hin, daß allein bei den Berliner Gerichten rund 240 jüdische Richter planmäßig angestellt gewesen seien. Darüber hinaus gebe es auch noch arische Richter, „deren körperliche oder geistige Fähigkeiten so vermindert sind, oder deren Amtsführung anderweit so erheblichen Bedenken [!] begegnet", daß sie nicht im Amt belassen werden könnten, ohne daß aber ein zeitraubendes Z wangspensionierungsverfahren sicheren Erfolg verspräche. Bei dem Mangel an Planstellen könne aber der $\S 6$ in der Justizverwaltung „nur praktische Bedeutung gewinnen“, wenn der Finanzminister die ausnahmsweise vorgesehene Wiederbesetzung von Eingangsstellen großzügig handhabe und sich mit der Wiederbesetzung von 100 Stellen einverstanden erkläre. Popitz bewilligte diese Bitte und erklärte sich außerdem damit einverstanden, daß aus diesen Gründen freigewordene Beförderungsstellen einstweilen kommissarisch ver-

\footnotetext{
$10 \mathrm{Vgl}$. Anm. 40 dieses Kapitels.

11 Vgl. Protokoll der Chefbespr. im preuß. StMin. v. 5.5.33 (Auszug in den Akten des preuß. JM, a.a.O.).

112 Vgl. G. zur Änderung des G. zur Wiederherstellung des Berufsbeamtentums v. 23.6.33 (RGB1. I, S. 389).
} 
waltet würden, bis er deren Wiederbewilligung "gelegentlich der Aufstellung des nächsten Haushaltsplans wohlwollend prüfen " könne. ${ }^{113}$

Der preußische Justizminister machte nunmehr die nachgeordneten Provinzialbehörden auf diese Möglichkeit aufmerksam, Richter, Staatsanwälte und Justizbeamte, die nicht unter die $\S \S 2$ bis 4 des Berufsbeamtengesetzes fielen, ,aus zwingenden dienstlichen Gründen“ dennoch in den Ruhestand versetzen zu können. Er ersuchte bis 20. September 1933 um Bericht, welche Beamte dafür in Frage kamen. Soweit diese Beamten das 60. Lebensjahr vollendet hatten, sollte ihnen nahegelegt werden, selbst die Versetzung in den Ruhestand zu beantragen, und zwar nach der preußischen Sparverordnung vom 23. Dezember 1931, die gegenüber der Zurruhesetzung nach $\S 6$ des Berufsbeamtengesetzes größere Vorteile bot. Da mit der Genehmigung für die Wiederbesetzung freiwerdender Eingangsstellen bzw. mit der Neuanschaffung wegfallender Beförderungsstellen durch den Finanzminister nur begrenzt zu rechnen war, sollten jedoch die Provinzialbehörden „bei der Prüfung der Vorschläge der nachgeordneten Behörden einen strengen Maßstab anlegen". ${ }^{114}$ Diese Vorgänge zeigen, wie weit der ursprünglich nicht „diffamierende“ $\S 6$ des Berufsbeamtengesetzes zu einer Art Ventil geworden war, um personalpolitische Ziele verwirklichen zu können.

Bei dem immensen Arbeitsaufwand, den die Durchführung des Berufsbeamtengesetzes besonders für die großen Reichs- und Landesverwaltungen sowie die Gemeinden bedeutete, und bei den ständigen Änderungen und Ergänzungen des Gesetzes und seiner Ausführungsbestimmungen war es nicht verwunderlich, daß das Gesetz bis zum 30. September 1933 nicht durchgeführt werden konnte. Damit blieb aber der beamtenrechtliche Ausnahmezustand mit seinen Eingriffen in die "wohlerworbenen Rechte" des Beamten sowie der Aufhebung der Unabsetzbarkeit und Unversetzbarkeit, d.h. der persönlichen Unabhängigkeit des Richters aufrechterhalten, den das Reichsjustizministerium möglichst noch vor dem 30. September 1933 hatte beendet sehen wollen. ${ }^{115}$ Schon auf der Tagung der Ministerpräsidenten und Innenminister der Länder am 25. April hatte Göring angekündigt, daß das vorgesehene halbe Jahr für die Durchführung in Preußen nicht ausreichen werde. Trotzdem - so suchte Göring den Einwand der Juristen zu entkräften - könne aber bei einer Verlängerung „von einer akuten Gefahr für die Rechtsprechung nicht die Rede sein. Es spreche nicht für den Richterstand, wenn er sich durch solches Gesetz beeinträchtigt fühle". ${ }^{116}$ In einer Referentenbesprechung am 17. Mai teilte der Staatssekretär im preußischen Innenministerium Grauert den Vertretern des preußischen Justizministeriums mit, daß die „unerläßliche“ Verlängerung des Gesetzes beim Reich beantragt worden sei, obwohl das Gegenargument „anerkannt werden müsse, daß baldmögliche Durchführung im Interesse der Beruhigung der Beamten liege“, mit dem die anwesenden Vertreter des preußischen Finanzministeriums die Einhaltung der ursprünglichen Frist forderten. ${ }^{17}$

113 Vgl. Schr. des preuß. JM (i.V. Freisler) an den preuß. FinanzM v. 11.7.33 und Antwortschr. Popitz' v. 29.7.33 (Akten des preuß. JM, a.a.O.).

114 Vgl. die RV des preuß. JM an die OLGPräs. v. 2.8.33 und an die Provinzialbehörden v. 18.8.33 (a.a.O.). Der KGPräs. und die OLGPräs. von Breslau und Frankfurt a. M. wurden nochmals gesondert auf die Anwendungsmöglichkeiten gegen jüdische Beamte hingewiesen, die aufgrund $\S 3$ BBG wegen der dort vorgesehenen Ausnahmen nicht entlassen werden konnten.

1is Vgl. voranstehend S. 137.

116 Vgl. Aufz. von Staatsrat Schultz (Hamburg) v. 27.4.33 (Mommsen, a.a.O., S. 162).

117 Vgl. Niederschr. des preuß. MdI über die Bespr. und Aufz. des Vertreters des preuß. JM vom gleichen Tage (Akten des preuß. JM, a.a.O.). 
Im Juli beauftragte auch das bayerische Kabinett seinen Ministerpräsidenten, bei der Reichsregierung für eine Verlängerung der Geltungsdauer des Gesetzes bis zum 1.Januar 1934 einzutreten. ${ }^{18}$ Das bereits in anderem Zusammenhang erwähnte Änderungsgesetz vom 23. Juni 1933 verlängerte daher zunächst die Frist für die Verfügungen nach $\S 5$ (Versetzung in ein anderes Amt) und $\S 6$ (Pensionierung aus dienstlichen Gründen) bis zum 31. März 1934. Vor allem das preußische Justizministerium benötigte Zeit, um die Anzahl weiterbeschäftigter jüdischer Richter in Berlin, Breslau und Frankfurt a. M. durch $Z$ wangsversetzung an andere Orte im Austausch gegen ,arische“ Richter zu vermindern. Freisler hatte die preußischen Oberlandesgerichtspräsidenten am 27.Juni 1933 aufgefordert, ihm leistungsfähige „arische“ Richter zu melden, die in die genannten Städte versetzt zu werden wünschten. Voraussetzung war allerdings, daß sich die dadurch freiwerdenden Stellen zur Besetzung mit jüdischen Richtern eigneten, d.h. weder Beförderungsstellen noch Stellen bei kleinen Gerichten oder in der Strafrechtspflege waren. Freisler erwartete, „daß das in der Übernahme jüdischer Richter aus einem anderen Bezirk liegende Opfer [!] ... bereitwillig gebracht" werde. ${ }^{119}$ Die Versetzungsaktion war äußerst zeitraubend, weil die komplizierten Austauschbedingungen entweder Schwierigkeiten in der Geschäftsverteilung der an sich in Frage kommenden Gerichte (zumindest bei der Regelung von Urlaubsvertretungen usw.) verursacht hätten, an anderen Orten wiederum Unannehmlichkeiten durch die „betont rassebewußte Einstellung der Bevölkerung“ bzw. den „extremen Standpunkt nationaler Verbände“ in der Judenfrage zu erwarten waren. Die Aktion konnte daher erst im November 1933 abgeschlossen werden.

Zehn Tage vor dem 30. September 1933 kündigte der Reichsinnenminister vertraulich die bevorstehende Verlängerung auch der Fristen für die Prüfung der Fälle nach den $\S \S 2$ bis 4 des Berufsbeamtengesetzes an ${ }^{120}$, die dann durch das dritte Änderungsgesetz vom 22. September in der Form realisiert wurde, daß der Termin für die Verfügungen nach diesen Paragraphen gleichfalls bis zum 31. März 1934 verschoben werden konnte - aber nur dann, wenn die Prüfung „bei der obersten Reichs- oder Landesbehörde bereits anhängig, aber noch nicht abgeschlossen " war. ${ }^{121}$ Bei der Beratung dieses Gesetzes im Reichskabinett stellte Gürtner nochmals klar, daß danach „die von den unterstellten Dienststellen eingeleiteten Untersuchungen am 30. September bei den obersten Reichs- oder Landesbehörden vorliegen müssen“, d.h. nach diesem Datum nicht erst neue Fälle eingeleitet werden durften. ${ }^{122}$

Anders als beim Berufsbeamtengesetz konnte Gürtner eine Verschleppung bei der Durchführung des Rechtsanwaltsgesetzes verhindern. Da er sich im Patentanwaltsgesetz vom April 1933 geschickterweise die alleinige Ermächtigung zum Erlaß von Durchführungsverordnungen sowohl für dieses wie auch für das Rechtsanwaltsgesetz

${ }_{118}$ Vgl. Prot. der Sitzung des bayer. Ministerrats v. 6.7.33 (GehStArch. München, Sign. MA 99 526).

119 Vgl. RV des preuß. JM (i.V. Freisler) an die OLGPräs. v. 27.6.33, Berichte der OLGPräs. und abschließende RV v. 16.11.33 (Akten des preuß. JM, a.a.O.).

120 Vgl. vertrauliches Schr. Fricks an die Obersten Reichsbehörden und die Landesregierungen v. 20.9 .33 (Akten des preuß. JM, a.a.O.).

121 Drittes G. zur Änderung des G. zur Wiederherstellung des Berufsbeamtentums v. 22.9.33 (RGBI. I, S.655). Die neue Frist 31. März 1934 galt auch für die nachträgliche Einleitung von Dienststrafverfahren gegen pensionierte oder entlassene Beamte nach $\S 14$ BBG.

122 Vgl. Niederschr. über die Sitzung des Reichskabinetts am 22. September 1933, nachm. 4.30 Uhr (Akten der Reichskanzlei. Die Regierung Hitler. Teil I, Bd.2 [s. Kapitel I, Anm.3], Dok. Nr.215, S.822 ff., und BA, Sign. R 43 I/1465). 
hatte erteilen lassen ${ }^{123}$, stellte er am 1.Oktober 1933 in einer Verordnung fest, daß die in beiden Gesetzen vorgesehenen Maßnahmen „seit heute“ abgeschlossen seien. Jeder Rechtsanwalt und Patentanwalt, der aufgrund dieser Gesetze in seinem Beruf geblieben sei, bleibe „nicht nur im vollen Genuß seiner Berufsrechte“, sondern habe auch „Anspruch auf die Achtung, die ihm als Angehöriger seiner Standesgemeinschaft zukommt“. Der ausdrücklich aufgenommene Satz, daß nun kein Anwalt mehr ,in der gesetzmäßigen Ausübung seines Berufes gehindert oder beeinträchtigt werden“ dürfe $^{124}$, sollte einmal künftige Gewaltakte gegen zugelassene jüdische Rechtsanwälte als illegal brandmarken und dadurch nach Möglichkeit verhindern, war aber zum anderen auch gegen diskriminierende Bestimmungen gerichtet, wie sie z.B. Kerrl für Preußen erlassen hatte: Am 26. Mai hatte der Gau Groß-Berlin des BNSDJ die Praxis von Gerichtsvorsitzenden, ,arischen“ Parteien jüdische Armenanwälte, Pflichtverteidiger, Pfleger oder Testamentvollstrecker zu bestellen, öffentlich als „bewußte Demonstration und Sabotage gegen die Maßnahmen der nationalen Regierung zur Wiederherstellung einer deutschen Rechtspflege“ bezeichnet und die Entfernung der betreffenden Richter (!) aufgrund des $\S 4$ des Berufsbeamtengesetzes gefordert, da diese Handlungsweise „den untrüglichen Beweis“ dafür böte, daß sie „nicht rückhaltlos für den nationalen Staat“ einträten. Alle BNSDJ-Mitglieder sollten derartige Fälle „unter genauer Bezeichnung des Richters" sofort an den Gauobmann des BNSDJ melden. ${ }^{125}$ Obwohl Gürtner auf der Zusammenkunft mit den Landesjustizministern am 6. Mai in Stuttgart davon abgeraten hatte ${ }^{126}$, hatte Kerrl fünf Tage nach der BNSDJ-Erklärung ein Verbot erlassen, jüdischen Rechtsanwälten Armensachen zuzuteilen oder sie als Pflichtverteidiger zu bestellen. ${ }^{127}$ Diese Verfügung, die mit Gürtners Verordnung im Widerspruch stand, wurde in der Folge wieder aufgehoben. ${ }^{128}$

War die Durchführung des Gesetzes über die Zulassung zur Rechtsanwaltschaft am 30. September 1933 abgeschlossen worden, blieben die Bestimmungen zur „Säuberung“ der Justizbeamtenschaft zunächst für ein weiteres halbes Jahr in Kraft. Am

123 Vgl. $\S 9$ des G. betr. die Zulassung zur Patentanwaltschaft und zur Rechtsanwaltschaft v. 22.4.33 (RGBI. I, S. 217).

124 Vgl. Zweite VO zur Durchf. der Gesetze über die Zulassung zur Rechtsanwaltschaft und Patentanwaltschaft v. 1.10.33 (RGBl. I, S.699). Auch Frank hatte in einer RV an die bayer. GStAe v. 12.9.33 darauf hingewiesen, daß der zugelassene jüdische RA, schon im Interesse der Rechtssicherheit und der arischen Anwaltsangestellten den Schutz des Staates für eine ungestörte Ausübung seines Berufes beanspruchen“ könne. Ubergriffe, „woher sie auch kommen mögen, sind im Rahmen der allgemeinen Strafgesetze rücksichtslos und unnachsichtlich zu verfolgen“ (Akten des bayer. JM, Bayer. HStArch., Abt. I, Sign. MJu 12003).

125 Vgl. Erklärung des BNSDJ Gau Groß-Berlin v. 26.5.33, gerichtet an den preuß. JM, die Gerichtspräsidenten, den Berliner Anwaltsverein zur Veröffentlichung im „Berliner Anwaltsblatt“ und Aushang in allen Anwaltszimmern (Akten des preuß. JM, a.a.O.).

126 Vgl. voranstehend S.148.

127 RV des preuß. JM v. 31.5 .33 (Akten des preuß. JM, GehStArch. Berlin, Sign. Rep. 84a/1603, vgl. Adam, a.a.O., S.67).

128 So erwähnte die Abhandlung über die Beiordnung des Armenanwalts in der DJ v. 15.12 .33 (S.810f.) das Verbot schon nicht mehr. Auch die einschlägige reichsrechtliche Regelung durch die AV des RuPrJM v. 10.12.34 (DJ 1934, S. 1572), die die Bestimmungen der LJVerw. ersetzte, sprach kein Verbot für die Beiordnung zugelassener jüdischer RAe aus, sondern lediglich davon, es werde „davon auszugehen sein, daß eine arische Partei die Beiordnung eines arischen Anwalts“ erwarte. Erst als gemäß der 1.VO zum ReichsbürgerG v. 14.11.35 (RGBl. I, S. 1333) Juden kein öffentliches Amt mehr bekleiden durften, sollten „die Gerichte bei Ausübung ihres richterlichen Ermessens" beachten, daß die Bestellung von Juden als Armenanwälte, Pflichtverteidiger, Konkursverwalter usw. „nicht im Sinne dieser Regelung liegen würde“ (AV des RJM v. 19.12.35, DJ 1935, S. 1858). 
17. März 1934 äußerte Gürtner auf einer Arbeitstagung der Akademie für Deutsches Recht, auf der er die Bedeutung der richterlichen Unabhängigkeit für die Justiz und deren Anerkennung durch Hitlers Regierungserklärung vom 23. März 1933 hervorhob, daß die Beschränkungen für die Unabsetzbarkeit des Richters nunmehr „mit Ablauf dieses Monats in Fortfall kommen, und zwar endgültig". ${ }^{129}$ Doch zu seiner Enttäuschung sollte auch dieser Termin nicht eingehalten werden: auf Wunsch der groBen Verwaltungen Preußens unterbreitete Frick dem Reichskabinett am 22. März 1934 einen Gesetzentwurf für die abermalige Verlängerung des Berufsbeamtengesetzes. Da von ,anderen Stellen [zu denen das Reichsjustizministerium gehörte] der baldige Abschluß der Maßnahmen für unbedingt notwendig gehalten " werde, schlug er vor, nur die Geltung der $\S \S 5$ und 6 des Gesetzes, und zwar erneut um ein halbes Jahr, zu verlängern. Göring bemerkte, daß er für die Durchführung des Gesetzes von vornherein eine Frist von zwei Jahren für zweckmäßig gehalten habe. Seine weiteren Ausführungen standen in offenem Gegensatz zu den Bestrebungen des Reichsjustizministeriums und ließen klar erkennen, daß die nationalsozialistische Führung nicht daran dachte, die Maßnahmen zeitlich zu beschränken und die persönliche Unabhängigkeit des Richters künftig wiederherzustellen: „Auch für die Zeit nach Ablauf des Gesetzes sei es notwendig, sich Möglichkeiten offen zu halten, unter gewissen Voraussetzugen Beamte zu entfernen; insbesondere müsse auch für Richter [!] die Möglichkeit ihrer Versetzung geschaffen werden." Reichsfinanzminister v. Krosigk versicherte sich demgegenüber des Einverständnisses des Kabinetts, daß die seinerzeit von seiten des Reichsjustizministeriums eingefügte Möglichkeit fortbestehe, daß einzelne Verwaltungen die Fristen von sich aus verkürzten und die Durchführung des Gesetzes für beendet erklären könnten, da in seinem Geschäftsbereich „die erforderlichen Maßnahmen durchgeführt und eine Beendigung des bisherigen Schwebezustandes im Interesse der Verwaltung notwendig" sei. ${ }^{130}$ Diese Feststellung nutzte jedoch dem Reichsjustizminister wenig, da die Justizverwaltung im Gegensatz zur Reichsfinanzverwaltung noch nicht „verreichlicht“ war und die Zuständigkeit für eine solche Erklärung bei den Landesjustizchefs lag. Das beschlossene Änderungsgesetz vom 22. März $1934^{131}$ verlängerte die Fristen für die $\S \S 5$ und 6 des Berufsbeamtengesetzes sowie für ein nachträgliches Dienststrafverfahren gegen ausgeschiedene Beamte ( $114 \mathrm{BBG}$ ) bis zum 30. September 1934. Es schuf zwar zugleich die Möglichkeit, daß bis zu diesem Termin Maßnahmen, die aufgrund der $\S \S 2$ bis 4 ergriffen worden waren, zugunsten des betroffenen Beamten zurückgenommen oder geändert werden konnten. Da dafür aber nur jene obersten Behörden zuständig waren, die sie verfügt hatten, ermächtigte diese Bestimmung das Reichjustizministerium nicht, Entscheidungen der Landesjustizverwaltungen zu korrigieren.

Im September 1934 wurden schließlich die von Göring schon ein halbes Jahr vorher angemeldeten Forderungen erfüllt und durch ein weiteres Änderungsgesetz der

129 Vgl. Gürtners Referat: Richter und Rechtsanwalt im neuen Staat, gehalten auf der Arbeitstagung der AkDR am 17.3.34 (Jb. der AkDR 1933/34, S.155ff., 156).

130 Vgl. Niederschr. über die Kabinettssitzung am 22. März 1934, nachm. 4.15 Uhr (Akten der Reichskanzlei. Die Regierung Hitler. Teil I, Bd. 2 [Kapitel I, Anm. 3], Dok. Nr. 321, S. 1201 ff., und BA, Sign. R I/1468).

131 Viertes G. zur Änderung des G. zur Wiederherstellung des Berufsbeamtentums v. 22.3.34 (RGBI. I, S. 203). 
Termin für die beiden Paragraphen 5 und 6 „bis zum Inkrafttreten des neuen deutschen Beamtengesetzes" verlängert. ${ }^{132}$ Damit sollten die Instrumente der Zwangsversetzung und -pensionierung gegen unliebsame Justizbeamte auch in den folgenden Jahren zur Verfügung stehen ${ }^{133}$ und die persönliche Unabhängigkeit des Richters aufgehoben bleiben. Der Richter mußte auch weiterhin befürchten, bei nicht konformem Verhalten von diesen Maßnahmen betroffen zu werden. In der Folge richtete sich das Bestreben des Reichsjustizministers darauf, die Unabhängigkeit des Richters durch eine entsprechende Ausgestaltung des neuen Beamtengesetzes - das schließlich im Juli 1937 in Kraft trat - zu sichern. ${ }^{134}$

Die Durchführung des Berufsbeamtengesetzes zeitigte bei der Reichsjustiz, der preußischen Justiz und der Justiz in den außerpreußischen Ländern entsprechend ihres verschiedenen Personalumfangs und Anteils jüdischer Beamter unterschiedliche zahlenmäßige Ergebnisse. Beim Reichsgericht, wo die Durchführung in der Hand des Reichsjustizministeriums lag, wurden 1 Senatspräsident, 6 Reichsgerichtsräte und 1 Reichsanwalt wegen jüdischer Abstammung ${ }^{135}$ entlassen. Bei dem Senatspräsidenten handelte es sich um den bereits Mitte März von Reichsgerichtspräsident Bumke beurlaubten ${ }^{136}$ siebenundsechzigjährigen Alfons David, der mit Wirkung vom 1.August 1933 in den Ruhestand trat. Da das einzige Reichsgerichtsmitglied, das wegen nationaler Unzuverlässigkeit aufgrund des $\S 4$ Berufsbeamtengesetz hätte entlassen werden müssen, der noch nicht fünfundfünfzigjährige Hermann Grossmann, bereits Anfang April selbst um seine Versetzung in den Ruhestand „mit sofortiger Wirkung“ gebeten hatte ${ }^{137}$, wurden von der Durchführung des Berufsbeamtengesetzes am Reichsgericht nur Juden betroffen. Aufgrund der Ausnahmebestimmungen des Gesetzes blieb nur ein Volljude, Reichsanwalt Richard Neumann, beim Reichsgericht im Amt, bis auch er aufgrund der Bestimmungen des Reichsbürgergesetzes 1935 ausscheiden mußte. Beim Reichspatentamt, das gleichfalls zur personellen Zuständigkeit des Reichsjustizministeriums gehörte, wurde ein jüdischer Gerichtsassessor entlassen. ${ }^{138}$ Die Personalveränderungen im Reichsjustizministerium selbst werden in anderem Zusammenhang behandelt.

Das preußische Justizministerium gab über die Durchführung des Berufsbeamtengesetzes in seinem Geschäftsbereich auf Anforderung des Reichsinnenministeriums Ende November 1933 einen Zwischenbericht. Danach waren entlassen bzw. in den Ruhestand versetzt worden:

132 Vgl. Sechstes G. zur Änderung des G. zur Wiederherstellung des Berufsbeamtentums v. 26.9.34 (RGBl. I, S.845).

133 Ein plastisches Beispiel für die Anwendung des $\S 6$ BBG in den Jahren 1935/36 ist der vom RJM vereitelte Versuch des sächsischen Reichsstatthalters/Gauleiters, einen der Bekennenden Kirche angehörenden Richter in den Ruhestand versetzen zu lassen. Vgl. die Dokumentation von L. Gruchmann, Ein unbequemer Amtsrichter im Dritten Reich. Aus den Personalakten des Dr. Lothar Kreißig (VfZ 1984, S. 463 ff.), S. $464 \mathrm{ff} ., 477 \mathrm{ff}$.

134 Vgl. dazu Kapitel III.1.c., S. $191 \mathrm{f}$.

$135 \mathrm{Vgl}$. Übersicht auf S. 167 und Kaul, a.a.O., S. $52 \mathrm{ff}$.

136 Vgl. voranstehend S.126.

137 A.a.O.

138 Vgl. Übersicht auf S.167. 


\begin{tabular}{|c|c|c|}
\hline gemäß $§ 2$ & (Parteibuchbeamte) & $=$ \\
\hline gemäß $§ 2 a$ & (kommunistische Betätigung) & $=$ \\
\hline gemäß $§ 3$ & (nichtarische Abstammung) & $\begin{array}{l}=1114, \text { davon } \\
\quad 804 \text { Referendare }\end{array}$ \\
\hline gemäß § 4 & (nationale Unzuverlässigkeit) & $\begin{array}{l}=108, \text { davon } \\
\quad 11 \text { Referendare }\end{array}$ \\
\hline gemäß $§ 5$ Abs. 2 & $\begin{array}{l}\text { (Zurruhesetzung auf eigenen Antrag } \\
\text { statt Zwangsversetzung ) }\end{array}$ & $=27$ \\
\hline yemäß $\S 6$ & $\begin{array}{l}\text { Verwaltungsvereinfachung oder } \\
\text { dienstliche Gründe) }\end{array}$ & $=107$ \\
\hline
\end{tabular}

zusammen also 1360 Beamte. Aufgrund $\S 5$ Abs. 1 waren 272 Beamte in ein anderes Amt zwangsversetzt worden. Das Justizministerium machte jedoch darauf aufmerksam, daß zu diesem Zeitpunkt noch ca. 100 Fälle zur Entscheidung anstanden. ${ }^{139}$

Als im März 1934 das Berufsbeamtengesetz in Preußen im wesentlichen durchgeführt war, hatte sich die im Bericht genannte Zahl von 1114 - zunächst aufgrund des $\S 3$ - ausgeschiedenen jüdischen Beamten durch die Anwendung der anderen Paragraphen des Gesetzes auf Angehörige dieser Kategorie, aber auch durch Tod, freiwilligen Abschied usw. auf 1373 (davon 873 Referendare) vergrößert. Waren im April 1933 von 45181 planmäßigen preußischen Justizbeamten 1704 Juden gewesen, so betrug diese Zahl im März 1934 nur noch 331. ${ }^{140}$

Von den dreizehn außerpreußischen Oberlandesgerichtsbezirken liegen nur Angaben für den richterlichen und den staatsanwaltschaftlichen Dienstzweig vor. Danach schieden von den 207 bei der Machtübernahme vorhandenen jüdischen Richtern und Staatsanwälten 95 aufgrund des Berufsbeamtengesetzes aus, 112 blieben noch im Amt. ${ }^{141}$ Für die Aufgliederung der ausgeschiedenen Juden nach Dienstgraden und Oberlandesgerichtsbezirken im Reich gibt nachfolgende Übersicht Aufschluß, die Amtsgerichtsrat Lorenzen vom Reichsjustizministerium zusammenstellte. ${ }^{142}$ In ihr sind die durch Tod, aufgrund freiwilligen Abschieds oder auf andere Weise zwischen dem 30. Januar 1933 und dem Inkrafttreten des Berufsbeamtengesetzes ausgeschiedenen Juden den aufgrund dieses Gesetzes ausgeschiedenen zugerechnet worden. In der Zahl der Assessoren sind außerdem die durch Zulassung zur Anwaltschaft ausgeschiedenen mit enthalten:

\footnotetext{
${ }^{139}$ Vgl. Aufstellung der Kalkulatur des preuß. JM, Schr. des preuß. JM v. 30.11.33 an das RMdI auf dessen Anforderung v. 17.11.33 (Geh. StArch. Berlin, Sign. Rep. 84 a/6334).

$140 \mathrm{Vgl}$. die auf damaligen Akten der JVerw. beruhenden Angaben des AGRats im RJM Lorenzen in: Die Juden und die Justiz. Bearbeitet im Auftrage des Reichsministers der Justiz v. Sievert Lorenzen, 2. Aufl., Berlin-Hamburg 1943, S.182 f.

141 A.a.O., S. 184. Die Angaben bei Lorenzen beruhen auf Berichten, die das RJM durch eine RV v. 23.9.36 (Akten des RJM-Hauptbüros, Arch. des BJM) von den OLGPräs. und GStAen anforderte. Zu den 4 bayerischen OLGBezirken (Angaben für das Jahr 1933) vgl. Kapitel III.2., S. 237.

142 Veröffentlicht in DJ 1939, S.965.
} 


\begin{tabular}{|c|c|c|c|c|c|c|c|c|}
\hline Bezirk & $\begin{array}{c}\text { Gerichts- } \\
\text { asses- } \\
\text { soren }\end{array}$ & $\begin{array}{l}\text { Amts- } \\
\text { und } \\
\text { Land- } \\
\text { gerichts- } \\
\text { räte } \\
\text { usw.") }\end{array}$ & $\begin{array}{c}\text { Landge- } \\
\text { richts- } \\
\text { Dir., } \\
\text { OLG- } \\
\text { Räte } \\
\text { usw.") }\end{array}$ & $\begin{array}{l}\text { LGPräs., } \\
\text { SenPräs. } \\
\text { b. OLG, } \\
\text { Vizepräs. } \\
\text { b. OLG, } \\
\text { RGRäte }\end{array}$ & $\begin{array}{c}\text { OLG- } \\
\text { Präs., } \\
\text { SenPräs. } \\
\text { b. RG }\end{array}$ & $\begin{array}{c}\text { Staats- } \\
\text { anwälte }\end{array}$ & $\begin{array}{c}\text { Ober- } \\
\text { staats- } \\
\text { anwälte }\end{array}$ & $\begin{array}{l}\text { ins- } \\
\text { gesamt }\end{array}$ \\
\hline 1 & 2 & 3 & 4 & 5 & 6 & 7 & 8 & 9 \\
\hline Reichsgericht... & - & - & - & 6 & 1 & - & $\begin{array}{c}1 \\
\text { (Reichs- } \\
\text { anwalt) }\end{array}$ & 8 \\
\hline R.-Patentamt . . & 1 & - & - & - & - & - & - & 1 \\
\hline Berlin .... & 79 & 111 & 22 & 2 & - & 11 & 3 & 228 \\
\hline Bamberg ....... & - & 1 & 2 & - & - & - & - & 3 \\
\hline Braunschweig .. & - & - & 1 & - & - & - & - & 1 \\
\hline Breslau ........ & 26 & 19 & 5 & 1 & - & 3 & - & 54 \\
\hline Celle .......... & 6 & 6 & 1 & 1 & - & - & - & 14 \\
\hline Darmstadt ..... & 2 & 5 & 2 & - & - & 1 & 1 & 11 \\
\hline Dresden ....... & 3 & 5 & - & - & - & 1 & - & 9 \\
\hline Düsseldorf ..... & 7 & 12 & 1 & - & - & 1 & - & 21 \\
\hline Frankfurt ..... & 11 & 23 & - & 1 & - & - & - & 35 \\
\hline Hamburg ..... & 1 & 16 & 12 & 2 & - & 1 & 1 & 33 \\
\hline Hamm $\ldots \ldots \ldots$ & 2 & 14 & 2 & 1 & - & 2 & 1 & 22 \\
\hline Jena...$\ldots \ldots$ & - & 1 & 1 & - & - & - & - & 2 \\
\hline Karlsruhe ...... & 6 & 8 & 4 & 2 & - & 1 & 1 & 22 \\
\hline Kassel . . . . . . . & 1 & 1 & - & - & - & - & - & 2 \\
\hline Kiel . . . . . . . & - & 1 & - & - & - & - & - & 1 \\
\hline Köln ......... & 11 & 5 & 4 & - & - & 1 & - & 21 \\
\hline Königsberg . . . . & 11 & 7 & - & - & - & - & - & 18 \\
\hline Marienwerder .. & - & 1 & - & - & - & - & - & 1 \\
\hline München ...... & - & 8 & 7 & 2 & - & 1 & 2 & 20 \\
\hline Naumburg . .... & 4 & 7 & 2 & 1 & - & - & - & 14 \\
\hline Nürnberg ...... & - & 7 & 5 & - & - & 2 & - & 14 \\
\hline Oldenburg ..... & - & - & - & - & - & - & - & - \\
\hline Rostock ...... & - & - & - & - & - & - & - & - \\
\hline Stettin ........ & 3 & 1 & 1 & - & - & - & - & 5 \\
\hline Stuttgart ....... & 1 & 7 & 1 & - & - & - & - & 9 \\
\hline Zweibrücken ... & - & 3 & 1 & - & - & 1 & - & 5 \\
\hline zusammen: & 175 & 269 & 74 & 19 & 1 & 26 & 10 & 574 \\
\hline
\end{tabular}

) Einschließlich Amts- und Landrichter.

Über die Zahl der aufgrund des Berufsbeamtengesetzes ausgeschiedenen „Arier“ geben die heute zugänglichen Akten des ehemaligen Reichsjustizminsteriums keinen Aufschluß ${ }^{143}$ Hier liegen nur die entsprechenden Zahlen für Preußen vor. Danach wurden betroffen:

\begin{tabular}{llrlr}
$\operatorname{vom} \S 2$ & $=$ & 2 & vom $\S 5$ Abs.2 & $=10$ \\
vom $2 \mathrm{a}$ & $=$ & 1 & vom 6 & $=128$ \\
\cline { 2 - 2 }$\S 4$ & $=64$ & insgesamt & $=205$
\end{tabular}

143 Die dafür notwendigen Recherchen bei den verschiedenen Landesarchiven bzw. Registraturen der heutigen Länderjustizministerien und Oberlandesgerichte konnten vom Verf. nicht geleistet werden. 
„arische“ Justizbeamte. 185 wurden aufgrund $\S 5$ Abs. 1 in ein anderes Amt versetzt. ${ }^{144}$ Wie diese Statistik erkennen läßt, war ihr Anteil an der Gesamtzahl der ausgeschiedenen Justizbeamten um ein Beträchtliches geringer als der der Juden. Das geht auch aus einer Aufstellung für den Bezirk des Oberlandesgerichts Hamburg hervor, die dessen Präsident ihm Jahre 1936 der Hamburger Gestapo auf Wunsch übermitteln ließ. ${ }^{145}$ Danach waren aufgrund des Berufsbeamtengesetzes 29 jüdische Richter und Staatsanwälte ausgeschieden, und zwar nach $\S 3$ (nichtarische Abstammung) nur 5, nach $\S 6$ („dienstliche Gründe“) dagegen 24 (!); demgegenüber betrug die Zahl der ausgeschiedenen „Arier“ 16 , von denen gemäß $\S 4$ (politische Unzuverlässigkeit) 2, gemäß $\S 5$ (Zurruhesetzung auf eigenen Wunsch statt Zwangsversetzung) 1, die übrigen 13 nach $\S 6$ entfernt wurden. Aus dieser Aufstellung wird zugleich deutlich, daß der $\S 6$ in erheblichem Maße dazu benutzt wurde, um jüdische Justizbeamte loszuwerden, die unter die Ausnahmen des $\S 3$ des Berufsbeamtengesetzes fielen.

b. Erlaß des Reichsbürgergesetzes und der ergänzenden Verordnungen 1935-1938: die endgültige Ausschaltung der Juden aus der Justiz und die Zulassung jüdischer Konsulenten

Die Forderung der Partei auf gänzliche Ausschaltung der Juden aus der Beamtenschaft, die sich im Bereich der Justiz durch die Opposition der nationalsozialistischen Landesjustizchefs gegen die reichsgesetzliche Regelung mit ihren zahlreichen Ausnahmen geäußert hatte, verstummte auch nach Durchführung des Berufsbeamtengesetzes nicht. Die auf Drängen der Parteistellen aufgenommenen Verhandlungen mit dem in erster Linie zuständigen Reichsinnenministerium über ein Gesetz, das die grundsätzliche Schlechterstellung der Juden als Staatsbürger unter Beschneidung weiterer Rechte und ohne die bisherigen Ausnahmen bringen sollte, zogen sich hauptsächlich wegen der unterschiedlichen Auffassung über die künftige Behandlung der „Mischlinge“ in die Länge: Die Ministerialbürokratie wollte die für das Berufsbeamtengesetz geltende Bestimmung - wonach bereits als „Nichtarier“ galt, wer auch nur einen jüdischen Großelternteil hatte, also „Vierteljude“ war - in ein solches grundlegendes Gesetz nicht übernehmen, da dadurch ein beträchtlicher, wertvoller und bisher loyaler Teil der Gesamtbevölkerung betroffen und dem Staat entfremdet worden wäre, während andererseits die Partei sogar die Einbeziehung von „Achteljuden“ forderte. Die überstürzte Formulierung der Nürnberger Gesetze und ihre Verabschiedung durch den Reichstag während des Parteitages im September 1935 wird im Zusam-

144 Vgl. Teil III der Statistik des preuß. JM - I 9629/34 - betr. Gesamtergebnis der Durchführung des G. zur Wiederherstellung des Berufsbeamtentums (abgedruckt bei H. Schorn, Der Richter im Dritten Reich. Geschichte und Dokumente, Frankfurt a. M. 1959, S. 730/731).

$145 \mathrm{Vgl}$. Schr. des OLG Hamburg v. 11.9.36 nebst namentl. Verzeichnis (Arch. der Forschungsstelle f. d. Geschichte des NS in Hamburg, Sign. Best. 3309). 
menhang mit der Entstehung des „Blutschutzgesetzes“ behandelt. ${ }^{1}$ Das in der Nacht vor der Reichstagssitzung von Beamten des Reichsinnenministeriums formulierte und von Hitler und Frick unterzeichnete Reichsbürgergesetz vom 15.September 1935 (RGBl. I, S. 1146), mit dem der Reichsjustizminister im Gegensatz zum „Blutschutzgesetz" nicht befaßt worden war, weil es keine strafrechtlichen Vorschriften enthielt, bestimmte, daß nur „der Reichsbürger ... der alleinige Träger der vollen politischen Rechte nach Maßgabe der Gesetze“ sein durfte $(\S 2)$. Obwohl dieser Satz erst durch Ausführungsbestimmungen konkreten Inhalt gewinnen konnte, die vom Reichsinnenminister im Einvernehmen mit dem Stellvertreter des Führers erlassen werden sollten $(\S 3)$, stand fest, daß die Befähigung, Beamter zu sein, auf jeden Fall zu diesen Rechten gehören würde. Um sich daher in seinem Geschäftsbereich ein Bild von den personellen Auswirkungen des Gesetzes zu machen, dessen Ausführung nach der „Verreichlichung“ der Justiz nunmehr bei seinem Ministerium lag, forderte Gürtner sofort nach der Verabschiedung des Gesetzes von den nachgeordneten Behörden telegrafisch Berichte darüber an, wie viele jüdische Richter und Staatsanwälte noch im Dienst standen. Die Berichte, denen zu diesem Zeitpunkt wohl noch die Definition des „Nichtariers“ nach dem Berufsbeamtengesetz zugrunde lag, ergaben - da unterdessen weitere jüdische Beamte freiwillig, durch Erreichung der Altersgrenze oder durch Tod ausgeschieden waren - die Zahl von 232. Als das Reichsinnenministerium am Tage des Inkrafttretens des Reichsbürgergesetzes - am 30.September 1935 durch Schnellbrief die Beurlaubung aller Beamten anordnete, die von drei oder vier „volljüdischen“ Großeltern abstammten, verfügte das Justizministerium telegrafisch, diese Justizbeamten mit sofortiger Wirkung bis auf weiteres zu beurlauben und unter namentlicher Benennung der Betroffenen Vollzug zu melden. ${ }^{2}$

Die Erste Verordnung zum Reichsbürgergesetz vom 14. November 1935 (RGB1. I, S. 1333), die das Tauziehen um die Einbeziehung der Mischlinge durch die Kompromißdefinition des „Juden“ unter Gleichstellung der „Vierteljuden“ und bestimmter Kategorien von „Halbjuden“ mit Deutschblütigen beendete $(\S 5)^{3}$, sah dann auch vor, daß Juden kein öffentliches Amt mehr bekleiden durften ${ }^{4}$ und jüdische Beamte mit Ablauf des Jahres 1935 in den Ruhestand versetzt werden mußten; waren sie „Frontkämpfer" gewesen, bekamen sie bis zur Erreichung der Altersgrenze die zuletzt bezogenen ruhegehaltsfähigen Dienstbezüge $(\S 4)$. Damit waren die Ausnahmebestimmun-

1 Vgl. Kapitel VIII.3.c., S.875f. Zur Entstehung des ReichsbürgerG vgl. insbesondere: Das Reichsministerium des Innern und die Judengesetzgebung. Aufzeichnungen von Dr. Bernhard Lösener (VfZ 1961, S. 162ff.), S. 275 f., darauf fußend auch U. D. Adam, Judenpolitik im Dritten Reich, Düsseldorf 1979, S. $125 \mathrm{ff}$.

2 Vgl. Schnellbrief des RuPrMdI an die Obersten Reichsbehörden, Telegr. und nachfolgende RV des RJM (i.V. Nadler) an die OLGPräs. und GStAe v. 30.9.35 (Akten des RJM, BA, Sign. R 22/1529), Namensverzeichnis der beurlaubten volljüdischen Justizbeamten v. Stand 10.10.35 (a.a.O., Sign. R 22/3791).

3 Zu Einzelheiten vgl. Kapitel VII.3.c., S.877f.

4 Jüdische Notare, die nach dem noch geltenden Landesrecht nicht Beamte waren und denen die Gebühren selbst zuflossen, waren als Träger eines öffentlichen Amtes davon betroffen und schieden am 15.11.35 aus, beamtete Notare erst am 31.12.35. Die jüdischen RAe waren davon nicht betroffen, dagegen ihre Bestellung zu Pflichtverteidigern, Armenanwälten usw., vgl. die AV des RJM v. 19.12.35 (DJ 1935, S. 1858, dazu Kapitel III.1.a., Anm. 128). 
gen des Berufsbeamtengesetzes für jüdische Beamte aufgehoben. Als Ersatz dafür war vorgesehen, daß Hitler „Befreiungen von den Vorschriften der Ausführungsverordnung erteilen" konnte $(\S 7)$. Diese Befreiungen sollten aber nur noch in besonderen Ausnahmefällen und in erster Linie im Interesse der Allgemeinheit und nicht des Gesuchstellers erfolgen. ${ }^{5}$

Um die nach dieser Verordnung auszuschließenden jüdischen Justizbeamten festzustellen, mußten nun auch „Altbeamte“, „Frontkämpfer“ und Nachkommen von Gefallenen einen vorgeschriebenen Einheitsfragebogen über die Abstammung ihrer Eltern und Großeltern ausfüllen, die Richtigkeit ihrer Angaben unter Berufung auf ihren Diensteid versichern und durch Urkunden belegen; bei Zweifelsfragen im Einzelfall sollte ein Gutachten der Reichsstelle für Sippenforschung eingeholt werden. ${ }^{6} \mathrm{Am}$ 3. Dezember wies das Reichsjustizministerium die höheren Justizbehörden an, ihm innerhalb von sieben Tagen Verzeichnisse jener ausscheidenden Beamten des höheren und mittleren Dienstes zuzusenden, deren Entlassung nach den allgemeinen Vorschriften entweder Hitler oder dem. Justizministerium vorbehalten war. ${ }^{7}$

Nach den Berichten, die das Reichsjustizministerium von den Oberlandesgerichtspräsidenten und Generalstaatsanwälten im September 1936 anforderte, waren bis Mitte Oktober jenes Jahres insgesamt 205 jüdische Richter und Staatsanwälte aufgrund des Nürnberger Gesetzes aus dem Dienst geschieden. ${ }^{8}$ Durch das deutsch-polnische Abkommen vom 15. Mai 1922 über den Minderheitenschutz in Oberschlesien blieben im Oberlandesgerichtsbezirk Breslau 4 jüdische Gerichtsassessoren und 16 Amts- und Landgerichtsräte zunächst verschont; sie traten erst mit Ablauf des 31. August 1937 in den Ruhestand.' Nach den Zahlen, die Amtsgerichtsrat Lorenzen aus dem Reichsjustizministerium im Jahre 1937 ermittelte, schieden aufgrund des Reichsbürgergesetzes bis zum 31. Dezember 1935 aus $^{10}$ :

s Zum Verfahren vgl. RdErl. des RuPrMdI v. 4.12.35 (MBliV, S. 1455).

${ }^{6} \mathrm{Vgl}$. RVen des RJM an die höheren Justizbehörden v. 7., 14. und 18.12.35 (Akten des RJM, BA, Sign. R 22/4433), ferner RdErl. des RuPrMdI v. 9.12.35 (MBliV, S. 1467).

7 Vgl. RV des RJM v. 3.12.35 an die Präs. des RG, VGH, Reichspatentamts, Landeserbhofgerichts in Celle, den OReiA, die OLGPräs. und GStAe (Akten des RJM, BA, Sign. R 22/4469).

${ }^{8}$ Vgl. RV des RJM v. 23.9.36 an die OLGPräs. und GStAe (Akten des RJM, Hauptbüro, Arch. des BJM) und S. Lorenzen, Die Juden und die Justiz, Hamburg 1943, S. 187, dort auch die Aufschlüsselung nach OLG-Bezirken. Die bei Lorenzen für Hamburg angegebenen Zahlen stimmen mit dem Ber. des OLGPräs. Rothenberger v. 13.10.36 an das RJM überein (Arch. der Forschungsstelle f. d. Geschichte des NS in Hamburg, Sign. Best. 3309).

9 Vgl. G. über Maßnahmen im ehemaligen oberschlesischen Abstimmungsgebiet v. 30.6.37 (RGBl. I, S.717). Danach wurden in diesem Gebiet auch Beamte, die jüdische Mischlinge (?) waren, bis 31.12.37 in den Ruhestand versetzt. Zu diesem Gebiet gehörten die LGBez. Gleiwitz, Oppeln, Ratibor, Beuthen und - soweit es sich um das AG Oberglogau handelte - Neiße.

10 Nachstehende Ubersicht veröffentlicht in DJ 1939, S.965. In Klammern laut Lorenzen „die durch das deutsch-polnische Abkommen über Oberschlesien (Minderheitenschutz) bis 31.12.1935 geschützt gewesenen Juden“. Nach Lorenzen, a.a.O. (voranstehende Anm.8), S. 187, Anm. 2, beruht die Ubersicht auf im Jahre 1937 ermittelten Zahlen, d.h. offensichtlich auf den Berichtsangaben, die das RJM durch die RV v. 16.11.37 von den höheren JBehörden bis 10.12.37 anforderte (Akten des RJM, BA, Sign. R 22/1500). 


\begin{tabular}{|c|c|c|c|c|c|c|c|c|}
\hline Bezirk & $\begin{array}{c}\text { Gerichts- } \\
\text { asses- } \\
\text { soren }\end{array}$ & $\begin{array}{c}\text { Amts- } \\
\text { und } \\
\text { Land- } \\
\text { gerichts- } \\
\text { räte usw. }\end{array}$ & $\begin{array}{l}\text { LGDir., } \\
\text { OLG- } \\
\text { Räte } \\
\text { usw. }\end{array}$ & $\begin{array}{c}\text { LGPräs., } \\
\text { SenPräs. } \\
\text { u.VizePräs. } \\
\text { b. OLG, } \\
\text { RGRäte }\end{array}$ & $\begin{array}{l}\text { OLG- } \\
\text { Präs., } \\
\text { SenPräs. } \\
\text { am RG }\end{array}$ & $\begin{array}{l}\text { Staats- } \\
\text { anwälte }\end{array}$ & $\begin{array}{l}\text { Ober- } \\
\text { staats- } \\
\text { anwälte }\end{array}$ & $\begin{array}{c}\text { ins- } \\
\text { gesamt }\end{array}$ \\
\hline 1 & 2 & 3 & 4 & 5 & 6 & 7 & 8 & 9 \\
\hline Reichsgericht & - & - & - & - & - & - & $\begin{array}{c}1 \\
\text { (Reichs- } \\
\text { anwalt) }\end{array}$ & 1 \\
\hline R.-Patentamt & - & 3 & 1 & 1 & - & - & - & 5 \\
\hline Berlin & 3 & 42 & 21 & 3 & - & 2 & - & 71 \\
\hline Bamberg & - & 3 & 3 & - & - & - & - & 6 \\
\hline Braunschweig & - & - & - & - & - & - & - & - \\
\hline Breslau & $\begin{array}{r}5 \\
(4)\end{array}$ & $\begin{array}{r}32 \\
(16)\end{array}$ & 5 & - & - & - & - & 42 \\
\hline Celle & - & 3 & - & - & - & - & - & 3 \\
\hline Darmstadt & - & 2 & - & - & - & 1 & - & 3 \\
\hline Dresden & - & 5 & - & - & - & - & - & 5 \\
\hline Düsseldorf & - & 8 & 2 & - & - & - & - & 10 \\
\hline Frankfurt & - & 3 & 2 & - & - & - & - & 5 \\
\hline Hamburg & - & 1 & 3 & 1 & - & - & - & 5 \\
\hline Hamm & - & 9 & 5 & - & - & - & - & 14 \\
\hline Jena & - & 2 & - & - & - & - & - & 2 \\
\hline Karlsruhe & 3 & 5 & 3 & - & - & - & - & 11 \\
\hline Kassel & - & - & 2 & - & - & - & - & 2 \\
\hline Kiel & - & 3 & 2 & - & - & - & - & 5 \\
\hline Köln & - & 5 & 4 & - & - & - & 1 & 10 \\
\hline Königsberg & - & 9 & 3 & - & - & - & - & 12 \\
\hline Marienwerder & - & - & - & - & - & - & - & - \\
\hline München & - & 7 & - & - & - & 1 & - & 8 \\
\hline Naumburg & - & 7 & - & - & - & - & - & 7 \\
\hline Nürnberg & - & - & - & - & - & - & - & - \\
\hline Oldenburg & - & 1 & - & - & - & - & - & 1 \\
\hline Rostock & - & 1 & - & - & - & - & - & 1 \\
\hline Stettin & 1 & 4 & 1 & - & - & - & - & 6 \\
\hline Stuttgart & - & 1 & - & - & - & - & - & 1 \\
\hline Zweibrücken & - & 3 & - & - & - & - & - & 3 \\
\hline zusammen: & 12 & 159 & 57 & 5 & - & 4 & 2 & 239 \\
\hline
\end{tabular}

Während bei der Durchführung des Berufsbeamtengesetzes vom April 1933 der Nachweis der ,arischen“ Abstammung nicht von jedem Justizbeamten, sondern nur in „zweifelhaften “ Fällen verlangt worden war ${ }^{11}$, wurden im Gefolge des Reichsbürgergesetzes die nachgeordneten Justizbehörden durch eine Rundverfügung vom 7. Dezember 1935 ersucht, „in geeigneter Weise darauf hinzuwirken“, daß nunmehr alle Beamten - soweit noch nicht geschehen - den urkundlichen Nachweis ,in nächster Zeit" erbrachten. Der Rundverfügung lag das Muster eines Einheitsfragebogens bei, den die Beamten auszufüllen hatten. Der Nachweis war bis zu den Großeltern zu führen und die Angaben durch eine wörtlich vorgeschriebene dienstliche Versicherung zu bestäti- 
gen. Soweit die erforderlichen Urkunden nicht beschafft werden konnten, hatte der Beamte „nachzuweisen, daß er alle Mittel zur Beschaffung der fehlenden Urkunden und Auskünfte erschöpft“ hatte. War der Nachweis „durch Urkunden nicht zweifelsfrei zu erbringen“, sollte ein Gutachten der Reichsstelle für Sippenforschung eingeholt werden. ${ }^{12}$ Da die Urkunden oft nicht leicht zu beschaffen waren, zog sich die Aktion über Jahre hin: so forderte das Ministerium die höheren Justizbehörden z. B. noch im Frühjahr 1938 auf, „bis zum Abschluß dieses Jahres zu berichten, ob dieser Nachweis nunmehr allgemein erbracht" sei. ${ }^{13}$

Am 14. Dezember 1935 verfügte das Justizministerium, daß die Justizbeamten „auch die Abstammung ihres Ehegatten durch Ausfüllung des Fragebogens“ darlegen sollten, widerrief aber bereits vier Tage später diese Anordnung. ${ }^{14}$ Der Grund dafür war, daß das Reichsinnenministerium die antijüdischen Maßnahmen auf ,jüdisch versippte“, d.h. mit Jüdinnen verheiratete „arische“ Beamte ausdehnen und auch diese entlassen wollte, diese Absicht jedoch als Ergebnis einer Chefbesprechung - zu der auch das Reichsjustizministerium geladen war - wieder fallenließ. ${ }^{15}$ Erst nachdem das Deutsche Beamtengesetz die künftige Ernennung ,jüdisch versippter“ Beamter ab 1.Juli 1937 ausschloß, ordnete das Reichsinnenministerium im April 1937 erneut an, daß in deutsch-jüdischer Mischehe lebende Beamte in den Ruhestand zu versetzen seien, und zwar - da es sich bei diesen Personen weder um Juden noch um national Unzuverlässige handelte - gemäß $\S 6$ des Berufsbeamtengesetzes. Die Begründung dafür lautete, daß es dem deutschblütigen, aber ,jüdisch versippten“ Ehegatten verboten sei, an seiner Wohnung die Reichs- und Nationalflagge zu hissen, und dieser Zustand für einen Beamten „auf die Dauer nicht tragbar“ sei (!). Von der Versetzung eines solchen Beamten in den Ruhestand sollte nur „in besonders gelagerten Ausnahmefällen“ abgesehen werden, „wenn eine strenge Prüfung ergeben hat, daß der Beamte nicht nur fachlich besonders tüchtig ist, sondern auch wegen besonderer Zuverlässigkeit, wegen schwerer Kriegsbeschädigung oder wegen besonderer Verdienste" der Belassung im Amt würdig sei. ${ }^{16}$ Im Gegensatz zu anderen Reichsministerien, die aufgrund dieses Erlasses rigoros vorgingen ${ }^{17}$, scheint die Justizverwaltung - auch in den Reihen des Reichsjustizministeriums selbst - von der Möglichkeit der Ausnahmen Gebrauch gemacht zu haben: Jedenfalls sollten die Oberlandesgerichtspräsidenten nicht nur darüber berichten, wie viele Beamte aus diesem Grunde bis zum 30. September $1937^{18}$ in

12 Vgl. RV des RJM v. 7.12.35 an die höheren JBehörden (Akten des RJM, BA, Sign. R 22/4433).

13 RV des RJM v. 28.4.38 an die höheren JBehörden (a.a.O.).

$14 \mathrm{Vgl}$. die RV des RJM an die höheren JBehörden v. 14. und 18.12.35 (a.a.O.).

15 Vgl. dazu Adam, a.a.O., S. $147 \mathrm{ff}$.

16 Vgl. Erl. des RuPrMdI v. 8.4.37, u.a. an die Obersten Reichsbehörden (Akten der RK, BA, Sign. R 43 II/ 595). Zum Flaggenverbot für Mischehen vgl. RdSchr. des RuPrMdI v. 7.12.36 (MBliV 1936, S. 1631).

17 Vgl. z.B. den Erl. des RuPrM f. Wissenschaft, Erziehung und Volksbildung v. 19.4.37 (H.-J. Fliedner, Die Judenverfolgung in Mannheim 1933-1945, Stuttgart 1971, S.69, Anm. 27). Bei Lehrkräften z. B. sollten deshalb keine Ausnahmen zugelassen werden, weil von einem Erzieher, dessen Ehegatte Nichtarier war, „nicht erwartet werden kann, daß er die nationalsozialistische Weltanschauung, zu deren wesentlichen Bestandteilen die Rassegrundsätze gehören, im Unterricht mit der erforderlichen Überzeugungskraft vertritt“ (vgl. die im Einvernehmen mit dem Leiter der PK aufgestellten Richtlinien für die Ausnahmegenehmigungen, enthalten in der RV des RJM v. 29.8.42 an die höheren JBehörden, Akten des RJM, BA, Sign. R 22/4435).

18 Bis zu diesem Datum mußten die Verfügungen nach §6 BBG zugestellt sein, da dieses Gesetz am 30.6.37 außer Kraft trat und ab 1.7.37 durch das DBG ersetzt wurde, vgl. dazu DurchfVO zum DBG v. 29.6.37 (RGBI. I, S.669), Punkt 9 zu $§ 184$ DBG. 
den Ruhestand versetzt, sondern auch, wie viele im Dienst belassen worden waren ${ }^{19}$, und im Oktober ordnete das Reichsjustizministerium an, daß die verbliebenen Richter mit jüdischen Ehefrauen „künftig nur noch in Grundbuch-, Register- oder Verwaltungssachen (jedoch nicht in Personalangelegenheiten) beschäftigt werden " sollten. ${ }^{20}$ Im Oktober 1941 verfügte das Justizministerium auf Veranlassung der Partei-Kanzlei eine vertrauliche Benennung der mit Jüdinnen oder jüdischen Mischlingen verheirateten Beamten; dabei sollte jedoch Bedacht genommen werden, daß „eine Beunruhigung der betroffenen Beamten “ möglichst vermieden wurde. ${ }^{21}$ Das Ergebnis dieser Maßnahme - nur zum Teil um die Abgänge korrigiert, die unterdessen durch Tod, Pensionierung usw. eingetreten waren - lag noch den Zahlenangaben zugrunde, die das Reichsjustizministerium am 1.Juli 1944 machte: danach waren 9 höhere Justizbeamte mit Jüdinnen und 24 mit Mischlingen 1. Grades (Halbjuden) verheiratet, bei den gehobenen, mittleren und einfachen Beamten zusammen lauteten die Zahlen 18 bzw. $28 .^{22}$

Abschließend sei noch ausgeführt, daß die Bestimmungen des Reichsbürgergesetzes und seine ergänzenden Verordnungen nach dem Anschluß Österreichs auch auf die dortige Justizbeamtenschaft angewendet wurden. Bereits am 15. März 1938 hatte Hitler angeordnet, daß österreichische Beamte, die - nach einer Definition, die derjenigen im $\S 5$ der Verordnung vom 14. November 1935 für das Altreich analog gestaltet war als "Juden" galten, gar nicht erst auf seine Person vereidigt zu werden brauchten. ${ }^{23}$ Nachdem das Reichsbürgergesetz nebst der erwähnten Verordnung in Österreich in Kraft getreten war ${ }^{24}$, bestimmte die „Verordnung zur Neuordnung des österreichischen Berufsbeamtentums“ vom 31. Mai 1938 (RGBl. I, S. 607) auch dort die Versetzung von Juden, Mischlingen und ,jüdisch versippten“ Beamten in den Ruhestand, wobei Ausnahmen zugunsten von Mischlingen, die „Altbeamte“ oder Frontkämpfer waren, sowie für ,jüdisch Versippte“ möglich waren ( $(3)$. Analog dem Berufsbeamtengesetz von 1933 regelte die Verordnung auch die Entfernung von Beamten aus politischen $(\S 4)$ und dienstlichen $(\S 6)$ Gründen. Während die Entlassung politisch unzuverlässiger Beamter bis zum Jahresende 1938 verfügt sein mußte, waren die anderen Maßnahmen bis spätestens zum 31. Dezember 1939 durchzuführen. Bis Juli 1938 wurden aus rassischen Gründen 21 österreichische Justizbeamte in den Ruhestand versetzt und 69 vorsorglich beurlaubt, für die politisch unzuverlässigen lauteten die entsprechenden Zahlen 46 und 44. Die Maßnahmen verzögerten sich dadurch, daß sie aufgrund der Verordnung dem Reichsstatthalter übertragen worden waren und deshalb nicht von der Justizverwaltung, sondern von Beamten der Reichsstatthalterei vorbereitet und die Einzelfälle vor der Entscheidung durch eigene bei dieser Behörde und

${ }^{19} \mathrm{Vgl}$. RV des RJM v. 16.11.37 an die höheren JBehörden (Akten des RJM, BA, Sign. R 22/1500). Die Berichtszahlen waren den Akten leider nicht zu entnehmen.

20 RV des RJM an die OLGPräs. v. 4.10.37 (Akten des RJM, Hauptbüro, Arch. des BJM).

$21 \mathrm{Vgl}$. RV des RJM v. 24.10.41 an die höheren JBehörden, veranlaßt durch das Schr. der Partei-Kanzlei (Bormann) an den RJM v. 10.10.41 (a.a.O., BA, Sign. R 22/4433).

22 Vgl. die für Thierack gefertigte Aufstellung v. 1.7.44 (a.a.O., BA, Sign. R 22 Gr. 5/321). Sie war gegenüber dem Stand vom Oktober 1941 nur hinsichtlich der höheren Beamten korrigiert.

${ }^{23}$ Vgl. Erl. des Führers und Reichskanzlers über die Vereidigung der Beamten des Landes Österreich v. 15.3.38 (RGBl. I, S. 245).

24 VO über die Einführung der Nürnberger Rassengesetze im Lande Österreich v. 20.5.38 (RGBI. I, S.594). 
den Landeshauptleuten bestellte Ausschüsse begutachtet wurden. ${ }^{25}$ Bis Februar 1941 waren jedoch allein im Bezirk des Oberlandesgerichts Wien 146 Juden, Mischlinge und ,jüdisch Versippte“ aus dem Justizdienst ausgeschieden, davon je 1 bei der damaligen Abteilung Österreich des Reichsjustizministeriums und beim ehemaligen Obersten Gerichtshof sowie 10 beim Oberlandesgericht Wien. ${ }^{26}$

Im Gegensatz zu den Justizbeamten und Notaren hatte das Reichsbürgergesetz die jüdischen Rechtsanwälte - die im September 1935 aufgrund der Ausnahmen des Rechtsanwaltsgesetzes vom 7. April 1933 noch etwa 2300 zählten ${ }^{27}$ - nicht betroffen. Deshalb hielt die Forderung nach ihrer Ausschaltung von seiten der Partei und der organisierten Anwaltschaft unvermindert an. Im Justizministerium vertrat diese Forderung vor allem Freisler. Schon im November 1934 hatte er an Staatssekretär Schlegelberger, dem die für die Gesetzgebung zum Anwaltsrecht zuständige Abteilung IV unterstand, ein Schreiben gerichtet, in dem er ausführte, er könne sich „kaum jemals außerhalb des Ministeriums bei Parteigenossen, insbesondere aus Anwaltskreisen, sehen lassen, ohne - und ich muß sagen mit Recht - vorwurfsvollen Fragen nach dem Stande der Anderung“ des Anwaltsrechts ausgesetzt zu sein. Es erscheine ihm „unerträglich ..., daß, während die Justiz im vorigen Jahre in der Säuberung des Standes von fremdrassigen Elementen führend war, in dieser Frage nichts mehr geschieht ${ }^{\text {“ }}{ }^{28}$ Ein wesentlicher Grund für diese Forderung war die schlechte wirtschaftliche Lage der Anwaltschaft, die sich seit Anfang 1933 angesichts des andauernden Zustroms zu diesem Beruf kaum merklich gebessert hatte: Selbst bei einer Hebung der wirtschaftlichen Gesamtlage war nach Ansicht des Justizministeriums in absehbarer Zeit nicht zu erwarten, daß sich die Tätigkeit der Anwälte belebte, „weil erfahrungsgemäß wirtschaftliche Vorgänge sich erst geraume Zeit später im Wachsen und Fallen der Zahlen von Prozessen und sonstiger Rechtspflegetätigkeit bemerkbar machen “. ${ }^{29}$ Die Notlage der Anwaltschaft hatte dazu geführt, bestimmte Landgerichtsbezirke zu „Notbezirken“ zu erklären, in denen simultan zugelassene Anwälte die ihnen übertragenen Landgerichts-Mandate an Landgerichts-Anwälte abgeben sollten, falls nicht ein besonderes Interesse der Prozeßpartei die Vertretung durch den Simultananwalt rechtfertigte. ${ }^{30}$ Trotz dieser Situation widersetzte sich der „gemäßigte“ Flügel im Reichsjustizministerium um Gürtner und Schlegelberger zunächst den Wünschen nach restloser Entfernung der jüdischen Anwälte aus Gründen, auf die noch eingegangen werden

${ }^{25}$ Vgl. Ber. des Leiters der Abt. Österreich im RJM, Untersts. Hueber, aus Wien v. 12.7.38 (Akten des RJM, BA, Sign. R 22/4690).

${ }^{26} \mathrm{Vgl}$. Aufstellung des Rechnungsamts beim OLG Wien für das RJM v. 14.2.41 (Lorenzen, a.a.O., voranstehende Anm. 8, S. 192). Hier auch die Aufschlüsselung auf die übrigen Gerichte und JBehörden des Bezirks.

${ }^{27}$ Nach telegraf. Erhebungen des RJM vom September 1935 (Lorenzen, a.a.O., S. 189, mit Aufschlüsselung nach OLG-Bezirken). Nach der Übersicht der Reichs-Rechtsanwaltskammer über die zahlenmäßige Entwicklung der Anwaltschaft 1935 waren am 1.1.36 von 18854 zugelassenen RAen 2552 ,jüdisch und nichtarisch“" (Mitteilungen der RRAK 1936, S.69). Am 1.1.38 betrugen diese Zahlen 17360 und 1753 (a.a.O., 1938, S. 25).

${ }^{28}$ Vgl. Schr. Freislers an Schlegelberger v. 16.11.34 (Akten des RJM, BA, Sign. R 22/4723).

29 So das RJM in seiner Begründung zum Entw. des Zweiten G. zur Änderung der Rechtsanwaltsordnung v. 13.12.35 (RGBI. I, S. 1470), durch das der Zustrom zur Rechtsanwaltschaft eingedämmt werden sollte (Akten der RK, BA, Sign. R 43 II/1534). Noch in der Bekanntm. der neuen Fassung der RAO v. 21.2.36 (RGBl. I, S. 107) hieß es, die Reichsregierung sehe „in dem jedes Bedürfnis übersteigenden Zustrom zur Anwaltschaft eine schwere Gefahr für den Berufsstand".

${ }^{30}$ Vgl. z. B. Schr. der Gaugeschäftsstelle Westfalen-Nord des NSRB an das RJM v. 9.6.37 mit der Klage, daß im „Notstandsbezirk“ des LG Münster $30 \%$ aller Verhandlungen vor den 4 Kammern des LG von simultan zugelassenen Anwälten geführt wurden (Akten des RJM, BA, Sign. R 22/253). 
wird. Das Justizministerium war auch im Jahre 1937 noch nicht bereit, den zugelassenen jüdischen Rechtsanwälten wenigstens das Auftreten als Prozeßbevollmächtigte vor den Arbeitsgerichten zu verbieten: die mit einer entsprechenden Forderung verbundene Kritik des Reichswalters des NSRB wies Schlegelberger mit dem Hinweis zurück, es sei die „in der Rechtsprechung überwiegend vertretene Ansicht“, daß über die Zuziehung eines jüdischen Anwalts je nach Lage des Einzelfalles entschieden werden müsse. ${ }^{31}$

Nach dem Anschluß Österreichs wurde für die dortigen Anwälte die gleiche Rechtslage geschaffen wie im Altreich. Um wilden Aktionen und Ausschreitungen gegen jüdische Rechtsanwälte, wie sie sich im März 1933 im Reich ereignet hatten, zuvorzukommen, bat Gürtner bereits am 16. März 1938 den in der Regierung Seyß-Inquart amtierenden Justizminister Hueber in Wien telegrafisch, ein „vorläufiges Vertretungsverbot zu erlassen, soweit nach Reichsrecht Juden von (der) Rechtsanwaltschaft ausgeschlossen sind“, und zur Beratung einer endgültigen Regelung einen Vertreter des Wiener Ministeriums nach Berlin zu schicken. ${ }^{32}$ Das Ergebnis dieser Beratungen war eine Verordnung vom 31. März, die es ermöglichte, allen jüdischen Rechtsanwälten und „Verteidigern in Strafsachen“ - also auch pensionierten Beamten, Hochschullehrern u. a. -, die nicht Frontkämpfer oder Altanwälte waren, die Ausübung ihres Berufs vorläufig zu untersagen. ${ }^{33}$ Aufgrund dieser Verordnung, der die Definition des "Juden" nach der Durchführungsverordnung zum Reichsbürgergesetz zugrunde lag, erhielten von den insgesamt 3393 österreichischen Anwälten 805, von den 98 Verteidigern in Strafsachen 9 Juden ein vorläufiges Vertretungsverbot; von den insgesamt 369 österreichischen Notaren wurden 9 vorläufig ihres Amtes enthoben. Von den Vertretungsverboten entfielen allein 781 auf den Wiener Bezirk, in den vor allem nach Auflösung der österreich-ungarischen Monarchie 1918 zahlreiche jüdische Anwälte aus den an Polen, Rumänien und die Tschechoslowakei gefallenen Gebieten zugezogen waren.

Die Tatsache, daß trotz dieser Maßnahmen im Wiener Bezirk immer noch rund 1000 jüdische Anwälte 725 ,arischen“ gegenüberstanden ${ }^{34}$, und die Prognose der Wiener Justizstellen, daß es unmöglich sein werde, „auf Grund der gegenwärtigen Vorschriften zu erreichen, daß die Mehrheit der österreichischen Rechtsanwälte arisch

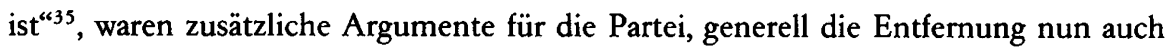
jener jüdischen Anwälte zu fordern, die als Frontkämpfer und „Altanwälte“ in ihrem Beruf belassen worden waren. Gegen die Erfüllung dieser Forderung sträubten sich jedoch die im Reichsjustizministerium Verantwortlichen aus zwei Gründen. Einmal wollten sie den Personenkreis der Betroffenen, die nach dem Ausscheiden aus ihrem Beruf ohne Versorgung dagestanden hätten, nicht der Proletarisierung preisgeben; zum zweiten erhob sich das Problem der künftigen anwaltschaftlichen Vertretung der

31 Vgl. Schr. des Reichswalters des NSRB v. 21.4.37 und Schr. des RJM (gez. Schlegelberger) an den NSRB v. 8.7.37 (a.a.O., Sign. R 22/2076).

32 Zitiert bei Lorenzen, a.a.O., S.192 f.

${ }^{33} \mathrm{Vgl}$. VO über Angelegenheiten der Rechtsanwälte, Verteidiger, Notare und Patentanwälte in Österreich v. 31.3.38 (RGBl. I, S.353). Die letzten Änderungswünsche zum Entw. der Abt. I des RJM wurden am 29.3.38 aus Wien telefonisch vorgebracht und berücksichtigt (Akten des RJM, Sign. R 22/253).

$34 \mathrm{Zu}$ den angegebenen Zahlen vgl. Ber. Huebers an das RJM v. 14.7.38 (a.a.O., BA, Sign. R 22/253).

35 Vgl. Ber. des Beauftragten des RJM, Abt. Österreich in Wien, Hueber, v. 12.7.38 an den RJM (a.a.O., Sign. R 22/4690). 
Juden vor Gericht: Da Rechtsanwälten, die der NSDAP angehörten oder Amtswalter des BNSDJ/NSRB bzw. Rechtsbetreuungsstellenleiter waren, die Vertretung von Juden parteiamtlich verboten war $^{36}$ und andere „arische“ Rechtsanwälte wegen der Wahrnehmung jüdischer Mandate öffentlich angegriffen wurden, konnten Juden für manche Gerichte schon jetzt keinen Rechtsanwalt finden. ${ }^{37}$ Am 5. April 1938 besprach Schlegelberger diese Probleme mit Vertretern der Anwaltschaft. ${ }^{38}$ Während der Präsident der Reichs-Rechtsanwaltskammer Neubert beantragte, im Falle des Ausscheidens der jüdischen Anwälte allen deutschen Rechtsanwälten die Vertretung jüdischer Parteien ausnahmslos zu gestatten, schlug der Reichswalter des NSRB Noack vor, nur besondere ,arische“ Judenvertreter ,in mehr oder weniger beamtenrechtlicher Stellung zu bestellen“. Schließlich drang jedoch die Forderung des Justizministeriums durch, wenigstens eine beschränkte Zahl jüdischer Anwälte - möglichst ehemalige Frontkämpfer - als ,jüdische Parteivertreter" zuzulassen - und zwar auch bei Gerichten, bei denen Anwaltszwang bestand, damit Juden auf alle Fälle einen Vertreter fänden. Um das Problem der Versorgung der allein im Altreich betroffenen ca. $1500 \mathrm{Ju}$ $\operatorname{den}^{39}$ zu lösen, die das Justizministerium als Grundvoraussetzung für diese Maßnahme ansah, schlugen die Vertreter der Anwaltschaft vor, daß die weiterhin zugelassenen jüdischen Konsulenten zwar die vollen Anwaltsgebühren erhalten, aber die über die Konsulentengebühren hinausgehenden Beträge an eine Garantiekasse abgeben sollten, aus der den früheren jüdischen Anwälten eine monatliche Versorgung in Höhe von etwa 300 RM gezahlt werden sollte. Da die Anwaltschaft außerdem beabsichtigte, eine Altersversorgung für alle Anwälte einzurichten, die aus den staatlichen Gebühren für Armensachen - auf die die Rechtsanwälte künftig verzichten wollten - gespeist werden sollte, sollte notfalls auch auf diese Mittel zur Versorgung der jüdischen Anwälte zurückgegriffen werden.$^{40}$ Erst nachdem sich die Justizleitung vergewissert hatte, daß Hitler mit den vorgeschlagenen Regelungen einverstanden $w^{4}{ }^{41}$, ging sie an die Realisierung dieses Planes. Am 4. Mai wurde mit den Vertretern der Anwaltschaft eine Einigung über die Einrichtung der Versorgungskasse für Rechtsanwälte und die Bezeichnung der wieder zuzulassenden jüdischen Anwälte als „Konsulenten“ erzielt. Auf dieser Besprechung äußerte Rechtsanwalt Noack die bemerkenswerte Absicht, nach dem Ausscheiden der Juden aus der Rechtsanwaltschaft die in ihr verblei-

${ }^{36}$ Vgl. VO des Reichsjuristenführers v. 2.9.35 (JW 1935, S.2707), durch die alle früheren diesbezüglichen VOen und Richtlinien gegenstandslos wurden. Darin hieß es u.a., die Reichsführung des BNSDJ lehne es ab, für ein Mitglied einzutreten, das wegen einer „auf eigenes Risiko übernommenen Judenvertretung in der Öffentlichkeit, in der Presse oder sonst angegriffen wird. Denn die Reichsführung des BNSDJ. und der Deutschen Rechtsfront ist nichts weniger als eine Juden-Schutztruppe."

${ }^{37}$ So z. B. beim OLG Marienwerder, vgl. Schr. des Präs. der RRAK an das RJM v. 7.1.38 (Diensttageb. des RJM, Eintr. v. 10.1.38, Bd.14, BA, Sign. R 22/945), ähnlich Schr. des OLGPräs. Celle v. 10.2.38 (a.a.O., Eintr. v. 15.2.38) und des OLGPräs. Hamm v. 20.5.38 (a.a.O., Eintr. v. 23.5.38, Bd. 15, Sign. R 22/946). Zur Brandmarkung ,arischer" RAe durch den "Stürmer" vgl. Schr. des Präs. der RRAK an das RJM v. 5.3.38 und 14.3.38 (a.a.O., Bd. 15, Eintr. v. 7.3.38 u. 14.3.38).

${ }^{38}$ Zum folgenden vgl. Verm. über die Bespr. Schlegelbergers mit Vertretern der Anwaltschaft am 5.4.38, an der außer den genannten Personen $u$. a. auch der Reichsgruppenwalter Rechtsanwälte im NSRB Droege teilnahm (Akten des RJM, BA, Sign. R 22/253).

39 Laut einem Aktenverm. v. 6.4.38 gab es im Altreich 1750 jüdische Anwälte, von denen 250 als Konsulenten weiter zugelassen werden sollten (a.a.O.).

${ }^{40}$ Vgl. vertraul. Verm. MinDir. Kritzingers für Lammers v. 12.4.38 über die Mitteilung Schlegelbergers. Der Aktenverm. wurde am 23.4.38 Hitler vorgetragen, der den Inhalt billigte (Akten der RK, BA, Sign. R 43 II/ 1535).

${ }^{41}$ Vgl. persönl. Schr. Lammers' an Gürtner v. 23.4.38 (a.a.O.). 
benden Mischlinge („Halb-“ und „Vierteljuden“), die im Sinne des Reichsbürgergesetzes nicht als ,Juden“ galten, auch in den NSRB aufzunehmen(!), um die „Rassenfrage“ in der Anwaltschaft als endgültig bereinigt anzusehen; er setzte aber hinzu, daß dieser Gedanke bei der Partei derzeit noch auf starken Widerstand stoße. ${ }^{42}$

Einen ersten Entwurf der geplanten Verordnung sandte das Reichsjustizministerium den beteiligten Stellen - dem Reichsinnenministerium und dem Stellvertreter des Führers - am 28. Juni zur Stellungnahme zu. Wie Schlegelberger in einem Begleitschreiben ausführte, waren davon ím Altreich ca. 1750 jüdische Rechtsanwälte, d.h. rund $10 \%$ der Anwaltschaft, betroffen. Nach den geplanten Vorkehrungen bereite hier die Maßnahme keine Schwierigkeiten mehr. Anders verhalte es sich jedoch im Bezirk Wien, wo wegen des hohen Anteils jüdischer Rechtsanwälte ein Teil von ihnen „für eine Übergangszeit“ im Beruf verbleiben müsse, soweit es sich um Frontkämpfer handele, die keine "Ostjuden“, d.h. seit mindestens 50 Jahren in Österreich ansässig waren. ${ }^{43}$ Während der Stellvertreter des Führers dem Entwurf vorbehaltlos zustimmte, forderte der Reichsfinanzminister, daß zwar den Frontkämpfern des Weltkrieges unter den ausgeschiedenen Anwälten eine Unterhaltszahlung gewährt werden solle, nicht jedoch auch den Vätern und Söhnen Gefallener, wie es das Justizministerium in Anlehnung an die Ausnahmebestimmungen der Aprilgesetze von 1933 vorgesehen hatte. Der Reichsinnenminister schloß sich dieser Forderung an und entschied, daß die beabsichtigte Verordnung als eine solche „zum Reichsbürgergesetz“ erlassen werden sollte. $^{44}$

Als die Absicht, den jüdischen Anwälten endgültig die Ausübung ihres Berufs zu verbieten, nach außen drang, übernahm der neunundachtzigjährige Generalfeldmarschall v. Mackensen die Rolle des Fürsprechers für die jüdischen Frontkämpfer, die seinerzeit beim Erlaß der Aprilgesetze von 1933 Hindenburg wahrgenommen hatte: am 30. Juli schrieb er an Gürtner, „Frontkämpfer des Weltkrieges“ hätten ihm in seiner „Eigenschaft als ihrem Heerführer und als ältestem Vertreter der alten Wehrmacht gemeldet, daß ihre und ihrer Familien Existenz durch vermutete Erwägungen über eine Neubestimmung für nichtarische Rechtsanwälte Gefahr“ laufe. Diese „Existenzzerstörung wenn auch (!) jüdischer Frontkämpfer“ stelle einen „Angriff auf das Kriegserlebnis und die Soldatenehre“ dar. Er bitte daher den „Feldzugsteilnehmer" Gürtner um „kameradschaftliche nachdrücklichste Anerkennung begründeter Wünsche von ehrenhaften und bedürftigen nichtarischen Frontkämpfern". Gürtner antwortete ihm, die Verhandlungen mit den beteiligten Reichsministern seien zwar noch nicht abgeschlossen, es bestehe jedoch bereits völliges Einverständnis darüber, daß für „bedürftige jüdische Frontkämpferanwälte Maßnahmen vorzusehen sind, die sie vor wirtschaftlicher Not schützen“. ${ }^{45}$

$\mathrm{Daß}$ die endgültige Ausschaltung der Juden aus der Anwaltschaft gerade in diesen Monaten forciert und betrieben wurde, hatte seinen Grund darin, daß sie Teil jener Maßnahmen war, die die nationalsozialistische Führung im Jahre 1938 ergriff, um die

42 Vgl. Verm. v. 6.5.38 über die Bespr. MinDir. Volkmars mit Neubert, Noack, Droege u.a. am 4.5.38 (Akten des RJM, BA, Sign. R 22/253). Zur Absicht Noacks auch schon Verm. v. 3.4.38 (a.a.O., Sign. R 22/254).

43 Vgl. Schnellbrief des RJM (i.V. Schlegelberger) v. 28.6 .38 an den RMdI, RFiM und St.d.F. (a.a.O., Sign. R 22/253).

44 Schr. des St.d.F. v. 8.7.38, des RFiM v. 6.7.38 und des RMdI v. 20.7 .38 an das RJM (a.a.O.)

45 Vgl. Schr. v. Mackensens an Gürtner v. 30.7 .38 und Antwortschr. Gürtners v. 27.8.38 (a.a.O.). 
Juden aus dem Wirtschafts- und Berufsleben zu verdrängen und damit zur Auswanderung zu bewegen. ${ }^{46}$ Als am 2. August im Reichsgesetzblatt die Vierte Verordnung zum Reichsbürgergesetz erschien, die den jüdischen Ärzten die Ausübung ihres Berufes verbot und ihre Bestallung am 30. September für erloschen erklärte ${ }^{47}$, richtete der Reichswalter des NSRB Noack voller Ungeduld ein vorwurfsvolles Schreiben an den zuständigen Referenten des Justizministeriums. Darin führte er aus, die Ärzteschaft sei nunmehr judenrein, nur bei der Anwaltschaft sei „natürlich“ immer noch nichts erreicht worden: „Ich wäre Ihnen außerordentlich dankbar, wenn Sie mit allem Nachdruck doch dafür sorgen wollten, daß nun endlich auch bei uns entsprechend meinem Vorschlag die Judenbereinigung kommt.“48 Der Reichswalter sollte sich jedoch noch ein reichliches Vierteljahr gedulden müssen.

Zwar hatte das Reichsjustizministerium den beteiligten Stellen schon am 1.August einen neuen Entwurf der Verordnung übermittelt, der u.a. die gewünschte Änderung enthielt, daß Väter und Söhne jüdischer Gefallener nicht in den Genuß einer Unterhaltszahlung kommen sollten. Da aber seine Bestimmungen auch im Land Österreich gelten sollten, mußte die Zustimmung des dortigen Reichsstatthalters Seyß-Inquart und des „Reichskommissars für die Wiedervereinigung Österreichs mit dem Deutschen Reich" Bürckel abgewartet werden. ${ }^{49}$ Erst am 27. August konnte Gürtner die bereits von ihm gegengezeichnete Ausfertigung der Fünften Verordnung zum Reichsbürgergesetz an Frick, Schwerin v. Krosigk und $\mathrm{Heß}$ mit der Bitte übersenden, sie der Reihe nach mitzuzeichnen und anschließend dem Chef der Reichskanzlei zum Vollzug durch Hitler zu übermitteln. ${ }^{50}$ In dieser Ausfertigung war vorgesehen, daß die $\mathrm{Zu}$ lassung der jüdischen Rechtsanwälte im Altreich zum selben Termin zurückgenommen werden sollte, an dem die Approbation der jüdischen Ärzte erlosch: zum 30. September 1938; für Österreich war der Termin 31. Dezember angegeben. Obwohl Heß als letzter der beteiligten Reichsminister die Ausfertigung noch auf dem Nürnberger Reichsparteitag, der vom 5. bis 12. September stattfand, unterschrieb ${ }^{51}$, blieb sie anschließend in seiner Münchener Dienststelle liegen. Sie wurde erst am 15. September auf dringende Veranlassung der Reichskanzlei an Lammers nach Berchtesgaden abgesandt, wo Lammers' nächster Vortrag bei Hitler unmittelbar bevorstand. ${ }^{52}$ Durch die eingetretenen Verzögerungen konnte jedoch der Termin 30. September für die Ausschaltung der jüdischen Rechtsanwälte im Altreich nicht mehr beibehalten werden: Nach der telefonisch eingeholten Zustimmung der beteiligten Stellen zu dem neuen Termin 30. November 1938 wurde mit Lammers vereinbart, daß er die Verordnung Hitler vorlegen und sich hierbei ermächtigen lassen sollte, die Ausfertigung nachträglich entsprechend zu korrigieren. Die genaue Formulierung der notwendigen Änderungen - es verschoben sich dadurch weitere Terminangaben in der Verordnung -

${ }^{46}$ Vgl. W. Scheffler, Judenverfolgung im Dritten Reich, Berlin 1960, S. 27 ff., Adam, a.a.O. (vgl. Anm.1), S. $172 \mathrm{ff}$

47 Vgl. Vierte VO zum ReichsbürgerG v. 25.7.38 (RGBl. I, S. 969); sie war von Gürtner mitgezeichnet worden, da sie bei Zuwiderhandlungen Gefängnis- bzw. Geldstrafen vorsah.

48 Vgl. Schr. Noacks an MinRat Pohle v. 5.8.38 (Akten des RJM, a.a.O.).

49 Vgl. Schr. des RJM v. 1.8.38 und Antwortschr. der beteiligten Stellen v. 10. bis 19.8.38 (a.a.O.).

so Vgl. Schnellbrief des RJM v. 27.8.38 an den RMdI, RFiM, St.d.F. und Chef der RK (Akten der RK, BA, Sign. R 43 II/598).

${ }^{31}$ Das geht aus dem Schr. des RFiM an die RK v. 16.9.38 hervor (a.a.O.).

32 Vgl. Schr. des St.d.F. an Lammers v. 15.9. 38 (a.a.O.) und Verm. MinRat Pohles v. 16.9.38 (Akten des RJM, a.a.O.). 
wurde für Lammers in einem Schreiben des Justizministeriums niedergelegt, das Ministerialdirektor Kritzinger noch am Abend des 16. September nach Berchtesgaden mitnahm..$^{53}$ Dort konnte die Verordnung jedoch Hitler zunächst nicht vorgelegt werden, da die gegengezeichnete Ausfertigung von der Dienststelle Heß' aus München erst am 20. September in Berchtesgaden einging. ${ }^{54}$ Nunmehr war Hitler jedoch völlig von den sich überstürzenden Ereignissen der Sudetenkrise in Anspruch genommen, die er durch seine Schlußansprache auf dem Nürnberger Parteitag am 12. September hochgespielt hatte: sie hatte drei Tage später Chamberlains Besuch in Berchtesgaden ausgelöst und führte vom 22. bis 24. September zu einem erneuten Treffen der beiden Staatsmänner in Bad Godesberg. Angesichts dieser Entwicklung setzte der Reichsjustizminister am 23. September eine zweite Ausfertigung der Fünften Verordnung bei den beteiligten Stellen zur Mitzeichnung in Umlauf, in der sämtliche Termine offengelassen waren. Er bat Lammers, den Zeitpunkt des Ausscheidens der jüdischen Anwälte darin so zu bestimmen, daß er mindestens sechs Wochen nach der Veröffentlichung im Reichsgesetzblatt lag; für die österreichischen Anwälte sogar noch einen Monat später. Sollte jedoch die Angelegenheit Hitler bis zum 12. Oktober vorgetragen werden können, so sollte ihm die Lammers bereits vorliegende erste Ausfertigung mit den Änderungen vom 16. September vorgelegt werden..$^{55}$ Hitler unterschrieb diese erste, von Lammers korrigierte Fassung der Verordnung am 27. September - am Tage nach seiner ultimativen Rede im Berliner Sportpalast und einen Tag vor dem Beginn der Münchener Konferenz -, verfügte aber, daß ihre Veröffentlichung „während des Andauerns der jetzigen außenpolitischen Hochspannung“ unterbleiben sollte. „Für den Fall, daß die in der Verordnung vorgesehenen Fristen sich dann als überholt herausstellen sollten“, ermächtigte Hitler den Justizminister, die notwendigen Änderungen im Einvernehmen mit dem Chef der Reichskanzlei vorzunehmen. ${ }^{56}$ In Unkenntnis dieses Vorgangs unterschrieb der Stellvertreter des Führers Heß am 6.Oktober - nachdem die Fristen der ersten Fassung, die er in Nürnberg unterzeichnet hatte, abgelaufen waren - die letzte Fassung der Verordnung vom 23. September und sandte sie am 6.Oktober der Reichskanzlei mit der Bitte, sie Hitler zum Vollzug zu unterbreiten. ${ }^{57}$ Alle Erwägungen der Reichskanzlei über die nunmehr überflüssig gewordene Erfüllung dieser Bitte wurden schließlich durch die weiteren Ereignisse überholt: nachdem die außenpolitische Krise durch die Münchener Konferenz beigelegt und die dort vereinbarte stufenweise Besetzung des Sudetenlandes durch deutsche Truppen abgeschlossen war, übermittelte Lammers dem Justizminister am 13. Oktober telefonisch die Zustimmung zur Veröffentlichung der Verordnung ${ }^{58}$, die am nächsten Tag erfolgte.

Aufgrund der Fünften Verordnung zum Reichsbürgergesetz vom 27. September 1938 (RGBl. I, S. 1403) schieden nunmehr sämtliche jüdischen Rechtsanwälte im Alt-

\footnotetext{
53 Vgl. Aktenverm., a.a.O., und Schr. des RJM an den Chef der RK v. 16.9.38 (Akten des RJM, a.a.O.).

s4 Vgl. Schnellbrief Lammers' an das RJM v. 19.9.38 nebst Verm. v. 20.9.38 (a.a.O.).

5s Vgl. Schr. des RJM an den Chef der RK sowie Schnellbrief des RJM an den RMdI, RFiM und St.d.F. v. 23.9 .38 (Akten des RK, a.a.O.).

56 Vgl. Verm. Lammers' v. 27.9.38 und sein Schr. an den RJM v. 29.9.38 nebst der von Hitler vollzogenen VO (a.a.O.).

$57 \mathrm{Vgl}$. Schr. des Adjutanten des St.d.F. an Lammers v. 6.10.38 (a.a.O.).

58 Vgl. Bestätigungsschr. Gürtners an Lammers v. 13.10.38 sowie die Verm. Kritzingers v. 14. und 18.10.38 (a.a.O.).
} 
reich bis zum 30. November, im Lande Österreich zum Jahresende 1938 aus. Nur bei Juden, die in der Liste der Rechtsanwaltskammer Wien eingetragen waren, konnte von der Löschung im Anwaltsregister vorläufig abgesehen werden, wenn sie Frontkämpfer des Weltkrieges waren und ihre Familie seit mindestens fünfzig Jahren in Österreich ansässig war $(\S 1)$. Für die Kündigung von Dienstverträgen und Mietverhältnissen wurde den ausscheidenden Anwälten hinsichtlich der Fristen Erleichterung gewährt $(\S \S 2,3)$. Die Besorgung fremder Rechtsangelegenheiten war ihnen nunmehr untersagt (\$4), da sie durch das Gesetz zur Verhütung von Mißbräuchen auf dem Gebiete der Rechtsberatung vom 13. Dezember 1935 (RGBl. I, S. 1478) ohne eine besondere Erlaubnis verboten war, die aber an Juden grundsätzlich nicht erteilt wurde. ${ }^{59}$ Den ausgeschiedenen jüdischen Anwälten konnten - soweit sie Frontkämpfer waren aus den Einnahmen der jüdischen Konsulenten „bei Bedürftigkeit und Würdigkeit jederzeit widerrufliche Unterhaltszuschüsse gewährt werden“. Je „nach Maßgabe der eingehenden Beträge“ sollten auch jüdische „Altanwälte“, die seit dem 1.August 1914 in der Rechtsanwaltsliste eingetragen waren, in den Genuß der Unterhaltszuschüsse kommen können $(\S 5)$, nicht jedoch Väter und Söhne von Kriegsgefallenen. Soweit Bedürfnis bestand, wurden zur rechtlichen Beratung und Vertretung von Juden widerruflich jüdische „Konsulenten“ zugelassen, wobei Frontkämpfer bevorzugt berücksichtigt werden sollten $(\S \S 8,9)$. Sie unterstanden der Aufsicht der Justizverwaltung (§13), durften nur Rechtsangelegenheiten jüdischer Einzelpersonen, Unternehmen, Vereine, Stiftungen, Anstalten usw. besorgen $(\S 10)^{60}$, konnten aber auch im Armenrecht, als Notvertreter oder Pflichtverteidiger beigeordnet werden $(\S 12)$. Für ihre berufliche Niederlassung wurde ihnen ein bestimmter Ort zugewiesen. Innerhalb eines bestimmten Bezirks konnten sie vor allen Gerichten und Behörden auftreten - ebenso vor übergeordneten Instanzen, die außerhalb ihres Bezirks lagen - und als Bevollmächtigte ihrer Auftraggeber tätig werden. Ansonsten unterlag ihre Berufstätigkeit keiner örtlichen Beschränkung ( $(11)$. Die von ihren Auftraggebern, aber auch von deren kostenpflichtigen „arischen“ Gegnern zu zahlenden Gebühren gingen an die von der Justizverwaltung eingerichtete Ausgleichskasse, aus der die erwähnten Unterhaltszuschüsse bestritten wurden. Den Konsulenten verblieb jedoch ein Anteil an den Gebühren als Vergütung und Erstattung ihrer Unkosten $(\S 14) \cdot{ }^{61}$ Übergangsvorschriften regelten das Verfahren bei einem Wechsel des Vertreters in schwebenden Prozessen, der durch das Ausscheiden eines jüdischen Rechtsanwalts notwendig geworden war.

Diese Verordnung wurde für das Land Österreich durch eine weitere begleitet, die die dortigen jüdischen Mischlinge unter den Rechtsanwälten betraf. Während im Altreich durch das Rechtsanwaltsgesetz vom 7. April 1933 auch die Viertel- und Halbjuden erfaßt worden waren, da diesem Gesetz die Definition des "Juden" nach dem Berufsbeamtengesetz vom gleichen Datum zugrunde lag, war bei der Ausschaltung

59 Gemäß $§ 5$ der AusfVO v. 13.12.35 (RGBl. I, S. 1481).

${ }^{60}$ Als Konsequenz wurde in der Folge allen nichtjüdischen RAen die Vertretung von Juden untersagt, außer bei der Verteidigung vor dem VGH, den SGen in Heimtückesachen und mit Ausnahmegenehmigung, vgl. AnO des St.d.F. v. 19.12.38, AnO des Reichsrechtsamts der NSDAP (Ausf.-Bestimmungen) v. 2.1.39 und AnO 1/39 des Präs. der RRAK (sämtl. veröffentlicht in: Mitteilungen der RRAK 1939, S. 2 f.).

61 Die Aufgaben der Ausgleichsstelle, die die RRAK wahmahm, die Vergütung der Konsulenten sowie die Gewährung und Höhe der Unterhaltszuschüsse (monatliche Höchstbeträge: 200 RM für Ledige, 250 RM für Verheiratete plus 10 RM pro Kind unter 16 Jahren) wurden in der AV des RJM v. 13.10.38 (DJ 1938, S. 1665) geregelt. 
der jüdischen Rechtsanwälte in Österreich durch die Verordnung vom 31.März $1938^{62}$ die Definition der Durchführungsverordnung zum Reichsbürgergesetz angewendet worden, die die Vierteljuden und eine gewisse Kategorie der Halbjuden nicht einbezog. Um den im Altreich bestehenden Rechtszustand auf Österreich zu übertragen, erließen Reichsjustizministerium und Reichsinnenministerium eine Verordnung $^{63}$, die dasselbe Datum trug wie die Fünfte Verordnung zum Reichsbürgergesetz. Danach konnten auch in Österreich die erwähnten jüdischen Mischlinge bis zum 31. Dezember 1938 in der Liste der Rechtsanwälte gestrichen werden mit Ausnahme jener Anwälte, die entweder Altanwälte, Frontkämpfer oder Väter bzw. Söhne Kriegsgefallener waren, soweit ibre Familien seit mindestens 50 Jabren in Österreich ansässig waren $(\$ 1)$. Auf dieser zusätzlich verschärfenden Bestimmung hatten Vertreter der österreichischen Anwaltschaft auf einer Besprechung mit Referenten des Reichsjustizministeriums in Salzburg ausdrücklich bestanden, um die nichtarischen Anwälte in Österreich drastischer reduzieren zu können. ${ }^{64}$ Bis zum Jahresende konnten auch Rechtsanwälte ausgeschieden werden, die vor dem Anschluß Österreichs ,gegen die nationalsozialistische Bewegung und ihre Anhänger gehässig aufgetreten“"waren, ihre Stellung mißbraucht hatten, „um völkisch gesinnte Volksgenossen zu verfolgen“, oder „,in anderer Weise als Feinde der nationalsozialistischen Bewegung tätig geworden“ waren $(\S 2)$. Diese Verordnung wurde zusammen mit der Fünften Verordnung zum Reichsbürgergesetz verkündet.

Für die Durchführung der Fünften Verordnung hatte das Reichsjustizministerium die Oberlandesgerichtspräsidenten rechtzeitig beauftragt, unter Beteiligung der jeweiligen Rechtsanwaltskammer ein Verzeichnis ihrer Landesgerichtsbezirke mit den Zahlen der Gerichtseingesessenen, der jüdischen Gerichtseingesessenen, der zugelassenen Rechtsanwälte und der jüdischen Rechtsanwälte im Sinne der Verordnung vom 14. November 1935 zum Reichsbürgergesetz aufzustellen und bis spätestens zum 1.September 1938 einzureichen. ${ }^{65}$ Während das Ministerium die Zulassung der in diesem Verzeichnis aufgeführten jüdischen Rechtsanwälte nach der Verkündung der Fünften Verordnung zurücknahm, bestimmte es aufgrund der anderen Angaben, wieviel und in welchen Landgerichtsbezirken jüdische Konsulenten zugelassen werden sollten. ${ }^{66}$ Gesuche um Zulassung als Konsulent ${ }^{67}$ - bei der in erster Linie schwerkriegsbeschädigte Frontkämpfer berücksichtigt werden sollten - waren von ausscheidenden jüdischen Anwälten beim Präsidenten desjenigen Oberlandesgerichts einzureichen, in dessen Bezirk der Ort der künftigen Niederlassung lag. Im Gesuch mußte der Antragsteller u.a. auch seine genauen Vermögensverhältnisse, frühere politische oder freimaurerische Betätigung sowie dienst- und ehrengerichtliche Strafen angeben.

$62 \mathrm{Vgl}$. voranstehende Anm.33.

${ }_{63} \mathrm{Vgl.} \mathrm{3}$. VO über Angelegenheiten der Rechtsanwälte, Rechtsanwaltsanwärter und Verteidiger in Strafsachen in Österreich v. 27.9.38 (RGBl. I, S. 1406).

${ }^{64} \mathrm{Vgl}$. Verm. v. 1.6.38 über die Besprechung (Akten des RJM, BA, Sign. R 22/253).

$65 \mathrm{Vgl}$. Schr. des RJM an den Präs. der RRAK und RV an die OLGPräs. v. 25.6.38 (Akten des RJM, Hauptbüro, Arch. des BJM), in der das Verfahren zur Feststellung der Abstammung und zur Behandlung von Widersprüchen niedergelegt war.

66 Das geht z. B. deutlich aus den Akten des OLG Bamberg hervor: hier wurde für die drei LG-Bezirke mit den meisten jüdischen Gerichtseingesessenen (Würzburg $=2546$, Schweinfurt $=2360$, Bamberg ca. 1300) je ein Konsulent zugelassen. Vgl. H. Schütz, Justiz im „Dritten Reich“. Dokumentation aus dem Bezirk des Oberlandesgerichts Bamberg, Bamberg 1984, S. 133.

${ }^{67}$ Zum folgenden vgl. AV des RJM v. 17.10.38 (DJ 1938, S. 1666). 
Der Oberlandesgerichtspräsident konnte das Gesuch von sich aus ablehnen, wenn der Betreffende nicht aufgrund der Fünften Verordnung zum Reichsbürgergesetz, sondern aus anderen Gründen ausgeschieden war oder um die Niederlassung in einem Ort nachsuchte, für den kein jüdischer Konsulent vorgesehen war. Der Oberlandesgerichtspräsident hatte den Präsidenten der Rechtsanwaltskammer seines Bezirks und die zuständige Gestapostelle über die Person sowie den Vorstand des bisherigen $\mathrm{Zu}$ lassungsgerichts über die bisherige Berufsausübung des Gesuchstellers zu hören; dagegen hatten der Stellvertreter des Führers und der NSRB auf jegliche Beteiligung bei der Zulassung der jüdischen Konsulenten verzichtet. ${ }^{68}$ Das Gesuch und die Unterlagen waren dem Reichsjustizministerium zur Entscheidung vorzulegen. Von der genehmigten Zulassung hatte der Oberlandesgerichtspräsident außer den gehörten Stellen auch den Gauleiter der NSDAP zu informieren. Der jüdische „Konsulent“ war verpflichtet, im Geschäftsverkehr stets diese Berufsbezeichnung sowie seinen jüdischen Vornamen bzw. den vorgeschriebenen zusätzlichen Vornamen „Israel“69 zu führen und sich vor der Übernahme einer Rechtsangelegenheit davon zu überzeugen, daß sein Auftraggeber Jude war. Auf Briefbögen und Schildern mußte er ausdrücklich hinzusetzen: „Zugelassen nur zur rechtlichen Beratung und Vertretung von Juden“. ${ }^{70}$ Seine Befugnis zum Auftreten vor übergeordneten Gerichten und Ämtern war nicht auf Verfahren beschränkt, die vor den in seinem Bezirk gelegenen Gerichten und Behörden in erster Instanz anhängig geworden waren. Der Präsident des Landgerichts, in dessen Bezirk der Konsulent zugelassen war, führte die Aufsicht über ihn und konnte ihn bei ordnungswidriger Geschäftsführung rügen. Beabsichtigte der Konsulent, seinen Niederlassungsort länger als eine Woche zu verlassen, mußte er dies unverzüglich dem Landgerichtspräsidenten anzeigen, sofern ihm nicht ein Vertreter bestellt war. Diese Bestellung war stets zu beantragen, wenn der Konsulent an der persönlichen Ausübung seines Berufs verhindert war. Hielt es der Landgerichtspräsident aus irgendwelchen Gründen für angezeigt, die Zulassung zu widerrufen, so hatte er den jüdischen Konsulenten - „soweit dies nicht untunlich“ war (!) - zu hören und dem Oberlandesgerichtspräsidenten zu berichten, der im Falle seiner Zustimmung ein vorläufiges Berufsverbot aussprechen konnte und dem Reichsjustizministerium zur abschlieBenden Entscheidung berichtete.

Im Altreich sollten 172 jüdische Konsulenten zugelassen werden, davon 49 im Kammergerichtsbezirk, im Lande Österreich später $83 .{ }^{71}$ Nur „zur Gewährleistung eines reibungslosen Überganges" durften die Oberlandesgerichtspräsidenten im Altreich bis Jahresende an einem Ort „mindestens um die Hälfte mehr“ Konsulenten befristet zulassen, als dort endgültig vorgesehen waren. ${ }^{72}$ Die Bestellung der Konsulenten konnte jedoch zunächst nicht überall erfolgen, da die Verhaftungswelle, die die

${ }^{68}$ Vgl. Verm. v. 5.9.38 über die Referentenbespr. am 2.9.38 (Akten des RJM, a.a.O.).

${ }^{69}$ Vgl. dazu $\S 3$ der 2. DurchfVO v. 17.6.38 zum G. über die Veränderung von Familiennamen und Vornamen (RGBl. I, S. 1044).

70 Vgl. AV des RJM v. 9.12.38 (DJ 1938, S. 1974).

1 Vgl. Bekanntm. des RJM v. 17.10.38 (DJ 1938, S. 1670): im OLGBez. Bamberg 3, Breslau 14, Celle 3, Darmstadt 3, Dresden 11, Düsseldorf 6, Frankfurt 5, Hamburg 8, Hamm 7, Jena 2, Karlsruhe 10, Kassel 2, Kiel 2, Köln 11, Königsberg 6, München 6, Naumburg 6, Nürnberg 5, Rostock 1, Stettin 2, Stuttgart 7, Zweibrükken 3. Für Österreich vgl. AV des RJM v. 12.12 .38 (a.a.O., S. 1974).

${ }^{72}$ AV des RJM v. 17.10.38 (DJ 1938, S. 1666). 
Gestapo dem Pogrom vom 9. und 10. November folgen ließ ${ }^{73}$, auch zahlreiche jüdische Rechtsanwälte erfaßt hatte. So berichtete z.B. der Vizepräsident des Oberlandesgerichts München am 15. November an das Reichsjustizministerium, daß gegenwärtig „etwa die Hälfte der jüdischen Rechtsanwälte Münchens in Haft" genommen und ein Teil von ihnen „bereits in das Konzentrationslager Dachau überführt und dort eingekleidet worden" seien. Unter diesen Umständen sei es ihm nicht möglich, die bislang eingegangenen Gesuche um Zulassung als Konsulenten weiterzubehandeln. Angeforderte ergänzende Unterlagen hätten nicht beigebracht werden können, da im Zuge der antijüdischen Aktion die Kanzleien aller jüdischen Rechtsanwälte in München geschlossen worden seien und die Gestapo laut Auskunft beabsichtige, das Aktenmaterial zwecks Prüfung teilweise „zu beschlagnahmen und aus den Kanzleien zu entfernen. Ob und wann den jüdischen Rechtsanwälten, soweit sie sich auf freiem Fuß befinden, der Zutritt zu ihren Büroräumen wieder möglich sein" werde, sei unbestimmt. Die Verhafteten müßten als vorzuschlagende Bewerber ohnehin ausscheiden, da „nicht beurteilt werden“ könne, ob sie im Falle der Zulassung als Konsulenten ihre Tätigkeit aufnehmen könnten. Darüber hinaus müsse in der gegenwärtig gespannten Atmosphäre „bei Auftreten jüdischer Rechtsanwälte oder Konsulenten vor Gericht mit der Möglichkeit unliebsamer Vorkommnisse in den Sitzungssälen gerechnet werden ..., wenn sich der Prozeßgegner der von dem Juden vertretenen Partei unter dem Einfluß der lebhaften antijüdischen Kundgebungen der letzten Tage bei der Verfechtung seiner Interessen nicht in dem gebotenen sachlichen Rahmen hält". Es sei daher „fraglich, ob es unter den obwaltenden Umständen zweckmäßig“ sei, überhaupt jüdische Konsulenten zuzulassen. ${ }^{74}$

Zehn Tage später äußerte auch der Präsident der Reichs-Rechtsanwaltskammer Neubert Bedenken, daß durch die Maßnahmen der Gestapo „die reibungslose Durchführung der 5. Verordnung zum Reichsbürgergesetz in Frage gestellt“ sei, da es angesichts der Verhaftungen an vertretungsberechtigten Personen mangele, die die Mandate ausscheidender Juden übernehmen könnten. Gegebenenfalls müßten nichtjüdische Rechtsanwälte kommissarisch mit der Vertretung und Abwicklung der Rechtsangelegenheiten betraut werden und für Parteigenossen oder Amtsträger des NSRB zu diesem Zweck Ausnahmegenehmigungen erwirkt werden. „Um aber überhaupt einen Überblick über den Umfang der erforderlichen Maßnahmen zu erhalten“, bat er das Ministerium, die Gestapo zu veranlassen, den Oberlandesgerichtspräsidenten und den Präsidenten der Anwaltskammern ein genaues Verzeichnis der verhafteten jüdischen Rechtsanwälte zu übermitteln. ${ }^{75}$ "Sollten durch die Verhaftungen in erheblichem Maße auch die in Aussicht genommenen Konsulenten betroffen sein", folgerte Neubert abschließend, so werde „zu erwägen sein, ob sich die Einrichtung jüdischer Konsulenten überhaupt wird aufrechterhalten lassen oder ob ein anderer Weg zur Lösung“ des Problems gefunden werden müsse. ${ }^{76}$ Neubert nährte offensichtlich die Hoffnung, die Situation doch noch zur Durchsetzung seiner Konzeption ausnutzen zu können,

${ }^{73}$ Vgl. dazu die Ausführungen in Kapitel V.2, S. 485 f., Anm. 8.

74 Schr. des OLGPräs. München (i. V. Castner) an das RJM v. 15.11. 38 (Akten des RJM, BA, Sign. R 22/254).

75 Aufgrund ihres eigenen RdErl.v. 20.5.35 war die Gestapo an sich verpflichtet, die Inschutzhaftnahme eines RAs - und diesen Status verloren die jüdischen Anwälte erst mit Wirkung v. 30.11.38 - dem zuständigen OLGPräs. mitzuteilen, vgl. dazu Kapitel VI.7.a., Anm.37.

${ }^{76}$ Vgl. Schr. des Präs. der RRAK Neubert an den RJM v. 25.11.38 (a.a.O.). 
daß alle „arischen“ Rechtsanwälte Juden vertreten und damit ihre schwierige wirtschaftliche Lage erleichtern konnten. Diese Hoffnung zerschlug sich jedoch, als die Gestapo die im Zusammenhang mit dem Novemberpogrom festgenommenen Juden nach wenigen Wochen wieder freiließ ${ }^{77}$

Die endgültige Zulassung als Konsulent gewährte einem Juden keinen Schutz vor dem Zugriff der Gestapo. Es erwies sich, daß die Gestapo die Verhaftung jüdischer Konsulenten der Justizverwaltung - die gemäß der Fünften Verordnung zum Reichsbürgergesetz immerhin die dienstliche Aufsicht über die Konsulenten führte - auch künftig nicht einmal mitteilte. Als Mitte Februar 1940 im Regierungsbezirk Stettin die Deportation der Juden nach dem Osten begann, erfuhr das Justizministerium die Verschleppung des für den dortigen Bezirk zugelassenen Konsulenten erst durch die Eingabe dreier Berliner Konsulenten und den Bericht des Stettiner Oberlandesgerichtspräsidenten, der über den Verbleib des Anwalts keine Auskunft geben konnte. ${ }^{78}$ Nachdem sich Freisler in Pommern an Ort und Stelle über die Vorgänge informiert hatte, wurde dem Oberlandesgerichtspräsidenten lediglich aufgegeben, die Zulassung dieses Konsulenten zu widerrufen. ${ }^{79}$ Die Festnahme des für den Landgerichtsbezirk Schneidemühl zugelassenen Konsulenten auf der Rückfahrt von einem Termin am Amtsgericht Berlin am 3. April 1940 erfuhr das Ministerium gleichfalls durch die drei erwähnten Berliner Konsulenten, an die sich die um das unbekannte Schicksal ihres Mannes besorgte Ehefrau gewandt hatte. ${ }^{80}$ Auf Anfrage beim Reichsführer SS und Chef der Deutschen Polizei bekam das Justizministerium erst nach über einem Monat Bescheid, daß der Konsulent - der mit dem Nachtzug von Berlin nach Schneidemühl zurückgefahren war - wegen Verstoßes gegen das Ausgehverbot für Juden verhaftet worden war. ${ }^{81}$ Beim Oberlandesgerichtspräsidenten Stettin ging später lediglich die Erklärung des Verhafteten ein, daß er "seinen Beruf als Konsulent aufgegeben“ habe. ${ }^{82}$ Mit der Wahrnehmung der Aufgaben der beiden verhafteten Konsulenten wurden vier in Berlin zugelassene Konsulenten betraut, deren Tätigkeitsbereich auf den Stettiner Oberlandesgerichtsbezirk ausgedehnt wurde ${ }^{83}$ Das Reichsjustizministerium nahm den Vorfall zum Anlaß, bei der Polizeiführung die Befreiung der Konsulenten vom nächtlichen Ausgehverbot für Juden zu beantragen, da sie einen großen Bezirk betreuten, Termine meist persönlich wahrnehmen mußten und „als Juden im fremden Ort

77 Vgl. Aktenverm. des Referenten im RJM v. 7.12.38, daß der Inhalt von Neuberts Schr. „durch die Ereignisse der Zwischenzeit überholt" sei und die RRAK daher „keinen schriftlichen Bescheid mehr“ erwarte (a.a.O.).

78 Vgl. gemeinsames Schr. der drei Konsulenten v. 22.2.40, das von einem der Konsulenten im RJM überreicht wurde, und Ber. des OLGPräs. Stettin v. 27.2.40 (Akten des RJM, BA, Sign. R 22/52). Die drei Konsulenten bildeten einen „Ausschuß von Vertrauensmännern der jüdischen Rechtsanwälte Deutschlands“, vgl. eidesstattl. Versicherung des RA Dr. Fliess v. 5.11.47 (Spruchkammerakten Gürtner, StArch. München).

79 Vgl. Schr. des OLGPräs. Stettin an den RJM v. 2.3.40 nach seiner Unterredung mit Freisler in Kolberg und Schr. des RJM (i. V. des Sts. gez. Hueber) v. 19.3.40 (Akten, a.a.O.).

${ }^{80}$ Vgl. die Eingaben der Konsulenten v. 8. und 16.4.40 nebst Ber. der jüdischen Ehefrau, die sich am 15.4.40 das Leben nahm, als sich die Nachricht verbreitete, daß auch im RegBez. Schneidemühl die Deportation bevorstand (a.a.O.).

81 Vgl Schr. des RJM an den RFSSuChdDtPol. v. 22.4.40 und Antwortschr. des Chefs der Sipo und des SD v. 28.5 .40 (a.a.O.).

82 Das vom 16.4.40 datierte Schr. ging erst am 28.5.40 beim OLGPräs. ein, vgl. Benachrichtigung des Chefs Sipo/SD durch das RJM v. 21.6.40 (a.a.O.).

${ }^{83}$ Vgl. Schr. des RJM an den KGPräs. v. 23.4.40 (a.a.O.). 
nur schwer ein Unterkommen für die Nacht finden“ konnten. Der Antrag wurde jedoch von der Gestapoführung „aus sicherheitspolizeilichen Gründen“ abgelehnt. ${ }^{84}$

Soweit die jüdischen Konsulenten nicht von der Deportation erfaßt oder zur Zwangsarbeit verpflichtet wurden, übten sie ihre Funktion bis zum Zusammenbruch des Regimes im Jahre 1945 aus. ${ }^{85}$ Ihr Auftreten als Strafverteidiger wurde jedoch eingeschränkt, noch ehe im Juli 1943 die Verfolgung der Straftaten von Juden der Justiz genommen und der Polizei übergeben wurde. ${ }^{86}$ Nach der Fünften Verordnung zum Reichsbürgergesetz vom September 1938 konnten die Konsulenten in Strafsachen zunächst ungehindert als Wahlverteidiger auftreten, die Strafakten einsehen, den verhafteten Beschuldigten unter richterlicher Überwachung besuchen usw. Außer bei Hochund Landesverratssachen vor dem Volksgerichtshof und dem Oberlandesgericht, bei denen die Wahl des Verteidigers generell der Genehmigung des Gerichtsvorsitzenden bedurfte ${ }^{87}$, gab es vorerst keine gesetzliche Handhabe, die Konsulenten von der Strafverteidigung auszuschließen. Das wurde bei verschiedenen Strafverfahren als „Mißstand“ empfunden, so bei „Rassenschande“-Fällen, „weil Konsulenten in der Hauptverhandlung die deutschblütige Hauptzeugin in aufdringlicher Weise [?] über ihre früheren geschlechtlichen Beziehungen" befragten und zur Würdigung des Sachverhalts sowie des Strafmaßes Ausführungen machten, „die dem deutschen Volksempfinden und dem Grundgedanken der Rasseschutzgesetzgebung zuwiderliefen“" ${ }^{88}$ Auch bei Verfahren, in denen im Interesse des Regimes geheimzuhaltende Angelegenheiten in den Strafakten auftauchten, wurde die Mitwirkung der Konsulenten ungern gesehen: so sollten sie z. B. bei Devisenstrafsachen möglichst keinen Einblick in die Ermittlungstätigkeit und -methoden der Fahndungsstellen erhalten. Deshalb wurde auf Anregung der Reichs-Rechtsanwaltskammer schon in einer Referentenbesprechung am 30. Juni 1939 mit Vertretern des Reichsinnenministeriums und des Stellvertreters des Führers erwogen, den Konsulenten das Auftreten als Wahlverteidiger in Hoch- und Landesverratssachen sowie vor den Sondergerichten in Heimtückesachen generell zu untersagen und für Strafsachen mit politischem Einschlag eine Genehmigungspflicht einzuführen; in allen übrigen Strafsachen sollte das Gericht den Konsulenten zumindest zurückweisen können. ${ }^{89}$ Solche Maßnahmen mußten jedoch zu einem erhöhten Bedarf an „arischen“ Rechtsanwälten für jüdische Beschuldigte führen, der angesichts der restriktiven Anordnungen, die Parteiführung und Reichs-Rechtsanwaltskammer für diese Rechtsanwälte erlassen hatten ${ }^{90}$, nur schwer gedeckt werden konnte. Bevor daher die zuständigen Stellen zur Änderung dieser einschränkenden Anordnungen veranlaßt werden sollten, forderte das Justizministerium vom Kammergerichtspräsidenten und den Oberlandesgerichtspräsidenten in Breslau, Dresden und Frankfurt a. M. - in deren Bezirken viele Juden lebten - Berichte an, ob die vorgeschriebene Ein-

${ }^{84} \mathrm{Vgl}$. Schr. des RJM an den RFSSuChdDtPol. v. 17.6.40 und Antwortschr. des Chefs der Sipo/SD v. 2.8.40 (a.a.O., Sign. R 22/52).

${ }^{85}$ So $z$. B. der in Hannover zugelassene, schwerkriegsbeschädigte und in „Mischehe“ lebende Konsulent Berkowitz, vgl. dessen instruktiven Bericht: Versehrt, verfolgt, versöhnt: Horst Berkowitz, Ein jüdisches Anwaltsleben, aufgezeichnet von U. Beer, Essen 1979.

${ }^{86}$ Durch die 13. VO zum ReichsbürgerG v. 1.7.43 (RGBl. I, S. 372).

$87 \mathrm{Vgl}$. Art. IV $\S 3$ des G. zur Änderung von Vorschriften des Strafrechts und des Strafverfahrens v. 24.4.34 (RGBI. I, S. 341).

${ }^{88}$ So Freisler im Schr. an den St.d.F. und den RMdI v. 5.4.40 (Akten des RJM, BA, Sign. R 22/955).

89 Über die Referentenbespr. v. 30.6 .39 s. a.a.O.

$90 \mathrm{Vgl}$. voranstehende Anm. 36. 
zelgenehmigung des zuständigen Hoheitsträgers für die Übernahme der Wahlverteidigung von Juden durch ,arische“ Rechtsanwälte in der Praxis großzügig gehandhabt wurde oder zu Schwierigkeiten und Verzögerungen der Strafverfahren geführt hatte. ${ }^{91}$ Offensichtlich wurden keine größeren Schwierigkeiten gemeldet, denn Anfang April 1940 teilte Freisler dem Reichsinnenminister und dem Stellvertreter des Führers mit, daß er nunmehr das Problem der Beschränkung jüdischer Strafverteidiger auf dem Verordnungswege zu lösen beabsichtige. Allerdings empfehle sich die erwogene Verpflichtung für Konsulenten, vor dem Auftreten in politischen Sachen die Genehmigung des Gerichtsvorsitzenden einzuholen, nicht, da die Abgrenzung der Straftaten mit politischem Einschlag „nur im grundsätzlichen und ohne Rücksicht auf den Einzelfall möglich“ sei und zudem „einer ständigen Ergänzung durch Anführung neu erlassener Strafbestimmungen bedürfen" würde. Deshalb solle für alle Strafsachen einheitlich die Möglichkeit einer Zurückweisung des Konsulenten durch den Gerichtsvorsitzenden vorgesehen werden. Diese Lösung habe den Vorteil größerer Beweglichkeit und vereinfache den Geschäftsgang, da sich ein Genehmigungsverfahren in den Fällen, in denen das Auftreten eines Konsulenten von vornherein unbedenklich sei, erübrige. Freisler bat um Stellungnahme zu der Frage, ob im Falle der Zurückweisung des Konsulenten „auch für die Strafsachen, in denen die Verteidigung nicht notwendig ist, gesetzlich bestimmt werden soll, daß auf Antrag des Beschuldigten diesem auf seine Kosten ein Rechtsanwalt als Verteidiger zuzuweisen" sei. Eine solche Bestimmung sei aber nur dann durchführbar, wenn der zugewiesene Rechtsanwalt zur Übernahme der Verteidigung des jüdischen Beschuldigten auch gesetzlich verpflichtet werde; andernfalls werde sich das Gericht - unter Umständen vergebens - darum bemühen müssen, einen Rechtsanwalt zu finden. Werde dagegen die Zuweisung eines Rechtsanwalts anstelle des zurückgewiesenen Konsulenten nicht vorgesehen, sei die Möglichkeit nicht auszuschließen, daß der Beschuldigte keinen Anwalt finde und „daher auf den Beistand eines Verteidigers verzichten " müsse. ${ }^{92}$ Nachdem das Reichsinnenministerium die Zuweisung eines Rechtsanwalts durch das Gericht im Falle der nicht notwendigen Verteidigung abgelehnt hatte, sandte Freisler den beiden genannten Stellen den Verordnungsentwurf mit der Bitte um Zustimmung zu. ${ }^{93}$

Die „Verordnung zur Durchführung der Fünften Verordnung zum Reichsbürgergesetz" vom 12.Juni 1940 (RGBl. I, S. 872) sah vor, daß Konsulenten als Strafverteidiger zurückgewiesen werden konnten, „wenn dies aus besonderen Gründen, insbesondere mit Rücksicht auf den Gegenstand des Verfahrens, geboten erscheint“ (§ 1). Über die Zurückweisung entschied der Vorsitzer des Gerichts, bei dem das Verfahren anhängig war, im Vorverfahren der Vorsitzer des Gerichts, das für die Hauptverhandlung zuständig wäre. Im Verwaltungsstrafverfahren lag die Entscheidung bei der für das Verfahren zuständigen Behörde, z. B. im Verfahren wegen Steuerhinterziehung beim Finanzamt, im Devisenstrafverfahren beim Zollamt usw. (§ 2). Wurde ein Konsulent erst in der Hauptverhandlung zurückgewiesen, so konnte das Gericht die Aussetzung der Verhandlung beschließen, um dem jüdischen Angeklagten die Beauftragung eines

91 Vgl. Verm. u. RV des RJM v. 31.10.39 an die genannten Präsidenten (Akten des RJM, a.a.O.).

92 Vgl. Schr. Freislers v. 5.4.40 (voranstehende Anm. 88).

93 Vgl. Verm. und Schr. des RJM (i.V. Freisler) v. 30.4 .40 an den St.d.F. und den RMdI (Akten des RJM, a.a.O.). 
„arischen“ Wahlverteidigers zu ermöglichen (§ 3); fand er keinen, so war das Gericht jedoch nicht verpflichtet, ihm einen Verteidiger zuzuweisen.

Ergänzend sei noch ausgeführt, daß im Herbst 1938 auch aus der Patentanwaltschaft alle Juden ausscheiden mußten. Eine entsprechende Verordnung wurde vom Reichsjustizministerium schon parallel mit der Verordnung über die Ausschaltung der jüdischen Rechtsanwälte vorbereitet. Ineressanterweise trat hier der Stellvertreter des Führers dafür ein, daß den ausgeschiedenen jüdischen Patentanwälten - analog der vorgesehenen Regelung bei den Rechtsanwälten - Unterhaltszuschüsse gewährt werden sollten: Da „die Einnahmen der Patentanwälte verhältnismäßig groß“ seien und „die Ausscheidenden nur ein Sechstel der Gesamtzahl darstellten“, sei es vertretbar, einen Teil der Mehreinnahmen, die den „arischen“ Patentanwälten dadurch zuflössen, für diesen Zweck zu beanspruchen. ${ }^{94}$ Das Justizministerium griff diesen Vorschlag auf und reichte nach Abstimmung auch mit dem Reichsinnen- und dem Reichsfinanzministerium am 19. September 1938 die von Gürtner bereits gegengezeichnete Sechste Verordnung zum Reichsbürgergesetz bei den beteiligten Stellen zur Mitzeichnung und anschließenden Vollziehung durch Hitler ein. ${ }^{95}$ Wie die Vorlage der Fünften Verordnung geriet auch sie in den Strudel der Ereignisse um die Sudetenkrise: Obwohl sie $\mathrm{Heß}$ als letzter der beteiligten Reichsminister schon am 6.Oktober unterzeichnete ${ }^{96}$, ließ Hitlers Unterschrift auf sich warten. Vorsorglich teilte der Leiter der Abteilung IV (Bürgerliches Recht), Ministerialdirektor Volkmar, der Reichskanzlei telefonisch mit, daß die in der Verordnung enthaltenen Stichtage - für das Ausscheiden der jüdischen Patentanwälte war wie bei den Rechtsanwälten der 30. November vorgesehen - geändert werden müßten, falls sie nicht bis Monatsende verkündet werden könne. ${ }^{97}$ Die Änderungen wurden jedoch nicht notwendig, da Hitler die Verordnung am 31. Oktober unterschrieb; sie konnte noch rechtzeitig am 3. November im Reichsgesetzblatt veröffentlicht werden.

Nach dieser Sechsten Verordnung zum Reichsbürgergesetz vom 31. Oktober 1938 (RGBl. I, S. 1545) schieden nunmehr auch jene jüdischen Patentanwälte mit Wirkung vom 30. November 1938 aus, die nach der Gesetzgebung des Jahres 1933 als Ausnahmen im Amt geblieben waren. Juden war von jetzt ab „der Beruf des Patentanwalts verschlossen“ $(\S 1)$ : hier durften jüdische Konsulenten eine Vertretung auch dann nicht übernehmen, wenn ihre Auftraggeber Juden waren ( $\$ 11)$. Von der Zulassung jüdischer „Patentkonsulenten“ wurde deshalb abgesehen, weil in den vom Patentamt bearbeiteten Angelegenheiten ein Anwaltszwang nur für Personen bestand, die weder ihren Wohnsitz noch ihre gewerbliche Niederlassung im Inland hatten. Bei ihnen ließ sich aber eine Unterscheidung zwischen jüdischen und anderen Auftraggebern nicht treffen, da im Ausland die Rassenzugehörigkeit nicht „zuverlässig“ festgestellt werden konnte. Andererseits konnten Personen - also auch Juden -, die ihren Sitz im Inland hatten, ihre Angelegenheiten gegenüber dem Reichspatentamt selbst wahrnehmen oder sich von jeder anderen Person vertreten lassen, die diese Tätigkeit nicht berufsmäßig ausübte. Die Fälle, in denen inländische Juden einen Patentanwalt wünschten,

94 Vgl. Schr. des St.d.F. (gez. Bormann) an das RJM v. 15.7.38 (Diensttageb. des RJM, Eintr. v. 19.7.38, Bd. 16,

BA, Sign. R 22/947).

95 Vgl. Schnellbrief des RJM v. 19.9.38 an den RMdI, RFiM, St.d.F. und Chef der RK (Akten des RK, BA, Sign. R 43 II/598).

96 Vgl. Schr. des Adjutanten des St.d.F. an Lammers v. 6. 10.38 nebst unterschriebener Ausfertigung (a.a.O.).

97 Vgl. Aktenverm. Kritzingers v. 18.10 .38 (a.a.O.). 
waren nach Ansicht des Justizministeriums künftig „schon deshalb selten ..., weil die Erwirkung und Bekämpfung gewerblicher Schutzrechte ganz überwiegend von der Industrie ausgeht, in der der jüdische Einfluß immer mehr zurücktritt“. Die wenigen Fälle könnten „keinen besonderen jüdischen Patentkonsulentenstand tragen“ und getrost auf die Gesamtheit der „arischen“ Patentanwälte verteilt werden, da die mangels Feststellung der Rassenzugehörigkeit im Ausland „sicher häufig vorkommende Vertretung ausländischer Juden ohnehin nicht zu vermeiden" sein werde. ${ }^{98} \mathrm{War}$ ein jüdischer Patentanwalt am Tage der Verkündung der Verordnung in einem anhängigen Patentverfahren als Vertreter gemeldet, durfte er die Vertretung noch bis Jahresende wahrnehmen (§ 2). Den aufgrund dieser Verordnung ausgeschiedenen Juden konnten, soweit sie Frontkämpfer waren, „aus Mitteln der Patentanwaltskammer bei Bedürftigkeit und Würdigkeit jederzeit widerrufliche Unterhaltszuschüsse gewährt werden“, und, falls die Mittel ausreichten, auch den seit dem 1.August 1914 eingetragenen „Altanwälten“ ( $(7)$. Den ausscheidenden Patentanwälten wurden analog der Regelung bei den Rechtsanwälten für die Kündigungsfristen bei Dienst- und Mietverträgen Erleichterungen gewährt ( $\S 3,4)$; weitere Vorschriften regelten die Fristen und patentamtlichen Gebühren für den Auftraggeber bei einem notwendig gewordenen Wechsel seines Vertreters $(\S \S 9,10)$. Die Verordnung galt auch für die jüdischen Patentanwälte in Österreich, mußte jedoch hinsichtlich der jüdischen Mischlinge unter ihnen durch eine spezielle Verordnung99 ergänzt werden, die den im Altreich bestehenden Rechtszustand auf Österreich übertrug und in den Einzelheiten analog der Verordnung über die Ausschaltung der Mischlinge unter den österreichischen Rechtsanwälten gestaltet war. ${ }^{100}$

Diejenigen jüdischen Mischlinge, die als Frontkämpfer und Altanwälte nach dem Rechtsanwaltsgesetz vom 7.April 1933 in der Anwaltschaft verblieben waren und auch von der Fünften Verordnung zum Reichsbürgergesetz nicht erfaßt wurden - im Altreich handelte es sich 1939 um etwa 170 Anwälte -, waren den rein „arischen“ Rechtsanwälten keineswegs gleichgestellt. Ihre anfänglich im Einvernehmen mit den Anwaltsorganisationen in Aussicht genommene Aufnahme in den NSRB scheiterte an der Haltung der Parteiführung. Die wirtschaftliche Lage dieser Anwälte war insofern schwierig, als sie einerseits keine Juden vertreten durften, andererseits aber von ,arischen" Auftraggebern kaum in Anspruch genommen wurden und selbst Mischlinge sich nur selten an sie wandten. Bei der Auswahl der Armenanwälte verengte der Grundsatz, „daß eine arische Partei die Beiordnung eines arischen Anwalts erwartet ${ }^{\star 101}$, ihr Tätigkeitsfeld erheblich. Wenn einmal ein Rechtsanwalt die Ausnahmegenehmigung zur Vertretung eines Juden erhielt, handelte es sich in der Regel nicht um einen Mischling. Der „Mischlings-Anwalt" konnte daher nur Mischlingen oder solchen deutschblütigen Parteien beigeordnet werden, die ausdrücklich darum nachsuchten. In den von den Gerichten angelegten Anwaltslisten mußten daher die Mischlinge - wenn auch nur "für den inneren Dienstgebrauch“ - besonders kenntlich gemacht werden. Nach Ansicht des Justizministeriums blieb nur die Möglichkeit, den Gerichten nahezulegen, im Einzelfall ,arischen Parteien, die keinen besonderen Wunsch äu-

\footnotetext{
98 Vgl. Erläuterung der VO im Schnellbrief des RJM v. 19.9.38 an die beteiligten Stellen (a.a.O.).

99 Vgl. VO über Angelegenheiten der Patentanwälte im Lande Österreich v. 31.10.38 (RGBI. I, S. 1548)

100 Vgl. voranstehend S. 181 und Anm. 63.

${ }^{101}$ Vgl. AV des RuPrJM v. 10.12.34 (DJ 1934, S. 1572).
} 
Bern, einen Mischling beizuordnen, wenn gegen seine Person im übrigen keinerlei Bedenken bestehen und von seiten der armen Partei ein Widerspruch nicht zu erwarten“ war. ${ }^{102}$ Im Juni 1944 gab es noch 127 Mischlinge 1 . Grades (Halbjuden) unter den Rechtsanwälten ${ }^{103}$, eine Neuzulassung von Mischlingen kam schon deshalb nicht mehr in Betracht, weil sie bereits als Referendare nicht übernommen wurden.

Hinsichtlich der ,jüdisch versippten“, d.h. mit Jüdinnen verheirateten Rechtsanwälte - über deren Zahl im Reichsjustizministerium 1939 noch „keine Unterlagen vorhanden waren" - hatten der Reichsgruppenwalter Rechtsanwälte im NSRB Droege und der Präsident der Reichs-Rechtsanwaltskammer Neubert vorgeschlagen, durch eine ergänzende Bestimmung zur Reichs-Rechtsanwaltsordnung den Ausschluß dieser Rechtsanwälte zu ermöglichen. Nachdem sie jedoch vom Justizministerium „auf die Bedenken gegen eine derartige Maßnahme hingewiesen“ worden waren, ließen sie den Gedanken fallen: entgegen ihrer ursprünglichen Absicht kamen sie in der Ressortbesprechung vom 24. Februar 1939 auf ihren Vorschlag nicht mehr zurück. ${ }^{104}$ Im Juni 1944 gab es daher noch 59 mit Jüdinnen und 55 mit Mischlingen 1. Grades (Halbjüdinnen) verheiratete Rechtsanwälte. ${ }^{105}$

\section{c. Änderung des Reichsbeamtengesetzes von 1873 und seine Ersetzung durch das Deutsche Beamtengesetz vom Januar 1937: das Problem der Unabbängigkeit des Richters}

Während das Berufsbeamtengesetz vom April 1933 und die Erste Verordnung zum Reichsbürgergesetz vom November 1935 der „Säuberung“ der bestehenden Justizbeamtenschaft dienten, mußten darüber hinaus die gesetzlichen Vorschriften für die künftige Ernennung bzw. Beförderung der Beamten und deren Disziplinierung umgestaltet werden, um Aufbau und Bestand der Justizbeamtenschaft im Sinne der nationalsozialistischen Führung zu gewährleisten. Zwar verfügte z.B. Kerrl als kommissarischer preußischer Justizminister schon zehn Tage nach Erlaß des Berufsbeamtengesetzes, daß von „Ernennungen und Beförderungen, die möglicherweise den Grundsätzen des Gesetzes“ - vor allem seinen Arierparagraphen - widersprachen, „zunächst abzusehen" sei; erforderlichenfalls sei dem Ministerium zu berichten. ${ }^{1}$ Aber eine entsprechende reichsgesetzliche Regelung erfolgte erst durch das Gesetz vom 30. Juni 19332,

102 Vgl. Verm. „Jüdische Mischlinge und jüdisch Versippte als Rechtsanwälte“ v. 3.4.39 (Akten des RJM, BA, Sign. R 22/254)

103 Vgl. Aufstellung des Leiters der Abt. I (Personalsachen) für Thierack v. 9.6.44 (a.a.O., Sign. R 22 Gr. 5/321).

104 Vgl. Verm. v. 3.4.39 (s. voranstehende Anm. 102).

105 Vgl. Aufstellung v. 9.6. 44 (voranstehende Anm. 103).

1 Vgl. RV des preuß. JM an die Provinzialbehörden v. 18.4.33 (Akten des preuß. JM, GehStArch. Berlin, Sign. Rep. 84 a/6334). Entsprechend bestimmte die 3.Durchf.VO v. 6.5 .33 (RGBl. I, S.245) zum $\S 5$ BBG, daß „bei der Wiederbesetzung von Stellen, die sich nach $\S \S 2$ bis 5 erledigen, sowie bei Neuernennungen und Beförderungen" die Grundsätze des BBG anzuwenden waren.

2 G. zur Anderung von Vorschriften auf dem Gebiete des allgemeinen Beamten-, des Besoldungs- und des Versorgungsrechts v. 30.6.33 (RGBl. I, S.433). Für die Beförderung wurden die entsprechenden Vorschriften in $\S 8$ der Reichsgrundsätze über Einstellung, Anstellung und Beförderung der Reichs- und Landesbeamten v. 14.10.36 (RGBl. I, S.893) niedergelegt. 
das in das geltende Reichsbeamtengesetz vom 31. März 1873 (RGBl., S. 61) einen § 1 a einfügte, nach dem zum Reichsbeamten nur berufen werden durfte, wer neben dem Nachweis der vorgeschriebenen Laufbahn oder besonderer Eignung „die Gewähr dafür bietet, daß er jederzeit rückhaltlos für den nationalen Staat eintritt“, ferner „arischer" Abstammung und nicht mit einer Jüdin verheiratet war. Ein Beamter, der künftig eine „Nichtarierin“ heiratete, war zu entlassen. Das Junigesetz legte insofern den Grund für die Vereinheitlichung des deutschen Beamtenrechts, als diese und andere seiner Bestimmungen für die übrigen Beamten der Länder, Gemeinden und sonstigen öffentlichen Körperschaften verbindlich erklärt wurden. Gleichfalls im Jahre 1933 setzte das Reichsinnenministerium in Zusammenarbeit mit dem Reichsfinanzministerium die bereits in der Weimarer Republik begonnenen Arbeiten an einem neuen Reichsbeamtengesetz fort, das das regional zersplitterte und in verschiedenen Reichsund Landesgesetzen niedergelegte Beamtenrecht mit der Gleichschaltung der Länder neu und im ganzen Reich einheitlich gestalten sollte. An dem Versuch, dabei die durch das Berufsbeamtengesetz - nach Meinung der Ministerialbürokratie vorübergehend - aufgehobenen beamtenrechtlichen Garantien möglichst wiederherzustellen, hatte die Justizleitung wegen der angestrebten Sicherung der Unabhängigkeit des Richters größtes Interesse. Als sich die Realisierung des neuen Beamtengesetzes, das ursprünglich nach Ablauf der zweimal verlängerten Fristen des Berufsbeamtengesetzes im September 1934 in Kraft gesetzt werden sollte, hauptsächlich wegen der Meinungsverschiedenheiten zwischen den staatlichen Ressorts und der Parteiführung verzögerte ${ }^{3}$, erwog das Reichsjustizministerium, aus der Übernahme der Landesjustizverwaltungen die Konsequenzen zu ziehen und in seinem Geschäftsbereich das Beamtenrecht auf der Grundlage des Reichsbeamtengesetzes in der Fassung vom 30. Juni 1933 selbständig zu regeln und fortzubilden. Die rechtliche Grundlage für die einheitliche Behandlung der Justizbeamtenschaft war durch das Dritte Gesetz zur Überleitung der Rechtspflege auf das Reich vom 24. Januar 1935 (RGBl. I, S. 68) gegeben, das die Justizbeamten der Länder zu unmittelbaren Reichsbeamten gemacht hatte. Das Anliegen der Justizverwaltung war insofern dringend, als nach diesem Gesetz die bisher für diese Beamten geltenden Landesvorschriften bis zu einer reichseinheitlichen Regelung sinngemäß weitergalten, so daß die Personalabteilung des Reichsjustizministeriums siebzehn verschiedene Beamtengesetze anwenden mußte. ${ }^{4} \mathrm{Da}$ es Reichsinnenminister Frick jedoch für nicht wünschenswert hielt, die bisherigen Landesjustizbeamten „zunächst vorübergehend dem geltenden Reichsbeamtenrecht zu unterstellen und dann später ihre Rechtsverhältnisse von neuem zu regeln"s - und auch befürchtete, durch ein selbständiges Vorgehen der Justiz seine zentrale Zuständigkeit als „Beamtenminister" zu verlieren -, trieb er in der Folgezeit die Verhandlungen über das neue Reichsbeamtengesetz voran, mußte als Preis dafür allerdings der Partei gegenüber größere Zugeständnisse machen.

${ }^{3}$ Zur Vorgeschichte des DBG von 1937 vgl. H. Mommsen, Beamtentum im Dritten Reich. Mit ausgewählten Quellen zur nationalsozialistischen Beamtenpolitik, Stuttgart 1966, S. $91 \mathrm{ff}$.

4 Vgl. dazu Kapitel II.S., S.116, und MinDir. Nadler, Die Arbeit der Personalabteilung des Reichsjustizministeriums im Jahre 1935 (DJ 1936, S. 3 ff.).

5 Vgl. Schnellbrief des RuPrMdI (gez. Frick) an die RK v. 16.1.36 (Akten der RK, BA, Sign. R 43 II/419 a) und Verm. Sts. Pfundtners v. 19.9.36 für den Ref. im RMdI mit der Forderung, „das JustMin. von weiterem Vorgehen abzuhalten“ (GehStArch. Berlin, Sign. Rep. 320), beide abgedruckt bei Mommsen, a.a.O., S. 205 f., 213. 
Das Deutsche Beamtengesetz, das nach Überwindung erheblicher Schwierigkeiten schließlich in der Kabinettssitzung vom 26. Januar 1937 verabschiedet und von Hitler am selben Tage unterzeichnet wurde ${ }^{6}$, trat am 1. Juli in Kraft und war von diesem Zeitpunkt an die Rechtsgrundlage für die Personalpolitik der Justizverwaltung. Es übernahm die rassemäßigen, vorbildungsmäßigen und politischen Voraussetzungen für die Ernennung zum Beamten aus dem Änderungsgesetz vom Juni 1933. Statt des Begriffs „arisch“ war in Fortentwicklung der Rassegesetzgebung nunmehr von „deutschem oder artverwandtem [d.h. im wesentlichen europäischem] Blut" die Rede; bei Genehmigung einer Ausnahme mußte neben dem Reichsinnenministerium nunmehr zusätzlich der Stellvertreter des Führers eingeschaltet werden (§ 25). Ferner mußte der Beamte nicht mehr nur für den „nationalen“, sondern für den „nationalsozialistischen“ Staat rückhaltlos eintreten ( $(26)$. Während er ohne Verfahren und ohne Versorgung entlassen werden konnte, wenn sich nach seiner Ernennung ein rassischer Makel an ihm oder seiner Ehefrau herausstellte $(\S 59)^{7}$, war für seine Versetzung in den Ruhestand wegen politischer Unzuverlässigkeit ein detailliertes Verfahren vorgesehen, um ihn vor haltlosen Beschuldigungen zu sichern $(\S 71)$ : Ergab sich der Verdacht, daß sich der nationalsozialistische Staat nach den Worten, Taten oder Unterlassungen eines Beamten nicht mehr auf ihn verlassen konnte, veranlaßte zunächst der Dienstvorgesetzte die notwendigen Ermittlungen und legte sie zusammen mit einer Stellungnahme des Beamten der obersten Dienstbehörde - bei der Justiz also dem Reichsjustizministerium - vor. Hielt das Ministerium aufgrund der Ermittlungsergebnisse den Verdacht weiterhin für begründet, leitete es ein Untersuchungsverfahren ein und ernannte dafür den Untersuchungsführer, der Zeugen und Sachverständige eidlich vernehmen konnte, den Beschuldigten zu Beginn und abschließend hörte und dem Justizministerium die Akten nebst einem zusammenfassenden Bericht vorlegte. Aufgrund der Untersuchungsergebnisse entschied das Ministerium, ob es im Einvernehmen mit dem Reichsinnenminister bei Hitler beantragen wollte, den Beamten in den Ruhestand zu versetzen. Hitler traf dann die letzte Entscheidung. Die Verantwortung für das Vorgehen gegen einen politisch „unzuverlässigen“ Justizbeamten blieb nach diesen Bestimmungen beim Reichsjustizminister; er war nur dann verpflichtet, einer Forderung des Stellvertreters des Führers nach Einleitung des Verfahrens nachzukommen, wenn der beschuldigte Beamte aus der NSDAP ausgetreten oder ausgeschlossen worden war. In diesem Falle mußte er den Stellvertreter des Führers vom Ausgang des Verfahrens unterrichten. ${ }^{8}$ Um die Unabhängigkeit des Richters zu sichern, war aber in das Gesetz die Bestimmung aufgenommen worden, daß die Versetzung eines richterlichen Beamten in den Ruhestand niemals ,auf den sachlichen Inhalt einer in Ausübung der richterlichen Tätigkeit getroffenen Entscheidung gestützt werden" dürfe (§ 171). ${ }^{9}$ Um die-

${ }^{6}$ RGBI. I, S. 39. Das G. wurde von Frick und Schwerin von Krosigk mitgezeichnet.

7 War die irrige Annahme der "Deutschblütigkeit“ allerdings ohne Verschulden des Beamten zustande gekommen, wurde er mit Versorgung in den Ruhestand versetzt.

${ }^{8}$ Vgl. die ergänzenden Bestimmungen zu $\S 71$ in der VO zur Durchf. des Deutschen Beamtengesetzes v. 29.6.37 (RGBI. I, S. 669).

9 Gemäß $\S 171$ durfte dem Richter u. a. auch die Fortführung seiner Dienstgeschäfte nach $\S 6$ nicht verboten werden, außer wenn gegen ihn ein Untersuchungsverfahren nach $\S 71$ eingeleitet und deshalb seine $Z$ wangspensionierung zu erwarten war oder schon seine Ernennung aus bestimmten Gründen ( $\$ 32$ Abs. 2 und 3) für nichtig zu erklären war. 
sen Paragraphen, der der Parteiführung ein Dorn im Auge war, sollte sich schon im Frühjahr 1938 eine Diskussion entwickeln, zu der Hitler den Anstoß gab.

Gürtner legte seine Auffassung über die richterliche Unabhängigkeit auf einer Tagung der Oberlandesgerichtspräsidenten im Januar 1938 dar und formulierte dabei erneut „seinen Glaubenssatz, daß die Unabhängigkeit der Rechtsprechung das unerläßliche und unwegdenkbare Fundament des ns. Staates sei. An diesen Satz habe er immer geglaubt und werde er weiter glauben." Diese Unabhängigkeit sei allerdings nicht als Privileg des Richterstandes, „sondern nur zugunsten des Volkes“ geschaffen. Zwar verzichte "die Staatsführung keinesfalls auf jeden Einfluß auf die Rechtsprechung“ und übe ihn durch „die Gesetzgebung, die Zuweisung des Aufgabengebietes an die Justiz und die Auswahl bei der Ernennung der Richter" aus. Dieser Einfluß finde jedoch seine Grenze an dem Grundsatz, daß „der Richter wegen des sachlichen Inhalts seines Spruches nicht angesprochen werden solle“, und darin, daß

„die Staatsführung aus eigenem Willen darauf verzichte, dem Richter für eine Entscheidung eine Anweisung zu geben. Bei der Erörterung dieser Frage in der letzten Zeit habe der Führer die Erstreckung seiner Führergewalt insoweit auch ausdrücklich abgelehnt mit der Erklärung: ,Da müßte ich ja am Ende jeden Prozeß selber entscheiden.“"10

Konnte Hitler die Richter bei der Urteilsfindung nicht ohne weiteres an die Anweisungen politischer Stellen binden, ohne die Rechtsprechung schlechthin aufzuheben, so beschäftigte ihn dennoch um diese Zeit die Frage, durch welche Mittel die richterliche Unabhängigkeit eingeschränkt werden konnte. Gerade in den letzten Monaten des Jahres 1937 hatte er sich über die auf ihre Unabhängigkeit pochenden Richter verschiedentlich geärgert, so z. B. über den Präsidenten des Landgerichts in Neiße, Fabig. Dieser Fall stellte einen Test dafür dar, inwieweit Hitler gewillt war, künftig ein für allemal auf eine Führerweisung an den entscheidenden Richter zu verzichten und beim Vorgehen gegen einen Richter die beamtenrechtlichen Verfahrensbestimmungen einzuhalten.

Fabig hatte einer querulierenden Parteigenossin, die schon einmal wegen Beleidigung der Vormundschaftsrichter verurteilt worden war, in einem neuen Prozeß das Armenrecht verweigert. Als ihre an Hitler persönlich gerichtete Beschwerde auf dem Dienstwege dem Landgerichtspräsidenten zur Stellungnahme zuging, belehrte er die Querulantin am 26. Oktober schriftlich,

„daß die Bewilligung des Armenrechts ausschließlich Sache der zuständigen Gerichte ist und daß der Führer mit Rücksicht auf die Unabhängigkeit der Gerichte nicht befugt [?] ist, den Gerichten in Ansehung ihrer Entscheidung in der Frage der Armenbewilligung Weisungen zu erteilen".

Diesen von der Parteigenossin gleichfalls an Hitler gesandten Brief legte der Chef der - für persönliche Eingaben zuständigen - „Kanzlei des Führers der NSDAP“, Reichsleiter Bouhler, am 4. Dezember Hitler vor, der sich sofort entschloß, dem Landgerichtspräsidenten, der sich anmaßte, ihm eine Befugnis abzusprechen, eine Lehre zu erteilen: Bouhler mußte Lammers den Auftrag Hitlers übermitteln, „der Reichsjustiz-

${ }^{10}$ Vgl. Ausführungen Gürtners auf der Tagung der OLGPräs. im RJM am 18.1.38, Ber. des OLGVizepräs. Hamburg, Letz (Arch. der Forschungsstelle f. d. Geschichte des NS in Hamburg, Sign. Best. 3308).

$"$ Vgl. Schr. des LGPräs. von Neiße, Fabig, v. 26.10.37 an Frau Anna L. (Akten der RK, BA; Sign. R 43 II/ 1507). Zum Fall Fabig s. auch H. Hattenhauer, Vom Reichsjustizamt zum Bundesministerium der Justiz. Stellung und Einfluß der obersten deutschen Justizbehörde in ihrer 100jährigen Geschichte (in: Festschrift zum 100jährigen Gründungstag des Reichsjustizamtes am 1.Januar 1877, Köln 1977, S. 83 ff.). 
minister möge dafür sorgen, daß der Landgerichtspräsident Fabig in Neiße binnen 24 Stunden seines Amtes enthoben werde". ${ }^{12}$ Zwei Tage später hielt Lammers nach Rücksprache mit Gürtner bei Hitler Vortrag und wies darauf hin, „daß nach den gesetzlichen Bestimmungen der Reichsjustizminister zu dieser Amtsenthebung nicht berechtigt sei“; selbst eine vorläufige Enthebung aus dem Amt sei nur „in dem gesetzlich vorgeschriebenen Disziplinarverfahren zulässig“, das in der vor fünf Monaten zusammen mit dem Deutschen Beamtengesetz - in Kraft gesetzten Reichsdienststrafordnung ${ }^{13}$ erschöpfend geregelt worden war. Der Justizminister könne den Landgerichtspräsidenten höchstens sofort beurlauben, müsse aber „das Weitere dem Disziplinarverfahren ... überlassen “. Widerstrebend beugte sich Hitler dem Argument, daß die erst kürzlich erfolgte gesetzliche Neuordnung des Beamtenrechts durch Nichtbeachtung ihrer Bestimmungen nicht desavouiert werden könne, und fand sich mit dem vorgeschlagenen Verfahren ab. Am nächsten Tag bestellte Gürtner den Landgerichtspräsidenten zu sich, um sich einen persönlichen Eindruck von ihm zu verschaffen. In dem Gefühl, Hitlers Vertrauen verloren zu haben, bat Fabig um seine Beurlaubung. Gürtner beurlaubte ihn mit sofortiger Wirkung und kündigte ihm an, daß er mit einem Verfahren nach $\S 71$ des Beamtengesetzes rechnen müsse.

Nunmehr wurden über Fabig sowohl politische wie fachliche Beurteilungen eingeholt. Die zuständige Gauleitung von Schlesien teilte Bouhler auf dessen telefonische Anforderung mit, daß Fabig kein Parteimitglied sei und vor der Machtübernahme im Lager der Deutschnationalen gestanden habe; vom Stahlhelm sei er im Rahmen der allgemeinen Überführung im November 1933 zur SA-Reserve gekommen und gehöre auch einigen der Partei angeschlossenen Verbänden wie dem NSRB, der NSV u.a. an. Obwohl demnach Fabig politisch "durchaus positiv“ zu beurteilen sei, trete die Gauleitung trotzdem für seine Amtsenthebung ein, um „ein durchaus angebrachtes Exempel“ zu statuieren: es sei nämlich beobachtet worden, „daß insbesondere die Präsidenten der Landgerichte und Oberlandesgerichte bei jeder sich bietenden Gelegenheit eine Betonung auf die ,Unabhängigkeit der Rechtsprechung “ legten, die für manche Stellen der Justiz lediglich einen willkommenen Vorwand abgäbe, „alle noch so berechtigten Ansinnen und Wünsche, die die Partei einmal vorzutragen hat, zurückzuweisen“. ${ }^{14}$ Das vom Justizministerium eingeholte Gutachten des Stellvertreters des Führers, das auf der Beurteilung der Gauleitung beruhte, bezeichnete Fabig „als durchaus zuverlässig im Sinne des Nationalsozialismus". ${ }^{15}$ Der Oberlandesgerichtspräsident von Breslau nannte ihn einen seiner zuverlässigsten und „wertvollsten Mitarbeiter“. Die beanstandete Formulierung Fabigs sei lediglich ein ,augenblicklicher Fehlgriff“ in der Verärgerung über die Querulantin gewesen. Da dem schwerkriegsbeschädigten Richter seine Beinprothese Beschwerden bereite, könne er „,vielleicht einmal in gequälter Mißstimmung sich im Ausdruck vergreifen“. Jedenfalls seien „die Vorausetzungen des $\S 71$ des Reichsbeamtengesetzes bei ihm keinesfalls erfüllt“ ${ }^{16}$ Nach einer

12 Vgl. Verm. Lammers' v. 10.12.37 über die Vorgänge v. 4. bis 7.12.37 (Akten der RK, a.a.O.).

${ }^{13}$ Vgl. Reichsdienststrafordnung (RDStO) v. 26.1.37 (RGBI. I, S.71), die zusammen mit dem DBG am 1.7.37 in Kraft getreten war.

${ }_{14}$ Vgl. Schr. der Gauleitung der NSDAP Schlesien (gez. stellv. Gauleiter Bracht) an Bouhler v. 4.12.37 nebst einer politischen Beurteilung Fabigs für den St.d.F. v. 17.7.37, beides am 17.1.38 der RK übersandt (Akten der RK, a.a.O.).

$15 \mathrm{Vgl}$. Schr. des Stabes des St.d.F. an den RJM v. 14.12.37 (a.a.O.).

16 Vgl. Schr. des OLGPräs. Breslau an Lammers v. 13.12.37 (a.a.O.). 
abermaligen Besprechung des Falles mit Lammers holte sich Gürtner noch Schützenhilfe beim Reichsinnenministerium, das bei einem eventuellen Verfahren nach $\S 71$ ohnehin zu beteiligen war: er bat um Stellungnahme, ob Anlaß zu einer Amtsenthebung Fabigs bestehe, fügte aber gleich hinzu, daß er selbst diese Frage verneine. Das Innenministerium stellte fest, daß die fragliche Äußerung Fabigs zwar geeignet sei, „ernste Zweifel zu erwecken“, ob Fabig noch jederzeit für den nationalsozialistischen Staat eintreten werde; aufgrund der positiven Beurteilungen der Persönlichkeit Fabigs und der „,ür sein Verhalten angeführten subjektiven Gesichtspunkte“ schließe sich der Innenminister jedoch der Auffassung des Justizministers an. ${ }^{17}$

Nunmehr begann Gürtner sein „Rettungswerk“ für den deutschnationalen Gesinnungsgenossen - eines der mehrfachen Beispiele dafür, daß sich die Justizverwaltung unter Gürtner schützend vor ihre Angehörigen stellte, solange sie im „nationalen“, fachlichen und moralischen Sinne integer waren. In einem Schreiben an Hitler hob der Justizminister die positive Beurteilung hervor, die der schwerkriegsbeschädigte, mit dem Eisernen Kreuz I. Klasse und anderen Orden ausgezeichnete Landgerichtspräsident von allen Seiten erhalten hatte; auch in seiner persönlichen Unterredung habe er die „soldatische, disziplinierte und männliche Haltung“ Fabigs feststellen können. Nach alledem sei er der Meinung,

„daß der beanstandete Satz zwar recht ungeschickt formuliert ist, daß es Fabig aber völlig ferngelegen hat, mit diesem Satz Ihre alle Gebiete des Staats- und Volksleben umfassende Führungsmacht und -recht [?] in Zweifel zu ziehen. Fabig ist davon ausgegangen, daß es Ihr eigener Wille sei, auf eine unmittelbare Einflußnahme auf die Entscheidungen der Gerichte [!] in Privatrechtsstreitigkeiten zu verzichten.“

Bei dieser Sachlage könne er aus der Formulierung Fabigs nicht schließen, daß dieser nicht mehr die Gewähr dafür biete, daß er jederzeit für den nationalsozialistischen Staat eintreten werde, und daher auch ,nicht vorschlagen, auf Fabig den $\S 71$ des DBG anzuwenden“. Er bitte vielmehr um Hitlers Entscheidung, daß der Beurlaubte seine Tätigkeit wieder aufnehmen dürfe, und ferner um die Ermächtigung, dem „hochverdienten Frontkämpfer, der unter dem Verluste Ihres Vertrauens schwer leidet, zu eröffnen, daß er wieder Ihr volles Vertrauen genießt“. Gürtner bat Lammers, ihm einen persönlichen Vortrag bei Hitler zu ermöglichen, falls dieser seinen Vorschlag ablehne. ${ }^{18}$ Hitler erklärte sich einverstanden, daß Fabig sein Amt wieder ausübe, sah jedoch in Fabigs Bescheid - ganz abgesehen von der Frage, ob er ,rechtlich einwandfrei“ (!) sei - „eine Äußerung, die in ihrer Auswirkung geeignet sein“ könne, „das Vertrauen zur Staatsführung zu beeinträchtigen“. Fabig sollte daher „eine ernste Warnung erteilt" werden, die jedoch "nicht die Form einer Dienststrafe zu erhalten“ brauche, deren Wortlaut Hitler aber vorher sehen wollte. ${ }^{19}$ In dieser von Hitler gebilligten Warnung ${ }^{20}$ an Fabig wurde nunmehr ausdrücklich erklärt, daß sein Bescheid vom 26. Oktober 1937 ,rechtlich nicht einwandfrei“ sei, und damit zum Ausdruck gebracht, daß Hitler in seiner verfassungsrechtlich uneingeschränkten Macht - in diesem Falle offensichtlich in seiner Eigenschaft als Oberster Richter - befugt war, den Gerichten

17 Vgl. Schr. des RuPrMdI (gez. Pfundtner) an das RJM v. 13.1.38 (a.a.O.).

18 Vgl. die beiden Schr. Gürtners an Hitler und an Lammers v. 3.2.38 (a.a.O.).

19 Vgl. Schr. Lammers' an Gürtner v. 2.3.38 (a.a.O.).

20 Wortlaut s. Schr. Gürtners an Lammers' v. 4.3.38, dazu das Antwortschr. Lammers' v. 9.3.38 (a.a.O.). 
Weisungen zu erteilen. Der Fall Fabig hatte gezeigt, daß Hitler zwar das gesetzlich vorgesehene Verfahren für die Entfernung eines richterlichen Beamten respektierte ${ }^{21}$, aber für die Zukunft nicht auf das Recht verzichten wollte, einem Richter für seine Entscheidung Anweisungen zu geben. Das Justizministerium zog aus diesem Fall noch eine besondere Lehre: es wies seine Behörden an, bei der Erledigung von Eingaben an Hitler nicht Formulierungen wie „Der Führer ist nicht befugt“ oder „Es ist nicht Sache des Führers“ zu verwenden, um jeden Eindruck zu vermeiden, als „wollten sie dem Führer das Recht bestreiten, sich um Angelegenheiten zu bekümmern, die in ihre eigene Zuständigkeit fallen“. ${ }^{22}$

Über das Hitler zu dieser Zeit besonders bewegende Problem einer Einschränkung der richterlichen Unabhängigkeit und der Ergreifung von Maßnahmen, um die Rechtsprechung nach dem Willen der politischen Führung zu gestalten, hatte Lammers am 6. April 1938 abermals eine Unterredung mit Gürtner, der daraufhin seinen persönlichen Referenten von Dohnanyi beauftragte, Lammers noch am selben Tage die Abschrift eines im Reichsjustizministerium erarbeiteten „Merkblattes“ zur Frage der richterlichen Unabhängigkeit zuzustellen. ${ }^{23}$ Darin wurde ausgeführt, daß die pflichtgemäß gebildete und geäußerte richterliche Überzeugung niemals Anlaß für Maßnahmen gegen einen Richter geben und seine Entscheidung in einem Strafverfahren z.B. nicht etwa deshalb zur Grundlage eines Verfahrens nach $\S 71$ DBG gemacht werden dürfe, weil das Justizministerium eine andere Strafe für angebracht hielt. Deshalb könne der im Rahmen des Gesetzes ergehende Tenor eines Urteils niemals Gegenstand eines solchen Verfahrens sein; aber auch in der Urteilsbegründung müsse der Richter die notwendigen Ausführungen ohne die Befürchtung dienstlicher Nachteile machen können, selbst wenn er darin vielleicht die Tätigkeit anderer Dienststellen des Staates oder der Partei beanstanden müsse. Lediglich unsachliche, zur Begründung der Entscheidung nicht notwendige und der Form nach verletzende Ausführungen, die nicht zum sachlichen Inhalt einer in Ausübung der richterlichen Tätigkeit getroffenen Entscheidung gehörten, könnten ein Verfahren nach $\S 71$ rechtfertigen. ,Jede darüber hinausgehende Beeinträchtigung der richterlichen Unabhängigkeit", stellte das Merkblatt fest, „birgt die Gefahr schwerer Erschütterungen des allgemeinen Rechtsbewußtseins in sich." Eine Beeinträchtigung bzw. Aufhebung der richterlichen Unabhängigkeit läge ferner vor, wenn der Richter entweder „hinsichtlich des sachlichen Inhalts seiner Entscheidung an Anweisungen politischer Stellen gebunden würde“ oder zum politischen Beamten gemacht würde, d.h. wie der Staatsanwalt nach § 44 DBG jederzeit in den Wartestand versetzt werden könnte, oder aber seine Unversetzbarkeit schlechthin aufgehoben würde: denn eine „Versetzung ad hoc kommt in der prakti-

21 Diese Feststellung gilt auch für die Zeit nach dem Reichstagsbeschluß v. 26.4.42, der Hitler ermächtigte, jeden Richter bei Pflichtverletzung ohne vorgeschriebenes Verfahren aus seinem Amt zu entfernen. Hier sei nur auf das Beispiel vom Juli 1942 verwiesen, bei dem Hitler beabsichtigte, gegen einen Richter wegen seines Urteils die „Kassation“ auszusprechen, d.h. ihm alle Beamtenrechte abzuerkennen, sich aber dann mit einem Verbot künftiger prozeßrichterlicher Tätigkeit des Betreffenden abfand (Akten des RK, BA, Sign. R 43 II/1560).

22 Vgl. RV des RJM an die höheren Justizbehörden v. 14.5.38 (Akten des RJM, BA, Sign. R 22/4237).

23 Vgl. Schr. Dohnanyis an Lammers v. 6.4.38 nebst „Merkblatt zur Frage der richterlichen Unabhängigkeit“, das im wesentlichen auf dem Kommentar von MinDir. Nadler und den MinRäten Wittland und Ruppert aus der Abt. I (Personalangelegenheiten) des RJM: Deutsches Beamtengesetz vom 26. Januar 1937, Berlin 1938, beruhte (Akten der RK, BA, Sign. R 43 II/1507). 
schen Wirkung der Weisungsgebundenheit gleich“. Ferner bringe die Furcht vor Versetzung „die Gefahr mit sich, daß eigennützige Erwägungen die sachliche Findung des Rechts beeinflussen".

Im Merkblatt wurde darauf hingewiesen, daß die Möglichkeiten der unfreiwilligen Versetzung eines Richters der ordentlichen Gerichtsbarkeit an ein anderes Gericht im geltenden ${ }^{24} \S 8$ des Gerichtsverfassungsgesetzes erschöpfend geregelt seien: Danach konnte sie durch die Justizverwaltung nur „bei einer Veränderung in der Einrichtung der Gerichte oder ihrer Bezirke“ verfügt werden ( 8 Abs. 3). Ansonsten durften Richter „wider ihren Willen nur kraft richterlicher Entscheidung [eines Dienststrafgerichts] und nur aus den Gründen und unter den Formen, welche die Gesetze bestimmen“, versetzt werden ( $\S 8$ Abs. 1). Es könne höchstens daran gedacht werden, zusätzlich eine Versetzung „im Interesse der Rechtspflege“ zuzulassen, wie sie in der Preußischen Dienststrafordnung vorgesehen war, wobei dort allerdings das Vorliegen dieser Voraussetzung auch durch das Dienststrafgericht festgestellt werden mußte. ${ }^{25}$ Alles jedoch, was durch eine Einführung der Versetzbarkeit des Richters bezweckt werden solle, könne im wesentlichen schon auf Grund des Gesetzes über die Geschäftsverteilung bei den Gerichten vom November $1937^{26}$ erreicht werden.

Den Inhalt des Merkblattes trug Lammers am 12. April 1938 Hitler vor und erhielt daraufhin den Auftrag, geeignete Möglichkeiten zu eruieren, um die Rechtsprechung in den Griff zu bekommen. Schon am nächsten Tag beauftragte er Ministerialdirektor Kritzinger, die verschiedenen Maßnahmen zusammenzustellen, die dafür in Erwägung gezogen werden konnten. ${ }^{27}$ In seiner Vorlage vom 23. April hielt Kritzinger die formale Aufhebung des $\S 71$ DBG zwar für „bedenklich“; es sei aber zu erwägen, auf diese einschränkende Bestimmung de facto keine Rücksicht zu nehmen und Verfahren nach $\S 71$ DBG auch auf richterliche Entscheidungen zu stützen. Das einzige Bedenken gegen derart begründete Verfahren sah Kritzinger darin, daß die Ressorts dann der Vorwurf treffen könnte, „das Berufsbeamtengesetz nicht hinreichend durchgeführt zu haben“. Um die Möglichkeit der Versetzung des Richters zu erweitern, könne die preußische Regelung einer Versetzung im Interesse der Rechtspflege aufgrund der Anordnung durch das Dienststrafgericht für das Reich übernommen werden, dabei aber nicht wie in Preußen von der ,im Interesse der Rechtspflege dringend gebotenen“ Versetzung, sondern nur von einer Versetzung ,im Interesse der Rechtspflege" gesprochen werden, um die Anordnung zu erleichtern. Eine zweite Möglichkeit bestehe darin, die Versetzung durch die Justizverwaltung zuzulassen; diese Maßnahme sei jedoch „als Dauereinrichtung nicht unbedenklich“ und höchstens vorübergehend - etwa im Zusammenhang mit der Neuordnung der Justiz im angeschlossenen Österreich - tragbar. Um zu vermeiden, daß die politische Führung die Verfolgung bestimmter Strafsachen durch unabhängige Gerichte weiterhin als ungenügend

24 Wegen der Fortgeltung des § 8 GVG wurde auf die Neufassung der Militärstrafgerichtsordnung v. 29.9.36 (RGBl. I, S.751) und das G. über das Reichswirtschaftsgericht v. 25.2.38 (RGBl. I, S. 216) hingewiesen, in denen die Fortgeltung ausdrücklich bestätigt wurde.

25 Diese Versetzung durfte ferner nur in ein anderes Richteramt von gleichem Range und gleichem Diensteinkommen erfolgen, vgl. $\S \S 82,84,85$ der Dienststrafordnung für die richterlichen Beamten v. 27.1.32 (Preuß. GS, S. 79) i.d.F. des Art. II des G. zur Anderung des Dienststrafrechts v. 18.8.34 (GS, S.353). Sie galt aufgrund $\S 171$, Abs. 1, Satz 1 DBG fort.

${ }^{26} \mathrm{Zu}$ diesem G. v. 24.11.37 (RGBI. I, S. 1286) s. Kapitel VIII.1.b., S.973f.

${ }^{27}$ Vgl. Verm. Lammers' v. 12.4.38 und Vorlage Kritzingers v. 23.4.38 (Akten der RK, a.a.O.). 
ansah, schlug Kritzinger schließlich als radikalste Maßnahme vor, politische Delikte der Justiz zu entziehen (!). Hiergegen sei allerdings einzuwenden, daß es sich bei den beanstandeten Gerichtsurteilen nicht nur um politische Strafsachen, sondern auch um gemeine Verbrechen gehandelt habe. Zum anderen bestehe die Schwierigkeit, anstelle der Gerichte andere geeignete Institutionen zu finden: „Will man keine unabhängigen Stellen, wie z. B. Sondergerichte, so bleibt nur übrig, Verwaltungsbehörden damit zu betrauen, das heißt also an Weisungen gebundene Stellen.“ Hier wurde eine Maßnahme angesprochen, die zu dieser Zeit von der Gestapo in Einzelfällen längst gehandhabt wurde und im Kriege bei der Strafverfolgung für „fremdvölkische“ Zwangsarbeiter und Juden generell eingeführt werden sollte.

Anhand von Kritzingers Aufzeichnungen hielt Lammers Hitler noch am selben Tag Vortrag. Das Ergebnis, das er Gürtner sofort telefonisch mitteilte, schlug sich in einem Schreiben nieder, das er Gürtner am 27. April im Auftrage Hitlers zusandte. ${ }^{28}$ Danach war Hitler der Auffassung, daß der $\S 71$ DBG für die Praxis nicht ausreiche, da er die Zwangspensionierung eines Richters nur dann ermögliche, wenn er nicht mehr die Gewähr dafür bot, daß er jederzeit für den nationalsozialistischen Staat eintreten werde. Ein Richter, bei dem diese Feststellung nicht getroffen werden könne, müsse demnach auch dann im Amt belassen werden, „wenn er seiner geistigen und politischen Einstellung nach der nationalsozialistischen Weltanschauung derart fernsteht, daß er nicht in der Lage ist, das Amt ... so zu versehen, wie die nationalsozialistische Volksgemeinschaft es erwarten" könne. Der Justizminister solle daher im Einvernehmen mit dem Reichsinnenminister gesetzliche Änderungen vorschlagen, „um auch in solchen Fällen ein Eingreifen zu ermöglichen“. Ferner halte es Hitler für notwendig, Richter genauso wie andere Beamte jederzeit versetzen zu können, „wenn das Interesse der Rechtspflege es erfordert, und zwar nicht nur auf Grund der Entscheidung eines Gerichts"; er wünsche auch dafür Vorschläge. Schließlich bitte Hitler den Justizminister zu prüfen, ob er es für „zweckmäßig“ halte, „die Verfolgung bestimmter Straftaten, insbesondere solche politischen Charakters, den ordentlichen Gerichten zu nehmen und anderen Stellen zu übertragen“. Lammers bat, die angeforderten Vorschläge bei ihm einzureichen, er wolle sich jedoch bemühen, für Gürtner einen baldigen Vortrag bei Hitler zu erwirken.

Bezeichnenderweise übersandte Gürtner dem zu beteiligenden Reichsinnenministerium abschriftlich nur jenen Teil des Lammers-Briefes, der sich mit der Änderung des $\S 71$ DBG befaßte, ließ aber die Passage über die Frage der Verfolgung von Straftaten durch „andere Stellen“ weg: Gürtner mußte befürchten, daß die in den Schutzhaftbestimmungen vom Januar 1938 mühsam erwirkte Abgrenzung mit der Gestapoführung in dieser Frage ${ }^{29}$ - an die sich die Gestapo ohnehin nicht immer hielt - hinfällig werden mußte, sobald der Polizeiführung diese konkrete Anregung Hitlers zu Ohren kam. Frick antwortete am 9. Mai, daß er aus dem mitgeteilten Auszug nicht ersehen könne, was Hitler zu seiner Forderung auf Abänderung des $\S 71$ DBG veranlaßt habe, er nehme aber an, „daß der Grund in Darlegungen zu suchen ist, die Richter in Urteilsbegründungen gemacht" hätten. Mit einem Seitenhieb auf die Justizverwaltung teilte er mit, daß in seinem Ressort „noch kaum ein Fall“" von Anwendung des $\S 71$

${ }^{28}$ Vgl. Verm. Lammers' v. 23.4. und sein Schr. an Gürtner v. 27.4.38 (a.a.O.).

29 Vgl. dazu Kapitel VI.2.a., besonders S. $561 \mathrm{f}$. 
DBG vorgekommen sei, weil hier die politisch unzuverlässigen Beamten auf Grund des Berufsbeamtengesetzes "unter Anlegung eines besonders strengen Maßstabes“ entfernt worden seien. Er sei aber der Meinung, daß dieser Paragraph in seiner gegenwärtigen Form Hitlers Absichten vollauf Rechnung trage: Wenn Hitler aus ihm vorgetragenen Tatsachen zu dem Schluß komme, daß der Beamte nicht in der Lage sei, sein Amt im Sinne des nationalsozialistischen Staates zu versehen, so biete er eben nicht mehr die Gewähr dafür, daß er jederzeit für diesen Staat eintreten werde. Der „Kern des Problems “ liege vielmehr in der Sonderbestimmung des $\S 171$ für die Richter, ,die anscheinend die Veranlassung zu der Willensmeinung des Führers" gegeben hätten; diese Bestimmung sei „mit Rücksicht auf einige richterliche Entscheidungen der letzten Zeit auch von anderen Dienststellen als Übelstand empfunden worden“. Frick schlug daher vor, den $\S 71$ unverändert zu lassen, dagegen die Sonderbestimmung für Richter im $\S 171$ durch ein Änderungsgesetz abzuschaffen. ${ }^{30}$

Die Stellungnahme des Reichsjustizministeriums verzögerte sich, da Gürtner bis zum 22. Mai anläßlich der Übernahme der Justiz in Österreich die dortigen Oberlandesgerichtsbezirke besuchte. Nachdem im Ministerium über die Frage der Versetzbarkeit von Richtern gegen ihren Willen am 31. Mai eine spezielle Besprechung stattgefunden hatte, an der neben Abteilungsleiter Ministerialdirektor Volkmar die Referenten für Gerichtsverfassungsrecht, Beamtenangelegenheiten und Dienststrafgerichtsbarkeit aus drei verschiedenen Abteilungen teilnahmen ${ }^{31}$, ging am nächsten Tag Gürtners Antwortschreiben an Lammers ab. Darin wurde ausgeführt, daß eine Änderung des $\S 71$ DBG notwendigerweise auch eine Änderung des $\S 26$ bedinge, und zwar dahingehend, daß nur derjenige, der die Gewähr für ein rückhaltloses Eintreten für den nationalsozialistischen Staat biete, Beamter bleiben - also nicht nur "werden" - könne. Wie der Reichsinnenminister sei auch er „zu dem Ergebnis gelangt, daß es keiner Änderung des $\S 71$ bedarf, um die Zurruhesetzung eines der nationalsozialistischen Weltanschauung völlig fremd gegenüberstehenden Beamten zu ermöglichen“, sie könne „vielmehr schon im Rahmen der jetzigen gesetzlichen Bestimmungen, und zwar sowohl bei nichtrichterlichen wie bei richterlichen Beamten ausgesprochen werden“" Statt einer Änderung des $\S 71$ schlage er daher vor, daß Hitler den obersten Dienstbehörden durch einen Erlaß die Tragweite des Paragraphen in dieser Hinsicht erläutern und sie anweisen solle, ihn entsprechend anzuwenden.

Geschickt und entschieden verteidigte Gürtner die vom Reichsinnenminister zur Streichung vorgeschlagene Ausnahmebestimmung des $\S 171$ für Richter: er glaube aus dem ihm „übermittelten, nur den $\S 71$ erwähnenden Auftrage des Führers und Reichskanzlers schließen zu müssen“, daß diese Bestimmung auch nach Hitlers Willen „unberührt bleiben“ solle: „Die Streichung dieser Vorschrift würde die Aufhebung des Richteramtes bedeuten“ (!). Sein Ministerium habe auch stets die Auffassung vertreten, „daß unsachliche, d.h. zur Begründung der gefällten Entscheidung nicht erforderliche Ausführungen, die Wahl verletzender Ausdrücke sowie die Einbeziehung neben der Sache liegender Umstände in die Entscheidungsgründe“ durch die Vorschrift nicht gedeckt seien: sie könnten nicht nur zur Einleitung eines Verfahrens nach $\S 71$ DBG, sondern auch zu dienststrafrechtlichen Maßnahmen Anlaß geben.

$30 \mathrm{Vgl}$. Schr. des RuPrMdI (gez. Frick) an Gürtner v. 9.5.38 (Akten der RK, a.a.O.)

31 Vgl. Referentenverm. v. 1.6.38 (Akten des RJM, BA, Sign. R 22/209). 
Zur Frage der Versetzbarkeit der Richter wies Gürtner darauf hin, daß die meisten früheren Beamten- oder Disziplinargesetze der Länder eine Versetzung des Richters auch außerhalb eines Dienststrafverfahrens „im Interesse der Rechtspflege“ ermöglicht hätten, dabei allerdings ein (Dienststraf-)Gericht darüber entscheiden ließen, ob die Voraussetzungen für eine solche Versetzung vorlagen. Wenn diese Regelung nicht für das Reich übernommen werden solle, so könne eine Vorschrift erwogen werden, wonach in einem dem $\S 71$ DBG angeglichenen Verfahren die Versetzung eines Richters durch Hitler ausgesprochen werden könne, „wenn das weitere Verbleiben des betreffenden Beamten an seinem bisherigen Dienstsitze mit den Interessen der Rechtspflege unvereinbar wäre“. Gürtner machte aber darauf aufmerksam, daß solche Bestimmungen nicht für die Justizverwaltung allein getroffen werden könnten, sondern alle Ressorts, bei denen Gerichte bestanden - d.h. das Oberkommando der Wehrmacht, das Reichsinnen-, Reichsfinanz-, Reichswirtschafts-, Reichsarbeitsministerium und das Reichsministerium für Ernährung und Landwirtschaft -, einbezogen und beteiligt werden müßten.

Was die Frage einer Übertragung der Verfolgung bestimmter Straftaten an justizfremde Stellen anging, so hielt es Gürtner aus den schon erwähnten Gründen „für zweckmäßig“, dieses Problem mit Lammers mündlich zu erörtern. ${ }^{32}$

Frick, der von Gürtner durch eine Abschrift informiert worden war, hielt gegenüber der Reichskanzlei den von Gürtner vorgeschlagenen, erläuternden Erlaß Hitlers für überflüssig, da sich alle Reichsminister über die erörterte Anwendungsmöglichkeit des $\S 71$ DBG einig seien. Wenn eine Meinungsäußerung Hitlers für erforderlich angesehen werde, solle sie sich vielmehr auf das vom Justizminister angeschnittene Problem erstrecken, was nicht als sachlicher Inhalt einer richterlichen Entscheidung im Sinne des $\S 171$ angesehen werden solle. Den Äußerungen Gürtners über die Versetzbarkeit der Richter trete er bei. ${ }^{33}$ Die Frage, der Justiz die Zuständigkeit für bestimmte Strafsachen zu entziehen, erwähnte Frick mit keinem Wort; sie sollte im Zusammenhang mit dem hier behandelten Thema auch nicht mehr auftauchen: Gürtner war es in persönlichen Unterredungen offensichtlich gelungen, dieses heikle Problem aus den weiteren Erörterungen herauszuhalten.

Hitler, dem für das Vorgehen gegen „ungeeignete“ Richter wirksamere Maßnahmen vorschwebten, stimmte Gürtners Vorschlag einer authentischen Erläuterung des $\S 71$ DBG nur mit halbem Herzen zu. Da das Reichsinnenministerium befürchtete, daß durch einen solchen Erlaß „eine allgemeine Beunruhigung entstehen“ könne, wurde die Form eines vertraulichen Rundschreibens der Reichskanzlei an die für die Anwendung des $\S 71$ DBG zuständigen Reichsminister gewählt. ${ }^{34}$ Das am 12. Juli 1938 von Berchtesgaden aus ergehende Rundschreiben gab Hitlers Auffassung kund, daß der $\S 71$ DBG nicht nur dann angewendet werden könne, wenn „ein Beamter die nationalsozialistische Weltanschauung bewußt ablehnt“, sondern auch dann, wenn er

\footnotetext{
32 Vgl. Schr. Gürtners an Lammers v. 1.6.38 (Akten des RK, a.a.O., auch Akten des RJM, BA, Sign. R 22/4435).

33 Vgl. Schr. Fricks an Lammers v. 23.6.38 (Akten des RK, a.a.O.).

34 Vgl. Verm. Kritzingers v. 27.6.38 über die Besorgnis des zuständigen Ref. des RMdI (a.a.O.). Im Entw. des RdSchr. wurde deshalb auch der Satz gestrichen, daß die RMin. die in ihrem Geschäftsbereich für die Anwendung des $\S 71$ DBG zuständigen Behörden davon unterrichten sollten.
} 
"durch die Art seiner Amtstätigkeit, im besonderen durch die von ibm getroffenen Entscheidungen, oder durch seine dienstliche oder außerdienstliche Führung erkennen" lasse, daß er dieser Weltanschauung "gefühls- und verstandesmäßig fremd gegenübersteht“. Dabei schließe die Vorschrift des $\S 171$ „nach Ansicht des Führers nicht aus, daß auch eine gerichtliche Entscheidung zum Anlaß genommen wird“, einen Richter nach $\S 71$ DBG in den Ruhestand zu versetzen, da unsachliche und verletzende Ausführungen in den Entscheidungsgründen durch diese Vorschrift nicht gedeckt seien. Hitler wünsche, daß die Reichsminister unter Beachtung dieser Auslegung und „unter schärferen Gesichtspunkten als bisher" ungeeignete Beamte aus ihren Ämtern entfernen sollten. ${ }^{35}$

Dem Justizminister übersandte Lammers das Rundschreiben mit einem Begleitbrief, in dem er mitteilte, Hitler habe sich mit Gürtners Vorschlag „einer Erläuterung des $\S 71$ DBG im Erlaßwege nur ungern einverstanden erklärt und ohne sich hiervon den gewünschten Erfolg zu versprechen". Hitler sehe daher

,in diesem Rundschreiben nur eine vorläufige Maßnahme und ist im übrigen der Auffassung, daß hinsichtlich der richterlichen Beamten schärfere gesetzliche Maßnahmen unerläßlich sind, die es ermöglichen, Richter, die durch ihre Entscheidungen erkennen lassen, daß sie der nationalsozialistischen Weltanschauung völlig fremd gegenüberstehen, aus dem Amte zu entfernen“.

Auch wenn die Entscheidungsgründe nicht wegen Unsachlichkeit zu beanstanden seien (!), könne aus einem Richterspruch hervorgehen, daß der betreffende Richter der nationalsozialistischen Weltanschauung so fern stehe, daß er keine Gewähr für ein jederzeitiges Eintreten für den nationalsozialistischen Staat biete. In extremen Fällen, z.B. wenn ein Richter ,aus seiner inneren Ablehnung des nationalsozialistischen Rassegedankens heraus bei Rassenschande ohne Rücksicht auf die Schwere des Einzelfalles grundsätzlich auf die Mindeststrafe erkennen wollte", würde ein schuldhaftes Dienstvergehen vorliegen und der Richter gemäß § 22 DBG in einem Dienststrafverfahren aus dem Amt entfernt werden können. Aber ,in der Regel werden die Fälle derart gelagert sein, daß sich ein Richter trotz guten Willens oder bei nicht erkennbar bösem Willen mit der nationalsozialistischen Welt- und Lebensauffassung nicht im Einklang zu halten vermag“. Das könne sich in einer Strafzumessung äußern, „die ein gesundes und richtiges Gefühl für die Wertordnung der verletzten Rechtsgüter vermissen läßt", oder auch in der Nichtanwendung des Analogieparagraphen $(\S 2$ StGB) ${ }^{36}$ In diesen Fällen könnten jedoch $\S 22$ DBG und - wegen der entgegenstehenden Vorschrift im $\S 171$ - auch $\S 71$ DBG nicht angewendet werden. Aber gerade solche Fälle seien es gewesen, „bei denen der Führer die Möglichkeit einer Entfernung des betreffenden Richters vermißt" (!) habe. Im Auftrage Hitlers müsse er Gürtner daher bitten, „baldmöglichst Vorschläge zu unterbreiten, die geeignet sind, in derartigen Fällen eine Entfernung von Richtern aus dem Dienst zu ermöglichen". ${ }^{37}$

Zur Frage einer leichteren Versetzbarkeit der Richter legte Lammers seinem Brief ein Schreiben an jene anderen Ressorts bei, bei denen gleichfalls Gerichte bestanden. Darin teilte er ihnen Hitlers Auffassung mit, „daß die nach geltendem Recht beste-

35 Vgl. RdSchr. des Chefs der RK v. 12.7.38 an die Reichsminister, den Preußischen Ministerpräsidenten und den Preußischen Finanzminister (a.a.O.). Die hervorgehobenen Worte wurden von Lammers handschriftlich in den von MinDir. Kritzinger verfaßten Entw. eingefügt.

36 Vgl. dazu Kapitel VII.3.b., S.861.

37 Vgl. Schr. Lammers' an Gürtner v. 12.7 .38 (a.a.O., ferner Akten des RJM, BA, Sign. R 22/4435). 
hende Unversetzbarkeit der Richter unter Umständen für die Interessen der Rechtspflege wesentliche Nachteile [!] zur Folge haben könne“. Hitler habe deshalb den Justizminister beauftragt, Änderungsvorschläge zu machen und die angesprochenen Ressorts bei der weiteren Behandlung der Angelegenheit zu beteiligen. ${ }^{38}$

Mit dem von Lammers übermittelten Ersuchen, Vorschläge zur Abschaffung der Unabsetzbarkeit und Unversetzbarkeit der Richter zu unterbreiten, war die Justiz praktisch aufgefordert worden, der Unabhängigkeit ihrer Gerichte endgültig das Grab zu schaufeln. Die Justizleitung regierte daher zunächst überhaupt nicht. Als Hitler auf den Bayreuther Festspielen am 25. Juli Lammers „erneut auf die Frage eines Gesetzes zur Abschaffung [!] oder Einschränkung der richterlichen Unabhängigkeit oder Unversetzbarkeit" ansprach, unterrichtete dieser zwei Tage später telefonisch den im Kampen auf Sylt weilenden Gürtner. Beide kamen überein, daß Gürtner nach Rückkehr aus seinem Urlaub - d.h. nach dem 4. August - Hitler Vortrag halten sollte ${ }^{39}$, bei dem der Justizminister offensichtlich seine Bedenken vortragen und Hitler von der gewünschten gesetzlichen Regelung abbringen wollte. Am 17. August entschied Hitler, daß Gürtners Vortrag erst nach dem Reichsparteitag stattfinden solle ${ }^{40}$, der vom 5. bis 12. September dauerte. Wegen der anschließenden Sudetenkrise, während der Hitler kaum Zeit für die notwendigste Gesetzgebungsarbeit fand ${ }^{41}$, dürfte die Angelegenheit nicht weiter verfolgt worden sein. Wann der Vortrag Gürtners in dieser Sache stattfand oder auf welche andere Weise Hitler von der beabsichtigten Einführung einer gesetzlichen Bestimmung abgehalten wurde, die die Entfernung eines Richters wegen des sachlichen Inhalts seines Urteils ermöglichen sollte, ist aus den vorliegenden Quellen nicht ersichtlich: fest steht, daß die Paragraphen 71 und 171 DBG nebst dem vertraulichen Rundschreiben Lammers' vom 12. Juli 1938 auch weiterhin die „Rechtsgrundlage" für die Zwangspensionierung eines Richters aus nichtdienststrafrechtlichen Gründen blieben. Dabei wurde jedoch die Vertraulichkeit des Lammersschen Rundschreibens durch das eigenmächtige Vorgehen Bormanns weitgehend aufgehoben, der die Dienststellen der Partei am 1. September 1938 vom Inhalt des Rundschreibens unterrichtete und sie anwies, ihm alle Beschwerden über Beamte und Richter, „die zu einer Zurruhesetzung gemäß $\S 71$ führen“ könnten, mit entsprechenden Unterlagen zuzuleiten. ${ }^{42}$ Obwohl sich der Reichsinnenminister gegen eine Bekanntgabe an nachgeordnete Stellen wandte, da die aufgrund des Rundschreibens in Frage kommenden Entscheidungen allein den betreffenden Ressortministern im Einvernehmen mit ihm vorbehalten waren, fand sich Lammers angesichts des Vorprellens der Parteiführung zu einer Bekanntgabe an die "nachgeordneten Behörden bis zur mittleren Stufe" bereit, damit auch sie in der Lage seien, den Ministerien entsprechende Vorgänge zu berichten. ${ }^{43}$ Daraufhin gab das Reichsjustizministerium den höheren Justizbehörden von dem Rundschreiben abschriftlich Kenntnis, verbot jedoch ausdrück-

\footnotetext{
${ }^{38}$ Vgl. Schr. des Chefs der RK v. 12.7.38 an den RMdI, RFiM, Chef des OKW, RWiM, RArbM sowie den RM für Ernährung und Landwirtschaft (a.a.O.).

39 Vgl. Schr. Lammers' aus Berchtesgaden v. 27.7.38 an Adjutant Albert Bormann in Bayreuth und dessen Antwortschr. v. 30.7 .38 (Akten des RK, a.a.O.).

40 Vgl. Verm. Lammers' v. 17.8.38 (a.a.O.).

41 Vgl. die Vorgänge um die 5.VO zum ReichsbürgerG., dargestellt in Kapitel III.1.b., S.178f.

42 Vgl. vertraul. Rdschr. Nr. 136/38 des St.d.F. (i.V. Bormann) v. 1.9.38 (Arch. des IfZ, Sign. Db 15.02).

$43 \mathrm{Vgl}$. Schr. des RMdI an die RMin. v. 21.9.38 und Schr. des Chefs der RK v. 18.10.38 an den RMdI, nachrichtlich an alle RMin. (Akten der RK, a.a.O.).
} 
lich eine weitere Bekanntgabe ${ }^{44}$ Erst als die Oberlandesgerichtspräsidenten berichteten, daß untere Parteidienststellen gegenüber Landgerichtspräsidenten mit ihrer Kenntnis von dem Rundschreiben auftrumpften und seinen Inhalt in einer Form verbreiteten, die geeignet war, „irrtümliche Vorstellungen über die Tragweite des Erlasses hervorzurufen und die Beamten, insbesondere die Richter, in der Ausübung ihrer Amtspflichten zu beunruhigen", lockerte auch das Justizministerium seine Bestimmungen über die Vertraulichkeit. ${ }^{45}$

Wie die ursprünglich von Hitler geforderte gesetzliche Einführung der Absetzung eines Richters - d.h. der Zwangspensionierung wegen des sachlichen Inhalts seiner Entscheidungen - unterblieb zunächst auch die gesetzliche Ermöglichung seiner beliebigen Versetzung aus diesem Grunde. Hierin dürfte der Justizleitung das schon im April 1938 ins Feld geführte Argument ${ }^{46}$ geholfen haben, daß im Ausnahmefall ein Richter schon aufgrund des Geschäftsverteilungsgesetzes vom November 1937 „im Interesse der Rechtspflege“ - wenn auch nur innerhalb des betreffenden Gerichts - versetzt werden konnte. Erst die Vereinfachungsmaßnahmen im Kriege räumten mit dem Prinzip der Unversetzbarkeit weitgehend auf: Schon mit Kriegsbeginn konnte ein Richter an jedes andere Gericht der Reichsjustizverwaltung ohne zeitliche Begrenzung - wenn auch unter Beibehaltung seiner Planstelle beim bisherigen Gericht - abgeordnet werden. Ferner vergrößerte die vermehrte Beschäftigung von Gerichtsassessoren - später sogar Referendaren - als nicht planmäßig angestellte „Hilfsrichter" selbst an höheren Gerichten die Gruppe jener Richter, denen die gesetzliche Garantie der persönlichen Unabhängigkeit ohnehin mangelte. ${ }^{47}$

Die unveränderte Fortgeltung der einschlägigen Bestimmungen des Deutschen Beamtengesetzes - die Gürtner als Verdienst angerechnet werden muß - ermöglichte es der Justizleitung, die Frage der Einleitung von Verfahren gemäß $\S 71$ gegen Richter nach eigenen Maßstäben zu entscheiden. Von den zehn Untersuchungsverfahren, die während der Amtszeit Gürtners gegen Justizbeamte des höheren Dienstes einschließlich Notare eingeleitet wurden, betrafen sechs Richter. Keinem dieser Richter 1 Oberlandesgerichtsrat, 1 Landgerichtsrat und 4 Amtsgerichtsräten - wurde seine Rechtsprechung vorgeworfen, es handelte sich vielmehr um in nationaler Hinsicht „unehrenhafte“ Gesinnung oder um ablehnende Bekundungen gegenüber dem NSRegime und seinen antijüdischen, antikirchlichen u.a. Maßnahmen. ${ }^{48}$ Die Handhabung dieser Verfahren führte daher schon zeitig zu Gegensätzen mit der Parteiführung. Der Leiter der Personalabteilung im Reichsjustizministerium, Ministerialdirek-

${ }^{44} \mathrm{Vgl}$. RV des RJM an die höheren Justizbehörden v. 5.11 .38 (Akten des RJM, BA, Sign. R 22/4469).

${ }^{45}$ Vgl. Ber. des OLGPräs. Marienwerder an das RJM v. 4.1 .39 nebst Ber. des LGPräs. Elbing v. 30.12.38, ferner Ber. des OLGPräs. Hamm an das RJM v. 16.12.38 (a.a.O.).

${ }^{46}$ Vgl. das von Dohnanyi am 6.4.38 Lammers übermittelte „Merkblatt" (voranstehend Anm. 23 und Text S. $195 \mathrm{f}$.

47 Vgl. VO über Maßnahmen auf dem Gebiete der Gerichtsverfassung und der Rechtspflege v. 1.9.39 (RGBI. I, S. 1658), dazu die Ausführungen in Kapitel VIII.1.b., S.974f. Zum Problem der Hilfsrichter s. Kapitel III.4.b., S. 317. Darüber hinaus konnte ein Richter im Kriege aufgrund der NotdienstVO v. 15. 10.38 (RGBI. I, S. 1441) und der DienstpflichtVO v. 13.2.39 (RGBI. I, S. 206) oder durch Aufhebung der uk-Stellung und Einberufung zur Wehrmacht jederzeit seiner richterlichen Tätigkeit entzogen werden.

${ }^{48}$ Die Einleitungsverfügungen wurden abschriftlich bei der Geschäftsstelle $\mathrm{a}^{9}$ (Beamtenrecht) des RJM gesammelt (Akten des RJM, BA, Sign. R 22/4469). Sie führten nicht immer zur Zurruhesetzung des Betreffenden, so z. B. nicht im Falle des erwähnten OLGRats. Die erste von Gürtner gez. Einleitungsverfügung stammt v. 30.5.38, die letzte v. 9.12.40, sie betraf den gegen die Euthanasieaktion opponierenden AGRat Kreyßig, vgl. dazu Kapitel V.3.c., S. 512. 
tor Nadler, ließ sich deshalb von der Reichskanzlei im Februar 1939 ausdrücklich bestätigen, daß das Ministerium in Fällen gegensätzlicher Auffassung von Justiz und Parteiführung gesetzlich nicht verpflichtet war, eine Entscheidung Hitlers herbeizuführen. In dem Bestätigungsschreiben bemerkte die Reichskanzlei, daß es dem Stellvertreter des Führers natürlich seinerseits freistehe, in einem solchen Fall Hitler unmittelbar Meldung zu erstatten und dieser „selbstverständlich“ die Einleitung einer Untersuchung anordnen könne. Um das gegenseitige Vertrauen zwischen Vorgesetzten und Untergebenen zu erhalten, müsse jedoch der Justizbeamte „das Gefühl haben, daß nach dem Führer für seine Beurteilung und sein Beamtenschicksal sein oberster Dienstvorgesetzter absolut die Verantwortung trägt" ${ }^{49}$ Bormann, den die gesetzliche Regelung nicht befriedigte, forderte Lammers im Dezember 1940 auf, bei Hitler eine Änderung zu erreichen, die eine förmliche Beteiligung der Parteiführung am Verfahren vorsah. Im Februar 1941 erneuerte er dem zögernden Lammers gegenüber seine Forderung, da "die bisherige Handhabung des $\S 71$ den politischen Bedürfnissen“ nicht entspreche und "die die Voruntersuchung führenden Beamten sich der in politischen Fragen anzulegenden Maßstäbe selbst nicht sicher" seien. ${ }^{30}$ Nach langwierigen Verhandlungen, bei denen sich die Justiz und die anderen Verwaltungen gegen eine Einflußnahme der Partei auf die materielle Entscheidung über die Zwangspensionierung wehrten, sollte der Parteiführung schließlich im Juli 1942 zugestanden werden, daß zumindest dann stets ein Untersuchungsverfahren einzuleiten war, „wenn der Leiter der Partei-Kanzlei dies beantragt“, und zwar unabhängig davon, ob der betreffende Beamte Mitglied der Partei war oder nicht. Auch künftig führte das Justizministerium selbst in einem solchen Falle das Verfahren in eigener Regie durch, es mußte die Partei-Kanzlei lediglich vom Untersuchungsergebnis und den beabsichtigten Maßnahmen unterrichten. ${ }^{51}$

d. Vorgeschriebene Mitwirkung der NSDAP bei der Personalpolitik: das Problem der "doppelten Loyalität", die Einflußnabme der Parteifübrung und ibre Auswirkung auf den Beitritt der Justizbeamten $z u$ den NS-Organisationen

War im Deutschen Beamtengesetz von 1937 die Einflußnahme der Partei auf die Entfernung eines Justizbeamten aus seinem Amt nicht zu ihrer Zufriedenheit geregelt worden, da sie ein entsprechendes Untersuchungsverfahren - das zudem ohne ihre Beteiligung ablief - nur dann veranlassen konnte, wenn der Beamte aus der NSDAP ausgeschlossen worden oder ausgetreten war, so hatte sie in diesem Gesetz einen weiteren Kompromiß schließen müssen: bei der Frage nämlich, inwieweit ein Justizbeamter, der Parteigenosse war, bei der Durchführung seiner Dienstgeschäfte der Partei verpflichtet war. Das Problem der „doppelten Loyalität“ dieser Justizbeamten gegenüber ihrem Ressort einerseits und der NSDAP andererseits - das besonders bei der Strafverfolgung und Prozessen gegen Funktionäre und Mitglieder der Bewegung auf-

49 Vgl. Verm. Kritzingers v. 8.2.39 und sein Schr. an Nadler v. 9.3.39 (Akten des RK, BA, Sign. R 43 II/446).

so Vgl. Schr. des St.d.F. (i. V. Bormann) an Lammers v. 5.12.40 und 20.2.41 (a.a.O., Sign. R 43 II/447).

31 Vgl. Sechste VO zur Durchf. des Deutschen Beamtengesetzes v. 29.7.42 (RGBl. I, S.483), die die Durchf.VO v. 29.6.37 zu $\S 71$ änderte, dazu Verm. Killys v. 23.10.42 (a.a.O., Sign. R 43 II/448). 
trat - zeigte sich schon in der Informationspflicht gegenüber der Partei, soweit sie die normale Verpflichtung der Justizbehörden zur Amtshilfe in der Form von Auskunft, Akteneinsicht, Aktenübersendung usw. ${ }^{1}$ übertraf. Bei den Verhandlungen über das Beamtengesetz hatte der Stellvertreter des Führers eine Bestimmung gefordert, daß der Beamte dienstliche Vorgänge, die der NSDAP schaden konnten, den Parteistellen melden müsse. Sie hätte ihm ermöglicht, die Tätigkeit der staatlichen Behörden und Gerichte zu kontrollieren und beamtete Parteigenossen wegen dienstlicher Handlungen innerparteilich zu maßregeln. Die Zulassung einer solchen Meldung unter Umgehung des Dienstweges lehnten die Ressortminister mit der Begründung ab, daß sie das Denunziantentum fördere, damit den Zusammenhalt unter den Beamten, aber auch die Beamtendisziplin und die Autorität des Vorgesetzten untergrabe, da nicht mehr dieser, sondern der meldende Beamte darüber entscheide, ob ein dienstlicher Vorgang der Partei schade. ${ }^{2}$ Als Kompromiß, den Hitler in einer Unterredung mit Frick und Lammers am 13. Januar 1937 schließlich selbst vorschlug ${ }^{3}$, wurde im $\S 42$ DBG bestimmt, daß jeder Beamte - auch der Nicht-Parteigenosse - parteischädigende Vorgänge unter Umgehung des Dienstweges nur seinem Ressortminister oder Hitler selbst melden sollte, der dann eine Entscheidung fällen oder die Meldung an Heß zur Erledigung weiterleiten konnte. Hitler begründete in der abschließenden Kabinettssitzung vom 26. Januar die Möglichkeit einer Umgehung auch des Ressortministers damit, es könne sich „um die schwersten Dinge, z. B. Landesverrat handeln, bei denen sich der Verdacht sogar gegen die Vorgesetzten richte“. ${ }^{4}$ Teilte der Beamte den Vorgang jedoch einer anderen als den beiden genannten Stellen mit, verstieß er gegen die im Deutschen Beamtengesetz bestimmte Gehorsamspflicht $(\S 7)$ und der Pflicht zur Amtsverschwiegenheit $(\S 8)^{5} \mathrm{He}$, der schon 1936 erklärt hatte, daß er sich schützend vor jeden Beamten stellen werde, der wegen der Meldung dienstlicher Vorfälle an die Partei von seinen Dienstvorgesetzten wegen Bruchs der Amtsverschwiegenheit belangt würde - der Staat dürfe „sich in keinem Fall zum Richter über die parteiamtliche Tätigkeit eines Beamten aufwerfen", zu der dieser durch Parteieid verpflichtet sei ${ }^{6}$-, suchte auch nach Erlaß des Beamtengesetzes die getroffene Regelung zu ändern, die ihn als direkten Adressaten einer solchen Meldung ausschloß. ${ }^{7}$

Die Verschwiegenheitspflicht mußte für die Partei vor allem bei der Beschaffung von Informationen zur politischen Begutachtung eines Beamten ein mißliches Hindernis darstellen. Deshalb hatte sie in der Durchführungsverordnung zum Deutschen

${ }^{1}$ Vgl. die AV des RJM v. 23.1.38 betr. Bekanntgabe von Akten an Dienststellen der NSDAP. und ihrer Gliederungen (DJ 1938, S.130), die eine Anzahl AVen und RVen der vorangegangenen Jahre zusammenfaßte und ergänzte. Danach waren innerdienstliche Vorgänge der JVerw. von der Bekanntgabe ausgeschlossen; Personal- und Dienststrafakten waren über das RJM zu leiten. Zur generellen Mitteilungspflicht der StAschaft in Strafsachen gegen Mitglieder der Bewegung s. Kapitel VIII.3., S. 1093.

${ }^{2}$ Über die einzelnen Stadien der Verhandlungen s. H. Mommsen, Beamtentum im Dritten Reich. Mit ausgewählten Quellen zur nationalsozialistischen Beamtenpolitik, Stuttgart 1966, S.99ff.

3 Vgl. Verm. Lammers' v. 13.1.37 (Akten der RK, BA, Sign. R 43 II/420 a).

4 Aktenverm. des RuPrMdI v. 26.1.37 (Mommsen, a.a.O., S.221), dazu Niederschrift über die Sitzung des Reichskabinetts am Dienstag, dem 26.Januar 1937, nachmittags 4.15 Uhr (Arch. des IfZ, Sign. Fa 203/5).

5 Auch für Beschwerden persönlicher Art mußte auf jeden Fall der Dienstweg eingehalten werden, vgl. AV des RJM v. 4.11.37 (DJ 1937, S. 1760).

6 Vgl. parteiinternes RdSchr. 71/36 des St.d.F. v. 13.5.36 (Verfügungen, Anordnungen, Bekanntgaben. Herausg. von der Partei-Kanzlei, Bd.II, S. 283). Der Paragraph über die „Verletzung des Dienstgeheimnisses“ war deshalb 1938 zwischen Gürtner und $\mathrm{Heß}$ auch einer der umstrittensten Punkte im Entw. eines neuen StGB, vgl. dazu Kapitel VII.2.d., S.809, $814 \mathrm{f} ., 816$.

7 Vgl. dazu Mommsen, a.a.O., S. $221 \mathrm{f}$. 
Beamtengesetz eine Bestimmung durchgesetzt, daß ein Beamter, der als gleichzeitiger Amtsträger der NSDAP von der Partei den Auftrag erhielt, sich über die politische Einstellung eines Kollegen zu äußern, von der Amtsverschwiegenheit ,insoweit zu befreien [war], als nicht dringende staatliche Belange entgegenstehen " ${ }^{8}$ Daraufhin verfügte das Reichsjustizministerium, daß aber die Entscheidung über eine Befreiung in jedem Fall den höheren Reichsjustizbehörden vorbehalten blieb. ${ }^{9}$ Die Parteiführung interpretierte diese Verfügung des Justizministers dahin, daß die Abgabe einer angeforderten Beurteilung keinesfalls der vorherigen Genehmigung des Dienstvorgesetzten bedürfe: beamtete Parteigenossen könnten der Partei über die politische Einstellung eines anderen Beamten „ohne weiteres alles Wissenswerte mitteilen“. Eine Genehmigung müßten sie nur dann einholen, wenn sie in ihren Bericht Tatsachen aufnehmen wollten, deren Geheimhaltung durch Gesetz oder dienstliche Anordnung ausdrücklich vorgeschrieben oder ihrer Natur nach erforderlich war. Sie seien aber nicht verpflichtet, dem Dienstvorgesetzten mitzuteilen, welche Schlüsse sie aus diesen Tatsachen ziehen wollten. Sofern sich im Einzelfall Schwierigkeiten ergäben, sollten sie dem Stellvertreter des Führers berichten. ${ }^{10}$

Wie die Amtsverschwiegenheit wurde auch die im Deutschen Beamtengesetz getroffene Regelung über die Gehorsamspflicht von der Partei für unbefriedigend angesehen. Konnte sich ein Justizbeamter, der Parteimitglied war, gegenüber einer Weisung seines Vorgesetzten - die für die Spruchtätigkeit des Richters allerdings von keiner Seite zulässig war - auf eine gegenteilige Anordnung von Parteistellen berufen, so hatte er laut Beamtengesetz seinem Dienstvorgesetzten zu gehorchen. Es war vielmehr Aufgabe des Vorgesetzten zu prüfen, in welcher Weise die Belange der Partei mit denen der Justiz in Einklang zu bringen waren: Notfalls hatte er „zu versuchen, Unstimmigkeiten durch eine Aussprache mit der Parteistelle auszuräumen“; blieb der Versuch erfolglos, hatte er auf dem Dienstweg zu berichten, damit auf höherer Ebene eine Einigung oder Entscheidung herbeigeführt werden konnte. ${ }^{11}$ Offen blieb im Beamtengesetz jedoch die Frage, inwieweit ein beamtetes Parteimitglied, das dadurch oder auf andere Weise bei seiner dienstlichen Tätigkeit mit der Partei in Konflikt geriet, vor einem Parteigericht zur Verantwortung gezogen werden durfte. Dieses Problem hatte schon 1935 zu einem Protestschreiben Gürtners an Heß geführt, als Parteiund SA-Stellen die am Urteil im Hohnstein-Prozeß Mitwirkenden disziplinarisch zur Rechenschaft gezogen hatten. ${ }^{12} \mathrm{Um}$ diese Verfahren wenigstens unter zentraler Kontrolle zu halten, hatte das Oberste Parteigericht im März 1936 die dafür örtlich zuständigen Gaugerichte angewiesen, sie nur mit seiner vorherigen Genehmigung einzuleiten. ${ }^{13} \operatorname{Im} \S 7$ des Deutschen Beamtengesetzes wurde nur lediglich vorgesehen, daß die Frage, „ob und inwieweit“ derartige Parteigerichtsverfahren gegen Beamte zulässig

8 Vgl. VO zur Durchf. des DBG v. 29.6.37 (RGBl. I, S.669) zu § 26.

$9 \mathrm{Vgl}$. RV des RJM an die höheren Justizbehörden v. 2.8.37 (Akten des RJM, Hauptbüro, Arch. des BJM).

10 Vgl. RdSchr. des St.d.F. (gez. Bormann) Nr. 11/38, dazu AnO des Gaurechtsamtes Berlin Nr.9/38 (Amtsblatt des Gaues Berlin der NSDAP v. 15.3. und 15.4.38).

11 Vgl. VO zur Durchf. des DBG v. 29.6.37 (RGBI. I, S.669) zu $§ 7$ des Gs.

12 Vgl. dazu Kapitel IV.3., S.371.

13 Vgl. Anordnung des OPG v. 31.3.36 (Der Parteirichter. Amtl. Mitteilungsblatt des Obersten Parteigerichts der NSDAP, 1936, S. 38). Diese Genehmigungspflicht fiel 1942 weg, vgl. Ziffer 53 der Geschäftsordnung für die Parteigerichte, die im Zusammenhang mit den neuen Richtlinien für diese Gerichte v. 30.12.42 erging (a.a.O., 1943, S.15). 
seien, durch einen Erlaß Hitlers noch entschieden werden sollte. Da dieser Erlaß nie zustande kam, weil sich der Reichsinnenminister mit dem Stellvertreter des Führers über die Bestimmungen nicht einigen konnte ${ }^{14}$, blieb es zugunsten der Partei beim Status quo. Um sich in jedem Falle einschalten zu können, behielt sich das Justizministerium gegenüber seinen nachgeordneten Behörden vor, einem Justizbeamten die Genehmigung zur Aussage zu erteilen, wenn er von einer Stelle außerhalb des Ressorts wegen einer Amtshandlung zur Verantwortung gezogen werden sollte. ${ }^{15}$ Interessanterweise wurde das Problem der Verantwortlichkeit gegenüber der Partei auch in der Rechtsanwaltschaft erörtert und von dieser gefordert, daß ein Rechtsanwalt wegen beruflicher Handlungen vor einem Parteigericht erst nach einer disziplinarischen Bestrafung im ehrengerichtlichen Verfahren zur Verantwortung gezogen werden dürfe: da die der Partei angehörenden Anwälte in einschlägigen Fällen die Interessen ihrer Auftraggeber aus Furcht vor einem Parteiverfahren nur noch gehemmt vertreten würden, habe „für jeden erkennbar sich gerade die Praxis mancher Anwälte, die nicht der Partei angehören, erheblich erweitert" ${ }^{\text {" }}{ }^{16}$

Ein Beispiel dafür, daß das Problem der "doppelten Loyalität“ von Justizbeamten ernst genommen wurde und sich daraus Konflikte entwickelten, ist die anfängliche Weigerung des Braunschweiger Oberlandesgerichtspräsidenten, sich als Amtswalter des Bundes Nationalsozialistischer Deutscher Juristen (BNSDJ) - er war dort Fachleiter für Richter und Staatsanwälte - vereidigen zu lassen. Als er am 22. Februar 1934 von einem Beauftragten des Gauführers aufgefordert wurde, sich auf dem drei Tage später in Hannover stattfindenden Gauparteitag zur Vereidigung einzufinden, teilte er diesem mit, daß er sich dazu nicht in der Lage sehe, da er „als Richter den Eid auf Wahrung der Gesetze geleistet" habe und nach $\S 1$ des Gerichtsverfassungsgesetzes „nur dem Gesetz unterworfen“ sei. ${ }^{16 a}$ Der ihm nunmehr abverlangte Eid fordere demgegenüber, daß er „Adolf Hitler unverbrüchliche Treue, ihm und den von ihm bestimmten Führern unbedingten Gehorsam schwöre", und kollidiere damit mit seinen Pflichten als Richter, da er „dann evtl. auch über das Gesetz hinaus [!] bestimmten Führern gegenüber gebunden sei“. Daher könne er den Eid nur leisten, „wenn in der Eidesformel stände, daß nichts Gesetzwidriges von ihm verlangt würde“. ${ }^{16 \mathrm{~b}}$ Daraufhin entzog ihm der nationalsozialistische braunschweigische Justizminister Alpers alle

14 Der Vorgang wurde im November 1940 ergebnislos zu den Akten gelegt, vgl. Mommsen, a.a.O., S. 103. Der ungeklärte Status quo kommt deutlich zum Ausdruck in: LGRat Kalle, Die Parteigerichtsbarkeit und der Beamte (DJ 1938, S. 1555 ff.). Unproblematisch war die Befugnis der Parteigerichte, einen Beamten (Pg.) wegen seines außerdienstlichen Verhaltens oder einer bereits strafrechtlich abgeurteilten dienstlichen Handlung zur Rechenschaft zu ziehen.

$15 \mathrm{Vgl}$. RV des RJM v. 2.8.37 an die höheren JBehörden (Akten des RJM, Hauptbüro, Arch. des BJM).

${ }^{16} \mathrm{Vgl}$. Schr. des Gaues Westfalen-Nord des NSRB an das RJM v. 9.6.37 (Akten des RJM, BA, Sign. R 22/253).

16a Zu § 1 GVG vgl. Kapitel VIII.1.a., S.935, und VIII.2.b., S.997. Der reguläre Beamteneid lautete gemäß der VO über die Vereidigung der Beamten und der Soldaten der Wehrmacht v. 2.12.33 (RGBl. I, S. 1017) für die Justizbeamten - wie für alle öffentlichen Beamten - wie folgt: „Ich schwöre: Ich werde Volk und Vaterland Treue halten, Verfassung und Gesetze beachten und meine Amtspflichten gewissenhaft erfüllen, so wahr mir Gott helfe." Erst im G. über die Vereidigung der Beamten und Soldaten der Wehrmacht v. 20.8.34 (RGBl. I, S. 785) hieß der Diensteid für die öffentlichen Beamten: „Ich schwöre: Ich werde dem Führer des Deutschen Reiches und Volkes Adolf Hitler treu und gehorsam sein [!], die Gesetze beachten und meine Amtspflichten gewissenhaft erfüllen, so wahr mir Gott helfe." Zum Vereidigungsvorgang und seinen Formalitäten vgl. RV des RJM v. 1.7.36 (Bestand RJM-Hauptbüro, Arch. des BJM).

16b Vgl. Verm. des BNSDJ-Funktionärs RegRat H. für den braunschweigischen JM v. 22.2.34 (Akten des RJM, Arch. des IfZ, Sign. MA-108). 
Funktionen der Bewegung innerhalb der Justizverwaltung und löste ihn noch im selben Jahr als Oberlandesgerichtspräsidenten ab. ${ }^{16 c}$

Für den einzelnen Justizbeamten war seine Einstellung und sein Verhalten zur "doppelten Loyalität" insofern von erheblicher Bedeutung, als die Partei bei Ernennungen und Beförderungen zu beteiligen war: durch diese Mitwirkung - die sich nicht nur auf Parteigenossen, sondern auf alle Justizbeamte erstreckte - übte die Partei ihren „stärksten Einfluß ${ }^{\text {“17 }}$ auf die Justizverwaltung aus. Nach den Durchführungsbestimmungen zu $\S 26$ des Deutschen Beamtengesetzes erfolgte die Feststellung, ob ein Beamtenanwärter oder Beamter die Gewähr für ein rückhaltloses Eintreten für den nationalsozialistischen Staat bot, erst nach Anhörung des vom Stellvertreter des Führers mit der Begutachtung beauftragten Hoheitsträgers der NSDAP. ${ }^{18}$ Laut $\S 31$ DBG sollte Hitler durch Erlaß bestimmen, ,inwieweit bei der Ernennung von Beamten der Stellvertreter des Führers oder die von ihm bestimmte Stelle zu hören“ war. Die Mitwirkung der Partei, die sich in unterschiedlichen Formen schon seit 1933 eingebürgert hatte ${ }^{19}$, war im September 1935 in der Form gesetzlich geregelt worden, daß bei der Ernennung von Beamten des höheren Dienstes - zu denen die Richter und Staatsanwälte gehörten - die Anhörung des Stellvertreters des Führers selbst erfolgen sollte. ${ }^{20}$ Daraufhin hatten sich die Gauleiter bei Hitler beklagt, daß sie seit der Verreichlichung der Justiz ihren unmittelbaren Einfluß auf die Besetzung dieser Stellen in ihrem Machtbereich zunehmend verlören. So beschwerte sich z. B. der thüringische Gauleiter Sauckel im Oktober 1935, es gelänge ihm seitdem „nicht einmal mehr, berechtigte und selbstverständliche Personalwünsche der Partei durchzusetzen“. Er würde es daher „im Interesse der Partei für dringend notwendig erachten“, daß „der Einfluß der Partei über die Gauleiter" wieder verstärkt würde. ${ }^{21}$ Die Gauleiter setzten schließlich eine besondere Abmachung zwischen dem Stellvertreter des Führers und dem Reichsjustizministerium durch, die auch bei höheren Justizbeamten eine unmittelbare Vorschaltung des zuständigen Gauleiters vorsah, während bei anderen Verwaltungen in diesen Fällen der Stellvertreter des Führers direkt angegangen wurde, der dann den Gauleiter lediglich als Informationsquelle für sich einschaltete. Das genaue Verfahren schrieb das Justizministerium in einer Allgemeinverfügung für die Justizbehörden vom 14. November 1935 vor $^{22}$ : Handelte es sich um Vorschläge für Beamte,

16c Der OLGPrās. hatte zwar zwei Tage nach seiner Weigerung die Bescheinigung mit der Eidesformel doch noch unterschrieben; jedoch konnte seine Vereidigung in Hannover durch den St.d.F. Heß mangels rechtzeitiger listenmäßiger Anmeldung nicht mehr erfolgen. Vgl. Verm. v. 28.2. und 2.3.34, von Alpers dem RJM am 2.3.34 übersandt (a.a.O.). Zur Ablösung des OLGPräs., die noch weitere Gründe hatte, vgl. Kapitel III.3.b., S. 271.

17 So der MinDir. und Hauptamtsleiter im Stab des St.d.F. Walter Sommer, Partei und Staat (DJZ 1936, Sp. 593 ff., 595)

18 Vgl. VO zur Durchf. des DBG v. 29.6.37 (RGBl. I, S.669) zu $§ 26$.

19 Vgl. Mommsen, a.a.O., S. 75 f., ferner z. B. Erl. des badischen JM v. 10.11.34, H. Weinkauff, Die deutsche Justiz und der Nationalsozialismus, Teil I, Stuttgart 1968, S.99.

$20 \mathrm{Vgl}$. den von Hitler, Heß und Frick unterzeichneten Erl. über die Beteiligung des Stellvertreters des Führers bei der Ernennung von Beamten v. 24.9.35 (RGBI. I, S. 1203).

21 Vgl. Schr. Sauckels an den Chef der RK Lammers v. 19.10.35 (Akten der RK, BA, Sign. R 22/1505).

22 Vgl. AV des RJM v. 14.11.35 (DJ 1935, S. 1656), dazu R. Freisler, Die Einheit von Partei und Staat in der Personalpolitik der Justiz. Zur Allgemeinen Verfügung des Reichsjustizministers vom 14.11.1935 (a.a.O., S. 1685 f.), ferner die nichtveröffentlichten AnOen des St.d.F. Nr. 52/36 (gez. Bormann) v. 30.3.36, die den 
deren Ernennung sich Hitler selbst vorbehalten hatte ${ }^{23}$ oder die dem Reichsjustizministerium zustand ${ }^{24}$, so hatte die höhere Justizbehörde, die für die zu besetzende Stelle zuständig war, unmittelbar beim jeweiligen Gauleiter eine Äußerung über die politische Zuverlässigkeit des Bewerbers einzuholen. In dem dafür verwendeten Formblatt wurden auch Angaben darüber erbeten, auf welche Tatsachen sich etwaige Bedenken gründeten, und ausgeführt, daß die Zuverlässigkeit des Bewerbers als gegeben angenommen werde, falls binnen drei Wochen keine gegenteilige Erklärung eingehe. ÄuBerte der Gauleiter keine Bedenken oder stimmte er zu, so war eine Abschrift seiner Auskunft zusammen mit dem Personal- und Befähigungsnachweis - der auch Angaben über frühere Partei- und Logenzugehörigkeit sowie über die Mitgliedschaft zur NSDAP und ihren Verbänden enthielt ${ }^{25}$ - an das Reichsjustizministerium einzureichen. Verneinte der Gauleiter dagegen die politische Zuverlässigkeit oder brachte er Zweifel zum Ausdruck, die sich auch durch eine Fühlungnahme mit ihm nicht ausräumen ließen, so hatte die höhere Justizbehörde „unter begründeter Darlegung ihres eigenen Standpunktes" dem Ministerium zu berichten.

Dieses Verfahren galt entsprechend auch für die Ernennungen, die den höheren Justizbehörden übertragen waren, d.h. den Präsidenten des Reichsgerichts, des Reichspatentamts, der Oberlandesgerichte sowie dem Oberreichsanwalt und den Generalstaatsanwälten, später (1936) auch dem Präsidenten und dem Reichsanwalt beim Volksgerichtshof und (1937) dem Präsidenten des Landeserbhofgerichts in Celle ${ }^{26}$ : Hatte der Gauleiter keine Bedenken, konnten sie die Ernennung vornehmen. Stellten sich seine Bedenken nach Aufklärung des Sachverhalts, die im Benehmen mit ihm zu erfolgen hatte, und nach Anhörung des Bewerbers ${ }^{27}$ als berechtigt heraus oder kamen Justizbehörden und Gauleiter zu unterschiedlichen Auffassungen, war an das Ministerium zu berichten. Freisler wünschte ausdrücklich über alle Fälle informiert zu wer-

Parteidienststellen die AV des RJM mitteilte, und Nr.1/37 v. 7.1.37 (Arch. des IfZ, Sign. Db 15.02), die bestimmte, daß von den OLGPräs. angeforderte politische Beurteilungen über höhere Justizbeamte unmittelbar abgegeben werden durften, während solche von anderen Behörden angeforderte Beurteilungen stets über den St.d.F. zu leiten waren.

23 Das waren die planmäßigen Beamten des höheren Justizdienstes von der Reichsbesoldungsgruppe A 2 c aufwärts (s. Kapitel III.4.a., S. 292 f.), vgl. Erl. des Führers und Reichskanzlers über die Ernennung und Entlassung der Reichsbeamten v. 1.2.35 (RGBl. I, S.74) nebst Ausführungs- und Übergangsbestimmungen v. 22.2.35 (RGBl. I, S. 268).

${ }^{24}$ Durch die Anordnung über die Ernennung und Entlassung der Beamten in der Reichsjustizverwaltung v. 20.3.35 (RGBl. I, S.391) i. d. F. v. 14.1.35 (RGBl. I, S. 1340) bestimmte der RJM, für welche Beamtengruppen er in dieser Hinsicht selbst die Zuständigkeit behielt und für welche Gruppen er die Zuständigkeit an die höheren Reichsjustizbehörden weiterübertrug. Vgl. dazu ferner die AV des RJM v. 30.3 .35 und v. 14.1.35 (DJ 1935, S.545 und 1797).

25 Vgl. Muster der Personal- und Befähigungsnachweisung, Anlage zur AV des RJM v. 1.4.35 (DJ 1935, S.546), die das gesamte Verfahren der Stellenbesetzung (Ausschreibung, Bewerbung usw.) im Bereich der JVerw. regelte.

$26 \mathrm{Vgl}$. Zweite Anordnung zur Änderung der Anordnung über die Ernennung und Entlassung der Beamten in der Reichsjustizverwaltung v. 12.6.36 (RGBI. I, S.489) und Anordnung über die Ernennung der Beamten der Reichsjustizverwaltung und die Beendigung des Beamtenverhältnisses v. 12.8.37 (RGBI. I, S.902). Bei der Besetzung der Stellen des RG und des VGH, deren Wirkungsbereich über einen Gau hinausging, war allerdings von vornherein der St.d.F. der entscheidende Partner für die Mitwirkung der Partei.

${ }^{27}$ Nach einer RV des RJM an die höheren RJBehörden v. 27.5.36 (Akten des RJM, Hauptbüro, Arch. des BJM) mußten dem Bewerber „die Angaben, aus denen der Gauleiter seine Bedenken herleitet, im einzelnen so mitgeteilt werden, daß ihm eine gründliche Stellungnahme zu allen gegen ihn gerichteten Vorwürfen ermöglicht" wurde. Auch in seinen Personalakten durften ungünstige Tatsachen erst dann vermerkt werden, wenn er sich vorher dazu äußern konnte (RV des RJM v. 4.9.36, a.a.O.). 
den, in denen die Gauleiter die Mitteilung von Tatsachen verweigert hatten, auf die sie ein ungünstige politische Beurteilung eines Bewerbers gründeten. ${ }^{28}$ In allen Fällen, in denen zwischen Gauleitern und Justizbehörden eine unterschiedliche politische Beurteilung des Bewerbers bestehenblieb, führte das Reichsjustizministerium auf der obersten Ebene mit dem Stellvertreter des Führers eine abschließende Klärung herbei. Solange aber das Veto der Partei nicht ausgeräumt war, durfte der Ernennungsvorschlag an Hitler nicht weitergereicht werden bzw. die Ernennung oder Beförderung des Beamten durch das Reichsjustizministerium oder die höheren Justizbehörden nicht erfolgen. Darüber hinaus hatten Ministerium und höhere Justizbehörden den zuständigen Gauleiter auch über jede Versetzung oder Entlassung von Planbeamten zu informieren. ${ }^{29}$

Diese Vorschriften vom November 1935 galten auch nach dem Inkrafttreten des Deutschen Beamtengesetzes fort. Durch den Erlaß vom 10. Juli $1937^{30}$ behielt sich Hitler weiterhin die Ernennung bzw. Beförderung ${ }^{31}$ und Versetzung in den Ruhestand aller Richter und Staatsanwälte von den Eingangsstufen (Besoldungsgruppe A 2 c 2) aufwärts ${ }^{32}$ vor, wobei die Ernennungen wie bisher der vorherigen Zustimmung des Stellvertreters des Führers bedurften. War die vorgeschaltete Prozedur bei den Gauleitern durchlaufen, übersandte daher das Reichsjustizministerium - noch vor der Vorlage bei Hitler - dem Stellvertreter des Führers einen Abdruck des formularmäßigen Ernennungsvorschlages, der außer den Angaben über Eignungsnachweis, bisherige Laufbahn, gerichtliche und parteigerichtliche Strafen, Militärverhältnis, deutschblütige Abstammung, Bejahung des Eintretens für den nationalsozialistischen Staat nach Beurteilung durch die Justiz ${ }^{33}$ auch Angaben über die Zugehörigkeit zu früheren politischen Parteien, Organisationen, Logen usw. und über die Mitgliedschaft bzw. Ämter in der NSDAP sowie ihrer Gliederungen und angeschlossenen Verbände enthielt. Erhob der Stellvertreter des Führers innerhalb von vier Wochen - 1938 präzisiert auf "dreißig Tage“ - keine Einwendungen, versah das Ministerium den Ernennungsvorschlag mit einem entsprechenden Vermerk und sandte ihn zusammen mit der vom Minister gegengezeichneten Ernennungsurkunde an den Chef der Präsidialkanzlei zum Vollzug durch Hitler. Von der Besoldungsgruppe A 1 a (Ministerialrat, Vizepräsident oder Senatspräsident beim Oberlandesgericht, Amtsgerichtspräsident,

${ }^{28}$ Vgl. Hausverfügung an sämtliche Personalref. des Ministeriums v. 23.2.38 (Akten des RJM, BA, Sign. R 22/ 4237).

29 Ab 1936 durften Justizbeamte, die Kreisleiter, Ortsgruppen- oder Stützpunktleiter der NSDAP oder mindestens Standartenführer der SA, SS oder des NSKK waren, überhaupt nur mit Zustimmung des St.d.F. versetzt werden, vgl. RdErl. des RuPRMdI v. 6.11.36, wiedergegeben in der AV des RJM v. 20.11.36 (DJ 1936, S. 1794), später $§ 35$ Deutsches BeamtenG v. 26.1.37 (RGBI.I, S. 39) nebst DurchfVO v. 29.6.37 (RGBI. I, S. 669).

30 Erl. des Führers und Reichskanzlers über die Ernennung der Beamten und die Beendigung des Beamtenverhältnisses v. 10.7.37 (RGBI. I, S. 769).

31 Als „Ernennung“ in diesem Sinne galt auch eine Beförderung, d.h. die Einweisung des Justizbeamten in eine andere Planstelle mit höherem Endgrundgehalt, wenn dabei seine bisherige Amtsbezeichnung geändert wurde. Erfolgte die Einweisung, ohne daß für den Justizbeamten eine Änderung der Amtsbezeichnung verbunden war, war nicht Hitler, sondern das RJM zuständig.

32 Zu den Eingangs- und Beförderungsstellen s. Kapitel III.4.a., S. $293 \mathrm{ff}$.

33 Das RJM hatte die OLGPrās. und GStAe durch die RV v. 12.3.36 (Akten des RJM/Hauptbüro, Arch. des BJM) angewiesen, ein eigenes Urteil über die politische Haltung des Bewerbers abzugeben und sich nicht auf die Wiedergabe des Zeugnisses der Parteistelle zu beschränken. Vgl. dazu auch Schr. des RJM an den OLGPräs. Darmstadt v. 3.8.35 (a.a.O., BA, Sign. R 22/4). 
Landgerichts[vize]präsident) an aufwärts unterschrieb Hitler jede Urkunde eigenhändig. Bei den darunterliegenden Besoldungsgruppen des höheren Justizdienstes, für die die Vorschläge in Sammellisten eingereicht wurden, verfügte Hitler die Ernennung durch eigenhändigen Vermerk auf der Liste insgesamt; die einzelnen Urkunden wurden dann aufgrund dieser Verfügung mit seiner faksimilierten Unterschrift und dem großen Reichssiegel in Trockenprägung versehen und dem Justizministerium zurückgereicht. ${ }^{34}$ Ab Januar 1938 erfolgten die Ernennungen durch Hitler nicht mehr „Im Namen des Reichs“, sondern „Im Namen des Deutschen Volkes“. ${ }^{35}$

Die vorgeschaltete Anforderung der Gauleiteräußerung bei der Ernennung von Justizbeamten des höheren Dienstes entfiel im Oktober 1940. Wenngleich das Reichsjustizministerium für sie von diesem Zeitpunkt an nur noch die Stellungnahme des Stellvertreters des Führers einholte ${ }^{36}$, blieb der Gauleiter dennoch eine zentrale Figur für die politische Beurteilung, da sich auch der Stellvertreter des Führers auf dessen Bericht stützte. Auf die Einholung einer zusätzlichen Stellungnahme des Reichsrechtsamtes der NSDAP hatte der Stellvertreter des Führers schon ab Juli 1937 verzichtet, „da die Beurteilungen der unabhängig voneinander gehörten Parteidienststellen vielfach nicht übereinstimmen“ und zu einer zeitraubenden „Klärung der häufigen Widersprüche zwangen" ${ }^{37}$ Der Gauleiter wiederum stützte sich auf die Angaben des Gaurechtsamts der NSDAP, vor allem aber auf die Beurteilung durch den zuständigen Kreisleiter, der sich die Unterlagen dafür von dem für den Wohnort des Betreffenden zuständigen Ortsgruppen- bzw. Stützpunktleiter und dem Kreisrechtsamt, dem die Führer des BNSDJ (ab 1936: NSRB) auf Kreisebene angeschlossen waren, beschaffte und auch die Außenstelle des SD - der politischen Nachrichtenstelle der Bewegung befragte. Um dabei auf örtlichen Gerüchten sowie auf persönlichen Gegensätzen oder Bevorzugungen basierende unsachliche Stellungnahmen möglichst auszuschließen, durften allein die Hoheitsträger vom Kreisleiter aufwärts politische Beurteilungen und Unbedenklichkeitserklärungen abgeben. Der Gauleiter hatte die Äußerungen der Hoheitsträger und der sonstigen Parteistellen gegeneinander abzuwägen - notfalls Widersprüche zu klären - und in einem Schlußgutachten zusammenzufassen. ${ }^{38}$

Die Einwirkung der Partei auf die Personalpolitik wurde von der Justizverwaltung als besonders mißlich empfunden, wenn ihre Absicht, bestimmte Stellen mit fachlich qualifizierten und als geeignet angesehenen Kräften zu besetzen, durch negative politische Beurteilungen verhindert wurde. Die Erfahrungen, die das Reichsjustizministerium in dieser Hinsicht schon 1934 bei der Besetzung des neugegründeten Volksgerichtshofs gemacht hatte, werden in anderem Zusammenhang geschildert. ${ }^{39} \mathrm{Zwar}$ ge-

\footnotetext{
34 Vgl. Durchführungsvorschriften über die Ernennung der Beamten und die Beendigung des Beamtenverhältnisses v. 12.7.37 (RGBl. I, S. 771) nebst Änderung v. 23.3.38 (RGBl. I, S. 323). Zu den Besoldungsgruppen s. Kapitel III.4.a., S. 293.

${ }^{35}$ Vgl. Durchführungsvorschriften v. 12.7 .37 (a.a.O.). Für die Emennungen bis zum OLGRat, OStA und Reg.Dir. durften bis 31.3 .38 die alten Urkundenvordrucke aufgebraucht werden (vgl. Hausverfügung Nadlers v. 22.12.37, Akten des RJM, BA, Sign. R 22/3791).

${ }^{36} \mathrm{Vgl}$. RV des RJM an die höheren RJBehörden v. 11.10.40 (Akten des RJM, BA, Sign. R 22/1500), die die AV des RJM v. 14.11.35 abänderte.

37 Vgl. Vertraul. RdSchr. des St.d.F. (gez. Bormann) Nr. 84/37 v. 15.7.37 (Arch. des IfZ, Sign. Db 15.02).

38 Zum Voranstehenden vgl. die AnOen des St.d.F. Nr.119/35 v. 14.6.35 (VOBl. der RL der NSDAP, S. 303), Nr. 52/36 v. 30.3 .36 und das vertraul. RdSchr. Nr.84/37 v. 15.7.37 (beide Arch. des IfZ, Sign. Db 15.02).

39 Vgl. Kapitel VIII.1.b., S. $961 \mathrm{ff}$
} 
lang es den höheren Reichsjustizbehörden - vor allem den in der Sache am meisten betroffenen Oberlandesgerichtspräsidenten - in Einzelfällen, die Bedenken des Gauleiters unter Anwendung der im November 1935 vorgeschriebenen Verhandlungen auszuräumen. ${ }^{40}$ Gürtner ermahnte die Oberlandesgerichtspräsidenten auf einer Besprechung im Januar 1938 ausdrücklich, „daß ein apodiktisches Urteil [einer Parteistelle] über die politische Zuverlässigkeit nicht zugelassen“ und keinesfalls „als unappellabel hingenommen“ werden dürfe, da in der Praxis "groteske Mißverständnisse“ vorgekommen seien: so sei einmal die Mitgliedschaft des betreffenden Richters in der SPD behauptet worden, „während er in Wirklichkeit dem Verein zur Bekämpfung der SPD. angehört habe“. In einem anderen Falle sei „eine Beurteilung auf Grund erwiesenermaßen gefälschter Briefe erfolgt" ${ }^{41}$ Wie Ministerialrat Haastert von der Personalabteilung des Justizministeriums auf einer Besprechung der Chefpräsidenten im $\mathrm{Fe}-$ bruar 1939 ausführte, wurde nach den Beobachtungen des Ministeriums von der Möglichkeit der Verhandlung mit dem Gauleiter ,in weitem Umfang nutzbringender Gebrauch gemacht, ohne daß allerdings von der Beamtenschaft das drückende Bewußtsein bereits gewichen wäre, zeitlebens in wenig durchsichtiger Form überwacht zu werden". Vor allem verlagere sich bei dem in der Partei angewandten Verfahren der Schwerpunkt der Beurteilung ,in den Bereich der untersten Parteiorgane, bei denen sich nicht selten eine zu engherzige und bisweilen auch - begünstigt durch die Heimlichkeit des Verfahrens - unsachliche Beurteilungsweise geltend" mache. ${ }^{42}$ Gerade aus diesem Umstand entwickelten sich die meisten Unzuträglichkeiten zwischen Justiz und Partei ${ }^{43}$ : Auf der einen Seite nahmen die Justizbeamten Anstoß an den Personen, auf denen die über ihr Berufsschicksal entscheidende Beurteilung letzten Endes beruhte und die ihnen nicht selten aus persönlichen Gründen übelwollten. Auf der anderen Seite waren die unteren Parteifunktionäre ungehalten darüber, daß sie ihre vertraulich abgegebene Beurteilung - von der sie nicht annahmen, daß sie den Betroffenen zur Kenntnis kam, da sie sie selbst den Betroffenen keinesfalls mitteilen durften rechtfertigen mußten, wenn der Justizbeamte nach Anhörung durch seinen Dienstvorgesetzten dagegen Einwendungen erhob. Das Problem lag darin, daß zwar die politische Beurteilung als solche dem Justizbeamten nicht bekanntgegeben werden durfte, ihm aber nachteilige Behauptungen tatsächlicher Art - z. B. regimekritische Äußerungen, Verweigerung von Spenden, Nichtanwendung des Hitlergrußes - mitgeteilt werden mußten, damit er sie gegebenenfalls widerlegen konnte. ${ }^{44}$

40 Mitteilungen darüber finden sich in den Lageberichten der OLGPräs., z. B. im Ber. des OLGPräs. Hamm v. 4.7.36 (Akten des RJM, BA, Sign. R 22/1187), des KGPräs. v. 26.10.40 (a.a.O., R 22/3356), für die späteren Jahre: des OLGPräs. Dresden v. 9.3.42 (a.a.O., R 22/3362); ferner bei H. Schütz, Justiz im „Dritten Reich“". Dokumentation aus dem Bezirk des Oberlandesgerichts Bamberg, Bamberg 1984, S. $98 \mathrm{ff}$., vgl. den dort (Anlage 11) durch Wiedergabe des Schriftwechsels in Faksimile belegten Fall aus dem Halbjahr 1937/38.

${ }^{41}$ Vgl. Tagung der OLGPräs. im RJM am 18.1.38. Ber. des OLGVizepräs. Hamburg, Letz (Arch. der Forschungsstelle f. d. Geschichte des NS in Hamburg, Sign. Best. 3308).

42 Vgl. Referat MinRat Haasterts über „Politische Beurteilung von Beamten“ auf der Besprechung der Präsidenten des RG, VGH und der OLGe im RJM am 27.2.39 (Akten des RJM, BA, Sign. R 22/4158).

43 Vgl. z. B. Lageber. des OLGPräs. Hamm v. 4.7.36 und 8.3.37 (Akten des RJM, BA, Sign. R 22/1187).

44 Vgl. voranstehende Anm. 27. Einen Anspruch auf Einsichtnahme in seine Personalakten besaß der Justizbeamte zwar grundsātzlich nicht mehr; Art. 129 Abs. 3 Satz 3 der Weimarer RV war ohne gesetzliche AnO außer Kraft gesetzt worden. Dagegen mußte er vor der Eintragung ungünstiger Tatsachen (nicht Werturteile) in seine Personalakten weiterhin gehört werden. Vgl. RdErl. des RMdI v. 12.4.34 (MBliV 1934, S.748), AV des PrJM v. 10.7.34 (DJ 1934, S. 885) und des RJM v. 18.7.35 (DJ 1935, S. 1020). 
Ein weiterer Mißstand für die Justizverwaltung ergab sich aus der Tatsache, daß das umständliche Begutachtungsverfahren die Ernennungen bzw. Beförderungen erheblich verzögerte, da die Hoheitsträger der Partei die vorgeschriebene Frist für die Abgabe ihrer Beurteilung dadurch unterliefen, daß sie ihre „vorläufige“ Nicht-Zustimmung erklärten, bis ihre Ermittlungen abgeschlossen waren. Daraus konnten sich Verzögerungen bis zu drei Monaten ergeben. ${ }^{45}$ Bei diesen Beeinträchtigungen der Personalpolitik der Justiz durch die Partei verwundert es nicht, daß das Ministerium die Justizbehörden wiederholt ermahnte, die Vorschriften über die Beteiligung der Partei auf keinen Fall ausdehnend auszulegen und nicht etwa schon bei einer Übernahme in den Vorbereitungs- oder Probedienst oder bei einem bloßen Versetzungsgesuch eine Äußerung des Gauleiters einzuholen. ${ }^{46}$ Auch der Wegfall der vorgeschalteten Gauleiteräußerung bei der Ernennung der Justizbeamten des höheren Dienstes im Oktober 1940 wurde daher von den Oberlandesgerichtspräsidenten als „eine fühlbare Beschleunigung der Ernennungsvorschläge " begrüßt. ${ }^{47}$

Die Gauleiter beschränkten ihre Einwirkung auf die Personalpolitik der Justiz jedoch nicht auf die negative Auslese der von der Justizverwaltung vorgeschlagenen Bewerber, sie wurden auch von sich aus aktiv und suchten die Oberlandesgerichtspräsidenten und Generalstaatsanwälte ihres Gaues zu veranlassen, bestimmte Bewerber zu ernennen oder zu befördern bzw. beim Justizministerium dafür vorzuschlagen. Nicht umsonst waren sie von der Parteiführung angehalten, in ihrem Machtbereich auch die Justizbeamtenschaft zu beobachten und möglichst „für sämtliche Beamte Unterlagen schon dann zu gewinnen, wenn Ernennung oder Beförderung des Einzelnen noch nicht in Frage steht" ${ }^{48}{ }^{48}$ Das zwischen Gauleitung und höherer Justizbehörde gehandhabte Verfahren informeller Einflußnahme, mündlicher Absprachen usw. ist heute ohne Einsicht in die Personalakten und Besetzungsberichte, in denen es sich auch nur teilweise niederschlug, schwer darstellbar. Es dürfte je nach der Persönlichkeit des Behördenchefs - seiner mehr oder weniger positiven Einstellung zum Nationalsozialismus, der Intensität seines Ressortdenkens und kollegialen „Korpsgeistes“ sowie seiner Standfestigkeit oder Nachgiebigkeit gegenüber dem mehr oder weniger massiv auftretenden Gauleiter - regional unterschiedlich funktioniert haben. Es dürfte auch bei den mittleren und unteren Justizbeamten, bei denen es z. B. für Altparteigenossen regelrechte Stellenvorbehalte gab ${ }^{49}$ und über deren Ernennung und Beförderung diese Be-

${ }^{45}$ Vgl. z. B. Schr. des OLGPräs. Stettin an das RJM v. 27.3.40 (Akten des RJM, BA, Sign. R 22/4502). Alljährlich mußten in der Zeit der Vorbereitung und Durchführung des Reichsparteitages die Ernennungsvorschläge an die Partei ohnehin um einen Monat, in der Weihnachts- und Neujahrszeit um drei Wochen zurückgestellt werden (vgl. die entsprechenden Schr. des St.d.F. und Hausverfügungen des RJM, a.a.O., Sign. R 22/3792).

${ }^{46} \mathrm{Vgl}$. z. B. die RVen des RJM an die Chefpräsidenten und GStAe v. 8.5.36 (Akten des RJM, BA, Sign. R 22/4553), v. 13.7.36 (a.a.O., R 22/1500) und 4.9.36 (a.a.O. Hauptbüro, Arch. des BJM).

47 Vgl. Lageber. des KGPräs. an das RJM v. 26.10 .40 (a.a.O., Sign. R 22/3356), dazu voranstehend S. 210.

${ }^{48}$ Vgl. AnO des St.d.F. Nr. 52/36 (gez. Bormann) v. 30.6.36 (Arch. des IfZ, Sign. Db 15.02).

49 Laut AnO Hitlers von 1935 mußten 10\% der verfügbaren Stellen dieser Laufbahnen mit geeigneten Pg.s besetzt werden, die der NSDAP vor dem 14.9.30 beigetreten waren (RdErl. des RuPrMdI v. 29.4.35, MBliV 1935, S. 640). Die Vorschrift wurde für das Rechnungsjahr 1936 ausgedehnt auf später beigetretene Pg.s, die aber vor diesem Datum der SA, SS oder HJ angehörten (RdErl. des RMdI v. 28.4.36, MBliV 1936, S. 585). Zur Handhabung durch die Justiz vgl. RV des RJM an die höheren Reichsjustizbehörden v. 28. 5.36 (Akten des RJM, Hauptbüro, Arch. des BJM). In den Rechnungsjahren 1935-1937 konnten 901 alte Kämpfer untergebracht werden; nach einer am 31.3.38 abgeschlossenen Sonderaktion im Strafvollzugsdienst waren es insgesamt 1600 . Vgl. Pg. Klatt, Die Unterbringung der alten Kämpfer in Beamtenstellen (Der Deutsche Justizbeamte 1938, S.837). 
hördenchefs selbst entschieden, möglicherweise für die Partei erfolgreicher gewesen sein als bei den Beamten des höheren Justizdienstes, deren fachliche Eignung auf jeden Fall vor dem Ministerium vertreten werden mußte. Als z. B. die Gauleitung Baden 1935 vom Oberlandesgerichtspräsidenten Karlsruhe die Versetzung von 27 „national unzuverlässigen“ Justizbeamten aus den Grenzbezirken forderte - ihnen wurde „Weigerung, die nationalsozialistische Presse zu abonnieren, häufiges Fehlen bei Parteiveranstaltungen, unfreundliches Verhalten bei Sammlungen, zum Teil offensichtliches Verharren in früherer politischer Gesinnung, sei es der SPD, des Zentrums oder auch reaktionärer Richtungen" vorgeworfen - und die Justizbehörde erwog, die betroffenen 16 mittleren Beamten tatsächlich zu versetzen, trat das Reichsjustizministerium dieser Absicht ,in einem scharfen Schreiben entgegen“: die Vorwürfe seien von Parteiseite im einzelnen zu konkretisieren „und im übrigen von eigenen Maßnahmen abzusehen “. ${ }^{49 a}$ Gürtner sprach vor den Oberlandesgerichtspräsidenten und Generalstaatsanwälten offen aus, daß die Beteiligung der Gauleiter zwar „formell ganz nach den Vorschriften" funktioniere, in der Sache dagegen oft anders aussehe:

„In manchen Bezirken sind dunkle Gewitterwolken wieder abgezogen, in anderen hat sich die Sonne plötzlich verdüstert. Solche Dinge kann man eben nicht mit Vorschriften ordnen. Geduld, Humor und Entgegenkommen sind hier das rechte Mittel. Wir müssen uns darüber klar bleiben, daß eine Zusammenarbeit stattfinden muß."50

Das Verhalten des Generalstaatsanwalts Frankfurt a. M., der den zuständigen Gauleiter im Dezember 1938 schon ein halbes Jahr vor dem Freiwerden der Oberstaatsanwaltsstelle beim dortigen Landgericht bat, ihm „möglichst bald etwaige dortige Wünsche bezüglich dieser Stellenbesetzung “ mitzuteilen, ging dem Justizministerium aber offensichtlich doch zu weit. Es wurde daher von Freisler im Februar 1939 auf einer Berliner Chefpräsidentenbesprechung behandelt ${ }^{51}$ : selbst nach Ansicht des nationalsozialistischen Staatssekretärs sollte die Justiz ihre Personalpolitik zwar in enger Fühlungnahme mit der Partei betreiben, aber ihre Gestaltung dabei nicht aus der Hand geben. Als die Partei bei der Neubesetzung der Oberlandesgerichtspräsidentenstelle in Bamberg 1938/39 der Justiz einen aus fachlichen Gründen abgelehnten Altparteigenossen aufzwingen wollte, stimmte auch Hitler der Auffassung Gürtners zu, daß die Partei nicht das Recht habe, von sich aus einen Bewerber zu präsentieren. ${ }^{52}$ Heß erließ im März 1939 eine entsprechende Anordnung, daß die Regelung für die Mitwirkung der Partei „bei mehreren Gauleitern zu Mißverständnissen geführt“ habe: die Gauleiter dürften nicht eigenmächtig mit Ernennungs- und Beförderungsvorschlägen an die Justiz herantreten. ${ }^{52 a}$ Das Justizministerium hatte z.B. schon 1936 den Vorschlag des Gauleiters Jordan abgelehnt, den in Ruhestand tretenden Generalstaatsanwalt von Naumburg a. S. durch den Oberstaatsanwalt beim Landgericht Celle zu ersetzen; es

\footnotetext{
${ }^{49 a}$ Vgl. Ber. des OLGPräs. Karlsruhe (gez. vom Vertreter, Senatspräs. Reinle) an das RJM, Eintr. v. 11. und 24.7.35 im Diensttageb. des RJM, Bd. 4 (BA, Sign. R 22/1059).

so Vgl. Prot. der Besprechung mit den Oberlandesgerichtspräsidenten und Generalstaatsanwälten im Reichsjustizministerium am 18. Juni 1937. Vormittag (Akten des RJM, BA, Sign. R 22/4277).

51 Vgl. Schr. des GStA Frankfurt a.M. v. 10.12.38 an den Gauleiter von Hessen-Nassau (Sprenger), Anlage 3 zum Tagesordnungspunkt „Einschaltung von Parteidienststellen vor Erstattung von Besetzungsberichten (Freisler)“ auf der Bespr. der Chefpräsidenten im RJM am 27.2.39 (Akten des RJM, BA, Sign. R 22/4158). Die Niederschr. über die Besprechung dieses Punktes liegt leider nicht vor.

52 Vgl. dazu Kapitel III.3.b., S.276f.

52a Vgl. AnO des St.d.F. Nr. 55/39 (gez. Heß) v. 9.3.39 (Arch. des IfZ, Sign. Db 15.02).
} 
folgte auch dem Wunsch des Gauleiters Sprenger nicht, den Landgerichtspräsidenten in Bonn zum Nachfolger des Oberlandesgerichtspräsidenten in Frankfurt a. M. zu machen, der Anfang 1939 die Altersgrenze erreichte. ${ }^{53}$ Diese Haltung schloß jedoch wiederum nicht aus, daß auch das Justizministerium einmal einen Landgerichtspräsidenten - der überdies der Partei nicht angehörte - „auf ausdrücklichen Wunsch des Gauleiters Bürckel für die Ernennung" bei Hitler vorschlug. ${ }^{54}$

Nach den Vorschriften des Reichsinnenministers, die auch für die Justizverwaltung galten, waren „Beamte, die sich im Kampf um die nationale Erhebung besonders verdient gemacht" hatten, bevorzugt zu befördern. Voraussetzung war allerdings, daß sie "nach Lebensalter und ihren dienstlichen Leistungen und Fähigkeiten den Anforderungen des höheren Amtes voll" entsprachen. ${ }^{55}$ Selbst Kerrl, der schon vor der Verreichlichung der Justizverwaltung in Preußen die bevorzugte Beförderung von Beamten angeordnet hatte, die vor dem 30. Januar 1933 der SA angehört hatten, vor diesem Tag Amtswalter der NSDAP gewesen waren oder eine Mitgliedsnummer unter 300000 besaßen, stellte diese Bedingung. ${ }^{56} \mathrm{Er}$ bestimmte ausdrücklich, daß die Zugehörigkeit zur NSDAP oder einer ihrer Formationen allein keine Voraussetzung für eine Beförderung sein könne. ${ }^{57}$ Wie detaillierte Regionaluntersuchungen der Personalpolitik anhand der Besetzungsberichte in den Oberlandesgerichtsbezirken Bamberg und Celle zeigen ${ }^{58}$, stellte die Justizverwaltung bei Ernennungen und Beförderungen im allgemeinen das Leistungsprinzip in den Mittelpunkt ihrer Überlegungen und benutzte die politische Beurteilung dazu, ihre sachlich motivierte Entscheidung zu untermauern, d.h. einen für geeignet angesehenen Bewerber durch sie zu unterstützen oder einen ungeeigneten abzulehnen. In einer kritischen Entschließung vom Juli 1939 stellten die Mitglieder des Reichsgruppenrates und die Gaugruppenwalter „Richter und Staatsanwälte" des NSRB daher fest, die Justizverwaltung sei bei der planmäßigen Anstellung der Richter und Staatsanwälte "geneigt, über politische Bedenken mit Rücksicht auf die angeblich oder tatsächlich vorhandene fachliche Bewährung“ hinwegzugehen. Die Folge sei, daß die Justizverwaltung mangels „weltanschaulich gefestigter" Behördenvorstände "weder mit der nötigen Schnelligkeit noch mit dem erforderlichen Nachdruck die Bereinigung wirklich schwerer Mißstände“ betreiben könne. ${ }^{59}$ Freisler wies diese Vorwürfe in einer Rundverfügung an die höheren Justiz-

53 Vgl. dazu weitere Beispiele in Kapitel III.3.b.

\$4 Vgl. Aufstellung des RJM v. 24.3.39 über die Emennung der großen LGPräs. (Besoldungsgruppe B 8) seit 1.4.35 (a.a.O., Sign. R 22/1792).

55 Vgl. RdSchr. des RMdI v. 20.3.34, den Justizbehörden durch die AV des RJM v. 23.8.35 (DJ 1935, S. 1254) zur Beachtung mitgeteilt.

56 Vgl. die AVen des PrJM v. 21.3.34 (DJ 1934, S.403) und v. 25.4.34 (a.a.O., S. 530).

${ }^{57} \mathrm{Vgl}$. AV des PrJM v. 15.6.33 (JMBl. 1933, S. 186). In einer ähnlichen RV an die bayerischen Chefpräs. und GStAe heißt es, Beförderungsgesuche mit einer derartigen Begründung seien „zur Vermeidung von Mißverständnissen den Beamten zurückzugeben“ (Akten des bayer. JM, BayerHStArch., Sign. MJu 10415).

58 Vgl. Schütz, a.a.O. (Anm. 40), S.92 ff., und U. Hamann, Das Oberlandesgericht Celle im Dritten Reich. Justizverwaltung und Personalwesen (in: Festschrift zum 275jährigen Bestehen des Oberlandesgerichts Celle, Celle 1986, S. 146 ff.), S. 200 ff. mit zahlreichen Beispielen. S. auch die Beispiele bei E. J. Thul, Das Landgericht Koblenz im nationalsozialistischen Unrechtsstaat, in: 150 Jahre Landgericht Koblenz, Boppard am Rhein 1970, S. $72 \mathrm{ff}$.

59 Vgl. Ergebnis der Beratungen während des fachlich-politischen Gemeinschaftslagers auf der Gauschulungsburg Hohenwerfen, Gau Salzburg (DR 1939, Ausg. B, S. 367 f.). Als Konsequenz wurde gefordert, daß an der Besetzung dieser Stellen „die Dienststellen des NSRB. maßgeblich beteiligt werden“ sollten. Zum Bestreben des NSRB, auf die Personalbesetzungen Einfluß zu nehmen, s. z. B. Lageber. des OLGPräs. Nürnberg an das RJM v. 3.3.41 (Akten des RJM, BA, Sign. R 22/3381). 
behörden, die allen Richtern und Staatsanwälten mitzuteilen war, in scharfer Form zurück: alle planmäßig angestellten Richter und Staatsanwälte könnten „-- auch nach der erwähnten Veröffentlichung - davon überzeugt sein, daß ihre politische Zuverlässigkeit bejaht worden" sei. ${ }^{60}$ Die Partei beanstandete jedoch selbst die Personalpolitik eines verhältnismäßig alten Parteizugehörigen wie des Oberlandesgerichtspräsidenten von Stettin, der schon 1932 der NSDAP beigetreten war, als „nicht im Einklang mit nationalsozialistischen Grundsätzen“ stehend, da er aktive Nationalsozialisten „bewußt von führenden Stellen ferngehalten und überwiegend politisch und weltanschaulich farblose Beamte gefördert und sich mit solchen auch in seiner Behörde umgeben“" habe. $^{61}$

Aber neben den Fällen, in denen leistungsstarken Bewerbern ihre frühere politische Vergangenheit von der Justizverwaltung nicht angerechnet und gegenüber den Parteistellen heruntergespielt wurde, gab es auch solche, bei denen Nationalsozialisten eindeutig bevorzugt wurden und politische Gründe gegenüber fachlicher Leistung sogar dann den Ausschlag gaben, wenn letztere mit besonderer Bewährung als Frontkämpfer gepaart war: der Bamberger Landgerichtsdirektor Ritter von Hock, dessen dienstliche Leistungen mit dem höchsten Prädikat bewertet wurden und der als Schwerkriegsbeschädigter und einziger bayerischer Richter den Bayerischen Militär-Max-Joseph-Orden trug, wurde weder 1936/37 zur Beförderung zum Landgerichtspräsidenten bzw. Senatspräsidenten noch 1939 zum Reichsgerichtsrat vorgeschlagen, weil er laut Beurteilung der Gauleitung „zu jener Kategorie von Intellektuellen [gehörte], die wohl die Erfolge des ,Dritten Reiches' anerkennen, aber an gewissen Programmpunkten der nat.-soz. Weltanschauung (Judenfrage und Katholizismus) nicht mehr mitkommen" ${ }^{62}$ Gerade die erneute Bewährung der Justizbeamten an der Front seit September 1939 suchte das Reichsjustizministerium im Sommer 1940 gegenüber der Betätigung für die NS-Bewegung als Kriterium für eine positive politische Beurteilung aufzuwerten. Am 1. August wurden die höheren Justizbehörden angewiesen, die Träger der höchsten Kriegsorden besonders zu fördern. ${ }^{63}$ Gleichzeitig versuchte Gürtner - selbst dekorierter Frontkämpfer des Ersten Weltkrieges - über das Reichsinnenministerium zu erreichen, daß die Partei den Fronteinsatz als ausreichend ansehe, um die politische Zuverlässigkeit zu bejahen. Obwohl Frick diese Forderung voll unterstützte - ein Beamter könne schließlich als Beweis für seine politische Zuverlässigkeit nicht mehr tun "als sein Leben für das deutsche Volk und den nationalsozialistischen Staat einsetzen“ -, lehnte sie der Stellvertreter des Führers ab: Zahlreiche Männer, die sich im Weltkrieg bewährt hätten und auch jetzt wieder bereitwillig der militärischen Einberufung folgten, ständen trotzdem dem Nationalsozialismus verständnislos oder sogar feindselig gegenüber. Die Erfüllung der militärischen Pflicht bedeute noch lange nicht, daß der Betreffende „an der Erreichung der politischen und sozialistischen Ziele

60 RV des RJM (i.V. Freisler) an die höheren Reichsjustizbehörden v. 11.8.39 (a.a.O., Sign. R 22/1500). Was die angeblichen Mißstände angehe, so hätten die „betroffenen Richter und Staatsanwälte pflichtgemäß gehandelt".

61 Vgl. die Beurteilung führender Juristen aus dem OLGBez. Stettin durch den Gaurechtsberater der NSDAP, LGDir. Paulick, die Thierack am 17.4.43 dem Leiter der Personalabteilung zuleitete (a.a.O., Sign. R 22 Gr. 5/485).

${ }_{62}$ Vgl. politische Beurteilung durch die Gauleitung v. 17.2.39 (Schütz, a.a.O., S.98).

63 Vgl. die folgende Anm.65. 
der nationalsozialistischen Bewegung mitzuarbeiten gewillt" sei. ${ }^{64}$ Bormann trat schließlich auch der „mißverständlichen Auffassung“ in der Verfügung des Justizministers vom August 1940 entgegen, daß der Besitz der dort genannten Kriegsauszeichnungen die Prüfung der politischen Zuverlässigkeit ersetzen könne. ${ }^{65}$ Freisler mußte die Oberlandesgerichtspräsidenten auf einer Besprechung über Bormanns Auffassung von dieser Verfügung informieren und bitten, sie bei den personalpolitischen Maßnahmen zu berücksichtigen. ${ }^{66}$

Da die Haltung des Justizbeamten zur NS-Bewegung und die Betätigung in ihren Reihen ein wesentliches Kriterium für sein „rückhaltloses Eintreten“ für den nationalsozialistischen Staat abgab, stellte sich für ihn auch aus Gründen der Berufskarriere die Frage eines Beitritts zur NSDAP. An sich war die Mitgliedschaft in der Partei weder für seine Ernennung noch für seine Beförderung formale Voraussetzung. Fricks Versuch von 1937, alle Beamten zur aktiven Tätigkeit wenigstens in einer der Gliederungen und angeschlossenen Verbände der NSDAP zu verpflichten, wurde durch die abwehrende Haltung der Ressorts vereitelt: besonders das Reichsjustizministerium lehnte diesen Vorschlag aus grundsätzlichen Erwägungen ab. ${ }^{67}$ Die Zugehörigkeit zur Partei oder einer ihrer Gliederungen wurde ab März 1939 nur den neuen Bewerbern für die Beamtenlaufbabn gesetzlich vorgeschrieben ${ }^{68}$, so daß die Referendare bei Eintritt in den Vorbereitungsdienst eine entsprechende Mitgliedschaft nachweisen mußten. Da schon die Justizausbildungsordnung vom Juli 1934 die Betätigung in einer dieser Gliederungen de facto zur Voraussetzung für die Zulassung zur ersten juristischen Staatsprüfung gemacht hatte ${ }^{69}$, war es nicht verwunderlich, daß der juristische Nachwuchs in die Gliederungen strömte: Von den 2098 Referendaren, die vom März bis Oktober 1936 das "Gemeinschaftslager Hanns Kerrl“ absolvierten, waren seit der Machtübernahme $24 \%$ der Partei, $47,8 \%$ der SA, 8,6\% der SS, 6,7\% dem NS-Kraftfahrkorps, 2,3\% der Hitler-Jugend und 2,5\% dem studentischen Arbeitsdienst beigetreten, während vor der Machtergreifung nur 8,7\% von ihnen der Partei, 2,8\% der SA und $0,5 \%$ der SS angehört hatten. ${ }^{70}$ Hinsichtlich dieser Forderung nach aktiver Betätigung in NS-Verbänden als Voraussetzung für die Erstanstellung fühlte sich Gürtner auf einer Besprechung der Oberlandesgerichtspräsidenten und Generalstaatsanwälte im Juni 1937 zu einem Hinweis verpflichtet, den ,man aber schriftlich schlecht mitteilen“ könne. In dieser Beziehung seien nämlich „einige Übertreibungen vorgekommen“, die die Nachwuchskräfte beunruhigten: zahlreiche „dienstlich sehr gut bezeugte junge Leute" seien aus diesen Gründen vor der Anstellung abqualifiziert worden. So genüge der Dienststelle des Stellvertreters des Führers z. B. eine aktive Betätigung im

${ }^{64}$ Vgl. die Schr. des RJM an den RMdI v. 8.7.40, des RMdI an den St.d.F. v. 13.9. und 2.10.40 sowie Antwortschr. des St.d.F. (gez. Bormann) v. 2.2.41 (Akten des RK, BA, Sign. R 43 II/425).

${ }^{65}$ Vgl. Schr. des St.d.F. (gez. Bormann) an den RMdI v. 21.3.41 (a.a.O.).

${ }^{66}$ Freisler verlas dabei das Schr. Bormanns (Niederschr. der Besprechung der OLGPräs. und GStAe im RJM am 31.3.42, Akten des RJM, BA, Sign. R 22/4162).

${ }^{67}$ Vgl. RdSchr. des RMdI (gez. Pfundtner) an die Obersten RBehörden v. 8.1.37 und Schr. des RJM (gez. Schlegelberger) v. 11.2.37 (Mommsen, a.a.O., S. 74).

$68 \mathrm{Vgl}$. 22 der VO über die Vorbildung und die Laufbahnen der deutschen Beamten v. 28.2.39 (RGBI. I, S.371).

${ }^{69}$ Vgl. dazu Kapitel III.4.b., S. 300.

70 Angaben durch den Kommandanten des Lagers, Hildebrandt, in: Grundsätzliches zum Dienst im Gemeinschaftslager Hanns Kerrl (DJ 1936, S. 1758). Bei diesen Zahlen ist zu berücksichtigen, daß die gleichzeitige Mitgliedschaft in der NSDAP und einer ihrer Gliederungen möglich war. 
NSRB nicht, „weil der Juristenbund die jungen Leute nicht mit der Volksgemeinschaft in Verbindung brächte“. Gürtner bat die Besprechungsteilnehmer, diese Situation „in geeigneter Weise den jungen Leuten zum Bewußtsein“ zu bringen, um sie vor Nachteilen zu bewahren. Da es aber nicht an allen Orten möglich sei, daß jeder Assessor in der Bewegung eine Funktion ausübe, habe es die für die Justizbeamten zuständige Gruppe im Beamtenbund übernommen, wenigstens die Bereitwilligkeit der jungen Nachwuchskräfte festzustellen, sich irgendwo aktiv zu beteiligen. ${ }^{71}$ Aus den dargestellten Gründen hatte Gürtner den Oberlandesgerichtspräsidenten schon vier Monate vorher einen Aufruf des „Reichsstellenleiters 10 - Reichsjustizbeamte - im Hauptamt für Beamte der Reichsleitung der NSDAP“" zur weiteren Bekanntgabe zugestellt. Wie der Aufruf hervorhebe, erläuterte Gürtner in der begleitenden Rundverfügung, genüge die bloße Mitgliedschaft in einem NS-Verband mit Zahlung der Beiträge und Besuch von Pflichtveranstaltungen nicht. Vielmehr müsse „von allen, vornehmlich den jungen Beamten“, persönliche Mitarbeit erwartet werden. Erfordere „schon die Gefolgschaftstreue, die jeder Beamte dem Führer geschworen“ habe, eine solche aktive Mitarbeit, so sei sie auch deshalb wichtig, weil sie „die Beamten mit Angehörigen aller Volksschichten in kameradschaftliche Berührung“ bringe und damit die beste Möglichkeit biete, „Anschauungsweise u. Bedürfnisse aller Volksgenossen näher kennen zu lernen $u$. ihr Vertrauen zu gewinnen“. Daraus erwachse „die Volksverbundenheit, die jeder Justizbeamte ebenso wie die Justiz in ihrer Gesamtheit zur nationalsozialistischen Rechtspflege benötigt ${ }^{\prime \prime}{ }^{72}$

Heß’ Forderung vom März 1939, daß zumindest in die Stellen der Besoldungsgruppe A 1 a - d.h. zu Ministerialräten im Ministerium, Vizepräsidenten oder Senatspräsidenten beim Oberlandesgericht, zu Landgerichtspräsidenten oder -vizepräsidenten und zu Amtsgerichtspräsidenten - sowie in Stellen höherer Besoldungsgruppen nur noch Parteigenossen befördert werden sollten, scheiterte am Widerstand der Ressorts. Sie argumentierten, daß dadurch hervorragend befähigte Beamte nicht mehr befördert werden könnten, gegenüber bereits beförderten Nicht-Parteigenossen zurückgesetzt und in die Privatwirtschaft abwandern würden. Hitler verschloß sich diesen Argumenten nicht und entschied nach Vortrag von Lammers im Juni 1939, daß „bis auf weiteres die Parteizugehörigkeit der in wichtige Stellen zu befördernden Beamten lediglich als ,erwünscht' zu bezeichnen sei“ ${ }^{73}$ Wie somit die Mitgliedschaft in der Partei keine Voraussetzung für die Beamteneigenschaft war, so zog auch der Austritt eines Justizbeamten aus der NSDAP - der dem Justizministerium vom Stellvertreter des Führers gemeldet wurde - keineswegs eine automatische Entlassung aus dem Justizdienst mit sich; es kam vielmehr auf die Motive an. War der Beamte ausgetreten,

71 Vgl. Prot. der Besprechung mit den Oberlandesgerichtspräsidenten und Generalstaatsanwälten im Reichsjustizministerium am 18. Juni 1937. Vormittag (Akten des RJM, BA, Sign. R 22/4277).

72 RV des RJM an die OLGPräs. v. 19.2.37 (Akten des RJM, BA, Sign. R 22/4470). Der Aufruf und ein Auszug aus der RV wurden am 5.3.37 in der DJ (1937, S. 364) veröffentlicht. Nach Lockerung der Mitgliedersperre 1937 erfolgten durch den Reichsbund der Deutschen Beamten und den NSRB auch auf regionaler Ebene massive Aufforderungen zum Parteieintritt (Schütz, a.a.O., Anl. 5 und 6).

73 Vgl. Aktenverm. Lammers' v. 7.6.39, abgedruckt bei Mommsen, a.a.O., S.191, dort (S. 185 ff.) auch das Fernschr. des St.d.F. an den RMdI v. 10.3.39 und die Stellungnahmen verschiedener Ressorts dazu. Immerhin waren $86 \%$ jener Beamten, die in der Zeit v. 1.4.35 bis 24.3.39 vom RJM neu in Spitzenstellungen ernannt wurden (d.h. Ministerialräte, Präsidenten, Vizepräsidenten, Senatspräsidenten und Räte beim RG bzw. VGH, Oberreichsanwälte, Reichsanwälte, OLG-Präsidenten, GStAe, LG-Präsidenten und OStAe), Parteimitglieder (vgl. Kapitel III.3.a., S. 263 f.). 
„weil er das Programm oder die politische Haltung der Partei“ ablehnte, konnte er allerdings kaum im Dienst verbleiben. Aber auch wenn dieser Grund nicht vorlag, mußte er mindestens damit rechnen, bei bevorzugten Beförderungen ausgeschlossen und bei normalen Beförderungen zurückgestellt zu werden. ${ }^{74}$

Über die Gesamtzahl der Parteigenossen unter den Justizbeamten im Reich liegen keine Angaben vor, obwohl jeder von ihnen schon bei der Durchführung des Berufsbeamtengesetzes von 1933 und auch in den späteren Jahren verpflichtet war, der vorgesetzten Dienstbehörde seine Mitgliedschaft zur Vervollständigung der Personalakte mitzuteilen. ${ }^{75}$ Vor der Machtübernahme war die Zahl der Parteimitglieder in der Justizverwaltung auf jeden Fall gering. Als preußischer Justizminister beklagte sich Kerrl 1934 vor der Presse, daß von den ca. 7000 ihm unterstellten Richtern „am 30. Januar [1933] ganze 30 aktiv der nationalsozialistischen Partei" angehörten, so daß ihm die Auswahl der neuen Behördenchefs "große Schwierigkeiten“ bereitet habe, zumal er keine Hoffnung hege, „daß das derzeitige Geschlecht der Richter ... voll in die nationalsozialistische Staatsauffassung hineinwachsen werde “. ${ }^{76}$ Ein unveröffentlichtes Rundschreiben des Stellvertreters des Führers $\mathrm{He} ß$ vom Mai 1935 bestätigt die Aussage Kerrls: Es sei „eine bekannte Tatsache, daß sich in der Reichsjustizverwaltung besonders wenig Beamte befinden, die schon vor der Machtübernahme Parteigenossen waren“, und folglich „auch heute noch bei manchen Beamten der Justizverwaltung sehr wenig Verständnis für die Grundanschauungen und Auffassungen des Nationalsozialismus vorhanden" sei. ${ }^{77}$ Nach einer Aufstellung des Reichsjustizministeriums aus dem Jahre 1936 waren von den planmäßigen Justizbeamten des höheren Dienstes einschließlich der seit Januar 1933 neu ernannten Assessoren ganze 682 vor dem 30. Januar 1933 der NSDAP oder einer ibrer Gliederungen, d.h. der SA, SS, dem NSKK, der HJ, dem NS-Dozentenbund, NS-Studentenbund und der NS-Frauenschaft ${ }^{78}$ beigetreten. Sie wurden in das vom Ministerium geführte „Braune Buch“ aufgenommen und ihre Personalakte durch Unterstreichungen des Aktenzeichens mit Braunstift gekennzeichnet. ${ }^{79}$ Von ihnen gehörten 19, darunter nur ein Ministerialdirektor und ein Ministerialrat, dem Ministerium an. Das Bestreben einiger Karrieremacher, zu diesem Kreis von Parteigenossen mit niedriger Mitgliedsnummer zu gehören, nahm teilweise groteske Formen an: es gab nachweislich zwei Staatsanwälte, deren Ehefrauen in der Weimarer Zeit der NSDAP beigetreten waren und die nach der Machtübernahme inzwischen zum Oberstaatsanwalt und Generalstaatsanwalt ernannt - beantragten, deren Mitgliedschaften auf sie umzuschreiben mit der Begründung, ihr Beitritt sei seinerzeit „unter dem Decknamen“ ihrer Ehefrauen erfolgt, um Schwierigkeiten mit der damaligen Justizverwaltung zu vermeiden. Diesen Anträgen wurde von der Reichslei-

${ }^{4}$ Vgl. RdErl. des RuPrMdI v. 27.2.36, wiedergegeben in der AV des RJM v. 3.3.36 (DJ 1936, S.350).

75 Vgl. RV des RJM v. 28.5.36 an die höheren RJBehörden (Akten des RJM, Hauptbüro, Arch. des BJM), AV des RJM v. 25.1.38 (DJ 1938, S. 130), ausgedehnt auf weitere Verbände und Organisationen durch die AV v. 23.9. 38 (a.a.O., S.1545).

76 Vgl. H. Kerrl, Die Bedeutung des Gemeinschaftslagers der Referendare in Preußen (DJ 1934, S. 237 ff., 238 ).

77 Vgl. RdSchr. des St.d.F. („Nicht zur Veröffentlichung“) Nr.99/35 v. 22.5.35 (Arch. des IfZ, Sign. Db 15.02).

78 Es handelte sich um eine Gerichtsassessorin ,alter Art“, die im Reichsbeamtenverhältnis stand. Vgl. Kapitel III.a., S. 268. Zur Übernahme von Frauen in den höheren Justizdienst allgemein vgl. Kapitel III.4.b., S.318f.

79 Vgl. die Hausverfügungen des RJM v. 13.7., 16.7., 23.9. und 5.10.36 nebst Namensverzeichnis zum Braunen Buch (Akten des RJM, BA, Sign. R 22/4237). 
tung der NSDAP tatsächlich stattgegeben, da sie „die einzigen Staatsanwälte waren, die sich in der Kampfzeit offen [!] zum Nationalsozialismus bekannt " hätten. ${ }^{\mathbf{8 0}}$

Hinsichtlich der Parteimitgliedschaft gaben die führenden Repräsentanten der Reichsjustizverwaltung nicht gerade leuchtende Vorbilder für ihr Ressort ab: Gürtner bekam erst anläßlich des vierten Jahrestages der Machtergreifung am 30. Januar 1937 - sozusagen „kollektiv“ mit den anderen Nicht-Parteigenossen im Reichskabinett von Hitler die Parteimitgliedschaft und das Goldene Ehrenzeichen der NSDAP verliehen. ${ }^{81}$ Staatssekretär Schlegelberger wurde zusammen mit Staatssekretären anderer Ressorts auf Verfügung Hitlers mit Wirkung vom 30. Januar 1938 in die Partei aufgenommen. ${ }^{82}$ Eine Ausnahme bildete hier Freisler, der der Partei seit Juli 1925 angehörte, 1933 von Kerrl zum Staatssekretär im preußischen Justizministerium ernannt und im folgenden Jahr bei der Vereinigung dieses Ministeriums mit dem Reichsjustizministerium nach dort übernommen wurde. ${ }^{83}$ Von den ab 1934 vorhandenen sechs Abteilungsleitern im Reichsjustizministerium waren zwei Parteigenossen: Crohne seit September 1932 und Nadler als „Märzgefallener" seit 1. Mai 1933; beide waren ebenfalls von Kerrl im Juni 1933 zu Ministerialdirektoren in seinem Ministerium ernannt worden und von dort ins Reichsjustizministerium gelangt. Einer der vier Nicht-Parteigenossen wurde schließlich im April 1941 Parteimitglied, der Aufnahmeantrag eines weiteren wurde 1943 nach dreijähriger „Bearbeitung“ abgelehnt, die übrigen zwei blieben bis zu ihrer Versetzung in den Ruhestand 1936 bzw. 1943 Nichtmitglieder. Da der 1936 ausscheidende Abteilungsleiter abermals durch einen Nicht-Parteigenossen ersetzt wurde, waren in der Ära Gürtner immer nur zwei der sechs Abteilungsleiter in der NSDAP. Rechnet man das Reichsjustizprüfungsamt - die spätere Abteilung VII des Ministeriums - unter Palandt hinzu, der der Partei seit 1. Mai 1933 angehörte und von Kerrl zum Präsidenten des preußischen Juristischen Landesprüfungsamts gemacht worden war, so ergibt sich das Verhältnis von 3 zu 7. ${ }^{84} \mathrm{Im}$ Dezember $1938 \mathrm{ge-}$ hörten von den 530 Beamten des Reichsjustizministeriums einschließlich des angegliederten Reichsjustizprüfungsamts 257 der NSDAP an, davon 106 als Politische Leiter. 25 waren Parteianwärter, 73 Mitglieder der SA, 10 der SS, 11 Fördernde Mitglieder der $\mathrm{SS}^{85}$, 14 Mitglieder des NS-Kraftfahrkorps (NSKK), 85 des NS-Fliegerkorps (NSFK) einschließlich seiner Fördernden Mitglieder, 508 der NS-Volkswohlfahrt und 346 des Reichs-Luftschutzbundes. Von den 91 Angestellten des Ministeriums waren 32 (davon 10 Politische Leiter), von den 65 Arbeitern (Lohnempfängern) ganze 6 in der Partei. ${ }^{86}$

80 Sie hatten an Veranstaltungen der SA teilgenommen, vgl. Schr. des RSchatzmeisters der NSDAP an die Gauleitung v. 15.2.36 (Personalunterlagen des OStA W., DC Berlin), ferner Diensttageb. des RJM, Bd.7, Eintr. v. 6.1.36 (BA, Sign. R 22/928).

81 Vgl. Schr. des Chefs der Kanzlei d. F. der NSDAP Bouhler an den Reichsschatzmeister der NSDAP Schwarz v. 9.2.37 (Personalunterlagen Gürtner, DC Berlin).

82 Vgl. Schr. des Chefs der Kanzlei d. F. der NSDAP Bouhler an den Reichsschatzmeister der NSDAP Schwarz v. 9.2.38 (Personalunterlagen Schlegelberger, DC Berlin).

83 Vgl. Personalunterlagen Freisler, DC Berlin.

84 Personalakten des RJM (BA Berlin).

$85 \mathrm{Zu}$ dieser Einrichtung s. H. Buchheim, Fördernde Mitgliedschaft bei der SS, in: Gutachten des Instituts für Zeitgeschichte, Bd. I, München 1958, S. 350 f.

86 Vgl. Aufstellung der Geschäftsstelle $\mathrm{P}^{1}$ (Beamten-Personalsachen) des RJM v. 17.12.38 (Akten des RJM, BA, Sign. R 22/21). 
Über die Parteizugehörigkeit jener Richter in 11 der damals existierenden 35 Oberlandesgerichtsbezirken, die bei Sondergerichten, Strafkammern und Amtsgerichten - also nicht in den Strafsenaten der Oberlandesgerichte - als Strafrichter tätig waren, geben Verzeichnisse vom Juni 1941 Auskunft, die das Reichsjustizministerium angefordert hatte ${ }^{87}$, um daraus Hilfsarbeiter zur Einberufung in die Strafrechtspflegeabteilung auswählen zu können. Von den aufgeführten 1790 Strafrichtern waren 1390 (= 77,65\%) Parteigenossen, 15 hatten die Mitgliedschaft beantragt, 298 gehörten der SA, 61 dem NSKK, 18 der SS, 17 der HJ, 5 dem NSFK an und 19 waren Fördernde Mitglieder der SS. Wenngleich das Datum des Parteieintritts in den Verzeichnissen nicht überall angegeben wurde, wird doch deutlich, daß das Gros der Beitritte vor der Mitgliedersperre vom 1. Mai 1933 liegt und ein weiterer Beitrittsschub nach der Lokkerung der Sperre im Jahre 1937 erfolgte. Es darf angenommen werden, daß bei den Zivilrichtern der Prozentsatz der Mitgliedschaft nicht so hoch war, da von ihnen viele gerade wegen ihrer politischen "Interesselosigkeit“ in diesen Zweig der Rechtsprechung versetzt wurden. Den einzigen Anhaltspunkt für den Anteil der Parteigenossen bei der Gesamtheit der Richter gibt Freislers Angabe aus dem Jahre 1938, daß 54,28\% aller Richter "der NSDAP oder ihren Gliederungen“ angehörten. ${ }^{88}$ Der Anteil war allerdings regional unterschiedlich. So gehörten z. B. im Oberlandesgerichtsbezirk Hamburg schon bis zum 1. Mai 1933 über die Hälfte aller Richter der Partei an, und ihre Mitgliederzahl stieg in den folgenden Jahren ${ }^{89}$; im Oberlandesgerichtsbezirk Celle waren es „etwa $90 \%$ aller Richter und Staatsanwälte“. ${ }^{90}$ Aus dem vorhandenen Zahlenmaterial wird deutlich, daß die Einflußnahme der Partei auf die Personalpolitik und damit auf das berufliche Schicksal des einzelnen in erheblichem Maße zum Eintritt der Justizbeamten in die NSDAP beitrug.

87 gl. Schnellbriefe des RJM v. 31.5.41 an den KGPräs. und die OLGPräs. in Bamberg, Celle, Dresden, Düsseldorf, Frankfurt a. M., Hamburg, Hamm, Köln, München, Nürnberg und die im Juni 1941 eingesandten Verzeichnisse (a.a.O., Sign. R 22/5046).

88 Vgl. R. Freisler, Justiz und Politik, in: 200 Jahre Dienst am Recht. Gedenkschrift aus Anlaß des 200jährigen Gründungstages des Preußischen Justizministeriums, herausg. von F. Gürtner, Berlin 1938, S. 203.

89 Vgl. AGRat H. Wogatzky, 120 Jahre oberste Hanseatische Gerichte, in: Das Hanseatische Oberlandesgericht. Gedenkschrift zu seinem 60jährigen Bestehen, herausg. von C. Rothenberger, Hamburg 1939, S.96; W. Johe, Die gleichgeschaltete Justiz. Organisation des Rechtswesens und Politisierung der Rechtsprechung 1933-1945, dargestellt am Beispiel des Oberlandesgerichtsbezirks Hamburg, Frankfurt a. M. 1967, S.71. Laut H.-K. Stein-Stegemann, In der „Rechtsabteilung“ (1992), S.173 ff. waren $194185 \%$ der Hamburger Justizjuristen Pg.s.

90 So ohne Quellenangabe OLGPräs. Frhr. v. Hodenberg, Der Aufbau der Rechtspflege nach der Niederlage von 1945, in: 250 Jahre Oberlandesgericht Celle 1711-1961, Celle 1961, S.135. Seine Angaben werden für das OLG Celle (nicht für den OLGBezirk) durch die Zahlen bestätigt, die U. Hamann, a.a.O. (voranstehende Anm. 58), S. 199, bringt. Danach waren am 6.2.41 von den 37 Richtem des OLG (ohne Hilfsrichter) 30 $(=80 \%)$ in der Partei, von den 125 weiteren Beamten, Angestellten und Arbeitern des Gerichts 66 $(=53 \%)$. Der Prozentsatz bei den Richtern erhöhte sich bis Kriegsende, da die bis dahin zu OLGRäten beförderten 6 Richter alle der NSDAP angehörten. In den vorliegenden Regionalstudien sind die Angaben entweder summarisch ohne Quellenbelege: so z.B. gleichfalls für den OLGBez. Celle H. Schmid, Erinnerungen aus den Jahren 1930 bis 1945 , a.a.O., S. 105: „der weitaus größte Teil der Richter“; J. Wolffram u. A. Klein, Recht und Rechtspflege in den Rheinlanden, Köln 1965, S.218: „die meisten Kölner Richter“; ebenso A. Klein, Hundert Jahre Akten - hundert Jahre Fakten, in: Justitia Coloniensis. Landgericht und Amtsgericht Köln erzählen ihre Geschichte(n), Köln 1981, S. 136; E. J. Thul, Das Landgericht Koblenz im nationalsozialistischen Unrechtsstaat, a.a.O. (Anm. 58), S.63: „ein Drittel aller Richter und Staatsanwälte“ (1933); oder sie geben Zahlen, lassen aber den Anteil nicht erkennen: H. Schütz, a.a.O. (Anm. 40), S.81. 
Viele Justizbeamte suchten eine Parteimitgliedschaft dadurch zu vermeiden, daß sie dem „Bund Nationalsozialistischer Deutscher Juristen“ (BNSDJ) beitraten, der im Oktober 1928 von Hans Frank gegründet worden war und einen der NSDAP angeschlossenen Verband darstellte. Dieser Bund, der zum Jahresende 1932 nur 1374 und auch im April 1933 erst 1624 Mitglieder zählte, sollte sich zu einer Massenorganisation entwickeln, nachdem ihm in der Phase der Gleichschaltung verschiedene Berufsverbände wie der Deutsche Richterbund und der Deutsche Anwaltverein zunächst korporativ beigetreten waren und bei ihrer endgültigen Auflösung ihren Angehörigen empfohlen hatten, sich dieser einzigen noch verbleibenden Standesorganisation der Juristen als Einzelmitglieder anzuschließen. Ende 1934 besaß der BNSDJ bereits 79951, Ende 1935 dann 82807 Mitglieder, davon allein 17460 in der Fachschaft „Richter und Staatsanwälte“.91 Im Mai 1939, nach dem Anschluß Österreichs, des Sudetenlandes und des Memellandes umfaßte der Bund, der im Mai 1936 in „Nationalsozialistischer Rechtswahrerbund“ (NSRB) umbenannt worden war, um die Wendung vom "Juristen“ als bloßem „Repräsentanten einer formalen Ordnung“ zum „Wahrer des Rechtes des deutschen Volkes" zu symbolisieren ${ }^{92}$, schließlich rund 104000 Mitglieder, von denen - einschließlich der Wehrmachtjuristen und Amtsanwälte - 21000 Richter und Staatsanwälte waren. Dieser "größten Rechtswahrerorganisation der Welt ${ }^{\text {‘93 }}$ gehörten die meisten Justizbeamten des höheren Dienstes an. Bei Ernennungen und Beförderungen nutzte die bloße Zugehörigkeit zum BNSDJ/NSRB allerdings wenig, da sie von der Parteiführung nicht als ausreichend angesehen wurde, um das rückhaltlose Eintreten des Justizbeamten für den nationalsozialistischen Staat zu gewährleisten.

\section{Die Personalpolitik der Landesjustizminister in Preußen und Bayern 1933/34: die Neubesetzung der leitenden Stellen in der Justizverwaltung}

In der preußischen Justiz nahm der seit 27. März 1933 kommissarisch amtierende und im April endgültig ernannte nationalsozialistische Justizminister Hanns Kerrl unverzüglich personelle Umbesetzungen vor. Zuständig für die Ernennung und Entlassung von Beamten in Preußen war Göring als Ministerpräsident, dem Hitler - dem hier die Rechte des Reichsstatthalters selbst zustanden - diese Befugnisse mit der Maßgabe

91 Mitgliederstand des BNSDJ jeweils zum Jahresende: $1928=20,1930=233,1931=701,1933=29823$, vgl. Mitgliederstandsbewegung des BNSDJ von 1928 bis 31 . Dezember 1935 (Jahrbuch des Deutschen Rechtsstandes 1936, herausg. vom Bund Nat.-Soz. Deutscher Juristen, Berlin o.J., S.7) und W. Heuber, Der Bund Nationalsozialistischer Deutscher Juristen und die Deutsche Rechtsfront (H. Frank, Nationalsozialistisches Handbuch für Recht und Gesetzgebung, München 1935, S. 1566).

92 Vgl. dazu H. Frank auf der Eröffnungskundgebung des Deutschen Juristentages am 18.5.1936 (Deutscher Juristentag 1936, 5. Reichstagung des Bundes National-Sozialistischer Deutscher Juristen, herausg. vom National-Sozialistischen Rechtswahrer-Bund, Berlin o.J., S. 27).

93 Vgl. auch zu den Zahlenangaben: Tag des Deutschen Rechts 1939, 6. Reichstagung des Nationalsozialistischen Rechtswahrerbundes, herausg. vom Nationalsozialistischen Rechtswahrerbund, Berlin-Leipzig-Wien 1939, S. 10, 425 u. 735. 
übertragen hatte, daß er sie weiterdelegieren durfte.' Entsprechend behielt sich Göring den Vollzug der von Kerrl vorgeschlagenen Personalmaßnahmen bei den Beamten des Justizministeriums vom Ministerialrat aufwärts sowie bei den Oberlandesgerichtspräsidenten und Generalstaatsanwälten vor, während der Justizminister für alle übrigen Justizbeamten zuständig wurde. ${ }^{2}$

Die Entfernung leitender Beamter aus dem Justizministerium erfolgte - oft nach vorangehender Beurlaubung ${ }^{3}$ - entweder aufgrund der Verordnung vom 26. Februar 1919, die die Versetzung der "politischen Beamten“ in den Wartestand ermöglichte oder aufgrund des $\S 5$ des Berufsbeamtengesetzes vom 7. April 1933 (BBG), das eine Versetzung in ein geringeres Amt unter Beibehaltung der bisherigen Amtsbezeichnung und Diensteinkommen zuließ. ${ }^{5}$ Aus dem Justizministerium ${ }^{6}$ wurde Staatssekretär Hölscher, der die preußische Justizverwaltung nach Papens „Preußenschlag“ vom Juli 1932 - anfänglich noch als Ministerialdirektor - kommissarisch geleitet hatte, auf den Posten des Kammergerichtspräsidenten versetzt. Gegen Hölscher, der von Parteiseite als "links stehender Zentrumsmann" angesehen wurde, war von Anfang an Sturm gelaufen worden. Während Gauleiter Kube im Februar Göring vorgeschlagen hatte, Hölscher schnellstens durch einen Breslauer Landgerichtsdirektor und Altparteigenossen seit 1928 zu ersetzen ${ }^{8}$, brachte Daluege - zu dieser Zeit Kommissar z.b.V. im preußischen Innenministerium - dafür den Berliner Oberstaatsanwalt und Parteigenossen seit 1931 Freiherrn von Steinaecker in Vorschlag.' Auch die Berliner Stelle der Beamtenabteilung in der Reichsleitung der NSDAP setzte sich Anfang März in einer Eingabe an Hitler für Steinaecker ein und betonte, daß er „als Berliner die Personalverhältnisse in dem Ministerium genau“ kenne und die nötige Energie besitze, „die vollkommen marxistisch und zentrümlich verseuchte Justizverwaltung rücksichtslos zu säubern “. ${ }^{10}$ Steinaecker selbst nahm am 10. März Hölschers Weigerung, den im Altonaer Bombenlegerprozeß vom Oktober 1930 zu sieben Jahren Zuchthaus verurteilten Herbert Volck zu begnadigen, zum Anlaß für einen Appell an Daluege, bei Göring

1 Vgl. Zweites G. zur Gleichschaltung der Länder mit dem Reich v. 7.4.33 (RGBl. I, S. 173) und Erl. über Ausfertigung und Verkündung der Landesgesetze, Beamtenernennungen und die Ausübung des Gnadenrechts in Preußen v. 25.4.33 (RGBI. I, S. 226).

2 Vgl. Sitzungsprotokoll des Preuß. Staatsministeriums v. 27.4.33 (Geh. StArch. Berlin, Sign. Rep. 90 A/41).

3 Vgl. auch zum folgenden: Säuberung der preußischen Justiz (Der Angriff v. 28.3.33, Arch. des IfZ, Sign. MZ $18 / 6$ ).

4 Vgl. $\S 3$ der VO betreffend die einstweilige Versetzung der unmittelbaren Staatsbeamten in den Ruhestand v. 26.2.1919 (Preuß. GS, S.33).

5 Das bedeutete aber auf alle Fälle den Verlust der Ministerialzulage. Zu den Paragraphen des BBG v. 7.4.33 vgl. Kapitel III.1.a., S. $137 \mathrm{f}$.

6 Die Umbesetzungen bei den preuß. Justizministerialbeamten, OLGPräs. und GStAen wurden den Personalvorschlägen Kerrls an den Preuß. Min.Präs. vom 22.5. bis 15.6.33 (Akten des PrJM, GehStArch. Berlin, Sign. Rep. 84a/12021), den Sitzungsprotokollen des Preuß. Staatsministeriums v. 5.5.33, 29.5.33, 15.6.33, 29.6.33 und 26.10.33 (GehStArch. Berlin, Sign. Rep. 90 A/41), ferner den laufenden Personalnachrichten im JMBl. bzw. der Preuß. J/DJ von 1933 entnommen.

7 Vgl. Schr. Gauleiter Kubes an Göring v. 11.2.33 (Personalunterlagen Hölscher, DC Berlin).

8 A.a.O. Der Vorgeschlagene wurde statt dessen zum GStA in Breslau bestellt, s. dazu im folgenden.

9 Vgl. Vorlage Dalueges für Göring v. 16. 2.33 zur Behandlung der Angelegenheit im preuß. Staatsministerium. Darin wurden neben Hölscher auch die Ministerialdirektoren Hartwig, Wirth und Herrmann „als schädliche Beamte im Preußischen Justiz-Ministerium" bezeichnet (a.a.O.). Zur Person Frhr. von Steinaeckers s. Das Deutschen Führerlexikon 1934/35, Berlin 1934, S. 473.

${ }^{10}$ Vgl. gemeinsames Schr. des Leiters der Fachschaft "Justiz" und des Referenten der Obersten Leitung der P.O./NS.-Beamtenabteilung, Zweigstelle Berlin, an Hitler vom 7.3.33 (Personalunterlagen von Steinaecker, DC Berlin). 
endlich die Entfernung Hölschers zu erreichen: erst wenn die Leitung des preußischen Justizministeriums in nationalsozialistische Hände komme, könne Volck geholfen werden. ${ }^{11}$ Durch die Ernennung Kerrls zum kommissarischen Justizminister nahm die Personalangelegenheit indessen einen anderen Verlauf: Nachfolger Hölschers als Staatssekretär wurde Freisler, den sich Kerrl schon Ende März als nichtplanmäßigen Beamten in der Stellung eines Ministerialdirektors ins Ministerium geholt hatte; gleichzeitig wurde Steinaecker zum Generalstaatsanwalt in Hamm ernannt.

Von den Abteilungsleitern im Justizministerium wurden die Ministerialdirektoren Hartwig und Wirth sowie Ministerialdirigent Bürger - die letzteren beiden Zentrumsmitglieder - unter Gewährung des gesetzlichen Wartegeldes einstweilen in den Ruhestand versetzt, Wirth 1934 als Oberstaatsanwalt in Dortmund wiederverwendet. Ministerialdirektor Lindemann kam als Senatspräsident zum Kammergericht. Zwei der auf drei reduzierten Abteilungen des Ministeriums ${ }^{12}$ erhielten als Leiter neue Ministerialdirektoren: der bisherige Senatspräsident beim Kammergericht Nadler - der schon aushilfsweise im Ministerium tätig war und im März um Aufnahme in die Partei nachgesucht hatte, da seine Beitrittserklärung vom Mai 1932 nicht als rechtswirksam anerkannt worden war - übernahm die Personalabteilung (Abteilung I). Der gleichfalls schon als Hilfsarbeiter ins Ministerium berufene bisherige Landgerichtsdirektor beim Landgericht III Berlin, Crohne, der 1931 ein knappes Jahr der Deutschen Volkspartei angehört hatte, im September 1932 aber der NSDAP beigetreten war, wurde Leiter der Abteilung für Strafrecht und Strafprozeß (Abteilung III). Ihm hatte Kerrl schon im April als besonderen Vertrauensbeweis das neue Sonderreferat des Ministeriums zur Bekämpfung der Korruption übertragen, das die bei jeder Staatsanwaltschaft bestellten Sonderdezernenten unmittelbar beaufsichtigte; Crohne wurde auch zur Mitarbeit an der Denkschrift des preußischen Justizministers über ein „Nationalsozialistisches Strafrecht" herangezogen. ${ }^{13}$ Die Abteilung für bürgerliches und öffentliches Recht (Abteilung II) leitete Ministerialdirektor Thiesing weiter, der dieses Amt schon seit 1925 innehatte.

Auch von den Ministerialräten und Hilfsarbeitern im höheren Dienst wurden eine Anzahl Beamter des Ministeriums abgelöst und teils anderweitig im Justizdienst verwendet, teils aufgrund des Berufsbeamtengesetzes in den Ruhestand versetzt. ${ }^{14}$ Unter

1 Vgl. Schr. von Steinaeckers an Daluege v. 10.3.33 (a.a.O.). Daluege hatte ihm ein an Göring gerichtetes Schr. Volcks, der sich schon seit August 1932 wegen Haftunfähigkeit auf freiem Fuß befand, zur Beantwortung übermittelt.

12 Neben der von Freisler geleiteten Zentralabteilung handelte es sich um folgende Abteilungen: Abt. I: Personalangelegenheiten, Organisation der Gerichte, Beamten- und Besoldungsrecht; Abt. II : bürgerliches und öffentliches Recht, Haushalts-, Kassen-, Finanzsachen einschließlich Bau- und Grundstücksverwaltung; Abt. III: Strafrecht und Strafprozeß, Strafvollzugswesen, Verwaltung der Gefangenenanstalten (vgl. H. Kerrl, Das Dritte Reich, in: 200 Jahre Dienst am Recht. Gedenkschrift aus Anlaß des 200jährigen Gründungstages des Preußischen Justizministeriums, herausg. von F. Gürtner, Berlin 1938, S. 168). Die ursprünglich vorhandenen 6 Abteilungen waren bereits aufgrund $\S 7$ der VO zur Vereinfachung und Verbilligung der Verwaltung v. 19.10.32 (Preuß. GS, S.333) auf 4 reduziert worden.

13 Zum Voranstehenden s. Personalakten Nadler und Crohne (BA); zur preuß. Denkschrift vgl. Kapitel VII.2.a., S. $760 \mathrm{ff}$.

14 Eine komplette Darstellung der Umbesetzungen im PrJM kann in diesem Zusammenhang nicht erfolgen. „Der Angriff“" v. 28.3.33 (s. Anm.3) nennt als im JM Abgelöste außer den in der Folge behandelten MinRäten Goldschmidt, Herrmann, Preuß, Corsing und Gentz noch die KGRäte Braun und Siehr, OLGRat Wittmann, LGRat Wicherts, StARat Altmeyer und OJRat Gillen. 
den Pensionierten befanden sich vier jüdische Ministerialräte, von denen zwei wegen ihrer Zugehörigkeit zur SPD und zum Republikanischen Richterbund als „national Unzuverlässige“ ( $(4 \mathrm{BBG})$ und einer aus „dienstlichen Gründen“ ( $(6 \mathrm{BBG})$ entlassen wurden $^{15}$ : keiner von ihnen konnte aufgrund des „Nichtarierparagraphen“ ( 33 BBG) entfernt werden, da sie schon vor August 1914 Beamte gewesen waren. Daß demgegenüber nichtjüdische Ministerialbeamte, die Mitglieder der SPD und gleichzeitig des Republikanischen Richterbundes waren, durchaus nicht immer entlassen, sondern lediglich in andere Ämter versetzt wurden ${ }^{16}$, beleuchtet den rigorosen Antisemitismus, von dem Kerrl und Freisler beseelt waren.

Die Neubesetzungen auf Ministerialratsebene können hier nicht behandelt werden. Von den ins Ministerium berufenen und später zu Ministerialräten beförderten Hilfsarbeitern seien nur zwei der Partei im Mai 1933 beigetretene junge Juristen erwähnt, die eine besondere Karriere machen sollten: Gerichtsassessor Joël, den Freisler offensichtlich von Kassel her kannte, sowie der gerade erst zum Staatsanwaltschaftsrat in Hamm i. W. ernannte von Haacke. Dieser übernahm die von Freisler im Juli 1933 eingerichtete Zentralstaatsanwaltschaft; Joël bearbeitete zunächst die Amnestie- und Niederschlagungsfälle und teilte sich ab November mit von Haacke in die Aufgaben der neuen Behörde. Er sollte 1937 zum Verbindungsmann zwischen Reichsjustizministerium und der SS- und Polizeiführung bestellt und zu diesem Zweck in die SS aufgenommen werden, bei der er es - besonders durch seine enge Zusammenarbeit mit der Sicherheitspolizei als Leiter des Sonderreferats für Kriegsdelikte im Kriege - bis zum SS-Obersturmbannführer bringen sollte. 1943 ernannte ihn Thierack schließlich zum Generalstaatsanwalt in Hamm. ${ }^{17}$

Das Juristische Landesprüfungsamt, das zum Geschäftsbereich des preußischen Justizministeriums gehörte, bekam 1933 ebenfalls eine neue Leitung. Zunächst wurde sein Vizepräsident, Sattelmacher, als Oberlandesgerichtspräsident nach Naumburg a.S. versetzt. Die Stelle bekam der Kasseler Oberlandesgerichtsrat Otto Palandt, der bislang politisch nicht hervorgetreten, aber Freisler von Kassel her bekannt und am 1. Mai 1933 auch der NSDAP beigetreten war. Durch die Herausgabe seines in zahlreichen Auflagen erscheinenden Kommentars zum BGB ab 1939 ist er allen Juristen zu einem Begriff geworden. ${ }^{18}$ Als auch der Präsident des Prüfungsamtes, Schwister, der Mitglied des Zentrums gewesen war und dieses Amt sechs Jahre innegehabt hatte, Ende 1933 als Oberlandesgerichtspräsident nach Düsseldorf versetzt wurde, rückte Palandt zum Präsidenten auf. Er behielt diesen Posten bei, als das Amt mit der Vereinigung des preußischen mit dem Reichsjustizministerium 1934 zum „Reichsjustizprüfungsamt" umgestaltet wurde. In der zweiten zum Geschäftsbereich des preußischen

15 Vgl. Verzeichnis der nach dem 9.11.1918 im RJM und PrJM im höheren Dienst tätig gewesenen Juden v. 3.3.38 (Akten des RJM, BA, Sign. R 22/4068) und Aufstellung MinDir. Schnellers v. 20.7.45 (Nürnbg. Dok. NG-560, Arch. des IfZ). Der jüdische MinDirig. Rosenfeld, SPD-Abgeordneter im preuß. Landtag und Mitgl. des Republikanischen Richterbundes, der schon im Dezember 1932 in den einstweiligen Ruhestand versetzt worden war, wurde nun aufgrund $\S 4$ BBG gleichfalls entlassen.

16 Als Beispiel sei MinRat Gentz erwähnt, der als AGRat in Berlin Verwendung fand, vgl. Aufstellung MinDir. Schnellers (a.a.O.) und Personalverzeichnis des höheren Justizdienstes. Bearbeitet im Büro des RJM, Berlin 1938.

17 Zur ZStAschaft s. Kapitel IV.2.b., S. 345 ff. Zu Joël vgl. Personalunterlagen im DC Berlin.

$18 \mathrm{Zu}$ Palandt s. H. Wrobel, Otto Palandt zum Gedächtnis. 1. 5. 1877-3.12.1951 (Kritische Justiz 1982, S. 1 ff.). 
Justizministeriums gehörenden Behörde, dem Landesamt für Familiengüter, behielt Ministerialdirigent Klässel die Leitung; er trat lediglich am 1. Mai 1933 der Partei bei. Von den dreizehn preußischen Oberlandesgerichtspräsidenten (einschließlich des Kammergerichtspräsidenten) wurde 1933 nur einer nicht abgelöst, obwohl auch er kein ausgesprochener Nationalsozialist war und sich der NSDAP erst im Mai 1933 anschloß: von Garßen in Celle, der dieses Amt im März 1932 nach mehr als zehnjähriger Tätigkeit im preußischen Justizministerium angetreten hatte und es bis 1945 behalten sollte. ${ }^{19}$ Der Präsident des Kammmergerichts, Tigges, den der Justizminister in der Regierung Braun, der Zentrumsminister Schmidt, im Landtag einmal als den „besten Mann der preußischen Justiz" bezeichnet hatte und der von Goebbels entsprechend als „Paradepferd“ des Weimarer „Systems“ beschimpft worden war, geriet mit Freisler in Konflikt und reichte sein Rücktrittsgesuch ein: er wurde daraufhin in den Ruhestand versetzt. ${ }^{20}$ Wie schon erwähnt, nahm Staatssekretär Hölscher seinen Platz ein. Von den übrigen 11 preußischen Oberlandesgerichtspräsidenten wurde 1 (Kuhnt in Kiel) aufgrund des Berufsbeamtengesetzes mit Ruhegehalt entlassen, 5 traten auf eigenen Antrag in den Ruhestand ${ }^{21}, 3$ wurden gemäß § 5 BBG auf die Stellen von Senatspräsidenten wegversetzt ${ }^{22}, 1$ (Jockwer in Hamm) hatte schon vor der Machtübernahme die Altersgrenze erreicht und 1 (Anz in Kassel) starb im Mai 1933. Ihre Stellen wurden mangels Altparteigenossen - nur vier der neu ernannten Oberlandesgerichtspräsidenten gehörten der NSDAP vor der Machtübernahme an - durch höhere Justizbeamte eingenommen, die entweder noch vor der Mitgliedersperre vom Mai 1933 in die Partei eingetreten waren oder auch ohne diesen Schritt als "national gesinnt" galten. ${ }^{23}$ Ihrer bisherigen Stellung nach rekrutierten sie sich aus Vize- oder Senatspräsidenten von Oberlandesgerichten, Landgerichtspräsidenten bzw. -direktoren und den erwähnten beiden Präsidenten bzw. Vizepräsidenten des preußischen Juristischen Landesprüfungsamtes.

19 Zu von Garßen vgl. U. Hamann, Das Oberlandesgericht Celle im Dritten Reich. Justizverwaltung und Personalwesen (in: Festschrift zum 275jährigen Bestehen des Oberlandesgerichts Celle, Celle 1986, S.146ff.); ferner 250 Jahre Oberlandesgericht Celle 1711-1961, Celle 1961, S. 102, 110 ff., 149f.; H. Schorn, Der Richter im Dritten Reich. Geschichte und Dokumente, Frankfurt a. M. 1959, S. 257 ff.

${ }^{20}$ Vgl. dazu den Ber. seines Neffen Dr. Hans Tigges v. 23.8.78 nebst Art. aus dem Berliner „Tempo“ v. 10.1.30, in K.-D. Godau-Schüttke, Rechtsverwalter des Reiches. Staatssekretär Dr. Curt Joël, Frankfurt a.M. 1981, S. $151 \mathrm{ff}$.

${ }^{21}$ Witte (Breslau), Schollen (Düsseldorf), Ehrhardt (Marienwerder), Werner (Naumburg a. S., aus Gesundheitsgründen) und Cormann (Stettin).

22 Hempen (Frankfurt a. M.) und Volmer (Köln) ans KG, Moehrs (Königsberg, Mitgl. der SPD und des Republikanischen Richterbundes) zum OLG Frankfurt a.M.

23 Den vier Altparteigenossen wird hier der 1934 ernannte OLGPräs. von Königsberg zugerechnet, der den 1933 bestellten, aber 1934 bereits die Altersgrenze erreichenden OLGPräs. Minde ersetzte. Nichtparteigenossen waren zum Zeitpunkt ibrer Ernennung die OLGPräs. Schwister (Düsseldorf), Schneider (Hamm), Minde (Königsberg), Sattelmacher (Naumburg) und KGPräs. Hölscher, von denen einige den Parteieintritt Jahre später nachholten. Die Parteigenossen unter den OLGPräs. werden aus Gründen des Persönlichkeitsschutzrechts namentlich nicht genannt, soweit die Informationen allein aus Personalakten stammen. Schneider war schon am 23.1.33 vor der Machtübernahme zum OLGPräs. in Hamm ernannt worden, trat aber sein Amt erst am 1.7.33 an, angeblich weil für ihn als Mitglied des deutsch-polnischen Schiedsgerichts für Oberschlesien ein Nachfolger gefunden werden mußte. Möglicherweise mußte jedoch vorher seine Haltung im Potempa-Prozeß von 1932 überprüft werden (vgl. Kapitel I.5., S.61), da er zu dieser Zeit LGPräs. in Beuthen gewesen war. Vgl. dazu L. Kewer, Aus der Geschichte des Oberlandesgerichts Hamm (in: Rechtspflege zwischen Rhein und Weser. Festschrift zum 150jährigen Bestehen des Oberlandesgerichts Hamm, Hamm 1970, S.98f.). 
Von den 14 preußischen Generalstaatsanwälten - das Landgericht Berlin I hatte einen eigenen, zusätzlichen Generalstaatsanwalt - blieben 1933 immerhin 4 im $\mathrm{Amt}^{24}, 7$ wurden zunächst in den Wartestand und anschließend in den Ruhestand versetzt ${ }^{25}, 1$ (Wiechmann beim Kammergericht) als Senatspräsident beim Kammergericht wiederverwendet, 1 (Hohmann in Hamm) erreichte die Altersgrenze und 1 (Hepke in Köln) trat auf eigenen Antrag in den Ruhestand. Bei der Ernennung ihrer Nachfolger richtete sich Kerrl nach denselben Auswahlprinzipien wie bei den Oberlandesgerichtspräsidenten: immerhin konnten hier sechs Stellen mit Altparteigenossen besetzt werden. ${ }^{26}$ Die neuen Generalstaatsanwälte waren vorher meist Oberstaatsanwälte oder Erste Staatsanwälte, einige aber auch Richter - Oberlandesgerichtsräte und Landgerichtsdirektoren bzw. -räte - gewesen.

Kerrl folgte bei den Neuernennungen häufig den Vorschlägen der Gauleiter, mit denen er teilweise regelrechte Konferenzen über diese Fragen abhielt, zu denen auch örtliche „Vertrauensleute“ der Bewegung aus dem Justizbereich hinzugezogen wurden. ${ }^{27}$ Die kommissarische Bestellung des neuen Generalstaatsanwalts in Breslau am 28. März 1933 - die am 5. Mai in eine endgültige Ernennung umgewandelt wurde und eine der ersten Amtshandlungen Kerrls als kommissarischer Justizminister war - beruhte z.B. auf dem Vorschlag Gauleiter Kubes, der Kerrl durch die Empfehlung seines Schulfreundes und Kriegskameraden aus der Verlegenheit half, da Kerrl den von Freisler für diesen Posten ausersehenen Berliner Oberstaatsanwalt nicht mochte. Da Kubes Schützling - bisher Landgerichtsdirektor - aufgrund seiner fachlichen Qualifikation kaum Chancen gehabt hätte, in diese Spitzenposition zu gelangen, handelte es sich um eine typisch politisch motivierte Beförderung: der Richter hatte bis $1928 \mathrm{der}$ Deutschnationalen Volkspartei - zeitweilig als Reichtagsabgeordneter - angehört, hatte aber 1932 seinen Weg zur NSDAP gefunden. Nicht immer sollte sich jedoch eine solche mehr auf Zufälligkeiten beruhende Auswahl auf die Dauer als glücklich erweisen: wie mancher andere von Kerrl ernannte höhere Justizbeamte erfüllte dieser Generalstaatsanwalt keineswegs „die Erwartungen ..., die in ihn als $\mathrm{Pg}$. von 1932 gesetzt worden waren“. ${ }^{28}$ Er wurde schon im Januar 1935 als Behördenleiter abgelöst

24 Wackermann (Frankfurt a. M.), Trautmann (Kassel) und Janßen (Marienwerder) waren erst im Herbst 1932 ernannt worden, Becker (Naumburg a. S.) nahm das Amt seit 1925 wahr.

${ }^{25}$ Wilde (LG Berlin), Krinke (Breslau), Bach (Celle), Wichmann (Düsseldorf), Hansen (Kiel), Danckwortt (Königsberg) und Mosler (Stettin).

${ }^{26} \mathrm{Zu}$ den sechs Alt-Pg.s wird hier der im November 1933 ernannte GStA beim KG gerechnet, der den im Mai 1933 ernannten, aber bereits im November wieder in den einstweiligen Ruhestand tretenden GStA Gutjahr ersetzte. Ein solcher Zweitwechsel ergab sich 1933 auch in Stettin, wo der neu ernannte GStA Stürenburg schon nach wenigen Wochen Selbstmord beging. Obwohl der VB, Süddt. Ausg., v. 15.12.33, in seiner Meldung behauptete, daß für den Selbstmord keine dienstlichen Gründe vorgelegen hätten, ist ein $\mathrm{Zu}$ sammenhang mit dem Terror der Stettiner SS-Führerclique nicht auszuschließen, die die dortige Polizei beherrschte und mit Unterstützung des 1934 abgesetzten Gauleiters/Oberpräs. Karpenstein das Vorgehen der Stettiner StAschaft gegen Mißhandlungen an politischen Gegnern und Juden unterdrückte (vgl. dazu Kapitel IV.2.b., S. 350). Von den neu ernannten bzw. verbleibenden GStAen waren zum Zeitpunkt ibrer Ernennung bzw. Úbernabme nicht Mitglieder der NSDAP: Wackermann (Frankfurt a. M.), Trautmann (Kassel), Janßen (Marienwerder) und Becker (Naumburg). Auf Angaben über einen eventuellen späteren Beitritt zur Partei und über die Namen der Parteigenossen unter den GStAen wird aus dem in Anm. 23 genannten Grund verzichtet.

27 So z. B. mit dem Gauleiter von Schleswig-Holstein, Lohse, am 27.6.33 in Westerland (Sylt), vgl. Kapitel III.1.a., S. $156 \mathrm{f}$.

${ }^{28}$ Vgl. Entw. eines Schr. des RJM an den St.d.F. vom März 1937 (Personalakten, BA). 
und in den einstweiligen Ruhestand versetzt, im April schließlich als Senatspräsident in Breslau wiederverwendet. ${ }^{29}$

Ein weiteres Beispiel für die „Enttäuschung“ der Partei durch eines ihrer alten Mitglieder war der neue Oberlandesgerichtspräsident von Stettin. Er war während seiner Zeit als Landgerichtsdirektor in Kassel mit dem damals dort als Rechtsanwalt tätigen Freisler bekanntgeworden und durch diesen 1932 zur NSDAP gestoßen. Bereits im Juni 1933 hatte Freisler seine Ernennung zum Landgerichtspräsidenten in Marburg erreicht, ihm aber schon einen Monat später den höheren Posten in Stettin verschafft. Obwohl der Oberlandesgerichtspräsident durchaus linientreue Züge aufwies - so entließ er z.B. im März 1936 einen Referendar aus dem Vorbereitungsdient, der sich gegen die Zurückdrängung des katholischen Einflusses aus dem öffentlichen Leben gewandt hatte ${ }^{30}$-, stellte die Partei in einer späteren Beurteilung fest, er habe es „im Laufe der Jahre in keiner Weise verstanden, ein wirklich aufrichtiges Verhältnis zur Partei zu finden“. Das mochte mit seiner Bindung an die evangelische Kirche zusammenhängen, die ihm einmal ein Verfahren vor dem Gaugericht einbrachte, weil er sich für die Beibehaltung einer Schule der Bekennenden Kirche eingesetzt haben sollte. Obwohl das Verfahren mit einem Freispruch endete, hielt die Partei „seine inneren Bindungen an die Bekenntnisfront" nicht für widerlegt. Entscheidend für seine Ablehnung durch die Partei war jedoch, daß er zu sehr Jurist blieb und in erster Linie die Interessen seines Ressorts vertrat: wie die Partei mißbilligend vermerkte, hob er in einer Dienstbesprechung vom Oktober 1942 als wichtigste Konsequenz der Übernahme des Reichsjustizministeriums durch den Nationalsozialisten Thierack hervor, daß nunmehr endlich alle Eingriffe der Partei in die Justiz unterbleiben müßten. Diese Einstellung und seine mehr auf fachliche als auf weltanschauliche Anforderungen ausgerichtete Personalpolitik ${ }^{31}$ führten zu dem negativen Fazit aus seiner zehnjährigen Tätigkeit, daß der Oberlandesgerichtspräsident „zu den in Spitzenstellen tätigen Justizbeamten gehört, von denen ein ehrliches Bekenntnis zum Nationalsozialismus nicht zu erwarten ist und die infolgedessen führungsmäßig nicht in der Lage sind, ihre Beamten auf die politischen Aufgaben einer nationalsozialistischen Rechtspflege auszurichten“. ${ }^{32}$ Er wurde 1944 von seinem Posten abgelöst, da er ,wegen Schwierigkeiten mit dem Gauleiter nicht mehr in Stettin belassen werden“ konnte. ${ }^{33}$

Während sich dẹr Stettiner Oberlandesgerichtspräsident immerhin bis 1944 halten konnte, endete das Amt einiger der von Kerrl 1933/34 Ernannten wesentlich früher. Auf den Fall des Generalstaatsanwalts in Breslau wurde schon hingewiesen. Der Generalstaatsanwalt beim Landgericht Berlin wurde im Februar 1936 abberufen und in den

29 Der GStA geriet 1934 wegen der Strafverfolgung von SS-Leuten im Zusammenhang mit der Röhm-Aktion in Konflikt mit der SS-Führung (vgl. dazu Kapitel V.1.d., S. 462 ff). Die Gründe für seine Ablösung lagen jedoch in anderen gegen ihn erhobenen Vorwürfen, obwohl ein diesbezügliches Dienststrafverfahren schon im Mai 1934 eingestellt worden war. Zum Voranstehenden vgl. außer den erwähnten Personalakten die Angaben im Urt. des OVG Berlin v. 28.1.64 (Arch. des IfZ, Sign. Gb 06.129), vor allem zur Frage der fachlichen Voraussetzungen seiner Ernennung.

${ }^{30} \mathrm{Vgl}$. Schorn, a.a.O., S. $353 \mathrm{ff}$.

31 Vgl. dazu Kapitel III.1.d., S.215.

$32 \mathrm{Vgl}$. die Beurteilung führender Juristen aus dem OLG-Bezirk Stettin durch den Gaurechtsberater der NSDAP, LGDir. Paulick, die Thierack am 17.4.43 dem Leiter der Personalabteilung zuleitete (Akten des RJM, BA, Sign. R 22 Gr. 5/485).

${ }^{33}$ Vgl. Aktenverm. v. 8.2.44 zum Schr. des RJM an den RFiM v. 25.1.44 betr. Versetzung des GStAs (Akten des RFiM, BA, Sign. R 2/23900). 
einstweiligen Ruhestand versetzt: die Gauleitung Berlin griff ihn heftig an und bezeichnete ihn als den "typische[n] Vertreter der alten Beamtenkaste“. ${ }^{34}$ Obwohl ihn auch der Gauleiter der Kurmark für eine Wiederverwendung, die als Landgerichtspräsident in Guben vorgesehen war, als ungeeignet beurteilte ${ }^{35}$, setzte ihn das Reichsjustizministerium 1937 schließlich als Senatspräsidenten beim Oberlandesgericht Breslau ein. Der von Kerrl zunächst zum Generalstaatsanwalt, 1934 zum Oberlandesgerichtspräsidenten in Königsberg ernannte Prenzlauer Oberstaatsanwalt - der sich während der mitteldeutschen Aufstände 1919/21 als politischer Dezernent der Staatsanwaltschaft Naumburg a. S. im ,nationalen“ Sinne bewährt hatte und seit 1931 Parteigenosse gewesen war - wurde 1937 auf eigenen Antrag in den Ruhestand versetzt, nachdem er mit Gauleiter Koch wegen eines Urteils des Landgerichts Lyck - das zuungunsten eines Kreisleiters ausgegangen und von Koch in öffentlicher Versammlung als „reaktionär" gebrandmarkt worden war - in einen unüberbrückbaren Konflikt geraten war. ${ }^{36}$

Selbst ein Mann wie der Erste Staatsanwalt beim Landgericht Kiel, Viktor Sauer, dessen weithin bekannte „nationale“ Gesinnung für Kerrl eine Empfehlung für die Ernennung zum Kieler Generalstaatsanwalt darstellte, sollte sich in den Augen der Partei auf diesem Posten als Versager erweisen. Sauer hatte im Dezember 1920 als Staatsanwalt vor dem Kasseler Schwurgericht Aufsehen erregt, weil er für vierzehn des Totschlags beschuldigte Angehörige der Marburger studentischen Zeitfreiwilligenorganisation, die in Thüringen aktiv gegen den Kapp-Putsch aufgetretene Arbeiter festgenommen und erschossen hatten, Freispruch beantragt hatte. Für seine Einstellung war bezeichnend, daß er nach dem Prozeß den Verteidiger der Angeklagten, den Staranwalt der Rechtsextremisten Luetgebrune, am 26. Dezember 1920 schriftlich gebeten hatte, die Unterstützung der Rechtsparteien für ihn zu mobilisieren, falls ihn der Justizminister auf die Kritik des "Judenblattes" Frankfurter Zeitung hin wegen seiner Tat maßregeln sollte. ${ }^{37}$ Dennoch fiel Sauer 1937 beim schleswig-holsteinischen Gauleiter Lohse in Ungnade, als die Kieler Staatsanwaltschaft einen Strafantrag Lohses nicht nach dessen Wünschen behandelte: Lohse erließ am 16. November 1937 an seine Parteidienststellen ein spezielles Rundschreiben „betr. Verkehr mit Generalstaatsanwalt Dr. Sauer" und forderte dessen Abberufung. Da sich auch der Reichsinnenminister dieser Forderung anschloß, trat Sauer 1938 auf eigenen Antrag in den

34 Vgl. Schr. der Gauleitung Berlin (Gaupersonalamt) an das RJM v. 14.12.36 (Diensttageb. des RJM, Bd.9, Eintr. v. 18.12.36, BA, Sign. R 22/930). Der unmittelbare Anlaß zur Versetzung des GStA in den Wartestand war jedoch ein Dienststrafverfahren mit unpolitischem Hintergrund, bei dem auch ein OStA sowie ein StARat seiner Dienststelle in den einstweiligen Ruhestand versetzt wurden und der OStA als Mitglied aus der amtlichen Strafrechtskommission ausschied, vgl. Schr. des RJM an den GStA beim KG v. 7.2.36 (Akten des RJM, BA, Sign. R 22/853).

35 Vgl. Schr. des St.d.F. an das RJM v. 9.4.37 (Diensttageb. des RJM, Bd.11, Eintr. v. 12.4.37, BA, Sign. R 22/721).

36 Vgl. Ruhestandsgesuch des OLGPräs. an das RJM v. 23.7.37 (Personalakten, BA); zu den Lycker Vorgängen vgl. Schorn, a.a.O., S.644 ff., sowie den Bericht des Königsberger Stadtrats Paul Wolff, Ohne Maske, Hamburg 1948, S. $123 \mathrm{ff}$.

37 Zum Kasseler Prozeß wegen der Tötungen von Mechterstädt vgl. ausführlich Howard N. Stern, Political Crime and Justice in the Weimar Republic, The John Hopkins University, Ph. D. Baltimore 1966, S. 185 ff., ferner H. und E. Hannover, Politische Justiz 1918-1933, Frankfurt a. M. 1966, S. 98 ff. 
Ruhestand.$^{38}$ Auch andere der 1933/34 ernannten preußischen Behördenchefs gerierten sich keineswegs als Nationalsozialisten und gerieten mit der Partei in Konflikt, ohne daß es allerdings deswegen zu ihrer Ablösung kam. ${ }^{39}$

Die von Kerrl ernannten bzw. im Amt bestätigten preußischen Oberlandesgerichtspräsidenten und Generalstaatsanwälte wurden 1935 sämtlich von der Reichsjustizverwaltung übernommen. Von diesen Oberlandesgerichtspräsidenten blieben neun bis zum Ende der Gürtner-Periode im Amt, die anderen vier schieden wegen Tod, Erreichung der Altersgrenze und Versetzung auf eigenen Antrag in ein anderes Amt bzw. in den Ruhestand aus. Von den in die Reichsjustiz übernommenen preußischen Generalstaatsanwälten blieben während dieser Periode sechs in ihren Stellungen, zwei wurden in der gleichen Position in andere Oberlandesgerichtsbezirke versetzt, einer zum Oberlandesgerichtspräsidenten und einer zum Reichsanwalt beim Volksgerichtshof ernannt, zwei wurden abgelöst und als Senatspräsidenten verwendet, einer trat auf eigenen Antrag und einer wegen Erreichung der Altersgrenze in den Ruhestand. ${ }^{40}$

Auf die Besetzung bei den über 80 preußischen Landgerichtspräsidentenstellen kann im Rahmen dieser Arbeit nicht im einzelnen eingegangen werden. Die meisten von ihnen wurden 1933/34 durch Kerrl neu besetzt; allein in der Sitzung des preußischen Ministerrats am 26. Oktober 1933 trug Kerrl 26 derartige Ernennungen vor. ${ }^{41}$ Kerrl verfolgte hier eine ähnliche Beförderungspolitik wie bei den Chefs der höheren Justizbehörden, warf allerdings die bisherigen Beförderungsgrundsätze in zahlreichen Fällen über Bord und griff auf Amtsgerichtsräte, Rechtsanwälte und Notare zurück. So wurde im Mai der Magdeburger Rechtsanwalt Richard Hoffmann zum Präsidenten des Landgerichts II in Berlin ernannt und übernahm nach der Zusammenlegung der drei Berliner Landgerichte im Juli 1933 die Leitung des neuen einheitlichen Landgerichts Berlin. ${ }^{42}$ Als Beispiel für eine Ernennung, die offensichtlich nicht aufgrund fachlicher Qualifikation, sondern aus politischen Motiven erfolgte, sei die Besetzung der Stelle des Landgerichtspräsidenten in Köln Ende 1933 durch einen Kölner Amtsgerichtsrat erwähnt, der zwar erst im Mai 1933 der NSDAP beigetreten war, nichtsdestoweniger aber von Gauleiter Grohé protegiert wurde, da er diesem seit Jahren „als national gesinnter und soldatisch empfindender Mann" bekannt war. Den Ausschlag gab dabei eine von Grohé arrangierte Begegnung des Richters mit Kerrl und Freisler in Bad Godesberg, nach der sich Kerrl zur Ernennung entschloß.$^{43}$ Daß es bei solchen Auswahlprinzipien auch zu ausgesprochenen Mißgriffen kam, bezeugt die Tatsache,

${ }^{38}$ Zum Voranstehenden vgl. Diensttageb. des RJM, Bd. 12, Eintr. v. 20.7.37, BA, Sign. R 22/678; Bd. 14, Eintr. v. 3. und 22.1.38, Sign. R 22/945; Bd.15, Eintr. v. 27.5.38, Sign. R 22/946; Bd. 16, Eintr. v. 28.6. und 29.7.38, Sign. R 22/947). Das RJM folgte dem Vorschlag Lohses nicht, als Nachfolger einen Flensburger LGDir. zu ernennen, der seit $1932 \mathrm{Pg}$. war.

39 Zum Konflikt des OLGPräs. Kassel mit der Gauleitung Kurhessen vgl. Diensttageb. des RJM, Bd. 2, Eintr. v. 15.4.35 (BA, Sign. R 22/603), auch Schorn, a.a.O., S. 251 f.; zum OLGPräs. Naumburg vgl. Schorn, a.a.O., S. 232 ff., Diensttageb. des RJM, Bd.7, Eintr. v. 2.3.36 (BA, Sign. R 22/928); zum OLGPräs. Köln vgl. J. Wolffram und A. Klein, Recht und Rechtspflege in den Rheinlanden, Köln 1969, S. 223; A. Klein, Hundert Jahre Akten - hundert Jahre Fakten (in: Justitia Coloniensis. Landgericht und Amtsgericht Köln erzählen ihre Geschichte(n)), Köln 1981, S. 154, 156.

40 Vgl. dazu Kapitel III.3.b.

41 Vgl. Sitzungsprot. des Preuß. Staatsministeriums v. 26.10.33 (GehStArch. Berlin, Sign. Rep. 90 A/41).

42 Vgl. Sitzungsprot. des Preuß. Staatsministeriums v. 5. 5.33 (a.a.O.), dort auch die Neubesetzung der LGPräs.Stellen in Potsdam und Kassel.

43 Vgl. die Angaben im Urt. des LG Bonn v. 17.6.53 gegen den früheren LGPräs. M. (Arch. des IfZ, Sign. Gb 09.02). 
daß der neu ernannte Landgerichtspräsident in Bonn schon nach wenigen Tagen wieder abgelöst werden mußte, da er sich als Alkoholiker entpuppte. ${ }^{44}$

Anders als in Preußen blieb die Besetzung der Spitzenpositionen in der bayerischen Justizverwaltung, die Hans Frank seit dem 10. März 1933 als Staatskommissar und ab 1. April als Justizminister leitete, nahezu unverändert. Zuständig für die Ernennung und Entlassung der unmittelbaren Staatsbeamten und Richter war in Bayern Reichsstatthalter Ritter von Epp, der sich die Entscheidung über die Personalmaßnahmen bei den Justizbeamten des höheren Dienstes (der bayerischen Besoldungsgruppen A 1 a mit A $2 \mathrm{f}$ ) und den Notaren selbst vorbehielt, ferner bei allen Justizbeamten über die Versetzung nach $\S 5$ Abs. 1 sowie die Ruhestandsversetzung nach $\S 5$ Abs. 2 und $\S 6$ des Berufsbeamtengesetzes vom 7. April 1933 (BBG) selbst entschied. ${ }^{45}$ Entsprechend beantragte Frank als Justizminister die gewünschten Personalmaßnahmen beim bayerischen Ministerpräsidenten Siebert als dem Vertreter des Gesamtministeriums, das gelegentlich über Franks Anträge regelrechte Kabinettsbeschlüsse faßte. ${ }^{46}$ Der Ministerpräsident übermittelte anschließend den Vorschlag dem Reichsstatthalter zur Entscheidung. Dabei kam es durchaus vor, daß Epp seine Zustimmung verweigerte: so lehnte er z.B. im September 1933 die Entlassung von drei Landgerichtsräten und zwei Amtsgerichtsräten ab, die Frank wegen ihrer früheren Mitgliedschaft bei der SPD bzw. dem Reichsbanner oder dem Republikanischen Richterbund nach § 4 BBG aus , ihren Ämtern setzen wollte. Unter ihnen befand sich auch ein jüdischer Landgerichtsrat, der offenbar als Frontkämpfer oder „Altbeamter“ nicht wegen seiner Abstammung aufgrund $\S 3$ BBG entlassen werden konnte. Frank war über diese Entscheidung Epps „außerordentlich überrascht" und gab dem Reichsstatthalter zu bedenken, es werde "der national gesinnten Beamtenschaft ... nicht zugemutet werden können, mit solchen Persönlichkeiten zusammenzuarbeiten “. ${ }^{47}$ Epp lehnte auch die Beförderung nationalsozialistischer „Überflieger“, die Rang- und Gehaltsklassen überspringen sollten, als mit den Grundsätzen einer geordneten Beamtenpolitik unvereinbar ab: er wies den Ministerpräsidenten an, Frank und die anderen Staatsminister davon zu unterrichten und Personalanträge, die diesen Grundsätzen widersprachen, nicht mehr an ihn weiterzuleiten. ${ }^{48}$

Mußte Frank aus Gründen der Zuständigkeit gelegentlich gegenteilige Entscheidungen des Reichsstatthalters hinnehmen, so reagierte er äußerst empfindlich, wenn seine Personalentscheidungen von seiten der Partei angefochten wurden: Als Strei-

${ }^{44}$ Vgl. A. Klein, Die rheinische Justiz und der rechtsstaatliche Gedanke in Deutschland - Zur Geschichte des Oberlandesgerichtsbezirks Köln und der Gerichtsbarkeit in seinem Bezirk (in: Recht und Rechtspflege in den Rheinlanden, herausg. von J. Wolffram und A. Klein, Köln 1969), S. 223 f. Dort auch über andere Neubesetzungen im OLGBez. Köln.

45 Vgl. Zweites G. zur Gleichschaltung der Länder mit dem Reich v. 7.4.33 (RGBI. I, S. 173) und die Erl. des RStH v. 24.6.33, Nr. 2751, v. 31.8.33, Nr. 4009, und v. 27.12.33, Nr. 8509 (Akten des bayer. JM, BayerHStArch., Sign. MJu 10415). Der bayer. Staatsreg. verblieben die Personalmaßnahmen für die Beamten der bayer. Besoldungsgruppen A $2 \mathrm{~g}$ mit A 12. Zu den Paragraphen des BBG v. 7.4.33 s. Kapitel III.1.a., S. $137 \mathrm{f}$.

46 So z. B. in der Sitzung v. 10.10.33 über Franks Antrag auf Ernennung der neuen OLGPräs. von Bamberg und Nürnberg (Auszug aus der Sitzungsniederschr., Bayer. HStArch., Sign. Reichsstatthalter 220).

47 Vgl. Antwortschr. Franks an Epp v. 26.9.33 auf dessen Schr. v. 21.9.33 (a.a.O., Sign. Reichsstatthalter 219). Epp verweigerte gelegentlich auch Versetzungen nach $\S 5$ BBG, vgl. sein Schr. an MinPräs. Siebert v. 8. 10.34 (a.a.O., Reichsstatthalter 221).

48 Vgl. Erl. des RStH v. Epp an den bayer. MinPräs. v. 24.10.34 (Akten des bayer. JM, a.a.O.). 
chers „Stürmer“ die „verantwortlichen Herren“ der Justizverwaltung angriff, weil sie einen angeblich „roten“ Beamten des Amtsgerichts Nürnberg im Dienst gelassen hatten, wies Frank in einem scharfen Schreiben an den fränkischen Gauleiter den Vorwurf eines Versäumnisses zurück, da der Betreffende von den allein dafür zuständigen Justizbehörden pflichtgemäß überprüft worden sei. Er forderte eine Berichtigung in Streichers Blatt und künftig seine persönliche Einschaltung vor der Veröffentlichung einer Kritik an seiner Personalpolitik. ${ }^{49}$ Anders als Kerrl in Preußen scheint Frank mit den sechs Gauleitern Bayerns in Fragen der Personalpolitik keinen engen Kontakt gepflogen zu haben, sondern sich auf dem Gebiet der Justiz selbst als Repräsentant Hitlers - als "sein eigener Gauleiter" - angesehen zu haben.

Der Grund dafür, daß Frank die obersten Spitzen der bayerischen Justizverwaltung kaum umzubesetzen brauchte, lag darin, daß ihr Beamtenkörper trotz der Revolutionswirren nach dem Ende des Ersten Weltkrieges auch unter den beiden sozialdemokratischen Justizministern Timm und Endres vom November 1918 bis Mai 1919 im „nationalen“ Sinne homogen geblieben war und während der langen und kontinuierlichen Ministerzeit Gürtners seit August 1922 erst recht blieb. Wie Frank auf seiner ersten Besprechung mit den bayerischen Chefpräsidenten und Generalstaatsanwälten am 31. März 1933 ausführte, war es vor allem Gürtner zu verdanken, daß es in Bayern „Zustände, wie sie sich in Preußen eingeschlichen hatten“, nicht gab, sonst "wäre vielleicht manches in den ersten Tagen der nationalsozialistischen Revolution auch personalpolitisch hier sogleich anders verlaufen".$^{50}$ Frank behielt daher auch den von Gürtner im Januar 1932 ernannten Staatsrat ${ }^{51}$ Spangenberger bei, der seit Gürtners Berufung zum Reichsjustizminister im Juni jenes Jahres das bayerische Justizministerium im Auftrage des Kabinetts Held geleitet hatte, das als geschäftsführende Regierung keinen neuen Minister hatte ernennen können. Spangenberger stand auch unter Frank im Ministerium weiterhin den Abteilungen A (Allgemeine Verwaltungsabteilung) und B (Bürgerliches Recht) vor. Er war mit Ausnahme einer dreijährigen Kriegsdienstzeit seit 1910 im bayerischen Justizministerium tätig gewesen, 1923 Ministerialdirektor geworden und vom Herbst 1926 bis zu seiner Berufung zum Staatsrat Oberlandesgerichtspräsident in Bamberg gewesen. Als „unpolitischer“ Fachmann mit national-konservativer Einstellung sollte er bis zu seiner Pensionierung am 1. Mai 1935 im Amt bleiben und auch die Ministerschaft Franks überdauern: in der letzten Phase der „Verreichlichung“ der bayerischen Justizverwaltung leitete er als Beauftragter des Reichsjustizministeriums noch dessen „Abteilung Bayern“.52 Auch Ministerialdirektor Degen - seit 1914 im Ministerium und gleichfalls kein Mitglied der

49 Vgl. Schr. Franks an Streicher v. 16.9.33 (a.a.O., Sign. MJu 12004).

so Vgl. Niederschr. über die Bespr. Franks mit dem Prās. des Obersten LandesG, den OLGPräs. und den GStAen am 31.3 .33 (a.a.O., Sign. MJu 16834).

51 Nach der bayerischen Verfassung v. 14.8.1919 war der auf Vorschlag des Ministers vom Gesamtministerium ohne Mitwirkung des Landtags ernannte „Staatsrat" der beamtete Stellvertreter des Ministers. Die Vertretung konnte jedoch auch einem „Staatssekretär“ übertragen werden, der auf Vorschlag des Ministers im Einverständnis mit dem Landtag durch das Gesamtministerium ernannt wurde und als politischer Stellvertreter nur dem Landtag gegenüber verantwortlich war. Von dieser zweiten Vertretungsmöglichkeit machte das bayer. JM nie Gebrauch. Vgl. dazu H. Rumschöttl, Das Bayerische Staatsministerium der Justiz 1799-1966 (in: Festschrift für Karl Bengl, München 1984, S.354f.).

52 Vgl. Spangenbergers damalige, für das bayer. JM niedergeschriebene Selbstbiographie, die auch Einblick in seine politische Einstellung vermittelt (Akten des bayer. JM, BayerHStArch., Sign. MJu 16934). Zur RJM/ Abteilung Bayern s. Kapitel II.5., S.112f. 
NSDAP -, der die Abteilung C (Strafrecht und öffentliches Recht) leitete und die Geschäfte des "Generalsekretärs" führte, d.h. im Ministerium den Geschäftsgang und den Dienst überwachte, arbeitete unter Frank weiter, bis ihm im Februar 1934 auf sein Ansuchen die Stelle eines Senatspräsidenten am Bayerischen Obersten Landesgericht übertragen wurde. ${ }^{53}$ Ebenso blieb Gürtners Schwager, Ministerialrat Dürr, der dem Ministerium seit 1919 als langjähriger Strafrechtsreferent angehörte und für die Dauer seiner Verwendung als stellvertretender bayerischer Bevollmächtigter zum Reichsrat die Amtsbezeichnung „Ministerialdirektor“ führte, weiter im Amt, obwohl er bei der Partei nicht beliebt war und erst Jahre später Parteimitglied wurde. Nach Auflösung des Reichsrats wurde er im April 1934 auch etatmäßig zum Ministerialdirektor ernannt, um gegenüber der Öffentlichkeit seine „Degradierung“ zum Ministerialrat zu vermeiden $^{54}$, zumal er die Vertretung der bayerischen Justizverwaltung in Berlin - u.a. in der Strafrechtskommission und der „kleinen“ Strafprozeßkommission - übernahm.

Von den übrigen sieben Ministerialräten wurden zwei - Meukel und Döbig - bis zur Auflösung des bayerischen Justizministeriums in ihren Stellungen weiterverwendet, der bisherige Personalreferent für höhere Beamte, Siegel, von Frank zum Oberlandesgerichtspräsidenten in Zweibrücken ernannt, zwei - Sauerländer als Rat und Widmann als Senatspräsident - ans Bayerische Oberste Landesgericht und zwei weitere - Ehard und Cammerer - als Senatspräsidenten ans Oberlandesgericht München versetzt. $^{55}$ In die Ministerialratsstellen, die durch diese Versetzungen und die erwähnte Beförderung Dürrs zum Ministerialdirektor frei wurden, ließ Frank Justizbeamte aufrücken, die außer einem - Oberregierungsrat Drescher - erst von ihm ins Ministerium geholt worden waren: den vormaligen Oberstaatsanwalt am Oberlandesgericht Zweibrücken, Kallenbach, den Münchener Oberamtsrichter Sprick, von dem noch die Rede sein wird, den Rat am Oberlandesgericht München Gipser und den Rat am Landgericht München I, Castner, die sämtlich von Frank inzwischen schon zu Oberregierungsräten ernannt worden waren. Die sechste Ministerialratsstelle besetzte Frank im August 1934 mit dem Landgerichtspräsidenten von Schweinfurt, Altparteigenossen und SA-Sturmführer Karl Engert, den er im April ins Ministerium abgeordnet hatte, um ihm das Personalreferat für den höheren Justizdienst zu übertragen. Engert, der Hitler seit 1920 persönlich kannte, der Partei erstmals schon 1921 und nach ihrer Neugründung zum zweiten Male im März 1927 beigetreten war, hatte bereits im Jahre 1924 das Augenmerk der Justizverwaltung auf sich gezogen, als er als Oberamtsrichter in Scheinfeld in seinem Amtsbezirk 700 Unterschriften für die Freilassung Hitlers aus der Haftanstalt Landsberg gesammelt und der bayerischen Regierung zugeleitet hatte. Mit seiner Ernennung zum Ministerialrat im Justizministerium sollte sich

53 Vgl. Personalakte Degen (a.a.O., Sign. MJu 19138). Seine Geschäfte als Abteilungsleiter und „Generalsekretär“" übernahm MinRat Meukel, der am 1.4.34 zum „Ministerialrat als Abteilungsleiter“ befördert wurde.

s4 Vgl. Beförderungsantrag Franks an v. Epp v. 6.3.34 (Akten des RStHs, a.a.O., Sign. Reichsstatthalter 221), ferner Personalakte Dr. Alfred Dürr (BA); da seine Haltung zum NS während der Weimarer Zeit von Parteikreisen als ablehnend angesehen wurde, wurde seinem Aufnahmeantrag in die NSDAP von 1935 erst am 1.5.37 entsprochen.

5s Bei Hans Ehard handelt es sich um den Vertreter des I. Staatsanwalts im Hitler-Prozeß von 1924 und den dritten bayerischen Ministerpräsidenten nach dem Zweiten Weltkrieg. Auch zu den folgenden Umbesetzungen 1933/34 durch Frank vgl. außer den im einzelnen genannten Quellen die Akten des Reichsstatthalters, Sign. 219-221 und 600, sowie die Akten des bayer. JM, Sign. 10415 und 16824-16826 (Bayer. HStArch.). 
ihm im nationalsozialistischen Staat eine besondere Karriere öffnen: er wurde 1936 Vizepräsident des Volksgerichtshofs und wechselte 1942 unter Thierack ins Reichsjustizministerium über, wo er als Ministerialdirektor die Abteilung XV leitete, die die mit Himmler vereinbarte Überstellung der ,asozialen“ Strafgefangenen an die Polizei besorgte. ${ }^{56}$

Daß die berufliche Förderung für den jeweiligen Protegé auch eine beträchtliche Abhängigkeit von der Willkür Franks bedeuten konnte, sollte der erwähnte Ministerialrat Gustav Sprick erfahren. Als Münchner Oberamtsrichter war er nach seinem Parteieintritt im März 1933 von Frank im April ins Ministerium abgeordnet und im Mai unter Fortverwendung im Ministerium zum Direktor und Abteilungsvorstand am Amtsgericht München befördert worden. Im Juli zum Oberregierungsrat ernannt, bekam er das Personalreferat für die höheren Justizbeamten und das Etatreferat übertragen und wurde bereits im September Ministerialrat. Sprick, den Frank in einem Schreiben an den Reichsstatthalter vom Juli 1933 als den „Vertrauensmann der Partei“ im Personalreferat bezeichnet hatte ${ }^{57}$, sollte ein halbes Jahr später in Ungnade fallen, als er die ihm von Frank eingeschärfte Maxime, daß ehemalige SPD-Angehörige in der Justizbeamtenschaft nichts mehr zu suchen hätten, auf einen Günstling Franks anwenden wollte. Frank hatte sich einen Regierungsrat von der bayerischen Landesanstalt für Kurzschrift als Protokollanten und Sekretär für vertrauliche Vorgänge ins Haus geholt und wünschte dessen Übernahme in die Justizverwaltung. Als Sprick aus den Personalakten ersah, daß der ehemalige Landtagsstenograf bis zum 8. März 1933 Mitglied der SPD gewesen und Frank diese Tatsache auch bekannt war, setzte er sich mit Franks Adjutanten im Ministerium Bühler in Verbindung, um mögliche Gefahren abzuwenden, die daraus sowohl der Partei wie auch Frank selbst durch Angriffe aus den eigenen Reihen erwachsen konnten. Beide kamen überein, den Reichsschatzmeister der NSDAP Schwarz zu bitten, seinem Freunde Frank ins Gewissen zu reden. Als Sprick sich Frank gegenüber weigerte, die Übernahme des Regierungsrats in den Justizdienst zu befürworten und die Sache gegebenenfalls ,an dritter Stelle“ vorzutragen drohte, kam es in einer Besprechung am 13. Januar 1934 zwischen beiden zum Bruch: Frank behauptete, der Regierungsrat sei im Auftrage führender Parteimitglieder als Spion bei der SPD gewesen, was der herbeigerufene Regierungsrat jedoch strikt verneinte. Als Sprick - wie mit Schwarz abgesprochen - seine Mitteilung an den Reichsschatzmeister bestritt, der ebenfalls herbeizitierte Bühler diese Tatsache aber zugab, beschuldigte der verärgerte Frank den Personalreferenten der Lüge und des Vertrauensbruchs und sprach dessen sofortige Beurlaubung und Entfernung aus dem Justizministerium aus. In der personalpolitischen Sachfrage erklärte Frank den Referenten mit einer Feststellung für „unzuständig“, die an das Göring zugesprochene Wort "Wer Jude ist, bestimme ich“ erinnert: „Was Nationalsozialismus ist oder nicht, entscheide ich nach dem Willen des Führers seit Jahren schon auf dem Gebiete des Rechts. ${ }^{\text {“5 } 8}$ Der Regierungsrat blieb im Ministerium und wurde nach einigen Monaten

56 Engert war schon seit 1939 SS-Oberführer im Stab des RFSS, nachdem er 1935 von der SA zur SS übergetreten war (vgl. Personalunterlagen Engert, DC Berlin).

$57 \mathrm{Vgl}$. Schr. Franks an RStH v. Epp v. 2.7.33 (Akten des RStH, Bayer. HStArch., Sign. Reichsstatthalter 219).

$58 \mathrm{Vgl}$. Schr. Franks an Sprick v. 16.1.34. Die geschilderten Vorgänge sind enthalten in den Schr. Spricks an Frank v. 14. und 19.1.34 sowie an den RStH v. 24.1.34 mit einer undatierten Aufz. als Anlage (sämtlich a.a.O., Sign. Reichsstatthalter 220). 
zum Landgerichtsrat befördert - Frank benutzte ihn später auch als Generalgouverneur noch als vertraulichen Protokollführer -, während Sprick am 1. Februar 1934 als Oberstaatsanwalt an die Staatsanwaltschaft des Bayerischen Obersten Landesgerichts versetzt wurde. Seine Ministerialratsstelle wurde mit Oberregierungsrat Resch - seit 1928 im Ministerium und seit 1931 in diesem Rang - besetzt, das Personalreferat hingegen von Staatsrat Spangenberger übernommen, der es ,in unmittelbarem Benehmen" mit Frank führte" ${ }^{59}$, bis mit der Berufung Engerts im April 1934 wieder ein geeigneter Mann für diese Funktion ins Haus kam.

Schon im März 1933 hatte Frank ,aus Anlaß der nationalen Revolution“ einige seiner Vertrauten aus dem Parteimilieu ins Ministerium berufen, um sie zur persönlichen Dienstleistung bei sich zu verwenden: so seinen Stellvertreter bei der Leitung der Rechtsabteilung in der Reichsleitung der NSDAP, den Parteigenossen seit 1926 Ludwig Fischer. Da Fischer nach seinem Referendarexamen zwar promoviert, aber nie die zweite juristische Staatsprüfung abgelegt hatte, konnte er auf seine Übernahme in den höheren Justizdienst nicht hoffen, solange Sprick das Personalreferat innehatte, da ihn dieser als einen „verbummelten Referendar" und „Versager auf der ganzen Linie“ beurteilte.$^{60}$ Deshalb - und weil ihm Sprick einige Personalwünsche zugunsten guter Bekannter nicht erfüllt hatte - war Fischer an der Ablösung Spricks beteiligt gewesen, indem er sich bei Frank beschwerte, daß „maßgebliche Herren der Partei“ mit dessen , Personalpolitik unzufrieden seien. ${ }^{61}$

Erst nach der Entfernung Spricks konnte Frank im Juni 1934 die Ernennung Fischers zum Regierungsrat mit dem Argument durchsetzen, Fischer habe sich der Staatsprüfung „bis jetzt mit Rücksicht auf seine Arbeit im Dienste der Bewegung nicht unterziehen" können. Er hatte dabei allerdings Ministerpräsident Siebert versichern müssen, daß dem Staat aus dieser Ernennung keine finanziellen Verpflichtungen erwuchsen. Fischer wurde deshalb zur Dienstleistung in seinem Parteiamt ohne Bezüge beurlaubt und bereits sechzehn Tage nach seiner Ernennung aus dem Staatsdienst wieder entlassen, durfte aber den Titel unter Verzicht auf alle finanziellen Ansprüche weiterführen: offensichtlich war es Frank nur darum gegangen, Fischer für sein weiteres Wirken in der Partei den Regierungsratstitel zu beschaffen. ${ }^{62}$

$\mathrm{Zu}$ den Männern, die Frank zu sich ins Justizministerium berief, gehörte auch der Leiter der rechtspolitischen Abteilung in der Rechtsabteilung der Reichsleitung der NSDAP und stellvertretende Geschäftsführer des BNSDJ, Rechtsanwalt und Altparteigenosse seit 1921 Rudolf Schraut, den er im Mai 1933 zum Regierungsrat und im Juli zum Oberregierungsrat ernannte. Schraut wurde für die Führung der Geschäfte Franks in dessen Eigenschaft als Reichsjustizkommissar beurlaubt und nahm auch die Stellvertretung Franks in dieser Funktion wahr; so vertrat er Frank z. B. in der amtlichen Strafrechtskommission des Reichsjustizministeriums. ${ }^{63}$ Als Schraut Anfang Oktober 1934 auf sein Ansuchen aus dem bayerischen Staatsdienst entlassen wurde - er

\footnotetext{
59 Vgl. Franks Ber. an den bayer. MinPräs. v. 6.3.34 (Akten des bayer. JM, Bayer. HStArch., Sign. MJu 10415).

60 Vgl. Schr. Spricks an Frank v. 19.1.34 und seine Aufz. für den RStH o. D. (a.a.O.).

61 Diese Mitteilung Fischers wurde von Frank in seinem Schr. an Sprick v. 16.1.34 (a.a.O.) als ein wesentlicher Entlassungsgrund angegeben.

${ }^{62}$ Vgl. dazu Schr. Franks an RStH v. Epp v. 18.4.34 nebst Personalvorschlag sowie seine Korrespondenz mit MinPräs. Siebert vom April 1934 (a.a.O., Sign. Reichsstatthalter 221).

63 Vgl. dazu Kapitel VII.2.a., S. 760.
} 
trat in eine öffentlich-rechtliche Körperschaft der gewerblichen Wirtschaft über -, übertrug Frank die Geschäfte des Reichsjustizkommissars seinem persönlichen Adjutanten Josef Bühler. Auch dem im März 1933 als Assessor ins Ministerium berufenen Bühler hatte Frank zu raschem Aufstieg verholfen: er war im April - gleichzeitig mit seinem Parteieintritt - zum Amtsanwalt, im Juli zum Amtsgerichtsrat und im Juli 1934 zum I. Staatsanwalt befördert worden. Im Ministerium nahm er insofern eine zentrale Stellung ein, als er alle Entwürfe von politischer, gesetzgeberischer und organisatorischer Bedeutung, die Frank zur Unterzeichnung vorzulegen waren, „vom Parteistandpunkt aus zu prüfen" und etwaige politische Bedenken vorzutragen hatte. ${ }^{64}$ Als Frank im Dezember 1934 seine Ernennung zum Oberregierungsrat beantragte, weil es „das Ansehen des Reichsjustizkommissariats“ erforderte ${ }^{65}$, hielt Ministerpräsident Siebert diesen Vorschlag wegen der kurzen Spanne seit der letzten Beförderung für „so außergewöhnlich“, daß er ihn an den Reichsstatthalter nur angesichts der Tatsache weiterreichte, daß das Reichsjustizministerium die Bezüge Bühlers übernommen hatte, da das Reichsjustizkommissariat eine Reichsangelegenheit war. Da Hitler wenige Tage später dieses Kommissariat aufhob, lehnte Epp den Beförderungsantrag ab. ${ }^{66}$ Frank, der unterdessen zum Reichsminister ohne Geschäftsbereich ernannt worden war, erneuerte seinen Antrag mit dem Argument, daß Bühler nunmehr Leiter seines neu zu errichtenden Ministeramts werde. ${ }^{67}$ Aber die Abteilung Bayern des Reichsjustizministeriums, die im Verlauf der Verreichlichung nunmehr für die Vorlage der Personalanträge beim Reichsstatthalter zuständig geworden war $^{68}$, befürwortete statt dessen die Anhebung Bühlers in die Stelle eines Oberstaatsanwalts beim Oberlandesgericht München. Mit diesem Rang trat Bühler in Franks Ministeramt ein und sollte es - auch in den folgenden Jahren von der Reichsjustizverwaltung beurlaubt - an der Seite Franks 1940 bis zum Staatssekretär und Stellvertreter des Generalgouverneurs in Polen bringen.

Ein weiterer Jurist, dem die Einberufung in das bayerische Justizministerium durch Frank eine nicht alltägliche Karriere öffnete, war Walter Stepp - Parteigenosse und SA-Mitglied seit 1931 -, der im Jahre 1933 als Amtsgerichtsrat in Frankenthal für einige Monate zum kommissarischen Bürgermeister bestellt und im Juni zum I. Staatsanwalt beim Landgericht München I ernannt worden war. Nach seiner Einberufung als Hilfsarbeiter ins Ministerium betraute ihn Frank im Herbst 1933 mit der Aufgabe eines Verbindungsmannes zur Bayerischen Politischen Polizei. ${ }^{69}$ Stepp, der in diesem Zusammenhang von der SA zur SS als Hauptsturmführer übertrat, wurde im Juli 1934 zum Landgerichtsrat befördert und bei der Auflösung des bayerischen Justizministe-

${ }^{64}$ Vgl. Geschäftsplan des bayer. JM, Stand v. 10.7.34 (Akten des bayer. JM, a.a.O., Sign. MJu 16846).

${ }^{65} \mathrm{Vgl}$. Schr. Franks an den RStH v. 7.12.34 (Akten des RStH, a.a.O.).

66 Vgl. Schr. MinPräs. Sieberts an den RStH v. 12.12.35 und Schr. Epps v. 11.1.35 an die Abt. Bayern des RJM, die unterdessen zuständig geworden war (a.a.O.).

67 Schr. Franks an RStH von Epp v. 14.1.35 (a.a.O.).

68 Laut Erl. des RJM v. 19.12.34 an die Beauftragten des RJM in München, Dresden, Stuttgart und Hamburg sollten in der Übergangszeit v. 1.1. bis 1.4.35 die Beauftragten die Personalvorschläge an die RStH geben, bei allen Gerichtspräsidenten, GStAen und OStAen nach Zustimmung des RJM (Akten des bayer. JM, a.a.O., Sign. MJu 10415). Da sich Hitler durch Erl. v. 1.2.35 (RGBl. I, S.74) die Emennung und Entlassung aller Beamten des höheren Dienstes selbst vorbehielt, mußte das RJM durch Erl. v. 6.2.35 die Beauftragten anweisen, daß diese Personalvorschläge nunmehr dem RJM zur weiteren Behandlung vorzulegen waren (Zur Ernennungsprozedur s. Kapitel III.1.d., S. 207 ff.).

69 Vgl. Näheres dazu Kapitel IV.4.d., S.406f. 
riums am 1. Januar 1935 „zur Geschäftsaushilfe“ an die politische Polizei abgeordnet. Während seiner Abordnung von der Abteilung Bayern des Reichsjustizministeriums im Februar 1935 zum Oberregierungsrat ernannt, trat er im Dezember von der Justiz ganz zur politischen Polizei über, als dort eine Oberregierungsratsstelle frei wurde. Heydrich ernannte ihn zu seinem Stellvertreter als Leiter der Bayerischen Politischen Polizei und nach der einheitlichen Organisation der Geheimen Staatspolizei zum Chef der Staatspolizeileitstelle München. Im Herbst 1937 trat Stepp - unterdessen bis zum SS-Oberführer befördert - zur Justiz zurück und wurde im Dezember Landgerichtspräsident in Kaiserslautern. Die Krönung seiner Karriere sollte Stepp Anfang 1943 erfahren, als ihn Thierack - der auf gute Beziehungen zwischen Justiz und Gestapo auch auf regionaler Ebene Wert legte - vom Kriegsdienst freistellen ließ und zum Oberlandesgerichtspräsidenten in München ernannte. ${ }^{70}$

Wie die Beamten in den Spitzenstellen des bayerischen Justizministeriums, so ließ Frank 1933 bis auf eine Ausnahme auch die Oberlandesgerichtspräsidenten und Generalstaatsanwälte in den vier bayerischen Oberlandesgerichtsbezirken im Amt. Die Ausnahme bildete der Inhaber des wichtigsten Postens der bayerischen Justizverwaltung außerhalb des Ministeriums, der Münchener Oberlandesgerichtspräsident Gerber, der als Miglied der Bayerischen Volkspartei (BVP) einer Versetzung in ein Amt von geringerem Rang durch seinen Antrag auf Versetzung in den Ruhestand nach $\S 5$ Abs. 2 BBG zuvorkam. Seine Stelle wurde auf Vorschlag Franks mit dem Vorsitzenden im Hitler-Prozeß von 1924 und nunmehrigen Präsidenten des Landgerichts Hof, Georg Neithardt, besetzt. ${ }^{71}$ Die Ernennung war ein geschickter Schachzug der Nationalsozialisten, die damit den Eindruck erweckten, daß sie keine billige Rache übten, sondern unbeirrbar Recht und Gesetz anerkannten: bei der Einführung Neithardts in sein Amt betonte Frank, er sei seinerzeit „dem Führer ein gerechter Richter gewesen “. ${ }^{72}$ Andere wiederum wollten in der Beförderung des Landgerichtspräsidenten, der sich zu diesem Zeitpunkt noch keineswegs der Partei angeschlossen hatte, nur die Anerkennung für sein Verdienst sehen, daß er Hitler seinerzeit die Ausweisung aus Deutschland erspart hatte. ${ }^{73}$

Der Oberlandesgerichtspräsident von Zweibrücken Friedrich Becker erreichte im Juni 1933 ohnehin die Altersgrenze, die in Bayern noch für das 68. Lebensjahr galt; wie bereits erwähnt, wurde er durch den Ministerialrat Siegel aus dem Justizministerium ersetzt. Im Herbst 1933 traten dann auf eigenes Ansuchen wegen nachgewiesener Dienstunfähigkeit die Oberlandesgerichtspräsidenten von Bamberg und Nürnberg - Aull und Burkhardt - in den Ruhestand. Ihre Nachfolger wurden der Präsident des Landgerichts Amberg, Heuwieser, und der Direktor am Landgericht München I, Bertram. ${ }^{74}$ Von den übernommenen Generalstaatsanwälten Döll (Bamberg), Sotier (Mün-

${ }^{70}$ Zu Stepp vgl. Akten des bayer. JM, a.a.O., Sign. MJu 16825; DJ 1943, S.127; S. Aronson, Reinhard Heydrich und die Frühgeschichte von Gestapo und SD, Stuttgart 1971, S. 131 ff., sowie Spruchkammerakten Dr. Stepp (Arch. des IfZ, Sign. Sp 4).

11 Vgl. Auszug aus der Niederschr. der Ministerratssitzung v. 18.7.33 (Akten des RStH, a.a.O., Sign. Reichsstatthalter 219), ferner Chronik der Bayerischen Justizverwaltung, Bd.VI, Eintr. v. 1.7.33 (Arch. des IfZ, Sign. Fa 285/6).

72 Vgl. den Ber. des scheidenden OLGPräs. Gerber v. 21.12.48 (Spruchkammerakten Georg Neithardt, StArch. München).

73 Zum Hitler-Prozeß von 1924 vgl. Kapitel I.3, S. 33 ff.

${ }^{74} \mathrm{Vgl}$. Auszug aus der Niederschr. der Ministerratssitzung v. 10.10.33 (a.a.O., Sign. Reichsstatthalter 220). 
chen), Leuchs (Nürnberg) und Troeltsch (Zweibrücken) schied während der Amtszeit Franks nur Döll wegen Erreichung der Altersgrenze aus und wurde Anfang April 1934 durch den Vorstand der Gefangenenanstalt Nürnberg, Oberregierungsrat Kahl, ersetzt. Auch den Präsidenten des Bayerischen Obersten Landesgerichts Gustav Müller und den Generalstaatsanwalt bei diesem Gericht Manglkammer beließ Frank 1933 in ihren Ämtern: erst mit der Auflösung dieses Gerichts am 1. April 1935 wurde Müller in den Wartestand und Manglkammer als Senatspräsident an das Oberlandesgericht München versetzt; mit ihm traten 21 Räte und 2 Oberstaatsanwälte von diesem Gericht an das Oberlandesgericht über. Sämtliche im April 1935 amtierenden bayerischen Oberlandesgerichtspräsidenten und Generalstaatsanwälte wurden von der Reichsjustizverwaltung übernommen. Von ihnen blieb bis zum Ende der Gürtner-Periode ein Oberlandesgerichtspräsident im Amt, drei traten in den Ruhestand; von den Generalstaatsanwälten verblieb gleichfalls einer in seiner Stellung, einer wurde zum Oberlandesgerichtspräsidenten ernannt und zwei traten in den Ruhestand. ${ }^{75}$

Auf die Umbesetzungen, die Frank 1933 und 1934 bei den bayerischen Landgerichtspräsidenten ${ }^{76}$ und den darunterliegenden Rängen des höheren Justizdienstes vornahm, kann hier nicht eingegangen werden. ${ }^{77}$ Zahlenmäßig wiesen diese beiden Jahre beim höheren Dienst einen außergewöhnlich starken Personalabgang auf. Waren aus der bayerischen Justiz im Jahre $1931=81(4,53 \%)$ und im Jahre $1932=88$ $(4,95 \%)$ höhere Beamte ausgeschieden, so erhöhte sich diese Zahl 1933 auf 153 $(8,75 \%)$. Dabei handelte es sich um 23 Todesfälle, 13 Abgänge durch Erreichung der Altersgrenze, 99 Pensionierungen und 18 Entlassungen. Von den 99 Pensionierungen erfolgten 14 wegen „nichtarischer Abstammung“ ( $33 \mathrm{BBG}), 12$ auf eigenen Antrag zur Vermeidung einer Zwangsversetzung in ein geringeres Amt ( $₹ 5$ Abs. 2 BBG), 19 betrafen jüdische Beamte, die wegen Dienstunfähigkeit teils von sich aus ${ }^{78}$, teils auf die Mitteilung hin, daß sie in ein anderes Amt zwangsversetzt würden, um ihre Pensionierung baten. Von den 18 Entlassungen wurden 4 wegen „politischer Unzuverlässigkeit“ $(\S 4 \mathrm{BBG})$ vorgenommen, die meisten übrigen Fälle betrafen junge Beamte, die in die innere Verwaltung oder in den Kommunaldienst überwechselten. Auch im Jahre 1934 schieden noch $110(6,29 \%)$ höhere Justizbeamte aus: 18 durch Tod, 23 durch Erreichung der Altersgrenze, 63 durch Pensionierung und 6 durch Entlassung.

Dieser starke Personalabgang verursachte 1933/34 einen außergewöhnlich großen Nachwuchsbedarf. Da die Zahl der unter Berücksichtigung des Numerus clausus eingetragenen Bewerber für die Besetzung der - überwiegend durch nachrückende Beför-

75 Vgl. dazu Kapitel III.3.b.

${ }^{76}$ Exemplarisch sei auf die Vorgänge um die Zurruhesetzung des LGPräs. von Bamberg Krapp (Anhänger der DVP) im Juli 1933 hingewiesen, nebst Dokumenten wiedergegeben bei $\mathrm{H}$. Schütz, Justiz im „Dritten Reich". Dokumentation aus dem Bezirk des Oberlandesgerichts Bamberg, Bamberg 1984, S. 48 ff. und Anhang 3.

77 Angaben dazu finden sich u.a. in den in Anm. 55 angegebenen Quellen. Der bayer. Justizverwaltung unterstanden in dieser Zeit 26 LGe, 240 AGe, 11 Strafanstalten und 350 Notariate. Sie betreute 7700 Beamte, Angestellte und Arbeiter, 2300 RAe und 1200 Referendare, vgl. Das Bayerische Staatsministerium der Justiz. Eine Rückschau, herausg. vom RJM, Abt. Bayern, München 1935, S. 25.

78 In der Begründung für die Pensionierung eines Münchener jüdischen LGRates heißt es bezeichnenderweise: „Infolge der mit den politischen Verhältnissen für ihn verbundenen Aufregungen leidet er an Nervenüberreizung. Er fühlt sich den Aufgaben des Richteramtes nicht mehr gewachsen und bittet um seine Versetzung in den dauernden Ruhestand“ (Antrag Franks an den RStH v. Januar 1934, Akten des RStHs, a.a.O.). 
derungen - freigewordenen Eingangsstellen nicht ausreichte, mußte eine große Zahl von Assessoren nachträglich in die Bewerberliste aufgenommen werden. Damit der letzte Prüfungsjahrgang dabei nicht zu stark vertreten war, wurden zum Ausgleich die ergänzenden Aufnahmen auf die Prüfungsjahrgänge 1932 bis 1929 - vereinzelt auch auf frühere - verteilt. Die Übernahme von Assessoren aus Preußen, wo seit Jahren ein Überangebot von Bewerbern herrschte, konnte 1934 noch nicht erfolgen, da die Vereinheitlichung der Ausbildung und der Anstellungsvorschriften im Reich erst im Werden begriffen war. ${ }^{79}$

Durch den erwähnten Personalabgang entwickelten sich in Bayern neben den Anstellungsverhältnissen auch die Beförderungsmöglichkeiten für die jüngeren Beamten ausgesprochen günstig: 1934 wurden z.B. auch Gerichtsassessoren mit schlechteren Noten schon zwei bis drei Monate nach ihrer nichtetatmäßigen Anstellung unmittelbar zu II. Staatsanwälten ernannt, so daß die hauptamtlichen Amtsanwälte allmählich durch II. Staatsanwälte ersetzt wurden. Damit änderte sich aber auch die Altersschichtung der höheren Justizbeamten in Bayern:

\section{Nach dem Stande vom}

$$
\text { 31.12.1932 31.12.1933 31.12.1934 }
$$

waren

60 Jahre und älter

59 Jahre bis 50 Jahre alt

49 Jahre bis 40 Jahre alt

39 Jahre bis 30 Jahre alt

29 Jahre alt und jünger

$\begin{array}{rrr}27,03 \% & 24,60 \% & 21,92 \% \\ 26,14 \% & 26,08 \% & 26,38 \% \\ 21,46 \% & 16,39 \% & 14,54 \% \\ 19,44 \% & 22,36 \% & 26,96 \% \\ 5,93 \% & 10,03 \% & 10,20 \%\end{array}$

Vom Jahresende 1932 bis Jahresende 1934 nahm somit die Zahl der höheren Justizbeamten bis zum 39. Lebensjahr um 12\% der Gesamtzahl der Beamten zu, während die Zahl der Beamten über 50 Jahre im gleichen Zeitraum um $5 \%$ sank. $^{80}$

Als der Reichsinnenminister mit Wirkung vom 30. Januar 1934 durch Funkspruch plötzlich alle Ernennungen und Beförderungen von planmäßigen Landesbeamten untersagte, sah Frank die Fortsetzung seiner Beförderungspolitik gefährdet, zumal zu diesem Zeitpunkt beim höheren Justizdienst gerade 37 etatmäßige Beamtenstellen unbesetzt waren. Zwar wurde die Beförderungssperre für den Bereich der Justizverwaltung am 23. Februar 1934 allgemein wieder aufgehoben, blieb jedoch für die höheren Ministerialstellen bestehen: die Stellenbesetzungen vom Ministerialrat aufwärts waren nunmehr an die Zustimmung des Reichsjustizministeriums und des Reichsfinanzministeriums gebunden. ${ }^{81}$ Das hatte seinen Grund darin, daß Gürtner die Landesjustizministerien vor ihrer Auflösung und der Übernahme des Personals durch das Reich möglichst schrumpfen lassen wollte. Schon Ende Februar 1934 wies er die Landesjustizverwaltungen darauf hin, daß allein in Preußen, Bayern, Sachsen, Württemberg und Hamburg nach den Haushaltsplänen von 1933 insgesamt 13 Stellen für Ministerialdirektoren, 4 Stellen für Ministerialdirigenten, 59 Stellen für Ministerialräte und 89 Stellen für Ministerialamtmänner bestanden. Diese Zahlen zeigten, „daß die restlose $\mathrm{Zu}$ sammenfassung der Ministerialbeamten aller Länder in einer Reichszentrale kaum

79 Vgl. dazu Kapitel III.4.b., S. 299 ff.

80 Zum Voranstehenden vgl. Chronik, a.a.O. (Anm.71), Eintr. v. 31.12.33 und 31.12.34.

81 Vgl. a.a.O., Eintr. v. 2.2.34. 
möglich, auch gar nicht wünschenswert sein würde“. Er bat daher, bei der Besetzung freier Stellen zurückhaltend zu sein und den Kreis der Ministerialbeamten nach und nach einzuschränken. ${ }^{82} \mathrm{Da}$ Frank diese Mahnung nicht beherzigte, sondern freiwerdende Ministerialstellen stets aufs neue besetzte ${ }^{83}$, indem er seine Ernennungsvorschläge immer wieder mit besonderen dienstlichen Ausnahmeverhältnissen begründete und Epp drängte, „die Zustimmung der zuständigen Reichsministerien dazu zu erwirken "84, konnte die überwiegende Mehrheit seiner höheren Ministerialbeamten 1935 nicht ins Reichsjustizministerium übernommen werden. Nach Franks Abtreten als bayerischer Justizminister mußte der Beauftragte des Reichsjustizministeriums den Personalabbau am 1. Februar 1935 mit der Versetzung des Abteilungsleiters Ministerialrat Meukel als Senatspräsidenten ans Oberlandesgericht München sowie des Ministerialrats Gipser als Rat an das Oberste Landesgericht und eines Oberregierungsrats als Oberlandesgerichtsrat nach Nürnberg beginnen ${ }^{85}$ Mit Wirkung vom 1. April wurden dann Ministerialdirektor Dürr als Senatspräsident, die Ministerialräte Castner und Resch sowie ein Oberregierungsrat als Räte ans Oberlandesgericht München versetzt. Ministerialrat Döbig ging als Oberlandesgerichtsrat nach Nürnberg. Ins Reichsjustizministerium wurden unter diesem Datum nur die Ministerialräte Drescher, Engert und Kallenbach sowie die restlichen zwei Oberregierungsräte übernommen. ${ }^{86}$

Von den Personalmaßnahmen, die die nationalsozialistischen Chefs der Justizverwaltungen in den anderen deutschen Ländern 1933/34 vor der „Verreichlichung“ ergriffen $^{87}$, kann hier nur die Besetzung der Spitzenpositionen in den acht Oberlandesgerichtsbezirken dieser Länder behandelt werden. In Thüringen blieben unter Justizminister Otto Weber sowohl der Präsident des Oberlandesgerichts wie der Generalstaatsanwalt in Jena - die seit 1925 bzw. 1929 amtierten - weiter in ihren Stellungen; sie traten schließlich 1936 bzw. 1937 der Partei bei. Ebenso verhielt es sich in Oldenburg unter Minister Pauly, wo die beiden leitenden Beamten am dortigen Oberlandesgericht ihre Übernahme durch ihren Parteieintritt am 1. Mai 1933 besiegelten. In beiden Ländern hatten schon seit Mitte 1932 nationalsozialistische Regierungen bestanden, die mit diesen Beamten offensichtlich zufrieden gewesen waren. In Sachsen blieb unter Thierack der Oberlandesgerichtspräsident von Dresden, Hüttner, im Amt, während im Mai 1933 der bisherige Oberstaatsanwalt Alfred Weber zum neuen Generalstaatsanwalt bestellt wurde. Justizminister Scharf in Mecklenburg ließ den Oberlandesgerichtspräsidenten von Rostock - den Nichtparteigenossen Burmeister - ebenfalls im

${ }^{82} \mathrm{Vgl.} \mathrm{RV} \mathrm{des} \mathrm{RJM} \mathrm{an} \mathrm{die} \mathrm{Landesjustizverwaltungen} \mathrm{v.} \mathrm{28.2.34} \mathrm{(Akten} \mathrm{des} \mathrm{bayer.} \mathrm{JM,} \mathrm{a.a.O.,} \mathrm{Sign.} \mathrm{MJu} \mathrm{10415).}$

${ }^{83}$ Laut Geschäftsplan v. 10.7.34 (a.a.O., Sign. MJu 16846) waren im bayer. JM die vorhandenen Planstellen des höheren Dienstes für 1 Staatsrat, 1 MinDir., 8 MinRäte und 4 ORRäte alle besetzt, ferner als Hilfsreferenten und -arbeiter 8 I.StAe, 1 II. StA, 2 LGRäte und AGRäte tätig.

${ }^{84} \mathrm{Vgl.} \mathrm{z.B}$. Antrag Franks beim RStH v. 6.3.34 zur ausnahmsweisen Beförderung eines MinDir. und zweier MinRäte wegen „besonderer Verhältnisse“ (Akten des RStHs, a.a.O., Sign. Reichsstatthalter 221).

${ }^{85}$ Vgl. Chronik, a.a.O. (Anm. 71), Eintr. v. 29.3.35.

$86 \mathrm{Vgl}$. Schr. des RJM v. 11.3.35 an den Beauftragten des RJM in München, Staatsrat Spangenberger (Akten des bayer. JM, a.a.O., Sign. MJu 16825), der selbst am 1.5.35 in den Ruhestand trat. Kallenbach wurde vom RJM zur Dienstleistung beim RFiM abgeordnet und trat später ganz in die RFiVerw. über. Vom RJM wurden am 1.4.35 aus dem bayer. JM ferner 1 Justizamtmann, 2 Justizoberinspektoren und 4 Justizinspektoren übernommen.

${ }^{87}$ Für Hamburg z. B. sei auf W. Johe, Die gleichgeschaltete Justiz. Organisation des Rechtswesens und Politisierung der Rechtsprechung 1933-1945 dargestellt am Beispiel des Oberlandesgerichtsbezirks Hamburg, Frankfurt a. M. 1967, S. $58 \mathrm{ff}$., für Braunschweig auf E.-A. Roloff, Bürgertum und Nationalsozialismus 1930-1933. Braunschweigs Weg ins Dritte Reich, Hannover 1961, S. 156, hingewiesen. 
Amt, ersetzte aber Generalstaatsanwalt Siegfried, der auf eigenen Antrag in den Ruhestand trat, im September 1933 durch einen Altparteigenossen von 1931, der 1932 aus dem Staatsdienst ausgetreten und zuletzt Landrat in Waren gewesen war. Ebenso verhielt es sich in Hessen, wo der Oberlandesgerichtspräsident von Darmstadt, Adolf Müller, vom Staatsministerium ${ }^{88}$ beibehalten wurde, obgleich er der Deutschen Volkspartei angehörte, während Generalstaatsanwalt Hoos durch den Gießener Staatsanwalt Eckert ersetzt wurde, der zu diesem Zeitpunkt gleichfalls kein Parteigenosse war. Auch in Baden wurde unter Justizminister Wacker der Oberlandesgerichtspräsident Karlsrube, Buzengeiger - obwohl weiterhin Nichtparteigenosse -, übernommen, Generalstaatsanwalt Hafner aber im August 1933 durch den Ministerialrat im badischen Justizministerium Brettle abgelöst, der erst 19.37 kurz vor seiner Ernennung zum Oberreichsanwalt beim Reichsgericht in die Partei eintrat. Umgekehrt war es in Württemberg, wo der Generalstaatsanwalt in Stuttgart, Heintzeler, von Justizminister Schmid übernommen wurde, während der seit 1926 amtierende Oberlandesgerichtspräsident Schmoller in den Ruhestand trat und durch den bisherigen Senatspräsidenten $\mathrm{He} ß$ abgelöst wurde, der aber im Februar 1935 auf eigenen Antrag hin auch schon in den Ruhestand ging. In den anderen Ländern wurden 1933 jeweils beide Behördenchefs von der Ablösung betroffen: der Justizminister und SS-Standartenführer Alpers in Braunschweig tauschte im Mai Oberlandesgerichtspräsident Röpcke durch den Oberlandesgerichtsrat Heusinger aus - der schon Ende 1934 wieder abberufen und zum Senatspräsidenten degradiert wurde ${ }^{89}$ - und ernannte im November 1933 den braunschweigischen Landgerichtsdirektor Heinrich Müller an Stelle von Paul Koch zum Generalstaatsanwalt. Das hamburgische Gesetz vom 3. Mai 1933, das die Altersgrenze für Richter auf 65 Jahre herabsetzte, ermöglichte es Justizsenator Rothenberger, den Präsidenten des Hanseatischen Oberlandesgerichts Kiesselbach im Juli in den Ruhestand zu versetzen und den Senatspräsidenten Engel, der im Frühjahr 1933 von der Deutschen Volkspartei zur NSDAP übergetreten war, in diese Position zu befördern; bereits im April hatte er Generalstaatsanwalt Lang, der um seine Ablösung gebeten hatte, durch Oberlandesgerichtsrat Drescher ersetzt. ${ }^{90}$

Alle diese von den verschiedenen Chefs der Landesjustizverwaltungen ernannten Oberlandesgerichtspräsidenten und Generalstaatsanwälte wurden wie in Preußen und Bayern 1935 von der Reichsjustizverwaltung übernommen. Nur in Braunschweig und Darmstadt mußte der Reichsjustizminister die beiden Neubesetzungen, die durch die Abberufung Heusingers und die Pensionierung Adolf Müllers notwendig geworden waren, noch vor Abschluß der „Verreichlichung“ selbst vornehmen.9"

${ }^{88}$ Die Ministerialabteilung I c (Justiz) im hessischen Staatsministerium wurde vom 13.3. bis 15.5.33 von Heinrich Müller, vom 15.5. bis 20.9.33 von Ferdinand Werner und vom 20.9.33 bis 4.12.34 (Utbernahme durch das RJM) von Philip Wilhelm Jung geleitet.

89 Es handelt sich um den 1960 zum Präsidenten des BGH ernannten Dr. Bruno Heusinger.

$90 \mathrm{Vgl}$. Johe, a.a.O., S.65 ff. Bei dem erwāhnten G. handelt es sich um das G. betr. Änderung des Gesetzes zur Ausführung des Gerichtsverfassungsgesetzes v. 3.5.33 (Hamb. GuVOBl. 1933, S. 128 f.). Dr. Wilhelm Kiesselbach wurde 1947 Präsident des Zentral-Justizamts für die Britische Zone.

91 In Braunschweig, Hessen und anderen kleinen Ländern übte das RJM die Funktion der obersten Landesbehörde schon seit Dezember 1934 unmittelbar aus (vgl. Kapitel II.5., S. 112). 


\section{Die Personalpolitik des Reichsjustizministeriums}

\section{a. Personalpolitische Maßnabmen innerbalb des Ministeriums 1933-1940: die allmäbliche Anpassung an die Forderungen der Partei}

Im Gegensatz zu den Landesjustizministerien erfolgten im Reichsjustizministerium nach der Machtübernahme 1933 zunächst keine wesentlichen personellen Veränderungen. Die Beamtenschaft dieses Ministeriums, die überwiegend aus besonders qualifizierten Fachleuten bestand, hatte sich auch während der Weimarer Zeit einen homogenen, national-konservativen Charakter bewahrt, da die ständig wechselnden Justizminister des Reiches mit der unterschiedlichsten parteipolitischen Couleur - von 1919 bis 1932 neunzehn an der Zahl - während ihrer jeweiligen kurzen Amtszeit keinen wirksamen Einfluß auf die Personalpolitik gewinnen konnten. Daß das Reichsjustizministerium diesen "unpolitischen“, nicht gerade von republikanischem und demokratischem Geist getragenen Charakter beibehielt und dadurch - zumindest in der Erwartung der Nationalsozialisten - 1933 ein „einsatzbereites, schlagkräftiges Instrument ${ }^{\text {"1 }}$ für ihre Ziele abzugeben schien, verdankte es paradoxerweise einem Juden: dem national empfindenden, konservativ gesinnten, parteilosen und überzeugten Berufsbeamten Curt Joël, der das Reichsjustizministerium von 1920 bis 1932 als Staatssekretär, zuletzt in Brünings 2. Kabinett acht Monate als Reichsminister leitete und für die Kontinuität der inneren Struktur unter den verschiedenen Ministern sorgte. ${ }^{2}$

Als Gürtner nach der Machtübernahme in seinem Amt bestätigt wurde, sah er daher keinerlei Veranlassung, seine bewährten Mitarbeiter, mit denen er seit seinem Amtsantritt im Juni 1932 zusammenarbeitete, auszuwechseln. Er behielt Schlegelberger als Staatssekretär, der - schon im Frühjahr 1918 als Kammergerichtsrat in das kaiserliche Justizamt eingetreten - in der Weimarer Zeit als Ministerialrat 1921 mit der Leitung der Abteilung III für Handels-, Gewerbe- und Wirtschaftsrecht, Bank- und Aufwertungsrecht u. a. betraut worden war und diese Abteilung ab 1927 als Ministerialdirektor führte, bis er im Oktober 1931 auf Vorschlag des eben zum Reichsjustizminister ernannten Joël als dessen Nachfolger auf den Posten des Staatssekretärs befördert wurde. Seine berufliche Förderung durch Joël verdankte der parteipolitisch nicht gebundene Schlegelberger seinen hervorragenden Fähigkeiten als Jurist, die ihm aufgrund zahlreicher Veröffentlichungen auf dem Gebiet des Zivil- und Handelsrechts wissenschaftliches Ansehen im In- und Ausland einbrachten; seit 1922 nahm er nebenamtlich eine Honorarprofessur an der Berliner Universität wahr, und 1926 verlieh ihm die Universität Königsberg die Ehrendoktorwürde der Staatswissenschaften. Als Praktiker hatte er sich vor allem bei der Aufwertungsgesetzgebung Verdienste erworben. Im Jahre 1933 schien der ehrgeizige, 57jährige Staatssekretär auf dem Höhepunkt seiner Beamtenkarriere zu stehen: doch durch den Tod Gürtners im Januar 1941 sollte er von Hitler für anderthalb Jahre auch noch mit der kommissarischen

1 So MinRat F. Sauer, Das Reichsjustizministerium, Berlin 1939, S.6.

${ }^{2} \mathrm{Zu}$ Joël vgl. K. D. Godau-Schüttke, Rechtsverwalter des Reiches. Staatssekretär Dr. Curt Joël, Frankfurt a. M. 1981, zur Personalpolitik bes. S. 141 ff., ferner H. Hattenhauer, Vom Reichsjustizamt zum Bundesministerium der Justiz (in: Festschrift zum 100jährigen Gründungstag des Reichsjustizamtes am 1.Januar 1866, Köln 1977, S.66f.), und L. Graf Schwerin von Krosigk, Es geschah in Deutschland. Menschenbilder unseres Jahrhunderts, Tübingen und Stuttgart 1951, S.321. 
Leitung des Reichsjustizministeriums beauftragt werden, obwohl er kein Nationalsozialist gewesen und 1938 lediglich durch eine Verfügung Hitlers in die Partei aufgenommen worden war. ${ }^{3}$

Wie der Staatssekretär, so blieben 1933 auch die Ministerialdirektoren und Leiter der drei bestehenden Abteilungen im Amt, obgleich sie nie der NSDAP beitraten. Ministerialdirektor Volkmar, der die Abteilung I für Bürgerliches Recht und bürgerliche Rechtspflege leitete, war als parteiloser Beamter schon seit Januar 1920 im Ministerium. ${ }^{4}$ Der Leiter der Abteilung II für Strafrecht, Strafrechtspflege und Strafvollzug, Ministerialdirektor Ernst Schäfer, der bis zu seinem Eintritt ins preußische Justizministerium im März 1921 der Deutschen Demokratischen Partei angehört hatte, war im April 1929 durch den Reichsjustizminister und Vorsitzenden dieser Partei Erich Koch als Ministerialdirektor ins Reichsjustizministerium übernommen worden, nachdem der bisherige Abteilungsleiter Bumke zum Reichsgerichtspräsidenten ernannt worden war. Bei der Auswahl dürften auch für Koch fachliche Gründe den Ausschlag gegeben haben - Schäfer hatte sich im preußischen Justizministerium bei den Strafrechtsreformarbeiten hervorgetan; er mußte die Ernennung Schäfers sogar gegen die Angriffe liberaler Kreise verteidigen, die den Katholiken Schäfer für einen Anhänger des Zentrums hielten und ihm vorwarfen, daß er seine Kinder katholisch erziehen ließ, obgleich er mit einer evangelischen Frau verheiratet war. ${ }^{5}$ Schäfer, von dem die Vossische Zeitung schrieb, es bestehe jedenfalls „keinerlei Zweifel daran, daß er der republikanischen Verfassung treu ergeben" sei $^{6}$, sollte über Gürtners Tod hinaus in seiner Stellung bleiben und wie sein Kollege Volkmar erst 1942 nach dem Amtsantritt Thieracks als Reichsjustizminister seine Versetzung in den Ruhestand beantragen. ${ }^{7}$

Der dritte Ministerialdirektor, Reinhold Richter, der die Abteilung III für Handelsund Wirtschaftsrecht, Staats-, Verwaltungs- und Völkerrecht leitete, war schon im März 1918 zusammen mit Schlegelberger ins Reichsjustizamt eingetreten, wie dieser im Herbst Geheimer Regierungsrat und Vortragender Rat - ab 1920 mit der geänderten Amtsbezeichnung „Ministerialrat ${ }^{\text {“8 }}$ - geworden und im Januar 1931 zum Ministerialdirektor befördert worden. Obwohl er „Halbjude“ war, hielt ihn Gürtner im Amt, wofür das Berufsbeamtengesetz vom April 1933 die rechtliche Handhabe gab, da Richter schon vor August 1914 Justizbeamter gewesen war. In der Folgezeit schirmte ihn Schlegelberger vor allen Angriffen ab. ${ }^{9}$ Selbst nach Inkrafttreten des Reichsbürgergesetzes konnte er noch ein halbes Jahr gehalten werden, dann mußte er in den

${ }^{3}$ Zu Schlegelbergers beruflichem Werdegang vgl. Personalakten des RJM (BA), zu seiner Aufnahme in die NSDAP s. Kapitel III.1.d., S. 219. Wie fast alle höheren Justizbeamten war Schlegelberger im Herbst 1933 lediglich dem BNSDJ beigetreten; seit Juli 1936 war er Förderndes Mitglied des NSFK.

4 Vgl. Personalakten des RJM (BA) und Personalunterlagen im DC Berlin. Volkmars Aufnahmeantrag in die NSDAP v. Juli 1940 wurde im Januar 1943 (!) schließlich abgelehnt.

5 Aus dem Nachlaß Koch-Weser, Aktenstück Nr.39 (BA, Sign. NL 12), zitiert bei Godau-Schüttke, S. 148 f., der die Ernennung Schäfers als „die einzig nachweisbare Personalentscheidung..., bei der Joël nicht konsultiert wurde", anführt.

6 Vgl. „Der Nachfolger Bumkes ernannt" (Vossische Zeitung v. 18.3.29).

Vgl. Personalakten des RJM (BA).

${ }^{8}$ Aufgrund einer VO des Reichspräs. vom Juni 1920 führten die Geheimen Regierungsräte künftig die Amtsbezeichnung Ministerialrat.

9 Vgl. dazu im folgenden S. $248 \mathrm{f}$. 
einstweiligen Ruhestand versetzt werden; mit Erreichen der Altersgrenze trat er Anfang 1939 endgültig in den Ruhestand. ${ }^{10}$

Die zwölf Ministerialräte des Reichsjustizministeriums ${ }^{11}$, von denen fast die Hälfte schon seit $1920 \mathrm{im}$ Hause arbeitete, blieben 1933 sämtlich im Amt. Unter ihnen gab es ein Mitglied der Deutschnationalen Volkspartei und einen früheren Angehörigen des Zentrums, aber keinen einzigen Parteigenossen. Erst ab 1939 sollten einige von ihnen den Weg zur NSDAP finden, als sie auf höhere Posten in- und außerhalb des Ministeriums befördert wurden ${ }^{12}$; zwei von ihnen sollte die Parteiführung allerdings die Aufnahme in die NSDAP verweigern. Von den Ministerialräten schied im März 1934 nur Georg Klauer aus, da er unbeschadet mangelnder Parteizugehörigkeit zum Präsidenten des Reichspatentamtes ernannt wurde. In seine Stelle rückte Oberregierungsrat Otto Wagner auf, der seit 1926 im Ministerium gearbeitet hatte und gleichfalls noch kein NSDAP-Mitglied war. Wie die Ministerialräte waren nach der Machtübernahme auch die fünf Oberregierungsräte des Reichsjustizministeriums ${ }^{13} \mathrm{im} \mathrm{Amt}$ geblieben. Als zwei von ihnen unter Beförderung in andere Ministerien überwechselten, wurden im Frühjahr 1934 zwei Nicht-Parteigenossen, der Karlsruher Landgerichtsrat Doerner - 1931 ein halbes Jahr Zentrumsmitglied - und der hamburgische Staatsanwalt Hans von Dohnanyi - der als persönlicher Referent Gürtners seit Juni 1933 das besondere Vertrauen des Ministers genoß - zu Oberregierungsräten ernannt. Bis zur Vereinigung mit dem preußischen Justizministerium im Oktober 1934 wies somit das Reichsjustizministerium - jedenfalls hinsichtlich seiner höheren Beamten $^{14}$ - eine ausgesprochen konservative und von Einflüssen der Partei unberührte Personalpolitik auf. Das im Volk kursierende Scherzwort: "wenn man in das Justizministerium gehe, müsse man das Parteiabzeichen abnehmen "14a, enthielt für diese Zeit einen wahren Kern.

Die politisch homogene Zusammensetzung änderte sich, als das Ministerium mit dem von Kerrl und Freisler seit anderthalb Jahren geleiteten preußischen Justizministerium zusammengeschlossen wurde. $\mathrm{Da}$ die Zahl der regulären Abteilungen durch

${ }^{10}$ Vgl. Personalakten des RJM (BA) und Aufstellung MinDir. Schnellers v. 20.7.45 über die nach 1933 aus dem RJM entfernten Beamten (Nürnbg. Dok. NG-560, Arch. des IfZ). Die Feststellung bei Godau-Schüttke, a.a.O., S. 149, Richter sei bis einschließlich 1938 Abteilungsleiter gewesen, ist falsch.

11 Brandis, Jonas, Klauer, Koffka, Kritzinger, Lehmann, Mettgenberg, Quassowski, Hans Richter, Sauer, Leopold Schäfer und Vogels. MinRat Kiesow, seit $1919 \mathrm{im}$ RJM, trat am 1.2.33 gerade sein neues Amt als Sen.Präs. beim RG an; die Ernennung war aber schon vor dem 30.1 .33 beschlossen worden.

12 Eine Ausnahme machte MinRat Kritzinger, der im Zusammenhang mit seiner Versetzung in die Reichskanzlei schon 1938 in die NSDAP eintrat, vgl. H. Mommsen, Aufgabenkreis und Verantwortlichkeit des Staatssekretärs der Reichskanzlei Dr. Wilhelm Kritzinger (Gutachten des Instituts für Zeitgeschichte, Band II, Stuttgart 1966, S.369ff.).

13 Neben Wagner: Harmening, Pätzold (gerade zum ORRat ernannt, vorher als LGRat Hilfsarbeiter im RJM), Riese und Schmölder. ORRat Schmölder wurde im Sommer 1933 zum MinRat im preuß. Ministerium für Wirtschaft und Arbeit ernannt, Harmening brachte es 1934 zum MinDir. im Reichsernährungsministerium.

14 Außer den erwähnten 3 MinDirektoren, 12 MinRäten und 5 ORegRäten hatte das RJM zum Zeitpunkt der Machtübernahme noch 6 auftragsweise verwendete Richter und StAe, 1 Ministerialbürodirektor, 16 Beamte des gehobenen, 9 des mittleren und 20 des einfachen Dienstes. Auf das berufliche Schicksal dieser Beamten sowie der Angestellten und Arbeiter im RJM kann hier nicht eingegangen werden.

${ }^{14 a}$ So wörtlich in einem späteren Ber. des SD-Abschnitts Würzburg mit dem Zusatz, daß dieses Wort über das RJM in der Bevölkerung „zwar im Spaß, aber doch mit einem guten Teil Ernst“ kolportiert werde (StArch. Würzburg, Bestand: Berichte der SD-Hauptaußenstelle Würzburg, Nr.24 [Datum unleserlich, nicht vor 24. 2.41]). 
die Zusammenlegung von drei auf sechs anwuchs ${ }^{15}$, standen neben den erwähnten Ministerialdirektoren Volkmar, Schäfer und Richter nunmehr die bereits an anderer Stelle charakterisierten ${ }^{16}$ Ministerialdirektoren Nadler und Crohne, die die wichtigen nunmehrigen Abteilungen I für Personalsachen und Gerichtsorganisation und III für Strafrechtspflege und Strafvollzugsverwaltung übernahmen. ${ }^{17}$ Die neue Abteilung VI, die anfänglich nur die preußischen, im Laufe der Verschmelzung aber sämtliche Haushaltssachen bearbeitete, leitete Ministerialdirigent Schneller, der bereits 1919 ins preuBische Justizministerium eingetreten war und seit 1933 in der preußischen Abteilung II für Bürgerliches und öffentliches Recht unter Ministerialdirektor Thiesing die Unterabteilung für Justizverwaltung geführt hatte; auch er sollte im Herbst 1936 zum Ministerialdirektor aufrücken, obwohl er noch kein Parteigenosse war. ${ }^{18}$ Thiesing wurde nach der Vereinigung der beiden Ministerien hingegen nicht mehr als Abteilungsleiter verwendet: er wurde im Dezember 1934 Beauftragter des Reichsjustizministeriums für die Abteilung Württemberg-Baden in Stuttgart und trat 1935 mit Erreichung der Altersgrenze in den Ruhestand. ${ }^{19}$

Neben Nadler, Crohne und Schneller kamen aus Preußen zwei weitere Abteilungsleiter ins Haus: Palandt, der Präsident des bisherigen Juristischen Landesprüfungsamtes und nunmehrigen Reichs-Justizprüfungsamtes, für das im Ministerium die Abteilung RJP (Ausbildung) eingerichtet wurde, und Ministerialdirigent Klässel, der Präsident des Landesamts für Familiengüter, der die neue Abteilung LA (Familiengüter und Hausvermögen) leitete. ${ }^{20}$

$\mathrm{Zu}$ den 12 Ministerialräten des Reichsjustizministeriums traten nunmehr 19 Ministerialräte des preußischen Justizministeriums ${ }^{21}$, von denen die meisten auch schon langjährige Mitarbeiter des Hauses, darunter ehemalige Mitglieder der Deutschen Demokratischen Partei und der Deutschen Volkspartei, waren. Auch von jenen fünf preußischen Ministerialräten, die erst nach der Machtübernahme in diese Stellung befördert worden waren, waren nur drei von außen gekommen, darunter ein Altparteigenosse und ein "Märzgefallener" ${ }^{22}$ Ferner wurden die vier Oberregierungsräte des Reichsjustizministeriums durch sechs preußische ergänzt. ${ }^{23}$

Obwohl das „Reichs- und Preußische Justizministerium“ nach dem Geschäftsverteilungsplan vom 22. Oktober 1934 einschließlich der als Hilfsarbeiter einberufenen

15 Außer den beiden „Zentralabteilungen“ der Staatssekretäre ZS und ZF sowie den Abteilungen RJP und LA, vgl. auch zum folgenden den Geschäftsverteilungsplan des RuPrJM v. 16./22.10.34 (Anlage 1 im Anhang) und Kapitel II.4., S. 106.

16 Zur Personalpolitik im preuß. JM 1933/34 vgl. Kapitel III.2., S. 223.

17 Während der Geschäftsbereich Schäfers dadurch auf die Strafgesetzgebung und das bäuerliche Recht (nurimehr Abt. II) beschränkt wurde, änderten sich bei den Abteilungen Volkmars (Bürgerliches Recht und bürgerliche Rechtspflege, nunmehr Abt. IV) und Richters (Handelsrecht, Verkehrsrecht, öffentliches Recht und Völkerrecht, nunmehr Abt. V) nur die Abteilungsziffern.

18 Vgl. Personalakten des RJM (BA).

19 Vgl. DJ 1934, S. 1618, und 1935, S.8.

$20 \mathrm{Zu}$ Palandt und Klässel vgl. Kapitel III.2., S. 224. Zur Parteizugehörigkeit der Abteilungsleiter vgl. auch Kapitel III.1.d., S. 219.

21 Laut Geschäftsverteilungsplan v. 16./22.10.34 (a.a.O., Anm.15): Busch, Dörffler, Hauptvogel, Herwig, Hesse, Koehler, Kriege, Krieger, Kunisch, Lentz, Lutterloh, Marx, Pritzsch, Reichau, Rietzsch, Edgar Schmidt, Staud, Weddige und Willers.

22 Vgl. Personalverzeichnis des höheren Justizdienstes, bearbeitet im Büro des RJM, Berlin 1938; Personalunterlagen im DC Berlin und Ernennungsvorschläge in den Akten des RFiM (BA, Sign. R 2/23918).

23 Bender, Dietz, Kollat, Kühn, Osburg und Sauthoff. 
Richter, Staatsanwälte und anderen höheren Beamten nunmehr ca. 100 Referenten zählte, mußte der Personalbestand weiter vergrößert werden, um die Aufgaben zu bewältigen, die durch die Übernahme aller Landesjustizverwaltungen im Reich anfielen. Um dem Ministerium den ausgesprochen „preußischen“ Charakter zu nehmen, den es nach der Vereinigung mit dem preußischen Justizministerium bekommen hatte, wurden Beamte aus den anderen deutschen Ländern herangezogen. Denn auch das Reichsjustizministerium hatte überwiegend aus der preußischen Justiz stammende Planstellenbeamte in die Vereinigung eingebracht: Ausnahmen bildeten die Ministerialräte Leopold Schäfer und Otto Wagner, die in den zwanziger Jahren aus Bayern bzw. Württemberg ins Ministerium gekommen waren, sowie die Oberregierungsräte Doerner und Dohnanyi, die aus der badischen bzw. hamburgischen Justiz stammten. Nichtpreußen hatte es dagegen häufiger unter den Hilfsarbeitern des Ministeriums gegeben, d.h. unter denjenigen Beamten, die von ihrer Landesjustizverwaltung zur Verwendung im Reichsjustizministerium beurlaubt worden waren. Auch Schlegelberger hatte z. B. im ersten Halbjahr 1934 als seine persönlichen Referenten den württembergischen Amtsgerichtsrat Heintzeler sowie den sächsischen Oberlandesgerichtsrat Wilke berufen, mit dem ihn außer einem engen Vertrauensverhältnis und gemeinsamer wissenschaftlicher und publizistischer Tätigkeit ein besonderes Schicksal verbinden sollte: bei einer gemeinsamen Dienstfahrt anläßlich der Übernahme der österreichischen Justiz erlitten beide am 17. Mai 1938 vor Wien einen Autounfall, bei dem Wilke ums Leben kam und Schlegelberger schwer verletzt wurde. ${ }^{24}$

Die Zahl der nichtpreußischen Hilfsarbeiter wurde um die Jahreswende 1934/35 auf 24 gebracht; von ihnen kamen 5 aus Württemberg, je 4 aus Bayern und Sachsen, 3 aus Thüringen und je 2 aus Baden, Hamburg, Hessen und Mecklenburg. Ihnen standen immer noch 43 preußische Hilfsarbeiter gegenüber. ${ }^{25}$ Mit der Auflösung der Landesjustizministerien traten am 1. April 1935 von dort auch Ministerialräte in die nun endgültig als „Reichsjustizministerium“ etablierte oberste Justizbehörde ein: Malzan aus Hessen, Zehrfeld aus Sachsen, Ruppert aus Baden, Bälz aus Württemberg sowie Drescher und Engert aus Bayern. Von ihnen war nur der Altparteigenosse Engert Nationalsozialist, bei den anderen scheinen für die Übernahme ausschließlich fachliche Gründe maßgebend gewesen zu sein ${ }^{26}$; Malzan, der Schwierigkeiten mit dem hessischen Gauleiter/Reichsstatthalter Sprenger hatte, galt sogar als ,ausgesprochener Vertreter des [Weimarer] Systems“. ${ }^{27} \mathrm{Da}$ auch der bereits erwähnte, aus Sachsen stammende Oberlandesgerichtsrat Wilke in eine Ministerialratsstelle befördert worden war,

${ }^{24}$ Zu Dr. Heintzeler vgl. W. Heintzeler, Der rote Faden, Stuttgart 1983; zu Dr. jur., Dr. rer. pol. Wilke, der Mitglied zahlreicher internationaler Gremien und wie Schlegelberger Dozent an der Berliner Universität war, vgl. den Nachruf in DJ 1938, S.799; zum Unfall Ber. Schlegelbergers an das RJM v. 6.8.38 (Personalakten Schlegelberger, BA).

25 Vgl. die Aufstellung der Referenten und Hilfsarbeiter der RuPrJM (Stand 1.1.35) im Handbuch über den Preußischen Staat, herausg. vom Preußischen Staatsministerium für das Jahr 1935, Berlin 1935, S. 72 ff. Die landsmannschaftliche Herkunft wurde dem Personalverzeichnis (s. Anm.22), Personalakten u.a. Quellen entnommen.

${ }^{26} \mathrm{Zu}$ Engert vgl. Kapitel III.2., S. $232 \mathrm{f}$. Bälz, der im württemb. JM noch ORegRat war, aber dort bereits aus einer MinRatsstelle besoldet wurde, war „Märzgefallener“, offenbar um seine bisherige DVP-Zugehörigkeit auszugleichen (Personalakten des RJM, BA). Auch zum folgenden vgl. Stellenbesetzung des RJM 1935, Kalender für Justizbeamte für das Jahr 1936, bearbeitet im Büro des RJM, Berlin 1936, S.22 f.

27 Vgl. den vertraul. Ber. des GStA Darmstadt an den RJM v. 6.5.36 (Personalakten des RJM Eckert, BA). Daraus geht hervor, daß Gürtner mit Malzan offenbar enge persönliche Beziehungen unterhielt und mit ihm zusammen musizierte. 
gab es nunmehr 7 „nichtpreußische“ Ministerialräte im Reichsjustizministerium. Sie ergänzten die anderen 33 Ministerialräte, die sich aus 11 Räten des „alten“ Reichsjustizministeriums ${ }^{28}, 16$,preußischen ${ }^{\text {“29 }}$ und 6 neu ernannten, aus der preußischen Justiz stammenden ${ }^{30}$ Ministerialräten zusammensetzten. $\mathrm{Zu}$ diesen neu Ernannten gehörte Johannes Haastert, Parteigenosse seit 1932, den sich Freisler schon im August 1933 als Hilfsarbeiter ins Haus geholt, in rascher Folge zum Amtsgerichtsdirektor und Oberlandesgerichtsrat befördert und zum persönlichen Referenten gemacht hatte: er sollte es 1939 zum Ministerialdirigenten und 1943 zum Oberlandesgerichtspräsidenten in Kiel bringen. Auch Freislers zweiter persönlicher Referent ab Oktober 1934, der junge Staatsanwalt Ebert, war NSDAP-Mitglied seit 1932 und wurde Verbindungsführer des NS-Kraftfahrkorps (NSKK) zum Ministerium. ${ }^{31}$

Die 40 Ministerialräte, die das Reichsjustizministerium 1935 besaß, wurden von 24 Referenten in planmäßigen Stellen unterstützt, zu denen die 3 aus dem ursprünglichen Reichsjustizministerium stammenden Oberregierungsräte ${ }^{32}$ nebst 4 solchen Regierungsräten gehörten. ${ }^{33}$ Die übrigen 10 Referenten-Planstellen wurden mit einigen bisher als Hilfsarbeiter tätigen, aber auch einigen neu von außen hinzutretenden nichtpreußischen Beamten besetzt, und zwar mit je 2 Oberregierungsräten aus Bayern und Thüringen, 1 Oberregierungsrat und 2 Regierungsräten aus Württemberg und $3 \mathrm{Be}-$ amten aus Sachsen. ${ }^{34} \mathrm{Zu}$ den Sachsen gehörte der Erste Staatsanwalt Herbert Klemm - Parteigenosse seit 1931 und SA-Sturmbannführer -, den der sächsische Justizminister Thierack schon seit März 1933 als persönlichen Referenten und Dezernenten für politische Strafsachen verwendet hatte. Freisler gab ihm in der Strafrechtsabteilung das Generalreferat für politische Strafsachen, und die Oberste SA-Führung bestellte ihn zum Verbindungsführer für das Reichsjustizministerium. Klemm sollte im Kriege weiter Karriere machen: nach einer mehrjährigen Abordnung zum Reichskommissar für die besetzten niederländischen Gebiete und zur Partei-Kanzlei sollte er im Dezember 1943 unter seinem früheren Chef Thierack zum Staatssekretär im Reichsjustizministerium ernannt werden. ${ }^{35}$

Bei dem starken Personalbestand an Ministerialräten, Referenten und Hilfsarbeitern, den das Reichsjustizministerium durch die „Verreichlichung“ der deutschen Ju-

${ }^{28}$ Von den 12 MinRäten des ursprünglichen RJM war Leopold Schäfer am 1.4.35 zum MinDirig. befördert worden.

${ }^{29}$ Von den in Anm.21 aufgeführten 19 preußischen MinRäten waren Lutterloh und Marx am 1.1.35 zu Min.Dirigenten befördert worden, Kunisch ans preuß. Ministerium für Wissenschaft, Kunst und Volksbildung gegangen.

${ }^{30}$ Anders und Heinrich Richter (vormals KGRäte), Haastert und Kutzner (vormals OLGRäte), die sämtlich schon 1934 als Hilfsarbeiter im Ministerium tätig waren, sowie Pätzold und Riese (vormals ORegRäte).

${ }^{31}$ Zu Haastert vgl. DJ 1943, S. 567 f., zu Ebert, der 1936 OStA und 1939 MinRat wurde, vgl. Ernennungsvorschlag v. 7.2.39 (Akten des RJM, BA, Sign. 1792).

32 Neben Doerner und Dohnanyi seit 1.2.35 Westfeld, der seit 1914 im RJM arbeitete und zuletzt Ministerialbürodirektor war.

${ }^{33}$ Für die Namen der preuß. ORegRäte vgl. Anm. 23, wobei an die Stelle Kühns, der Anfang 1935 auf Antrag in den Ruhestand ging, der bisherige LGRat Knapp (Pg. seit 1928 und Fachgruppenleiter der Fachschaftsgruppe Justizministerium) trat, der am 22.7.35 im Alter von 33 Jahren in seinem Amtszimmer an Herzschlag starb (vgl. DJ 1935, S. 1051, 1974). Der siebente preuß. ORegRat war der am 1.4.35 ernannte bisherige RegRat Klee. Die erwähnten vier preuß. RegRäte waren: Lauterbach, Porath, Stampe und Urlacher.

${ }^{34}$ Holzbauer, Lechner (Bayern), Huber, Willi Schmidt (Thüringen), Paul Schmidt, Däubler, Emil Müller (Württemberg), AGDir. Dittrich, LGDir. Eichler und EStA Klemm (Sachsen).

35 Zu Klemm, der im April 1939 zum MinRat und im Dezember 1942 zum MinDir. befördert wurde, vgl. Personalakten des RJM (BA), Personalunterlagen im DC Berlin sowie DJ 1944, S.2. 
stizverwaltung aufwies, bekamen 1935 die Leiter der Abteilungen I bis III je einen Ministerialdirigenten zur Seite gestellt. Für die Abteilung I unter Nadler wurde dazu Lutterloh ernannt, der bereits 1919 ins preußische Justizministerium berufen und seit 1921 Ministerialrat war. Zum Ministerialdirigenten in der Abteilung II, die Ernst Schäfer leitete, wurde Ministerialrat Leopold Schäfer ausersehen - auch er schon 1920 Geheimer Regierungsrat und Vortragender Rat im Reichsjustizministerium. In der von Crohne geführten Abteilung III wurde Marx Ministerialdirigent, der seit Mitte der zwanziger Jahre als Oberregierungsrat im Berliner Strafvollzugs- und Gefängniswesen gearbeitet hatte und seit 1931 Ministerialrat im preußischen Justizministerium gewesen war. ${ }^{36}$ Daß keiner der neuen Ministerialdirigenten der NSDAP angehörte, zeigt, daß bei den Personalentscheidungen für die leitenden Posten im Ministerium immer noch eine politisch gemäßigte und fachlich orientierte Linie eingehalten werden konnte. Zusammen mit den Leitern der Abteilung V, Schneller, und der Abteilung LA, Klässel, zählte das Reichsjustizministerium 1935 nunmehr fünf Ministerialdirigenten.

Der Gesamtpersonalbestand des Reichsjustizministeriums belief sich zum Jahresende 1935 auf 508 Beamte, 85 Angestellte und 53 Arbeiter, d.h. auf insgesamt 646 Kräfte. ${ }^{37}$ Von den Beamten stammten 90 aus nichtpreußischen Ländern. Nach 1935 sank die Zahl der Beamten ${ }^{38}$ im Ministerium vorübergehend - im November 1936 betrug sie 486 -, stieg aber ab 1938 ständig an. Vor Kriegsausbruch besaß das Ministerium mit 599 Beamten - davon 249 des höheren, 214 des gehobenen, 65 des mittleren und 71 des einfachen Dienstes -, 108 Angestellten und 71 Arbeitern insgesamt 778 Kräfte. ${ }^{39}$ Der Personalbestand wuchs auch im Kriege weiter und erreichte bis zum Tode Gürtners im Januar 1941662 Beamte - 284 des höheren, 222 des gehobenen, 76 des mittleren und 76 des einfachen Dienstes nebst 4 einberufenen Ruhestandsbeamten -, 154 Angestellte und 76 Arbeiter, also insgesamt 892 Personen. ${ }^{40} \mathrm{Da}$ jedoch 28 Gefolgschaftsmitglieder (26 Beamte und 2 Angestellte) zu anderen Behörden abgeordnet und 213 (189 Beamte, 16 Angestellte und 8 Arbeiter) zur Wehrmacht einberufen worden waren, standen dem Reichsjustizministerium zu diesem Zeitpunkt nur 651 Kräfte tatsächlich zur Verfügung.

Seit seiner Ủbernahme in das Reichsjustizministerium nahm Freisler, der als Staatssekretär gleichberechtigt neben Schlegelberger stand, auf die Personalpolitik Einfluß. Zwar teilte er sich mit diesem die Aufsicht über die Personalabteilung und war inso-

${ }^{36} \mathrm{Zu}$ Lutterloh, Marx und Leopold Schäfer vgl. Personalakten des RJM (BA).

${ }^{37}$ Die Beamten gliederten sich in: 1 Minister, 2 Staatssekretäre, 6 Ministerialdirektoren (ihnen wurde planstellenmäßig der Präs. des RJP - der späteren Abt. VII - Palandt zugerechnet), 6 Ministerialdirigenten (einschließlich des Vizepräs. des RJP Creutzfeld), 40 Ministerialräte, 23 weitere planmäßige Beamte des höheren Dienstes (nach dem Tod des ORegRats Knapp, vgl. Anm. 33), 62 Hilfsarbeiter, 39 Amts- und Landrichter sowie Gerichtsassessoren, 204 planmäßige Beamte des Büro-, Kanzlei- und Amtsgehilfendienstes, 110 Hilfsarbeiter dieses Dienstes, 11 planmäßige hauptamtliche und 4 nichtplanmäßige Prüfer des RJP. Auch im folgenden sind die Zahlen den Akten des RJM (BA, Sign. R 22/5043) entnommen.

38 Stets einschließlich der nichtplanmäßigen beamteten „Hilfsarbeiter".

39 Stand 1.7.39. Die bei F. Sauer (MinRat im RJM), Das Reichsjustizministerium, Berlin 1939, S. 54, für Juni 1939 veröffentlichten Zahlen stimmen mit dem in den Akten für 1.4.39 angegebenen Personalbestand überein, wobei Sauer allerdings bei den Beamten des höheren Dienstes die Prüfer des RJP nicht mit einbezieht.

${ }^{40}$ Stand 1.1.41; einschließlich der Kräfte beim „Reichskommissar für die Behandlung feindlichen Vermögens", der dem RJM angegliedert war. 
fern nur für bestimmte Personalbereiche zuständig, besaß aber bei sämtlichen Personalsachen, die leitende Beamte betrafen, ein Mitzeichnungsrecht. ${ }^{41}$ Freisler war noch keine vier Wochen im Haus, als er sich für „verpflichtet“ hielt, Schlegelberger in einem Schreiben darauf aufmerksam zu machen, es gehe „das Gerücht, daß einer der Herren Ministerialdirektoren jüdischer Abstammung sei“. Er habe versucht, sich „in diskreter Weise“ darüber Klarheit zu verschaffen, um dem Gerücht im Interesse des Ministeriums entgegentreten zu können, habe sich aber aus den vorhandenen Unterlagen „weder nach der einen noch nach der anderen Richtung ein Bild“ machen können. Die gleiche Behauptung werde auch hinsichtlich eines Ministerialrats aufgestellt; wenn sie sich bewahrheite, erhebe sich die Frage, ob der Betreffende - selbst wenn er nach dem Berufsbeamtengesetz Beamter bleiben könne - weiter im Ministerium tätig sein dürfe. Ferner werde auch von zwei Reichsgerichtsräten und einem Reichsanwalt gesagt, daß sie keine „Arier“ seien. Er „würde eine solche Tatsache für vollkommen unmöglich halten “ und habe bereits Gürtner telefonisch darüber informiert, da er „für die Strafrechtspflege die Verantwortung trage“. Er bitte daher dringend, ihm „mitzuteilen, welche Folgerungen daraus gezogen“ würden. Da „die Frage der Arbeit von Nichtariern in besonders hervorgehobenen Stellen, um die es sich hier handelt, eine grundsätzliche Frage“ sei, sei er "an der weiteren Behandlung der Angelegenheit besonders interessiert" ${ }^{42}$ Bei den von Freisler Beanstandeten handelte es sich um den bereits erwähnten Abteilungsleiter Ministerialdirektor Richter und um einen Ministerialrat, der schon seit 1927 diesen Posten im Reichsjustizministerium einnahm und in Richters Abteilung arbeitete, ferner um die Reichsgerichtsräte Koehne und Königsberger sowie um den Reichsanwalt Neumann, die Schlegelberger mit der Maßgabe in ihren Ämtern belassen hatte, daß die Richter einem Zivilsenat des Reichsgerichts überwiesen würden und der Reichsanwalt nicht mehr öffentlich in Sitzungen auftreten sollte. ${ }^{43}$ In seiner Domäne der Strafjustiz war Freisler mit dieser Intervention erfolgreich: Reichsanwalt Neumann wurde im Mai 1935 in den Wartestand ${ }^{44}$, die beiden Reichsgerichtsräte im weiteren Verlauf des Jahres in den Ruhestand versetzt. ${ }^{45}$ Dagegen konnte er hinsichtlich der beiden Ministerialbeamten zunächst nichts ausrichten, obwohl sich Gürtner und Schlegelberger darüber im klaren sein mußten, daß sie diese "Nichtarier“ in leitenden Stellungen gegenüber dem Drängen der Partei auf die Dauer kaum würden halten können.

Daß sich Freisler über die „rassische Abstammung“ Richters anhand der im Ministerium geführten Personalunterlagen kein rechtes „Bild“ hatte machen können, war nicht verwunderlich. Nachforschungen in diese Richtung wurden hier ohne besonderen Eifer betrieben, um nicht erst schlafende Hunde zu wecken. Bis zum Erlaß des Berufsbeamtengesetzes vom 7. April 1933 war die Abstammungsfrage innerhalb des Mi-

${ }^{41}$ Vgl. Kapitel II.4., S. 106, dazu Schr. Freislers an Schlegelberger v. 15.11.34 über die gegenseitige Abgrenzung ihrer Zuständigkeiten, besonders hinsichtlich der Bearbeitung der Personalfragen (Akten des RJM, BA, Sign. R 22/4723).

42 Vgl. Schr. Freislers an Schlegelberger vom „November 1934“, a.a.O.

43 Vgl. dazu Kapitel III.1.a., S. 127.

${ }^{44}$ Neumann war vom Januar bis Ende April 1935 krank, bei seiner Rückmeldung wurde er beurlaubt und aufgrund $\S 149$ Abs. 2 GVG in den Wartestand, zum Jahresende aber endgültig in den Ruhestand versetzt, vgl. F. K. Kaul, Geschichte des Reichsgerichts, Band IV, 1933-1945, Glashütten im Taunus 1971, S.319f.

45 Koehne ab 1.8.35, vgl. a.a.O., S. 277. Königsberger ist jedenfalls im Besetzungsplan des RG für den III. Zivilsenat ab 1936 nicht mehr aufgeführt (a.a.O., S. $334 \mathrm{ff}$.). 
nisteriums überhaupt nicht aufgerollt worden. Auch danach verzichtete man auf jegliche Angaben über die Abstammung von Eltern und Großeltern, sobald feststand, daß ein Mitarbeiter „Altbeamter" seit 1914 oder „Frontkämpfer" des Weltkrieges war. Deshalb hatte Schlegelberger am 23. bzw. 29. September 1933 zu den Personalakten der beiden gefährdeten Ministerialbeamten nur den lakonischen Vermerk nehmen lassen, daß die Prüfung nach den Paragraphen des Berufsbeamtengesetzes „keinen Anlaß zu Maßnahmen gegeben" habe. Wahrscheinlich beruhte Freislers Vorstoß gegen den erwähnten Ministerialrat auf einer Denunziation, die ein Berliner Parteigenosse und SA-Mann schon am 14. September 1934 bei der Reichskanzlei mit der Bitte eingereicht hatte, sie an das Reichsjustizministerium weiterzuleiten. Durch gezielte Nachforschungen hatte dieser Parteigenosse in Erfahrung gebracht, daß der Ministerialrat einen jüdischen Großvater hatte. Da auf seine Eingabe nichts erfolgte, sandte er Anfang Februar 1935 selbst eine Abschrift seiner Denunziation an das Justizministerium ${ }^{46}$, wo sie schließlich beim zuständigen Personalreferenten landete. Am 11. Februar unterrichtete der Ministerialrat daraufhin Gürtner in einem persönlichen Handschreiben, er „sehe sich gezwungen“ mitzuteilen, daß die Eltern seines Großvaters väterlicherseits Juden gewesen seien und sich der Großvater erst später evangelisch habe taufen lassen. Zur Mitteilung dieser Tatsache, die ihm selbst erst durch Nachforschungen eines Verwandten bekannt geworden sei, fühle er sich besonders deshalb verpflichtet, weil er vor einiger Zeit in einer Unterredung mit dem Personalreferenten eine jüdische Abstammung nach bestem Wissen verneint habe. Er habe bislang schon deshalb keine Zweifel an seiner ,arischen“ Abstammung gehabt, als seine Angehörigen alle dafür erforderlichen Bescheinigungen anstandslos erhalten hätten und die Söhne seiner Schwester in die SS aufgenommen worden seien, ,in der der eine auch die für die Eheschließung erforderlichen Nachweise erbracht" habe. Gürtner verfügte nach Kenntnisnahme dieses Schreibens kurzerhand, daß gegen den Ministerialrat auch weiterhin nichts zu veranlassen sei. ${ }^{47}$

Der von Gürtner zur Durchführung des Berufsbeamtengesetzes herausgegebene Fragebogen vom 23. Mai $1933^{48}$, der im Juni an die Angehörigen des Ministeriums verteilt worden war, hatte sich lediglich auf die gegenwärtige oder frühere Mitgliedschaft und Funktion bei einer politischen Partei, einer kommunistischen Hilfs- oder Ersatzorganisation, beim Reichsbanner, der Liga für Menschenrechte, dem Republikanischen Beamten- bzw. Richterbund oder der Eisernen Front bezogen. Für die Richtigkeit und Vollständigkeit der Angaben stand der Beamte mit seinem Diensteid ein. Der Minister konnte jedoch weitere Auskünfte fordern oder Ermittlungen anordnen. Im Gegensatz zu den beamteten Mitarbeitern waren die Angestellten des Ministeriums zu dieser Auskunft nicht verpflichtet; denjenigen von ihnen, die demnächst Beamte werden wollten, wurde jedoch die Beantwortung dieser Fragen anheimgestellt. Die Fragebögen waren binnen einer Woche verschlossen im Personalbüro des Ministeriums abzugeben und wurden nach Prüfung zu den Personalakten genommen.

46 Die erwähnten Schr. finden sich in der Personalakte des MinRats (BA). Die Denunziation v. 14.9.34 richtete sich gleichzeitig gegen zwei Neffen des MinRats, die trotz des erwähnten jüdischen Vorfahren in die SS eingetreten waren. Da die RK das Schr. auf Wunsch des Denunzianten auch dem zuständigen SS-Oberabschnitt zuleitete, erhielt es das RJM am 21.3.35 nochmals vom RFSS/Chef des SS-Hauptamtes zugesandt.

47 Vgl. Schr. des MinRats an Gürtner v. 11.2.35 nebst Verm. Schlegelbergers v. 12.2.35 (a.a.O.)

48 Diese und die im folgenden geschilderten Fragebogenaktionen wurden den Personalakten des RJM (BA) entnommen. 
Wie aus diesen Akten hervorgeht, mußten die Ministerialbeamten in den folgenden Jahren eine Reihe solcher Fragebogenaktionen über sich ergehen lassen. Die nächste vom 10. April 1935 betraf zunächst nur die Beamten des höheren Dienstes und bezog sich auf die frühere Zugehörigkeit zu einer Freimaurerloge und den Freimaurergrad. Sie wurde durch ein Schreiben des Stellvertreters des Führers vom 9. Februar ausgelöst, der es „für eine Selbstverständlichkeit“ ansah, daß ehemalige Freimaurer - wie bisher schon in den Organisationen der Bewegung - auch im Staatsapparat nicht neu in leitende Stellen ernannt und darüber hinaus künftig grundsätzlich von jeder Beförderung ausgeschlossen bleiben sollten. Als Grund wurde die Gefahr der Vetternwirtschaft unter ehemaligen Logenbrüdern angeführt. Ausnahmen sollten nur zugelassen werden, wenn sich der zu Befördernde vor der Machtübernahme aktiv in der Bewegung betätigt hatte. ${ }^{49}$ Diese Fragebogenaktion wurde im Juli 1935 auf alle Beamten des Reichsjustizministeriums einschließlich der mittleren und unteren Dienste ausgedehnt. ${ }^{50}$ Sie war für ehemalige Freimaurer auch insofern von Bedeutung, als Betroffene ohne ausdrückliche Zustimmung des Stellvertreters des Führers nicht mehr mit Personalangelegenheiten beschäftigt, d.h. zu Behördenvorständen, Personalreferenten und Mitgliedern von Dienststrafgerichten bestellt werden durften. ${ }^{51}$

Am 2. September 1935 wurden alle Beamten des Ministeriums aufgefordert, binnen einer Woche ihre frühere Zugehörigkeit zu Beamtenvereinigungen mit möglichst genauen Daten anzugeben, gleich ob die Vereine „auf berufsethischer, beamtenpolitischer, beamtenwirtschaftlicher, konfessioneller oder sonstiger Grundlage " beruhten; auch Sport- und Wohnungsvereine waren einbezogen. ${ }^{52}$

Am 14. September 1935, einem Sonnabend, wurde auf Veranlassung Freislers angeordnet, daß die Beamten der ihm unterstehenden Abteilungen des Ministeriums durch Ausfüllen eines Fragebogens „sofort - spätestens bis Montag Mittag“ - offenlegen mußten, ob sie Mitglied der NSDAP waren, wie ihre Mitgliedsnummer und das Eintrittsdatum lauteten. Was Freisler zu dieser plötzlichen Maßnahme veranlaßte, ist aus den Akten nicht ersichtlich. Es hatte sich aber generell herausgestellt, daß die Vermerke über die Zugehörigkeit zur NSDAP und ihren Organisationen in den Personalakten nicht zuverlässig waren, da die Angaben in dem erwähnten Fragebogen vom Mai 1933 veraltet oder ohne nähere zeitliche Bestimmung gemacht worden waren. Für die anderen Abteilungen des Ministeriums wurde diese Aktion daher „zur Vervollständigung der Akten" am 16. Oktober 1935 nachgeholt. ${ }^{53}$ Da bei Freislers vorausgegangener Aktion viele Beamte, die die Frage der Parteimitgliedschaft verneinen mußten, zum Ausgleich vermerkt hatten, daß sie immerhin dieser oder jener anderen Organisation der Bewegung angehörten, wurde der Fragebogen diesmal auf die Mitgliedschaft bei den Gliederungen der Partei - SA, SS und NS-Kraftfahrkorps

49 Das Schr. des St.d.F. v. 9.2.35 ist in der RV des RJM an die höheren RJBehörden v. 10.4.35 (Akten des RJM, BA, Sign. R 22/4470) auszugsweise wiedergegeben.

so Vgl. AV des RJM v. 25.7.35 (DJ 1935, S. 1084). Sie beruhte auf einem entsprechenden RdErl. des RuPrMdI v. 10.7.35.

51 Vgl. RdErl. des RuPrMdI v. 2.9.36 mit Regelung der Ausnahmen, wiedergegeben in der AV des RJM v. 12.9.36 (DJ 1936, S. 1428); dazu die RV des RJM an die höheren RJBehörden v. 8.11.36 (Akten des RJM, a.a.O.).

52 Die Anordnung beruhte auf einem RdErl. des RuPrMdI vom 17.8.35, vgl. AV des RJM v. 2.9.35 (DJ 1935, S. 1320).

53 Vgl. Personalaktenbestand des RJM (BA). 
(NSKK) - und den angeschlossenen Verbänden der Partei: BNSDJ, NS-Volkswohlfahrt (NSV), NS-Kriegsopferversorgung (NSKOV), Reichsbund Deutscher Beamten (RDB) und Deutsche Arbeitsfront (DAF) ausgedehnt. Im Februar 1938 mußten die Ministerialbeamten schließlich auch über ihre Mitgliedşchaft beim NS-Fliegerkorps, Reichsluftschutzbund, dem Deutschen Roten Kreuz, der Technischen Nothilfe, dem Reichsbund der Kinderreichen und bei Sportvereinen nebst ihrer Stellung und Beitrittsdatum Auskunft erteilen. ${ }^{54}$

Die Klärung der arischen Abstammung wurde für die Beamten des Reichsjustizministeriums auch nach der Ersten Verordnung zum Reichsbürgergesetz vom 14. November 1935, die die Ausnahmebestimmungen des Berufsbeamtengesetzes für Juden aufhob, nur zögernd vorangetrieben. Während die nachgeordneten Justizbehörden im Dezember aufgefordert wurden, von allen Beamten - soweit noch nicht geschehen die Beantwortung eines vom Ministerium vorgeschriebenen Einheitsfragebogens über die „arische“ Abstammung bis zu den beiderseitigen Großeltern nebst Vorlage der erforderlichen Urkunden zu veranlassen und über die Maßnahmen, die aufgrund der Ergebnisse ergriffen wurden, bis zum 15. Januar 1936 zu berichten ${ }^{55}$, war zu diesem Termin noch nicht einmal die Befragung der Beamten des Ministeriums angeordnet worden. Als der zuständige Referent Ende Januar darüber Vortrag hielt und betonte, daß für die Beamten des Ministeriums doch „dasselbe verlangt“ werden müsse wie von anderen Justizbeamten, erhielt er den Bescheid, mit einer solchen Anordnung für das Haus solle „zunächst noch bis Ende März 1936 zugewartet werden“.56 Unterdessen wurde im Februar Ministerialdirektor Richter in den Wartestand versetzt: es war wohl klargeworden, daß er nach der bevorstehenden Offenlegung seiner Abstammung nicht mehr gehalten werden konnte. ${ }^{57}$ Schließlich erging am 15. April 1936 an sämtliche Beamten des Reichsjustizministeriums die Aufforderung, für sich und ihre Ehefrauen den erwähnten Einheitsfragebogen auszufüllen und für die Angaben Urkunden beizubringen. Dabei mußten die Beamten unter Berufung auf ihren Diensteid versichern, daß ihnen „keine Umstände bekannt [seien], welche die Annahme rechtfertigen könnten", daß sie oder ihre Frauen nichtarischer Abstammung waren. Frist war bis zum 10. Oktober 1936 gesetzt. Die Unterlagen waren in verschlossenem Umschlag beim Hauptbüro des Ministeriums einzureichen und wurden normalerweise vom Ministerialbürodirektor geprüft. Soweit es sich jedoch um Beamte des höheren Dienstes handelte, gingen die Unterlagen verschlossen an zwei Ministerialräte weiter, die als Personalreferenten für den höheren Dienst mit der Prüfung beauftragt waren und zunächst auch als einzige Einblick in die vertraulich zu behandelnden Unterlagen hatten. Beamte, die den Nachweis der ,arischen“ Abstammung erbracht hatten, erhielten eine

54 Anlaß war der RdErl. des RuPrMdI v. 5.1.38 (AV des RJM v. 25.1.38, DJ 1938, S. 130). Durch den RdErl. des RuPrMdI v. 22.8.38 (AV des RJM v. 23.9.38, DJ 1938, S. 1545) wurde die Mitteilungspflicht für die Personalakten auf den NS-Deutschen Reichskriegerbund (Kyffhäuser), den Reichskolonialbund, den Altherrenbund der Deutschen Studenten (NS-Studentenkampfhilfe), den Deutschen Reichsbund für Leibesübungen sowie auf die Freiwilligen Feuerwehren ausgedehnt. Zum Ergebnis dieser Erhebungen (Stand 17.12.38) s. Kapitel III.1.d., S.219.

5s Vgl. RV des RJM an die höheren Justizbehörden v. 7., 14. und 18.12.35 (Akten des RJM, BA, Sign. R 22/4433).

$56 \mathrm{Vgl}$. Referentenverm. v. 31.1 .36 (a.a.O.).

57 Der Versuch, durch Hitler eine Ausnahme nach $\S 7$ der Ersten VO zum ReichsbürgerG zu erwirken, war angesichts der Haltung der Partei, die sich auch schon in Freislers Vorstoß gegen den Verbleib Richters vom November 1934 kundgetan hatte, als aussichtslos anzusehen. 
vom Leiter der Personalabteilung gezeichnete Bescheinigung des Ministeriums. „Fälle, in denen die arische Abstammung zweifelhaft oder ihr Nachweis als nicht erbracht anzusehen" war, mußten die beiden Personalreferenten Gürtner persönlich vortragen. ${ }^{58}$ Anläßlich des Vortrages über den erwähnten Ministerialrat entschied Gürtner am 16. Oktober, „daß es bei seiner früheren Weisung verbleiben“ und der Ministerialrat „, seiner derzeitigen Verwendung belassen werden“ solle" ; da es sich um einen „Vierteljuden“ handelte, war Gürtners Entscheidung rechtlich durch die Bestimmungen der Ersten Verordnung zum Reichsbürgergesetz gedeckt. ${ }^{60}$ Die einschlägigen Vorgänge wurden zu den Personalakten des Ministerialrats in einen verschlossenen Umschlag genommen, der ohne Zustimmung des Personalreferenten oder dessen Dienstvorgesetzten nicht geöffnet werden durfte: der Beamte blieb bis zu seinem Tode im Amt. ${ }^{61}$

Als sich bei dieser Fragebogenaktion auch an der ,arischen“ Abstammung der Ehefrau eines Ministerialdirektors Zweifel herausstellten, wies Gürtner den Personalreferenten an, zunächst nichts zu unternehmen, sondern ein Gutachten der Reichsstelle für Sippenforschung abzuwarten, das ein Verwandter der Frau für eigene Zwecke beantragt hatte. Selbst nachdem sich die Nachforschungen dieser Stelle schon über Monate hingezogen hatten, da Urkunden aus dem Ausland herbeigeschafft werden mußten, entschied Gürtner, daß das Ergebnis „nach wie vor abgewartet $u$. die ganze Abstammungsangelegenheit bis dahin weiter streng vertraulich behandelt [!] werden" sollte. Obwohl aus dem Abstammungsbescheid der Reichsstelle vom April 1938 schließlich hervorging, daß die Frau jüdischer „Mischling 2. Grades“ war ${ }^{62}$, blieb der Ministerialdirektor dennoch im Amt.

Auch in anderer Hinsicht wurde diese Fragebogenaktion für die Beamtenschaft des Ministeriums großzügig gehandhabt. Als nach dem Verstreichen der gestellten Frist noch 129 Ariernachweise ausstanden, wurden die Säumigen Anfang November 1936 zwar aufgefordert, ihrer Verpflichtung nachzukommen oder die Hinderungsgründe mitzuteilen. ${ }^{63}$ Trotzdem blieb in der Folgezeit eine Liste unerledigter Ariernachweise übrig, die zunāchst monatlich, dann in größeren Abständen überprüft und auf den neuesten Stand gebracht wurde. Die Säumigen unter den Beamten des höheren Dienstes befanden sich dabei in erlauchter Gesellschaft: Als der Ministerialbürodirektor am 26. Januar 1938 [!] vermerkte, daß in den Personalakten von Schlegelberger und Freisler „Fragebogen über ihre arische Abstammung und die arische Abstammung ihrer Ehefrauen nicht enthalten" seien, und diesbezüglich um eine Entscheidung bat, wurde er durch den lakonischen Satz des Personalreferenten beschieden, es sei „nichts zu veranlassen" ${ }^{64}$ In der Tat finden sich die Fragebogen zur arischen Abstammung - im Gegensatz zu den Fragebogen der anderen erwähnten Erhebungen - in den Personalakten der beiden Staatssekretäre nicht. Folglich blieb auch in ihren Personalbögen, die

58 Vgl. Hausverf. Gürtners v. 15.4.36 an sämtliche Beamten des RJM einschließlich des RJP (Akten des RJM, BA, Sign. R 22/3792).

59 Vgl. Verm. des Personalref. v. 16.10.36 (Personalakten, a.a.O., s. Anm. 46).

${ }^{60} \mathrm{Zu}$ dieser VO vgl. Kapitel III.1.b., S.169f., und Kapitel VII.3.c., S. 877 f.

${ }^{61}$ Der Umschlag wurde erstmals in der Zeit Thieracks 1943 wieder geöffnet und erneut verschlossen. Vgl. die Verm. v. 10.4. und 5.10.43 (a.a.O.).

62 Zum Voranstehenden vgl. die Verm. des zuständigen MinRats v. 17.10.36 bis 31.7.37 sowie den Abstammungsbescheid der Reichsstelle für Sippenforschung v. 6.4 .38 (Personalakten, BA).

${ }^{63} \mathrm{Vgl}$. die Referentenverm. v. 28.10., 3. und 25.11.36 (Akten des RJM, BA, Sign. R 22/4433), diesen Aktenbestand auch zum folgenden.

${ }^{64}$ Vgl. Verm. v. 26. und 28.1.38 (Personalakte Schlegelberger, BA). 
für die höheren Beamten des Reichsjustizministeriums seit 1937. verwendet wurden ${ }^{65}$ und in denen alle Informationen übersichtlich angeordnet waren, die Spalte 3 „Deutschblütige Abstammung: (wodurch nachgewiesen?)“ bis 1945 leer. Das trifft auch auf Gürtner zu, der darüber hinaus nie seine frühere Zugehörigkeit zur Deutschnationalen Volkspartei (Bayerische Mittelpartei) zu den Personalakten zu geben brauchte. Ende September 1938 wurde die zuständige Geschäftsstelle im Ministerium z. B. angewiesen, auch den fehlenden Ariernachweis jenes Ministerialrats „nicht mehr zu überwachen“, d.h. nicht mehr zur Wiedervorlage zu bringen, den Gürtner als „Mischling 2. Grades“ im Amte belassen hatte. ${ }^{66}$ Der Partei gegenüber war eine solche stillschweigende Protektion allerdings nur bei Beamten möglich, die in gesicherten Positionen saßen und auf keine Beförderung mehr angewiesen waren. Andernfalls mußten sich sofort Schwierigkeiten ergeben, seitdem die Partei bei Beförderungen regelrecht mitzuwirken hatte. Wie Gürtner diesen Schwierigkeiten zu begegnen suchte, sei am Beispiel seines persönlichen Referenten Hans von Dohnanyi gezeigt.

Dohnanyi, der schon 1929 - damals als 27jähriger hamburgischer Assessor - von Minister Koch(-Weser) als persönlicher Referent ins Reichsjustizministerium berufen worden war und diese Stellung auch unter den Ministern Guérard, Bredt und Joël bis März 1932 beibehalten hatte, dann nach einer Tätigkeit als Staatsanwalt in Hamburg zum Jahreswechsel persönlicher Referent des Reichsgerichtspräsidenten Bumke geworden und schließlich im Juni von Gürtner wieder ins Justizministerium geholt worden war $^{67}$, stand gleichfalls auf der Liste jener Beamten, die den geforderten Ariernachweis nicht geführt hatten, da in seinem Falle die „arische“ Abstammung seines Großvaters mütterlicherseits umstritten war. ${ }^{68}$ Die von einer Synagogengemeinde in Ungarn ausgestellte Geburtsurkunde dieses Großvaters - Dohnanyi entstammte einem österreichisch-ungarischen Adelsgeschlecht - wies zwar beide Eltern als Angehörige der jüdischen Religion aus. Keines der vorhandenen Dokumente enthielt aber Angaben über die Religionszugehörigkeit des Großvaters selbst, der in einer Urkunde als „Dissident" bezeichnet wurde, offenbar nie einer jüdischen Gemeinde angehört hatte und auch christlich begraben worden war. $\mathrm{Zu}$ diesen $\mathrm{Zweifeln}$ über die Religionszugehörigkeit trat die Familienüberlieferung, daß dieser Großvater als uneheliches Kind auch blutsmäßig von einer anderen Mutter abstammte und nur als ehelich eingetragen worden war, um den "Seitensprung“ aus gesellschaftlichen Gründen zu vertuschen. Solange jedoch diese Überlieferung durch Urkunden nicht zu erhärten war und die vorhandenen Unterlagen den Großvater demgegenüber als Juden kennzeichneten, mußte Dohnanyi nach den formalen Bestimmungen und in den Augen der nationalsozialistischen Machthaber als „Vierteljude“ gelten.

${ }_{65}$ Der neue Personalbogen (Vordruck 188) wurde für die Beamten der richterlichen und staatsanwaltschaftlichen Laufbahn durch die RV des RJM v. 20.7.36 an die OLPräs. und GStAe (a.a.O., Sign. R 22/3791), für die Beamten des höheren Dienstes im RJM durch die Hausverf. des RJM v. 30.6.37 an die Personalgeschäftsstellen (a.a.O., Sign. R 22/4237) eingeführt.

${ }^{66}$ Im Falle eines anderen MinRats, dessen fehlender Abstammungsnachweis weiterhin „überwacht“ wurde und bei dem die Beschaffung der erforderlichen Urkunden aus Polen Schwierigkeiten bereitete, reichten die Wiedervorlagefristen bis zum Frühjahr 1945 (a.a.O., Sign. R 22/4433).

${ }^{67} \mathrm{Vgl}$. dazu u. a. Dohnanyis selbst verfaßten Lebenslauf und die Nachkriegsaufzeichnungen seiner Frau Christine v. Dohnanyi, geb. Bonhoeffer (Arch. des IfZ, Sign. ZS 603).

$68 \mathrm{Vgl}$. auch zum folgenden die Korrespondenzen, die in den Akten der RK (BA, Sign. R 43 II/1145 b) enthalten sind. 
Gürtner hatte jedoch ein besonderes Interesse, den jungen begabten und gewandten Juristen im Ministerium zu seiner persönlichen Verfügung zu behalten und beruflich zu fördern, da er in ihm - der zwar nie einer politischen Partei angehörte, aber in seinem Denken und Handeln von einer christlich-liberalen Einstellung geprägt war einen absolut vertrauenswürdigen Helfer in den Auseinandersetzungen mit der Parteiund Gestapoführung wegen der Eingriffe in die Justiz gefunden hatte. Mit Gürtners Billigung ${ }^{69}$ führte Dohnanyi u.a. seit 1934 ein chronologisches Diensttagebuch, in dem die amtliche Korrespondenz mit Partei- und Staatsstellen über ungesetzliche Handlungen von Angehörigen der Bewegung gegen politische, rassische und kirchliche Gegner, über damit zusammenhängende Niederschlagungsverfahren, über die Schutzhaftwillkür und Mordfälle in den Konzentrationslagern, über Korruptionsaffären von Parteiführern usw. teils inhaltlich, teils in Auszügen und Abschriften festgehalten wurde. ${ }^{70}$ Der Einblick in den verbrecherischen Charakter des Regimes, den ihm seine Position gewährte, und die Erkenntnis, daß mit den juristischen Argumentationen des Reichsjustizministers gegen die Willkür der politischen Führung nichts auszurichten war, ließen Dohnanyi den Entschluß zum aktiven Widerstand fassen und Verbindung zu oppositionellen militärischen und zivilen Kreisen knüpfen. Im Zusammenhang mit dem Diensttagebuch legte er insgeheim eine Kartei über die Delikte der einzelnen Parteiführer an, die auch Hinweise auf die entsprechenden Akten gab und nach einem eventuellen Umsturz Verwendung finden sollte, um dem Volk die Augen über den wahren Charakter der nationalsozialistischen Führung zu öffnen. ${ }^{71}$ Seine Personalkenntnisse und seine ausgedehnten Verbindungen ermöglichten ihm auch, Verfolgten gelegentlich zu helfen. Obwohl er sich bemühte, möglichst hinter den Kulissen zu wirken, blieb der Parteiführung seine ablehnende Haltung gegenüber dem Regime nicht verborgen. Bei ihrem Vorstoß, ihn aus seiner Stellung in der unmittelbaren Umgebung Gürtners zu entfernen, sollte das Argument seiner mangelnden „arischen“ Abstammung eine wesentliche Rolle spielen.

Da Dohnanyi nach Lage der Dinge bei den Nationalsozialisten als „Vierteljude“ gelten mußte, hätte er bereits aufgrund der Bestimmungen des Berufsbeamtengesetzes vom April 1933 aus dem Justizdienst entlassen werden müssen. Um daher die Offenlegung seiner Abstammung von vornherein zu vermeiden, wurde ihm - obwohl er Jahrgang 1902 war - vom Ministerium die Eigenschaft als „Frontkämnfer“" zuerkannt. Duhnanyi gab dazu im Juni 1933 die Erklärung ab, daß er 1919 als Unterprimaner freiwilliger Helfer der Technischen Nothilfe gewesen sei und in dieser Eigenschaft

69 Daß dieses Tagebuch im RJM von Dohnanyi nicht ohne Wissen Gürtners "geheim" geführt wurde, geht aus den Randbemerkungen und Paraphen Gürtners u. a. Beamter des Ministeriums hervor. Es ist sogar wahrscheinlich, daß es von Gürtner angeregt wurde, der die Einrichtung einer "Chronik“ aller rechtspolitisch wichtigen Ereignisse vom bayerischen JM her kannte, wo sie seit 1918 bis zur Auflösung des Ministeriums 1935 geführt wurde. Dazu neuerdings Strohm, Theologische Ethik (1996), S. 343 ff.

70 Das erhaltengebliebene Diensttagebuch aus den Jahren 1934-1938 - gelegentlich fälschlicherweise als „Gürtner-Tagebuch“ bezeichnet - diente im Nürnberger Hauptkriegsverbrecherprozeß 1945/46 als Beweismittel und wird als Fotokopie im BA verwahrt. In der vorliegenden Arbeit wird es verschiedentlich als Quelle zitiert.

${ }^{71} \mathrm{Zu}$ dieser Kartei vgl. Aufzeichnungen von Christine von Dohnanyi, geb. Bonhoeffer, 1945/46 über die „Zossener Akten“, abgedruckt bei E. Bethge, Dietrich Bonhoeffer. Theologe. Christ. Zeitgenosse, München 1967, S. 1096 ff. Zu Dohnanyis Widerstandstätigkeit, insbesondere bei der Abwehr ab August 1939, und zu seiner Tötung im KZ Sachsenhausen am 8.4.45 vgl. a.a.O., S.703 ff., sowie H. C. Deutsch, Verschwörung gegen den Krieg, München 1969, S. 93 ff. 
„zum Schutze bestreikter lebenswichtiger Betriebe an den Kämpfen während der Spartakus-Aufstände beteiligt gewesen" ${ }^{\text {"72 }}$ sei. Als Beweismittel konnte er allerdings nur einen Passierschein vorlegen, der besagte, daß der „Nothelfer v. Dohnanyi ... seine Bekleidungs- und Ausrüstungsstücke ordnungsmäßig zurückgegeben“ habe und damit die Erlaubnis zum Verlassen des Industriewerkes erhalte. ${ }^{73}$ Dieser mehr als wacklige Nachweis für die Frontkämpfereigenschaft wäre normalerweise kaum anerkannt worden, wenn er im Ministerium nicht von Gürtner gedeckt worden wäre. War damit die Klippe des Berufsbeamtengesetzes umschifft worden, so tauchte mit der im April 1936 nicht mehr vermeidbaren Fragebogenaktion für sämtliche Mitarbeiter des Ministeriums eine neue Gefahr auf. Wie geschildert, konnte zwar die Prozedur des „Ariernachweises" innerhalb des Ministeriums ohne unmittelbare Auswirkung für seine Mitarbeiter verzögert werden, doch war eine Entscheidung in dem Moment unumgänglich, in dem Dohnanyi befördert werden sollte. In dieser Situation ergriff Gürtner den Stier bei den Hörnern: anläßlich eines Vortrags bei Hitler am 14. Oktober 1936 gelang es ihm, von Hitler die mündliche Erklärung zu erlangen, daß v. Dohnanyi aus den Zweifeln, die sich aus der Geburtsurkunde seines Großvaters an seiner „rein deutschblütigen" Abstammung ergeben konnten, kein Nachteil erwachsen sollte. ${ }^{74}$ Diese Entscheidung teilte Gürtner dem Personalreferenten geschickterweise gleichzeitig mit den Schwierigkeiten mit, auf die Dohnanyi bei dem Nachweis seiner ,arischen“ Abstammung gestoßen war. Die Berufung auf diese Entscheidung sollte bereits aktuell werden, als Dohnanyi im Frühjahr 1937 bevorzugt vom Oberregierungsrat zum Ministerialrat befördert werden sollte: „bevorzugt“ nicht nur wegen seines für diesen Rang außergewöhnlich niedrigen Lebensalters, sondern weil dabei von der - gesetzlich möglichen - Abweichung von den „Reichsgrundsätzen“ vom Oktober 1936 Gebrauch gemacht werden mußte, da Dohnanyi die vorgeschriebene Mindestdienstzeit als planmäßiger Beamter und bei Behörden der Außenverwaltung noch nicht abgeleistet hatte. ${ }^{75}$ Der Personalreferent wurde angewiesen, die im Vordruck des Beförderungsvorschlags enthaltene Frage, wodurch die deutschblütige Abstammung nachgewiesen sei, wie folgt zu beantworten: „Er ist nach persönlicher Entscheidung des Führers als deutschblütig zu behandeln." Darüber hinaus teilte Schlegelberger dem Personalreferenten mit, daß die Angelegenheit mit der Dienststelle des Stellvertreters des Führers „durch H. Minister mit H. Reichsminister Heß" und mit Staatssekretär Ptundtner vom Reichsinnenministerium "persönlich besprochen“ werde. ${ }^{76}$

72 Gemäß der 3. DurchfVO zum BBG v. 6.5.33 (RGBI. I, S. 245) war die Teilnahme an Kämpfen gegen „Spartakisten" der Teilnahme an den Kämpfen des Weltkrieges gleichzustellen.

73 Der Wortlaut der Erkl. Dohnanyis v. 15.6.33 und des Passierscheins ist enthalten im Schr. des Fachschaftsgruppenleiters der Fachschaftsgruppe RJM v. 30.4.37 (s. Anm. 77).

74 Eine schriftliche Bestätigung der mündlichen Entscheidung Hitlers übersandte die RK dem RJM zur Übermittlung an Dohnanyi erst am 17.11.38 (Akten der RK, BA, Sign. R 43 II/1145 b).

75 Vgl. $§ 12$ der Reichsgrundsätze über Einstellung, Anstellung und Beförderung der Reichs- und Landesbeamten v. 14.10.36 (RGBl. I, S.893). Nach $\S 17$ war eine Abweichung von diesen Bestimmungen nur mit ausdrücklicher Genehmigung des RFiM und RMdI möglich.

76 Vgl. Verm. des Personalref. v. 22.3.37 (Akten des RJM, BA, Sign. R 22/1792). Der hier verkürzten Formulierung des Hitler-Entscheides entspringt offenbar die verschiedentlich aufgestellte falsche Behauptung, Hitler habe den „Mischling“ Dohnanyi kurzerhand zum „Arier“ erklärt. Nach dem schriftlichen Bescheid an Dohnanyi (vgl. Anm. 74) handelte es sich jedoch lediglich darum, „daß Dr. Hans von Dohnanyi aus den Zweifeln, die sich aus der Geburtsurkunde seines Großvaters mütterlicherseits an seiner rein deutschblütigen Abstammung ergeben könnten (!), keinen Nachteil haben soll und daß er daher in jeder Hinsicht als deutschblütig zu behandeln ist“. 
Nunmehr begann die Partei gegen Dohnanyi zu schießen. Im April 1937 sandte der Fachschaftsgruppenleiter der Fachschaftsgruppe Reichsjustizministerium des nationalsozialistischen Beamtenbundes - ein im Ministerium tätiger Kammergerichtsrat und Parteigenosse seit 1932 - eine vom Gau Groß-Berlin angeforderte Stellungnahme über Dohnanyi direkt an die Dienststelle des Stellvertreters des Führers, da er ein Bekanntwerden in Berliner Kreisen und im Ministerium vermeiden wollte. Aufgrund der Personalakten, in die ihm der Personalreferent Einblick gewährt hatte, stellte er fest, daß Dohnanyi , $1 / 2$ Ungar, $1 / 4$ Deutscher, $1 / 4$ Jude“ sei und „entsprechend seiner rassischen Zusammensetzung, die man ihm äußerlich freilich nicht anmerkt“ (!), die Rassenpolitik des Dritten Reiches ablehne: so habe er "geäußert, die rassische Haltung des Nationalsozialismus sei unmöglich, weil sie mit der christlichen Auffassung der evangelischen Kirche in Widerspruch stehe“. Es sei daher ausgeschlossen, daß von seiten Dohnanyis, der übrigens keiner einzigen NS-Organisation angehöre, ,jemals ein mannhaftes, rückhaltloses Eintreten für den nationalsozialistischen Staat erwartet werden“ könne. Deshalb stelle sich die

„grundsätzliche Frage: kann der engste und nächste Berater eines Ministers im Dritten Reich ein Judenstämmling sein oder nicht? ... In allen Fällen, in denen sich Schwierigkeiten bei der Behandlung von Rasse- oder sonstigen weltanschaulichen Fragen ergeben, und in denen Parteistellen und Justizministerium verschiedener Meinung sind, wird man sagen, daß er ja von einem Judenstämmling beraten werde. Nach außen wird das Ansehen der Justiz - nicht nur des Ministers - sinken. Nach innen ... wird die Stellung des Herrn Ministers zur Gefolgschaft dort, wo der Tatbestand bekannt wird, ungeheuer erschwert werden."

Freisler, dem er die Sache vorgetragen habe, teile seine Bedenken und habe „bereits erreicht, daß die Beförderungsangelegenheit einstweilen zurückgestellt worden " sei."

Tatsächlich wurden am 1. April 1937 nicht nur die Beförderungsanträge für Dohnanyi, sondern auch für eine Reihe anderer Anwärter auf Ministerialratsposten vom Justizministerium vorläufig zurückgestellt. Das hatte jedoch seinen Grund darin, daß das Reichsfinanzministerium seine Zustimmung zu den Beförderungen unter Abweichung von den „Reichsgrundsätzen“ in den Vorverhandlungen verweigert hatte. ${ }^{78} \mathrm{Da}$ mit hörten aber die Angriffe der Partei gegen Dohnanyi keineswegs auf. Im Gegenteil verstärkten offenbar Dohnanyis Bemühungen in der Fritsch-Affäre, die von der Gestapo erlogenen Beschuldigungen gegen Generaloberst Frhr. von Fritsch zu entlarven, das Streben der Parteiführung, Dohnanyi von seinem Posten zu entfernen. Am 7. Juli 1938 übersandte Bormann dem Chef der Reichskanzlei neben anderen Dohnanyi betreffenden Schriftstücken auch die erwähnte Stellungnahme des Fachschaftsgruppenleiters vom April 1937 und stellte fest, daß es mit den von Dohnanyi vorgelegten Dokumenten „für einen Mischling niemals möglich gewesen wäre, seine FrontkämpferEigenschaft zu beweisen, wenn er nicht an einflußreicher Stelle im Ministerium tätig wäre“, und daß Dohnanyi deshalb schon 1933 aufgrund des Berufsbeamtengesetzes hätte ausscheiden müssen. Bormann behauptete u.a., daß der ehrgeizige Dohnanyi Anfang 1935 einen Ruf an den Lehrstuhl für Strafrecht an der Universität Leipzig keineswegs wegen der Verbundenheit mit seiner Arbeit im Justizministerium und wegen

77 Vgl. Schr. des Fachschaftsgruppenleiters der Fachschaftsgruppe RJM des Reichsbundes der Deutschen Beamten (RDB, angeschlossener Verband der NSDAP) v. 30.4.37 an den persönl. Ref. von Bormann im Stabsamt des St.d.F. nebst polit. Gutachten (Akten der RK, BA, Sign. R 43 II/1145 b).

${ }^{78}$ Vgl. Verm. des Personalref. v. 24.3. und 1.4.37 (Akten des RJM, a.a.O.). 
seines Treueverhältnisses zum Minister abgelehnt habe - wie Dohnanyi vorgegeben habe und der dafür dankbare Gürtner glaube -, sondern weil er „nicht in der Lage sein konnte, den ihm überreichten Personalfragebogen befriedigend auszufüllen, weil dabei seine jüdische Abstammung zutage treten mußte“. Wenn Dohnanyi auch noch die Stirn habe, „das gegen seine charakterliche Haltung vorgebrachte Tatsachen-Material zu bestreiten“, so könne man daraus nur schließen, „daß er eine Reihe von persönlichen Eigenschaften hat, die wir als typisch jüdisch zu bezeichnen pflegen“ (!). Er forderte Lammers daher auf, eine Entscheidung Hitlers darüber herbeizuführen, „ob v. Dohnanyi unter diesen Umständen in der immer noch von ihm eingenommenen Stellung verbleiben soll“" ${ }^{79}$ Von diesem Schreiben seines Stabsleiters scheint der Stellvertreter des Führers, Reichsminister Heß, bezeichnenderweise noch am 12. Juli keine Kenntnis gehabt zu haben, da er in einer Unterredung mit Gürtner im Braunen Haus gegen die Absicht, Dohnanyi demnächst für die Besetzung einer freien Ministerialratsstelle im Justizministerium vorzuschlagen, keinen Widerspruch erhob. ${ }^{\mathbf{8 0}}$

Als Reichskanzleichef Lammers Bormanns Wunsch nachkam und Hitler am 25. Juli - gelegentlich der Festspiele in Bayreuth - auf die Angelegenheit ansprach, beauftragte ihn dieser, deswegen mit Gürtner Fühlung zu nehmen. Zwei Tage später erörterte Lammers die Sache telefonisch mit Gürtner, der in Kampen auf Sylt Urlaub machte, und übersandte ihm anschließend eine Abschrift des Bormann-Briefes nach dort. ${ }^{81}$ In diesem Telefongespräch muß Lammers dem Justizminister wohl deutlich gemacht haben, daß er Dohnanyi als persönlichen Referenten im Ministerium nicht mehr werde halten können, ihm aber auch schon zugestanden haben, daß Dohnanyi dann auf einen anderen Posten - etwa den eines Reichsgerichtsrates - „wegbefördert“ werden sollte. Beide kamen bei diesem Gespräch offensichtlich auch überein, Bormann dabei möglichst zu umgehen und den "weicheren“ Heß für diese Absicht zu gewinnen. Denn noch am selben, spätestens aber am nächsten Tag erwirkte Lammers telefonisch von $\mathrm{Heß}$ die Zusage, daß der Stellvertreter des Führers dem Vorschlag einer. Ernennung Dohnanyis zum Reichsgerichtsrat kein Hindernis in den Weg legen werde: Heß bat in diesem Zusammenhang ausdrücklich, Lammers möge Bormanns Brief vom 7. Juli „als nicht geschrieben betrachten“. ${ }^{82}$ Als Heß in einer Unterredung, die Gürtner am 13. August nach seiner Rückkehr aus dem Urlaub mit ihm führte, bei seiner Zusage blieb ${ }^{83}$, unterrichtete Lammers Hitler vier Tage später von der Beförderungsabsicht und vergewisserte sich, daß Hitler zu seiner Entscheidung hinsichtlich der Behandlung Dohnanyis vom Oktober 1936 stand. ${ }^{84}$ Offensichtlich um möglichen Quertreibereien Bormanns zuvorzukommen, ließ er Hitler die Urkunde über die Ernennung Dohnanyis zum Reichsgerichtsrat am 4. September 1938 in Berchtesgaden unterschreiben, obwohl dazu weder die Einwilligung des Reichsinnenministers noch die formale Zustimmung des Stellvertreters des Führers eingeholt worden war, sondern nur diejenige des Reichsfinanzministers vorlag, die Gürtner bereits am 22. Au-

79 Vgl. Schr. des St.d.F. (i.V. Bormann) an den Chef der RK Lammers v. 7.7.38 nebst Anlagen (Akten der RK,
a.a.O.).
80 Vgl. Verm. Gürtners v. 12.7 .38 über die Unterredung, abschriftlich in den Akten der RK (a.a.O.).
81 Vgl. Schr. Lammers' an Gürtner v. 27.7 .38 (a.a.O.).
82 Vgl. den nachträglichen zusammenfassenden Verm. Lammers' v. 4.9.38 (a.a.O.).
83 Vgl. Schr. Gürtners aus München an Lammers v. 14.8.38 (a.a.O.).
84 Vgl. Verm. Lammers' v. 17.8.38 und sein Schr. an den Chef der Kanzlei des Führers Bouhler v. 23.10.38 (a.a.O.). 
gust von Schwerin-Krosigk erwirkt hatte. ${ }^{85}$ Nachdem sich Lammers die Billigung des Reichsinnenministers auf telefonischem Wege beschafft hatte, teilte er Heß in einem persönlich an diesen gerichteten Schreiben mit, daß die Ernennung Dohnanyis inzwischen in die Wege geleitet und die Ernennungsurkunde von Hitler bereits vollzogen sei; aufgrund seines Telefonats mit Heß vom 27. oder 28. Juli habe er dessen Zustimmung „als im voraus gegeben“ angesehen und hoffe, daß diese Erledigung dem Wunsche von Heß entspreche. ${ }^{86}$ Am 8. September ergab sich auf dem Parteitag in Nürnberg für Lammers die Gelegenheit, die Ernennungsurkunde an Gürtner - der um ihre Übersendung nicht ins Ministerium, sondern in seine Wohnung (!) gebeten hatte persönlich zu übergeben, damit er sie Dohnanyi aushändigen konnte. ${ }^{87}$ Wenngleich es Gürtner im Zusammenspiel mit der Ministerialbürokratie gelungen war, Bormanns Angriff auf die berufliche Existenz Dohnanyis abzufangen und in eine Beförderung vom Oberregierungsrat zum Reichsgerichtsrat - der besoldungsmäßig immerhin dem Rang eines Ministerialdirigenten gleichstand - umzuwandeln, so hatte die Parteiführung in der Sache doch gesiegt und im Reichsjustizministerium eine personalpolitische Entscheidung nach ihrem Willen erzwungen: v. Dohnanyi wurde aus seiner Stellung als persönlicher Referent und aus dem Reichsjustizministerium entfernt. Zu seinem Nachfolger als persönlichen Referenten nahm sich Gürtner Kammergerichtsrat Sommer, der seit Oktober 1934 als Hilfsarbeiter im Ministerium tätig war und mit dem ihn gleichfalls ein Vertrauensverhältnis verband.

Bis zu diesem Zeitpunkt - Herbst 1938 - hatte sich die personelle Besetzung in den oberen Rangstufen der Beamten des höheren Dienstes im Reichsjustizministerium seit 1935 wie folgt verändert. Nach der geschilderten Versetzung Ministerialdirektor Reinhold Richters in den einstweiligen Ruhestand war mit der Leitung der Abteilung V im März 1936 Leo Quassowski beauftragt worden, der seit 1919 - ab 1921 als Ministerialrat - im Ministerium arbeitete, zu den besten Kennern des Aufwertungsrechts gehörte und kein Parteigenosse war. Im Oktober 1936 bekam er den seiner leitenden Funktion angemessenen Rang eines Ministerialdirigenten; gleichzeitig wurde Ministerialdirigent Schneller - Leiter der Abteilung VI - zum Ministerialdirektor befördert. Von den Ministerialdirigenten trat Prof. Klässel, der die Abteilung für Familiengüter und Hausvermögen geleitet hatte ${ }^{88}$, im Frühsommer 1938 wegen Erreichung der Altersgrenze in den Ruhestand.

Aus der Gruppe der Ministerialräte waren bis zum 1. Oktober 1938 drei Beamte verstorben $^{89}$, Quassowski wie erwähnt zum Ministerialdirigenten befördert, vier Beamte zum Reichsgericht bzw. zur Reichsanwaltschaft ${ }^{90}$ und fünf an andere Behörden versetzt worden: Der Nationalsozialist Engert ging im Mai 1936 als Senatspräsident

${ }^{85}$ Vgl. die Verm. Lammers' v. 4. und Kritzingers v. 7.9 .38 (a.a.O.).

${ }^{86} \mathrm{Vgl}$. Schr. Lammers' an Heß v. 8.9 .38 (a.a.O.)

87 Vgl. Verm. Lammers' v. 8.9 .38 (a.a.O.).

${ }^{88}$ Diese „Abteilung LA“ war schon vorher als eigene Abteilung aufgehoben und als „Gruppe $F$ (Familienfideikommisse, Lehen, Stammgüter, Hausvermögen u. dergleichen, Adelsgesetze, Angelegenheiten der ehemaligen Landes- und Standesherren sowie Familienstiftungen einschl. der Gesetzgebung)“ der Abteilung IV für Bürgerliches Recht und bürgerliche Rechtspflege angegliedert worden (vgl. Geschäftsverteilungsplan des RJM v. April 1938, Akten des RJM, BA, Sign. R 22/59).

${ }^{89}$ Hauptvogel am 21.12.35 (vgl. DJ 1936, S.42), Busch am 31.1.38, Wilke am 17.5.38 verunglückt (vgl. DJ 1938, S. 293 u. 799).

90 Hans Richter (1.1.36 ReiA), Brandis (1.1.37 SenPräs.), Kutzner (1.3.37 RGRat) und Jonas (1.5.38 SenPräs.), bis auf Kutzner sämtlich schon vor 1933 MinRäte im RJM. 
zum Volksgerichtshof, um Anfang 1938 dort Vizepräsident zu werden. Drescher kehrte im Frühjahr 1937 als Präsident des Augsburger Landgerichts in seine bayerische Heimat zurück. Wagner wurde im Oktober 1937 zum Generalstaatsanwalt in Stuttgart befördert und Lehmann als Senatspräsident ans Reichskriegsgericht versetzt; als Ministerialdirektor leitete er ab 1938 die Rechtsabteilung im Oberkommando der Wehrmacht. Kritzinger schließlich wechselte Anfang 1938 als Ministerialdirektor und Abteilungsleiter in die Reichskanzlei über.

Die freigewordenen Ministerialratsstellen wurden 1936 mit vier Beamten besetzt, die sich sämtlich bereits längere Zeit als Hilfsarbeiter im Ministerium bewährt hatten: mit Senatspräsident beim Kammergericht Grau, der an der Reform des Strafrechts maßgeblich beteiligt war, mit den Kammergerichtsräten Wille und Wittland sowie Landgerichtsdirektor Grußendorf, der u.a. mit der Auswahl der Assessoren für den Probe- und Anwärterdienst für das ganze Reichsgebiet betraut worden war. Für die zunehmende Bedeutung der Parteimitgliedschaft bei Beförderungen im Ministerium ist kennzeichnend, daß drei von ihnen der NSDAP - wenn auch erst seit 1. Mai 1933 - angehörten. ${ }^{91}$ Gegen Ministerialrat Wittland, der u.a. die Personalsachen für Richter im Oberlandesgerichtsbezirk Darmstadt bearbeitete, sollte Gauleiter Sprenger schon wenige Monate später die Beschuldigung der „Sabotage der nationalsozialistischen Personalpolitik“ erheben und gegen ihn die Einleitung eines Disziplinarverfahrens fordern, weil Wittland dem Landgerichtspräsidenten in Gießen in einem Telefongespräch, das der Gestapo zur Kenntnis kam, empfohlen hatte, bei Personalvorschlägen „auf die Parteizugehörigkeit keine Rücksicht zu nehmen, da diese im Ministerium keine Rolle spiele“.92

Im Frühjahr 1937 führte das Reichsjustizministerium mit dem Reichsinnenministerium Verhandlungen, um weitere acht der freien Ministerialratsstellen wiederzubesetzen. Unter den zur Beförderung Vorgesehenen befanden sich mehrere Beamte - zu ihnen gehörte damals noch Dohnanyi -, die nicht die vorgeschriebene Mindestdienstzeit in einer Planstelle des Ministeriums und im Außendienst abgeleistet hatten. Da die genannten Ministerien für sie aber eine Abweichung von den „Reichsgrundsätzen“ verweigerten ${ }^{33}$, konnten im November zunächst nur zwei der Vorgeschlagenen - beide Parteigenossen - zu Ministerialräten ernannt werden. ${ }^{94}$ Im Februar 1938 erneuerte der Justizminister seinen Vorstoß, um „einmal den Beamten, die im ersten Jahre der nationalsozialistischen Revolution als ältere Mitglieder der NSDAP zum Ministerialdienst einberufen worden “ waren, „das ihrer Verwendung entsprechende Amt übertragen“ und darüber hinaus „einige ungewöhnlich tüchtige jüngere Referenten“ befördern zu können. Die Vorgeschlagenen seien „ohne Nachteil für die von ihnen betreuten Arbeitsgebiete“ nicht entbehrlich und könnten „daher auch nicht zur Ableistung des fehlenden Außendienstes an Behörden der Außenverwaltung"versetzt wer-

91 Vgl. die Ernennungsvorschläge des RJM v. 16.1.36 (Akten des RFiM, BA, Sign. R 2/23916).

92 Vgl. persönl. Schr. Sprengers an Gürtner, Eintr. v. 18.9.36 im Diensttageb. des RJM, Bd.9 (BA, Sign. R 22/930). Die Einleitung eines Dienststrafverfahrens konnte vom RJM offensichtlich abgebogen werden.

93 Vgl. die Verm. des Personalreferenten v. 12.3. bis 7.8.37 (Akten des RJM, BA, Sign. R 22/1792). Zu den „Reichsgrundsätzen“ s. Anm.75.

94 Der aus der württemb. Justiz stammende, seit 1.4.35 im RJM arbeitende ORegRat Paul Schmidt und der von der sächs. Justiz kommende, seit 1.4.35 als LGDir. im RJM arbeitende Eichler. Zu beiden vgl. Personalunterlagen im DC Berlin. 
den..$^{95}$ Von den elf vorgeschlagenen Beamten waren außer Dohnanyi, einem Kammergerichtsrat und einem Oberlandesgerichtsrat - beide seit 1932 bzw. 1937 im Reichsjustizministerium beschäftigt - alle Parteigenossen, davon fünf schon aus der Zeit vor der Machtübernahme. ${ }^{96}$ Trotzdem konnten im April 1938 zunächst nur drei Beamte - sämtlich Parteigenossen -, die sich z.T. durch mehrjährige Mitarbeit im Ministerium bewährt hatten und für die keine Abweichung von den „Reichsgrundsätzen“ erforderlich war, zu Ministerialräten ernannt werden. ${ }^{97} \mathrm{Da}$ somit von den 13 seit 1935 ausgeschiedenen Ministerialräten Ende 1938 lediglich 9 hatten ersetzt werden können, hatte das Reichsjustizministerium zu diesem Zeitpunkt nur 36 Ministerialräte. ${ }^{98}$

$\mathrm{Zu}$ ihnen rechneten allerdings nicht die 10 Ministerialräte der „Abteilung Österreich" in Wien, die nach dem Anschluß Österreichs aus dem dortigen Bundesministerium für Justiz gebildet worden war. ${ }^{99}$ Diese Abteilung stand unter der Leitung des Notars Franz Hueber, der von 1919 bis Juni 1933 dem österreichischen Heimatschutz angehört hatte, Anfang 1934 der NSDAP beigetreten war und am 11. März 1938 kurz vor dem deutschen Einmarsch von dem neuen nationalsozialistischen Bundeskanzler Seyß-Inquart zum Justizminister ernannt worden war. Als Gürtner diese Abteilung am 1. März 1939 auf Wunsch des Reichskommissars Bürckel in Wien auflöste, wurden von ihren Mitarbeitern Hueber und vier weitere Beamte nach Berlin übernommen, die in Stellen vom Ministerialrat aufwärts eingesetzt wurden: Um dem Exminister eine angemessene Position zu geben, wurde Hueber am 1. April 1939 zum Unterstaatssekretär mit den Bezügen eines Ministerialdirektors ernannt, da sowohl Gürtner wie Hitler die Einrichtung eines dritten Staatssekretärs im Reichsjustizministerium ablehnten. ${ }^{100}$ In dieser Eigenschaft vertrat Hueber die sich sonst gegenseitig vertretenden Staatssekretäre bei Verhinderung beider und übernahm einen eigenen Geschäftsbereich. ${ }^{101}$ Sektionschef Suchomel, der seit 1917 im österreichischen Justizministerium arbeitete und kein Parteigenosse war, wurde als Ministerialdirigent ins Reichsju-

$95 \mathrm{Vgl}$. den Entw. eines Schr. des RJM an den RMdI v. 28.2.38 (Akten des RJM, a.a.O.).

96 Vgl. „Verzeichnis der für eine Beförderung zu Ministerialräten im RJM in Aussicht genommenen Beamten“ (a.a.O.).

97 KGRat Ficker, seit 1.1.35 Hilfsarbeiter im RJM; OLGRat Schoetensack, seit 1.3.37 Hilfsarbeiter im RJM, und ORegRat Toebert, seit 7.6.33 Hilfsarbeiter zunächst im preuß. JM, dann im RJM, seit 1.2.36 ORegRat, vgl. Ernennungsvorschlag des RJM v. 10.1.38 (Akten des RFiM, BA, Sign. R 2/23917).

98 Vgl. Kalender für Reichs-Justizbeamte 1939, Teil 2, S. 25 f. (Stand 1. 10.38). Dazu kamen folgende Sachbearbeiter in planmäßigen Stellen: 8 ORegRäte, 1 OStA und 3 RegRäte. Die Personalentwicklung bei diesen Beamtengruppen des höheren Dienstes kann in diesem Zusammenhang nicht verfolgt werden.

99 Sie bestand aus 1 Minister, 2 Sektionschefs, 10 Ministerialräten und 5 Sektionsräten (a.a.O., S. 26). Ihr Gegenstück im RJM war die im März 1938 gebildete Abt. VIII unter MinDirig. Lutterloh für die „Mitarbeit an allen Fragen, die sich aus der Wiedervereinigung Österreichs mit dem Deutschen Reich ergeben“. In ihr sollten Vertreter der Abt. I bis VII für das jeweilige Fachgebiet dafür „sorgen, daß die Bedürfnisse und Notwendigkeiten der Rechtspflege des Landes Österreich gebührend zur Geltung kommen, insbes. auch bei der Einführung geltenden Rechts im Lande Österreich und bei der Neubildung deutschen Rechts“. Die Abt. VIII wurde im Oktober 1938 wieder aufgehoben (vgl. Hausverf. Gürtners v. 17.3. und 19. 10.38, Akten des RJM, BA, Sign. R 22/3793).

100 Vgl. Schr. Lammers' an Gürtner v. 22.2.39 und Entw. eines Schr. Gürtners an Heß v. März 1939 (Personalakten Hueber, BA). Hueber war v. 1.10. bis 4.12.30 in der österreichischen Regierung Vaugoin schon einmal JM gewesen.

101 Die Verwaltungs- und Gesetzgebungsarbeiten auf dem Gebiet der RAe und Notare, die landwirtschaftliche Entschuldung, das bäuerliche Recht und die Fideikommißsachen (vgl. Hausverf. Gürtners v. April 1939, Akten des RJM, a.a.O.) 
stizministerium berufen ${ }^{102}$ und trat in der Strafgesetzgebungsabteilung (Abteilung II) neben Ministerialdirektor Schäfer, um die Rechtsangleichung in Österreich zu bearbeiten. Durch die Übernahme zweier österreichischer Ministerialräte und die Beförderung eines Sektionsrates (Oberregierungsrates) zum Ministerialrat ${ }^{103}$ war jedoch der Fehlbestand an Ministerialräten im Reichsjustizministerium bis März 1939 immer noch nicht aufgefüllt.

Diese Ergänzung erfolgte erst durch den „Ministerialrats-Schub“ vom April 1939, durch den - mit Ausnahme des ans Reichsgericht versetzten Dohnanyi - nunmehr diejenigen zehn Beamten befördert wurden, deren Ernennung das Ministerium Anfang 1938 erfolglos betrieben hatte. $\mathrm{Zu}$ den neuen Ministerialräten gehörten Oberstaatsanwalt Krug, der u.a. mit der Gesamtredaktion des Amtsblattes „Deutsche Justiz" beauftragt war, ferner der Nationalsozialist und Generalreferent für politische Strafsachen Oberstaatsanwalt Klemm, der Presse- und Rundfunkreferent des Ministeriums, Landgerichtsdirektor Mitzschke, sowie die beiden persönlichen Referenten Freislers: der bereits erwähnte Altparteigenosse Oberstaatsanwalt Ebert und Kammergerichtsrat Kurt Friedrich, der gleichzeitig Referent für das Gemeinschaftslager Hanns Kerrl war. ${ }^{104}$ Bei diesen Ernennungen ging es u. a. darum, fünf Altparteigenossen, die 1933 von Kerrl und Freisler als Hilfsarbeiter ins preußische Justizministerium geholt worden und dadurch 1934 ins Reichsjustizministerium gelangt waren, in Ministerialratsstellen zu bringen. Von den übrigen fünf Beförderten war einer ein „Märzgefallener", während drei den Weg zur Partei offensichtlich erst gefunden hatten, als ihre Beförderung in absehbare Nähe rückte. Hieran wird der wachsende Kotau vor der Parteiführung deutlich sichtbar.

Gleichzeitig - aber von diesem Schub getrennt - wurde auch der Nachfolger Dohnanyis als persönlicher Referent bei Gürtner, Kammergerichtsrat Sommer, zum Ministerialrat befördert. ${ }^{105}$ Bis zum Tode Gürtners sollten nur noch zwei Ministerialräte ernannt werden ${ }^{106}$ : auf Wunsch Hans Franks im August 1939 Oberstaatsanwalt Büh-

102 Suchomel war seit September 1933 Mitglied der von Dollfuß gegründeten „Vaterländischen Front“ gewesen, einer Sammlung regierungstreuer Kreise, die gegenüber den Nationalsozialisten für die Unabhängigkeit Österreichs eintraten (Personalakten des RJM, BA).

${ }^{103}$ Bei diesen drei Beamten handelte es sich um: MinRat Beier, OLGRat in Wien, seit Mai $1938 \mathrm{Pg}$. und seit 1.10.38 MinRat in der Abt. Österreich (vgl. DJ 1939, S. 50); MinRat Stagel, Pg. seit 1932, MinRat seit 1.7.37; Sektionsrat Bistritschan, Sektionsrat seit 27.2.34, seit Oktober 1933 Mitglied der „Vaterländischen Front“ (vgl. Ernennungsvorschläge in den Akten des RFiM, BA, Sign. R. 2/23917). Unterhalb der Ministerialratsebene wurden am 1.4.39 als ORegRäte von der Abt. Österreich übernommen: Merth und Klemenz (vgl. Akten des RJM, BA, Sign. R 22/1792). Zu diesem Zeitpunkt waren aus Österreich einschließlich der Hilfsarbeiter 11 Beamte des höheren Dienstes ins RJM einberufen worden (vgl. Aktenvermerk v. 27.4.39, a.a.O., Sign. R 22/5043).

104 Ferner ORegRat Huber (seit 1.1.35 aus der thür. JVerw. ins RJM abgeordnet), KGRat Kühnemann (seit 1.1 .32 als Hilfsarbeiter im RJM), OStA Nörr (seit 1.4.31 Hilfsarbeiter im bayer. JM, nach der Verreichlichung im RJM), LGDir. Altmeyer (seit 2.1.31 Hilfsarbeiter im preuß. JM bzw. RJM) und OLGRat Wilhelm Friedrich (aus der hessischen Jusitz stammend, seit 19.5.37 Hilfsarbeiter im RJM). Vgl. den Ernennungsvorschlag v. 7.2.39 (Akten des RFiM, BA, Sign. R 2/23917).

$105 \mathrm{Vgl}$. Ernennungsvorschlag des RJM v. 7.2.39 (a.a.O.).

106 Dafür schied ein MinRat aus: Riese, seit 1929 ORegRat, seit 1934 MinRat im RJM, wurde im Oktober 1940 als SenPräs. ans OLG Düsseldorf versetzt. Er war vorher 1939/40 in die Schweiz abgeordnet worden, um einen Lehrstuhl an der juristischen Fakultät der Universität Lausanne wahrzunehmen (Akten des RJM, BA, Sign. R 22/5043). Erst während seines Schweiz-Aufenthaltes trat er 1939 der Auslandsorganisation der NSDAP bei (Personalunterlagen Riese im DC Berlin). 
ler ${ }^{107}$, der seit 1935 vom Reichsjustizministerium für die Leitung des Frankschen Ministeramts abgeordnet war, und im Januar 1940 Landgerichtsdirektor Dittrich ${ }^{108}$, der im April 1935 von der sächsischen Justiz als Hilfsarbeiter ins Ministerium gekommen war. Durch die geschilderten Personalveränderungen hatte sich die Zusammensetzung der Gruppe der Ministerialräte hinsichtlich der Zugehörigkeit zur NSDAP seit 1935 wesentlich verändert. ${ }^{109}$

Wie sehr der Stellvertreter des Führers bei der Beförderung höherer Beamter auf die Zugehörigkeit zur NSDAP sah, sollte sich 1939 bei der Absicht des Reichsjustizministeriums zeigen, den Ministerialdirigenten Quassowski, der seit Frühjahr 1936 die Handels- und öffentlich-rechtliche Abteilung V leitete, zum Ministerialdirektor zu ernennen. Da Quassowski der NSDAP nicht angehörte, wurde im Ernennungsvorschlag außer auf seine fachliche Qualifikation und seine politische Zuverlässigkeit darauf hingewiesen, daß er „den ganzen Weltkrieg über an der Front, ... schwer verwundet worden und Inhaber des Eisernen Kreuzes I. Klasse" war. ${ }^{10}$ Während das Reichsinnenministerium und das Reichsfinanzministerium seiner Ernennung zustimmten, machte der Stellvertreter des Führers Schwierigkeiten. Nachdem sein Stab im Januar zunächst mitgeteilt hatte, daß der Beförderung "vorläufig nicht zugestimmt werden “ könne ${ }^{111}$, lehnte sie Heß am 10. März 1939 mit der Begründung ab, daß „die sich mehrenden Ernennungen von Beamten in Spitzenstellen, die Nichtparteigenossen sind, eine Quelle ernster Besorgnis“ seien. Beförderungen in solche Stellen halte er „nur dann für vertretbar, wenn die Beamten durch ihr Verhalten eindeutig ihre Verbundenheit mit der Bewegung und dem nationalsozialistischen Staat bewiesen" hätten. Obwohl er nach den vorliegenden Berichten Quassowski die politische Zuverlässigkeit nicht absprechen könne, seien ihm ,andererseits auch keine Tatsachen bekannt geworden, die für eine besondere Einsatzbereitschaft des Ministerialdirigenten Quassowski für die Bewegung" sprächen:

"Quassowski ... hat es nicht für notwendig gehalten, Mitglied der NSDAP zu werden, auch 1937 [d.h. nach der Lockerung der Mitgliedersperre] nicht. Von den Beamten in Spitzenstellen muß ich aber verlangen, daß sie ihre innere Verbundenheit zum nationalsozialistischen Staat und zur Bewegung auch dadurch äußerlich zum Ausdruck bringen [!], daß sie Mitglied der NSDAP. werden."

Da Quassowski nach dem 30. Januar 1933 somit nicht bewiesen habe, „daß er jederzeit rückhaltlos für den nationalsozialistischen Staat eintritt und ihn wirksam vertritt“, könnten „die in den Reichsgrundsätzen für die Beförderung von Beamten niedergelegten Voraussetzungen" bei Quassowski nicht für gegeben angesehen werden. ${ }^{112}$

Um die Behauptung des Stellvertreters des Führers, daß sich bei der Justiz die Ernennungen von Nicht-Parteigenossen in die Spitzenstellungen mehrten, auf ihre Stichhaltigkeit zu prüfen und möglichst zu widerlegen, ordnete Gürtner bei der

107 Vgl. Ernennungsvorschlag des RJM v. 10.5.39 (Akten des RFiM, a.a.O.). Zu Bühler s. auch Kapitel III.2., S. 235.

${ }^{108}$ Vgl. Ernennungsvorschlag des RJM v. 13.10.39 (a.a.O.). Dittrich war vor dem 30.1.33 der Partei beigetreten.

109 Vgl. dazu die Aufstellung im folgenden auf S. 263.

110 Vgl. Ernennungsvorschlag des RJM v. 16.12.38 (Akten des RJM, BA, Sign. R 22/1792).

11 Vgl. Schr. des St.d.F. an das RJM v. 16.1.39 (a.a.O.). Dort auch die Zustimmungsschr. des RMdI v. 24.12.38 und des RFiM v. 11.1.39.

112 Vgl. Schr. von $\mathrm{He} \beta$ an den RJM v. 10.3 .39 (a.a.O.). 
Personalabteilung eine statistische Untersuchung an. Die Aufstellung, die Ministerialdirektor Nadler dem Minister am 24. März 1939 vorlegte, zeigte folgendes aufschlußreiches Ergebnis. Vom 1. April 1935 - dem Tage der Verreichlichung der Justiz - bis zum genannten Stichtag (24.3.39) waren auf Vorschlag des Reichsjustizministeriums ernannt worden:

10 Ministerialräte; von ihnen waren 8 im Zeitpunkt des Ernennungsvorschlages Mitglieder der NSDAP gewesen (werden der geschilderte „Ernennungsschub“ vom April 1939 und die nachfolgenden Ernennungen bis zum Tode Gürtners dazugerechnet, ergibt sich für die Ära Gürtner: 23 Ministerialräte, von denen 20 Parteigenossen waren);

9 Senatspräsidenten beim Reichsgericht, davon 3 Parteigenossen;

38 Reichsgerichtsräte, von ihnen waren 26 zum Zeitpunkt des Ernennungsvorschlages Parteimitglieder, 1 wurde nachträglich in die Partei aufgenommen;

1 Oberreichsanwalt bei der Reichsanwaltschaft beim Reichsgericht, Parteimitglied;

1 Reichsanwalt bei der Reichsanwaltschaft beim Reichsgericht, Nicht-Parteimitglied;

1 Oberstaatsanwalt bei der Reichsanwaltschaft beim Reichsgericht, Parteimitglied;

1 Präsident des Volksgerichtshofs, Parteimitglied;

1 Vizepräsident des Volksgerichtshofs, Parteimitglied;

2 Senatspräsidenten des Volksgerichtshofs, beide Parteimitglieder;

8 Volksgerichtsräte, davon 7 Parteigenossen;

1 Oberreichsanwalt bei der Reichsanwaltschaft beim Volksgerichtshof, Parteimitglied;

4 Reichsanwälte bei der Reichsanwaltschaft beim Volksgerichtshof, sämtlich Parteimitglieder;

1 Oberstaatsanwalt bei der Reichsanwaltschaft beim Volksgerichtshof, Parteimitglied;

9 Oberlandesgerichtspräsidenten, davon 7 zum Zeitpunkt der Ernennung Parteigenossen, 2 wurden am 1.5.1937 in die Partei aufgenommen;

11 Generalstaatsanwälte, davon 9 zum Zeitpunkt der Ernennung Parteigenossen, 2 wurden am 1.5.1937 aufgenommen;

25 Große Landgerichtspräsidenten (Besoldungsgruppe B 8), davon 18 zum Zeitpunkt des Ernennungsvorschlags Parteimitglieder, 3 später in die Partei aufgenommen $^{113}$;

55 Kleine Landgerichtspräsidenten (Besoldungsgruppe A 1 a), davon 46 zum Zeitpunkt des Ernennungsvorschlags Parteimitglieder, 2 später in die Partei aufgenommen;

17 Große Oberstaatsanwälte (Besoldungsgruppe A 1 b), davon 16 zum Zeitpunkt des Ernennungsvorschlags Parteigenossen, 1 später beigetreten; und

45 Kleine Oberstaatsanwälte (Besoldungsgruppe A 2 b), von denen 40 zum Zeitpunkt des Ernennungsvorschlags in der Partei waren und 2 nachträglich beitraten. ${ }^{114}$

113 Dazu heißt es quasi entschuldigend in der Aufstellung, ein Nicht-Parteigenosse sei „auf ausdrücklichen Wunsch des Gauleiters Bürckel zum Landgerichtspräsidenten vorgeschlagen worden“".

114 Vgl. die Aufstellungen in den Akten des RJM (a.a.O.). 
Diese Zusammenstellung ließ klar erkennen, wie stark das Reichsjustizministerium die Parteizugehörigkeit bei Beförderungsvorschlägen seit $1935^{115}$ berücksichtigt hatte. Schlegelberger übersandte sie an Heß mit der Feststellung, daß dessen Besorgnis über die Personalpolitik des Ministeriums unbegründet sei, da schließlich 86 Prozent der aufgeführten Stellen mit Parteimitgliedern besetzt worden seien. Er bat daher, den Ernennungsvorschlag Quassowski erneut zu prüfen, da dieser als Leiter der Abteilung V unersetzbar sei. Im Falle der Ablehnung müsse Quassowski „für sein ganzes weiteres Beamtenleben die Arbeitslast und Verantwortung eines Ministerialdirektors tragen“, sich dabei aber „mit dem Range und den Bezügen eines Ministerialdirigenten begnügen“. Daß Quassowski für den gegenwärtigen Staat eintrete, dafür übernehme er „auf Grund langjähriger eigener Beobachtung jede Gewähr". ${ }^{116}$ Daraufhin stimmte Heß dem Beförderungsvorschlag zu und führte aus, daß sich die geäußerte Besorgnis nicht speziell auf die Personalpolitik des Justizministeriums bezogen, sondern „allgemeine Bedeutung" gehabt habe. ${ }^{117}$ Quassowski wurde mit Wirkung vom 1. April 1939 zum Ministerialdirektor befördert.

Auch nach dieser Beförderung betrug die Zahl der Ministerialdirigenten im Reichsjustizministerium durch die gleichzeitige Übernahme Suchomels aus Österreich weiterhin fünf. Im April erklärte sich das Reichsfinanzministerium bereit, weitere sechs solcher Stellen zu bewilligen. Sie waren für Ministerialräte bestimmt, die entweder als ständige Stellvertreter der Abteilungsleiter (Ministerialdirektoren) fungierten oder Arbeitsbereiche zu betreuen hatten, die „nach Umfang und Bedeutung über das gewöhnliche Maß eines Referats erheblich" hinausgingen, und dabei gleichzeitig eine mindestens fünfjährige Bewährung in einer Reichsministerialratsstelle aufzuweisen hatten. Dafür sollten fünf Ministerialratsstellen im Haushalt des Ministeriums wegfallen. ${ }^{118}$ Nach dem Einspruch des Stellvertreters des Führers vom März hätte man annehmen können, daß das Justizministerium die neu geschaffenen Ministerialdirigentenstellen nunmehr überwiegend mit Parteimitgliedern besetzen werde. Aber das Gegenteil geschah; wie im Falle Quassowski richtete sich die Justizleitung nach fachlichen Gesichtspunkten, wobei ihr die erwähnten Richtlinien des Finanzministeriums eine willkommene Stütze boten: sie beförderte in diese Stellen bis auf eine Ausnahme Ministerialräte, die diesen Rang schon vor der Machtübernahme innegehabt hatten und zur Zeit der Ernennung keine Parteigenossen waren. $\mathrm{Zu}$ den vier noch im selben Jahr 1939 zu Ministerialdirigenten Beförderten ${ }^{119}$ gehörten Mettgenberg, der seit 1920 im Reichsjustizministerium arbeitete, 1923 Ministerialrat geworden war und die Unterabteilung III A für nichtpolitische Einzelstrafsachen leitete ${ }^{120}$, sowie Vogels, der 1930 als

115 Vgl. demgegenüber z. B. die Vorgänge bei der Erstbesetzung des VGH im Sommer 1934 (Kapitel VIII.1.b., S.961 ff.) und bei der im vorliegenden Kapitel geschilderten Besetzung des RJM bis zur Vereinigung mit dem preuß. JM im Oktober 1934.

116 Vgl. den von Schlegelberger paraphierten Entw. eines Schr. des RJM an Heß v. 28.3.39 mit Abgangsverm. (Akten des RJM, a.a.O.).

117 Vgl. Schr. Heß an den RJM v. 1.4.39 (a.a.O.).

118 Vgl. Schr. des RFiM Schwerin v. Krosigk an das RJM v. 12.4.39 und Referentenverm. v. 27.4.39 (a.a.O. und Sign. R 22/1793).

11 Mit Wirkung v. 1.12.39. Zum folgenden vgl. Ernennungsvorschlag des RJM v. 13.10.39 (Akten des RFiM, BA, Sign. R 2/23917).

120 Mettgenberg wurde wegen seiner späteren Beteiligung an der Durchführung der „Nacht- und Nebel“-Verfahren 1942-44 im Nürnberger Juristenprozeß am 4.12.47 zu 10 Jahren Zuchthaus verurteilt. 
Ministerialrat aus dem Reichskommissariat für die besetzten rheinischen Gebiete ins Reichsjustizministerium übergewechselt und ständiger Vertreter des Leiters der Abteilung IV für Bürgerliches Recht und bürgerliche Rechtspflege war. Unter ihnen befand sich ferner Sauer, der seit 1921 im Reichsjustizministerium - ab 1927 als Ministerialrat - tätig war und die Haushaltssachen des Ministeriums sowie die Grundstückverwaltungs- und Bausachen der obersten zentralen Justizbehörden bearbeitete. Eine Ausnahme bildete der bereits erwähnte, von Freisler geförderte Altparteigenosse Haastert $^{121}$, der erst 1934 Ministerialrat im preußischen Justizministerium geworden war und nunmehr das Generalreferat für Beamtenangelegenheiten, die Personalsachen der höheren Beamten des Ministeriums und die Betreuung der Jungjuristen wahrnahm. Im Frühjahr 1940 erfolgten zwei weitere Beförderungen zu Ministerialdirigenten, die zugleich die letzten dieser Art in der Amtszeit Gürtners waren ${ }^{122}$ : die Ernennung Krieges, der seit 1922 Hilfsarbeiter, ab 1929 Ministerialrat im preußischen Justizministerium gewesen war und als Referent für Völkerrecht im Reichsjustizministerium zum Präsidenten des zu Kriegsbeginn eingerichteten Oberprisenhofs bestellt worden war, und die Emennung Willers, der bereits 1921/22 als Justizrat im preußischen Justizministerium gearbeitet hatte, nach einer Zwischenzeit als Richter 1930 dort Ministerialrat geworden war und im Reichsjustizministerium u.a. das Generalreferat für die Angelegenheiten der Beamten des gehobenen, mittleren und einfachen Dienstes sowie der Angestellten und Arbeiter wahrnahm. ${ }^{123}$ In seinem Zustimmungsschreiben vom Februar 1940 hatte der Stellvertreter des Führers abermals darauf hingewiesen, „daß bei der Besetzung so wichtiger Stellen ... die Berücksichtigung besonders bewährter Nationalsozialisten in politischer Hinsicht erwünscht" sei und bei künftigen Beförderungsvorschlägen nach Möglichkeit beachtet werden sollte. ${ }^{124} \mathrm{Da}$ seit Frühjahr 1939 eine Mitgliedschaft in der NSDAP auch für diejenigen wieder möglich war, die sich nicht vorher in ihren Nebenorganisationen bewährt hatten ${ }^{125}$, hatte das Justizministerium diesmal offensichtlich darauf gesehen, daß die Beförderten spätestens nach ihrer Ernennung ihre Aufnahme in die Partei beantragten. Während drei der neuen Ministerialdirigenten im Jahre 1940 - teilweise unter Rückdatierung des Eintritts auf

$121 \mathrm{Zu}$ Haastert s. dieses Kapitel S.246.

122 Die Ernennung Reichaus zum MinDirig., der seit 1926 MinRat im preußischen JM, ab 1935 im RJM war und die Besoldungsangelegenheiten sowie die Ersatzforderungen gegen den Justizfiskus bearbeitete, wurde zwar unter Gürtner noch vorbereitet, erfolgte aber erst am 1.4.41. Er wurde Vertreter MinDir. Schnellers in der Haushalts-Abteilung (vgl. Ernennungsvorschlag des RJM v. 30.1.41, Akten des RFiM, BA, Sign. R 2/23917, und Personalakten, BA).

123 Beide wurden mit Wirkung v. 1.4.40 ernannt. Vgl. Ernennungsvorschlag des RJM v. 13.1.40 (a.a.O.). Den darin enthaltenen Vorschlag, einen weiteren MinRat, der die „Gruppe Justiz“ im Generalgouvernement unter Frank leitete, gleichfalls zum MinDirig. zu befördern, lehnte der RFiM ab, da er weder ständiger Vertreter eines MinDir. war noch seit 5 Jahren eine MinRats-Stelle innehatte (vgl. Verm. Nadlers v. 8.3. und Schr. v. Krosigks v. 13.4.40, Akten des RJM, BA, Sign. R 22/1793).

124 Vgl. Schr. des St.d.F. an das RJM v. 8.2.40 (Akten des RJM, BA, Sign. R 22/1793).

125 Durch die AnO 34/39 des Reichsschatzmeisters der NSDAP v. 10.5.39 (Arch. des IfZ, Sign. Db 23.10) war die Mitgliedersperre v. 1.5.33 mit Wirkung v. 1.5.39 aufgehoben worden. Darin hieß es aber, daß Bewerber, die die Mitgliedschaft „als Mittel für ein besseres berufliches oder wirtschaftliches Fortkommen oder als Gewähr für eine berufliche oder wirtschaftliche Sicherstellung ansehen“, der Partei „unter allen Umständen fernzuhalten“ waren. Durch die AnO v. 20.4 .37 (a.a.O.) war die Sperre bereits gelockert worden, um denjenigen die Aufnahme in die NSDAP zu ermöglichen, die sich in den Gliederungen und angeschlossenen Verbänden der Partei bewährt hatten. Da für diese Aufnahmen das einheitliche Datum 1. Mai 1937 festgestellt wurde, erklärt sich, daß in den Personalien vieler Justizbeamten gerade dieses Datum als Eintrittsdatum erscheint. 
den 1. Dezember 1939 - nachträglich in die NSDAP aufgenommen wurden ${ }^{126}$, lehnte die Parteiführung zwei von ihnen als Mitglieder ab. ${ }^{127}$ Beide blieben bis 1945 in ihren Ämtern.

Hinsichtlich ihrer sozialen Herkunft wies die höhere Beamtenschaft des Reichsjustizministeriums vom Ministerialrat aufwärts eine ziemlich homogene Zusammensetzung auf. Von den 85 Beamten einschließlich des Ministers, die im Zeitraum vom Januar 1933 bis zum Tod Gürtners im Januar 1941 in diesen Beamtenrängen tätig waren, konnte von 36 der Beruf des Vaters festgestellt werden. ${ }^{128}$ Von ihnen stammten 24 aus Familien, deren Väter höhere Beamte - darunter drei in der Justizverwaltung gewesen waren, 3 kamen aus unteren und mittleren Beamtenfamilien, 2 der Väter waren freiberufliche Akademiker - und zwar Rechtsanwälte und Notare -, 2 waren Kaufleute, 2 leitende Angestellte und 3 Handwerker gewesen. Trotz der zahlenmäßig schmalen Basis berechtigen diese Feststellungen, die sich z. B. mit fast dem gleichem Ergebnis über die Herkunft der Oberlandesgerichtspräsidenten und Generalstaatsanwälte treffen lassen, zu der Annahme, daß die höheren Justizministerialbeamten fast ausschließlich dem mittleren und gehobenen Bürgertum und zu einem erheblichen Anteil wiederum dem Beamtentum entstammten. Auf die Bedeutung der sozialen Herkunft der höheren Justizbeamtenschaft für das Problem ihrer Haltung gegenüber dem politischen Regime wird an anderer Stelle eingegangen. ${ }^{129}$

Die Personalveränderungen ab 1935 bei den höheren Beamten des Reichsjustizministeriums unterbalb der Ministerialratsebene - Ende 1940 gab es dort 17 Oberregierungsräte, 8 Regierungsräte und etwa 170 Hilfsarbeiter ${ }^{130}$ - können hier nicht in gleicher Ausführlichkeit dargestellt werden. Daß die geschilderten personalpolitischen Grundsätze auch auf diese Beamtengruppen angewendet wurden, sei an vier „Beförderungsschüben“ aus den Jahren 1939 und 1940 gezeigt, die 34 als Hilfsarbeiter im Ministerium beschäftigte Staatsanwälte, Amts- und Landgerichtsräte betrafen. $\mathrm{Zu}$ den beiden ersten Schüben vom März und August 1939, bei denen 5 dieser Hilfsarbeiter zu Oberregierungsräten ernannt und weitere 13 zu Oberlandesgerichtsräten bzw. Kammergerichtsräten befördert wurden, um in entsprechende Planstellen für Hilfsarbeiter des Ministeriums eingewiesen zu werden, gehörten 2 Altparteigenossen, 12 Parteigenossen und 4 Nicht-Parteigenossen. ${ }^{131}$ Bei den folgenden beiden Schüben vom Januar und Oktober 1940 waren von den 16 zu Oberlandesgerichts- bzw. Kammerge-

126 Vgl. Personalunterlagen im DC Berlin und Personalakten im BA.

127 A.a.O. Einer der beiden MinDirig. hatte von 1922 bis zur Auflösung 1933 der DVP angehört und noch 1932 für den preuß. Landtag kandidiert. Im Ablehnungsschr. des St.d.F. (gez. Bormann) an den Reichsschatzmeister der NSDAP v. 2.9.40 hieß es ferner, daß er noch Ende 1938 der Deutschen Bekenntnisfront nahegestanden habe (DC Berlin, Partei-Correspondence). Er hatte sich im Oktober 1936 der Aufforderung, dem NSRB beizutreten, mit der Begründung entzogen, daß dadurch seine Tätigkeit in der internationalen Gemischten Kommission für Oberschlesien unter dem Vorsitz des Schweizers Calonder erschwert würde. Das wurde ihm noch 1938 vorgehalten (vgl. Schr. des St.d.F. an das RJM v. 14.7.38 mit anschließender Korrespondenz bis September 1938, Personalakten, BA).

128 Als Quellen dienten Personalakten des RJM (BA), Personalunterlagen des DC Berlin sowie zeitgenössische Handbücher.

129 Vgl. dazu die Feststellungen hinsichtlich der OLGPräs. und GStAe in Kapitel III.3.b., S.288f.

130 Vgl. Kalender für Reichsjustizbeamte 1941, Teil 2, S.30, und Personalübersicht in den Akten des RJM (BA, Sign. R 22/5043), beide Stand 1.10.40.

131 Vgl. Ernennungsvorschläge des RJM v. 21.11.38 bzw. 4.3.39 (Akten des RJM, BA, Sign. R 22/1792) sowie v. 8.7. bzw. 16.8.39 (a.a.O., Sign. R 22/1793). ORegRäte wurden: 1 Altparteigenosse, 3 Parteigenossen und 1 Nicht-Parteimitglied. 
richtsräten Ernannten 2 Parteianwärter und 13 Parteigenossen, darunter 2 Altparteigenossen. ${ }^{132}$

Als junge Nachwuchskräfte für das Ministerium wurden entweder Gerichtsassessoren oder jüngere Planbeamte aus den nachgeordneten Justizbehörden gewonnen. Um geeignete Gerichtsassessoren zu finden, wies Gürtner das Reichs-Justizprüfungsamt im Juni 1935 an, ihm „über den Abschluß der großen Staatsprüfung eines jeden Assessors zu berichten, der beide Prüfungen mit ,lobenswert" bestanden " hatte und in den Justizdienst gehen wollte. Diese Assessoren sollten - beginnend mit dem 1. Juli 1935 - für mehrere Monate als Hilfsarbeiter ins Ministerium einberufen werden, „sofern sie sich auch nach ihrem Charakter und ihrer politischen Haltung zu einer derartigen Verwendung“ eigneten. Aber auch bei diesem Bestreben, eine Nachwuchselite für das Ministerium zu schaffen, mußten politische Konzessionen gemacht werden: dafür konnten auch Assessoren herangezogen werden, die „zwar die Staatsprüfungen nicht mit ,lobenswert' bestanden, aber durch offenes Eintreten für die nationalsozialistische Bewegung während der Kampfzeit besondere Verdienste erworben“, insbesondere ihren Beitritt zur NSDAP vor dem 14. September 1930 erklärt hatten. ${ }^{133}$ Nach Bewährung im ministeriellen Dienst und günstiger Beurteilung durch den zuständigen Abteilungsleiter wurden die Assessoren entweder zur Anstellung als Amtsgerichtsräte, Landgerichtsräte oder Staatsanwälte für den Außendienst bei Gerichten oder Staatsanwaltschaften vorgeschlagen, um später gegebenenfalls wieder ins Ministerium zurückgeholt zu werden, oder sie wurden als Landgerichtsräte in freie Planstellen für Hilfsarbeiter des Ministeriums eingewiesen. Diese Nachwuchskräfte waren meistens Mitglieder der Partei oder zumindest einer ihrer Gliederungen, da diese Mitgliedschaft nach der Ausbildungsordnung von 1934 de facto die Voraussetzung für die Zulassung zur ersten juristischen Staatsprüfung ${ }^{134}$ und ab Februar 1939 für den Eintritt in die Beamtenlaufbahn ${ }^{135}$ war. So waren beispielsweise im Oktober 1938 von 12 Assessoren, die sich im Ministerium bewährt hatten und für eine Anstellung bei nachgeordneten Justizbehörden vorgeschlagen wurden, 2 Parteianwärter, 9 Parteigenossen, davon zwei mit Eintrittsdatum vor 1933; 9 von ihnen waren gleichzeitig SAAngehörige. ${ }^{136}$ Im Juli 1939 war z.B. unter 6 im Ministerium bewährten Assessoren,

$132 \mathrm{Vgl}$. Emennungsvorschläge des RJM v. 26.10 .39 bzw. 13.1 .40 (a.a.O.) sowie v. 18.7. bzw. September 1940 (a.a.O., Sign. R 22/1794). Die Institution des „Parteianwärters“ gab es zwar nur in der Zeit nach der Lockerung der Mitgliedersperre (1.5.37) bis zu ihrer völligen Aufhebung (1.5.39). Da die betreffenden LGRäte zur Wehrmacht einberufen waren, hatten ihnen aber offenbar die Mitgliedskarten noch nicht ausgehändigt werden können.

133 Vgl. Hausverf. Gürtners betr. Einberufung von Assessoren in das Justizministerium v. 13.6.35 (Akten des RJM, BA, Sign. R 22/3792). Der 14. September 1930, an dem die NSDAP mit 107 Reichstagssitzen ihren ersten Wahlerfolg errang, wurde deshalb als Stichtag genommen, weil es nach Ansicht der Parteiführung „unter den vor diesem Datum eingetretenen Parteigenossen ... im wesentlichen keine Konjunkturritter gegeben haben“ konnte, "da ein bedeutender öffentlicher Erfolg für die Partei noch nicht gegeben war“, vgl. Partei-Statistik 1935, Bd.I, herausg. vom Reichsorganisationsleiter der NSDAP, o.J., als Manuskript gedruckt, S. VII (Arch. des IfZ, Sign. Db 20.02).

134 Vgl. dazu Kapitel III.4.b., S.300.

135 Vgl. $§ 2$ der VO über die Vorbildung und die Laufbahnen der deutschen Beamten v. 28. 2.39 (RGBl. I, S. 371) und Kapitel III.1.d., S. 216. Im Kriege wurden die OLGPräs. in den Zustimmungsschr. des RJM für die Emennung von Rechtskandidaten zu Gerichtsreferendaren, denen der Erwerb der Mitgliedschaft vor ihrer Einberufung zur Wehrmacht nicht möglich gewesen war, ausdrücklich gebeten, dem Betreffenden „aufzugeben, sich nach Entlassung aus dem Wehrdienst um seine Aufnahme in die NSDAP oder eine ihrer Gliederungen zu bemühen“ (Beispiele v. Mai 1940 in den Akten des RJM, BA, Sign. R 22/4502).

$136 \mathrm{Vgl}$. Ernennungsvorschlag des RJM an den St.d.F. v. 3.10.38 (Akten des RJM, BA, Sign. R 22/1792). 
die nunmehr für eine planmäßige Anstellung als Landgerichtsräte auf Hilfsarbeiterstellen im Ministerium vorgeschlagen wurden, ebenfalls ein einziger Nicht-Parteigenosse. ${ }^{137}$ Bezeichnenderweise stimmte der Stellvertreter des Führers zwar der Ernennung des betreffenden aus Wien stammenden „Volksgenossen“ zum Landgerichtsrat zu, bat jedoch, auf seine Verwendung im Ministerium zu verzichten, da er für die Bewegung in keiner Weise „seine Einsatzbereitschaft unter Beweis gestellt" habe. Erst als der gleichfalls aus Österreich stammende Unterstaatssekretär Hueber, bei dem der Betreffende persönlicher Referent war, sich für ihn eingesetzt und als SA-Brigadeführer für seine Aufnahme in die SA gesorgt hatte, ließ die Parteiführung ihre Bedenken fallen. ${ }^{138}$

Ein besonderes Problem war die Beschäftigung weiblicher Beamter des höheren Dienstes im Reichsjustizministerium. Um einigen besonders befähigten Gerichtsassessorinnen zu helfen, denen im nationalsozialistischen Staat als Frauen die Laufbahn des Richters, Staatsanwalts und Rechtsanwalts nicht mehr offenstand, beschäftigte das Ministerium drei von ihnen als Hilfsarbeiter. Obwohl Hitler im August 1937 entschieden hatte, daß Frauen auch in der Verwaltung nur noch im Einzelfall zu Beamtinnen des höheren Dienstes ernannt werden sollten ${ }^{139}$, schlug das Ministerium im März 1940 die Beförderung dieser drei Gerichtsassessorinnen und einer Regierungsoberinspektorin - sämtlich unverheiratet - zu planmäßigen Regierungsrätinnen vor. Von ihnen war nur eine Parteimitglied und außer ihr nur eine zweite Mitglied bei der NS-Frauenschaft $^{140}$, die die Gliederung der Partei für die Frauen darstellte. Die vier Vorgeschlagenen wurden ernannt und bekamen Planstellen beim Kammergericht, behielten aber als Hilfsarbeiterinnen im Justizministerium ihre speziellen Arbeitsgebiete z.B. im Strafvollzug für Frauen und Jugendliche, bei der Jugendschutzgesetzgebung, im Erbhofrecht u.a., da die planmäßige Anstellung von Frauen nach der Laufbahnverordnung vom Februar 1939 nur für solche Beamtenstellen zugelassen war, „die ihrer Art nach mit weiblichen Beamten besetzt werden müssen “. ${ }^{141}$ Obwohl Frick als Generalbevollmächtigter für die Reichsverwaltung im Mai 1940 diese Bestimmung angesichts der angespannten Personallage im Kriege dahingehend gemildert hatte, daß es sich auch um Stellen handeln konnte, „zu deren Besetzung sich Frauen besser eignen als Männer “142, erhob der Stellvertreter des Führers gegen die Ernennung weiterer Regierungsrätinnen durch das Justizministerium Bedenken, da die für sie vorgesehenen Arbeitsgebiete diesem Erlaß Fricks widersprächen: der gegenwärtige Personalmangel, der nur „vorübergehender Natur“ sei, dürfe keinesfalls „dazu führen, von den grundsätzlichen Anforderungen des auf eine Führer-Entscheidung zurückgehenden Erlasses“ abzugehen; er dürfe daher nicht „durch Maßnahmen abgewendet werden, die sich weit über die Zeit des besonderen Bedürfnisses hinaus auswirken müssen“. Es war deutlich, daß die Parteiführung die Anstellung von Frauen im höheren Justizdienst auch unter

$137 \mathrm{Vgl}$. Ernennungsvorschlag des RJM an den St.d.F. v. 14.7 .39 (a.a.O., Sign. R 22/1793). In diesen Akten auch weitere einschlägige Einzelbeispiele.

$138 \mathrm{Vgl}$. Schr. des St.d.F. an das RJM v. 20.10.39 und die Reaktion des RJM v. 2.11.39 (a.a.O.).

139 Zum Problem der Frauen im Justizdienst s. Kapitel III.4.b., S. 318 ff.

140 Vgl. Ernennungsvorschlag des RJM v. 27.3.40 (Akten des RJM, BA, Sign. R 22/1794). Sie wurden mit Wirkung v. 1.6.40 ernannt.

141 Vgl. § 1 Abs.3 der VO über die Vorbildung und die Laufbahnen der deutschen Beamten v. 28.2.39 (RGBl.I, S. 371). Hervorhebung vom Verfasser.

142 Vgl. RdSchr. des GBV für die Reichsverwaltung an die Obersten Reichsbehörden v. 20. 5.40, den höheren Reichsjustizbehörden vom RJM in einer RV v. 1.6.40 mitgeteilt (a.a.O., Sign. R 22/1500). 
den Bedingungen des Krieges abblocken wollte. Den Einwand des Justizministeriums, daß es Fricks Erlaß der pflichtgemäßen Beurteilung des zuständigen Ministeriums überließ, inwieweit im Einzelfall die Besetzung einer Stelle durch eine Gerichtsassessorin in Frage kam, konterte Bormann mit dem unverzichtbaren Anspruch, „bei der Mitwirkung an Personalmaßnahmen auf Umstände hinzuweisen, deren Beachtung mir aus allgemein-politischen Gründen [!] notwendig erscheint" ${ }^{143}$ Beide kamen überein, sich bei künftigen Stellenbesetzungen mit Gerichtsassessorinnen vorher über das für sie in Aussicht genommene Arbeitsgebiet zu einigen. ${ }^{144}$ Selbst im Kriegsjahr 1944 sollte das Reichsjustizministerium nur fünf Beamtinnen des höheren Justizdienstes außer den erwähnten vier Regierungsrätinnen eine weitere - beschäftigen. ${ }^{145}$

Um den Personalbedarf des Ministeriums nicht nur durch Gerichtsassessoren, sondern auch durch jüngere Beamte des höheren Dienstes decken zu können, die bei den nachgeordneten Justizbehörden planmäßig angestellt waren, wurden die Oberlandesgerichtspräsidenten im Frühjahr 1937 angewiesen, dem Ministerium erstmals zum 15. Juni und

„in Zukunft alle 2 Jahre jeweils zum 1. April - also nächstmals bis zum 1. April 1939 - aus den größeren Bezirken 2-4, aus den kleineren Bezirken 1-2 jüngere Planbeamte des höheren Dienstes (Amts- oder Landgerichtsräte usw.) namhaft zu machen, die zur Mitarbeit im Reichsjustizministerium besonders geeignet erscheinen".

Bei den „hochgespannten Anforderungen“, die dabei an den einzelnen gestellt werden müßten, seien aber nur „dienstlich hervorragend“ bewährte Beamte vorzuschlagen, die gleichzeitig die Gewähr für ein rückhaltloses Eintreten für den nationalsozialistischen Staat boten und „über die Charaktereigenschaften verfügen, welche die Rechtspflege vornehmlich erfordert". Besondere Leistungen oder Erfahrungen sollten im Befähigungsnachweis speziell vermerkt werden. Aus dem Reservoir der vorgeschlagenen Beamten beabsichtigte das Ministerium, einzelne für eine mehrmonatige Probezeit auszuwählen, die nach Bestätigung ihrer Eignung dann „mit einer mehrjährigen Beschäftigungsdauer im Reichsjustizministerium“ rechnen konnten. ${ }^{146}$

Daraufhin schlugen die Oberlandesgerichtspräsidenten und Generalstaatsanwälte im Juni 1937 aus ihren Bezirken insgesamt 102 junge Amts- bzw. Landgerichtsräte und Staatsanwälte vor. Unter ihnen befanden sich bezeichnenderweise nur 7, die weder der Partei noch einer ihrer Gliederungen angehörten, dagegen 59 Parteigenossen, von denen 3 Altparteigenossen von 1932, 20 gleichzeitig in der SA und 1 gleichzeitig im NS-Kraftfahrkorps (NSKK) waren. 17 der Vorgeschlagenen waren ausschließlich Mitglieder der SA, 5 der SS und 4 des NSKK. ${ }^{147}$ Unter den 10, von denen anhand der erreichbaren Unterlagen mit Sicherheit gesagt werden kann, daß sie in den folgenden Jahren bis Anfang 1941 ausgewählt und als Hilfsarbeiter ins Ministerium einberufen wurden, waren immerhin 2, die keiner Parteigliederung angehörten; 1 war SA-Mitglied und 7 waren Parteigenossen, darunter zwei Altparteigenossen: als Staatsanwälte

\footnotetext{
143 Schr. des St.d.F. (i.V. Bormann) an das RJM v. 21.3.41 (a.a.O., Sign. R 22/1794). In diesem Fall handelte es sich um die schließlich doch erfolgende Ernennung von 4 Assessorinnen zu RegRätinnen an OLGen, die nicht als Hilfsarbeiter im RJM arbeiten sollten.

144 Vgl. Schr. des RJM an den St.d.F. v. 2.4.41 (a.a.O.).

$145 \mathrm{Vgl}$. Übersicht über den Personalbestand des RJM am 31.5.44 (Akten des RJM, BA, Sign. R 22/5043)

146 Vgl. RV des RJM an die OLGPräs. v. 8.5.37 (a.a.O., Sign. R 22/2139).

147 Vgl. die nach OLG-Bezirken gegliederte Vorschlagsliste in den Akten des RJM (BA, Sign. R 22/5046).
} 
kamen diese beiden 1937/38 in die Strafrechtspflegeabteilung, einer wurde im März 1939 Oberregierungsrat, der andere im Mai 1940 persönlicher Referent Freislers.

Bei der zweiten Vorschlags-Aktion vom März 1939 hielten die Provinzialbehördenchefs ihre bis dahin nicht berücksichtigten Benennungen aufrecht und ersetzten nur diejenigen durch neue, die unterdessen schon ins Reichsjustizministerium einberufen worden waren oder deren Verwendung im Ministerium durch anderweitigen dringenden Einsatz nicht mehr in Frage kam. ${ }^{148}$ Unter den neu Vorgeschlagenen gab es nunmehr nur noch ganz vereinzelt Beamte, die weder Mitglied der NSDAP noch einer ihrer Gliederungen waren.

Dieser Überblick zeigt, daß sich von 1933 bis zum Ende der Amtszeit Gürtners der Prozentsatz der Parteimitglieder bei den Beamten des Reichsjustizministeriums einmal durch den Nachwuchs, der aufgrund der Ausbildungs- und Anstellungsvorschriften in der Mitgliedschaft die beste Gewähr für das berufliche Fortkommen sehen mußte, zum anderen aber auch durch den Beitritt alter Ministerialkräfte zur NSDAP erheblich vergrößert hatte. ${ }^{149}$ Dennoch war die Zugehörigkeit zur Partei noch nicht das entscheidende Kriterium für die Auslese und Beförderung der Ministerialbeamten geworden; in vielen Fällen dürfte es sich auch um eine bloß „nominelle“ Mitgliedschaft gehandelt haben. Jedenfalls stellte der SD im Reichssicherheitshauptamt nach dem Tode Gürtners fest, daß das Reichsjustizministerium ,in personeller Hinsicht immer noch eine dem Nationalsozialismus im wesentlichen verschlossene Front" darstelle. ${ }^{150}$ Dennoch mußte sich aber das allmähliche Einschieben echter Nationalsozialisten und "Altparteigenossen“ in wichtige Schlüsselpositionen, etwa bei der politischen Strafrechtspflege - für das vor allem Freisler sorgte -, auf ein reibungsloses Funktionieren des Ministeriums im Sinne der politischen Führung auswirken.

\section{b. Stellenbesetzung bei den höberen Reicbsjustizbebörden 1935-1940:}

Berücksichtigung der Gauleiterwünsche bei der Ernennung der Oberlandesgerichtspräsidenten und Generalstaatsanwälte

Auf eine erschöpfende Darstellung der Personalpolitik des Reichsjustizministeriums bei der Besetzung sämtlicher ihm unmittelbar unterstellter Justizbehörden - dem Reichsgericht, dem Volksgerichtshof nebst den zugehörigen beiden Reichsanwaltschaften, dem Reichspatentamt, dem Reichs-Justizprüfungsamt, dem Obersten Fideikommißgericht und dem Landeserbhofgericht in Celle - soll verzichtet werden. Dagegen soll die Umbesetzung bei den Chefs der höheren regionalen Justizbehörden, d.h. den Oberlandesgerichtspräsidenten und Generalstaatsanwälten behandelt werden. Nach der Machtübernahme von den neuen Landesjustizverwaltungen eingesetzt oder bestätigt, wurden sie am 1. April 1935 von der Reichsjustizverwaltung zunächst unverändert übernommen. Stärker als bei den Besetzungen im eigenen Haus mußte hierbei

148 Vgl. z. B. die Einberufungsvorschläge des KGPrās. v. 25.3.39 und des OLGPräs. Hamm v. 24.3.39 aufgrund der RV des RJM v. 8.5.37 (a.a.O.).

149 Vgl. die absoluten Zahlen im Kapitel III.1.d., S. 219: schon im Dezember 1938 waren von den 530 Beamten des RJM 257 in der Partei.

$150 \mathrm{Vgl}$. Niederschrift über die Tagung des SD im RSHA am 26.2.41 (Arch. des IfZ, Sign. Fa 396/11). Der Bericht fährt fort: „Die künftige Entwicklung unter einem neuen Justizminister müsse abgewartet werden.“ 
das Reichsjustizministerium schon ab 1935 die Wünsche der Partei, vor allem der Gauleiter, berücksichtigen.

Das zeigte sich bereits, als noch vor dem Abschluß der generellen „Verreichlichung" die ersten Ernennungen in Braunschweig und Hessen vorgenommen werden mußten, wo das Reichsjustizministerium schon im Dezember 1934 die Funktion der obersten Landesjustizbehörde wahrnahm. ${ }^{1}$ In Braunschweig mußte Oberlandesgerichtspräsident Heusinger ersetzt werden, der sich durch Proteste gegen das ungesetzliche Vorgehen von Angehörigen der Bewegung gegen politische Gegner bei der regionalen NS-Führung unbeliebt gemacht hatte und offensichtlich noch durch den braunschweigischen Justizminister, SS-Standartenführer Alpers, seines Postens enthoben worden war. ${ }^{2}$ Das Reichsjustizministerium behielt ihn jedoch am Oberlandesgericht Braunschweig als Senatspräsidenten und beließ ihm auch seine Präsidentenbezüge. An seine Stelle trat mit Wirkung vom 1. Januar 1935 Günther Nebelung, der seit 1928 Parteigenosse, Träger des Goldenen Ehrenzeichens der NSDAP und vor seiner Ernennung zum Senatspräsidenten am Braunschweiger Oberlandesgericht im Juli 1934 Rechtsanwalt und Notar gewesen war. Er sollte 1944 in den Volksgerichtshof berufen werden. ${ }^{3}$

Auch in Hessen, wo der 1933 beibehaltene Oberlandesgerichtspräsident von Darmstadt, Adolf Müller, Ende Januar 1935 in den Ruhestand ging, wurde dessen Stelle mit einem Altparteigenossen besetzt. Es handelte sich um den späteren Staatssekretär im Reichsinnenministerium Wilhelm Stuckart, der der NSDAP erstmals 1922 und nach der Neugründung - erneut 1930 beigetreten war, als Rechtsanwalt im Gau Pommern die Rechtsstelle der Partei eingerichtet und geleitet hatte, dann im April 1933 für einige Wochen zum kommissarischen Oberbürgermeister von Stettin und im Mai zum Ministerialdirektor im preußischen Kultusministerium berufen worden war, um im Juni dort Staatssekretär zu werden. ${ }^{4}$ Da der Posten des Darmstädter Oberlandesgerichtspräsidenten für Stuckart offensichtlich nur eine Überbrückung darstellte - er ging bereits Mitte März 1935 ins Reichs- und Preußische Innenministerium -, stand die Justizleitung erneut vor der Aufgabe, diese Stelle mit einem geeigneten Mann zu versehen. Das war insofern problematisch, als der amtierende Vizepräsident des Oberlandesgerichts und sein Personalreferent mit Gauleiter und Reichsstatthalter Sprenger in Konflikt geraten waren und darin von dem gerade ins Reichsjustizministerium übernommenen hessischen Ministerialrat Malzan ${ }^{5}$ bestärkt wurden. Das „Gerücht“, über das der Darmstädter Generalstaatsanwalt vertraulich dem Ministerium berichtete: - „die Wahl des neuen Oberlandesgerichtspräsidenten biete dem Reichsjustizministe-

1 Vgl. Kapitel II.5., S. 112.

2 Alpers hatte bereits in einem Schr. an Gürtner v. 20.2.34 (Arch. des IfZ, Sign. MA 108) von „dem mangelnden Verständnis des obersten Richters des Landes Braunschweig für die nationalsozialistische Bewegung" gesprochen. Zu Heusinger vgl. ferner S. 206f., 240, A. Lein, Braunschweiger Justiz im Nationalsozialismus: zwischen Anpassung und ninnerer Emigration" (in: Braunschweig unterm Hakenkreuz, herausg. von H. Kramer, Braunschweig 1981), S.73, und M. Flotho, Bruno Heusinger (1989).

3 Zu Nebelung vgl. Fall 3. Das Urteil im Juristenprozeß, gefällt am 4. Dezember 1947 vom Militärgerichtshof III der Vereinigten Staaten von Amerika, herausg. von P. A. Steiniger und K. Leszczynski, Berlin 1969, S. $81 \mathrm{f}$, ferner Ernennungsvorschlag des RJM zum SenPräs. beim VGH v. 5.4.44 (Akten der RK, BA, Sign. R 43 II/1517 c). Nebelung wurde 1944 zum Präs. des IV. Senats beim VGH berufen und wegen dieser Tätigkeit im Nümberger Juristenprozeß angeklagt, aber freigesprochen.

Zu Stuckart vgl. Degeners Wer ist's?, X. Ausgabe, Berlin 1935, S. 1578.

5 Zu Malzan vgl. Kapitel III.3.a., S. 245. 
rium besondere Schwierigkeiten, weil ein Mann gefunden werden müsse, der dem Reichsstatthalter gegenüber Rückgrat zeige ${ }^{\text {"6 }}$ - dürfte allein angesichts der Tatsache nicht ohne Grundlage gewesen sein, daß die Stelle fast ein Jahr lang unbesetzt blieb. Auch Sprenger hatte sich bereits im März bei Freisler beklagt, daß sich die Richter in seinem Gau seit der Verreichlichung seiner Einwirkung entzögen, sie würden „rein paragraphenmäßig auf Partei und Parteigenossen herumreiten" und das Ansehen der Partei dadurch „vor die Hunde“ gehen. Er brauche daher als Chefpräsidenten einen Mann, der dafür sorge, „daß bei der Bearbeitung aller Rechtsfragen die nationalsozialistische Weltanschauung zugrunde gelegt" werde. ${ }^{7}$ Sprenger, der für diesen Posten einen ehemaligen hessischen Ministerialdirektor vorschlug, einigte sich mit dem Justizminister schließlich auf den Limburger Landgerichtspräsidenten Scriba, der 1919 bis 1921 der Deutschnationalen Volkspartei angehört, im Dezember 1932 aber zur NSDAP gefunden und „sich schon vor der Machtergreifung offen zur NSDAP bekannt" hatte. ${ }^{8}$ Um die Darmstädter Krise beizulegen, betonte Gürtner in seiner Rede zur Einführung des neuen Oberlandesgerichtspräsidenten am 17. Februar 1936, daß es im Geiste der Arbeitskameradschaft „keine Frage mehr über die Zusammenarbeit ... mit den Dienststellen der NSDAP“ geben dürfe, denn ,alle gingen den gleichen Weg und dienten dem gleichen Ziele".9 Seine bei dieser Gelegenheit ostentativ geführten „langen und offensichtlich freundlichen Gespräche“ mit Sprenger hatten auf die anwesenden Darmstädter Juristen „eine starke Suggestivwirkung“: „Der auf besondere Ursachen zurückzuführende Glaube, man könne sich durch eine feindliche Haltung (gegenüber dem Gauleiter) bei der Zentrale in Berlin beliebt machen", berichtete der Generalstaatsanwalt nach Berlin, sei nunmehr „ins Wanken geraten“.10

Beim Oberlandesgericht Rostock mußte das Reichsjustizministerium 1935 eine Umbesetzung vornehmen, da Gauleiter Hildebrandt die Abberufung des 1933 übernommenen Präsidenten Burmeister betrieb. Im Oktober 1934 hatte der Gauführer des BNSDJ dem mecklenburgischen Justizminister eine Entscheidung des Senats unter Burmeisters Vorsitz mitgeteilt, die „wieder einmal in krassem Widerspruch zur nationalsozialistischen Weltanschauung“ stand und „zum Anlaß eines Kesseltreibens“ der mecklenburgischen Nationalsozialisten gegen Burmeister wurde. ${ }^{11}$ Obwohl sich im November achtzehn Anwälte am Rostocker Oberlandesgericht in einer Eingabe für ihn verwandten, wurde Burmeister beurlaubt. Die Beurlaubung wurde jedoch im Dezember 1934 wieder zurückgenommen und „die endgültige Entscheidung über sein Verbleiben " nunmehr dem Reichsjustizministerium in Berlin überlassen. ${ }^{12}$ Angesichts der gespannten Lage entschied sich das Reichsjustizministerium, Burmeister ab 1. Fe-

${ }^{6}$ In seinem vertraul. Lageber. an das RJM v. 31.3.36, den er auf Wunsch des Ministeriums am 6.5.36 ergänzte, schilderte der GStA Darmstadt nachträglich die Krise und betonte „die feindliche Einstellung gegen den Reichsstatthalter im Kreis der Berufskameraden“ mit der Folgewirkung, „daß jeder, der auf gutes Einvernehmen mit dem Reichsstatthalter und Gauleiter und den Parteistellen hielt, als abhängig und hörig, ja geradezu als Rechtsbeuger verschrieen wurde" (vgl. Personalakten des RJM, Eckert, BA).

7 Vgl. Schr. Sprengers an Freisler v. 26.3.35, Eintr. v. 29.3.35 im Diensttageb. des RJM, Bd. 2 (BA, Sign. R 22/603).

${ }^{8}$ Vgl. Schr. des RJM v. 12.12.35 an den RFiM und den RuPrMdI (Akten des RFiM, BA, Sign. R 2/23976).

9 Vgl. Einweisung des Oberlandesgerichtspräsidenten in Darmstadt (DJ 1936, S. 297).

10 Vgl. vertraul. Lageber. des GStA Darmstadt v. 31.3 .36 (s. voranstehende Anm.6).

1 Vgl. Ber. des SenPräs. Huther, der das OLG stellvertretend leitete, an das RJM v. 3. 5. 35, Eintr. v. 7.5.35 im Diensttageb. des RJM, Bd.3 (BA, Sign. R 22/1056).

${ }_{12}$ Vgl. Eintr. v. 28.11.34 und Schr. Burmeisters an das RJM v. 28.12.34, Eintr. v. 29.12.34, a.a.O., Bd. 1 (BA, Sign. R 22/131). 
bruar 1935 als Rat ans Reichsgericht zu versetzen. Um die Nachfolge begann ein monatelanges Tauziehen, da Hildebrandt - von Bormann unterstützt - auf diesem Posten den Rostocker Landgerichtsdirektor und Bezirksobmann des BNSDJ Zastrow sehen wollte, den das Justizministerium jedoch ablehnte. Es bekam Schützenhilfe von den Reichsministern des Innern und der Finanzen, die ihre Zustimmung zur Ernennung Zastrows gleichfalls verweigerten. ${ }^{13}$ Weder Hildebrandts Hinweis, „daß die politische Führung in Mecklenburg sich für Zastrow festgelegt habe " und eine andere Besetzung daher eine „Schädigung des Ansehens der Bewegung im Gau“ bedeute, noch eine Unterredung des Ministerialrats Sommer vom Stab des Stellvertreters des Führers mit Freisler im September ${ }^{14}$, noch eine erneute schriftliche Intervention Bormanns beim Justizministerium von Ende September 1935 konnten daran etwas ändern. Selbst als Hildebrandt dem Reichsinnenminister bei einem Staatsbesuch dessen Einverständnis zu Zastrows Ernennung abrang, erklärte Frick, „er könne allerdings an anderweitiger Besetzung nichts mehr ändern" ${ }^{15}$ Sie erfolgte schließlich im Dezember 1935 durch einen Kompromiß: Zum Oberlandesgerichtspräsidenten wurde der bisherige Vizepräsident des Kammergerichts Goetsch ernannt, auf den sich Gürtner mit Heß offensichtlich unmittelbar geeinigt hatte. ${ }^{16}$ Wie sein Konkurrent war Goetsch der Partei schon vor der Machtübernahme beigetreten und hatte seinen Posten am Kammergericht im Juni 1933 nach einem kurzen Zwischenspiel im preußischen Justizministerium erhalten. ${ }^{17}$ Hildebrandt fügte sich knurrend: Er könne "die getroffene Entscheidung nicht hindern und werde pflichtgemäß die Autorität des neuen OLGPräs. verteidigen müssen“. ${ }^{18}$ Als Gegenleistung wurde gleichzeitig Zastrow zum Senatspräsidenten am Rostocker Oberlandesgericht befördert, um im März 1936 dessen Vizepräsident zu werden. Den ersehnten Posten des Chefpräsidenten sollte er unter Thierack nach einer Periode als Rostocker Generalstaatsanwalt im Jahre 1942 - doch noch 1943 erreichen. ${ }^{19}$

Im Jahre 1935 mußte das Reichsjustizministerium drei weitere Oberlandesgerichtspräsidentenstellen neu besetzen. In Stuttgart, wo Oberlandesgerichtspräsident Heß auf eigenen Antrag in den Ruhestand trat, wurde am 1. April der Präsident des dortigen Landgerichts Küstner als Nachfolger ernannt, der seit 1928 bis zu seiner Beförderung zum Landgerichtspräsidenten im Juli 1934 im württembergischen Justizministerium tätig gewesen war. ${ }^{20}$ In Hamburg trat Oberlandesgerichtspräsident Engel kurz vor Erreichen der Altersgrenze in den Ruhestand, um am 1. April dem bisherigen Justizse-

13 Vgl. Eintr. v. 15.6.35, a.a.O., Bd.3. Als Argument diente u. a. das Alter Zastrows, der das 38. Lebensjahr noch nicht vollendet hatte.

14 Auch Freisler hatte gegen Zastrow Vorbehalte, vgl. Schr. Hildebrandts an das RJM, Eintr. v. 9.7.35, a.a.O., Bd. 4 (BA, Sign. R 22/1059).

15 Vgl. Schr. des St.d.F. (gez. Bormann) an das RJM v. 26.9.35, Eintr. v. 3.10.35, a.a.O., Bd.5 (BA, Sign. R 22/1088). Frick hatte schon am 19.8.35 der Ernennung Goetschs zugestimmt, vgl. sein Schr. an das RJM, Eintr. v. 20.8.35, a.a.O., Bd.4 (BA, Sign. R 22/1059)

16 Vgl. Schr. des St.d.F. an den RJM v. 31.7.35, Eintr. v. 6.8.35, a.a.O.

17 Goetsch, seit 1920 KGRat, wurde am 10.5.33 zum MinDirig. im preuß. JM, aber schon am 1.6.33 zum Vizepräs. des KG ernannt (vgl. JMBl.1933, S.173; Personalverzeichnis des höheren Justizdienstes 1938, S. 76); zu seiner Amtseinführung am 2.12.35 vgl. DJ 1935, S.1776.

$18 \mathrm{Vgl}$. Schr. Hildebrandts an das RJM, Eintr. v. 9.7.35 im Diensttageb. des RJM, Bd. 4 (BA, Sign. R 22/1059).

$19 \mathrm{Zu}$ Zastrow vgl. Ernennungsvorschläge des RJM v. 8.6.42 und 16.3.43 (Akten des RFiM, BA, Sign. R 2/23980) und Personalakten des RJM, BA.

20 Küstner war 1920-26 schon einmal im württemb. JM tätig gewesen, vgl. Personalverzeichnis des höheren Justizdienstes, Berlin 1938, S. 142. 
nator und Beauftragten des Reichsjustizministeriums für die Abteilung Nord, Curt Rothenberger, Platz zu machen. Der Nationalsozialist Rothenberger, der 1942 unter Thierack Staatssekretär werden sollte, war der Günstling des Gauleiters Kaufmann: Er hatte schon seit 1931 als Oberregierungsrat in der hamburgischen Justizverwaltung und als Landgerichtsdirektor mit der NSDAP zusammengearbeitet, damals aber auf Anraten Kaufmanns auf eine Mitgliedschaft bei der Partei verzichtet, da er „als guter Kenner der Hamburgischen Verwaltung und Personalverhältnisse ohne Bindung zur Partei weitaus bessere Dienste leisten " konnte. ${ }^{21}$

Die letzte Umbesetzung im Jahre 1935 betraf das Oberlandesgericht Breslau. Sein Präsident wurde wegen eines Steuerdelikts belangt und beantragte deshalb auf Anregung des Gauleiters im Herbst seine Versetzung, die als Senatspräsident ans Kammergericht erfolgte. ${ }^{22}$ Nachfolger wurde im Januar 1936 der bisherige Generalstaatsanwalt in Hamm, Freiherr von Steinaecker. Er hatte 1930 als Oberstaatsanwalt im SklarekProzeß mitgewirkt und war als Parteigenosse von 1931 schon vor der Machtübernahme als Parteiredner und Mitarbeiter der Berliner Gauleitung tätig gewesen und außerdem Obersturmbannführer der SA. ${ }^{23}$

Im Jahre 1937 traten in Bayern zwei Oberlandesgerichtspräsidenten, die 1933 von Hans Frank eingesetzt worden waren, wegen Erreichung der Altersgrenze in den Ruhestand: Georg Neithardt in München und Otto Bertram in Nürnberg. ${ }^{24}$ Gürtner besetzte die Posten mit zwei Beamten, die schon viele Jahre vor der Machtübernahme unter ihm im bayerischen Justizministerium tätig gewesen waren. In München wurde am 1. Mai der bisherige Vizepräsident und Schwager Gürtners Dürr Oberlandesgerichtspräsident, in Nürnberg am 1. Oktober der dortige Generalstaatsanwalt Döbig. ${ }^{25}$ Obwohl die Gauleitung München-Oberbayern Döbigs politische Zuverlässigkeit dem Stellvertreter des Führers gegenüber zufriedenstellend beurteilt hatte, dürfte diese Ernennung beim fränkischen Gauleiter Streicher auf keine große Gegenliebe gestoßen sein. ${ }^{26}$ Döbig hatte als Strafrechtsreferent im bayerischen Justizministerium 1933/34 bei der Verfolgung nationalsozialistischer Ausschreitungen in Franken eine Rolle gespielt. ${ }^{27}$ Auf Betreiben der Gauleitung wurde er 1943 aus seinem Amte entfernt. ${ }^{28}$

21 Vgl. Schr. Kaufmanns an den Reichsschatzmeister der NSDAP v. 10.2.37, in dem er die Rückdatierung des Eintrittsdatums Rothenbergers in die Partei befürwortete, die daraufhin tatsächlich auf den 1.12.31 erfolgte (Personalunterlagen Rothenberger, DC Berlin). Zu Rothenberger vor allem: W. Johe, Die gleichgeschaltete Justiz. Organisation des Rechtswesens und Politisierung der Rechtsprechung 1933-1945, dargestellt am Beispiel des Oberlandesgerichtsbezirks Hamburg, Frankfurt a. M. 1967, S.61 ff., und Personalakten des RJM, BA.

22 Vgl. dazu die Eintr. im Diensttageb. des RJM v. 21.9.35 (Bd.5) und 19.11.35 (Bd.6) (BA, Sign. R 22/1088-89), ferner Personalakten des RJM, BA. Gauleiter und RMdI forderten in einem Schr. an das RJM v. 4.3.36 auch seine Abberufung aus dem Schiedsgericht für Oberschlesien, da „wegen der bekannten Vorgänge“ das Ansehen des Reichs geschädigt werden könne, Eintr. v. 7.3.36, a.a.O., Bd. 7 (BA, Sign. R 22/928).

${ }^{23} \mathrm{Zu}$ Steinaecker vgl. Kapitel III.2., S. 222 f. und dort angegebene Quellen, vor allem Führerlexikon 1934/35; ferner Ernennungsvorschlag des RJM v. 18.10.35 (Akten der RK, BA, Sign. R 43 II/1145 b).

$24 \mathrm{Zu}$ Neithardt und Bertram vgl. Kapitel III.2., S. 236.

$25 \mathrm{Zu}$ Dürr und Döbig vgl. a.a.O., S. 232 und 239.

26 Vgl. Anforderung der Beurteilung durch den St.d.F. v. 12.6.37 und Stellungnahme der Gauleitung München-Oberbayern v. 29.6.37 (Persọnalunterlagen Döbig, DC Berlin). Döbig behauptete, daß schon seine „Ernennung zum Generalstaatsanwalt in Nürnberg gegen den Willen der Gauleitung erfolgte“ (vgl. seine schriftliche Äußerung v. 26.9.46, Spruchkammerakten Döbig, StArch. München).

27 Vgl. dazu Kapitel IV.4.b., S. 392, und 4.c., S. 403 f.

28 Vgl. die scharf ablehnende Beurteilung durch den Gaurechtsberater v. 18.12.42, die Thierack nebst der Forderung nach Abberufung vom stellv. Gauleiter Holz am 11.1.43 übermittelt wurde (Abschriften in den Spruchkammerakten, a.a.O.). 
Gleichfalls die Altersgrenze erreichte im Frühjahr 1937 der Oberlandesgerichtspräsident von Karlsruhe Buzengeiger, der dieses Amt schon drei Jahre vor der Machtübernahme innegehabt hatte und 1933 übernommen worden war. ${ }^{29}$ Sein Nachfolger wurde am 1. Juni der Senatspräsident am Karlsruher Oberlandesgericht Reinle, seit 1932 Parteigenosse und ab 1933 bis zur Verreichlichung im badischen Justizministerium tätig. $\mathrm{Da}$ er seinen Chef bei Verhandlungen mit Parteidienststellen ohnehin meistens vertreten hatte ${ }^{30}$, war er vom Stellvertreter des Führers als Nachfolger vorgeschlagen worden. ${ }^{31}$

Im selben Jahr 1937 mußte auch das Oberlandesgericht Marienwerder in Ostpreußen wiederbesetzt werden, dessen Präsident Karge - von Kerrl im August 1933 eingesetzt - am 25. Oktober 1936 verstorben war. ${ }^{32}$ Vor einer Neubesetzung holte Gürtner Hitlers Entscheidung ein, ob das 1772 von Friedrich dem Großen errichtete Oberlandesgericht, das zu den kleinsten des Reiches gehörte, überhaupt bestehenbleiben sollte. Zwei seiner drei Landgerichte - Meseritz und Schneidemühl - lagen westlich des polnischen Korridors in der damaligen preußischen Provinz „Grenzmark PosenWestpreußen“, so daß der Oberlandesgerichtspräsident bei seinen dienstlichen Besuchen stets den Korridor durchqueren mußte. Um die Bezirksabgrenzungen jenen der allgemeinen Staatsverwaltung Preußens anzupassen, stellte Gürtner anheim, die beiden erwähnten Landgerichte dem Kammergerichtsbezirk zuzuschlagen und das dritte, östlich des Korridors gelegene Landgericht Elbing dem Oberlandesgericht Königsberg einzugliedern - eine Lösung, die vor allem der ostpreußische Gauleiter Koch befürwortete. Nachdem Hitler, der ohnehin beabsichtigte, den polnischen Korridor eines Tages zurückzuholen, am 10. März den Fortbestand des Oberlandesgerichts Marienwerder angeordnet hatte ${ }^{33}$, wurde die Präsidentenstelle am 21. Juni 1937 mit dem Duisburger Landgerichtspräsidenten Draeger besetzt, obwohl Koch bereits im Januar dafür den Halberstadter Landgerichtspräsidenten Szelinski vorgeschlagen hatte, der 1933/34 in Ostpreußen Präsident des Landgerichts Lyck gewesen war. Draeger hatte von 1921 bis 1932 der Deutschnationalen Volkspartei in Danzig angehört und war nach seinem Eintritt in die NSDAP von 1933 bis zu seiner Ernennung zum Landgerichtspräsidenten im Jahre 1935 Staatsrat und Leiter der Wirtschaftsabteilung des Danziger Senats gewesen. Er schien dem Justizministerium daher "mit den bedeutungsvollen Fragen des Deutschtums im Osten besonders vertraut" ${ }^{34}$ Durch die überraschende Entwicklung beim Oberlandesgericht Königsberg sollte jedoch Szelinski schon wenige Monate später den Präsidentenposten am Oberlandesgericht Marienwerder bekommen: Da der Königsberger Oberlandesgerichtspräsident wegen seines Konflikts mit Gauleiter Koch in der Lycker Affäre um seine Versetzung in den Ruhe-

$29 \mathrm{Zu}$ Buzengeiger vgl. Kapitel III.2., S. 240.

30 So z. B. bei schwierigen Personalverhandlungen, vgl. seine Ber. an das RJM, Eintr. v. 11. und 24.7.35 im Diensttageb. des RJM, Bd.4 (BA, Sign. R 22/1059).

31 Vgl. Schr. des St.d.F. an das RJM v. 30.3.37, Eintr. im Diensttageb. des RJM, Bd. 11 (BA, Sign. R 22/721).

32 Vgl. Nachruf in DJ 1936, S. 1702 f. Karge war seit 1922 KGRat, nach seinem Eintritt in die NSDAP im April 1933 ins preuß. JM berufen und am 1.8.33 zum OLGPräs. ernannt worden, s. Deutsches Führerlexikon 1934/35, Berlin 1934, S. 222.

33 Vgl. Schr. Gürtners an den Chef der RK Lammers v. 16.2.37, Lammers' Verm. v. 10.3.37 über Hitlers Entscheidung, die dem RJM mit Schr. v. 12.3.37 mitgeteilt wurde (Akten der RK, BA, Sign. R 43 II/1511 a). Das OLG Marienwerder wurde erst bei der Neuordnung am 1.1.43 aufgehoben und seine LGBezirke dem KG und den OLGen Stettin und Danzig zugeordnet (vgl. Erl. über die Aufhebung des Oberlandesgerichts Marienwerder v. 5.10.42, RGBl. I, S. 576).

34 Vgl. Ernennungsvorschlag des RJM v. 18.4.37 (Akten des RFiM, BA, Sign. R 2/23977). 
stand bat und bereits Anfang August „zur Wiederherstellung seiner Gesundheit" in Urlaub ging ${ }^{35}$, wurde Draeger am 1. November nach Königsberg versetzt. Szelinski konnte dessen Platz am Oberlandesgericht Marienwerder einnehmen. ${ }^{36}$

Im Jahre 1938 erreichte ein weiterer der 1933 in Bayern von Frank eingesetzten Oberlandesgerichtspräsidenten die Altersgrenze: in Bamberg ging am 1. November Heuwieser in den Ruhestand. ${ }^{37}$ Da sich die Wiederbesetzung seiner Stelle wegen der Differenzen zwischen Justiz und Partei um ein Jahr verzögerte, führte unterdessen Vizepräsident Stammler die Geschäfte. Die beiden Gauleiter von Mainfranken und der Bayerischen Ostmark, mit deren Gauen sich der Dienstbereich des Oberlandesgerichts deckte, versteiften sich auf den Landgerichtspräsidenten von Würzburg Karl Bauer als Nachfolger. Er war verdienter Altparteigenosse von 1925, Träger des Goldenen Ehrenzeichens und Vorsitzender des Würzburger Kreisgerichts der NSDAP ${ }^{38}$, wurde aber vom Reichsjustizministerium mangels fachlicher Eignung abgelehnt. Da der vom Justizministerium ursprünglich für diesen Posten vorgesehene persönliche Referent Schlegelbergers, Ministerialrat Wilke, im Mai tödlich verunglückt war $^{39}$, schlug das Ministerium - wie bei der Besetzung der anderen bayerischen Chefpräsidentenstellen - einen langjährigen Mitarbeiter des früheren bayerischen Justizministeriums vor. Es handelte sich um den Präsidenten des Landgerichts München I, Ernst Dürig. Dürig, der erst im November 1937 Parteianwärter geworden war - seine Aufnahme erfolgte 1938 unter Rückdatierung seines Beitritts auf den 1. Mai $1937^{40}$ - und gegen dessen Ernennung zum Landgerichtspräsidenten im Oktober 1937 die Partei keine politischen Bedenken geäußert hatte, wurde nunmehr vom Stellvertreter des Führers abgelehnt. ${ }^{41}$ In einer Beurteilung, die die Gauleitung Bayerische Ostmark von der Gauleitung München-Oberbayern nach seiner Ernennung angefordert hatte, hieß es, er trage "fast niemals das Parteiabzeichen“, sei „der typische Vorgesetzte alten Stils“ ohne Eigenschaften zur Menschenführung und werde „niemals aktiv im Sinne der nationalsozialistischen Weltanschauung wirken, wenn ihm auch die Staatstreue nicht abgesprochen werden" könne und „seine nationale Einstellung über jeden Zweifel erhaben" sei. ${ }^{42}$ Als sich die Besetzungsangelegenheit wegen der Differenzen schon monatelang hingezogen hatte, wandte sich Gürtner im August 1939 schließlich an Reichskanzleichef Lammers mit der Bitte, die Frage „dem Führer zur Entscheidung zu unterbreiten und die Ernennung des Landgerichtspräsidenten Dr. Dürig zu erwirken“. Eine von ihm gegengezeichnete Ernennungsurkunde fügte Gürtner bei. ${ }^{43} \mathrm{Da}$ der

${ }^{35} \mathrm{Zu}$ den Vorgängen am LG Lyck s. Kapitel III.2., S. 228.

36 Vgl. Ernennungsvorschlag des RJM v. 30.9.37 (Akten des RFiM, a.a.O.).

37 Zu Heuwieser vgl. Kapitel III.2., S.236, und Personalunterlagen im DC Berlin.

38 Vgl. die Schr. des St.d.F. an das RJM v. 5.4.38, Eintr. unter demselben Datum im Diensttageb. des RJM, Bd. 15 (BA, Sign. R 22/946), und v. 15.10.38, Eintr. v. 17.10.38, a.a.O., Bd. 16 (BA, Sign. R 22/947).

39 Zu Wilke vgl. Kapitel III.3.a., S. 245.

$40 \mathrm{Zu}$ Dürig vgl. H. Schütz, Justiz im „Dritten Reich“. Dokumentation aus dem Bezirk des Oberlandesgerichts, Bamberg 1984, S. $101 \mathrm{ff}$;; ders., Bamberger Berichte. Über Stimmung und Haltung der Bevölkerung des Oberlandesgerichtsbezirks Bamberg während des 2. Weltkrieges, Bamberg 1983, S. $133 \mathrm{ff}$.

41 Vgl. seine frühere Beurteilung durch den Gau München-Oberbayern der NSDAP v. 12.6.37 (Personalunterlagen Dürig im DC Berlin) und Schr. des St.d.F. an das RJM v. 21.11.38 (Akten der RK, BA, Sign. R 43 II/ $1511 \mathrm{~b})$.

42 Vgl. Beurteilung durch das Gaurechtsamt der NSDAP von München-Oberbayern v. 28.11.39 (Personalunterlagen Dürig im DC Berlin).

43 Vgl. Schr. Gürtners an den Chef der RK Lammers v. 18.8.39 (Akten der RK, a.a.O.). 
Kriegsausbruch die Sache verzögerte, Heß beim Justizministerium aber auf die Ernennung Bauers drang, mahnte Schlegelberger Mitte September bei der Reichskanzlei die erbetene Entscheidung telefonisch an. Vor dem Vortrag bei Hitler holte Lammers jedoch nochmals eine Stellungnahme zum Ernennungsvorschlag des Justizministers von $\mathrm{Heß}$ ein, der unbeirrt auf dem Personalvorschlag der Partei beharrte. ${ }^{44}$ Unter Berufung auf eine Erläuterung des Reichsinnenministers in einem gleichgelagerten Fall - es handelte sich um die Besetzung des Grazer Regierungspräsidentenpostens - kam die Reichskanzlei „zu dem Ergebnis, daß das Recht des Stellvertreters des Führers aus $\S 31$ DBG [d.h. das Recht auf Anhörung bei Beamtenernennungen nach dem Deutschen Beamtengesetz] darauf beschränkt sei, politische Bedenken geltend zu machen, daß das Vorschlagsrecht jedoch ausschließlich bei dem Fachressort" liege. Andernfalls könne der Ressortminister "die Verantwortung für seine Verwaltung nicht tragen“. Folglich sei Hitler der Personalvorschlag des Justizministers zu unterbreiten. ${ }^{45}$ Da sich für Lammers' Vortrag aber zunächst keine Gelegenheit zu bieten schien, bat Gürtner den pensionierten Oberlandesgerichtspräsidenten Heuwieser, die Geschäfte einstweilen weiterzuführen, was dieser aus Gesundheitsrücksichten ablehnte. ${ }^{46}$ Als Lammers' Vortrag endlich zustande kam, entschloß sich Hitler, „dem Vorschlag des Herrn Reichsministers der Justiz als des für die Personalpolitik seines Ressorts verantwortlichen Ministers seine Zustimmung zu erteilen": die Ernennung Dürigs wurde von Hitler am 23. Oktober mit Wirkung vom 1 . November 1939 unterschriftlich vollzogen. ${ }^{47}$ Da nach alledem für eine Zusammenarbeit Dürigs mit Bauer Schwierigkeiten vorauszusehen waren - wohl auch als Konzession an die Partei -, wurde Bauer in die bisherige Stelle Dürigs als Präsident an das Landgericht München I versetzt, was einer Beförderung gleichkam, da es sich hier um eine "große Landgerichtspräsidentenstelle“ handelte, deren Inhaber in die Reichsbesoldungsgruppe B 8 eingestuft war. Die beiden Gauleiter verziehen Dürig diese Schlappe nicht: an der Einführung des neuen Oberlandesgerichtspräsidenten in Bamberg durch Gürtner am 3. November 1939 nahmen sie nicht teil..$^{48}$ Unter Thierack verlangten sie Dürigs Abberufung und erreichten 1944 schließlich, daß er nach Leitmeritz versetzt und seine Stelle von Bauer eingenommen wurde. ${ }^{49}$

Im Jahre 1938 wurden auch die durch den Anschluß Österreichs hinzugetretenen drei Oberlandesgerichte mit neuen Präsidenten versehen. In Wien wurde Hofrat Schober, der im Januar 1938 zum Rat des Obersten Gerichtshofes ${ }^{50}$ ernannt worden war und - obwohl Nicht-Parteigenosse - im Einvernehmen mit der NSDAP das Wie-

${ }^{44}$ Vgl. Schr. Lammer's an Heß v. 19.9.39; Heß antwortete am 9.10.39 (a.a.O.).

45 Vgl. Aktenverm. Kritzingers v. 12.10.39 (a.a.O.).

$46 \mathrm{Vgl}$. Schr. Schlegelbergers an Lammers v. 4.10.39, Aktenverm. Kritzingers v. 17.10.39 (a.a.O.) u. schriftl. Äußerung Heuwiesers v. 27.6.46 (Spruchkammerakten Heuwieser, StArch. München). Über die Möglichkeit der Weiterbeschäftigung pensionierter Justizbeamter im Kriege s. Kapitel III.4.a., S.298.

47 Vgl. die Schr. Lammers' v. 26.10.39 an den RJM und den St.d.F. (a.a.O.).

${ }_{48}$ Am Festakt nahm nur der Kreisleiter von Bamberg teil, vgl. Einführung des Oberlandesgerichtspräsidenten Dr. Dürig in Bamberg (DJ 1939, S.1726).

$49 \mathrm{Vgl}$. Schütz, a.a.O. (voranstehende Anm.40).

so Der Oberste Gerichtshof entsprach etwa dem deutschen RG: im bürgerlichen Streitverfahren war er oberste (dritte) Instanz; im Strafverfahren, das nur zwei Instanzen kannte, ging jedoch lediglich das Rechtsmittel der "Nichtigkeitsbeschwerde“ (vgl. dazu Kapitel VIII.2.f., S. 1084f.) an ihn. Der Oberste Gerichtshof wurde durch die VO zur weiteren Ủberleitung der Rechtspflege im Lande Österreich und in den sudetendeutschen Gebieten v. 28.2.39 (RGBl. I, S.358) aufgehoben, seine Zuständigkeiten übernahm das RG. 
ner Oberlandesgericht seit 17. März kommissarisch leitete, im November zum Präsidenten ernannt. ${ }^{51}$ Zum selben Zeitpunkt erfolgte auch die Ernennung des bisherigen kommissarischen Leiters des Oberlandesgerichts in Graz, des Senatsvorsitzenden beim dortigen Landgericht für Zivilsachen, Meldt. In Innsbruck, wo der bisherige kommissarische Oberlandesgerichtspräsident Greinz im November 1938 starb $^{52}$, wurde Stritzl - seit 1934 Vizepräsident des Wiener Landgerichts für Zivilsachen - erst im April 1939 zum Präsidenten ernannt. Obwohl Stritzl im Mai 1938 in die Partei gegangen war, erfolgte seine Ernennung gegen den Widerstand des Gauleiters von TirolVorarlberg, Hofer. ${ }^{53}$ Der Gauleiter verübelte dem Richter offenbar, daß er 1934 der "Vaterländischen Front" beigetreten war, in der der österreichische Bundeskanzler Dollfuß alle regierungstreuen Kreise zusammengefaßt hatte und die im Mai 1934 die einzige Trägerin der politischen Willensbildung in Österreich geworden war. ${ }^{54} \mathrm{Als}$ im Frühjahr 1939 in Linz ein eigenes Oberlandesgericht errichtet wurde - ihm wurden vier vom Wiener Oberlandesgerichtsbezirk abgetrennte Landgerichte zugeteilt -, bekam die Präsidentenstelle Sektionschef Krautmann. Er war seit 1919 im österreichischen Justizministerium tätig gewesen, 1935 in den Ruhestand versetzt und - als Parteigenosse von 1932 - im April 1938 in der Abteilung Österreich des Reichsjustizministeriums bis zu deren Auflösung wiederbeschäftigt worden. ${ }^{55}$

Ein weiteres neues Oberlandesgericht, dessen Präsidentenstelle im Frühjahr 1939 besetzt werden mußte, war das im März errichtete Oberlandesgericht Leitmeritz. Nach der Angliederung des Sudetenlandes war im Oktober 1938 zunächst nur ein oberlandesgerichtlicher Senat beim Landgericht in Reichenberg gebildet worden, dessen Vorsitz dem bisherigen Rechtsanwalt David anvertraut worden war. ${ }^{56}$ David war Mitglied der Deutschen Nationalsozialistischen Arbeiterpartei (DNSAP) - von 1928 bis zu ihrer Auflösung 1933 - und ab 1935 Mitglied der Hauptleitung und Leiter des Rechtsamtes der Sudetendeutschen Partei (SdP) Henleins gewesen. Da ihm im Oktober 1938 zugleich die einstweilige Leitung der Justizverwaltung im Sudetenland - er war Beauftragter der Justizverwaltung beim Reichskommissar für die sudetendeutschen Gebiete Henlein - mit allen Zuständigkeiten übertragen worden war, die „zum Aufgabenkreis einer der obersten Reichsjustizbehörde unmittelbar nachgeordneten Behörde gehören“, nahm er praktisch schon die Aufgaben eines Oberlandesgerichtspräsidenten wahr. Auf Wunsch Henleins wurde er am 1. April 1939 zum Präsidenten des neuen Oberlandesgerichts in Leitmeritz ernannt. ${ }^{57}$

Im Altreich mußten 1939 drei Oberlandesgerichtspräsidentenposten neu besetzt werden, da ihre Inhaber die Altersgrenze erreicht hatten. Für die Stelle des scheiden-

51 Vgl. Ernennungsvorschlag des RJM v. 21.10.38 (Akten der RK, BA, Sign. R 43/II/1511).

52 Vgl. DJ 1938, S. 1811. Meldt und Greinz wurden schon in den Berichten über die Festakte in Graz und Innsbruck am 18. bzw. 20.5.38 anläßlich der Úberleitung der österreichischen Justiz in die Reichsjustiz als kommissarische OLGPräs. bezeichnet (a.a.O., S. 835). Meldt trat erst im Mai 1938 der Partei bei, vgl. Personalunterlagen Meldt im DC Berlin.

53 Diese Tatsache geht aus einem späteren Schr. des RJM an den Chef der RK v. 21.2.42 hervor (Akten der RK, BA, Sign. R 43 II/1511 b).

54 Vgl. Ernennungsvorschlag des RJM v. 23.12 .38 (Akten des RFiM, BA, Sign. R 2/23978).

3s Zu Krautmann vgl. Ernennungsvorschlag des RJM v. 9.2.39 (Akten der RK, a.a.O.).

$56 \mathrm{Vgl}$. 5 der VO zur vorläufigen Ausübung der Rechtspflege in den sudetendeutschen Gebieten v. 8.10.38 (RGBl. I, S.1345) und DJ 1938, S.1730.

57 Vgl. Emennungsvorschlag des RJM v. 25.2.39 (Akten der RK, a.a.O.), Personalakten des RJM, BA, und Personalunterlagen David im DC Berlin. 
den Oberlandesgerichtspräsidenten in Frankfurt a. M., Stadelmann, schlug Gauleiter Sprenger schon geraume Zeit vorher den Landgerichtspräsidenten von Bonn vor, der "fachlich und weltanschaulich gut qualifiziert" sei und von dessen Leistungen er sich habe „persönlich überzeugen“ können. Das Justizministerium, das zunächst die Versetzung des Zweibrückener Chefpräsidenten Siegel nach Frankfurt erwog, ließ statt dessen im Juni den bisherigen Vizepräsidenten des Oberlandesgerichts, Ungewitter, in diese Stelle aufrücken. Hierbei handelte es sich offensichtlich um eine Ernennung, die ausschließlich auf fachlichen Qualitäten beruhte: Ungewitter - 1930 einige Zeit Angehöriger der Deutschen Staatspartei und erst im Mai 1933 der NSDAP beigetreten wurde vom Justizministerium als hochbegabter Richter und vorzüglicher Kenner des Zivil- und Strafrechts beurteilt. ${ }^{58}$ Er erhielt bald auch eine Professur an der Frankfurter Universität.

In Dresden trat Anfang August 1939 der vom sächsichen Justizminister Thierack 1933 übernommene Hüttner in den Altersruhestand und wurde durch den Zwickauer Landgerichtspräsidenten Beyer ersetzt. Gauleiter Mutschmann und der Stellvertreter des Führers hätten Beyer, der seit 1932 der Partei und der SA angehörte und den sich Thierack 1933 in sein Ministerium geholt hatte, schon 1935 gern als Nachfolger des verstorbenen Dresdner Generalstaatsanwalts Weber gesehen..$^{59}$ Im Oktober 1938 war Beyer mit dem Vorsitz des Sondergerichts im sudetendeutschen Reichenberg betraut und nach der Besetzung Prags einige Wochen ins Protektorat abgeordnet worden. Er wurde am 1. August 1939 zum Dresdener Oberlandesgerichtspräsidenten ernannt. Da der 48jährige jedoch schon bei Kriegsausbruch zur Wehrmacht eingezogen wurde, wurden die Geschäfte bis Januar 1940 vertretungsweise von seinem Vorgänger Hüttner geführt. ${ }^{60}$

Auch in Oldenburg erreichte Oberlandesgerichtspräsident Högl die Altersgrenze und wurde am 1. Oktober 1939 durch den Vizepräsidenten des Oberlandesgerichts Celle, Reuthe, ersetzt. Gauleiter Röver und der Stellvertreter des Führers hatten als Nachfolger einen Altparteigenossen vorgeschlagen, der nach zehnjähriger Tätigkeit als Rechtsanwalt im Oktober 1934 zum Präsidenten des Oldenburger Landgerichts avanciert war. Sie gaben sich jedoch schließlich mit dem „Märzgefallenen“ Reuthe zufrieden, der schon 1928 Senatspräsident in Celle gewesen war, im November 1934 Vizepräsident des Landeserbhofgerichts und im April 1935 des Celler Oberlandesgerichts geworden war. ${ }^{61}$

Gleichfalls im Oktober 1939 wurde der Präsidentenposten am deutschen Oberlandesgericht in Prag besetzt, das im April nach der Errichtung des Protektorats Böhmen und Mähren eingerichtet worden war. Sein Bezirk umfaßte das deutsche Landgericht in Prag mit sieben Amtsgerichten in Böhmen und das deutsche Landgericht Brünn mit fünf Amtsgerichten in Mähren. ${ }^{62}$ Mit seinem Aufbau und der Leitung war am 16.

58 Vgl. Schr. Gauleiter Sprengers an das RJM v. 23.7.38, Eintr. v. 25.7.38 im Diensttageb. des RJM, Bd.16 (BA, Sign. R 22/947), Personalakte Siegel des RJM, BA, und Ernennungsvorschlag des RJM v. 14.3.39 (Akten der RK, a.a.O.).

s9 Vgl. dazu im folgenden S.282.

60 Vgl. zu Beyer Ernennungsvorschlag des RJM v. 5.4.39 (Akten der RK, a.a.O.) und Personalakten des RJM, BA. Über die Weiterbeschäftigung pensionierter Justizbeamter im Kriege s. Kapitel III.4.a., S. 298.

${ }^{61}$ Vgl. Ernennungsvorschlag des RJM v. 4.7.39 (Akten der RK, a.a.O.) und Personalakten des RJM, BA.

62 Vgl. VO über die deutsche Gerichtsbarkeit im Protektorat Böhmen und Mähren v. 14.4.39 (RGBl. I, S.752). Ihr unterstanden die deutschen Staatsangehörigen, also die ehemaligen volksdeutschen Bewohner, in bestimmten Fällen aber auch die tschechischen Bewohner des Protektorats. 
April der Landgerichtspräsident von Glatz, Bürkle, beauftragt worden. Er wurde dazu Anfang Oktober in die Planstelle des Landgerichtspräsidenten von Hannover eingewiesen, die eine entsprechend "große Landgerichtspräsidentenstelle“ der Reichsbesoldungsgruppe B 8 darstellte. Anders als im Sudetenland, wo der Vertreter der politischen Territorialgewalt den dezidierten Wunsch geäußert hatte, die Präsidentenstelle mit einem bestimmten Favoriten zu besetzen, schlug im Prager Fall das Reichsjustizministerium von sich aus Bürkle vor und holte die Zustimmung des Reichsprotektors für dessen Ernennung ein. ${ }^{63}$ Maßgebend dafür war, daß sich Bürkle, der der Partei im Mai 1933 beigetreten war, nicht nur als qualifizierter Richter, sondern beim Aufbau der Protektoratsgerichtsbarkeit auch als „hervorragender Verwaltungsbeamter“ erwiesen hatte. ${ }^{64}$

In der ehemaligen Freien Stadt Danzig, die am ersten Kriegstag durch einen Reichstagsbeschluß dem Deutschen Reich eingegliedert wurde und dessen Obergericht die Zuständigkeiten eines Oberlandesgerichts übertragen bekam ${ }^{65}$, wurde der bisherige Präsident dieses Gerichts Wohler am 1. November zum Oberlandesgerichtspräsidenten ernannt. Wohler war als Landgerichtsrat in Danzig schon im August 1932 zur NSDAP gegangen und wurde im Juni 1933 - nachdem die Nationalsozialisten im Danziger Volkstag die Mehrheit erhalten hatten - bis 1937 zum Danziger Senat abgeordnet und dort als leitender Referent bei der Abteilung des Innern beschäftigt. Anfang 1934 zum Landgerichtsdirektor befördert, war er im Februar 1937 Präsident des Obergerichts und gleichzeitig des Landgerichts in Danzig geworden. ${ }^{66}$

Zum Präsidenten des neuen Oberlandesgerichts in Posen, zu dem die acht Landgerichte des - aus eingegliederten polnischen Gebieten gebildeten - „Reichsgaues Wartheland" gehörten, wurde im Januar 1940 der ehemalige Danziger Polizeipräsident Froböß ernannt. Froböß hatte bis zu seiner Tätigkeit als Regierungsrat im Polizeipräsidium Berlin 1920 der Deutschnationalen Volkspartei angehört, war 1921 nach einer kurzen Tätigkeit als Hilfsarbeiter im preußischen Justizministerium zur Danziger Polizei gegangen und dort noch im selben Jahr Polizeipräsident geworden. Als Greiser 1939 von seinem Posten als Danziger Senatspräsident abgelöst und Gauleiter sowie Reichsstatthalter in Posen wurde, berief er Froböß zum Amtschef der dortigen Justizverwaltung. Die endgültige Ernennung Froböß' in das Amt des Oberlandesgerichtspräsidenten, „mit dessen einstweiliger Wahrnehmung er seit Beginn betraut“" war, entsprach dem „besonderen Wunsch des Reichsstatthalters und Gauleiters“.67 Froböß war ihm „bereits als Polizeipräsident in Danzig ein treuer Mitarbeiter und persönlicher Freund und Kamerad gewesen“ und brachte „aus seiner langjährigen Tätigkeit bewährte Erfahrungen im deutschen Volkstumskampf für sein neues Amt" mit. ${ }^{68}$

Froböß war der letzte Oberlandesgerichtspräsident, der in Gürtners Amtszeit ernannt wurde. Abschließend seien noch die Ưberlegungen erwähnt, die das Reichsju-

${ }^{63}$ Vgl. Schr. des RJM an den Reichsprotektor v. 5.9.39 (Akten des RJM, BA, Sign. R 22/29) und Antwort Neuraths an Gürtner v. 12.10.39 (a.a.O., Sign. R 22/30).

${ }^{64}$ Vgl. Ernennungsvorschlag des RJM (Akten des RFiM, BA, Sign. R 2/23979) und Personalakten des RJM, BA.

${ }^{65}$ Vgl. VO zur Ausübung der Rechtspflege im Gebiet der bisherigen Freien Stadt Danzig v. 5.12.39 (RGBl. I, S.2375).

${ }^{66} \mathrm{Zu}$ Wohler vgl. Personalunterlagen im DC Berlin.

${ }^{67} \mathrm{Vgl}$. Amtseinführung des Oberlandesgerichtspräsidenten in Posen (am 2.4.40) (DJ 1940, S. $409 \mathrm{f}$.).

${ }^{68}$ Vgl. Ernennungsvorschlag des RJM v. 11.1.40 (Akten des RFiM, BA, Sign. R 2/23979). 
stizministerium bereits im Sommer 1939 anstellte ${ }^{69}$, um den wichtigen Posten des Kammergerichtspräsidenten neu zu besetzen, da Hölscher am 1. Mai 1940 die Altersgrenze erreichte und zu diesem Zeitpunkt an sich in den Ruhestand treten mußte. Als Nachfolger wollte das Ministerium bemerkenswerterweise keinen ausgesprochenen Nationalsozialisten, sondern den Oberlandesgerichtspräsidenten von Garßen vorschlagen, der sein Amt in Celle schon seit März 1932 ausübte. $^{70}$ An dessen Stelle sollte in Celle der Generalstaatsanwalt beim Kammergericht, Friedrich Jung, treten, der Niedersachse war und sich auf seinem Berliner Posten seit November 1933 bewährt hatte. Diese „bedeutsamste Generalstaatsanwalts-Stelle des Reiches“ wiederum sollte der „älteste nationalsozialistische Kämpfer" unter den westfälischen Juristen, der Generalstaatsanwalt in Hamm, Semler, bekommen. ${ }^{71}$ Auf den Posten in Hamm wollte das Ministerium dann Oberstaatsanwalt Thissen setzen, der der Partei erst im Mai 1933 beigetreten war, seit Juni 1936 als Vertreter des Generalstaatsanwalts beim Kammergericht und seit Ende Oktober 1938 als Hilfsarbeiter im Reichsjustizministerium arbeitete. Dieses geplante Revirement unterblieb jedoch, da Hölscher kriegsbedingt seine Tätigkeit über die Altersgrenze hinaus als Beamter auf Widerruf bis Ende 1942 fortsetzte.

Während die bei diesem Revirement vorgesehene Versetzung eines Oberlandesgerichtspräsidenten auf eine andere Oberlandesgerichts- bzw. Kammergerichtspräsidentenstelle im Frieden zu den Ausnahmen gehörte - sie fand nur einmal 1937 bei der Versetzung Draegers von Marienwerder nach Königsberg statt -, war ein solcher Austausch bei den Generalstaatsanwälten, die als nichtrichterliche Beamte nicht unter die Bestimmungen des Gerichtsverfassungsgesetzes über die Unversetzbarkeit ohne Einverständnis des Betroffenen fielen, häufiger. Der erste Posten eines Generalstaatsanwalts, den das Reichsjustizministerium 1935 besetzen mußte, war die Stelle des Generalstaatsanwalts in Breslau, dessen Inhaber im Januar in den einstweiligen Ruhestand versetzt worden war. ${ }^{72} \mathrm{Zu}$ diesem Zweck wurde der von Kerrl im Juli 1934 ernannte Stettiner Generalstaatsanwalt Sturm nach Breslau versetzt. Er war seit 1926 als Oberstaatsanwalt bei zwei Berliner Landgerichten und zuletzt als Vertreter des Generalstaatsanwalts tätig gewesen und im Mai 1933 in die Partei eingetreten. ${ }^{73}$ Seine Stelle in Stettin bekam am 1. April 1935 der Landgerichtspräsident von Greifswald, Stäcker, ein „Mann der alten Schule mit starken kirchlichen Bindungen“, dessen „äußerlich tragbares Verhältnis“" zur NSDAP - der auch er erst 1933 beigetreten war - nach einer späteren Beurteilung durch die Partei „reinen Zweckmäßigkeitserwägungen“ entsprach: wenngleich er Beziehungen zur Gauleitung pflege, heißt es dort, gehe er „Anregungen der Partei möglichst aus dem Wege“ und habe auch "in keiner Weise versucht, seine Staatsanwälte politisch auszurichten" ${ }^{74}$

\footnotetext{
$69 \mathrm{Vgl}$. die beiden von MinDir. Nadler paraphierten Briefentwürfe vom August 1939, die an Heß persönlich gerichtet waren, deren Ausfertigung aber offensichtlich wegen des Kriegsausbruchs unterblieb, nebst Ernennungsvorschlägen (Akten des RJM, BA, Sign. R 22/1793).

$70 \mathrm{Zu}$ Hölscher und von Garßen vgl. Kapitel III.2., S. 222 und 225.

$71 \mathrm{Zu}$ Semler vgl. im folgenden S.282f.

72 Vgl. dazu Kapitel III.2., S. $226 \mathrm{f}$.

${ }^{73}$ Vgl. Degeners Wer ist's?, Berlin 1935, S.1582, und Personalakten des RJM, BA.

74 Vgl. Beurteilung führender Rechtswahrer im OLGBez. Stettin durch Paulick mit Verm. Thieracks v. 17.4.43 (Akten des RJM, Sign. R 22 Gr. 5/485).
} 
Im Sommer 1935 erreichten zwei der von Hans Frank nach der Machtübernahme in ihren Ämtern belassenen Generalstaatsanwälte die Altersgrenze. Es handelte sich einmal um den Nürnberger Generalstaatsanwalt Leuchs. Er wurde im Juli durch den schon mehrfach erwähnten Nicht-Parteigenossen Döbig ersetzt, der bei der Verreichlichung des bayerischen Justizministeriums am 1. April 1935 zum Rat am Nürnberger Oberlandesgericht ernannt worden war. ${ }^{75}$ Der zweite war der Generalstaatsanwalt von Zweibrücken, Troeltsch, dessen Amt im August der Würzburger Oberstaatsanwalt Hahn übernahm. Hahn, der seit 1925 Landgerichtsrat in Frankenthal gewesen und bis 1930 der Deutschen Volkspartei angehört hatte, war erst im Zusammenhang mit seiner Beförderung zum Oberstaatsanwalt im April 1933 der NSDAP beigetreten. ${ }^{76}$

Als im Juni 1935 der von Thierack 1933 ernannte Dresdener Generalstaatsanwalt Weber starb, setzten sich Gauleiter Mutschmann und in seinem Gefolge auch der Stellvertreter des Führers für den Landgerichtspräsidenten in Zwickau, Altparteigenossen Beyer, als Nachfolger ein. ${ }^{77}$ Mitte November fand sich Mutschmann jedoch schließlich mit dem vom Reichsjustizministerium vorgeschlagenen „Märzgefallenen“, dem Königsberger Oberstaatsanwalt Heinrich Jung, ab. Seit 1923 Rat beim Landgericht III Berlin, war Jung im Januar 1934 als Oberstaatsanwalt in Erfurt in den staatsanwaltschaftlichen Dienst übergewechselt und im Oktober 1935 Oberstaatsanwalt in Königsberg geworden. Jung wurde am 15. Januar 1936 in sein Amt eingeführt. ${ }^{78}$

Im selben Monat wurde die Stelle des Generalstaatsanwalts in Hamm frei, da von Steinaecker zum Oberlandesgerichtspräsidenten von Breslau ernannt wurde. ${ }^{79}$ Die Nachfolge trat „der älteste nationalsozialistische Kämpfer unter den Juristen im Gau Westfalen-Nord und Mitglied der alten Garde" an, der Bielefelder Rechtsanwalt und Notar Semler. Er gehörte seit Oktober 1922 der NSDAP an und war ihr nach Verbot und Neugründung im Mai 1925 wiederum beigetreten. ${ }^{80}$ Für seine Ernennung zum Generalstaatsanwalt hatte sich bereits im November 1935 der Gauleiter von Westfalen-Nord, Alfred Meyer, eingesetzt und war dabei von den anderen beiden beteiligten Gauleitern von Westfalen-Süd und Essen sowie von der Reichsführung des BNSDJ nachdrücklich unterstützt worden; auch der Stellvertreter des Führers hatte diesen Vorschlag „sehr begrüßt". ${ }^{81}$ Anläßlich eines Besuches in Bielefeld hatte Freisler Semler zugesagt, sich für seine Ernennung bei Gürtner einzusetzen. ${ }^{82}$ Semlers Einführung

73 Zu Döbig vgl. Kapitel III.2., S. 239, und voranstehend S. 274.

$76 \mathrm{Zu}$ Hahn vgl. Personalverzeichnis des höheren Justizdienstes, Berlin 1938, S.87, und Personalakten des RJM, BA.

77 Vgl. Schr. Gauleiter Mutschmanns an das RJM v. 6.8.35 (Personalakten Heinrich Jung, BA) und Schr. des St.d.F. an das RJM v. 27.9.35, Eintr. v. 3.10.35 im Diensttageb. des RJM, Bd.5 (BA, Sign. R 22/1088). Zu Beyer s. voranstehend S. 279.

${ }^{78} \mathrm{Zu}$ Jung vgl. Ernennungsvorschlag des RJM v. 22.11.35 (Akten des RFiM, BA, Sign. R 2/23976), Personalunterlagen im DC Berlin und: Einweisung des neuen Generalstaatsanwalts des Oberlandesgerichtsbezirks Dresden Dr. Jung (DJ 1936, S. 150).

79 Vgl. dazu voranstehend S. 274.

${ }^{80} \mathrm{Zu}$ Semler vgl. Ernennungsvorschlag des RJM v. 7.7.36 (Akten des RFiM, BA, Sign. R 2/23976), Schr. des St.d.F. (gez. Bormann) an das RJM und: Einführung des Generalstaatsanwalts Semler in Hamm durch Staatssekretär Dr. Schlegelberger (DJ 1936, S. 1620).

81 Vgl. Schr. des St.d.F. an das RJM v. 26.11.35, Eintr. v. 30.11.35 ins Diensttageb. des RJM, Bd.6 (BA, Sign. R 22/1089), Schr. des stellv. Reichsjuristenführers Raeke an das RJM, Eintr. v. 3.4.36, a.a.O., und Schr. des St.d.F. (gez. Bormann) an das RJM, Eintr. v. 23.7.36, a.a.O., Bd.8 (BA, Sign. R 22/929).

$82 \mathrm{Vgl}$. Schr. Gauleiter Meyers an das RJM, in dem er nochmals um Semlers Ernennung bat, Eintr. v. 7.4.36, a.a.O. 
ins Amt erfolgte am 16. Oktober 1936. Drei Jahre später wurde im Reichsjustizministerium seine Versetzung an das Kammergericht erwogen, aber unter Thierack sollte er 1943 schließlich in Hamm Oberlandesgerichtspräsident werden. ${ }^{83}$

Im Februar 1936 wurde der Generalstaatsanwalt beim Landgericht Berlin, Thomas, in den einstweiligen Ruhestand versetzt. ${ }^{84}$ Sein Nachfolger wurde Ernst Lautz. Er war seit 1932 Oberstaatsanwalt beim Landgericht I Berlin gewesen und im November 1934 an die Staatsanwaltschaft beim Kammergericht versetzt worden, wo er die ständige Vertretung des dortigen Generalstaatsanwalts wahrgenommen hatte. An der Tatsache, daß Lautz vor seinem Beitritt zur NSDAP im Mai 1933 der Deutschen Volkspartei angehört hatte, hatte die Gauleitung bei ihrer Zustimmung vom 24. Juni keinen Anstoß genommen. ${ }^{85}$ Seine Amtseinführung erfolgte am 1. September 1936.

Als im selben Monat der 1933 von Kerrl übernommene Naumburger Generalstaatsanwalt Ludwig Becker in den Altersruhestand trat, schlug der Gauleiter von Halle-Merseburg den Oberstaatsanwalt beim Landgericht Halle vor, einen Parteigenossen, dem „die Verhältnisse in seinem Gau genauestens vertraut" waren. ${ }^{86}$ Statt dessen versetzte das Reichsjustizministerium Anfang Oktober 1936 den Generalstaatsanwalt von Zweibrücken, Hahn, nach Naumburg. ${ }^{87}$ An dessen Stelle in Zweibrücken trat Oberstaatsanwalt Welsch. Er war bis 1934 Staatsanwalt in Saarbrücken, anschlieBend 1934/35 Leiter der Staatspolizeistelle in Trier gewesen und mit der Übernahme der saarländischen Justizverwaltung durch das Reich am 1. März 1935 Oberstaatsanwalt in Saarlautern geworden, wo das Oberlandesgericht Köln auswärtige Senate eingerichtet hatte. Er wurde am 19. Oktober 1936 in sein neues Amt als Generalstaatsanwalt eingeführt. ${ }^{88}$

Im zweiten Halbjahr 1937 geriet die Personallandschaft der Generalstaatsanwälte verstärkt in Bewegung. Zunächst wurde im Juni Emil Brettle, der seit 1933 Generalstaatsanwalt in Karlsruhe war, zum Oberreichsanwalt beim Reichsgericht befördert. Auf seinen Posten wurde der bereits erwähnte Generalstaatsanwalt beim Landgericht Berlin, Lautz, nach Karlsruhe versetzt. ${ }^{89}$ Seine Stelle in Berlin wiederum nahm der bisherige Oberstaatsanwalt beim Kölner Landgericht Seebens ein. Ihn hatte das Reichsjustizministerium zunächst als Generalstaatsanwalt in Königsberg vorgesehen, war aber bei Gauleiter Koch auf Ablehnung gestoßen, der diesem „Märzgefallenen“ einen Altparteigenossen vorzog. ${ }^{90}$ Eine zweite solche Versetzungswelle wurde im Juli 1937 durch die Beförderung des Generalstaatsanwalts von Celle, Parey, zum Reichsan-

83 Vgl. voranstehend S. 281 und DJ 1943, S. 173.

84 Vgl. dazu Kapitel III.2., S. 227 f.

85 Zu Lautz vgl. Ernennungsvorschlag des RJM v. 25.6.36 (Akten des RFiM, BA, Sign. R 2/23976), Amtseinführung (DJ 1936, S. 1345) und seine eidesstattl. Erklärung v. 17.1.47 (Nürnbg. Dok. NG-659, Archiv des IfZ).

${ }^{86}$ Vgl. Schr. der Gauleitung Halle-Merseburg an das RJM v. 25.6.36, Eintr. v. 26.6.36 ins Diensttageb. des RJM, Bd. 8 (BA, Sign. R 22/929). Der OStA wurde im Frühjahr 1937 LGPräs. in Halle, vgl. Vorschlag der Gauleitung v. 9.12.36, Eintr. v. 11.12.36, a.a.O., Bd.9 (Sign. R 22/930).

$87 \mathrm{Zu}$ Hahn vgl. voranstehend S. 282.

88 Welsch wurde 1938-40 mit einem Sonderauftrag nach Wien abgeordnet und im Frühsommer 1940 Leiter der Abt. Justiz beim Chef d. Zivilverwaltung in Lothringen (Personalakten des RJM, BA).

$89 \mathrm{Zu}$ Brettle vgl. Kapitel IIl.2., S. 240; zu Lautz voranstehend; zur Amtseinführung beider DJ 1937, S. 1163 und $1234 \mathrm{f}$.

90 Dazu vgl. im folgenden S. 284. Zu Seebens vgl. Ernennungsvorschlag des RJM v. 16.6.37 und Schr. an den RFiM v. 17.8.37 (Akten des RFiM, BA, Sign. R 2/23977), Personalunterlagen Seebens im DC Berlin. Zur Amtseinführung am 5.10.37 vgl. DJ 1937, S.1587. 
walt beim Volksgerichtshof ${ }^{91}$ ausgelöst. Als Nachfolger wurde der Düsseldorfer Generalstaatsanwalt Schnoering nach Celle versetzt, den Kerrl seinerzeit als Altparteigenossen von 1932 ernannt hatte. ${ }^{92}$ Dessen Platz in Düsseldorf wiederum nahm der Königsberger Generalstaatsanwalt Hagemann ein, der - vorher Oberstaatsanwalt in Köln - gleichfalls noch von Kerrl zum Generalstaatsanwalt gemacht worden war. ${ }^{93}$ Als der Gauleiter von Ostpreußen, Erich Koch, von der Abberufung Hagemanns und der Absicht des Reichsjustizministeriums erfuhr, als Nachfolger den Kölner Oberstaatsanwalt Seebens vorzuschlagen, teilte er dem Ministerium am 8. Juli verärgert mit, daß er wegen dieser „ohne seine vorherige Kenntnisnahme“ unternommenen Schritte „persönlich vorsprechen“ werde: er beabsichtige, sich „über derartige Fälle einmal grundsätzlich mit dem Herrn Justizminister zu unterhalten ". ${ }^{94}$ Ob diese Aussprache stattfand, ist ungewiß; Koch setzte sich jedenfalls dafür ein, zum Generalstaatsanwalt in Königsberg den Oberstaatsanwalt Vollmer zu ernennen, der schon 1922 Mitglied der alten NSDAP gewesen und der Partei im März 1932 erneut beigetreten war. Rechtsanwalt Vollmer war im Juni 1933 beim Landgericht Königsberg Oberstaatsanwalt geworden und als gleichzeitiger Gauführer des BNSDJ mit dem dortigen Oberlandesgerichtspräsidenten Minde derart in Konflikt geraten, daß ihn das Justizministerium im Einverständnis mit Ministerpräsident Göring im Juli 1934 aus Ostpreußen abberief und ihn mit der Verwaltung einer freien Oberstaatsanwaltsstelle in Stendal (Oberlandesgerichtsbezirk Naumburg) beauftragte. Nachdem sich Koch bei Göring vergebens um die Rückkehr Vollmers nach Königsberg bemüht hatte, wurde Vollmer im Februar 1935 als Hilfsarbeiter im Reichsjustizministerium untergebracht und als Referent für Rechtsanwaltsfragen beschäftigt; zu diesem Zwecke wurde er im Oktober auf eine Stelle bei der Staatsanwaltschaft des Kammergerichts versetzt. Nunmehr im Sommer 1937 - die Chefpräsidentenstelle in Königsberg war längst anders besetzt, und Göring erklärte sich mit der Rückkehr Vollmers nach Ostpreußen einverstanden - war das Reichsjustizministerium bereit, den „besonderen Wunsch“ Kochs zu erfüllen und Vollmer statt Seebens für die Ernennung zum Generalstaatsanwalt in Königsberg vorzuschlagen, zumal er aufgrund seiner früheren Tätigkeit in Ostpreußen mit den dortigen Verhältnissen „aufs engste vertraut“ war. ${ }^{95}$ Vollmer wurde am 1. Dezember 1937 ernannt und trat nach Abwicklung seines Auftrags im Reichsjustizministerium am 5. Januar 1938 seinen Dienst in Königsberg an.

Gleichfalls im zweiten Halbjahr 1937 war die Stelle des Generalstaatsanwalts in Stuttgart neu zu besetzen, wo der 1933 übernommene Heintzeler Anfang Oktober in den Altersruhestand trat. Seine Stelle bekam der gleichfalls aus der württembergischen Justizverwaltung hervorgegangene Ministerialrat Otto Wagner; er war schon $1922 \mathrm{Re}-$

${ }^{1}$ Zu Parey vgl. Kapitel VIII.1.b., S.971, ferner Ernennungsvorschlag des RJM v. 22.5.37 (Akten des RFiM, a.a.O.)

92 Vor seiner Ernennung zum GStA im September 1934 war Schnoering ab 1927 LGRat in Hannover, ab April 1933 MinRat im preuß. Kultusministerium gewesen, vgl. Personalverzeichnis des höheren Justizdienstes, Berlin 1938, S. 230, und Personalunterlagen im DC Berlin.

93 Vgl. Personalverzeichnis des höheren Justizdienstes, Berlin 1938, S. 86.

94 Vgl. Schr. des Gauleiters und Oberpräsidenten Koch an das RJM v. 8.7.37, Eintr. v. 12.7.37 im Diensttageb. des RJM, Bd. 12 (BA, Sign. R 22/678).

95 Vgl. Ernennungsvorschlag des RJM v. 10.10.37, auch zum Voranstehenden Personalakten des RJM, BA. Vollmer leitete vom November 1941 bis Ende 1942 das Rechtsamt beim Reichskommissariat Ukraine unter Koch und wurde von Thierack 1943 zum MinDir. und Leiter der Strafrechtspflegeabteilung im RJM ernannt (DJ 1943, S. 223). 
gierungsrat im württembergischen Justizministerium geworden, fünf Jahre später ins Reichsjustizministerium übergetreten und 1934 zum Ministerialrat befördert worden. Seine Einführung ins Amt erfolgte am 7. Oktober 1937.96

Die letzte Umbesetzung im Jahre 1937 fand in Nürnberg statt, wo der bisherige Generalstaatsanwalt Döbig am 1. Oktober für den aus Altersgründen ausscheidenden Bertram zum Oberlandesgerichtspräsidenten ernannt wurde. Neuer Nürnberger Generalstaatsanwalt wurde der erst am 1. März 1937 zum Präsidenten des Landgerichts Nürnberg-Fürth ernannte Bems. Obwohl Bems, der ursprünglich der Deutschnationalen Volkspartei angehört hatte, der NSDAP erst im Mai 1937 beitrat - auch in die SA war er aus dem Stahlhelm erst 1934 übergeleitet worden -, hatte Gauleiter Streicher schon 1936 die Ernennung des damaligen Nürnberger Amtsgerichtsdirektors Bems zum Landgerichtspräsidenten gewünscht. Das Reichsjustizministerium hatte es damals jedoch „aus dienstlichen Gründen für zweckmäßig“ gehalten, Bems im Mai 1936 zum Senatspräsidenten beim Oberlandesgericht Bamberg zu ernennen und ihn dort zum Vizepräsidenten zu bestellen. Als Anfang 1937 die Nürnberger Landgerichtspräsidentenstelle frei geworden war, hatte Streicher seinen Wunsch durchgesetzt; auch die Beförderung Bems' zum Generalstaatsanwalt am 1. Oktober 1937 entsprach daher seinen Intentionen. ${ }^{97}$

Im Jahre 1938 mußte das Reichsjustizministerium nur eine Generalstaatsanwaltsstelle neu besetzen, als der 1933 von Frank übernommene Münchener Generalstaatsanwalt Sotier die Altersgrenze erreichte. Nachfolger wurde Landgerichtspräsident Leimer. Er hatte dieses Amt in Kempten seit August 1935 inne und war vorher seit 1931 Landgerichtsdirektor in Nürnberg gewesen. Leimer, der der Partei erst im Mai 1937 beitrat, wurde vom Ministerium wegen seiner fachlichen Fähigkeiten geschätzt und war von 1933 bis 1936 auch Mitglied der amtlichen Strafrechtskommission gewesen. Er wurde am 3. Mai 1938 in sein neues Amt eingeführt. ${ }^{98}$

Der Aufbau einer neuen Justizverwaltung in den zugewonnenen Gebieten des Reichs machte im Jahre 1939 die Ernennung einer ganzen Reihe von Generalstaatsanwälten notwendig. Im Januar wurde der Erste Staatsanwalt bei der Staatsanwaltschaft Wien II, Meißner, der bereits nach dem Anschluß Österreichs mit der vorläufigen Leitung der Oberstaatsanwaltschaft in Graz betraut worden war, zum dortigen Generalstaatsanwalt ernannt. Er war nach 1918 zunächst Mitglied der Großdeutschen Volkspartei Österreichs, im Dezember 1937 aber der illegalen österreichischen NSDAP geworden. ${ }^{99}$ Anfang Februar folgte die Ernennung des Innsbrucker Staatsanwalts Moser zum Generalstaatsanwalt. Moser, der sich zunächst ebenfalls der Großdeutschen

96 Vgl. Einführung des Generalstaatsanwalts Wagner in Stuttgart durch Reichsjustizminister Dr. Gürtner (DJ 1937, S. 1627); zu Wagner vgl. Personalverzeichnis des höheren Justizdienstes, Berlin 1938, S. 270, Personalakten des RJM, BA, und Personalunterlagen Wagner im DC Berlin. Wagner beantragte erst im November 1937 seine Aufnahme in die Partei, die unter Rückdatierung auf den 1.5.37 erfolgte.

${ }_{77} \mathrm{Zu}$ Döbig vgl. voranstehende Anm. 75. Zu Bems vgl. Ernennungsvorschlag des RJM zum LGPräs. Nürnberg v. 30.11.36 (Akten des RFiM, BA, Sign. R 2/23976), Personalunterlagen im DC Berlin und Spruchkammerakten StArch. München. Die Amtseinführung beider fand in Nürnberg am 15.10.37 statt (vgl. DJ 1937, S. 1687).

98 Vgl. Ernennungsvorschlag des RJM v. 28.2.38 (Akten des RFiM, BA, Sign. R 2/23977) und Personalakten des RJM, BA. Zur Amtseinführung vgl. DJ 1938, S. 764.

99 Vgl. Ernennungsvorschlag des RJM v. 31.10.38 (Akten des RFiM, BA, Sign. R 2/23978) und DJ 1939, S. 51. Im Ernennungsvorschlag wurde hervorgehoben, daß Meißner „einer der wenigen Beamten“ war, die der „Vaterländischen Front“ in Österreich nicht beigetreten waren. 
Volkspartei angeschlossen hatte, war zwar 1935 in die „Vaterländische Front“, zugleich aber illegal in die verbotene NSDAP eingetreten, hatte für sie während der Verbotszeit in Österreich Nachrichtendienste geleistet und wurde deswegen später von der Gauleitung Tirol-Vorarlberg als „alter Kämpfer" der Ostmark anerkannt. Auch er war bereits im März 1938 kommissarisch mit der Leitung der Staatsanwaltschaft beim Oberlandesgericht Innsbruck betraut worden. ${ }^{100}$ Schließlich wurde im April 1939 der Staatsanwalt Stich, der die Staatsanwaltschaft Wien I ebenfalls schon kommissarisch leitete, zum Generalstaatsanwalt in Wien ernannt. Er war der österreichischen NSDAP erstmals 1919, dann 1930 beigetreten und hatte wegen seiner nationalsozialistischen Betätigung verschiedene dienststrafrechtliche Maßnahmen über sich ergehen lassen müssen. Er war im Juli 1934 fast einen Monat in politischer Haft und anschlieBend trotz Eintritts in die „Vaterländische Front“ ein Jahr lang mit Gehaltskürzungen vom Dienst suspendiert gewesen. ${ }^{101}$ Seine Amtseinführung erfolgte am 2. Mai 1939.

Bei der Staatsanwaltschaft des neu errichteten Oberlandesgerichts Linz wurde Anfang April 1939 der Landgerichtsdirektor in Steyr, Köllinger, zum Generalstaatsanwalt ernannt. Auch er war von 1920 bis 1924 und ab 1933 Mitglied der österreichischen NSDAP gewesen und hatte sich geweigert, der „Vaterländischen Front“ beizutreten. ${ }^{102}$

Die Stelle des Generalstaatsanwalts bei dem ebenfalls neu errichteten Oberlandesgericht Leitmeritz wurde im Mai mit dem Staatsanwalt aus Eger, Stein, besetzt, der von 1924 bis 1928 der DNSAP und seit März 1938 der Sudetendeutschen Partei angehört hatte. Bei der Einrichtung der Justizverwaltung im Sudetenland war er vorläufig in den Reichsdienst übernommen und mit der einstweiligen Leitung der Staatsanwaltschaft beim Landgericht Eger beauftragt worden. Im Frühjahr 1939 war er vorübergehend beim Generalstaatsanwalt in Breslau tätig gewesen, um sich in sein künftiges Aufgabengebiet einzuarbeiten. ${ }^{103}$

Im Altreich waren 1939 zwei neue Generalstaatsanwälte zu ernennen. Nach dem unfreiwilligen Abgang des Kieler Generalstaatsanwalts Sauer im November $1938^{104}$ wurde dessen Stelle im April mit dem Erfurter Oberstaatsanwalt Kramberg besetzt, obwohl der Gauleiter von Schleswig-Holstein Lohse als Nachfolger einen Flensburger Landgerichtsdirektor vorgeschlagen hatte, der seit September 1932 Parteigenosse war. ${ }^{105}$ Lohse stimmte aber schließlich der Ernennung Krambergs zu, der zu diesem Zeitpunkt vorerst nur Parteianwärter und schon im Februar 1934 vom BNSDJ nicht besonders günstig beurteilt worden war. ${ }^{106}$ Das Reichsjustizministerium hatte Kram-

${ }^{100}$ Vgl. Ernennungsvorschlag des RJM v. 15.11.38 (Akten des RFiM, a.a.O.) und Personalunterlagen im DC Berlin. Moser wurde auf Wunsch des Gauleiters Hofer im Frühjahr 1941 abberufen, vgl. Schr. des RJM an den Chef der RK v. 21.2.42 (Akten der RK, BA, Sign. R 43 II/1511 b).

101 Vgl. Emennungsvorschlag des RJM v. 7.2.39 (Akten des RFiM, a.a.O.) und Personalunterlagen im DC Berlin. Zur Amtseinführung vgl. DJ 1939, S.810.

102 Vgl. Beurteilung Köllingers durch den Stab des RKommissars f. d. Wiedervereinigung Österreichs mit dem Deutschen Reich v. 24.1.39 für das RJM/Abt. Österreich und Ernennungsvorschlag des RJM v. 13.2.39 (Akten der RK, BA, Sign. R 43 II/1511).

103 Vgl. Ernennungsvorschlag des RJM v. 6.5.39 (Akten des RFiM, a.a.O.).

104 Vgl. dazu Kapitel III.2., S.228.

105 Vgl. Schr. des St.d.F. an das RJM v. 28.7.38, Eintr. v. 29.7.39 im Diensttageb. des RJM, Bd. 16 (BA, Sign. R 22/947).

106 Zu Kramberg vgl. Ernennungsvorschlag des RJM v. 19.12.38 (Akten des RFiM, a.a.O.) und Personalakten des RJM, BA. Zur Amtseinführung vgl. DJ 1939, S. 760. 
berg 1937 zunächst zum Generalstaatsanwalt beim Landgericht Berlin befördern wollen, hatte diese Stelle aber dann mit dem Kölner Oberstaatsanwalt Seebens besetzt, da sich dessen Ernennung zum Generalstaatsanwalt in Königsberg wegen der Haltung Gauleiter Kochs zerschlagen hatte. ${ }^{107}$ Die Einführung Krambergs in sein Kieler Amt erfolgte am 26. April 1939. Im Juli wurde in Karlsruhe die Stelle des Generalstaatsanwalts frei, da Lautz zum Oberreichsanwalt beim Volksgerichtshof befördert wurde. ${ }^{108}$ Seinen Posten übernahm der Präsident des Landgerichts Waldshut, Frey. Er hatte bis Ende 1938 eine staatsanwaltschaftliche Tätigkeit ausgeübt und war als Mannheimer Oberstaatsanwalt im Mai 1937 der Partei beigetreten. ${ }^{109}$ Er wurde am 17. Oktober 1939 in sein neues Amt eingeführt.

Gleichfalls im Oktober wurde die Stelle des Generalstaatsanwalts beim neuen Oberlandesgericht in Prag mit Oberstaatsanwalt Gabriel vom Landgericht Hamm besetzt. Wie der neue Prager Oberlandesgerichtspräsident war auch Gabriel nicht wegen besonderer Verdienste um die Bewegung - er war der Partei erst im Mai 1933 beigetreten -, sondern wegen seiner beruflichen und organisatorischen Begabung für diesen Posten ausgewählt worden. Er hatte sie seit Oktober 1938 beim Aufbau der Staatsanwaltschaft im Sudetenland und anschließend seit April 1939 als kommissarischer Leiter der Staatsanwaltschaft beim Prager Oberlandesgericht bewiesen. ${ }^{110}$

Im Jahre 1939 wurde schließlich noch der Generalstaatsanwalt beim Oberlandesgericht des eingegliederten Danzig, Graßmann, übernommen, der seit 1920 bei der Danziger Staatsanwaltschaft tätig und im Mai 1936 vom Danziger Senat zum Generalstaatsanwalt am Obergericht ernannt worden war. Er erhielt am 1. November 1939 eine Planstelle des Reiches. ${ }^{111}$

Die letzte Ernennung eines Generalstaatsanwalts in der Amtszeit Gürtners betraf den Leiter der Staatsanwaltschaft beim neuen Oberlandesgericht in Posen. Diesen Posten bekam im Juni 1940 der Oberstaatsanwalt beim Oberlandesgericht Breslau, SSHauptsturmführer Drendel. Er gehörte seit 1932 der Partei an und war während seiner Tätigkeit als Berliner Staatsanwalt 1933/34 ein Jahr zum Geheimen Staatspolizeiamt beurlaubt worden, um an der Aufklärung von Korruptionsfällen bei Krankenkassen mitzuwirken, bevor er im Herbst 1934 Oberstaatsanwalt am Oberlandesgericht Stettin und im März 1935 am Oberlandesgericht Breslau geworden war. Schon im März 1940 war Drendel zur Staatsanwaltschaft nach Posen entsandt worden, um den seit November 1939 dorthin abgeordneten Breslauer Generalstaatsanwalt Sturm beim Aufbau der neuen Justizverwaltung zu unterstützen. Er hatte Sturm im Mai abgelöst und die Geschäfte des Generalstaatsanwalts in Posen kommissarisch übernommen.

107 Vgl. Ernennungsvorschlag des RJM v. 17.6.37, widernufen durch das Schr. an den RFiM v. 17.8. 37 (Akten des RFiM, BA, Sign. R 2/23977). Dazu auch voranstehend S.283.

${ }^{108} \mathrm{Zu}$ Lautz voranstehend S. 283, zur Amtseinführung am 4.7.39 vgl. DJ 1939, S.1150. Wegen seiner Tätigkeit als OReiA beim VGH wurde er im Nürnberger Juristenprozeß am 4.12.47 vom amerikanischen Militärgerichtshof III wegen Kriegsverbrechen und Verbrechen gegen die Menschlichkeit zu 10 Jahren Zuchthaus verurteilt, 1951 aber vom amerikanischen Hohen Kommissar McCloy amnestiert.

109 Vgl. Personalunterlagen Frey im DC Berlin und Personalakten des RJM, BA. Zur Amtseinführung s. DJ 1939, S. 1671.

${ }^{10}$ Vgl. DJ 1938, S. 1730, Ernennungsvorschlag des RJM v. 13.10.39 (Akten des RFiM, BA, Sign. R 2/23979) und Personalakten des RJM, BA.

111 Vgl. Personalverzeichnis des höheren Justizdienstes, Anhang für die Freie Stadt Danzig, Berlin 1938, S. 295, und Kalender für Reichsjustizbeamte 1941, 2. Teil, Berlin 1940, S. 489. Nähere Personalangaben waren nicht zu erlangen. 
Nach seiner endgültigen Ernennung wurde er am 24. Juni 1940 in sein Amt eingeführt. ${ }^{112}$

Dieser Überblick zeigt, daß das Reichsjustizministerium bei der Besetzung der Posten der Oberlandesgerichtspräsidenten und Generalstaatsanwälte die Personalwünsche der Gauleiter weitgehend berücksichtigte, sich ihnen aber auch widersetzte, wenn es sie aus fachlichen Gründen nicht für vertretbar hielt. Die Einflußnahme von seiten der Parteiführung hatte immerhin zur Folge, daß es am Ende der Amtszeit Gürtners unter den 34 amtierenden Oberlandesgerichtspräsidenten nur noch drei gab, die nicht Mitglieder der NSDAP waren: Kammergerichtspräsident Hölscher in Berlin, Schwister in Düsseldorf, die beide in der Weimarer Zeit Bindungen zum Zentrum gehabt hatten, und Schober in Wien, der bis zum Anschluß Österreichs der von Dollfuß gegründeten „Vaterländischen Front" angehört hatte. ${ }^{113}$ Dagegen waren 10 Oberlandesgerichtspräsidenten schon vor 1933 Parteigenossen gewesen, 11 waren der Partei 1933 und weitere 10 in den Jahren nach 1933 beigetreten. ${ }^{114}$ Die 35 Generalstaatsanwälte waren offensichtlich sämtlich Mitglieder der NSDAP, von ihnen gehörten 8 der Partei schon vor 1933 an, 14 hatten die Mitgliedschaft 1933, 12 in den darauffolgenden Jahren erworben. ${ }^{115}$ Sicher wurden nicht alle diese nach der Machtübernahme in die Partei eingetretenen höheren Justizbeamten waschechte „Nationalsozialisten“ - dagegen sprechen schon die zahlreichen Umbesetzungen, die der nationalsozialistische Reichsjustizminister Thierack nach 1942 vornahm -, es darf aber davon ausgegangen werden, daß sich auch in dem Parteibeitritt jene Anpassung an das Regime dokumentierte, die den damaligen Justizapparat in seiner Gesamtheit auszeichnete. Für die Bereitwilligkeit zur Anpassung war die soziale Herkunft der Angehörigen dieser wichtigen Gruppe innerhalb der Justizverwaltung, die sich aus den Berufen ihrer Väter ergibt, nicht unerheblich. Von den 97 Oberlandesgerichtspräsidenten und Generalstaatsanwälten, die im Zeitraum vom 1. Januar 1935 bis zum Ende der Gürtner-Periode im Januar 1941 - also nicht nur zum letztgenannten Zeitpunkt selbst - jeweils unterschied-

112 Vgl. Ernennungsvorschlag des RJM v. 4.5.40 (Akten des RFiM, a.a.O.), Personalakten des RJM über Drendel und Sturm, BA, sowie DJ 1940, S.806.

113 Zu Hölscher vgl. Kapitel III.2., S. 222 f. Schwister war bis 1931 Mitglied der Zentrumspartei (Personalakten des RJM, BA). Bei Schober ist die Nichtmitgliedschaft dokumentarisch zwar nur bis Ende Oktober 1938 belegt (Ernennungsvorschlag des RJM v. 21.10.38, Akten des RFiM, BA, Sign. R 2/23978); da er jedoch nicht wie seine Kollegen in Innsbruck und Graz im Mai 1938 in die Partei aufgenommen wurde, ist seine Nichtzugehörigkeit zur NSDAP auch für Ende 1940 anzunehmen.

114 Als Quellen dienten Ernennungsvorschläge und Personalakten des RJM (BA) und Personalunterlagen aus dem DC Berlin. Die Parteibeitritte nach 1933 verteilen sich wie folgt: $1936=1,1937=5,1938=3$ und $1940=1$. D. Majer standen für ihre Aussagen zu dieser Frage, die sich offensichtlich auf die Amtszeit Schlegelbergers beziehen (,damals 35 OLG-Bezirke“; „Stand vor 1942"), die Angaben über 23 OLGPräs. und 19 GStAe zur Verfügung, vgl. „Fremdvölkische“ im Dritten Reich. Ein Beitrag zur nationalsozialistischen Rechtssetzung und Rechtspraxis in Verwaltung und Justiz unter besonderer Berücksichtigung der eingegliederten Ostgebiete und des Generalgouvernements, Boppard a. Rhein 1981, S.81.

115 Für einen GStA fehlen dem Verf. zwar die konkreten Angaben, seiner Karriere nach ist jedoch eine Parteimitgliedschaft als sicher anzunehmen. 1937 traten der Partei 9 der GStAe bei, $1938=2$ und $1939=1$.

Bei den im Januar 1941 amtierenden 69 OLGPräs. und GStAen konnte von 24 die frühere Zugehörigkeit zu anderen politischen Parteien und Organisationen festgestellt werden: Deutschvölkische Freiheitspartei $=1$; Deutschnationale Volkspartei $=7$ (davon 3 zugleich im Stahlhelm); Deutsche Vaterlandspartei $(1917 / 1918)=1$; Deutsche Volkspartei $=4$; Deutsche Staatspartei $=1$; Zentrum $=2$ (plus 1 der Partei nahestehend); Großdeutsche Volkspartei (Österreich) = 3; Deutsche Nationalsozialistische Arbeiter Partei (Sudeten) $=2$; Deutschvölkischer Schutz- und Trutzbund $=2$. Für die übrigen 45 waren die Angaben entweder negativ oder sie standen dem Verf. nicht zur Verfügung. 
lich lang amtierten, konnte bei 70 der väterliche Beruf festgestellt werden. ${ }^{116}$ Dabei kamen 27 aus Familien, in denen die Väter höhere Beamte waren ${ }^{117}$, darunter fünf Justizbeamte in den Rängen vom Oberstaatsanwalt bis zum Landgerichtspräsidenten. 11 Väter gehörten der unteren und mittleren Beamtenschaft an - davon aus dem Justizbereich ein Amtsanwalt ${ }^{118}$-, 10 waren Kaufleute, 6 Unternehmer, 5 freiberufliche Akademiker - darunter zwei Rechtsanwälte und Notare -, 5 Landwirte ${ }^{119}, 3$ leitende Angestellte $^{120}$ und 3 Handwerker. Daß kein einziger der Oberlandesgerichtspräsidenten und Generalstaatsanwälte aus der Familie eines Arbeiters oder kleinen Angestellten hervorging, ist nicht verwunderlich, da diese Familien bei dem Schul- und Ausbildungssystem, das in den hier in Frage kommenden Jahrzehnten bestand, wirtschaftlich nicht in der Lage waren, ihren Kindern eine Hochschulbildung zu ermöglichen. Diese Justizbeamten entstammten deshalb fast ausschließlich dem mittleren und gehobenen Bürgertum ${ }^{121}$, das überwiegend national und konservativ dachte, und zu einem erheblichen Anteil dem Beamtentum, das die legale Autorität zu respektieren und ihr mit einem besonderen Staatsethos zu dienen gewohnt war. Diese Einstellung ihrer Herkunftfamilien, in der die Oberlandesgerichtspräsidenten und Generalstaatsanwälte aufgewachsen waren, bewirkte eine gewisse Affinität zu den vorgegebenen „nationalen“ Zielen der nationalsozialistischen Führung und förderte damit die Bereitschaft, sich dem Regime anzupassen. Diese Anpassung bedeutete aber zugleich, die radikalen Auswüchse des Regimes hinzunehmen und an seine verbrecherischen Praktiken, die an sich den ererbten Vorstellungen vom Beamtenethos zuwiderliefen, Zugeständnisse zu machen. Insofern bot das Verhalten dieser Elitegruppe in der Justizverwaltung ein getreues Abbild des Verhaltens der damaligen Justiz schlechthin. Auch sie war bestrebt, sich durch Anpassung und Konzessionen - die aber nur unter Aufgabe rechtsstaatlicher Grundsätze möglich waren - die eigene Zuständigkeit und Funktion bei der Aufrechterhaltung der Rechtsordnung zu bewahren, wurde aber dadurch zum Instrument eines Regimes, das in dieser Rechtsordnung nur ein Mittel zur Sicherung seiner Herrschaft und zur Durchsetzung seiner politischen Ziele sah.

116 Als Quellen dienten die in Anm.114 genannten Unterlagen sowie zeitgenössische Handbücher verschiedenster Art. Für die Zeit nach Gürtners Tod vgl. die Feststellungen bei D. Majer, a.a.O., S.77, die auf den Angaben über 22 OLGPräs. und 19 GStAe beruhen und zur gleichen Aussage führen.

117 Darunter nur ein Militär (Generalleutnant).

118 Sonst meist Volksschullehrer, mittlere Zoll- und Postbeamte, jedoch ein Lokomotivführer als unterer Eisenbahnbeamter.

119 Ein Rittergutsbesitzer wurde den Unternehmern zugerechnet.

120 Direktoren und Prokuristen.

121 M. Janowitz, Soziale Schichtung und Mobilität in Westdeutschland (Kölner Zeitschrift für Soziologie und Sozialpsychologie 1958, S. 1 ff.), ordnet die genannten Berufe der „Oberen Mittelschicht“ und der „Unteren Mittelschicht“ zu. Auch im ersten Jahrzehnt der Bundesrepublik entstammten die Richter der OLGe fast ausschließlich diesen Mittelschichten, vgl. W. Richter, Die Richter der Oberlandesgerichte der Bundesrepublik. Eine berufs- und sozialstatistische Analyse (Hamburger Jahrbuch für Wirtschafts- und Gesellschaftspolitik, Jg. 5/1960, S.241 ff.), und R. Dahrendorf, Bemerkungen zur sozialen Herkunft und Stellung der Richter an Oberlandesgerichten. Ein Beitrag zur Soziologie der deutschen Oberschicht (a.a.O., S. 260 ff.). 


\section{Der hierarchische Aufbau der Justizbeamtenschaft und ihre laufende Ergänzung}

\section{a. Laufbabnregelung, Besoldung und Planstellenzabl: die Entwicklung der Richter- und Staatsanwaltstellen ab 1938}

Wie aus der Tradition des Kaiserreichs und der Weimarer Republik überkommen, blieb der Richter auch im nationalsozialistischen Staat in die Stellen- und Besoldungshierarchie der allgemeinen Beamtenschaft eingebunden. Die vereinzelten Sonderbestimmungen des Deutschen Beamtengesetzes von 1937, die den ,richterlichen Beamten " betrafen, gaben ihm in dieser Hinsicht keinen Sonderstatus. ${ }^{1}$ Dieser Umstand begünstigte eine angepaßte Haltung des Richters und war nicht dazu angetan, seine innere Unabhängigkeit und das Bewußtsein zu fördern, ein aus dem übrigen Beamtentum herausgehobenes Organ mit besonderen Rechten und Pflichten zu sein: nicht umsonst nahm daher das Grundgesetz von 1949 den Richter aus dem allgemeinen Beamtenrecht heraus und schrieb die Regelung seiner Stellung durch ein eigenes Richtergesetz vor. ${ }^{2}$

In der Justizbeamtenschaft trat der hierarchische Aufbau außer in den Dienstrangbezeichnungen und -titeln auch äußerlich in der neugestalteten Amtstracht in Erscheinung. Das Hoheitsabzeichen auf der Robe - Adler und Hakenkreuz -, das Hitler den Justizbeamten im Juni 1936 verlieh und das am 1. Oktober im ganzen Reich erstmals getragen wurde ${ }^{3}$, war für die Richter und Staatsanwälte beim Reichsgericht, beim Volksgerichtshof und den Oberlandesgerichten in Gold, bei den übrigen Gerichten und für alle Urkundsbeamten in Silber vorgesehen. Obwohl sich die Standesorganisation der Rechtsanwälte - die nach nationalsozialistischer Vorstellung zumindest als Strafverteidiger "Organe der Strafrechtspflege" waren ${ }^{4}$ - darum bemühte, wurde ihnen das Tragen des Hoheitszeichens auf dem Talar nicht gestattet. ${ }^{5}$ Wie die Justizwachtmeister und die Strafanstaltsbeamten im Reich eine einheitliche Dienstkleidung erhielten, wurde auch die Amtstracht der Justizverwaltung einheitlich gestaltet und dabei nach Funktion und Rang differenziert. Während Richter und Staatsanwälte auf der schwarzen Robe und Kopfbedeckung den Besatz in Sammet - die Amtsanwälte wiederum in einer anderen Abmessung - trugen, war der Besatz der Rechtsanwälte aus Seide, der der Urkundsbeamten aus Wollstoff. Die „Rangabzeichen“ wurden am Barett getragen: das genau festgelegte Arrangement von Besatzschnüren und Spangen reichte von $z$ wei goldenen Schnüren für die Oberlandesgerichtspräsidenten und Generalstaatsanwälte bis zu zwei silbernen Spangen für die Oberamtsrichter und Ersten

1 Vgl. A. Wagner, Die Umgestaltung der Gerichtsverfassung und des Verfahrens- und Richterrechts im nationalsozialistischen Staat (Die deutsche Justiz und der Nationalsozialismus, Teil I, Stuttgart 1968), S. 232.

$2 \mathrm{Zu}$ diesem Problem vgl. R. Wassermann, Kontinuität oder Wandel; Konsequenzen aus der NS-Herrschaft für die Entwicklung der Justiz nach 1945, Hannover 1984, S. $15 \mathrm{ff}$.

3 Vgl. Erl. des Führers und Reichskanzlers über die Amtstracht in der Reichsjustizverwaltung v. 19.6.36 (RGBl. I, S. 503) und RV des RJM an die höheren Justizbehörden v. 22.9.36 (Akten des RJM, Hauptbüro, Arch. des BJM).

4 Vgl. den Entw. der neuen StVO v. 27.2.36 (dazu Kapitel VHI.2.a., S.986).

5 Es sei denn als Mitglieder der Ehrengerichte der RAe und Patentanwälte (vgl. AV des RJM v. 6.10.38, DJ 1938, S. 1621). 
Staatsanwälte. ${ }^{6}$ Wie bisher der Präsident des Reichsgerichts bekamen nun auch der Präsident des Volksgerichtshofs und die Oberlandesgerichtspräsidenten Amtsketten verliehen. Neben die Robe mit stahlblauem Besatz für die Mitglieder des Reichspatentamtes und die dunkelrote Robe des Reichsgerichts trat die hellrote für den Volksgerichtshof.

$\mathrm{Da}$ sich diese Amtstrachten nicht für alle öffentlichen Veranstaltungen eigneten und darüber hinaus auch nicht von allen Beamten der Justizverwaltung getragen werden konnten, wurde es bald als mißlich empfunden, daß die Vertreter der Justiz bei solchen Anlässen gegenüber den uniformierten Angehörigen von Partei und Wehrmacht in den Hintergrund gedrängt und sogar bei der Zuteilung von Sitzplätzen benachteiligt wurden. ${ }^{7}$ Diesem offensichtlich nicht nur bei der Justiz empfundenen Manko wurde 1940 durch die Einführung einer allgemeinen Beamtenuniform abgeholfen. ${ }^{8}$ Zum Tragen dieser dunkelblauen Uniform - die bei der Justiz zur Unterscheidung von anderen Verwaltungszweigen weinrote Hosenbiesen aufwies - waren die Angehörigen des Reichsjustizministeriums bis hinab zum Ministerialrat, die Präsidenten und Vizepräsidenten der Gerichte bis hinab zu den Präsidenten größerer Landgerichte, die Oberreichsanwälte, Generalstaatsanwälte und leitenden Oberstaatsanwälte bei den Landgerichten berechtigt bzw. bei Anordnung verpflichtet. Die Uniform wies am linken Ärmel „Dienstgradabzeichen“ mit unterschiedlichen Silberstikkereien und einer verschiedenen Anzahl von silbernen Sternen auf, die sich nach Besoldungsgruppen richteten. Beamte, die in der Partei oder einer ihrer Gliederungen einen Dienstgrad vom Kreisleiter bzw. Standartenführer an aufwärts bekleideten, sollten jedoch statt dessen die Parteiuniform tragen', offensichtlich um die Verbundenheit von Justizbeamtenschaft und Bewegung zu demonstrieren. Welche Bedeutung der Uniformfrage zugemessen wurde, geht aus den verschiedentlich geäußerten Beschwerden der Aufsichtsführenden Richter bei den Amtsgerichten hervor, daß sie bei offiziellen Veranstaltungen weiter im „verpönten Zylinderhut“ erscheinen mußten, während z. B. der Landrat und der Vorsteher des Finanzamtes uniformiert auftreten durften. ${ }^{10}$ Im Protektorat und in den annektierten polnischen Gebieten war die Uniformierung der dorthin abgeordneten Justizbeamten unumgänglich, um die Autorität der Justiz nicht einmal so sehr gegenüber den Einwohnern als vielmehr gegenüber den deutschen Militär-, Polizei- und Parteidienststellen zu wahren und ihre Angehörigen vor der peinlichen Behandlung als vermeintliche Tschechen bzw. Polen zu schützen. ${ }^{11}$ In diesen Gebieten erhielten sie zunächst eine feldgraue Beamtenuniform mit geflochtenen Schulterstücken für die Richter und Staatsanwälte sowie gerippten Leutnants-

${ }^{6}$ Vgl. im einzelnen AV des RJM v. 26.6.36 (DJ 1936, S.990) und RV des RJM an die Chefpräs. und GStAe v. 2.7.36 (Akten des RJM, a.a.O.).

7 Vgl. z. B. die Ausführungen in den Lageber. des OLGPräs. Hamm v. 8.3. und 5.7.37 (Akten des RJM, BA, Sign. R 22/1187).

${ }^{8} \mathrm{Zu}$ den Motiven des RMdI für die Einführung der Beamtenuniform s. H. Mommsen, Beamtentum im Dritten Reich, Stuttgart 1966, S. 118.

9 Vgl. Erl. des Führers und Reichskanzlers über die Einführung einer Beamtenuniform v. 30.3 .39 (RGBl. I, S.761) nebst Uniformvorschrift des RMdI v. 8.3.40 (RGBI. I, S.463), AV des RJM v. 10.4.40 (DJ 1940, S. 427) und RV des RJM v. 25.9.40 und 12.2.41 (Akten des RJM, Hauptbüro, BA).

$10 \mathrm{Vgl.} \mathrm{z.B.} \mathrm{Lageber.} \mathrm{des} \mathrm{OLGPräs.} \mathrm{Braunschweig} \mathrm{v.} \mathrm{4.1.41} \mathrm{(Akten} \mathrm{des} \mathrm{RJM,} \mathrm{BA,} \mathrm{Sign.} \mathrm{R} \mathrm{22/3357)} \mathrm{und} \mathrm{des}$ OLGPräs. Darmstadt v. 10.11.41 (a.a.O., Sign. R 22/3361), ferner Lageber. des OStA Hamm v. 29.11.40 hinsichtlich der nichtleitenden OStAe (Akten des RJM, BA, Sign. R 22/3367).

1 Solche Vorfälle werden geschildert in der zeitgenössischen "Chronik des Land- und Amtsgerichts Litzmannstadt" (Lodz), S. 23f. (Akten der RJM, Ministerbüro, BA). 
schulterstücken für die gehobenen und mittleren Beamten. Obwohl sich die dortigen Justizstellen im Frühjahr 1940 gegen die Einführung der weniger militärisch zugeschnittenen und unpraktischen dunkelblauen Uniform - die zudem nicht alle Beamten tragen durften - sträubten und darin vom Justizministerium gegenüber dem Reichsinnenministerium unterstützt wurden ${ }^{12}$, mußten ihre Angehörigen im April die Schulterstücke ablegen und durften die feldgraue Uniform nur noch ein Jahr lang auftragen. ${ }^{13}$ Trotz der repräsentativen silbernen Feldbinde, dem Dolch und der Ausstattung des „Festanzuges“ mit silbernen Fangschnüren erfreute sich die blaue Uniform bei den Juristen keiner Beliebtheit. Thierack lehnte später den höheren Justizbeamten gegenüber jede Verantwortung für die Einführung dieser „unschönen“ Uniform ab und bat sie, lieber „als SA-Truppführer" zu erscheinen, wenn sie nicht als „repräsentative Figur irgendeines hohen Gerichts in Erscheinung treten müßten "14; in einer Rundverfügung empfahl er ihnen, „ohne Rücksicht auf ihren politischen Dienstrang bei amtlichen Anlässen anstelle der Beamtenuniform ihre Parteiuniform anzulegen“15, soweit sie Mitglieder der Bewegung waren.

Nach dem Stand vom 1. September 1938 bot der hierarchische Aufbau der Justizbeamtenschaft im Altreich - für die Justizbeamten im angeschlossenen Österreich galten noch eigene, überkommene Vorschriften - folgendes Bild. Bei den Beamten für die Gerichte und Staatsanwaltschaften ${ }^{16}$ wurden vier Laufbahngruppen unterschieden: der höhere Dienst, der gehobene mittlere Dienst, der einfache mittlere Dienst und der untere Dienst. ${ }^{17}$ Während die Beamten des höheren Dienstes auf Vorschlag des Reichsjustizministeriums von Hitler ernannt wurden ${ }^{18}$, erfolgte die Ernennung aller anderen Beamten durch den Oberlandesgerichtspräsidenten oder Generalstaatsanwalt. Alle Justizbeamten traten normalerweise mit 65 Jahren in den Ruhestand. ${ }^{19}$ Ihre Besoldung richtete sich nach dem für alle Beamten geltenden Besoldungsgesetz vom 16. Dezember 1927 (RGBI. I, S. 239) und den dazu erlassenen Änderungs- und Ausführungsbestimmungen. Danach war die große Mehrheit der planmäßig - d.h. in einer bestimmten im Haushaltsplan des Reiches vorgesehenen Beamtenstelle - angestellten Justizbeamten in der Besoldungsordnung A (Aufsteigende Gehälter) aufgeführt, die Beamten in hohen Stellungen in der Besoldungsordnung B (Feste Gehälter). Innerhalb dieser Besoldungsordnungen waren sie in verschiedene Besoldungsgruppen eingestuft.

Beamte des böberen Dienstes waren die Richter und Staatsanwälte. Voraussetzung für ihre Anstellung war die „Fähigkeit zum Richteramt“ ( $\$ \S 2$ und 148 des Gerichtsverfassungsgesetzes von 1877), die durch ein mindestens dreijähriges Studium der Rechts-

12 Vgl. Lageber. des GStA Breslau v. 27.6.40 (Akten des RJM, BA, Sign. R 22/3358), Lageber. des OLGPräs. Danzig v. 6.11.40 (a.a.O., Sign. R 22/3360) und die Schr. Gürtners an das RMdI v. 23.3. und 24. 5.40 (a.a.O., Sign. R 22/1500), in denen er „auf Grund persönlicher Wahrnehmungen“" generell statt der Dienstrangabzeichen am Ärmel für Schulterstücke eintrat, da grundsätzlich jedes Abzeichen so angebracht sein sollte, "daß es erkennbar ist, wenn man den Träger der Uniform von vorne sieht“.

13 Vgl. die AV des RJM v. 27.6.40 und 20.9.40 (DJ 1940, S.732, 1083).

14 Vgl. Niederschr. über die Arbeitstagung der OLGPräs. und GStAe am 10./11. Februar 1943 in Berlin (Akten des RJM, BA, Sign. R 22/4278).

15 RV des RJM an die höheren RJBehörden v. 8.2.43 (a.a.O., Sign. R 22/1500).

${ }^{16}$ Zum Strafvolizugsdienst s. im folgenden.

17 Spăter aufgrund § 12 der VO über die Vorbildung und die Laufbahnen der deutschen Beamten v. 28.2.39 (RGBl. I, S. 371) umbenannt in: höheren, gehobenen, mittleren und unteren Justizdienst (vgl. RV des RJM v. 28.3.39, Akten des RJM, BA, Sign. R 22/4430).

${ }_{18}$ Zur Ernennungsprozedur vgl. Kapitel III.1.d., S. $207 \mathrm{ff}$.

19 Vgl. VO über die Altersgrenze der Beamten der Reichsjustizverwaltung v. 27.7.36 (RGB1.I, S. 575). 
wissenschaft an einer Universität, die Ablegung der ersten Juristischen Staatsprüfung (Referendarprüfung), eine dreijährige praktische Ausbildung bei Gerichten, bei der Staatsanwaltschaft, Rechtsanwälten sowie Verwaltungsbehörden und schließlich durch die Ablegung der großen Staatsprüfung (Assessorenprüfung) erworben wurde. Danach konnte sich der Assessor um die Ủbernahme in den zweijährigen Probe- und Anwärterdienst für das Amt des Richters oder Staatsanwalts bewerben ${ }^{20}$ und wurde bei Eignung je nach der gewünschten Laufbahn als Amtsgerichtsrat, Landgerichtsrat oder Staatsanwalt (sämtlich Eingangsstellen in der Besoldungsgruppe A 2 c $2^{21}$ ) planmäßig und auf Lebenszeit angestellt.

Die richterliche Laufbabn bot die Möglichkeit der Beförderung zum

Oberamtsrichter (Vorstand eines Amtsgerichts mit mindestens 3 planmäßig angestellten Richtern oder Abteilungsleiter bei einem größeren Amtsgericht; Besoldungsgruppe A 2 c 1),

Amtsgerichtsdirektor (Vorstand eines Amtsgerichts mit mindestens 6 planmäßig angestellten Richtern),

Landgerichtsdirektor (vorsitzender Richter bei einem Landgericht),

Oberlandesgerichtsrat (beisitzender Richter bei einem Oberlandesgericht) (alle drei Stellen in den Besoldungsgruppen A 2 b und A 1 b),

Senatspräsidenten (vorsitzender Richter bei einem Oberlandesgericht),

Vizepräsidenten (Vertreter des Behördenvorstandes bei einem Oberlandesgericht),

20 Näheres zur Ausbildung und Laufbahn im höheren Justizdienst und ihrer Umgestaltung s. Kapitel III.4.b., insbesondere S. $299 \mathrm{ff}$., $316 \mathrm{ff}$.

21 Nach der im September 1938 geltenden Neufassung der ReichsbesoldungsO durch das G. über die Einunddreißigste Änderung des Besoldungsgesetzes v. 9.12.37 (RGBl. I, S. 1355) bezogen die im Text erwähnten Besoldungsgruppen folgendes Jahresgehalt (Grundgehalt ohne Wohnungsgeldzuschuß):

I. Höherer Dienst

A 2 c 2 zwischen 4800 und 8400 RM (je nach Dienstaltersstufe)

A 2 c 1 zwischen 4800 und 8800 RM

A 2 b zwischen 7000 und 9700 RM

A 1 b zwischen 6200 und 10600 RM

A 1 a zwischen 8400 und 12600 RM

B 913000 RM

B 814000 RM

B 7 a 16000 RM

B 617000 RM

B $5 \quad 18000 \mathrm{RM}$

B 3 a 24000 RM

Il. Gehobener mittlerer Dienst

A 4 c 2 zwischen 2800 und 5000 RM

A 4 c 1 zwischen 2800 und 5300 RM

A 4 b 2 zwischen 3000 und 5500 RM

A 4 b 1 zwischen 4100 und 5800 RM

A $3 \mathrm{c}$ zwischen 3600 und $6600 \mathrm{RM}$

$A 3$ b zwischen 4800 und 7000 RM

A 2 c 2 zwischen 4800 und 8400 RM

III. Einfacher mittlerer Dienst

A 8 a zwischen 2000 und 2700 RM

$A 7$ b zwischen 2400 und 3200 RM

A 7 a zwischen 2350 und 3500 RM

A 5 b zwischen 2300 und 4200 RM

IV. Unterer Dienst

A $10 \mathrm{~b}$ zwischen 1600 und 2300 RM

A 9 zwischen 1700 und 2600 RM

A 8 a zwischen 2000 und 2700 RM 
Amtsgerichtspräsidenten (Vorstand eines besonders großen Amtsgerichts)

(alle drei Stellen in der Besoldungsgruppe A 1 a),

Landgerichtspräsidenten oder -vizepräsidenten (Besoldungsgruppe A1 a oder B 8),

Reichsgerichtsrat oder Volksgerichtsrat (beisitzender Richter beim Reichsgericht oder beim Volksgerichtshof; Besoldungsgruppe B 7 a),

Senatspräsidenten (vorsitzender Richter beim Reichsgericht oder beim Volksgerichtshof; Besoldungsgruppe $\mathrm{B}$ 6),

Oberlandesgerichtspräsidenten (Besoldungsgruppe B 6 oder B 5) und

Präsidenten des Reichsgerichts oder des Volksgerichtshofs (Besoldungsgruppe B 3 a).

Die Aussichten auf eine Beförderung hingen naturgemäß vom zahlenmäßigen Verhältnis der Eingangsstellen zu den aufgeführten Beförderungsstellen ab. Im Jahre $1938^{22}$ standen in der richterlichen Laufbahn 7408 Eingangsstellen als Amtsgerichtsrat oder Landgerichtsrat 2818 Beförderungsstellen gegenüber, und zwar:

414 Stellen für Oberamtsrichter,

1940 Stellen für Amtsgerichtsdirektoren, Landgerichtsdirektoren, Oberlandesgerichtsräte,

184 Stellen für Amtsgerichtspräsidenten, Senatspräsidenten oder Vizepräsidenten bei Oberlandesgerichten,

157 Stellen für Landgerichtspräsidenten und Landgerichtsvizepräsidenten,

82 Stellen für Reichsgerichtsräte und Volksgerichtsräte,

13 Stellen für Senatspräsidenten beim Reichsgericht und beim Volksgerichtshof, 26 Stellen für Oberlandesgerichtspräsidenten und

2 Stellen für die Präsidenten des Reichsgerichts und des Volksgerichtshofs.

In der staatsanwaltschaftlichen Laufbabn war eine Beförderung möglich zum:

Ersten Staatsanwalt (Abteilungsleiter bei einer größeren Staatsanwaltschaft; Besoldungsgruppe A 2 c 1),

Oberstaatsanwalt (Vorstand der Staatsanwaltschaft bei einem Landgericht; Besoldungsgruppe A 2 b oder A 1 b),

Generalstaatsanwalt (Vorstand der Staatsanwaltschaft bei einem Oberlandesgericht; Besoldungsgruppe B 9 oder B 8),

Reichsanwalt (Staatsanwalt an der Staatsanwaltschaft beim Reichsgericht oder beim Volksgerichtshof; Besoldungsgruppe B 7 a) und

Oberreichsanwalt (Vorstand der Staatsanwaltschaft beim Reichsgericht oder beim Volksgerichtshof; Besoldungsgruppe B 5).

In dieser Laufbahn gab es 979 Eingangsstellen für Staatsanwälte und 474 Beförderungsstellen:

231 Stellen für Erste Staatsanwälte,

206 Stellen für Oberstaatsanwälte,

26 Stellen für Generalstaatsanwälte,

9 Stellen für Reichsanwälte und

2 Stellen für Oberreichsanwälte.

22 Die folgenden Angaben über die Zahl der Planstellen beruhen auf einer im RJM nach dem Stand vom 1.9.38 bearbeiteten Aufstellung (Akten des RJM, BA, Sign. R 22/4430). Sie weichen von den statistischen Angaben über den höheren Justizdienst im Kalender für Reichsjustizbeamte 1939, 2. Teil, Berlin 1938, die nach dem Stand vom 1.10.38 gefertigt wurden, ab. 
Da für Richter und Staatsanwälte eine einheitliche Laufbahn bestand, war auch der Übertritt aus einem richterlichen Amt in ein staatsanwaltschaftliches oder umgekehrt sowohl durch eine Versetzung in eine gleich hohe Stellung wie auch durch eine Beförderung möglich.

Die Beamten des gebobenen mittleren Justizdienstes erledigten einfachere richterliche Geschäfte in Grundbuch-, Vormundschafts-, Registersachen usw., arbeiteten als Urkundsbeamte und nahmen das Kosten-, Kassen- und Rechnungswesen der Justizbehörden wahr. Voraussetzung für die Anstellung war eine abgeschlossene Mittelschulbildung, eine dreijährige praktische Ausbildung bei Gerichten und Staatsanwaltschaft in allen Geschäften dieses Dienstzweiges und die Ablegung einer Prüfung. Der Bewerber stand während der Ausbildung bereits im Beamtenverhältnis. Im Jahre 1938 war die Hälfte der Stellen „Versorgungsanwärtern“, d.h. nach 12jähriger Militärdienstzeit ausscheidenden Angehörigen des Unteroffizierkorps, vorbehalten. Nach bestandener Prüfung wurden die Bewerber zu Justizpraktikanten ernannt und nach einer Dienstzeit von mindestens anderthalb Jahren als Justizinspektoren (Besoldungsgruppe A 4c2) auf Lebenszeit planmäßig angestellt, konnten in die Besoldungsgruppe A 4 c 1 aufrücken und nahmen dann im allgemeinen die Aufgaben geschäftsleitender Beamter bei kleineren Amtsgerichten wahr. Sie konnten zum Justizoberinspektor (Besoldungsgruppe A 4 b 2 oder A 4 b 1), zum Justizamtmann oder Justizverwaltungsrat (Besoldungsgruppe A 3 b) befördert werden oder bei besonderer Tüchtigkeit zum Justiz- und Kassenrat (Besoldungsgruppe A 2 c 2) aufsteigen. Während die Justizoberinspektoren geschäftsleitende Beamte bei größeren Amtsgerichten, kleineren Landgerichten und Staatsanwaltschaften waren, die Justizamtmänner diese Stellung bei größeren Landgerichten und großen Amtsgerichten und Staatsanwaltschaften innehatten, stand der Justiz- und Kassenrat als Leiter eines Rechnungsamtes dem gesamten Kassen-, Haushalts- und Rechnungswesen eines Oberlandesgerichtsbezirks vor. Als Abteilungsleiter im Rechnungsamt waren Justizverwaltungsräte tätig.

Eine besondere Aufstiegslaufbahn des gehobenen mittleren Dienstes war die Laufbahn der Amtsanwälte, d.h. der staatsanwaltschaftlichen Beamten bei den Amtsgerichten. Hatten sich die Bewerber in ihrem bisherigen Dienstzweig bewährt, erhielten sie eine einjährige Sonderausbildung und wurden nach Bestehen einer Prüfung als Amtsanwälte (Besoldungsgruppe A 3 c) angestellt. Sie konnten zu Oberamtsanwälten befördert werden, erhielten dann die Leitung größerer Amtsanwaltschaften und eine Zulage von $400 \mathrm{RM}$ jährlich.

Im gehobenen mittleren Dienst standen 9309 Eingangsstellen für Justizinspektoren im September 1938 insgesamt 3877 Beförderungsstellen gegenüber:

878 Stellen für Justizinspektoren der Besoldungsgruppe A 4 c 1,

2398 Stellen für Justizoberinspektoren,

348 Stellen für Justizamtmänner und Justizverwaltungsräte,

26 Stellen für Justiz- und Kassenräte,

196 Stellen für Amtsanwälte und

31 Stellen für Oberamtsanwälte.

Die Beamten des einfachen mittleren Dienstes verwalteten das Schriftgut bei Gerichten und Staatsanwaltschaften, versahen die Registraturarbeiten und führten in den Gerichtssitzungen Protokoll. Hier waren 90\% der Stellen den erwähnten „Versorgungsanwärtern" aus dem Stande der Berufssoldaten vorbehalten. Als Voraussetzung für die 
Anstellung genügte der Nachweis einer genügenden Allgemeinbildung, eine einjährige praktische Ausbildung - während der die Bewerber als ,Justizanwärter" bereits im Beamtenverhältnis standen - und die Ablegung einer Prüfung, nach der sie zum außerplanmäßigen Justizassistenten ernannt wurden. Nach einem halben Jahr wurden sie als planmäßige Justizassistenten (Besoldungsgruppe A 8 a) auf Lebenszeit angestellt und konnten ohne weitere Prüfung und ohne Änderung ihrer Tätigkeit zu Justizsekretären (Besoldungsgruppe $\mathrm{A} 7$ a) befördert werden. ${ }^{23}$

Als besondere Aufstiegslaufbahn des einfachen mittleren Justizdienstes gab es den Dienst als Gerichtsvollzieher, der beim Amtsgericht angestellt war, bei bürgerlichen Rechtsstreitigkeiten die Zwangsvollstreckung in beweglichen Sachen durchführte und die förmliche Zustellung von Schriftstücken besorgte. Nach bestandener Prüfung für den einfachen mittleren Dienst erhielten die Bewerber eine einjährige Sonderausbildung und übten nach einer besonderen Prüfung mindestens ein Jahr eine selbständige Tätigkeit im Gerichtsvollzieherdienst aus, bis sie bei Eignung als Gerichtsvollzieher (Besoldungsgruppe A 5 b) angestellt wurden. Neben ihrem Gehalt bekamen sie einen Anteil an den für ihre Tätigkeit zu zahlenden Gebühren. ${ }^{24}$

In der Laufbahn des einfachen mittleren Dienstes standen nach Durchführung einer im September gerade in Gang befindlichen Änderung den rund 5900 Eingangsstellen für Justizassistenten rund 8800 Beförderungsstellen - etwa 5900 Stellen für Justizsekretäre und etwa 2900 Stellen für Gerichtsvollzieher - gegenüber.

Die Beamten des unteren Dienstes nahmen den Sitzungs-, Sicherheits-, Ordnungsdienst usw. in den Gerichtsgebäuden wahr und besorgten den Aktenverkehr sowie die Hauswartsgeschäfte der Justizbehörden. Im September 1938 waren diese Stellen ausschließlich den „Versorgungsanwärtern“ vorbehalten. Voraussetzung für die Anstellung war eine ausreichende Allgemeinbildung und eine halbjährige praktische Ausbildung, die die Bewerber als "Justizwachtmeister auf Probe“ bereits im Beamtenverhältnis absolvierten, um anschließend als Justizwachtmeister (Besoldungsgruppe A $10 \mathrm{~b}$ ) zu Beamten auf Lebenszeit ernannt zu werden. Sie konnten ohne Prüfung und Änderung ihrer Diensttätigkeiten zum Justizoberwachtmeister mit einer Zulage von 200 RM jährlich aufrücken. Auch hier gab es eine Nebenlaufbahn: den Dienst der ,Justizvollstreckungsassistenten" (Besoldungsgruppe A 8 a), die die Geldstrafen, Kostenforderungen usw. zugunsten des Reichs einzogen. ${ }^{25}$

In der Laufbahn des unteren Dienstes standen ca. 2950 Eingangsstellen für Justizwachtmeister etwa 2050 Beförderungsstellen gegenüber: ca. 1830 Stellen für Justizoberwachtmeister und 219 für Justizvollstreckungsassistenten.

In den 1120 Vollzugsanstalten - Zuchthäusern, Gefängnissen, Sicherungsanstalten und einigen Arbeitshäusern - waren die Vorstandsbeamten der 158 großen „Besonderen Anstalten" Beamten des höheren Dienstes. Die restlichen kleineren Anstalten waren entweder den Besonderen Anstalten angegliedert oder gehörten als „Gerichtsgefängnisse" zu einem Gericht und unterstanden damit dessen Vorstand. In die Laufbahn des böberen Strafvollzugsdienstes wurden regelmäßig Gerichtsassessoren - also Beamte, die die Fähigkeit zum Richteramt besaßen - übernommen. Nach einer nicht-

${ }^{23}$ Vgl. AusbildungsO für den einfachen mittleren Justizdienst (AV des RJM v. 8.7.38, DJ 1938, S. 1098).

${ }^{24}$ Vgl. AusbildungsO für die Gerichtsvollzieher (AV des RJM v. 8.7.38, DJ 1938, S. 1089).

25 Vgl. dazu Ausbildungs- und Dienstordnung für die Justizvollstreckungsassistenten (AV des RJM v. 8.7.38,

DJ 1938, S. 1094). 
planmäßigen Dienstzeit von mindestens zwei Jahren und entsprechender praktischer Sonderausbildung wurden sie als Vorstand einer Besonderen Vollzugsanstalt oder als dessen Mitarbeiter mit der Amtsbezeichnung Regierungsrat (Besoldungsgruppe A 2 c 2) planmäßig auf Lebenszeit angestellt. Im Laufe ihrer Dienstzeit konnten sie in Regierungsratsstellen der Besoldungsgruppe A 2 c 1 aufrücken und zum Oberregierungsrat (Besoldungsgruppe A 2 b) oder Regierungsdirektor (Besoldungsgruppe A 1 b) befördert werden. Den 59 Eingangsstellen als Regierungsrat standen 64 Beförderungsstellen gegenüber: 27 Stellen für Regierungsräte der Besoldungsgruppe A 2 c 1, 34 Stellen für Oberregierungsräte und 3 für Regierungsdirektoren.

Die Beamten des gebobenen mittleren Strafvollzugsdienstes unterstützten den Vorstand in den Verwaltungsgeschäften, besorgten das Kassen- und Rechnungswesen, den Arbeitsbetrieb und wirkten auch im eigentlichen Vollzugsdienst mit. Die Voraussetzungen für die Anstellung entsprachen denen im sonstigen gehobenen mittleren Justizdienst. Planmäßig auf Lebenszeit angestellt wurden diese Beamten als Verwaltungsinspektoren (Besoldungsgruppe A 4 c 2), befördert werden konnten sie zum Verwaltungsinspektor der Besoldungsgruppe A 4 c 1, zum Verwaltungsoberinspektor (Besoldungsgruppe A 4 b 2 oder A 4 b 1) und zum Verwaltungsamtmann (Besoldungsgruppe A 3 b). Den 506 Eingangsstellen als Verwaltungsinspektor standen insgesamt 290 Beförderungsstellen gegenüber: davon waren 69 Stellen für Verwaltungsinspektoren der Besoldungsgruppe A 4 c 1, 157 Stellen für Verwaltungsoberinspektoren und 64 Stellen für Verwaltungsamtmänner vorgesehen.

Die Beamten des einfachen mittleren Strafvollzugsdienstes nahmen die büromäßige Bearbeitung der Verwaltungsgeschäfte wahr. Ihre planmäßige Anstellung auf Lebenszeit fanden sie als Verwaltungsassistent (Besoldungsgruppe A 8 a); sie konnten zum Verwaltungssekretär (Besoldungsgruppe A 7 a) befördert werden. Hier standen 226 Eingangsstellen 225 Beförderungsstellen gegenüber.

Im unteren Strafvollzugsdienst gab es einmal die Laufbahn des Aufsichtsdienstes, dem die Verwahrung und Beaufsichtigung der Gefangenen, in den Beförderungsstellen auch die Verwaltung der Kleider- und Wäschekammern, die Überwachung des Küchendienstes usw. in den Vollzugsanstalten oblag. Voraussetzung für die Anstellung war eine genügende Allgemeinbildung, ein halbjähriger Ausbildungsdienst und eine Prüfung. Die Beamten wurden als Oberwachtmeister (Besoldungsgruppe A 9) planmäßig auf Lebenszeit angestellt und konnten zum Hauptwachtmeister (mit $\mathbf{4 0 0}$ RM jährlicher Zulage), zum Ersten Hauptwachtmeister (mit 600 RM jährlicher Zulage), zum Verwalter (Besoldungsgruppe A 7 a) und Oberverwalter (Besoldungsgruppe A 5 b) befördert werden. Im Aufsichtsdienst standen 6739 Eingangsstellen als Oberwachtmeister insgesamt 2000 Beförderungsstellen gegenüber: 1225 Stellen für Hauptwachtmeister, 633 Stellen für Erste Hauptwachtmeister, 64 Stellen für Verwalter und 78 Stellen für Oberverwalter.

Für die Laufbahn des technischen Werkdienstes, die - von einigen Stellen abgesehen $^{26}$ - gleichfalls zum unteren Strafvollzugsdienst gehörte, war eine technische, handwerkliche oder ähnliche Vorbildung erforderlich. Die planmäßige Anstellung dieser Beamten, die die Gefangenenwerkstätten oder die landwirtschaftliche Arbeit der

${ }^{26}$ Einige Stellen des technischen und Werkdienstes, die eine besondere Fachausbildung erforderten und daher in höhere Laufbahnen und Besoldungsgruppen eingereiht waren, können hier außer Betracht bleiben, ebenso die Stellen hauptamtlich angestellter Gefängnisgeistlicher, -ärzte und -lehrer. 
Gefangenen leiteten, erfolgte als Werkführer (Besoldungsgruppe A 9) mit der möglichen Beförderung zum Ersten Werkführer (Besoldungsgruppe A 8 a), Werkmeister (Besoldungsgruppe A 7 b) und Betriebsleiter (Besoldungsgruppe A 5 b).

Die Zahl der Stellen für Richter und Staatsanwälte nahm in den folgenden Jahren nach 1938 allein durch die Erweiterung des Reichsgebiets laufend zu. Die voranstehend für 1938 genannten 10226 Richter- und 1453 Staatsanwaltstellen im Altreich, denen 1276 Richter und 114 Staatsanwälte der neu hinzugekommenen Oberlandesgerichtsbezirke Graz, Innsbruck und Wien zugerechnet werden müssen ${ }^{27}$, waren 1939 - als es im Großdeutschen Reich 34 Oberlandesgerichtsbezirke gab ${ }^{28}$ - auf 13008 bzw. $2051^{29}$, im Jahre 1940 schließlich auf 14031 bzw. $2213^{30}$ Stellen angestiegen.

Die Personalentwicklung im höheren Justizdienst sei hier in aller Kürze über den Zeitraum der Amtszeit Gürtners hinaus skizziert: Im Jahre 1942 betrugen die Planstellen für Richter 14048, für Staatsanwälte 2249. ${ }^{31}$ Durch die Einberufungen zur Wehrmacht entsprach die Zahl der tatsächlich beschäftigten Kräfte im Kriege jedoch keineswegs mehr der Zahl der Planstellen, obwohl geeignete Ruhestandsbeamte wieder eingestellt und auch Rechtsanwälte mit der Wahrnehmung der Geschäfte beauftragt wurden, um dem Personalmangel entgegenzuwirken. Dabei wurden die über 65 jährigen Justizbeamten, die weiter Dienst taten, zwar in den Ruhestand versetzt, um dem meist im Felde stehenden Nachwuchs das Nachrücken in die Beförderungsstellen nicht zu versperren, aber als Beamte auf Widerruf in ihrer bisherigen Tätigkeit belassen. ${ }^{32}$ Bereits im Mai 1940 betrug der durchschnittliche Beschäftigungsstand im richterlichen Dienst nur noch $65,9 \%$ der Planstellenzahl. Besonders unterbesetzte Oberlandesgerichtsbezirke waren Braunschweig mit 54,1\% und Königsberg mit $54,9 \% .^{33}$ Im Juli 1941 waren z. B. beim Amtsgericht Berlin, das über 281 richterliche Planstellen verfügte, nur noch 132 Richter tätig, von denen 46 (ca. 35\%) über 65 Jahre alt waren. Auch beim Berliner Landgericht waren trotz der erfolgten Abordnung von 15 Senatspräsidenten und Kammergerichtsräten sowie der Einberufung von etwa 20 Ruhestandsbeamten an dieses Gericht noch nicht die Hälfte der richterlichen Planstellen besetzt; rund $30 \%$ der Richter waren über 60 Jahre alt. ${ }^{34}$ Im Oberlandesgerichtsbezirk Darmstadt waren von den bei Kriegsbeginn beschäftigten 276 Richtern (Planstelleninhaber und nicht planmäßig angestellte Hilfsrichter) Ende September 1943 noch 135 Richter tätig, davon als Hilfsrichter 14 pensionierte Beamte sowie

${ }^{27}$ Vgl. Kalender für Reichsjustizbeamte 1939, 2.Teil, Berlin 1938, S. 23.

28 Im Altreich bestanden ursprünglich 26 OLGBezirke. Außer den genannten 3 (1938) kamen 1939 noch hinzu: Leitmeritz, Prag, Danzig, Posen, Linz (wurde eigener OLGBez.). Im Jahre 1941 wurde der OLGBez. Kattowitz errichtet. Als Ende 1942 der OLGBez. Marienwerder aufgehoben wurde, reduzierte sich die Zahl wieder auf 34 .

29 Kalender für Reichsjustizbeamte 1940, 2. Teil, Berlin 1939, S. 22 f. Bei den staatsanwaltschaftlichen Planstellen sind die bei den Amtsanwaltschaften tätigen 29 StAe mitgerechnet. Da der Stand v. 1.10.39 zugrunde liegt, wurde das OLG Posen noch nicht berücksichtigt.

30 Kalender für Reichsjustizbeamte 1941, 2. Teil, Berlin 1940, S.24f. Auch hier einschließlich der 30 bei den Amtsanwaltschaften tätigen StAe.

31 Stand v. 1.1.42, vgl. Handbuch der Justizverwaltung. Bearbeitet im Büro des Reichsjustizministeriums, Berlin 1942, S. 20 f. Die staatsanwaltschaftlichen Planstellen auch hier einschließlich der 31 bei den Amtsanwaltschaften beschäftigten StAe.

32 Vgl. RV des RJM an die höheren Justizbehörden v. 28.5.40 (a.a.O., Sign. R 22/1500).

33 Vgl. Referentenverm. für den Leiter der Personalabteilung (Abt. I) im RJM, MinDir. Nadler, v. 31.5.40 (Akten des RJM, BA, Sign. R 22/2740).

34 Vgl. Lageber. des KGPräs. an das RJM v. 2.7 .41 (a.a.O., Sign. R 22/3356). 
4 Rechtsanwälte und Notare; 54 der Richter waren über 60 - zum Teil über 70 (!) Jahre - alt. ${ }^{35}$ Bis 1944 sank der Durchschnitt der besetzten richterlichen Planstellen im Reich auf $42,25 \%$, im staatsanwaltschaftlichen Dienst auf $62,5 \% .{ }^{36}$ Die Abhilfemaßnahmen, die die Justizleitung auf dem Gebiet des Gerichtsverfassungsrechts traf - etwa um Referendare schon nach abgekürzter Vorbereitungszeit selbständig die Geschäfte eines Richters oder Staatsanwalts wahrnehmen zu lassen, um die Besetzung der Gerichte zu verkleinern, die Strafgewalt des Amtsrichters zu erhöhen usw. -, werden in anderem Zusammenhang behandelt. ${ }^{37}$

b. Ausbildung und Auslese für den böheren Justizdienst: die Ausbildungsordnung von 1934, das „Gemeinschaftslager Hanns Kerrl", der Abbau des Assessorenstaus und Nachwuchsprobleme

Beim Aufbau einer „nationalsozialistischen Rechtspflege“ kam der Heranziehung eines geeigneten Nachwuchses zentrale Bedeutung zu. Deshalb wurde die Ausbildung der Volljuristen - der künftigen Richter, Staatsanwälte, Notare und Rechtsanwälte durch die Justizausbildungsordnung v. 22. Juli 1934 (RGBl. I, S. 727) nach „nationalsozialistischen Grundsätzen“ ausgerichtet und für das ganze Reich einheitlich geregelt. Für die juristische Ausbildung hatten bis dahin nur einige grundsätzliche reichsgesetzliche Vorschriften bestanden, ihre Ausgestaltung war Ländersache gewesen und hatte auch durch die Vereinbarung zwischen Reich und Ländern über die juristische Vorbildung vom September $1930^{1}$ keine Vereinheitlichung erfahren. Diese Länderzuständigkeit hatte es auch Hanns Kerrl als preußischem Justizminister ermöglicht, schon zeitig einzelne Ausbildungsbestimmungen im nationalsozialistischen Sinne zu ändern². So gestattete er z. B. im April 1933 Rechtskandidaten und Referendaren, „die als Mitglieder eines der anerkannten nationalen Verbände im vaterländischen Dienste“ eine gewisse Zeit tätig gewesen waren, „zum Ausgleich einer dadurch verursachten Behinderung des Ausbildungsganges" die juristischen Prüfungen in abgekürzter Form abzulegen ${ }^{3}$. Die bayerische Justiz folgte mit einer entsprechenden Verordnung im Juni 1933 und bestätigte diese Vergünstigung nochmals für die Staatsprüfung des Jahres $1934^{4}$.

35 Vgl. Lageber. des OLGPräs. Darmstadt an das RJM v. 1.12.43 (a.a.O., Sign. R 22/3361).

$36 \mathrm{Vgl}$. Zusammenstellung der Übersichten über den Kräftebedarf und Kräfteeinsatz im höheren Dienst bei den Gerichten und Staatsanwaltschaften nach dem Stande vom 3. Oktober 1944 (Akten des RJM, BA, Sign. R 22 Gr. 5/II - 4). Bei den Gerichten fehlen die Angaben der OLGBez. Posen, Köln und Zweibrücken, bei den Staatsanwaltschaften die Angaben der OLGBez. Köln und Posen.

37 Vgl. dazu Kapitel VIII.1.b., S.979f.

1 Vgl. Bekanntm. über die juristische Vorbildung v. 20.9.30 (RMBl. 1930, S. 547). Braunschweig hatte sich der Vereinbarung nicht angeschlossen.

2 Auf einige der von Kerrl eingeführten Neuerungen, die in die JustizausbildungsO des Reichs übernommen wurden, wird im folgenden hingewiesen.

3 Einzelheiten dazu vgl. AV des preuß. JM v. 5.4 .33 (JMBl., S. 112).

$4 \mathrm{Vgl}$. VO über die juristischen Prüfungen der an der Nationalen Erhebung beteiligten Referendare und Studierenden (bayer. GVOBl. 1933, S. 168) und Bekanntm. der bayer. StM der Justiz und des Innern v. 18.4.34 (DJ 1934, S. 567). 
Durch die Justizausbildungsordnung vom Juli 1934 wurde nunmehr die Erziehung des juristischen Nachwuchses vereinheitlicht. Wie Freisler dazu feststellte, konnte der Nationalsozialismus dabei ,auch der inneren Einstellung seiner Juristen nicht neutral gegenüberstehen "5. Laut Vorspruch sollte daher die Ausbildung nicht nur fachliches Wissen vermitteln, sondern „den ganzen Menschen ergreifen, Körper und Geist zu gutem Zweiklang bringen, den Charakter festigen und den Willen stärken, [sowie] die Volksgemeinschaft im jungen Menschen zu unverlierbarem Erlebnis gestalten ...“. Deshalb mußte der Bewerber vor der ersten juristischen Staatsprüfung den damals noch freiwilligen Arbeitsdienst geleistet haben, um den Nachweis zu führen, daß er „mit Volksgenossen aller Stände und Berufe in enger Gemeinschaft gelebt, die körperliche Arbeit kennen und achten gelernt, Selbstzucht und Einordnung geübt und sich körperlich gestählt“ hatte. Er sollte „durch Bescheinigung geeigneter Stellen dartun“, daß er „seine körperliche Ausbildung und die Verbundenheit mit anderen Volksgruppen" auch nach dem Arbeitsdienst gepflegt hatte ( $(2)$ : Obwohl es die Ausbildungsordnung nicht in Worten ausdrückte, war damit gemeint, daß sich der Bewerber in einer der Gliederungen der Partei betätigen sollte. Für das Universitätsstudium war nicht nur wie bisher eine Mindestzahl von sechs Semestern, sondern auch eine Höchstzahl von zehn Semestern vorgeschrieben $(\S 3)$, um den „ewigen“ Rechtskandidaten abzuschaffen ${ }^{6}$. Wenn „eine gründliche, gewissenhafte Fachausbildung“ auch im Mittelpunkt des Studiums stand - die für die Prüfung erforderlichen Rechtsgebiete waren vorgeschrieben, und der urkundliche Nachweis über Vorlesungen, Übungen usw. mußte erbracht werden -, so sollte sich der Bewerber als Student doch auch „einen Überblick über das gesamte Geistesleben der Nation verschaffen“. Dazu gehörte „die ernsthafte Beschäftigung mit dem Nationalsozialismus und seinen weltanschaulichen Grundlagen, mit dem Gedanken der Verbindung von Blut und Boden, von Rasse und Volkstum, mit dem deutschen Gemeinschaftsleben und mit den großen Männern des deutschen Volkes“ (§ $($ ). Bei der Meldung zur ersten juristischen Staatsprüfung, die vor einem der - den Oberlandesgerichten angegliederten - Justizprüfungsämter stattfand und deren Gang im einzelnen vorgeschrieben war, mußte der Bewerber neben den üblichen Papieren eine Erklärung über die „arische“ Abstammung für sich und gegebenenfalls für seine Ehefrau abgeben $(\S 10)$. Da diese Prüfung keine akademische Abschlußprüfung, sondern die Eingangsprüfung für den Staatsdienst (Vorbereitungsdienst) darstellte, wurde damit verhindert, daß ein Jude oder ,jüdisch Versippter“ Gerichtsreferendar werden konnte ${ }^{7}$. Ab 1936 mußte der Bewerber ferner erklären, daß er nicht bei einem jüdischen Repetitor gehört hatte ${ }^{8}$. Hatte der Prüfling bestanden und

5 Vgl. Geleitwort zu O. Palandt / H. Richter, Die Justizausbildungsordnung des Reiches, Berlin 1939, S. VI. Zum folgenden auch MinRat M. Jonas, Die Justizausbildungsordnung vom 22. Juli 1934 (DJ 1934, S. 995 ff.).

6 In der späteren Fassung der JustizausbildungsO v. 4.1.39 wurde präzisiert, daß der Bewerber bei Úberschreitung der Semesterzahl nur dann zur Prüfung zugelassen wurde, wenn er „durch besonders zeitraubende Beschäftigung für Volk und Staat“, Krankheit 0. ä. am ordnungsgemäßen Studium verhindert gewesen war.

7 Die Ausnahmen des Berufsbeamtengesetzes v. April 1933 für Kriegsteilnehmer oder Söhne von Gefallenen galten hier nicht, sie waren schon in die Änderung des Reichsbeamtengesetzes durch das G. v. 30.6 .33 (s. Kapitel III.1.c.) nicht aufgenommen worden.

${ }^{8} \mathrm{Vgl}$. RV des RJM an die Vors. der Justizprüfungsämter bei den OLGen v. 23.4.36 (Akten des RJM, Hauptbüro, Arch. des BJM); ihr lag ein entsprechendes Verbot des RuPrM für Wissenschaft, Erziehung und Volksbildung v. 13.1.36 zugrunde. 
wurde sein Antrag auf Übernahme in den dreijährigen? Vorbereitungsdienst vom Reichsjustizministerium positiv entschieden, so wurde er als „Gerichtsreferendar" Beamter auf Widerruf und machte verschiedene Ausbildungsstationen bei Gerichten, der Staatsanwaltschaft, beim Rechtsanwalt und in der Verwaltung durch und lernte dabei in zunehmendem Maße, Aufgaben selbständig zu erledigen. Seine Ausbildung wurde von dem Oberlandesgerichtspräsidenten geleitet, in dessen Bezirk er den Vorbereitungsdienst ableistete. Dieser Dienst war unentgeltlich zu versehen; bedürftigen und tüchtigen Referendaren konnte jedoch aus Mitteln der Justizverwaltung ein jederzeit widerruflicher Unterhaltszuschuß gewährt werden ${ }^{10}$. Neben der praktischen Ausbildung in den einzelnen Stationen hatte der Referendar fast zwei Jahre in einer „Arbeitsgemeinschaft" mitzuwirken, die jeweils etwa 20 Referendare umfaßte und von einem Richter oder Staatsanwalt geleitet wurde, der als „überzeugter Nationalsozialist und tüchtiger Jurist" vom Oberlandesgerichtspräsidenten und Generalstaatsanwalt ausgesucht und ab 1935 vom Reichsjustizministerium bestellt wurde ${ }^{11}$. In diesen Arbeitsgemeinschaften, die Kerrl für Preußen schon im Frühjahr 1934 eingeführt hatte ${ }^{12}$, sollten nicht nur Studienfahrten und -besichtigungen unternommen, praktische juristische Fälle besprochen und neue Rechtsentwicklungen behandelt werden, sondern der Referendar zur nationalsozialistischen Staatsauffassung, zu „williger Einordnung und lebendiger Kameradschaft" erzogen werden (§ 34). Zur Ausbildung der Referendare gehörte auch die Teilnahme an einer Lagergemeinschaft $(\S 42)$, so etwa im Arbeitsdienstlager Lütjensee, wo die Hamburger Referendare zusammen mit $\mathrm{Ar}$ beitsdienstwilligen seit September 1933 Pflichtdienst taten ${ }^{13}$, sowie im „Hans-FrankLager" in Rastatt, das der BNSDJ im Oktober für die badischen, hessischen und rheinpfälzischen Referendare gegründet hatte ${ }^{14}$, oder im Referendarlager „Hanns Kerrl“, das der preußische Justizminister im Juni 1933 für die zur großen Staatsprüfung zugelassenen Referendare in Jüterbog eingerichtet hatte und das nach der Verreichlichung der Justizverwaltung das zentrale Gemeinschaftslager wurde ${ }^{15}$. Jeder Ausbilder, dem ein Referendar während des Vorbereitungsdienstes überwiesen wurde, hatte sich in einem Zeugnis über dessen Fähigkeiten und Charakter zu äußern (§ 36); dazu gehörte auch der Kommandant des Gemeinschaftslagers. Am Ende des Vorbereitungsdienstes leitete der Oberlandesgerichtspräsident, wenn er die Voraussetzungen für erfüllt erachtete, die Zeugnisse und Unterlagen dem Reichs-Justizprüfungsamt zu, dessen Präsident über die Zulassung zur großen Staatsprüfung entschied (§ 41). Dabei hatte der Oberlandesgerichtspräsident bei Referendaren, die schon vor der Machtüber-

9 Nach Kriegsausbruch wurde die Vorbereitungszeit zunächst auf $2 \frac{1}{2}$ Jahre, 1943 auf $1 \frac{1}{2}$ Jahre gekürzt, auch die erforderliche Semesterzahl herabgesetzt und beide juristische Staatsprüfungen vereinfacht, vgl. VO über die Vereinfachung der juristischen Staatsprüfungen v. 2.9.39 (RGBl. I, S. 1606), VO über die Anrechnung von Wehrdienst bei der Zulassung zu den juristischen Staatsprüfungen v. 27.11.42 (RGBl. I, S. 1530) nebst AV des RJM v. 13.5.41 (DJ 1941, S. 577) und AV des RJM v. 17.2.43 (DJ 1943, S. 125).

10 Die einheitliche Regelung für das Reich erfolgte durch die AV des RJM v. 16.5.35 (DJ 1935, S.767) und 16.6.37 (DJ 1937, S.924).

${ }^{11}$ Vgl. RV des RJM v. 22.12.34 und v. 9.1.35 (Palandt/Richter, a.a.O., S. 149 ff.).

12 Vgl. AV des preuß. JM v. 16.5.34 (DJ 1934, S.631). Darüber hinaus „erwartete“ Kerrl von den Referendaren (und Gerichtsassessoren), „daß sie sich freudig in den Dienst der Bewegung stellen“, d.h. Dienst in der PO der Partei oder in der SA taten (AV des PrJM v. 11.5.34, DJ 1934, S.632).

13 Vgl. Hamb. JVerwBl. 1933, S.38.

14 Vgl. Der deutsche Rechtspfleger, Zeitschr. der Reichsfachgruppe Rechtspfleger im BNSDJ, 1934, S. 246.

15 Über dieses Lager und seine Entwicklung s. im folgenden S. $303 \mathrm{ff}$. 
nahme der NSDAP angehört hatten, auch Angaben darüber zu machen, ob sich der Betreffende „besondere Verdienste um die Bewegung erworben“ hatte, und nötigenfalls darüber Auskünfte bei der zuständigen Gauleitung einzuholen ${ }^{16}$. Bei der Prüfung, deren Ablauf in der Ausbildungsordnung im einzelnen geregelt war, mußte der Referendar auch eine Aufsichtsarbeit schreiben, in der er „sein Verständnis für die deutsche Geschichte und Fragen der Gegenwart" beweisen mußte ${ }^{17}$. Ebenso hatte ein Prüfer, der nicht Jurist zu sein brauchte, in der mündlichen Prüfung die Aufgabe, den Referendar auf dem Gebiet der Staats- und Volkskunde, d.h. Geschichte, Politik, Tagesfragen usw. zu prüfen ${ }^{18}$; er wurde daher von den Referendaren treffend der "völkische Beobachter" genannt. Mit der Ablegung der großen Staatsprüfung erwarb der Referendar die Befähigung zum Richteramt und schied mit dem Titel „Assessor" aus dem Beamtenverhältnis aus. Mit der Befähigung zum Richteramt konnte er - wenn er nicht in die freie Wirtschaft oder in eine andere öffentliche Verwaltung gehen wollte - seine Aufnahme entweder in den staatlichen Probe- und Anwärterdienst für das Amt des Richters, Staatsanwalts oder höheren Vollzugsbeamten oder in den anwaltlichen Probe- und Anwärterdienst beantragen, wenn er später als Rechtsanwalt zugelassen werden wollte.

Die Justizausbildungsordnung wurde im Januar 1939 neu gefaßt ${ }^{19}$ und einigen Änderungen unterworfen. Eine der Voraussetzungen für die Zulassung zur ersten juristischen Staatsprüfung war nunmehr die Ableistung der unterdessen eingeführten Arbeitsdienst- und Wehrpflicht bzw. der Nachweis über eine Zurückstellung oder Befreiung von diesem Dienst. Da sich die Ausbildung der Gerichtsreferendare als zu kurz erwiesen hatte - eine Verlängerung aber aus bevölkerungspolitischen Überlegungen abgelehnt wurde, um der akademischen Jugend möglichst früh die Eheschließung zu ermöglichen -, wurde auf eine Unterweisung in der Verwaltung verzichtet und die gewonnene Zeit für andere Ausbildungsabschnitte des dreijährigen Vorbereitungsdienstes, vor allem für die Beschäftigung mit Strafsachen verwendet. Der Verzicht war möglich geworden, da die innere Verwaltung seit 1937 ihre Regierungsreferendare selbst ausbildete. War jedoch ein Referendar von vornherein entschlossen, später nicht bei der Justiz zu bleiben, sondern in die Wirtschafts-, Heeres-, Gemeinde-, Staats- oder Parteiverwaltung zu gehen, so gab ihm die neue Ausbildungsordnung die Möglichkeit, sich im Rahmen des Vorbereitungsdienstes ein halbes Jahr in dem entsprechenden Verwaltungszweig ausbilden zu lassen; er mußte dann in der Regel auf die Ausbildung am Oberlandesgericht verzichten. So konnten sich Referendare z. B. auch bei der Geheimen Staatspolizei ausbilden lassen, wenn ihre spätere Übernahme nach dort beabsichtigt $\operatorname{war}^{20}$. Als eine weitere Neuerung waren die Befugnisse des Oberlandesgerichtspräsidenten verstärkt worden, den Ausbildungsgang des Referendars im Vorbereitungsdienst den Bedürfnissen des Einzelfalles anzupassen: er konnte einen Ausbildungsabschnitt zugunsten eines anderen kürzen oder ihn auch verlängern, je nachdem

${ }^{16}$ RV des RJM v. 11.7.35 (Palandt/Richter, a.a.O., S. 195).

17 Die geschichtliche Aufsichtsarbeit hatte Kerrl in Preußen schon durch die AV des PrJM v. 27.6.34 (DJ 1934, S. 818) eingeführt.

18 Dieser zusätzliche Prüfer war schon von Kerrl durch die AV des preuß. JM v. 7.7.33 (DJ 1933, S. 217) eingeführt worden.

19 Vgl. Art. IV der VO über die Beförderung zum Richteramt, zur Staatsanwaltschaft, zum Notariat und zur Rechtsanwaltschaft v. 4.1.39 (RGBl. I, S.5). Die neue JAO trat am 1.4.39 in Kraft.

$20 \mathrm{Vgl}$. RV des RJM v. 11.12.35 (Palandt/Richter, a.a.O., S. 180). 
der Referendar das jeweilige Ausbildungsziel früher oder noch nicht erreicht hatte. Er durfte auch die an sich vorgeschriebene Reihenfolge der Ausbildungsabschnitte ändern, falls der Referendar nur dadurch eine besondere Ausbildungsgelegenheit wahrnehmen konnte. Diese beweglichere Gestaltung des Vorbereitungsdienstes war vor allem für die Anwärter in Österreich und im Sudetenland von Bedeutung, für die die neue Ausbildungsordnung nunmehr ebenfalls galt und denen die Umstellung ihrer laufenden Ausbildung Übergangsschwierigkeiten bereitete. Neu war ferner, daß die Referendare ihre zweimonatige Lagerzeit zentral im Gemeinschaftslager Hanns Kerrl abzuleisten hatten, das „die Referendare aus allen deutschen Gauen in enger Kameradschaft" zusammenfaßte.

Dieses Lager, das geradezu zum Symbol der Juristenausbildung im Dritten Reich wurde, wurde von Kerrl im Juni 1933 in einem bis dahin von der Reichswehr benutzten Lager („Neues Lager“) bei Jüterbog in der märkischen Heide für die zur großen Staatsprüfung zugelassenen Referendare eingerichtet. Der sechswöchige Lagerdienst, der jedem amtsärtzlich für tauglich befundenen Referendar zur Pflicht gemacht wurde, sollte dazu dienen, den Charakter des Teilnehmers ,im Zusammenleben mit anderen" zu prüfen, und ihn in der Zeit zwischen der Abgabe der schriftlichen Arbeit und der mündlichen Prüfung davon abhalten, „unnützen Gedächtniskram in sich hineinzuwürgen“ ${ }^{\text {"21 }}$ : die Lagerinsassen sollten sich „sportlich und in sonst geeigneter Weise betätigen“, jedoch keinerlei Beschäftigung mit „der unmittelbaren sogenannten Examensvorbereitung in ihren Arbeitsplan aufnehmen“. SA-Sturmbannführer Oberstaatsanwalt Spieler, den Kerrl zum „Führer des Gemeinschaftslebens“, d.h. zum Lagerkommandanten, ernannt hatte, wurde beauftragt, am Ende des Lagerlebens über die Charaktereigenschaften jedes Teilnehmers ein Zeugnis abzugeben, das zu den Prüfungs- und Personalakten genommen wurde ${ }^{22}$. Das Stammpersonal des Lagers unterstand dem Chef des Ausbildungswesens der SA (Chef AW), offenbar bis zur Auflösung dieser Dienststelle im Februar 1935.

Zogen schon am 10. Juli 1933 erstmals 43 Referendare in das Lager, um dort von Staatssekretär Freisler persönlich begrüßt zu werden, so wurde es bis zum Herbst für eine Kapazität von 500 Mann ausgebaut; nunmehr wurden auch die Klausurarbeiten der großen Staatsprüfung im Lager geschrieben. Das Stammpersonal des Lagers bestand aus SA- und SS-Führern, die die Aufgaben von Zug- und Gruppenführern wahrnahmen, sowie aus einigen Assessoren als Abteilungsführern, die das Lager als Referendare selbst durchlaufen hatten und aktive Frontkämpfer gewesen waren. Das Lager war zunächst militärähnlich organisiert und auf körperliche Ertüchtigung ausgerichtet, selbst die weltanschauliche Schulung war in dieser Phase noch beschränkt ${ }^{23}$.

Die Meinung über die Zweckdienlichkeit dieser Art von „Ausbildung“ war bei den Juristen von Anfang an geteilt. Zwar hob der damalige Vizepräsident des Preußischen Landesprüfungsamts - der spätere Präsident des Reichs-Justizprüfungsamtes Otto $\mathrm{Pa}$ landt - nach dreimonatiger Erfahrung lobend hervor, daß der Lagerdienst die Prüfungsergebnisse "günstig beeinflußt“ habe, obwohl die Prüfungsanforderungen keines-

21 So Kerrl in einem Presseinterview (abgedruckt in DJ 1934, S. 237 ff., 239).

22 Vgl. Verf. des preuß. JM v. 29.6.33 (PrJMBl. 1933, S. 210). Die Benennung „Hanns Kerrl“ erhielt das Gemeinschaftslager erst durch die AV des PrJM v. 11.12.33 (DJ 1933, S.806).

23 Vgl. den Ber. des Lagerleiters OStA und SA-Obersturmbannf. Spieler, Preußischer Geist im Gemeinschaftslager in Jüterbog (DJ 1933, S.641 ff.). 
wegs herabgesetzt worden seien. Schon das äußere Bild der Prüflinge habe sich zum Vorteil gewandelt: so beträten „heute die Referendare wettergebräunt, hellen Auges, in aufrechter Haltung, zuversichtlich und voller Vertrauen“ den Prüfungssaal, der vordem „manchen hohläugigen, blaßwangigen Prüfling gesehen hat, dessen nachlässige Haltung und hilfloser Blick“ bei den Prüfern höchstens Mitleid ausgelöst habe ${ }^{24}$. Dennoch wurden einige organisatorische Änderungen getroffen, als das Lager 1935 eine zentrale Reichseinrichtung wurde. Durch eine Verordnung vom März 1935 wurde der Lageraufenthalt vom Prüfungsverfahren getrennt und als eigener Ausbildungsabschnitt in den Vorbereitungsdienst der Referendare gelegt. Ferner sollte den Teilnehmern ,in Zukunft mehr als bisher ... geistige Anregung und Schulung in Vorträgen, Schulungskursen und freier Gruppenarbeit" geboten werden ${ }^{25}$. Zu diesem Zweck wurden mehr Schulungskräfte einberufen, ab Sommer 1935 jeweils einige - meist schon als Leiter von Arbeitsgemeinschaften tätige - Richter und Staatsanwälte vorübergehend abgeordnet und auswärtige Redner aus Staat, Partei und Wirtschaft herangezogen $^{26}$. Schon im Januar 1935 war der von Kerrl zum Lagerkommandanten ernannte Spieler wegen mehrmaligen Randalierens in Trunkenheit - er wurde deshalb aus der Partei geworfen und später in einem Disziplinarverfahren der Justizverwaltung verurteilt $^{27}$ - durch Arbeitsführer Hildebrandt ersetzt worden. Für die Einberufung zum nunmehr achtwöchigen Dienst im Lager reichten die Oberlandesgerichtspräsidenten zum 1. und 15. jeden Monats Vorschlagslisten an den Lagerkommandanten ein, der dann die Antrittstermine bestimmte und die Einberufungen erlie $\mathfrak{B}^{28}$. Jeweils alle zwei Wochen wurde eine Abteilung in Stärke von drei Zügen zu 55 Referendaren einberufen.

Trotz der organisatorischen Änderungen wurde das Jüterboger Referendarlager aus den unterschiedlichsten Motiven kritisiert und seine Abschaffung gefordert. So bezeichnete die Gauleitung der NSDAP in Sachsen das Lager gegenüber der Führung des Arbeitsdienstes als „vollkommen überflüssig“, weil es „im Gegensatz zum Arbeitsdienst eine Angelegenheit der jüngeren Generation aus den ,besseren Ständen“" sei und damit nicht dem Aufbau der Volksgemeinschaft diene ${ }^{29}$. Im August 1935 kritisierte der Vizepräsident des Oberlandesgerichts Stuttgart den Lagerbetrieb äußerst scharf mit dem deutlichen Ziel, die bevorstehende Abkommandierung auch der württembergischen Referendare nach Jüterbog zu verhindern: Die Referendare würden im

24 O. Palandt, Drei Monate Prüflinge aus dem Gemeinschaftslager der preußischen Referendare (a.a.O., S. 640 ff.). Präs. des LandesJPA war damals noch Schwister, der im Dezember 1933 als OLGPräs. nach Düsseldorf versetzt wurde.

25 Vgl. VO über den weiteren Ausbau des Gemeinschaftslagers Hanns Kerrl v. 9.3.35 (RGBI. I, S. 359), dazu die AV des RJM v. 9.3.35 mit den Durchf.- und Úbergangsbestimmungen (DJ 1935, S. 388).

${ }^{26} \mathrm{Vgl}$. AGRat Friedrich, Das Gemeinschaftslager Hanns Kerrl (DJ 1936, S.759ff.). Die vom 1.6.35 bis 30.4.36 im Lager gehaltenen Reden nebst den Vortragenden sind aufgeführt a.a.O., S.783.

${ }^{27} \mathrm{Vgl}$. Einstweilige Verf. des St.d.F. (gez. Heß) v. 5.2.35 (Akten der Pers. Adjutantur des Führers, BA, Sign. NS 10/184) sowie Ber. des GStA beim $K G$ an das RJM v. 3.10.35 (Diensttageb. des RJM, Eintr. v. 7. 10.35, Bd. 5, BA, Sign. R 22/1088).

${ }^{28} \mathrm{Vgl}$. AV des RJM v. 13.4.35 (DJ 1935, S.612).

${ }^{29} \mathrm{Vgl}$. Schr. der Gauleitung der NSDAP Sachsen an den RKommissar für den freiwilligen Arbeitsdienst v. 23.5.35, dem RJM am 7.6.35 übermittelt (Diensttageb. des RJM, Eintr. v. 15.6.35, Bd.3, BA, Sign. R 22/1056). Das gleiche Motiv hatte Rothenberger 1933 bewogen, die Hamburger Referendare nicht nach Jüterbog, sondern in das Arbeitsdienstlager Lütjensee zu schicken, in dem sie zusammen mit Arbeitsdienstfreiwilligen Dienst taten (s. W. Johe, Die gleichgeschaltete Justiz, Frankfurt a.M. 1967, S.219). Diese Regelung endete 1935 mit der Verreichlichung der JVerw. 
Lager überwiegend auf militärische Art körperlich gedrillt, statt in den für das Volk bedeutungsvollen Fragen geschult zu werden. Damit stehe die tatsächliche Handhabung des Lagerbetriebes „in krassem Gegensatz“ zur Verordnung des Reichsjustizministeriums vom März. Die Tätigkeit der hauptamtlichen, der SA oder früher der Reichswehr angehörenden Ausbilder sei reiner Selbstzweck, und die „Heranziehung möglichst vieler Referendare auf möglichst lange Zeit solle (lediglich) die Existenzberechtigung des Lagers" und ihrer Führer erweisen. Den Referendaren wiederum könne bei der bekannten wirtschaftlichen Misere der Jungjuristen „nicht zugemutet werden, für die Schuldentilgung des unter ungeheuren Kosten errichteten Lagers" mit einem obligatorischen Kostenbeitrag aufzukommen ${ }^{30}$. Das Justizministerium in Berlin sei auch über die wahre Stimmung des betroffenen Nachwuchses nicht im Bilde: "Während nach preußischen Verlautbarungen die Referendare das Lager enthusiastisch begrüßt" hätten, berichtete der Vertreter der württembergischen Jungjuristen, „daß gerade von den preußischen Referendaren das Lager einmütig abgelehnt werde“. Diese Stimmung sei „wohl deswegen nicht zum Ausdruck gekommen, weil Protestierende befürchteten, gemaßregelt oder sonst in ihrem Fortkommen geschädigt zu werden“. Schwerste Kritik aber verdiene das Zustandekommen des Lagerzeugnisses: der „Lagerkommandant steht auf dem Standpunkt, daß er in der Lage sei, durch einen 25km-Gepäckmarsch den Charakter des einzelnen festzustellen“. Auch das Unterpersonal berichte ihm nach rein militärischen Gesichtspunkten und sei sicher „nicht in der Lage, sich in die Stammesart der süddeutschen Referendare einzufühlen“. Deshalb lehnten auch der Gauführer des BNSDJ und der Gauleiter in Württemberg das Jüterboger Lager aufs schärfste ab und befürworteten die Schulung der württembergischen Referendare mit geringeren Kosten in kleineren Lagern und Kursen im Lande selbst, wie sie vom Gaurechtsamt mit Erfolg in Monbachtal durchgeführt würden. Das Schreiben endete mit der Bitte, aus allen diesen Gründen von der Einberufung der Referendare des Stuttgarter Oberlandesgerichtsbezirks nach Jüterbog abzusehen, das dortige "Lager aufzulösen und seine Überführung für Zwecke der Wehrmacht ins Auge zu fassen “31. Diese Bitte sollte allerdings nicht erfüllt werden, vielmehr wurden am dritten Jahrestag der Machtergreifung 1936 auch die süddeutschen Referendare zum Dienst im Gemeinschaftslager Hanns Kerrl verpflichtet ${ }^{32}$.

Mochte die Kritik aus Stuttgart auch vom süddeutschen Ressentiment gegen PreuBen gefärbt gewesen sein, so sollte das Reichsjustizministerium bald auch aus anderen Quellen erfahren, daß sie nicht aus der Luft gegriffen war. Die im Lager praktizierten Methoden waren offensichtlich nicht dazu angetan, die Referendare für das Regime einzunehmen: so berichtete - gleichfalls im August 1935 - der Präsident des Landgerichts Landsberg (Warthe) über seine Eindrücke aus dem Lager, daß die Referendare in ihrer politischen Einstellung „überwiegend dem neuen Staat ablehnend gegenüberständen “33. Das lag nicht zuletzt am Verhalten des unteren Ausbildungspersonals, das

30 Die Referendare mußten einen Lagerkostenbeitrag von täglich 2 RM entrichten, der vor Antritt des Lagerdienstes als Vorschuß in Höhe von $100 \mathrm{RM}$ zu zahlen war (vgl. AV des RJM v. 15.4.35, DJ 1935, S.612).

31 Schr. des OLGPräs. Stuttgart (gez. Trukenmüller) an das RJM v. 3.8.35 (Diensttageb. des RJM, Eintr. v. 8.8.35, Bd.4, BA, Sign. R 22/1059).

32 Vgl. AV des RJM v. 30.1.36 (DJ 1936, S. 167).

33 Vgl. Schr. des LGPrās. Landsberg, dem RJM am 23.8.35 vom Lagerkommandanten mit der Bemerkung übersandt, „daß ihm diese Eindrücke nicht neu seien“ (a.a.O., Eintr. v. 26.8.35). 
zu den Referendaren häufig nicht die richtige Einstellung fand - über dessen Zusammensetzung das Justizministerium aber nicht verfügen konnte. Unter dem Personal befanden sich typische Landsknechtsnaturen, teilweise recht zweifelhafter Art: als im September 1935 eine Abteilung des Referendarlagers in Jessen $(25 \mathrm{~km}$ südlich von Jüterbog) vorübergehend ein Zeltlager bezog, begingen die begleitenden Ausbilder nach reichlichem Alkoholgenuß gegen die Einwohner des Ortes schwere Ausschreitungen. Dabei tat sich besonders ein im Referendarlager als Säufer und Schläger bekannter Obertruppführer - genannt „Knüppelkunze“ - hervor, den der Lagerkommandant aber trotz Vorstellungen des Ministeriums hielt. $\mathrm{Zu}$ solchen Gewaltsamkeiten kam es gelegentlich auch im Ort Jüterbog und zwischen den Ausbildern im Lager selbst ${ }^{34}$, so daß die Referendare einer Abteilung im Februar 1935 eine Eingabe an das Reichsjustizministerium richteten, in der sie ironisch bemerkten, diese Ausbilder machten nichtsdestoweniger „weiter zum Segen der Referendare Dienst, geben uns Zeugnisse

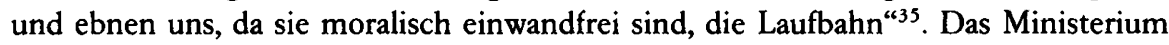
bemühte sich, den Unzuträglichkeiten entgegenzuwirken; so stellte es im März 1936 dem Lagerkommandanten Hildebrandt den Amtsgerichtsrat Lawall als Stellvertreter zur Seite, der Frontkämpfer des Ersten Weltkrieges, Freikorpskämpfer und ab Juni 1933 Parteimitglied war und später als Ritterkreuzträger sowie 1943 als Oberlandesgerichtspräsident von Köln Karriere machen sollte. Aber der Versuch des Justizministeriums, in stärkerem Maße Assessoren auch als Truppführer im Außendienst einzusetzen, um das juristisch nicht vorgebildete Ausbildungspersonal zu verringern, stieß auf den Widerstand Hildebrandts: Da die Referendare die Assessoren als Vorgesetzte nicht ernst nähmen, würden Autorität und Disziplin so sehr leiden, daß „der Außendienst nur noch schwer aufrechterhalten werden könne“. Bei „der bekannten Zusammensetzung der Referendare bezüglich ihrer politischen Gesinnung" kämen überdies für deren Beurteilung nur ältere Parteigenossen als Truppführer in Frage. Um im Gegenteil das bisherige Ausbildungspersonal zu halten, müßten dringend dessen Bezüge und Zukunftsaussichten verbessert werden ${ }^{36}$. Die Justizleitung konnte wenigstens erreichen, daß an den Vormittagen statt des sportlichen und militärischen Programms grundsätzlich Unterricht abgehalten wurde, dem die übermüdeten Referendare am Nachmittag häufig nicht mehr hatten folgen können ${ }^{37}$.

Problematisch blieb nach wie vor das Zustandekommen des Lagerzeugnisses, das der Lagerkommandant ausstellte und das für die Referendare nicht unwichtig war, da es gleichwertig an die Seite der anderen Zeugnisse aus dem Vorbereitungsdienst trat. Der Kommandant mußte sich dabei weitgehend auf die Äußerungen stützen, die seine Unterführer über Charakter und kameradschaftliche Haltung der Referendare abgaben, da die Lehrer für Sport und Schulung - juristischer und weltanschaulicher

${ }^{34}$ Vgl. dazu: Ber. des RegPräs. Merseburg v. 18.9.35 (a.a.O., Eintr. v. 21.9.35, Bd. 5, BA, Sign. R 22/1088); Schr. des Oberpräs. Magdeburg v. 24.9.35 nebst Ber. der Stapo Halle v. 20.9.35 (a.a.O., Eintr. v. 26.9.35); Ber. des Lagerkommandanten Jüterbog v. 22.11 .35 nebst Prot. der StAschaft Torgau (a.a.O., Eintr. v. 26.11.35, Bd.6, BA, Sign. R 22/1089); Ber. des Lagerkommandanten Jüterbog v. 8.8 .36 (a.a.O., Eintr. v. 12.8.36, Bd. 8, BA, Sign. R 22/929), letzterer mit dem Verm. des RJM: „Es entsteht die Frage, warum der Lagerkommandant Kunze ... nicht schon längst beseitigt hat."

${ }^{35}$ Eingabe der Referendare der Abt. III des Lagers Jüterbog an das RJM v. 21.2.36 (a.a.O., Eintr. v. 25. 2.36, Bd. 7, BA, Sign. R 22/928).

${ }^{36}$ Vgl. Schr. des Lagerkommandanten v. 11.1 .37 an das RJM (a.a.O., Eintr. v. 12.1.37, Bd.10, BA, Sign. R 22/706).

37 Vgl. MinRat H. Richter, Gemeinschaftsleiter im Hanns-Kerrl-Lager (DJ 1936, S.1761 ff., 1762). 
Unterricht wurde im Lagerzeugnis ohnehin nicht berücksichtigt -, die die einzelnen Referendare kaum dem Namen nach kannten, dafür ausfielen. Ebenso stand es mit den wenigen Abteilungsleitern, denen jeweils vier Züge, d.h. 200 bis 240 Mann unterstanden. Eine maßgebliche Rolle bei der Beurteilung kam daher den Zugführern zu, die jeweils mit ihren ca. 60 Mann - zwei Stubengemeinschaften - den engsten Kontakt hatten. Das Urteil dieser Soldatennaturen über die jungen Akademiker war aber häufig durch Mißverständnisse oder durch deren körperliche Ungeschicklichkeit oder auch Untauglichkeit für bestimmte Übungen getrübt, die als „Drückebergerei“ ausgelegt wurde. Nutzte ein durch seine schwächere körperliche Konstitution Erschöpfter die Freistunden zu Schlaf und Erholung aus, statt sich "fröhlichem Beisammensein“ zu widmen, wurde ihm das als „bewußte Absonderung“ und „Unkameradschaftlichkeit" ausgelegt. Schon bald beschwerten sich Referendare über ungerechte Lagerzeugnisse und deren Zustandekommen. Da diese Erklärungen nicht ohne weiteres zu den oberlandesgerichtlichen Akten genommen werden durften, sondern wie Zeugnisbeschwerden durch die Oberlandesgerichtspräsidenten dem Reichsjustizministerium vorzulegen waren ${ }^{38}$, erfuhr das Ministerium auch auf diesem Wege Einzelheiten über die Vorgänge im Lager ${ }^{39}$. In einem Stimmungsbericht über das Lager, den ein Düsseldorfer Referendar im Auftrag einer Dienststelle der „Deutschen Arbeitsfront“ angefertigt hatte und den der Oberlandesgerichtspräsident der Zeugnisbeschwerde des Referendars beilegte, hieß es, daß „das in einem Lagerleben notwendige kameradschaftliche Band zwischen Führerpersonal und Lagerinsassen" fehle und Gegensätze zwischen den militärischen Ausbildern und den Schulungsleitern bestünden, die offen verkündeten, „das Lager sei in seiner jetzigen Form nicht geeignet, den Lagerzweck zu erfüllen“. Es kam hinzu, daß die Lagerleitung für manche jugendliche Scherze der Referendare kein Organ hatte, übertrieben - z.B. mit der Anordnung eines 20-kmSchweigemarsches - reagierte und sogar Besichtigungsfahrten aus Furcht vor Disziplinwidrigkeiten untersagte. Der Stimmungsbericht kam zu dem Schluß, daß das Lager keine nationalsozialistische Erziehung vermittelte, „sondern durch die Art der Mißverhältnisse geeignet ist, eine vorhandene positive Einstellung in eine negative zu verwandeln".40

Berichte wie dieser - der übrigens an die Reichsleitung der NSDAP gelangte - waren Wasser auf die Mühle von Partei und Bewegung, die die weltanschauliche Schulung aller Glieder des Volkes für sich in Anspruch nahmen. Schon im Februar 1936 forderte daher der Reichsinspekteur des BNSDJ Raeke in einem Schreiben an das Reichsjustizministerium, das Lager, das "nach seiner Gründung eine große Aufgabe erfüllt“ habe, „so bald wie möglich völlig aufzuheben“. Die militärische Ausbildung der Referendare sei nunmehr durch die Einführung der Wehrpflicht gesichert. Auch

38 Vgl. RV des RJM (i. A. Palandt) an die OLGPräs. v. 25.6.36 (Akten des RJM, Hauptbüro, Arch. des BJM).

39 Vgl. z.B. die Beschwerden von Referendaren über ihre Lagerzeugnisse, die der OLGPräs. München am 15.10.36 und der OLGPräs. Frankfurt a. M. am 20.10.36 dem RJM vorlegten (Diensttageb. des RJM, Eintr. v. 24.10.36, Bd.9, BA, Sign. R 22/930).

${ }^{40} \mathrm{Vgl}$. Schr. des OLGPräs. Düsseldorf an das RJM v. 19.3.37 mit Beschwerde des Referendars S. über sein Lagerzeugnis und umfangreichem "Stimmungsbericht über das Gemeinschaftslager Hanns Kerrl“ (a.a.O., Eintr. v. 23.3.37, Bd. 10, BA, Sign. R 22/706). Lagerkommandant Hildebrandt antwortete dem RJM am 21.6.37 darauf ziemlich allgemein und bat, auf den Ber., der ihn „peinlich an die Gepflogenheiten der Emigrantenpresse“ erinnere, nicht weiter eingehen zu müssen, „zumal der Bericht verantwortliche Angaben über Zeit und Personen vermissen" lasse (a.a.O., Eintr. v. 23.6.37, Bd. 12, BA, Sign. R 22/678). 
die arbeitsdienstliche Schulung erfolge nun im obligatorischen Reichsarbeitsdienst, während der Referendar durch sinnlose Beschäftigung im Lager „keine Achtung vor der Handarbeit“ bekomme: es sei „vorgekommen, daß an einem Tage eine Abteilung einen Graben ausgehoben und am anderen Tage eine andere Abteilung denselben Graben wieder zugeschüttet" habe. Das Gemeinschaftsleben werde den Referendaren mittlerweile bereits in den verschiedenen Gliederungen der Bewegung anerzogen. Es sei auch unmöglich, „das Lager zu einer weltanschaulichen Schule“ zu machen, denn ein solche Schulung des Juristen könne nur durch das Reichsrechtsamt der NSDAP und den BNSDJ durchgeführt werden. Der Referendar werde „dadurch, daß er sich in dem Lager nur Halbheiten auf jedem Gebiet gegenübersieht, zu Kritik und Skepsis gezwungen“, die Staat und Bewegung schadeten. Selbst die charakterliche und kameradschaftsmäßige Beurteilung der Referendare im Lager sei problematisch, denn dazu gehöre „ein psychologisch geschulter und geschärfter Blick, der den einfachen Soldatennaturen der über die charakterliche Beschaffenheit der Referendare befindenden Ausbilder mangelt". Gerade unkameradschaftliche Referendare schnitten dabei gut ab, weil sie sich bei ihren Vorgesetzten beliebt zu machen verstünden. Schließlich werde auch der den Referendaren abverlangte Kostenbeitrag als „besonders drückend“ empfunden ${ }^{41}$.

Für eine Aufhebung des Gemeinschaftslagers trat schließlich auch der Reichsfinanzminister ein. Nachdem er schon im Dezember 1936 das Reichsjustizministerium um Prüfung gebeten hatte, „ob in der Gegenwart noch ein die Ausgabe rechtfertigendes Sachbedürfnis für das Lager" bestehe, äußerte er im Februar 1937 dezidiert seine Ansicht, daß dem Lager nur noch „die Bedeutung einer Übergangseinrichtung“ zukomme, da „bei der rasch fortschreitenden Verankerung des nat.soz. Gedankenguts“ die weltanschaulich-fachliche Schulung der Referendare von den Arbeitsgemeinschaften übernommen werden könne. Er bat, „schon jetzt Maßnahmen einzuleiten, um die künftige Aufhebung des Lagers vorzubereiten“; insbesondere werde die Mehrzahl der Gruppen- und Zugführer nunmehr entbehrlich und ihre Aufgabe von Referendaren übernommen werden können ${ }^{42}$.

In dieser Situation mußte sich die Justizleitung über die Zukunft des Jüterboger Gemeinschaftslagers Gedanken machen. Ob im Justizministerium tatsächlich „ein Kampf um die Fortführung des Lagers in der jetzigen Form entbrannt war" - wie die Lagerführung Ende 1936 zu beobachten glaubte ${ }^{43}-$, sei dahingestellt. Es ist durchaus möglich, daß Staatssekretär Freisler, der das Lager 1933 zusammen mit Kerrl gegründet hatte und in dessen Geschäftsbereich das Gemeinschaftslager im Ministerium fiel, an der ursprünglichen Konzeption festhalten wollte. Demgegenüber dürfte Gürtner, dem stets die solide fachliche Ausbildung des juristischen Nachwuchses am Herzen lag, zumindest für eine grundlegende Reform des Ausbildungslagers eingetreten sein. Bereits in seiner Ansprache anläßlich des ersten Spatenstichs zum Neubau des Führerhauses im Lager am 19. Juni 1934 hatte Gürtner den Referendaren klargemacht, daß

41 Vgl. Schr. des Reichsinspekteurs des BNSDJ Raeke an das RJM v. 29.2.36 (a.a.O., Eintr. v. 7.3.36, Bd.7, BA, Sign. R 22/928).

42 Vgl. die Schr. des RFiM an das RJM v. 22.12.36 (a.a.O., Eintr. v. 29.12.36, Bd.9, BA, Sign. R 22/930) und 26.2.37 (a.a.O., Eintr. v. 1.3.37, Bd.10, BA, Sign. R 22/706).

43 So laut dem in Anm. 40 nachgewiesenen Bericht. 
zwar „der Staat der Gegenwart“ den Dienst im Lager, der ,in erster Linie der körperlichen Ausbildung und Schulung dient, ... als einen ebenso wichtigen und unentbehrlichen Bestandteil der Gesamtausbildung“ des Juristen ansehe „wie die geistige und fachliche Ausbildung“. Er müsse jedoch der „nicht allzu selten“ gehörten Vorstellung entgegentreten, daß

„in Zukunft der Besitz von Wissen und Können nicht mehr ganz so wichtig sein werde wie in der Vergangenheit. Ich möchte auch hier warnen, sich einem Gedanken hinzugeben, der in die Irre führen muß. So wenig der Handwerker sein Handwerk ausüben ... kann, wenn er die Technik seiner Werkzeuge nicht beherrscht, so wenig würde ein Richter oder Staatsanwalt sein Amt gedeihlich ausüben können, wenn er die Technik seiner Kunst und die Werkzeuge seines Handwerks nicht wirksam beherrscht." ${ }^{\text {“4 }}$

Diesem Zweck diente aber der immerhin zwei Monate dauernde Lagerabschnitt des Vorbereitungsdienstes unter den gegebenen Umständen nicht.

$\mathrm{Zu}$ denjenigen Juristen der höheren Justizverwaltung, die beim Reichsjustizministerium auf eine Umgestaltung des Gemeinschaftslagers drangen, gehörte der Hamburger Oberlandesgerichtspräsident Rothenberger, der sich von jeher mit dem Aufbau eines nationalsozialistischen Juristenstandes beschäftigte und 1942 als Staatssekretär im Reichsjustizministerium mit entsprechenden Plänen für eine grundlegende Reform der Richterschaft hervortreten sollte. Als der Hamburger Landgerichtsdirektor Romeiß nach einer dreiwöchigen Abordnung im Lager dem für das Gemeinschaftslager zuständigen Referenten des Justizministeriums, Amtsgerichtsrat Friedrich, seine Erfahrungen und Änderungsvorschläge mitteilte, wurde er zu einem ausführlichen Bericht aufgefordert. Rothenberger, der das Lager aus eigener Vortragstätigkeit kannte, übersandte dem Ministerium diesen Bericht mit der Bemerkung, daß die darin vertretenen Gedankengänge im wesentlichen seiner Auffassung entsprachen. Auch dieser Bericht ging davon aus, daß es nach Einführung der Wehr- und Arbeitsdienstpflicht nicht mehr Zweck eines achtwöchigen Lagerdienstes sein könne, die Referendare militärisch zu drillen und ihnen das Gemeinschaftserlebnis zu vermitteln. Es sei sogar fraglich, ob der Erwerb des SA-Sportabzeichens, für den allein täglich drei Stunden verwendet wurden, „Ziel eines Lagers sein kann, das berufen ist, Rechtswahrer heranzubilden“. Statt des bisher alles beherrschenden Außendienstes solle daher „die Schulung in den Mittelpunkt der Lagerausbildung treten“, die aber überwiegend weltanschaulich sein müsse, da sich der Referendar mit fachlichen Fragen während der übrigen Ausbildungszeit hinreichend beschättigen könne. Neben den bisherigen Vorträgen auf Zug-, Abteilungs- und Lagerebene sollten die Referendare zu „Arbeitsgemeinschaften von nicht mehr als 20 Mann" zusammengeschlossen werden, um den Vortragsstoff vertiefen und durch eigene Vorträge anreichern zu können. Dafür müßten einmal die äußeren räumlichen Voraussetzungen geschaffen werden, da die mit 28 Mann belegte Stube und der überfüllte Lesesaal für geistige Arbeit nicht geeignet seien. Dem Referendar müsse aber für seine eigene Weiterbildung auch mehr Freizeit gegeben werden. Nur durch eine solche Umgestaltung werde dem Lager „ein neuer Inhalt gegeben, der zu der Erwartung berechtigt, daß die Referendare das Lager künf-

44 An die jungen Juristen! Rede des Reichsministers Dr. Gürtner, gehalten im Gemeinschaftslager „Hanns Kerrl“ am 19. Juni 1934 (DJ 1934, S. 786 f.). 
tig mit dem Gefühl verlassen, in jeder Hinsicht eine Bereicherung erfahren zu haben“45.

Die Umgestaltung des Lagers, die das Reichsjustizministerium im Oktober 1937 durch die Allgemeinverfügung zum „Ausbau des Gemeinschaftslagers Hanns Kerrl“ ${ }^{\text {«6 }}$ vornahm, entsprach im wesentlichen diesen Vorschlägen und schloß nur hinsichtlich der sportlichen Betätigung der Referendare einen Kompromiß. Als Zweck des Lagerdienstes wurde nunmehr herausgestellt, die Referendare „in ernster gemeinsamer Arbeit“ zu schulen, „die weltanschaulichen Grundlagen ihres Wissens zu vertiefen“ und „ihr fachliches Können zu fördern“. Dagegen hieß es ausdrücklich, daß „eine Ausbildung in militärischer Form unterbleibt“, da soldatische Haltung bei den Referendaren nunmehr vorausgesetzt werden könne. Dennoch trugen die Referendare - später bei Ausgang aus dem Lager nicht mehr - weiterhin Uniform. Die Referendare sollten im Lager vor allem mit jenen Rechtsgebieten wie dem Rasse- und Erbgesundheitsrecht, dem Bauernrecht sowie dem Arbeitsrecht und ihrer Anwendung vertraut gemacht werden, mit denen sie während ihrer übrigen Ausbildung weniger in Berührung kamen, ferner mit Gesetzen, die seit ihrem Abgang von der Universität geändert worden waren. Hierbei sollten sie ,an praktischen Fällen unter kundiger Leitung in der Rechtsfindung geschult“ werden. Daneben sollte ihnen Allgemeinbildung und „Verständnis für das politische Geschehen der Zeit" vermittelt werden. Durch selbstgewählte Vorträge auf den Gebieten des Rechts, der Geschichte, Politik und Wirtschaft mit anschließender Diskussion sollten sich die Referendare in der freien Rede üben ${ }^{47}$. Unter Anleitung von Sportlehrern sollten sie dennoch Gelegenheit haben, für das SAund das Reichssportabzeichen zu trainieren ${ }^{48}$. Vor allem aber sollte dem Referendar nunmehr für die eigene „Weiterbildung, für Erholung und Entspannung“ genügend Zeit zur Verfügung stehen.

Außer dem Kommandanten Hildebrandt bestand das Führungspersonal nur noch aus Juristen. Die Referendare wurden zu „Kameradschaften“ von je 20 Mann zusammengefaßt, die jeweils von einem Kameradschaftsführer geleitet wurden, der als Richter oder Staatsanwalt vom Justizministerium aus dem Kreis bewährter Leiter von Referendar-Arbeitsgemeinschaften bestellt wurde. Ihm stand ein Kameradschaftsältester zur Seite, den der Lehrgangsleiter auf Vorschlag des Kameradschaftsführers aus den Reihen der Referendare ernannte. Mehrere Kameradschaften bildeten einen „Lehrgang“, an dessen Spitze als Lehrgangsleiter ein auch vom Ministerium ernannter Richter oder Staatsanwalt stand. Die Ausbildung der Referendare oblag dem Ausbildungsleiter; diesen Posten besetzte das Justizministerium mit dem stellvertretenden Lager-

45 Vgl. Ber. des LGDir. Romeiß v. 22.9.36, dem RJM durch Rothenberger am 13.10.36 übersandt (Akten des OLG Hamburg, Arch. der Forschungsstelle für die Geschichte des NS in Hamburg, Sign. Best. 3328), dazu ferner Johe, a.a.O., S. $221 \mathrm{ff}$.

${ }^{46}$ AV des RJM v. 21.10.37 (DJ 1937, S. 1636).

47 Eine Aufstellung der Vortragsthemen, die sich die Referendare des ersten Lehrgangs 1937 wählten, findet sich in DJ 1938, S. $51 \mathrm{f}$.

48 Außerdem wurde besonders Boxsport betrieben, vgl. die beiden Nachkriegsberichte ehemaliger Teilnehmer: OLGPräs. a. D. H. Schütz, Justiz im Dritten Reich. Dokumentation aus dem Bezirk des Oberlandesgerichts Bamberg, Bamberg 1984, S. 110 ff. (bezieht sich auf das Frühjahr 1939), und unveröffentlichter Bericht von RA G. Krauss, Rheinische Erinnerungen an das Gemeinschaftslager „Hanns Kerrl“ (Herbst 1937), der dem Verf. freundlicherweise überlassen wurde. 
kommandanten und Juristen Lawall. Das Einberufungsverfahren durch den Kommandanten blieb im wesentlichen unverändert ${ }^{49}$.

Ein Blick auf die Liste der 1937 von auswärtigen Gästen im Lager gehaltenen Vorträge zeigt, daß die Referendare außer auf dem Gebiet des Rechts in Weltanschauung, Politik, Geschichte, Rassenkunde, Wirtschaft und Kunst unterrichtet wurden. Neben Beamten des Reichsjustizministeriums und Vertretern der Rechtswissenschaft wie Graf Gleispach, Dahm, Siegert erschienen außer Reichsrednern der NSDAP und Gauleitern auch höhere SS-Führer wie Best, Behrends und Hartl auf der Rednerliste ${ }^{50}$. Obwohl nunmehr die Ausbildung im Lager nach dem Motto erfolgte: „Der Rechtswahrer dient seinem Führer und seinem Volke nun einmal nicht nur mit dem Marschstiefel, sondern mit dem Kopf ${ }^{\text {"51 }}$, und das Ministerium auch die beanstandeten finanziellen Kostenbeiträge der Referendare beseitigte ${ }^{52}$, verstummte die Kritik am Gemeinschaftslager nicht. Als Gürtner in seiner Schlußansprache auf der Tagung der Oberlandesgerichtspräsidenten in Berlin am 18. Januar 1938 bat, ihn über das Echo zu unterrichten, das die Reform des Lagers bei den Referendaren gefunden habe ${ }^{53}$, sandte Rothenberger einen kritischen Bericht ein, für den er umfassende Auskünfte von Hamburger Referendaren eingeholt hatte. In dem Bericht, der die kritischsten Äußerungen der Referendare außer acht lie $\beta^{54}$, beanstandete Rothenberger, daß es im Lager immer noch „an wirklich guten juristischen Lehrkräften“ fehle. Die großen Lagervorträge von Gastreferenten seien zum Teil enttäuschend. Auch hätten die Referendare aus räumlichen Gründen keine Gelegenheit, in der vorgesehenen Arbeitsstunde ruhig zu arbeiten, da sich dazu der allein zur Verfügung stehende Eß- und Schlafraum der zwanzigköpfigen „Kameradschaft“ nicht eigne. Während zwischen den aus allen Teilen Deutschlands stammenden Referendaren gute Kameradschaft geschlossen werde, habe sich das Verhältnis zur Lagerführung immer noch nicht gebessert, ,insbesondere bestehe keinerlei Kontakt zwischen dem Kommandanten und den Referendaren“. Die Lagerführung verhalte sich nach wie vor kleinlich, „sogar selbstverständlicher Lagerhumor" werde von ihr bestraft, da sie vor jedem Scherz geradezu Angst habe. Rothenberger sah daher die Gefahr, daß im Lager „ein Geist der Kleinlichkeit und des Duckmäusertums großgezüchtet wird“"55.

Obwohl sich das Justizministerium bemühte, den beanstandeten Raummangel durch Neubauten und auch die anderen Mängel durch geeignete Maßnahmen zu beheben, blieben Existenz und innere Organisation des Lagers bis zu seiner Schließung bei Kriegsausbruch umstritten und stießen sowohl bei den Referendaren wie bei den höheren Justizstellen auf keine besondere Gegenliebe. Bei der Mehrzahl der Referen-

49 Vgl. RV des RJM an die OLGPräs. v. 1.2.39 (Akten des RJM, Hauptbüro, Arch. des BJM); die Referendare hatten nunmehr ihr selbstgewähltes Vortragsthema dem Kommandanten vier Wochen vor Dienstantritt anzuzeigen.

50 Vgl. O. Palandt, Die Arbeit der Ausbildungsabteilung (RJP) im Jahre 1937 (DJ 1938, S. 22 ff.).

s1 So LGDir. Schumacher, 14 Tage „Kurgast“ im Hanns-Kerrl-Gemeinschaftslager (DJ 1938, S. 1081).

52 Durch die AV des RJM v. 14.3.38 (DJ 1938, S. 400).

$53 \mathrm{Vgl}$. Ber. des OLGVizepräs. Hamburg Letz über die Tagung der OLGPrās. im RJM am 17./18.1.38 (Akten des OLG Hamburg, Arch. der Forschungsstelle für die Geschichte des NS in Hamburg, Sign. Best. 3308).

s4 Vgl. dazu Johe, a.a.O., S. 222 ff., der einige Ber. der Referendare inhaltlich wiedergibt.

5s Auszug aus dem Lageber. des OLGPräs. Hamburg v. 4.5.38 (Akten des OLG Hamburg, Arch. der Forschungsstelle für die Geschichte des NS in Hamburg, Sign. Best. 3328). Die Lageber. der OLGPräs. an das RJM aus dieser Zeit sind bis auf Ausnahmestücke nicht mehr erhalten; in den vorhandenen Stücken fanden sich keine Ausführungen über das Lager. 
dare dürfte dabei keineswegs eine bewußte Ablehnung nationalsozialistischer Ideen, sondern einfach ein gewisser Überdruß gegenüber der von den unterschiedlichsten Seiten einsetzenden weltanschaulichen Schulung eine Rolle gespielt haben, die gerade während des Vorbereitungsdienstes für die große Staatsprüfung als auf Kosten der juristischen Ausbildung gehend empfunden wurde. Auf der anderen Seite tadelte wiederum die Partei die unzureichende politische Schulung. In einer Entschließung vom Juli 1939 beanstandeten die Mitglieder des Reichsgruppenrates und die Gaugruppenwalter „Richter und Staatsanwälte“ des NSRB, daß „sogar nationalsozialistisch ausgerichtete und im illegalen Kampf erprobte Referendare" aus dem angeschlossenen Österreich in Jüterbog ,weder weltanschauliche Vertiefung noch weitere politische Fortbildung erfahren" hätten. Die Entschließung gipfelte in der Forderung, daß das Lager „nunmehr endlich aufzulösen sei, wenn weitere schwere Schädigungen in der Erziehung des Nachwuchses im nationalsozialistischen Sinne verhütet werden sol-

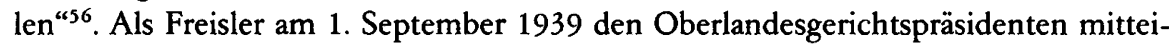
len mußte, daß das Lager nunmehr für das Heer benötigt werde und daher alle bereits ausgesprochenen Einberufungen zum Lagerdienst widerrufen $\operatorname{seien}^{57}$, ging die über sechs Jahre währende Ära der Referendarausbildung im Gemeinschaftslager Hanns Kerrl zu Ende, ohne daß sie jenes geschlossene Korps von nationalsozialistischen Nachwuchsrichtern und -staatsanwälten geschaffen hatte, das der politischen Führung als Ideal vorschwebte.

Mit dem Nachwuchs für den höheren Justizdienst hatte die Justizverwaltung ohnehin die verschiedenartigsten Probleme. Die Zahl der erstsemestrigen Rechtsstudenten ${ }^{58}$, die im Jahre $1932=3611$ und 1933 noch 3107 betragen hatte, sank in den folgenden Jahren weiter ab: 1934 waren es $1448,1935=1519$ und 1936 nur noch 750. Neben den kriegsbedingt geburtenarmen Jahrgängen lag der Grund für diesen plötzlichen Einbruch in der Einführung der Arbeitsdienst- und Wehrpflicht sowie im Aufbau der Wehrmacht und neuer Verwaltungen wie dem Reichsnährstand, der Deutschen Arbeitsfront, verschiedener Organisationen der Partei usw., die für die berufliche Betätigung vielfach kein Hochschulstudium voraussetzten. Im Jahre 1937 begannen 1113 Studenten das Rechtsstudium, im Jahre 1938 insgesamt 1553, von denen jedoch schätzungsweise 150 Jurastudenten den hinzugekommenen österreichischen Gebieten zuzurechnen waren.

Eine ähnliche Entwicklung nahm die Gesamtzabl der Recbtsstudenten, die im Jahre $1928=22000$ betragen hatte ${ }^{59}$, dann aber 1932 auf 17000,1933 auf 16200 und 1934 auf 10800 abgesunken war. Diese rückläufige Bewegung hielt in der Folge trotz

$56 \mathrm{Vgl}$. Ergebnis der Beratungen während des fachlich-politischen Gemeinschaftslagers auf der Gauschulungsburg Hohenwerfen, Gau Salzburg (DR 1939, Ausg. B, S. 367).

${ }^{57}$ RV des RJM (i.V. Freisler) an die OLGPräs. v. 1.9.39 (Akten des RJM, Hauptbüro, Arch. des BJM).

58 Den im folgenden wiedergegebenen Zahlen liegen folgende Quellen zugrunde: Entwicklung der Lage der Rechtsstudenten, Referendare und Assessoren von 1925-1935, Ausarbeitung des RJM v. 13.12.35 (Akten des RJM, BA, Sign. R 22/4594); Vortrag Sts. Freislers über Fragen der Justiz, ihres Nachwuchses und ihrer Stellung, gehalten am 23.4.41 vor den OLGPräs. und GStAen (Manuskript, a.a.O., Sign. R 22/246, Wortprotokoll, a.a.O., Sign. R 22/245); Material für die Rede des RJM Thierack vor den Universitätsprofessoren in Cochem, zusammengestellt am 14.6.44 vom stellv. Leiter der Abt. II (Prüfungswesen und Nachwuchsfragen) des RJM (a.a.O., Sign. R 22 Gr. 5/316).

59 Durch die Rückkehr von fünf Kriegsteilnehmerjahrgängen war die Gesamtzahl der Jurastudenten 1920 mit 17100 über den Vorkriegsstand $(1913=10265)$ gestiegen und hatte 1923 den Höchststand von 22700 (18\% aller Studierenden) erreicht. 
der gebiets- und bevölkerungsmäßigen Vergrößerung des Reiches an: im Sommersemester 1937 studierten 4694 Studenten Jura (Wintersemester 1937/38 = 4897), im Sommersemester $1938=4275$ (Wintersemester $1938 / 39=4936$ ) und im Sommersemester 1939 noch 4554 .

Gürtner wies schon auf einer Besprechung im Juni 1937 darauf hin, es „dürfte auch dem Blindesten nicht verborgen bleiben“, daß die Justiz „in etwa 3 bis 4 Jahren“ vor einer sehr ernsten Nachwuchskrise stehen werde. Bis dahin habe sie noch eine gewisse Personalreserve in der großen Zahl der „Assessoren, die abseits vom ordentlichen Dienst beschäftigt sind ${ }^{\text {“60 }}$. Dagegen nahm Freisler auf der Tagung der Oberlandesgerichtspräsidenten im April 1941 die zahlenmäßige Entwicklung der Erstsemester und Gesamtzahlen der Rechtsstudenten ab 1937 zum Anlaß, den ständigen „Unkenrufen“ entgegenzutreten, daß die Rechtspflege für die akademische Jugend an ideeller Anziehungskraft verloren, daher keinen Nachwuchs und folglich keine Zukunft mehr habe, da ihr Ansehen durch Kritik von politischer Seite geschmälert worden sei. In der Tat wiesen verschiedene Oberlandesgerichtspräsidenten in ihren Lageberichten darauf hin, daß neben der öffentlichen Kritik vor allem die Übernahme von Justizaufgaben durch Verwaltungsstellen - insbesondere durch die SS und Polizei -, ferner die Einschränkung der Selbständigkeit und die vermehrte Verwaltungstätigkeit des Richters die richterliche Berufsfreude trübe und jene jungen Kräfte von der Wahl des Juristenberufs abhalte, die nach selbständiger und verantwortungsvoller Tätigkeit strebten ${ }^{61}$. Freisler räumte auf der erwähnten Tagung zwar ein, daß der Übergang zum Führerstaat der Justiz verantwortliche Aufgaben genommen habe: so habe sie z. B. „keine Kontrolle echter Führungshandlungen“ mehr. Aber der Justiz seien dafür „starke neue Aufgaben gegeben worden": die Erbgesundheitspflege, das Erbhofwesen, das Entschuldungswesen, die Vertragshilfe, „ferner die Ausdehnung der Strafrechtspflege auf die Sicherungsmaßnahmen über die Gesetzesbegrenzung hinaus" (!). Hinsichtlich des Nachwuchsbedarfs habe das Justizministerium „berechnet, soweit man es berechnen kann, daß 1500 erstsemestrige Studenten im Altreich, 1800 im Großdeutschen Reich das richtige wären“. Diese Zahlen seien „schon fast“ erreicht, und angesichts der Gesamtzahl der Rechtsstudenten bestehe daher "gar kein Grund zur Besorgnis ... In einem gesunden Volk finden sich immer genug kernige junge Männer, um der Arbeit des Rechtes ihr Leben zu weihen, wenn der Rechtswahrerstand selbst gesund ist." Dafür müsse eben gesorgt werden ${ }^{62}$. Freislers Optimismus sollte sich jedoch in der Folgezeit nicht bestätigen: Im Kriege sank die Zahl der Rechtsstudenten gewaltig ab, 1943 bis auf 2500, d.h. etwa die Hälfte der Zahl von 1939 und auf rund 5\% der gesamten Studentenschaft. Der Grund dafür lag allerdings auch in der Tatsache, daß das Jurastudium bei Beurlaubungen und Freistellungen von der Wehrmacht gegenüber den technischen und medizinischen Fächern hintangesetzt wurde. Von den Rechtsstudierenden wollte wiederum nur ein Bruchteil in den Justizdienst eintreten. Nach

60 Vgl. Prot. der Besprechung mit den Oberlandesgerichtspräsidenten und Generalstaatsanwälten im Reichsjustizministerium am 18. Juni 1937 (a.a.O., Sign. R 22/4277).

61 Vgl. die Lageber. der OLGPräs. Braunschweig v. 6.5.39, 4.1.41 (Akten des RJM, BA, Sign. R 22/3357); Kassel v. 4.3.41 (R 22/3371); aus den folgenden Jahren: Bamberg v. 29. 10.42, 3.4.44 (R 22/3355); Darmstadt v. 1.12.43 (R 22/3361); Düsseldorf v. 29.3.43 (R 22/3363); Hamburg v. 5. 1.42, 12.4.44, 5.8.44 (R 22/3366); Kiel v. 18.7.42 (R 22/3373); Köln v. 2.7.42 (R 22/3374) und Königsberg v. 9.11.43 (R 22/3375).

62 Vortrag Freislers (voranstehende Anm. 58). 
den Feststellungen der juristischen Fakultät Gießen z. B. beabsichtigten im Herbst $194360 \%$ der Jurastudenten in die Verwaltung, 30\% in die Wirtschaft zu gehen, nur $10 \%$ wollten Richter, Staatsanwalt oder Rechtsanwalt werden ${ }^{63}$.

Bei den Gerichtsreferendaren nahm die zahlenmäßige Entwicklung einen anderen Verlauf. Im Gegensatz zur Zahl der Rechtsstudenten war die Zahl der preußischen Referendare - für das Reich lagen erst ab 1935 Angaben vor - unter dem Einfluß des Ersten Weltkrieges und der Inflation gegenüber dem Vorkriegsstand $(1913=7200)$ im Jahre 1923 auf 4200 gesunken, da die berufliche Tätigkeit in der Wirtschaft dem Staatsdienst offensichtlich vorgezogen wurde. Das Ende der Inflation brachte jedoch den Umschwung: die Zahl stieg allmählich wieder an und erreichte ihren Höhepunkt - der Rechtsstudentenwelle von 1928 um fünf Jahre nachfolgend - 1933 mit 10065 (preußischen) Referendaren. Im Jahre 1935 betrug die Gesamtzahl der Referendare im Reich 12640 (davon in Preußen 8568). Angesichts dieses Überangebots an Nachwuchskräften wurde den Referendaren nahegelegt, Berufe außerhalb der Justiz zu ergreifen, z. B. Offizier in der im Aufbau befindlichen Wehrmacht zu werden. Wie die Berichte der Oberlandesgerichtspräsidenten und Generalstaatsanwälte auf eine entsprechende Rundverfügung des Reichsjustizministeriums vom Juni 1935 ergaben, war die wirtschaftliche Lage der Referendare miserabel: $30 \%$ der Referendare besaßen nicht das Existenzminimum, 50\% befanden sich in bedrückenden finanziellen Verhältnissen und hatten keine ausreichenden Mittel für einen standesgemäßen Lebensunterhalt. Zu ihnen gehörte die große Zahl der „Haussöhne“, die in die erste Kategorie fielen, sobald sie nicht mehr im Elternhaus wohnen und essen konnten. Nur die restlichen $20 \%$ waren wirtschaftlich so gestellt, daß sie standesgemäß leben konnten. Im selben Jahr 1935 konnte aus den Mitteln der Justizverwaltung jedem 11. Referendar im Reich ein staatlicher Unterhaltszuschuß gewährt werden ${ }^{64}$, im Jahre 1938 etwa einem Viertel aller Referendare ${ }^{65}$. Der Plan des Justizministeriums, statt dieses nur im Bedürfnisfall gewährten Zuschusses ausnahmslos allen Referendaren eine auskömmliche Besoldung zu gewähren, scheiterte 1938 an den Bedenken des Reichsfinanzministers $^{66}$. Entsprechend der zahlenmäßigen Entwicklung bei den Rechtsstudenten sank auch die Zahl der Referendare in den Jahren nach 1935 laufend - von 12083 am Jahresanfang 1936 auf 7501 am Jahresanfang $1942^{67}$ - und erreichte im Kriegsjahr 1944 den Stand von rund 7000, von denen $6300(88 \%)$ bei der Wehrmacht dienten.

${ }^{63}$ Vgl. Lageber. des OLGPräs. Darmstadt an das RJM v. 1.12.43 (Akten, a.a.O., Sign. R 22/3361). Im Sommer 1944 wollten von der verhältnismäßig kleinen, 118 Studenten zählenden juristischen Fakultät der Universität Hamburg ganze 11 zur Justiz gehen, davon 6 Rechtsanwälte und nur 5 Richter werden, vgl. Lageber. des OLGPräs. Hamburg v. 5.8.44 (a.a.O., Sign. R 22/3366).

${ }^{64}$ Zum Voranstehenden vgl. Ausarbeitung des RJM v. 13.12.35 (s. Anm. 58). Die Zahl der Zuschußempfänger bezieht sich auf das Reich ausschließlich Sachsens, wo die Referendare 1935 - wie schon vorher - als Urkundsbeamte besoldet und nicht nur als Protokollanten, sondern auch im Nachlaß- und Vormundschaftswesen, für richterliche Vernehmungen usw. eingesetzt wurden; vgl. die Ausführungen des sächs. JM Thierack, der sich auf der Konferenz der LandesJM in Stuttgart am 6.5.33 deshalb gegen eine Freizügigkeit der Referendare im Reich wandte (Niederschrift in den Akten des bayer. JM, BayerHStArch., Sign. MJu 16833).

65 Zur Höhe der Unterhaltszuschußmittel, sowohl absolut als auf den Kopf berechnet, in Preußen bzw. im Reich 1933-1938 vgl. R. Freisler, Personalpolitik im höheren Justizdienst, volkspolitisch gesehen (DJ 1939, S. 1342 ff., 1350).

${ }^{66} \mathrm{Vgl}$. Antwortschr. des RFiM v. 19.8.38 auf das Schr. des RJM v. 1.6.38 (Akten des RFiM, BA, Sign. R 2/10868).

67 Die Zahlen für 1937-1939 s. bei Freisler, a.a.O. 


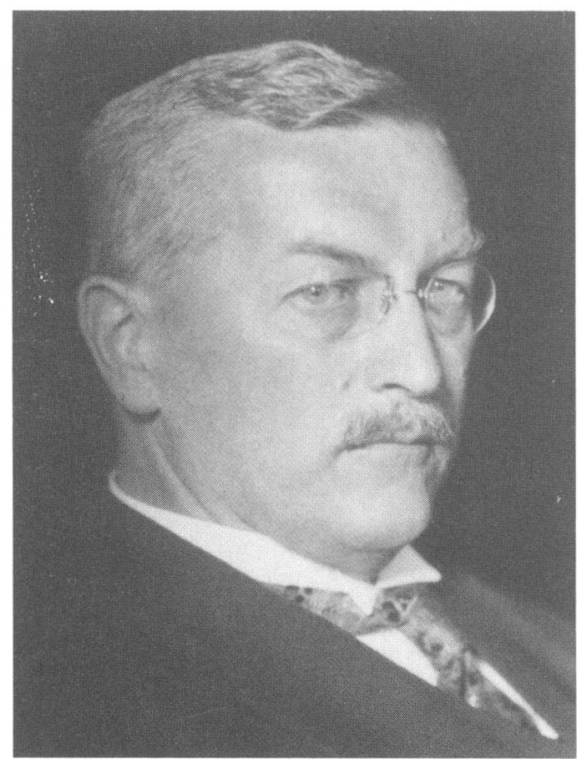

Dr. h.c. Franz Gürtner

Reichsminister der Justiz

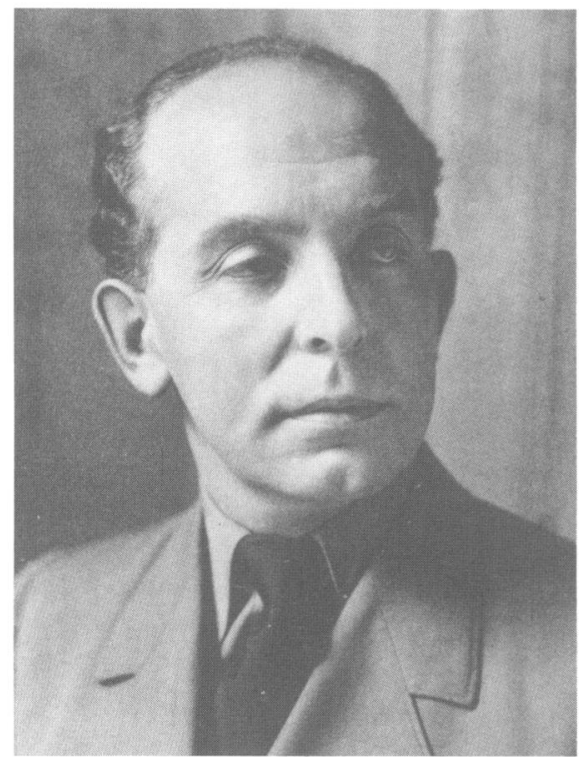

Dr. Roland Freisler

Staatssekretär im Reichsjustizministerium, ab August 1942 Präsident des Volksgerichtshofes

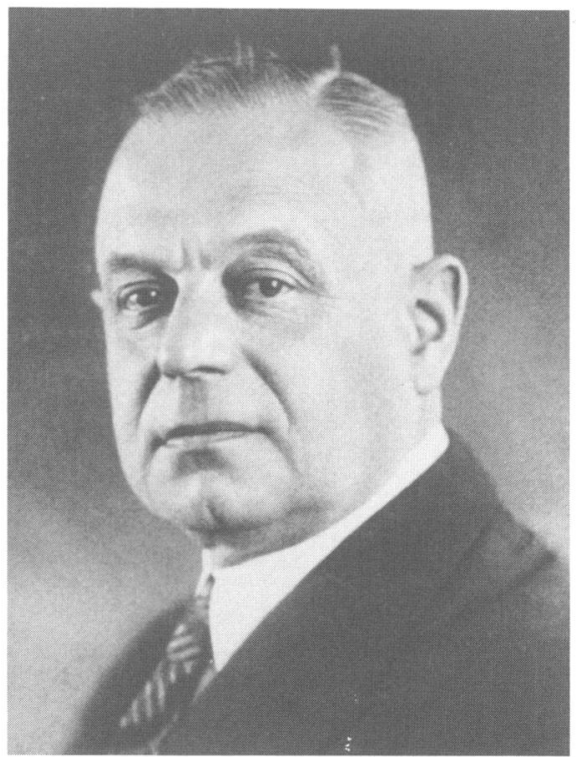

Dr. Dr. h.c. Franz Schlegelberger

Staatssckretär im Reichsjustizministerium

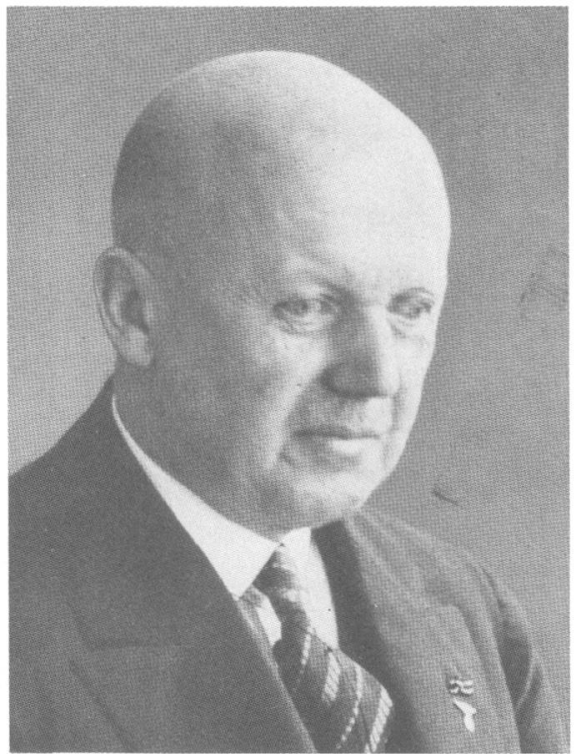

Dr. Hans Heinrich Lammers

Reichsminister und Chef der Reichskanzlei, Mittler zwischen Hitler und dem

Reichsjustizminister 


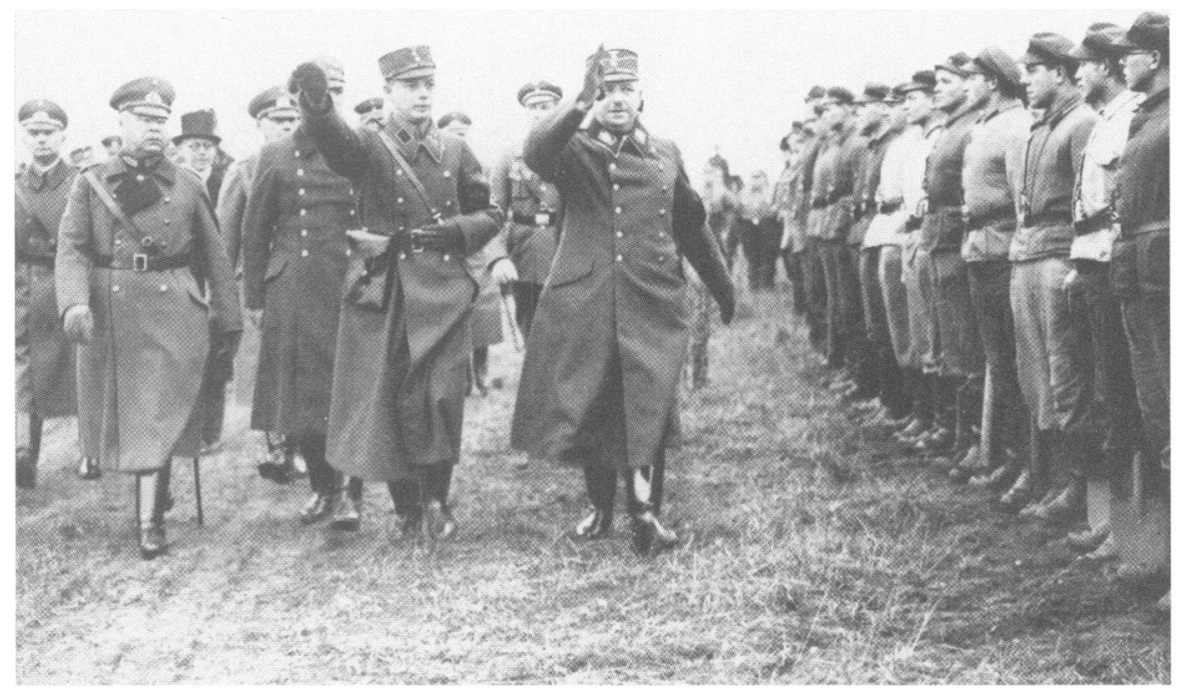

Der preutische Justizminister Hanns Kerrl besichtigt das von ihm gegründete Referendarlager in Jüterbog

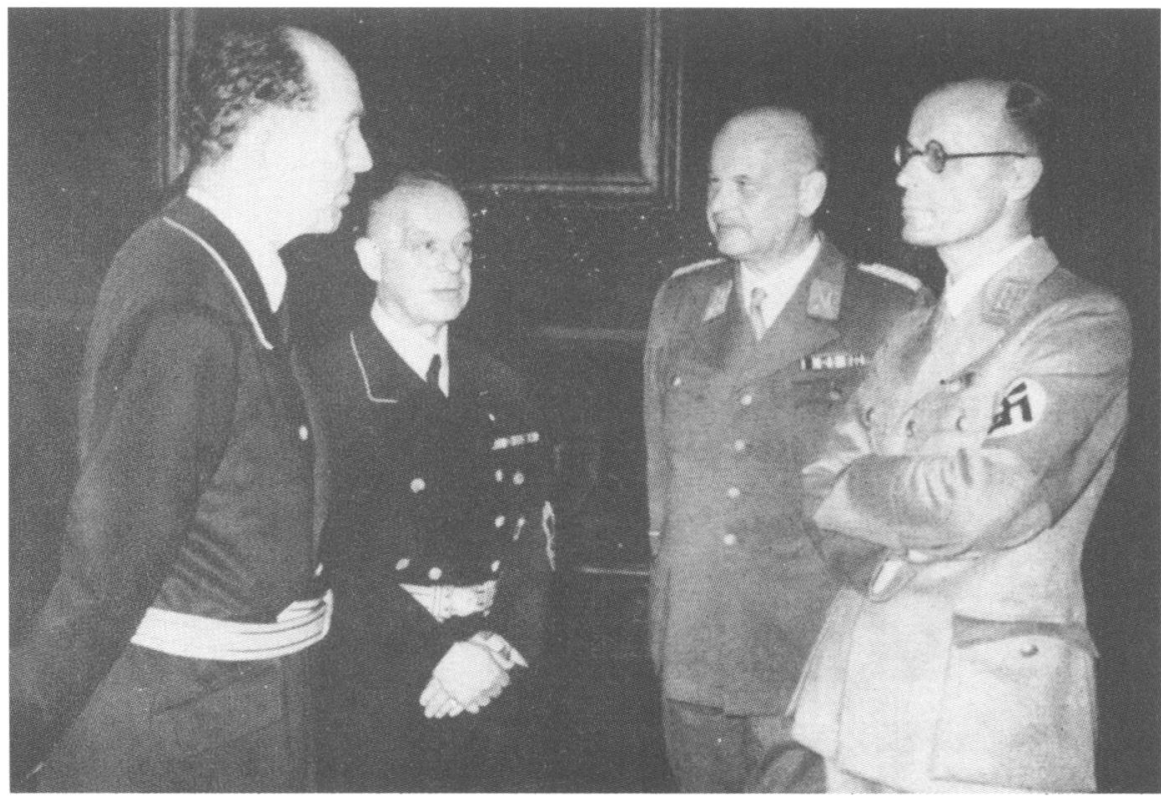

Von links nach rechts: die Staatssekretäre Freisler und Schlegelberger im Gespräch mit dem Präsidenten des Volksgerichtshofs Dr. Thierack und dem Hamburger Oberlandesgerichtspräsidenten Dr. Rothenberger, die im August 1942 als Minister und Staatssekretär das Reichsjustizministerium übernahmen 


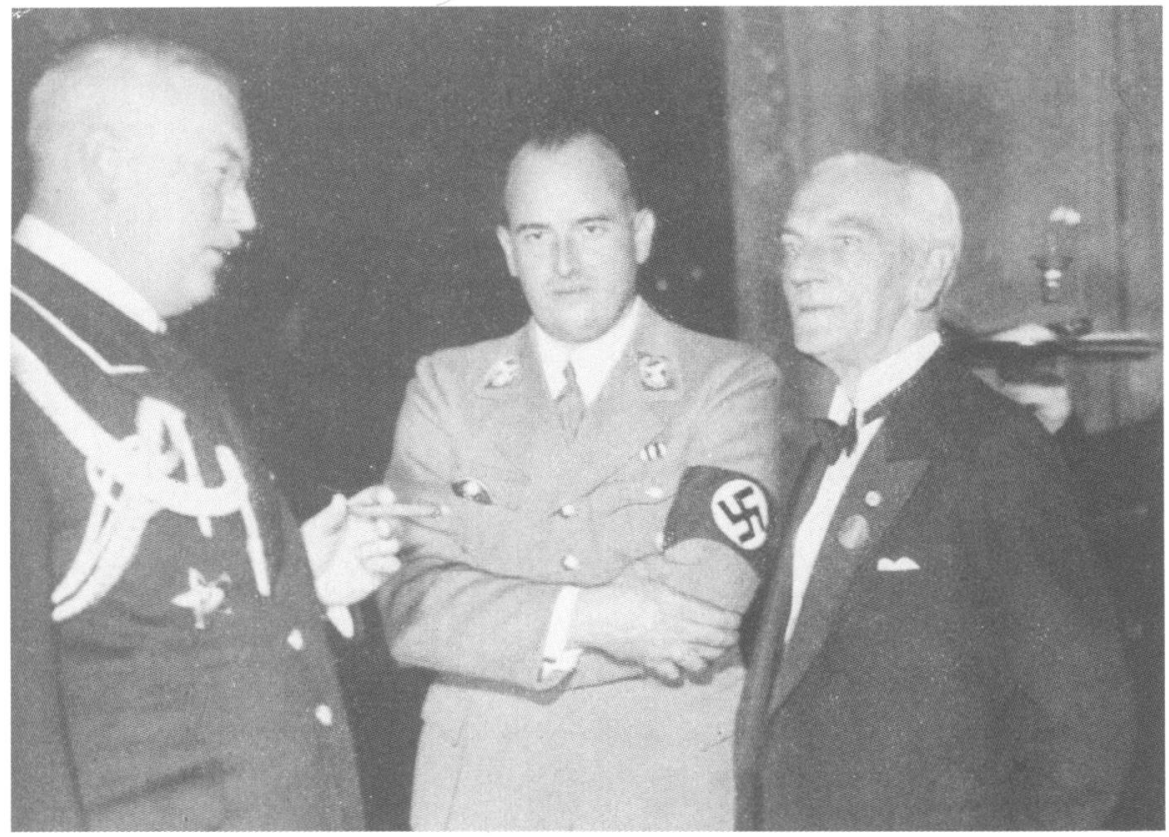

Von links nach rechts: Reichsminister Gürtner in der „unbeliebten“ Beamtenuniform, „Reichsrechtsführer" Dr. Hans Frank, 1933/34 gleichzeitig Reichsjustizkommissar und bayerischer Justizminister, und Reichsgerichtspräsident Dr. Erwin Bumke

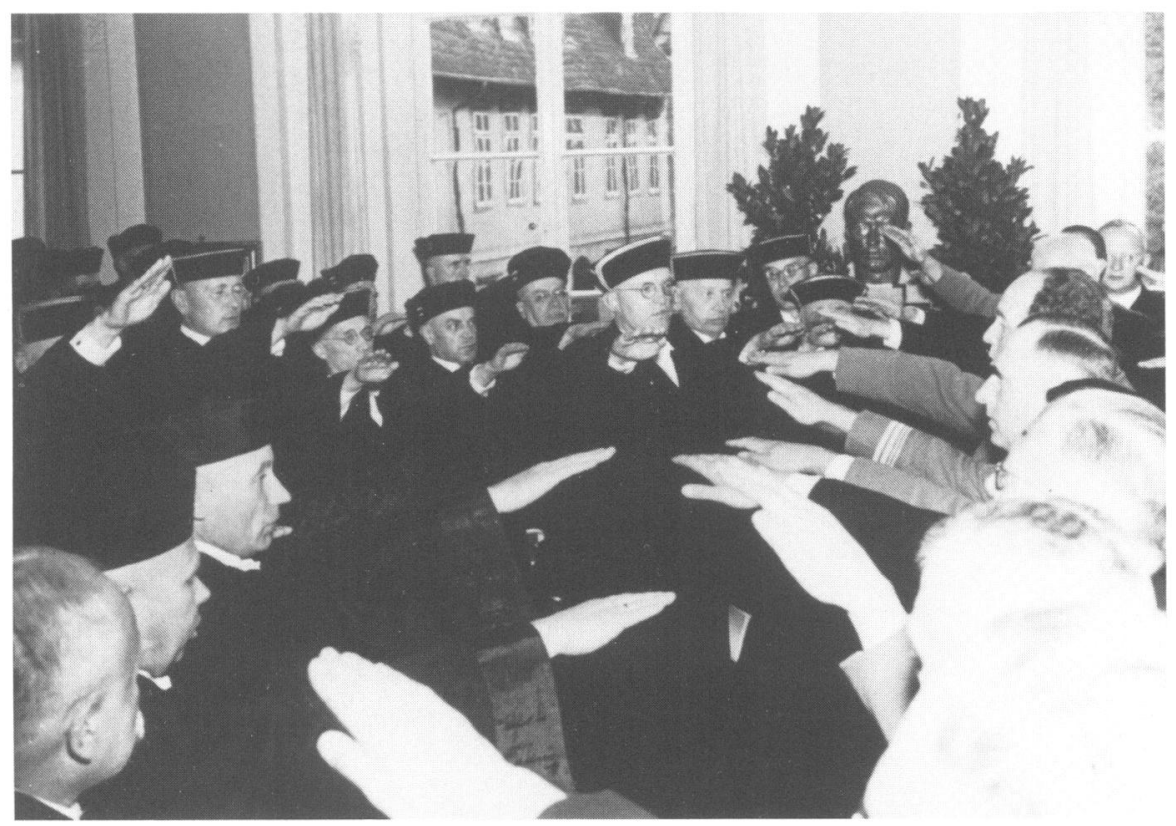

225-Jahrfeier des Oberlandesgerichts Celle am 14. Oktober 1936. Im Plenarsaal links von der Hitler-Büste die Richter, Staatsanwälte und Rechtsanwälte, rechts die Vertreter von Staat und Partei, darunter Staatssckretär Freisler, Gauleiter von Ost-Hannover Otto Telchow und SAGruppenführer Kasche 


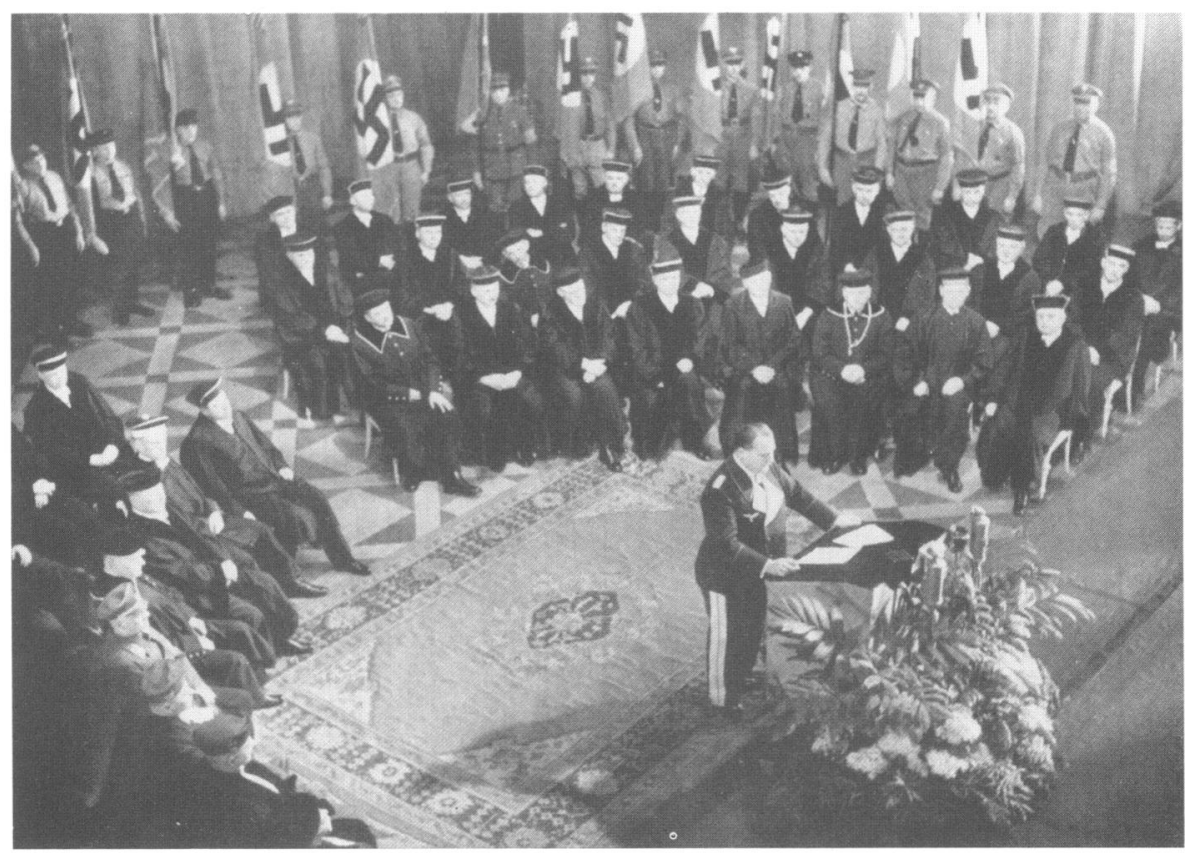

Festakt in der Berliner Staatsoper am 2. April 1935 anlä1lich der ,Verreichlichung" der Justiz. Am Rednerpult Göring, im Halbkreis auf der Bühne die Chetpräsidenten des Reichsgerichts und der Oberlandesgerichte, der Oberreichsanwalt und die Generalstaatsanwälte

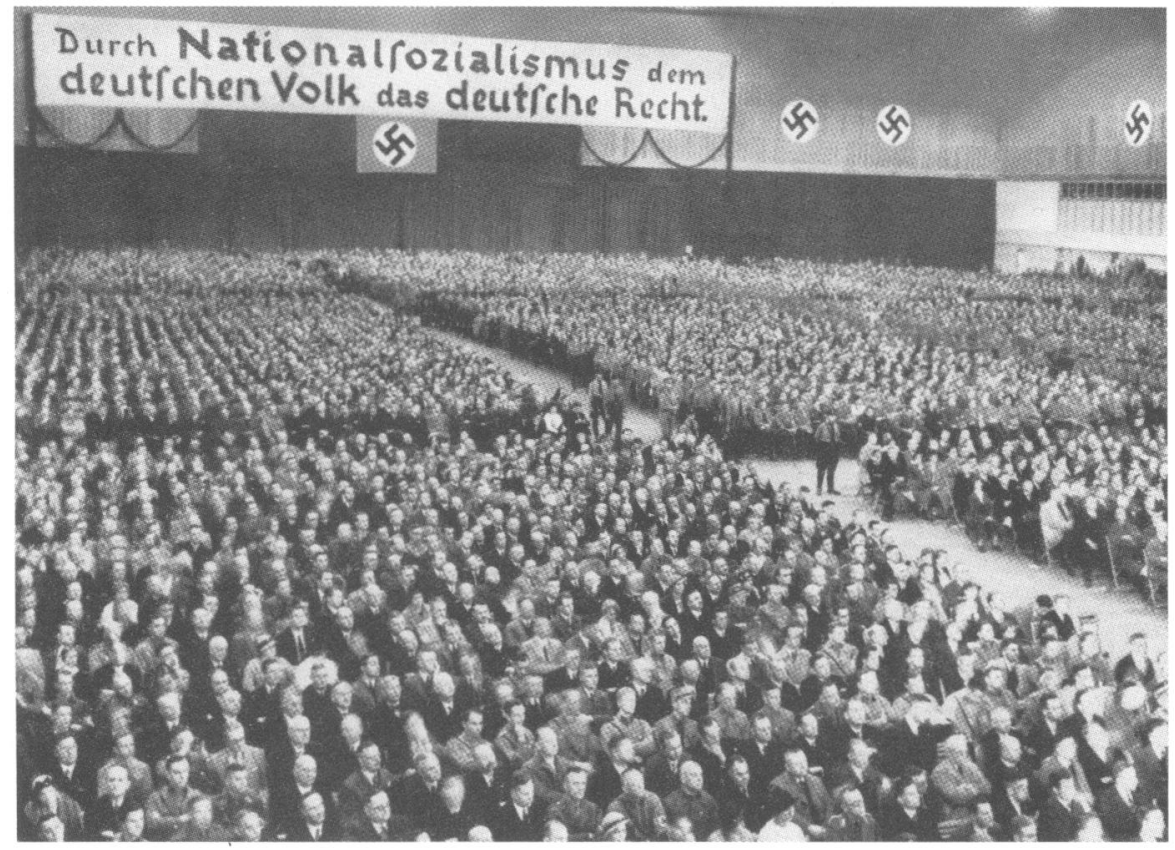

Schlulikundgebung des Deutschen Juristentages am 3. Oktober 1933 in der Leipziger Messehalle VII. Zugleich als 4. Reichstagung des Bundes Vationalsozialistischer I)eutscher Juristen begangen, unterschied er sich wesentlich won dem bisherigen Deutschen Juristentag 
Die größten Probleme bereitete der Justizverwaltung die Entwicklung bei den Assessoren, da die Zahl der Gerichtsassessoren, die im Verlauf eines Jahres ernannt wurden, ständig wuchs. In Preußen betrug der jährliche Zugang
$1922=783$
$1932=1607$
$1929=1205$
$1933=1948$
$1931=1388$
$1934=2649$.

Auch die vom preußischen Justizminister Kerrl im Frühjahr 1933 eingeführte „Auslese“ bei der Übernahme in den Justizdienst mit Hilfe einer politischen Prüfung durch eine besondere Kommission ${ }^{68}$ - die mit dem Inkrafttreten der reichseinheitlichen Justizausbildungsordnung Anfang Oktober 1934 wieder weggefallen war - hatte diese Entwicklung nicht aufhalten können. Zwar stieg die Gesamtzahl der preußischen Gerichtsassessoren nicht im gleichen Maße, da ein Teil von ihnen in anderen staatlichen Verwaltungen, im Kommunalwesen, in der Wirtschaft, NS-Organisationen usw. Anstellung fand. Dennoch wuchs sie erheblich und betrug - jeweils am 1. Januar ${ }^{69}$ :

$\begin{array}{ll}1922=1731 & 1933=3855 \\ 1929=2411 & 1934=4382 \\ 1931=3051 & 1935=5402 . \\ 1932=3433^{70} & \end{array}$

Am 1. April 1935 - dem Zeitpunkt der Verreichlichung der Justizverwaltung hatte diese Zahl 5696 erreicht, der außerhalb Preußens die Gesamtzahl von ca. 1000 Assessoren gegenüberstand. Während die meisten anderen Länder den Numerus clausus eingeführt hatten, entstand in Preußen diese „Assessorenschwemme“ dadurch, daß ausnahmslos alle Gerichtsreferendare nach dem Bestehen der großen Staatsprüfung zu Gerichtsassessoren ernannt wurden und - sofern sie nicht selbst ihre Entlassung beantragten - im Justizdienst blieben, auch wenn für sie keine entgeltliche Beschäftigung vorhanden und in absehbarer Zeit mit ihrer planmäßigen Anstellung nicht zu rechnen war. Beamtenrechtlich stellten sie nichtplanmäßige, lebenslänglich angestellte Beamte dar, die nur durch ein Dienststrafverfahren aus dem Beamtenverhältnis entfernt werden konnten, andererseits aber auch unentgeltlich beschäftigt werden durften ${ }^{71}$. Den 5696 Gerichtsassessoren standen 1935 in Preußen etwa 6400 Planstellen im höheren Justizdienst gegenüber, von denen im Laufe eines Jahres durchschnittlich nur etwa 250 Eingangsstellen frei wurden. Das bedeutete, daß mehr als 22 Jahre erforderlich gewesen wären, um die in Preußen vorhandenen Gerichtsassessoren planmäßig anzustellen, von denen die zuletzt angestellten dann fast 50 Jahre alt gewesen wären. Auch das hätte nur unter der unmöglich zu realisierenden Voraussetzung geschehen können, daß den jüngeren Jahrgängen, die nach dem 1. April 1935 die große juristische Staatsprüfung bestanden, die Anstellung im höheren Justizdienst gesperrt worden wäre. Auch die Tatsache, daß ein Teil der preußischen Assessoren nach der Verreichlichung der Justiz in Eingangsstellen anderer Länder untergebracht werden konnte und die

68 Vgl. dazu Näheres in Kapitel III.1.a., S.140 f. und dortige Anm. 70.

69 Vgl. R. Freisler, Neue Grundsätze für die Auslese der Rechtswahrer (DJ 1935, S. 583 ff.).

70 Im Jahre 1932 bezogen allein in Berlin ca. 100 von ihnen Wohlfahrtsunterstützung, s. O. Heilbrunn, Rechtspflegerassessoren (DRiZ 1933, S. 11).

71 Die Zahl der in der preußischen Justiz unentgeltlich beschäftigten Assessoren betrug 1933 zwischen 530 und 1100, 1934 zwischen 400 und 1200 (Freisler, a.a.O., S. 584). 
Reichsjustiz in Preußen über 250 ständige Hilfsarbeiterstellen verfügte, dort auch vorübergehende, bezahlte Beschäftigungsaufträge erteilen konnte - deren Zahl am 1. April $1935=1422$ betrug -, änderte an der Notwendigkeit einer grundlegenden Lösung des Problems nichts. Denn für die Justiz bedeutete dieser Zustand zugleich eine Überalterung des Nachwuchses, da das durchschnittliche Dienstalter der preußischen Gerichtsassessoren bei ihrer Anstellung je nach Oberlandesgerichtsbezirk zwischen 8 Jahren 7 Monaten (Frankfurt) und 3 Jahren 11 Monaten (Marienwerder) lag $^{72}$.

Die Justizleitung des Reichs mußte sich zur „Liquidierung des traurigen Erbes“ entschließen, das die Folge der preußischen Personalpolitik war. Dabei wurde der Weg, für die ohnehin rückläufige Immatrikulation von Rechtsstudenten einen Numerus clausus einzuführen, verworfen, weil er laut Freisler „die Rettung des lebenden Geschlechts auf Kosten des kommenden" bedeutet ${ }^{73}$ und sich auch frühestens erst in sieben Jahren ausgewirkt hätte. Das Reichsjustizministerium mußte vielmehr den entscheidenden Schritt tun und sich das Recht verschaffen, aus den zur Verfügung stehenden Kräften eine Auslese zu treffen und Anwärter für das Amt des Richters oder Staatsanwalts nur in einer dem wirklichen Bedarf entsprechenden Zahl in den Justizdienst aufzunehmen - auch wenn der einzelne dadurch hart getroffen und ihm das ohnehin illusorische Sicherheitsgefühl genommen wurde, als könne er sich durch jahrelanges Warten schließlich doch noch eine Richter- oder Staatsanwaltsstelle „ersitzen“. Durch die „Verordnung über die Laufbahn für das Amt des Richters und Staatsanwalts" vom 29. März 1935 (RGBl. I, S. 487), deren Vorschriften am 1. April in Kraft traten, wurde daher bestimmt, daß jeder Gerichtsreferendar, der die große Staatsprüfung bestand, mit dem Titel „Assessor“ aus dem Beamtenverhältnis zunächst ausschied. Unter denjenigen Assessoren, die sich für das Amt eines Richters oder Staatsanwalts bewarben, wählte das Reichsjustizministerium jährlich entsprechend dem anfallenden Nachwuchsbedarf Geeignete für den Probedienst aus, der in der Regel ein Jahr dauerte und in dem die Assessoren die Geschäfte eines Richters oder Staatsanwalts schon selbständig führten. Ihr Einkommen war nunmehr durch eine feste Besoldung garantiert: die unentgeltliche Beschäftigung von Assessoren, wie sie in Preußen und anderen Ländern bis dahin üblich war, gab es im Justizdienst fortan nicht mehr. Damit sollte zugleich „die volkspolitisch so wichtige frühe wirtschaftliche Heiratsfähigkeit des Rechtswahrernachwuchses" gesichert werden ${ }^{74}$. Nach einjährigem Probedienst, der abgekürzt oder bei außerordentlicher Befähigung auch ganz wegfallen konnte, entschied das Reichsjustizministerium über die Aufnahme des Assessors als Anwärter für das Amt des Richters oder Staatsanwalts. Als „Gerichtsassessor“ wurde er damit außerplanmäßiger Reichsbeamter mit festen Bezügen und konnte bei Bewährung mit der endgültigen Anstellung im Justizdienst rechnen. Um den Stau der vor dem 1. April 1935 ernannten Gerichtsassessoren abzubauen, wurde bestimmt, daß sie - soweit sie nicht in die Erprobung übernommen wurden - zu einem vom Justizministerium zu bestimmenden Zeitpunkt, spätestens jedoch am 31. März 1939, aus dem Beamtenverhältnis ausschieden. Die Übergangszeit von vier Jahren sollte dem einzel-

72 A.a.O. Es handelt sich um die Wartezeit für Richter (1934). Die Wartezeit für Staatsanwälte schwankte 1934 zwischen 5 Jahren 11 Monaten (Frankfurt) und 3 Jahren 10 Monaten (Kassel), s. R. Freisler, Personalpolitik im höheren Justizdienst, volkspolitisch gesehen (DJ 1939, S. 1342 ff., S. 1344).

73 A.a.O., DJ 1935, S. 585.

74 Vgl. Freisler, a.a.O., DJ 1939, S. 1349. 
nen Gerichtsassessor ermöglichen, sich nach einer anderen Arbeitsmöglichkeit umzusehen. Durch die Verordnung wurde nicht nur die bisher in den Ländern völlig unterschiedliche Laufbahn und Beschäftigung der Assessoren geregelt - einzelne Länder hatten die für geeignet befundenen Assessoren auf eine Bewerberliste gesetzt, aus der sie dann in bestimmter Reihenfolge nach Bedarf einberufen wurden -, sie regelte auch ihre Befugnisse einheitlich: wie bisher schon in Preußen durften die Assessoren nunmehr im ganzen Reich bei Amtsgerichten und Landgerichten richterliche Geschäfte wahrnehmen sowie bei jeder Staatsanwaltschaft als Staatsanwalt tätig sein.

Im Mai 1939 wurden die Laufbahnbestimmungen dahingehend geändert ${ }^{75}$, daß der Assessor nach der großen Staatsprüfung ohne Vorschaltung des „Probedienstes“ sofort mit dem Titel "Gerichtsassessor" als Anwärter für das Amt des Richters oder Staatsanwalts übernommen werden konnte. Dafür konnte seine Entlassung durch Widerruf nach Ablauf des ersten Jahres oder - falls die Justizverwaltung sich das am Anfang des zweiten Jahres vorbehielt - noch zum Abschluß des zweiten Jahres erfolgen.

An dieser Stelle sei darauf hingewiesen, daß mit der Beschäftigung von Gerichtsassessoren als abhängige, nicht planmäßig angestellte „Hilfsrichter" - die zunächst nur bei den Amts- und Landgerichten ${ }^{76}$, im Kriege aber auch bei den Oberlandesgerichten und sogar als Vorsitzende möglich war ${ }^{77}$ - für einen Teil der Richterschaft die persönliche Unabhängigkeit aufgehoben war $^{78}$ : im Oktober 1944 standen in den Oberlandesgerichtsbezirken 12940 richterliche Planstellen 464 Stellen für Hilfsrichter gegenüber $^{79}$. Neben diesen jüngeren Hilfsrichtern, die naturgemäß um Anpassung bemüht sein mußten, um ihre Ernennung auf Lebenszeit nicht zu gefährden, gehörten dem Kreis der abhängigen Richter im Kriege auch die gleichfalls nur noch auf Widerruf weiterbeschäftigten, über 65 Jahre alten Richter sowie die mit richterlichen Geschäften beauftragten Rechtsanwälte und Notare an ${ }^{80}$.

Nach $\S 6$ der Laufbahnverordnungen von 1935 und 1939 bestimmte der Reichsjustizminister im Einvernehmen mit dem Reichsfinanzminister alljährlich die Zahl der in den Probedienst zu übernehmenden Assessoren bzw. der Anwärter. Diese Zahlen wurden in den verschiedenen Jahren teils unter, teils über dem normalen jährlichen Nachwuchsbedarf festgesetzt, der ungefähr $4 \%$ der vorhandenen Gesamt-Planstellen ausmachte. Während der Einrichtung des Probedienstes im Jahre 1935 z. B. blieben sie übergangsweise unter diesem Jahresbedarf ${ }^{81}$. Dagegen wurde im Jahre 1942 die

75 Vgl. VO über die Laufbahn für das Amt des Richters und Staatsanwalts v. 16.5.39 (RGBl. I, S. 917).

76 Vgl. § 10 der VO zur einheitlichen Regelung der Gerichtsverfassung v. 20.3.35 (RGBI. I, S.403).

77 Zur (1.) VereinfachungsVO v. 1.9.39 (RGBl. I, S. 1658) vgl. Kapitel VIII.1.b., S. 975.

${ }^{78} \mathrm{Zu}$ diesem Problem s. A. Wagner, Der Richter. Geschichte. Aktuelle Fragen. Reformprobleme, Karlsruhe 1959, S. 73; ders., Die Umgestaltung der Gerichtsverfassung und des Verfahrens- und Richterrechts im nationalsozialistischen Staat (Die deutsche Justiz und der Nationalsozialismus, Teil I, Stuttgart 1968), S.235f.

79 Ohne die OLGBez. Posen, Köln und Saarbrücken, vgl. Übersicht über den Kräftebedarf und Kräfteeinsatz im höheren Dienst bei den Gerichten nach dem Stande vom 3.10.44 (Akten des RJM, BA, Sign. R 22 Gr. 5/II - 4). In Preußen machte schon 1926 die Zahl der abhängigen Hilfsrichter ein Viertel der Gesamtzahl der Richter aus, s. Wagner, Der Richter, a.a.O.

${ }^{80}$ Vgl. dazu Kapitel III.4.a., S.298. Wiederbeschäftigte Ruhestandsbeamte, vorübergehend eingesetzte RAe und Beamte, die die Altersgrenze überschritten hatten, machten im September $1942=1401$, d.h. $15 \%$ der beschäftigten Kräfte aus; vgl. die geheime Ausarbeitung „Grundsätze zur Úbernahme der Gerichtsassessoren“ v. 18.9.42 für den Leiter der Personalabteilung und Sts. Rothenberger (Akten des RJM, BA, Sign. R $22 / 246)$.

81 Vgl. RV des RJM an die OLGPräs. und GStAe v. 29.6.35 nebst Verteilung der 377 Probedienststellen auf die OLGBezirke (Akten des RJM, Hauptbüro, Arch. des BJM). 
prozentuale „Normalquote“ für die Übernahme - die in diesem Jahr an sich 652 betragen hätte - mit Rücksicht auf den Kräftebedarf in den eingegliederten Gebieten und zum Ausgleich für die Kriegsverluste überschritten und 825 Stellen für diesen Zweck eingerichtet ${ }^{82}$. Diese Stellen konnten jedoch bis zum Ende des Rechnungsjahres nur zu einem geringen Teil besetzt werden, da die seit 1939 zunächst zurückgestellten Anträge auf Ưbernahme unterdessen berücksichtigt worden waren und neue Anträge unter den Bedingungen des Krieges „nur spärlich“ eingingen ${ }^{83}$.

Die Gesamtzahl der Gerichtsassessoren, die nach 1935 zunächst bewußt gedrosselt und bis 1938 auf 3761 gesunken war, sollte sich im Kriege bis zum 1. Januar 1944 auf 1000 verringern, da - von den Kriegsverlusten abgesehen - die Masse der im Felde stehenden Referendare die große Staatsprüfung nicht ablegen konnte. Um letztere gegenüber den in der Heimat Gebliebenen nicht zu benachteiligen, wurden diejenigen Gerichtsreferendare, die den Vorbereitungsdienst nicht antreten oder beenden konnten, aufgrund der Bestimmungen über den Härteausgleich vom Februar $1943^{84}$ ohne Prüfung zu außerplanmäßigen Beamten, also zu „Assessoren“ ernannt, sobald ohne den Kriegsdienst ihr dreijähriger Vorbereitungsdienst abgelaufen wäre. Ausbildung und Prüfung sollten sie später im außerplanmäßigen Dienstverhältnis nachholen. Im Unterschied zu den geprüften Assessoren führten diese Kriegsassessoren den Zusatz „(K)“. Am 1. Januar 1944 stand eine Zahl von 5300 „Assessoren (K)“ den erwähnten 1000 Gerichtsassessoren gegenüber, die nach der besorgten Feststellung des Reichsjustizministeriums vom Juni angesichts der Zahl der unbesetzten Planstellen bis Jahresende ,aufgebraucht" sein würden ${ }^{85}$. Die Justiz sah sich zu diesem Zeitpunkt denselben Nachwuchsproblemen gegenüber, vor denen der staatliche Verwaltungsdienst generell stand ${ }^{86}$.

Die Möglichkeit, den Mangel an Gerichtsassessoren im Kriege durch entsprechende weibliche Kräfte auszugleichen, hatte sich der nationalsozialistische Staat grundsätzlich verbaut: durch Hitlers Entscheidung durften Frauen den Beruf eines Richters, Staatsanwalts oder Rechtsanwalts nicht mehr ausüben. Seit in der Weimarer Republik 1922 die Frauen zu juristischen Ämtern und Berufen zugelassen worden waren $^{87}$, waren z. B. in Preußen bis zur Machtübernahme 176 Gerichtsassessorinnen ernannt worden ${ }^{88}$. Bereits im September 1935 beauftragte das Reichsjustizministerium die Oberlandesgerichtspräsidenten, den noch nicht im Beamtenverhältnis stehenden Gerichtsassessorinnen mitzuteilen, daß ihre Übernahme in die richterliche und staats-

${ }^{82}$ Vgl. die geh. Ausarbeitung vom 18.9.42 (a.a.O., BA, Sign. R 22/246).

${ }^{83} \mathrm{Vgl}$. Aktenverm. über die Entwicklung bei der UUbernahme von Assessoren als Anwärter (Gerichtsassessoren) v. 8.2.43 (a.a.O.).

84 Vgl. AV des RJM v. 15.2.43 (DJ 1943, S. 125).

${ }^{85}$ Vgl. Zusammenstellung des RJM v. 14.6.44 (s. voranstehende Anm. 58).

86 UUber die ideellen und materiellen Gründe dafür vgl. die Feststellungen von K.-H. Seifert, Das Nachwuchsproblem des Staatsdienstes (Deutsche Verwaltung, Mai 1944, S.121 ff.).

${ }^{87}$ Vgl. G. über die Zulassung der Frauen zu den Amtern und Berufen der Rechtspflege v. 11.7.22 (RGBI. I, S. 573). Zur Zulassung und Verdrängung 1922-45 vgl. Juristinnen (1998), S.15-30.

${ }^{88}$ Nach dem Stand v. 1.2.33. Von ihnen waren 11 ausgeschieden, 60 RAinnen geworden, 6 planmäßig in der Justizverwaltung angestellt, 6 mit ständigem Kommissorium betraut, die übrigen 93 ohne festes Kommissorium (vgl. Auskunft des BJM, zitiert bei Bundesrichterin a.D. Meier-Scherling, Die Benachteiligung der Juristin zwischen 1933 und 1945, DRiZ 1975, S.11). In der Statistik des Anwaltsblattes wurden für den $1.1 .31=55$, für den $1.1 .32=79$ weibliche Anwälte angegeben (vgl. F. Ostler, Die deutschen Rechtsanwälte 1871-1971, Essen 1982, S. 174). 
anwaltschaftliche Laufbahn nicht mehr beabsichtigt sei ${ }^{89}$. Um „besonderen Härten“ abzuhelfen, sollten sie jedoch in beschränkter Zahl in den oberen Dienst bei Gerichten - aber nur zu verwaltender Tätigkeit - und bei Strafvollstreckungsbehörden eintreten können ${ }^{90}$. Im August 1936 teilte der Stellvertreter des Führers dem Reichsjustizministerium als weitere Entscheidung Hitlers mit, daß Frauen auch nicht mehr als Rechtsanwältinnen zugelassen werden dürften, sondern nur noch in der Verwaltung verwendet werden sollten ${ }^{11}$. Ohne die Reichs-Rechtsanwaltsordnung formell abzuändern, lehnte das Reichsjustizministerium die erforderlichen Anträge von Gerichtsassessorinnen auf Zulassung zum anwaltschaftlichen Probedienst einfach ab. Ab Januar 1937 wurden die Referendarinnen schon bei ihrer Ernennung schriftlich darauf hingewiesen, daß sie zwar auch weiterhin in den Vorbereitungsdienst aufgenommen, aber „auch nach bestandener großer Staatsprüfung weder zum Probedienst für die Laufbahn des Richters und Staatsanwalts noch zum anwaltlichen Probedienst zugelassen werden“ könnten"2 . Da die Beschäftigungsmöglichkeit für Juristinnen in der Justizverwaltung beschränkt war, bat das Reichsjustizministerium die anderen Obersten Reichsbehörden, sie nach Möglichkeit in ihrem Geschäftsbereich unterzubringen ${ }^{93}$. Durch Hitlers Entscheidung vom August 1937, zu Beamten des böberen Dienstes grundsätzlich nur Männer zu ernennen und Frauen in diese Laufbahn nur noch ,im Einzelfall ... auf dem Gebiete der Wohlfahrtspflege, des Erziehungswesens und des Gesundheitswesens“ zu übernehmen ${ }^{94}$, wurden den Frauen auch im Verwaltungsdienst die Berufsmöglichkeiten weiter beschnitten. Es war daher nicht verwunderlich, daß sie in den folgenden Jahren dem Juristenberuf den Rücken kehrten: in den Jahren 1939 bis Mitte 1941 wurden nur mehr 92 Gerichts referendarinnen ernannt ${ }^{95}$. Selbst als im Januar 1942 Gerichtsassessorinnen wegen des dringenden Personalmangels in Ausnahmefällen wieder neu in den Probedienst eingestellt werden durften, wurde ausdrücklich bestimmt, daß sie - wie die noch von früher her im richterlichen Dienst stehenden Frauen - nur Grundbuch- und Registersachen bearbeiten, aber nicht als Vormundschafts-, Nachlaß- oder Konkursrichter verwendet werden durften. Auch als ihr Tätigkeitsbereich nach einer eigens eingeholten Entscheidung Hitlers im März 1942 auf alle Gebiete der freiwilligen Gerichtsbarkeit ausgedehnt wurde, sollte die Ausnahme „nur zur Behebung eines Personal-Notstandes für die Kriegsdauer“ und in der Regel nur für größere Gerichte gelten: auch im Kriege durften Frauen keinesfalls als Spruchrichter im Streitverfahren oder als Staatsanwälte verwendet werden ${ }^{96}$.

89 Vgl. Erl. des RJM an die OLGPräs. und GStAe v. 17.9.35 (zit. bei Meier-Scherling, a.a.O.).

90 Vgl. RV des RJM an die OLGPräs. und GStAe in Preußen v. 10.1.36 (Akten des RJM, Hauptbüro, Arch. des BJM).

91 Schr. des St.d.F. (i.V. Bormann) an den RJM v. 24.8.36 (Akten der RK, BA, Sign. R 43 II/427).

$92 \mathrm{Vgl}$. RV des RJM an die OLGPräs. v. 15.1.37 (Akten des RJM, a.a.O.).

93 Schr. des RJM an die Obersten Reichsbehörden v. 16.1.37 (Akten der RK, a.a.O.).

94 Vgl. Schr. des RuPrMdI an die Obersten Reichsbehörden v. 24.8.37 (a.a.O.).

95 Vgl. die namentliche Aufstellung des RJM v. 20.6.41 für die Reichsfrauenführung in der Reichsleitung der NSDAP (Akten des RJM, BA, Sign. R 22/4502).

96 Vgl. RV des RJM an die OLGPräs., nachrichtlich an die GStAe v. 16.1. und 27.3.42 (Akten des RJM, Hauptbüro, Arch. des BJM). Als das RJM im Februar 1944 erfuhr, daß beim LG Mannheim eine seit 1934 planmäßig eingestellte Richterin noch als Einzelrichter in Ehesachen tätig war, veranlaßte es den OLGPräs. Karlsruhe, die Richterin zur ausschließlichen Verwendung auf dem Gebiet der freiwilligen Gerichtsbarkeit dem AG zuzuweisen (vgl. Schr. des RJM an den OLGPräs. Karlsruhe v. 8. 2.44 und Antwortschr. v. 22. 2. 44, a.a.O., BA, Sign. R 22/4495). 